UNIVERSIDADE DE BRASÍLIA

INSTITUTO DE GEOCIÊNCIAS

PÓS-GRADUAÇÃO EM GEOCIÊNCIAS APLICADAS

Dissertação de Mestrado No 112

\title{
O PAPEL DAS ÁREAS PROTEGIDAS NA CONTENÇÃO DO DESMATAMENTO NO BIOMA CERRADO
}

Área de concentração: Geoprocessamento e Análise Ambiental

Rodrigo José Oliveira Paiva

Orientador: Prof. Dr. Ricardo Seixas Brites (Universidade de Brasília)

Brasília - DF 
UNIVERSIDADE DE BRASÍLIA

INSTITUTO DE GEOCIÊNCIAS

PÓS-GRADUAÇÃO EM GEOCIÊNCIAS APLICADAS

O papel das áreas protegidas na contenção do desmatamento no bioma cerrado

Dissertação de Mestrado apresentada ao Programa de Pós-Graduação em Geociências Aplicadas da Universidade de Brasília, como requisito parcial para obtenção do título de Mestre.

Área de concentração: Geoprocessamento Aplicado à Análise Ambiental.

Rodrigo José Oliveira Paiva

Orientador: Ricardo Seixas Brites

Brasília - DF 
BANCA EXAMINADORA

Prof. Dr. Ricardo Seixas Brites

Universidade de Brasília - Orientador

Prof. Dr. Ricardo Bomfim Machado

Universidade de Brasília - Examinador Interno

Prof. Dr. Carlos Alberto de Mattos Scaramuzza

Ministério do Meio Ambiente - Examinador Externo

Prof. Dr. Edson Eiji Sano

Universidade de Brasília - Suplente

Brasília - DF 


\section{FICHA CATALOGRÁFICA}

\section{Paiva, Rodrigo J. O.}

O papel das áreas protegidas na contenção do desmatamento no bioma cerrado. Rodrigo José Oliveira Paiva; orientação de Ricardo Seixas Brites. Brasília, 2017.

$278 \mathrm{p}$.

Dissertação de Mestrado - Universidade de Brasília; Instituto de Geociências, 2017.

1. Áreas Protegidas; 2. Conservação da Biodiversidade; 2. Desmatamento; 3. Mapeamento de Uso e Cobertura da Terra; 4. Cerrado.

Paiva, Rodrigo José Oliveira. O papel das áreas protegidas na contenção do desmatamento no bioma cerrado. Brasília, Instituto de Geociências, Universidade de Brasília, 2017, 278p. Dissertação de mestrado. 
"Nem tudo que é torto é errado. Veja as pernas do Garrincha $e$ as árvores do Cerrado."

Nicholas Behr 
A meu pequenino

pedaço de sorriso,

Caetano. 


\section{AGRADECIMENTOS}

Agradeço à Universidade de Brasília, instituição pela qual tenho especial carinho e à qual devo a maior parte da minha instrução formal, também sendo agradecido pelo fundamental papel que desempenha na sociedade. Agradeço ao Instituto de Geociências pela acolhida nesta empreita.

Agradeço a todos os professores, servidores e colegas da Pós-Graduação em Geociência Aplicadas pela oportunidade de desenvolvimento nessa interessante área do conhecimento, com caráter multidisciplinar e com importantes aplicações para diversas finalidades, inclusive para a conservação da biodiversidade e do meio ambiente, tópico especialmente explorado nesta dissertação.

Agradeço especialmente ao Professor Ricardo Brites, pelo apoio sempre presente, mesmo em momentos menos favoráveis, pelo trabalho sempre visando a qualidade e sempre disponível a novas ideias, qualidades fundamentais a um excelente pesquisador, e, não menos importante, pela ótima relação que pudemos construir.

Agradeço a todas as pessoas que participaram deste momento da minha vida. Aos colegas de trabalho por, sempre que possível, facilitarem a minha participação neste curso. A meus amigos, pelos momentos de descontração tão indispensáveis.

Agradeço com amor a minha família e a minha companheira.

Agradeço à vida. 


\section{RESUMO}

As áreas protegidas são reconhecidas como uma das mais efetivas ferramentas empregadas para a conservação da biodiversidade e, também, para a manutenção do habitat natural. Tendo em vista objetivos específicos a serem atingidos e recursos limitados, essas unidades territoriais passaram a ser tópico de importante interesse para o planejamento territorial voltado à conservação. Além do planejamento relativo à alocação e implementação das áreas protegidas e ações de conservação relacionadas, é relevante nesse contexto a avaliação do desempenho das unidades existentes no atingimento de objetivos determinados. Neste trabalho, tivemos por objetivo principal a avaliação do desempenho das Unidades de Conservação, Terras Indígenas e Terras Quilombolas existentes no Bioma Cerrado em relação à capacidade dessas em conter o desmatamento, bem como eventuais variações de desempenho em função de atributos específicos dessas. Em virtude da baixa disponibilidade de dados relativos ao uso e cobertura da terra para a área de estudo, objetivou-se, também, a obtenção de informações espacializadas dessa natureza para períodos históricos, especificamente para os anos de 1985 e 1995. O capítulo 2 foi dedicado à aplicação de metodologia de mapeamento com a utilização de análise de imagens baseada em objetos (GEOBIA) e a atualização de base de dados oficial relativa ao uso e cobertura da terra para os anos de 1985 e 1995. O trabalho foi realizado em quatro etapas principais: obtenção e pré-processamento das imagens; identificação dos melhores parâmetros de segmentação; determinação de atributos relevantes para a discriminação de feições entre as classes de interesse, com a utilização da mineração de dados; obtenção de agrupamentos de objetos por meio da análise de agrupamento e interpretação visual. Observou-se que em 1985 o Cerrado era recoberto majoritariamente por áreas naturais, as quais ocupavam $75,66 \%$ de sua totalidade. Áreas pertencentes à classe antrópica ocupavam 23,69\% e corpo d'água $0,65 \%$. No período entre 1985 e 2002 houve a supressão de 19,77\% de áreas naturais $\left(404.482 \mathrm{~km}^{2}\right)$. O mapeamento do ano de 1985 apresentou como indicador de qualidade Índice Kappa de $87 \%$ e o mapeamento do ano de 1995 apresentou Índice Kappa no valor de $85 \%$. Teste realizado comparando resultados obtidos por meio da metodologia proposta com o mapeamento oficial de referência apontou grande concordância entre os produtos gerados, obtendo-se Índice Kappa q $(\mathrm{Kq})$ com valor médio de 82\%. A metodologia desenvolvida com a utilização de GEOBIA foi determinante para a obtenção de resultados de forma ágil e com elevada qualidade. No Capítulo 3 realizou-se avaliação sobre o efeito de Unidades de Conservação, Terras Indígenas e Terras Quilombolas existentes no Bioma Cerrado, levando-se em consideração a capacidade dessas unidades em conservar o habitat natural. Com a finalidade de se acessar o efeito das áreas protegidas utilizou-se o método de matching excluindo-se a área de influência imediata das unidades territoriais investigadas (buffer), realizando-se, dessa forma, o controle de outras variáveis sobre o estimador (efeito da 
correlação) e o controle da autocorrelação sobre os resultados (efeito da autocorrelação e efeito vazamento). As análises realizadas neste trabalho indicam que as unidades investigadas desempenham importante papel na proteção do habitat natural na região do Bioma Cerrado, evitando, em conjunto, que $12,18 \mathrm{ha} / \mathrm{km}^{2}$ fossem convertidos para uso antrópico. Diferenças no desempenho das unidades foram observadas em função dos tipos de unidades consideradas (UC's, TI's e TQ's), níveis de restrição das unidades e tempo decorrido desde a data de criação dessas. Outras características, como o tamanho e a esfera governamental, nem sempre apresentaram influência relevante, variando entre subgrupos de unidades. Além de servir como um diagnóstico da situação efetivamente observada, os resultados do trabalho sugerem que políticas públicas que considerem a utilização de áreas protegidas para a contenção do desmatamento no Cerrado observar o elevado desempenho das unidades de conservação das categorias IUCN I, II e IV e a área reduzida por elas ocupada no Cerrado, bem como adotar ações de conservação específicas voltadas a aumentar a capacidade de unidades pertencentes às categorias V e VI em evitar a ocorrência do desmatamento. Aponta, também, a necessidade de se considerar nessas políticas o papel desempenhado pelas Terras Indígenas, haja vista sua grande capacidade em promover a preservação do habitat.

Palavras-Chave: Áreas Protegidas, Conservação da Biodiversidade, Desmatamento, Cerrado. 


\begin{abstract}
Protected areas are known as one of the most effective tools used for the biodiversity conservation and also for the maintenance of natural habitat. Due to the specific goals to be achieved and limited resources, these territorial units have become a relevant topic for the territorial planning for biodiversity conservation. Besides the systematic planning for the allocation and implementation of protected areas, it is relevant to assess the performance of existing units in achieving specific objectives. The main objective of this work was to evaluate the performance of Conservation Units, Indigenous Lands and Quilombola Lands (occupied by traditional groups of African origin) on maintaining the natural habitat, as well as possible variations of performance due to specific attributes of these territorial units. Due to the low availability of data on land use and land coverage change (LULC) for the study area, it was also an objective to obtain historical LULC data, specifically for the years 1985 and 1995. Chapter 2 was devoted to the application of mapping methodology with the use of object-based image analysis (GEOBIA) and the update of the official LULC database for the years 1985 and 1995. The work was carried out in four main stages: obtaining and pre-processing the images; identification of the best segmentation parameters; use of data mining to determine the best set of attributes aimed to discriminate objects between mapping classes; cluster analysis and visual interpretation. After the LULC mapping, it was observed that in 1985 the Cerrado was covered mostly by natural areas, which occupied $75.66 \%$ of the total area. The anthropic class occupied $23.69 \%$ and water $0.65 \%$. Between 1985 and 2002 there was the suppression of $19.77 \%$ of natural areas $\left(404,482 \mathrm{~km}^{2}\right)$. The 1985 's LULC mapping achieved a Kappa Index quality indicator of $87 \%$ and the 1995 's presented Kappa Index of $85 \%$. A test performed comparing results obtained through the methodology proposed with the official reference mapping showed a great agreement between the products generated (Kappa q index of 82\%). The methodology developed for the LULC mapping, using object-based image analysis (GEOBIA), was determinant to obtain results in an agile and high quality way. Chapter 3 was devoted to evaluate the effectiveness of protected areas to prevent the advance of the conversion of natural areas in the Brazil's Cerrado Biome. In order to access the effect of the protected areas, it was used the matching method approach, thus controlling the spatial correlation effect and the autocorrelation effect. The results indicate that the investigated units play an important role in protecting the natural habitat in the Cerrado Biome, avoiding the anthropic conversion of 12.18 ha $/ \mathrm{km}^{2}$. Differences in unit performance were due especially to the types (UC's, IT's and TQ's), the restriction levels and the time elapsed since the creation of those units. Other characteristics, such as size and government sphere, didn't have a relevant influence among all unit subtypes. In addition to serving as a diagnostic, the results of the study suggest that public policies that consider the use of protected areas to contain deforestation in the Cerrado should
\end{abstract}


prioritize the increase of the total area of conservation units in the IUCN categories I, II and IV, as well as to adopt specific conservation actions aimed at increasing the capacity of units belonging to categories $\mathrm{V}$ and $\mathrm{VI}$ in avoiding the occurrence of deforestation. It is also important to consider in these policies the role played by the Indigenous Lands, given the great capacity of those units to promote habitat preservation.

Key Words: Protected Areas, Biodiversity Conservation, Deforestation, Cerrado. 


\section{SUMÁRIO}

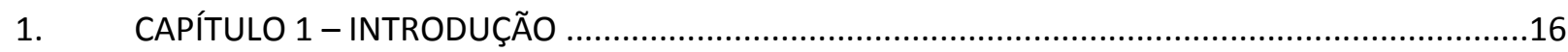

2. CAPÍTULO 2 - ANÁLISE DE IMAGEM BASEADA EM OBJETOS (GEOBIA) APLICADA AO MAPEAMENTO DO USO E COBERTURA DA TERRA NO BIOMA CERRADO: IDENTIFICAÇÃO DE DESMATAMENTOS PARA OS ANOS DE 1985 E 1995 .. .39

3. CAPÍTULO 3 - O EFEITO DAS ÁREAS PROTEGIDAS SOBRE A MANUTENÇÃO DO HABITAT NATURAL NO BIOMA CERRADO 164 


\section{LISTA DE ABREVIATURAS E SIGLAS}

ANA - Agência Nacional de Águas

APA - Área de Proteção Ambiental

ARIE - Área de Relevante Interesse Ecológico

ARVI - Atmospherically Resistant Vegetation Index

ATT - Efeito Médio Absoluto do Tratamento (Average Treatment Effect on the Treated)

ATT\% - Efeito Relativo do Tratamento

CART - Classification and Regression Trees

CDB - Convenção Sobre a Diversidade Biológica

CNUC/MMA - Cadastro Nacional de Unidades de Conservação do Ministério do Meio Ambiente

COP - Conferência das Partes da Convenção sobre Diversidade Biológica

CPAC/EMBRAPA - Centro de Pesquisa Agropecuária dos Cerrados

CSR/IBAMA - Centro de Sensoriamento Remoto do IBAMA

Deter-B - Sistema de Detecção do Desmatamento e Alterações na Cobertura Florestal em Tempo Quase Real

DNIT - Departamento Nacional de Infraestrutura de Transportes

EMATER - Empresa de Assistência Técnica e Extensão Rural

EMBRAPA - Empresa Brasileira de Pesquisa Agropecuária

EPAMIG - Empresa de Pesquisa Agropecuária de Minas Gerais

ESEC - Estação Ecológica

ESP - Estimation of Scale Parameter

FLONA - Floresta Nacional

FUNAI - Fundação Nacional do Índio

GARI - Green Atmospherically Resistant Index

GEOBIA - Análise de Imagem Baseada em Objetos (Geographic Object-Based Image Analysis) 
GIS - Sistema de Informações Geográficas (Geographic Information System)

GLCF - Global Land Cover Facility

IBAMA - Instituto Brasileiro do Meio Ambiente e dos Recursos Naturais Renováveis

IBGE - Instituto de Brasileiro de Geografia e Estatística

INCRA - Instituto Nacional de Colonização e Reforma Agrária

INPE - Instituto Nacional de Pesquisas Espaciais

IUCN - International Union for Conservation of Nature

KDD - Descoberta de Conhecimento em Bases de Dados (Knowledge Discovery in Databases)

LULC - Alterações no Uso e Cobertura da Terra (Land-Use and Land-Cover Change)

LWM - Land and Water Mask Index

MMA - Ministério do Meio Ambiente

MN - Monumento Natural

ND - Número Digital (Digital Number)

PARNA - Parque Nacional

PMABB - Programa de Monitoramento Ambiental dos Biomas Brasileiros

PMDBBS - Projeto de Monitoramento do Desmatamento dos Biomas Brasileiros por Satélite

PNAP - Plano Estratégico Nacional de Áreas Protegidas

POLOCENTRO - Programa de Desenvolvimento das Áreas de Cerrados

PPCerrado - Plano de Ação Para Prevenção e Controle do Desmatamento e das Queimadas no Cerrado

PROBIO - Projeto de Conservação e Utilização Sustentável da Diversidade Biológica Brasileira

PROCEDER - Programa de Cooperação Nipo-Brasileira de Desenvolvimento dos Cerrados PRODES - Projeto de Estimativa do Desflorestamento Bruto da Amazônia

PS - Propensity Score

RAPAM - Avaliação Rápida e Priorização do Manejo de Unidades de Conservação (Rapid Assessment and Priorization of Protected Area Management) 
RDS - Reserva de Desenvolvimento Sustentável

REBIO - Reserva Biológica

REFAU - Reserva de Fauna

RESEX - Reserva Extrativista

RPPN - Reserva Particular do Patrimônio Natural

RVS - Refúgio da Vida Silvestre

SIAD - Sistema Integrado de Alerta de Desmatamento

SNUC - Sistema Nacional de Unidades de Conservação

TI - Terras Indígenas

TQ - Terras Quilombolas

UA - Unidades amostrais

UC - Unidades de Conservação

UNEP - Unated Nations Environment Programme

USGS - United States Geological Survey 
CAPÍTULO 1 - INTRODUÇÃO. 


\section{SUMÁRIO}

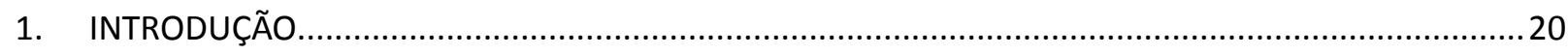

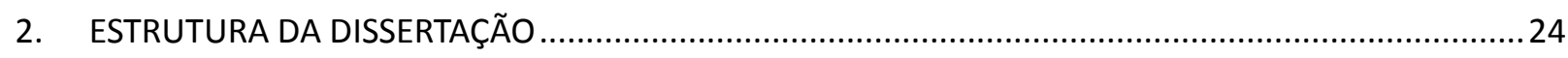

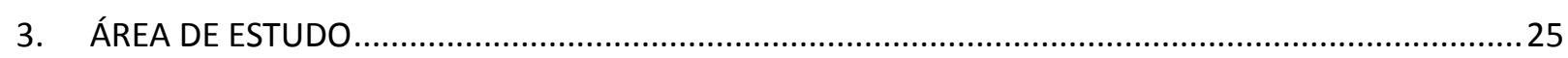

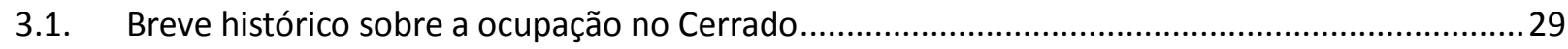

3.2. Monitoramento de alterações no uso e cobertura da terra......................................................... 31

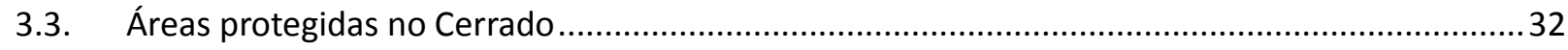

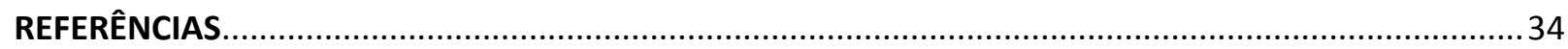




\section{TABELAS}

Tabela 1 - Área de cobertura por diferentes formações vegetacionais no Cerrado observadas para o ano de 2002

Tabela 2 - Número de espécies catalogadas no Cerrado, no Brasil e no Mundo. 29

Tabela 3 - População da região Centro-Oeste do Brasil entre 1950 e 2010 (unidade: mil habitantes). ... 30 Tabela 4 - Variação no percentual de áreas de remanescentes naturais no Cerrado entre 2002 e 2011. Área total de referência do Cerrado de $2.039 .386 \mathrm{~km}^{2}$. 31

Tabela 5 - Unidades de Conservação, Terra Indígena e Terra Quilombola, considerando toda a extensão do território continental brasileiro $\left(8.514 .085 \mathrm{~km}^{2}\right)$ e toda a extensão do Bioma Cerrado (2.040.167)...33 


\section{FIGURAS}

Figura 1 - Fluxograma considerando etapas de planejamento, implementação, gestão e avaliação de objetivos relacionados às áreas protegidas. Fonte: adaptado de Knight, Cowling e Campbell (2006)....21 Figura 2 - Áreas protegidas e uso da terra na região definida para o estudo. 


\section{INTRODUÇÃO}

As áreas protegidas são reconhecidas como uma das mais efetivas ferramentas empregadas para a conservação da biodiversidade e, também, para a manutenção do habitat natural (Chape, Spalding e Jenkins, 2008; Naughton-Treves, Holland e Brandon, 2005; Schmitt et al., 2009). Tendo em vista objetivos específicos a serem atingidos e recursos limitados, dentre eles o próprio espaço, essas unidades territoriais passaram a ser tópico de importante interesse em um contexto do planejamento territorial voltado à conservação. Dois aspectos são especialmente relevantes neste contexto: um primeiro relacionado ao planejamento para a alocação e implementação dessas unidades e ações de conservação relacionadas; e, um segundo, a avaliação do desempenho das unidades no atingimento de objetivos determinados.

O planejamento para a conservação que considere diretamente o papel desempenhado pelas áreas protegidas pode ser dividido em: determinação de espaços prioritários nos quais serão alocados esses tipos de unidades territoriais (Systematic Conservation Assessment); especificação de metas, ações e responsabilidades a serem implementadas (Implementation Strategy); e elaboração/implementação de estratégias de conservação efetivas (Conservation Management) (Brooks, 2010; Knight, Cowling e Campbell, 2006; Margules e Pressey, 2000). Nesse processo são reconhecidas falhas ou gaps entre a etapa de planejamento e implementação (planning gap) e entre as etapas de implementação e a de realização de ações de conservação (action gap) (Figura 1). As falhas mencionadas podem se refletir em diversos aspectos que são empiricamente quantificáveis, inclusive sobre os objetivos finais de uma área protegida.

Avaliações tendo como enfoque os alvos/metas finais das áreas protegidas têm abordado o desempenho dessas sobre a manutenção de populações de espécies biológicas (eg. Stoner et al., 2007) ou sobre a manutenção do habitat natural (eg. Andam et al., 2008) (Geldmann et al., 2013). Nesse tipo de estudo considera-se a análise do conjunto de unidades existentes, obtendo-se um diagnóstico sobre a situação observada em momento posterior às etapas de implementação das unidades. Portanto, avalia-se uma situação fática, efetivamente observada no território, considerando a rede de áreas protegidas existente.

Planejamento sistemático e avaliação/diagnóstico de desempenho são etapas que se retroalimentam e podem trazer informações capazes de influenciar de forma relevante o processo de decisão para a criação de novas áreas protegidas ou de nortear estratégias de conservação mais adequadas para a situação efetivamente observada. 


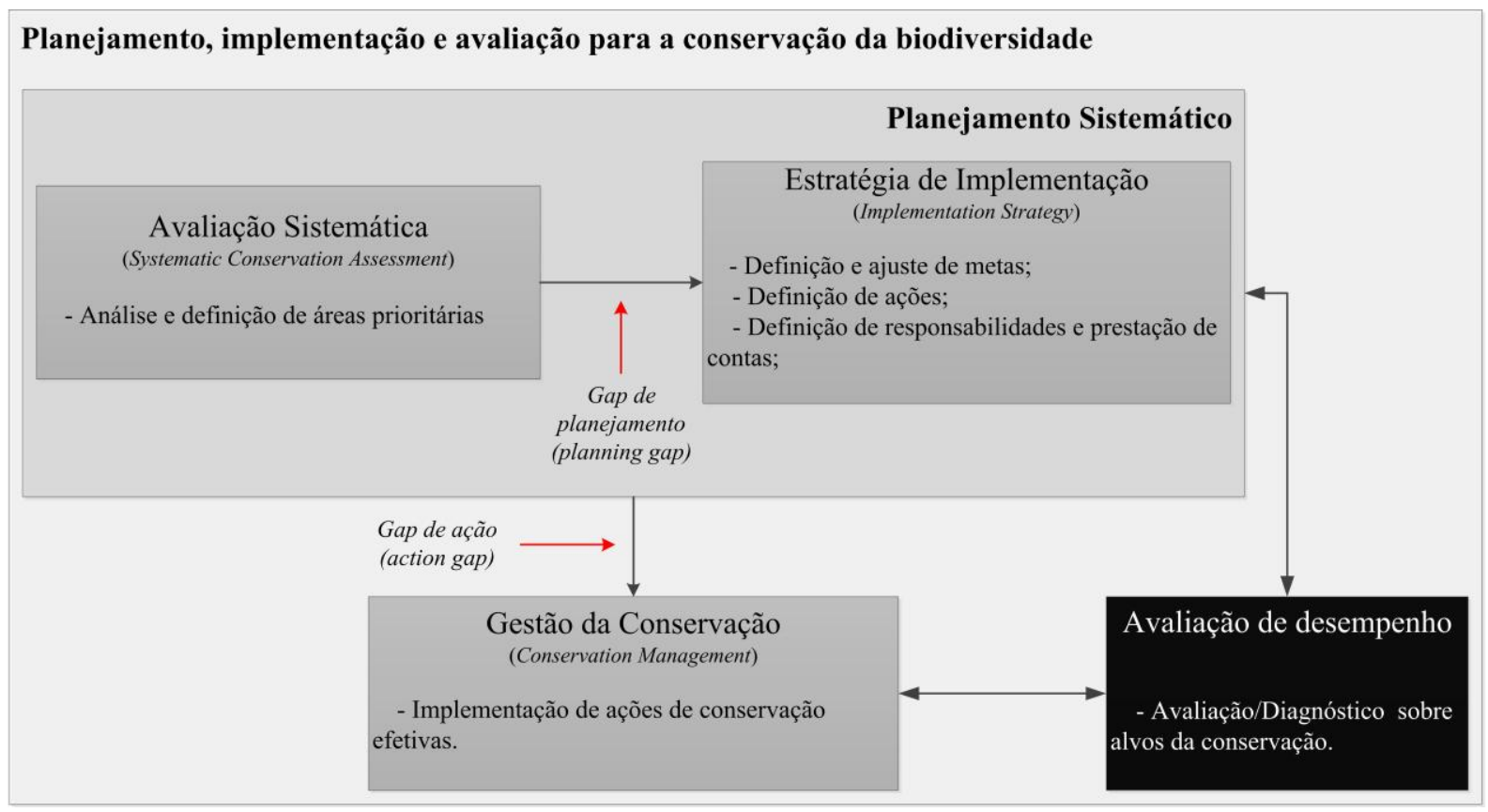

Figura 1 - Fluxograma considerando etapas de planejamento, implementação, gestão e avaliação de objetivos relacionados às áreas protegidas. Fonte: adaptado de Knight, Cowling e Campbell (2006).

No presente estudo, faz-se uma avaliação sobre o desempenho das áreas protegidas em relação à sua capacidade de manter o habitat natural, levando-se em consideração diferentes características dessas unidades, tais quais: nível de restrição, esfera governamental, tamanho, tempo decorrido desde o ato de criação. Além de Unidades de Conservação, também se levou em consideração as Terras Indígenas e as Terras Quilombolas existentes na área de estudo, o Cerrado.

Este é uma das regiões biogeográficas mais ricas em espécies e ameaçadas do mundo por eventos relacionados à conversão antrópica (Myers et al., 2000). Ela sofre com acelerado processo de desmatamento, sendo a área natural convertida para uso antrópico estimada em 49\% (997.063 km²) no ano de 2011, segundo dados do Projeto de Monitoramento do Desmatamento dos Biomas Brasileiros por Satélite - PMDBBS (IBAMA, 2015), e em 44\% para o ano de 2013, segundo dados do TerraClass Cerrado (MMA, 2015). A diferença entre os dados estaria associada à utilização de métodos diversos entre esses mapeamentos (metodologia de execução, escala e área mínima mapeada).

Processos relacionados ao desmatamento estão ligados a múltiplos fatores. Geist e Lambin (2002) relacionaram fatores mediatos e imediatos, locais e regionais, que se originam a partir de combinações de características diversas do contexto social, político, econômico e cultural, como elementos que favorecem ou dificultam sua ocorrência. Um dos importantes 
fatores que podem influenciar de forma mediata a ocorrência deste tipo de evento são políticas voltadas à conservação da biodiversidade, como é o caso das áreas protegidas.

Dadas as características multicausais de eventos de desmatamento, para se acessar o desempenho das áreas protegidas, é necessário considerar múltiplas variáveis, de forma explícita e espacializada, levando-se em conta dados que reflitam características ambientais, sociais, econômicas, dentre outras que tenham influência relevante sobre os eventos investigados.

Nesse contexto, a disponibilidade de dados primários relacionados a alterações no uso e cobertura da terra constituem-se elementos fundamentais. Em regra, a compreensão e modelagem de fenômenos relacionados ao desmatamento requerem a formação de uma série temporal mínima capaz de abranger alterações históricas no uso e cobertura da terra (Sohl e Sleeter, 2011), sendo relevante a obtenção e disponibilização de dados atuais e históricos, representados por produtos cartográficos.

Em função da baixa disponibilidade de dados relacionados ao mapeamento de uso e cobertura na área de estudo, neste trabalho, como requisito prévio para as análises posteriores, realizou-se o desenvolvimento de solução metodológica para a produção eficiente desse tipo de mapeamento. A metodologia desenvolvida valeu-se de Análise de Imagem Baseada em Objetos (Geographic Object-Based Image Analysis - GEOBIA), conjunto de técnicas e ferramentas que têm por principal vantagem sobre os métodos tradicionais, baseados em análise pixel-pixel, a consideração de múltiplas características dos objetos (image-objects) que expressam a identidade de uma feição real no território (Hay \& Castilla, 2008). Nesse tipo de análise é possível levar-se em conta como atributos dos objetos suas características espectrais, textura, forma, relação com outros objetos, além de índices espectrais variados, os quais, em conjunto, possibilitam a classificação dos objetos com um menor nível de intervenção por parte do interprete.

Neste trabalho tivemos por objetivo principal a avaliação do desempenho das Unidades de Conservação, Terras Indígenas e Terras Quilombolas existentes no Cerrado em relação à sua capacidade de manter o habitat natural. Foi também objetivo verificar eventuais variações no desempenho das unidades em função de suas características, em especial o grau de restrição, esfera governamental a que pertencem, tamanho das unidades e tempo decorrido desde seu estabelecimento.

Objetivou-se, ainda, a obtenção de informações espacializadas relativas ao uso e cobertura da terra para períodos históricos em que ainda não houve a disponibilização de 
dados oficiais, especificamente para os anos de 1985 e 1995. A obtenção de tais informações permitiu, em conjunto com dados oficiais já publicados, a formação de uma série histórica de maior extensão, possibilitando que as análises sobre o desempenho das áreas protegidas, anteriormente mencionada, apresentem maior qualidade e sejam mais assertivas. 


\section{ESTRUTURA DA DISSERTAÇÃO}

Além do presente capítulo, onde se discute as principais motivações para a realização deste trabalho e são abordadas características gerais da área de estudo, a presente dissertação conta com dois capítulos principais. Cada um dos capítulos foi estruturado de forma a conter todos os elementos informativos necessários.

No Capítulo 2, apresentamos a metodologia desenvolvida para a realização de mapeamento do uso e cobertura da terra com a utilização de Análise de Imagem Baseada em Objetos - GEOBIA, além dos resultados alcançados. Objetivou-se com o mapeamento a identificação de áreas antrópicas, áreas naturais e corpos d'água para os anos de 1985 e 1995, abrangendo toda a área de estudo, em escala correspondente àquela utilizada pelo mapeamento de referência. Utilizou-se como mapeamento base aquele realizado pelo Projeto de Monitoramento do Desmatamento dos Biomas Brasileiros por Satélite - PMDBBS (CSR/IBAMA), o qual adotou como escala 1:50.000, com a identificação de áreas mínimas de 2 hectares. A metodologia teve como etapas principais: o reconhecimento de atributos identificadores das feições de interesse; a obtenção de objetos; a realização de análise de agrupamento; e a classificação de grupos de feições para as classes finais de interesse.

O Capítulo 3 foi dedicado à quantificação e avaliação do efeito das áreas protegidas sobre a manutenção do habitat natural. Foram consideradas como unidades territoriais de interesse as Unidades de Conservação, as Terras Indígenas e as Terras Quilombolas existentes na área de estudo. Para a realização da avaliação foram definidas, em toda a região pesquisada, unidades amostrais com $1 \mathrm{~km}^{2}$, as quais pertencem às áreas protegidas (grupo tratamento) ou à região em seu exterior (grupo controle). Para cada unidade amostral foram obtidas a variável tratamento (existência ou não de unidade de conservação), a variável resposta (área antrópica no interior de cada unidade amostral) e 19 covariáveis. O efeito médio das áreas protegidas foi acessado comparando-se unidades amostrais do grupo tratamento e controle que apresentassem a maior similaridade em relação a múltiplas covariáveis.

Os capítulos mencionados, embora possam ser compreendidos de forma independente, estão inter-relacionados, já que os dados obtidos com o mapeamento realizado (Capítulo 2) foram imprescindíveis para a avaliação do desempenho das áreas protegidas na área de estudo (Capítulo 3), tendo sido utilizados para a formação de séries históricas mais extensas relativas a eventos de alteração no uso e cobertura da terra na região, tendo impacto direto sobre a confiabilidade dos resultados obtidos no Capítulo 3. 


\section{3. ÁREA DE ESTUDO}

O estudo teve como área de interesse o Bioma Cerrado, adotando-se os limites definidos pelo Mapa de Biomas do Instituto de Brasileiro de Geografia e Estatística - IBGE (IBGE, 2004) (Figura 2).

Ocupando a maior parte da região central do Brasil, o Cerrado conta com uma área total de 2.036.448 (23,92\% da área continental brasileira), abrangendo regiões de 12 estados (Bahia, Distrito Federal, Goiás, Minas Gerais, Mato Grosso, Mato Grosso do Sul, Maranhão, Paraná, Piauí, Rondônia, São Paulo e Tocantins).

O Bioma pode ser definido como um complexo vegetacional com uma formação do tipo savana tropical, com destacada sazonalidade e grande diversidade, constituído por "áreas com árvores e arbustos espalhados sobre um estrato graminoso, sem a formação de dossel contínuo" (Ribeiro e Walter, 1998; Walter, Carvalho e Ribeiro, 2008). Por vezes tal complexo vegetacional aparece relacionado na literatura aos conceitos de domínio fitogeográfico (Coutinho, 2006) ou província vegetacional (Eiten, 1972), sendo Bioma o termo mais aplicado (Dias, 1994; Oliveira e Marquis, 2002; Ratter, Ribeiro e Bridgewater, 1997; Scariot, Sousa-Silva e Felfili, 2005; Walter, Carvalho e Ribeiro, 2008). Embora o termo bioma tenha aplicação controversa quando aplicado ao Cerrado e com menor rigor científico, conforme discutido por Coutinho (2006), esse foi adotado neste estudo em função de ser correntemente utilizado por iniciativas e estudos que enfoquem aspectos territoriais da região (eg. PMDBBS, PPCERRADO, TERRACLASS), sendo utilizado, inclusive, na própria definição de seus limites espaciais (IBGE, 2004).

O clima no Cerrado é caracterizado por marcada sazonalidade, com invernos secos e verões chuvosos. Pela classificação de Köppen, há a ocorrência de dois tipos principais de clima, tropical úmido (Aw), na maior parte do Bioma, e temperado quente (Cwa), em regiões de Minas Gerais e Mato Grosso do Sul (Silva, Assad e Evangelista, 2008). A precipitação média anual varia entre regiões, sendo uma média mínima de $400 \mathrm{~mm}$ (em regiões do Piauí) e máxima de $2.400 \mathrm{~mm}$ (em regiões de Tocantins). Os meses de maior pluviosidade são aqueles entre outubro e março, em especial os meses de novembro, dezembro e janeiro. O período de seca se estende por cerca de 6 meses, entre abril e outubro, registrando alta deficiência hídrica climática. As menores temperaturas médias anuais variam de 18 a $22^{\circ} \mathrm{C}$ (Goiás, Minas Gerais e Mato Grosso do Sul) e as maiores médias anuais variam de 23 a $27^{\circ} \mathrm{C}$ (Maranhão, Piauí e Bahia). A umidade relativa do ar média atinge níveis baixos durante a estação seca (40 a 60\%), e níveis de moderado a alto durante o verão chuvoso (60 a 90\%) (Silva, Assad e Evangelista, 2008). 

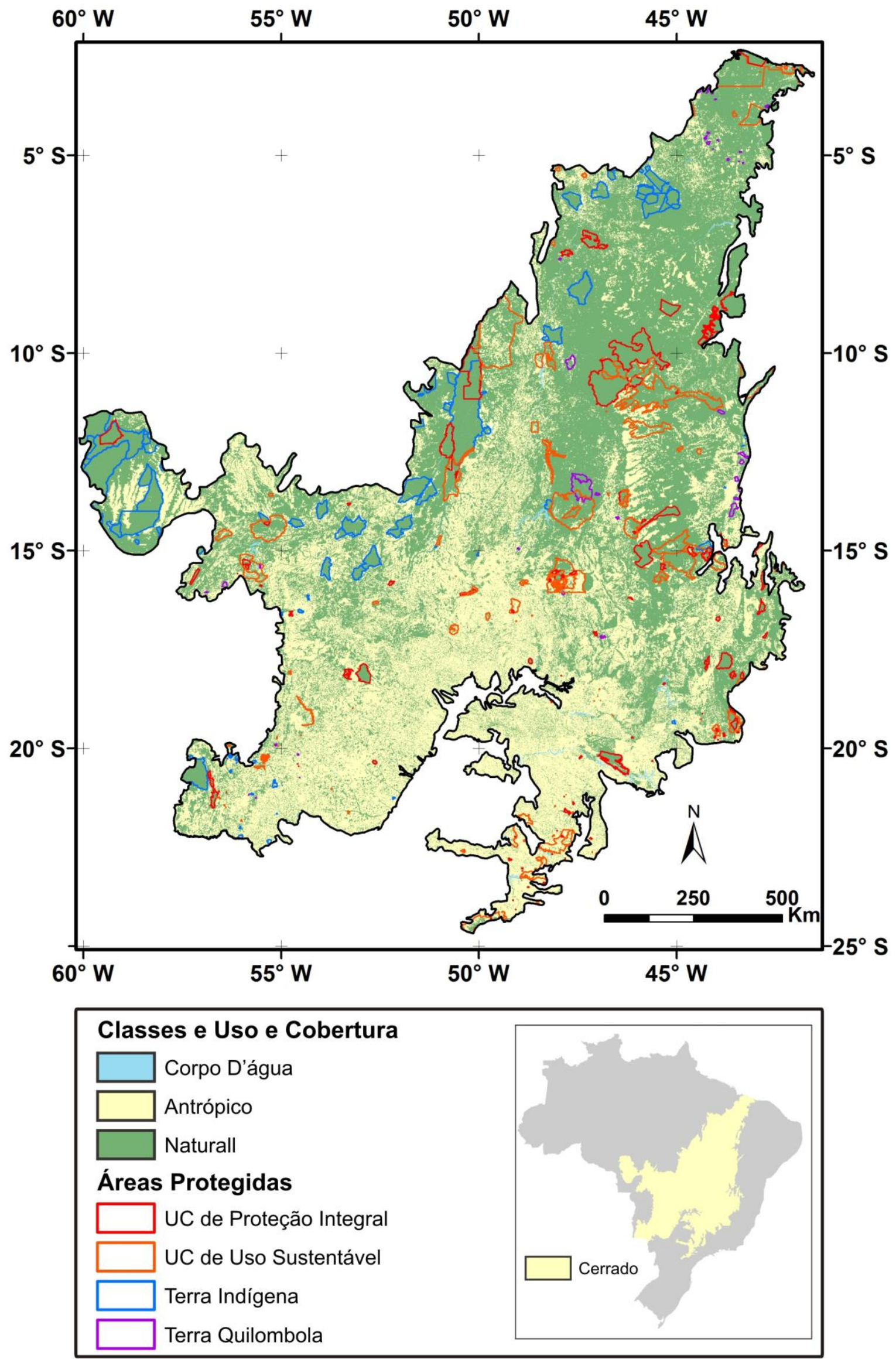

Figura 2 - Unidades Territoriais consideradas e uso da terra na região definida para o estudo. 
Os solos dominantes na região de estudo são muito antigos, intemperizados, ácidos e com altas concentrações de alumínio (Haridasan, 1994), geralmente, profundos, bem drenados e com baixa disponibilidade de nutrientes, além de baixa capacidade de troca catiônica (Goedert, 1986; Haridasan, 1994; Reatto et al., 2008). As maiores classes de solos são Latossolos, os quais respondem por 48,66\% de toda área do Bioma (24,56\% de Latossolos Vermelho-Amarelo e 22,1\% de Latossolo Vermelho), e Neossolos Quartzarênicos, os quais recobrem 14,46\% do Cerrado (Reatto et al., 2008).

Uma grande diversidade fitofisionômica, biogeográfica, ambiental e biológica é característica do Cerrado. Ribeiro \& Walter (1998) identificaram 11 tipos fitofisionômicos principais, distribuídos entre os três grandes grupos de formações vegetacionais (campestres, savânicas e florestais): 1) Formações Campestres - Campo Sujo, Campo Limpo, Campo Rupestre; 2) Formações Savânicas - Cerrado Sentido Restrito (Denso, Típico, Ralo e Rupestre), Parque de Cerrado, Palmeiral, Vereda; 3) Formações Florestais - Mata Ciliar, Mata de Galeria, Mata Seca e Cerradão). Mais recentemente, em uma classificação que busca padronizar as diferentes formações vegetacionais em um contexto nacional, o Manual Técnico da Vegetação Brasileira (IBGE, 2012) cita como tipos vegetacionais ocorrentes na região do Cerrado as formações de savanas (florestadas, arborizadas, parque e gramíneo-lenhosa, com e sem mata de galeria), além de florestas estacionais deciduais (terras baixas, montana e submontana) e semideciduais (aluvial, terras baixa, montana e submontana).

Tais variações fitofisionômicas geralmente estão relacionadas à influência de gradientes edáficos associados com variações geomorfológicas, a exemplo de profundidade do solo, presença de concreções no perfil, proximidade da superfície do lençol freático, drenagem e fertilidade (Haridasan, 2000; Walter, 2006). É relevante, ainda, o papel desempenhado pelo fogo, tendo efeito não só sobre a fenologia de espécies vegetais, mas também no impacto sobre as variações na ocorrência de diferentes tipologias fitofisionômicas (Coutinho, 1990; Mistry, 1998; Moreira, 2000).

Em termos de área, as fisionomias savânicas respondem pelo maior percentual da área natural do Cerrado, sendo seguida por formações florestais e campestres (Sano et al., 2010), como apresentado na Tabela 1. 
Tabela 1 - Área de cobertura por diferentes formações vegetacionais no Cerrado observadas para o ano de 2002.

\begin{tabular}{lrr}
\hline Formações & Área $\left(\mathbf{k m}^{2}\right)$ & $\mathbf{( \% )}$ \\
\hline Florestais & $402.290,98$ & $32 \%$ \\
Savânicas & $756.550,44$ & $61 \%$ \\
Campestres & $8.0615,76$ & $7 \%$ \\
\hline Total de Área natural & $\mathbf{1 . 2 3 9 . 4 5 7 , 1 8}$ & $\mathbf{6 0 \%}$ \\
\hline
\end{tabular}

Fonte: Sano et al. (2010).

Além de diferentes fitofisionomias, o Bioma Cerrado exibe padrões de distribuição de espécies de sua flora e fauna marcadamente diferentes entre regiões (Blamires et al., 2008; Camargo, Soares e Torezani, 2008; Costa et al., 2007; Ratter, Bridgewater e Ribeiro, 2003). No que se refere a regiões florísticas, Ratter, Bridgewater, Atkinson, \& Ribeiro (1996) e Ratter et al. (2003) indicaram a existência de ao menos seis grandes grupos florísticos no Bioma, além de regiões disjuntas com ocorrência na Amazônia Legal.

Em termos de diversidade ambiental, enquanto biomas com formações tipicamente florestais apresentam grande heterogeneidade espacial em um sentido vertical, o Cerrado apresenta variação principalmente em um sentido horizontal, com grande diversidade de ambientes em áreas relativamente pequenas (Machado et al., 2004). Tal diversidade pode ser apreendida por meio do conceito de sistema de terras (Cochrane et al., 1985), o qual representa um grupo de áreas que apresentam padrão de clima, paisagem e solos semelhantes. Considerando-se tais atributos, foram identificados 70 sistemas de terra e 25 unidades fisiográficas no Cerrado (Felfili e Silva Júnior, 2005).

Essa alta diversidade de ambientes se reflete sobre a riqueza de espécies, o que dá ao Cerrado o status de savana mais rica do planeta (Myers et al., 2000), com cerca de 30\% de todas as espécies com ocorrência no Brasil e cerca de 5\% da riqueza total de espécies no mundo (Tabela 2). Além da grande diversidade, a biota vegetal e animal do Cerrado apresenta especial importância pelo grande grau de endemismo ocorrente em vários grupos biológicos (Medonça et al., 2008; Myers et al., 2000; Silva e Bates, 2013). 
Tabela 2 - Número de espécies catalogadas no Cerrado, no Brasil e no Mundo.

\begin{tabular}{|c|c|c|c|c|c|}
\hline Grupos & Cerrado & Brasil') & Mundo $^{(11)}$ & Cerrado/Brasil (\%) & Cerrado/Mundo (\%) \\
\hline Plantas & $12.356^{(1)}$ & $43.535^{(2)}$ & 281.052 & 28,38 & 4,40 \\
\hline Mamíferos & $251^{(3)}$ & $701^{(3)}$ & 5.501 & 35,81 & 4,56 \\
\hline Aves & $864^{(4)}$ & $1.832^{(5)}$ & 10.064 & 47,16 & 8,59 \\
\hline Répteis & $247^{(6)}$ & $744^{(7)}$ & 9.789 & 33,20 & 2,52 \\
\hline Anfíbios & $152^{(6)}$ & $946^{(8)}$ & 7.044 & 16,07 & 2,16 \\
\hline Peixes & $1.200^{(9)^{*}}$ & $3.598^{(10)}$ & 32.500 & 33,35 & 3,69 \\
\hline Total & 15.070 & 51.356 & 345.950 & 29,33 & 4,35 \\
\hline
\end{tabular}

\subsection{Breve histórico sobre a ocupação no Cerrado}

Iniciativas no sentido de promover a ocupação de regiões do Cerrado passaram a receber especial atenção governamental a partir do período Vargas, entre 1930-1945, com um enfoque na promoção da integração nacional, desenvolvimento econômico e ocupação efetiva do que era então considerado um vazio demográfico (Bezerra e Cleps Jr., 2004; Dias, 2008; Klink e Moreira, 2002). A ação governamental, nesse período, passou pela promoção da fundação de novos núcleos urbanos, como a fundação da cidade de Goiânia (1933), a integração da região à rede viária existente, além de incentivos à migração e produção agrícola e pecuária (Alho e Martins, 1995; Fernandes e Pessôa, 2011). Tais medidas governamentais ficaram claramente delineadas no programa "Marcha para o Oeste" (Garfield, 2000), o qual teve como principais resultados o desenvolvimento da pecuária extensiva na região.

Com a construção e fundação de Brasília, a partir da década de 50, houve uma intensificação do processo de ocupação da região central do Cerrado, fato que teve reflexo sobre a rede urbana local, o desenvolvimento da infraestrutura regional, economia e demografia. Políticas específicas para o fomento ao desenvolvimento e modernização das atividades agropecuárias também foram intensificadas, sendo acompanhadas por investimentos em infraestrutura (estradas, armazenamento, eletrificação rural), apoio tecnológico por meio de órgãos federais e estaduais (EMBRAPA, CPAC, EMATER, EPAMIG), além de grande aporte de recursos destinado à disponibilização de crédito aos produtores (Cunha et al., 1994; Franco, 2001; Salim, 1986). 
Tiveram destaque nesse contexto o Programa de Desenvolvimento das Áreas de Cerrados - POLOCENTRO, com vigência entre 1974 e 1982 (Alho e Martins, 1995; Salim, 1986) e o Programa de Cooperação Nipo-Brasileira de Desenvolvimento dos Cerrados PROCEDER, com três etapas entre 1979 e 1999 (Inocêncio e Calaça, 2009; Yoshii, Camargo e Orioli, 2000). Os programas tiveram como objetivo promover o desenvolvimento e a modernização das atividades agropecuárias na região do Cerrado e, como impacto direto, resultaram na incorporação de mais de 2,5 milhões de hectares à agricultura e pecuária (Cunha et al., 1994; Inocêncio e Calaça, 2009).

Na região de estudo, as medidas governamentais voltadas para o desenvolvimento agrário resultaram na implantação de uma agricultura comercial, com forte expansão do cultivo e com extensiva incorporação de terras (Ribeiro et al., 2005), transformando a região em um dos polos de maior produção agrícola do Brasil.

Acompanhando a expansão econômica e de infraestrutura, a população teve um crescimento de quase 10 vezes entre 1950 e 2010 (Tabela 3). Considerando-se apenas a região Centro-Oeste, no período indicado, a população da região passou de 1,5 milhões para 14,1 milhões de habitantes em 2010, representando 7,4\% da população nacional (IBGE, 2013). Exemplo de grande expansão demográfica, Goiás e Distrito Federal, com uma população de aproximadamente um milhão de habitantes em 1950 (1,95\% da população nacional), passou a ter uma população mais de oito milhões de habitantes em 2010 (4,49\% da população nacional), um crescimento maior do que 8 vezes em apenas 50 anos (IBGE, 2013), como apresentado na Tabela 3.

Tabela 3 - População da região Centro-Oeste do Brasil entre 1950 e 2010 (unidade: mil habitantes).

\begin{tabular}{lrrrrrrr}
\hline Região & 1950 & 1960 & 1970 & 1980 & 1991 & 2000 & 2010 \\
\hline Centro-Oeste & 1.533 & 2.678 & 4.630 & 7.004 & 9.412 & 11.617 & 14.058 \\
Brasil & 51.944 & 70.992 & 945.09 & 121.151 & 146.917 & 169.591 & 190.756 \\
\hline Centro-Oeste /Brasil (\%) & $2.95 \%$ & $3.77 \%$ & $4.90 \%$ & $5.78 \%$ & $6.41 \%$ & $6.85 \%$ & $7.37 \%$ \\
\hline
\end{tabular}

Fonte: IBGE (2013).

O processo de ocupação e a transformação da região em uma potência produtiva agrícola foi levado a cabo deixando em segundo plano a preservação de recursos naturais e da biodiversidade. Acompanhando o crescimento demográfico, o desenvolvimento de uma rede urbana, a implantação da infraestrutura viária e o desenvolvimento e expansão agropecuária, alterações extensivas do uso e cobertura da terra ocorreram em um curto espaço de tempo, colocando em risco a biota e o meio ambiente. 


\subsection{Monitoramento de alterações no uso e cobertura da terra}

Estimativas sobre a cobertura vegetal natural e conversões para uso antrópico no Bioma Cerrado foram realizadas por meio de dados cadastrais (Alho e Martins, 1995; Dias, 1994; Sano, Jesus e Bezerra, 2001) ou obtidos a partir de dados de sensores remotos (Aguiar et al., 2005; Eva et al., 2004; Ferreira, Venticinque e Almeida, 2005; Machado et al., 2004; Mantovani e Pereira, 1998; MMA e SBF, 2002; Rocha et al., 2011; Sano et al., 2010). Diferentemente do Bioma Amazônico que conta com monitoramento sistemático desde 1988 por meio do Projeto de Estimativa do Desflorestamento Bruto da Amazônia - PRODES (INPE, 2015), apenas recentemente importantes iniciativas foram propostas no sentido de promover o monitoramento contínuo na região.

Destacam-se nesse contexto a iniciativa no âmbito do Projeto de Conservação e Utilização Sustentável da Diversidade Biológica Brasileira - PROBIO I (Sano et al., 2010); o Projeto de Monitoramento do Desmatamento dos Biomas Brasileiros por Satélite - PMDBBS (IBAMA, 2016); o Sistema Integrado de Alerta de Desmatamento - SIAD (LAPIG/UFG, 2012); e iniciativas mais recentes no âmbito do Programa de Monitoramento Ambiental dos Biomas Brasileiros (PMABB), o programa TerraClass Cerrado (MMA, 2015) e o Sistema de Detecção do Desmatamento e Alterações na Cobertura Florestal em Tempo Quase Real (Deter-B) (Valeriano et al., 2016).

O Centro de Sensoriamento Remoto do IBAMA - CSR/IBAMA, por meio do PMDBBS, apresenta a maior série histórica relativa ao monitoramento do uso e cobertura da terra na região. Esse programa realizou o monitoramento do Cerrado com base na análise de imagens dos satélites CBERS2B e LANDSAT entre os anos 2002 e 2011, com a identificação de áreas a partir de 2 hectares (IBAMA, 2016). Evidenciou, apenas no período em destaque, a conversão de mais de 5\% de toda a área do Bioma, alcançando 48,89\% de cobertura pela classe antrópico no ano de 2011 (Tabela 4) (IBAMA, 2015).

Tabela 4 - Variação no percentual de áreas de remanescentes naturais no Cerrado entre 2002 e 2011. Área total de referência do Cerrado de $2.039 .386 \mathrm{~km}^{2}$.

\begin{tabular}{lccccc}
\hline \multicolumn{1}{c}{ Descritor } & Anterior a 2002 & $2002-2008$ & $2008-2009$ & $2009-2010$ & $2010-2011$ \\
\hline Área desmatada $\left(\mathrm{Km}^{2}\right)$ & 890636 & 85074 & 7637 & 6469 & 7247 \\
Antrópico (\%) & 43.67 & 47.84 & 48.22 & 48.54 & 48.89 \\
Natural (\%) & 56.33 & 52.16 & 51.78 & 51.46 & 51.11 \\
\hline
\end{tabular}

Fonte: (IBAMA, 2015). 
Ainda que em termos relativos outros biomas encontrem-se em situação mais grave, como é o caso do Bioma Mata Atlântica, que possui apenas 22\% de cobertura natural (IBAMA, 2016), o Cerrado tem apresentado, recorrentemente, as maiores taxas de desmatamento entre os biomas brasileiros nos últimos anos ${ }^{1}$. Além disso, em termos absolutos, esse apresenta a maior área desmatada entre os biomas, num total de $997.063 \mathrm{~km}^{2}$, superando até mesmo biomas com área total muito superior, como é o caso do Bioma Amazônico².

Há um padrão consistente na distribuição das áreas desmatadas no Cerrado. O desmatamento histórico acumulado atinge principalmente as porções centro-sul, sudoeste e sudeste do Bioma, correspondente às regiões centro-sul dos Estados de Goiás, Distrito Federal, Mato Grosso do Sul, sul de Mato Grosso, Minas Gerais, São Paulo e Paraná, estando normalmente relacionado a regiões muito povoadas $\mathrm{e}$ intensamente exploradas economicamente nas últimas cinco décadas (Rocha et al., 2011; Sano et al., 2010).

\section{3. Áreas protegidas no Cerrado}

De especial interesse para este estudo são as Unidades de Conservação (UC's), Terras Indígenas (TI's) e Terras Quilombolas (TQ's) existentes no Cerrado. Conforme dados do Cadastro Nacional de Unidades de Conservação - CNUC/MMA estão presentes no bioma 384 UC's, ocupando 8,26\% da área total do Cerrado. Dentre tais unidades, 120 pertencem ao grupo de Proteção Integral (PI), correspondendo a 3,09\% da área total $\left(62.982 \mathrm{~km}^{2}\right)$; e 264 pertencem ao grupo de Uso Sustentável, 5,48\% da área total $\left(111.786 \mathrm{~km}^{2}\right)$. Além das UC's, estão presentes 102 Terras Indígenas (96.638 km² ou 4,74\% da área do Cerrado) e 52 Terras Quilombola (5.651 km² ou 0,28\% da área do Cerrado) (Tabela 5).

Em conjunto, as áreas protegidas no Cerrado recobrem um percentual substancialmente inferior àquele constante de compromisso firmado pelo Brasil junto à $10^{\mathrm{a}}$ Conferência das Partes da Convenção sobre Diversidade Biológica - COP 10 (UNEP/CDB/COP-10, 2010), conhecido como as Metas de Aichi, ou em relação às metas estabelecidas pela Resolução $\mathrm{n}^{\circ} \quad 6$ da Comissão Nacional de Biodiversidade (MMA/CONABIO, 2013). Além disso, o percentual de área recoberto por Unidades de

\footnotetext{
${ }^{1}$ Por exemplo, para o ano de 2011, as taxas mostraram-se superiores ao dobro daquelas observadas para a Amazônia Legal - 0,12\% (6.418 $\mathrm{km}^{2}$ de área desmatada de um total de $\left.5.020 .000 \mathrm{~km}^{2}\right)$ e 0,35\% para o Cerrado (7.247 $\mathrm{km}^{2}$ de área desmatada em um total de 2.039.386) (IBAMA, 2015; INPE, 2015).

${ }^{2}$ O Cerrado representa $24 \%$ do território nacional $\left(2.036 .448 \mathrm{~km}^{2}\right)$, enquanto o Bioma Amazônico representa 49\% (4.196.943 $\left.\mathrm{km}^{2}\right)$ (IBGE, 2004).
} 
Conservação e Terras Indígenas é inferior àquele observado em um âmbito nacional (Tabela 5) e em outros biomas, a exemplo do Bioma Amazônico, onde UC's recobrem 27,30\% e TI's 25,10\% (CNUC/MMA, 2016; FUNAI, 2015).

Tabela 5 - Unidades de Conservação, Terra Indígena e Terra Quilombola, considerando toda a extensão do território continental brasileiro $\left(8.514 .085 \mathrm{~km}^{2}\right)$ e toda a extensão do Bioma Cerrado (2.040.167).

\begin{tabular}{cccc|ccc}
\multicolumn{1}{c}{ Grupo } & $\mathbf{c}$ & \multicolumn{3}{c}{ Cerrado } \\
& $\mathbf{N}$ & Área $\left(\mathbf{k m}^{2}\right)$ & $\boldsymbol{\%}$ & $\mathbf{N}$ & Area $\left(\mathbf{k m}^{2}\right)$ & $\%$ \\
\hline UC's sem sobreposição & 2012 & 1491287 & $17.52 \%$ & 384 & 168442 & $8.26 \%$ \\
Proteção Integral (PI) & 622 & 535783 & $6.29 \%$ & 120 & 62982 & $3.09 \%$ \\
Uso Sustentável (US) & 1390 & 991762 & $11.65 \%$ & 264 & 111786 & $5.48 \%$ \\
Terra Indígena (TI) & 588 & 1164849 & $13.68 \%$ & 102 & 96638 & $4.74 \%$ \\
Terra Quilombola (TQ) & 305 & 23234 & $0.27 \%$ & 52 & 5651 & $0.28 \%$ \\
\hline Total - UC's, TI's e TQ's & 2905 & 2679370 & $31.47 \%$ & 538 & 270731 & $13.28 \%$ \\
\hline
\end{tabular}

Fonte: CNUC de 09/08/2016 (CNUC/MMA, 2016); FUNAI (2015); INCRA (2015).

Aspectos específicos e outras características relevantes relacionadas à área de estudo são tratados nos capítulos 2 e 3. 


\section{REFERÊNCIAS}

AGUIAR, L. M. DE S.; MACHADO, R. B.; MARINHO-FILHO, J. A Diversidade Biológica do Cerrado. In: AGUIAR, L. M. DE S.; CAMARGO, A. J. A. DE (Eds.). . Cerrado: ecologia e caracterização. Brasília: Embrapa Cerrados, 2004. p. 19-42.

AGUIAR, M. C. DE et al. Mapeamento do Uso do Solo e da Cobertura Vegetal do Bioma Cerrado a partir de dados orbitais MODIS e SRTM e dados Censitários. Anais XII Simpósio Brasileiro de Sensoriamento Remoto, n. 1998, p. 2799-2801, 2005.

ALHO, C. J. R.; MARTINS, E. DE S. (EDS.). De Grão em Grão, O Cerrado Perde Espaço: Cerrado - Impactos do Processo de Ocupação. Brasília: WWF, 1995.

ANDAM, K. S. et al. Measuring the effectiveness of protected area networks in reducing deforestation. Proceedings of the National Academy of Sciences of the United States of America, v. 105, n. 42, p. 16089-94, 21 out. 2008.

BÉRNILS, R. S.; COSTA, H. C. Brazilian reptiles: list of species. Version 2012.2. Disponível em: <http://www.sbherpetologia.org.br>. Acesso em: 3 jun. 2013.

BEZERRA, L. M. C.; CLEPS JR., J. O desenvolvimento agrícola da região Centro-Oeste e as transformações no espaço agrario do Estado de Goiás. Caminhos de Geografia, v. 2, n. 12, p. 29-49, 2004.

BLAMIRES, D. et al. Habitat use and deconstruction of richness patterns in Cerrado birds. Acta Oecologica, v. 33, p. 97-104, 2008.

BRITES, V. L. DE C. et al. The Herpetofauna of the Neotropical Savannas. In: UNESCOEOLSS (Ed.). . Encyclopedia of Life Support Systems. Paris: Unesco-Eolss, 2009. v. Xp. Vol. X.

BROOKS, T. M. Conservation planning and priorities. In: SODHI, N. S.; EHRLICH, P. R. (Eds.). . Conservation Biology for All. New York: Oxford University Press, 2010. p. 199219.

CAMARGO, A. J. A. DE; SOARES, R. DOS S.; TOREZANI, K. R. DE S. Saturniidae (Lepidoptera) do Cerrado: Biodiversidade e aspectos biogeograficos. IX Simpósio Nacional do Cerrado, 2008.

CBRO, C. B. DE R. O. Lista das aves do Brasil. Disponível em: <http://www.cbro.org.br>. Acesso em: 29 out. 2013.

CHAPE, S.; SPALDING, M.; JENKINS, M. (EDS.). The World's Protected Areas: status, values and prospects in the 21st century. London, England: UNEP-WCMC, 2008.

CNUC/MMA. Cadastro Nacional de Unidades de Conservação: tabela consolidada das Unidades de Conservação. Disponível em: <http://www.mma.gov.br/areasprotegidas/cadastro-nacional-de-ucs/dados-consolidados>. Acesso em: 9 ago. 2016.

COCHRANE, T. T. et al. Land in Tropical America. [s.1.] CIAT/EMBRAPA - CPAC, 1985.

COSTA, G. C. et al. Squamate richness in the Brazilian Cerrado and its environmental climatic associations. Diversity and Distributions, v. 13, p. 714-724, 2007.

COUTINHO, L. M. Fire in the ecology of the Brazilian Cerrado. In: Fire in the Tropical Biota. [s.1: s.n.]. v. 84p. 82-105.

COUTINHO, L. M. O conceito de bioma. Acta Botanica Brasilica, v. 20, n. 1, p. 13-23, 2006. 
CUNHA, A. S. et al. Uma avaliação da sustentabilidade da agricultura nos cerrados. Brasília, DF: IPEA, 1994.

DIAS, B. F. DE S. Conservação da Natureza no Cerrado Brasileiro. In: PINTO, M. N. (Ed.). . Cerrado: caracterização, ocupação e perspectivas. Brasília: Editora Universidade de Brasília, 1994. p. 607-681.

Conservação da Biodiversidade no Bioma Cerrado: histórico dos impactos antrópicos no Bioma Cerrado. In: FALEIRO, F. G.; NETO, A. L. DE F. (Eds.). . Savanas: desafios e estratégias para o equilíbrio entre sociedade, agronegócios e recursos naturais. Brasília, Distrito Federal, Brazil: Embrapa Informação Tecnológica, 2008. p. 303-333.

EITEN, G. The Cerrado Vegetation of Brazil. The Botanical Review, v. 38, n. 2, p. 201-327, 1972.

EVA, H. D. et al. A land cover map of South America. Global Change Biology, v. 10, p. 114, 2004.

FELFILI, J. M.; SILVA JÚNIOR, M. C. DA. Diversidade alfa e beta no cerrado sensu strictu, Distrito Federal, Goiás, Minas Gerais e Bahia. In: SCARIOT, A.; SOUSA-SILVA, J. C.; FELFILI, J. M. (Eds.). . Cerrado: Ecologia, Biodiversidade e Conservação. Brasília, DF: MMA, 2005. p. 141-154.

FERNANDES, P. A.; PESSÔA, V. L. S. O Cerrado e suas atividades impactantes: uma leitura sobre o garimpo, a mineração e a agricultura mecanizadas. Observatorium: Revista Eletrônica de Geografia, v. 3, n. 7, p. 19-37, 2011.

FERREIRA, L. V.; VENTICINQUE, E.; ALMEIDA, S. O desmatamento na Amazônia e a importância das áreas protegidas. Estudos Avançados, v. 19, n. 53, p. 157-166, 2005.

FRANCO, J. B. S. O papel da Embrapa nas Transformações do Cerrado. Caminhos de Geografia, v. 2, n. 3, p. 31-40, 2001.

FUNAI. Mapa de Terras Indígenas do Brasil. Disponível em: <http://mapas.funai.gov.br/>. Acesso em: 10 out. 2015.

GARFIELD, S. As raízes de uma planta que hoje é o Brasil : os índios e o Estado-Nação na era Vargas. Revista Brasileira de História, v. 20, n. 39, p. 15-42, 2000.

GEIST, H. J.; LAMBIN, E. F. Proximate Causes and Underlying Driving Forces of Tropical Deforestation. BioScience, v. 52, n. 2, p. 143-150, 2002.

GELDMANN, J. et al. Effectiveness of terrestrial protected areas in reducing habitat loss and population declines. Biological Conservation, v. 161, n. March, p. 230-238, 2013.

GOEDERT, W. J. (ED.). Solos dos Cerrados: tecnologias e estratégias de manejo. Planaltina, DF / São Paulo: Embrapa-CPAC / Nobel, 1986.

HARIDASAN, M. Solos. In: PINTO, M. N. (Ed.). . Cerrado: caracterização, ocupação e perspectivas. Brasília: Editora Universidade de Brasília, 1994. p. 321-344.

Nutrição mineral de plantas nativas do cerrado. Revista Brasileira de Fisiologia Vegetal, v. 12, n. Tabela 2, p. 54-64, 2000.

HAY, G. J.; CASTILLA, G. Geographic Object-Based Image Analysis (GEOBIA): A new name for a new discipline. In: BLASCHKE, T.; LANG, S.; HAY, G. J. (Eds.). . ObjectBased Image Analysis. Berlin: Springer Berlin Heidelberg, 2008. p. 75-89.

IBAMA. Relatorio Técnico de Monitoramento do Desmatamento nos Biomas Brasileiros Por Satélite: Cerrado 2010-2011. Relatório Técnico, p. 1-16, 2015. 
Projeto de Monitoramento do Desmatamento dos Biomas Brasileiros por Satélite PMDBBS: Mapa de áreas desmatadas no Biomas Cerrado - 2002 a 2011. Disponível em: $<$ http://siscom.ibama.gov.br/monitora_biomas/PMDBBS - CERRADO.html>. Acesso em: 1 maio. 2016.

IBGE. Mapa de Biomas do Brasil. Disponível em: <http://www.ibge.gov.br/home/presidencia/noticias/21052004biomas.shtm>. Acesso em: 8 jan. 2013.

Manual Técnico da Vegetação Brasileira. Rio de Janeiro: IBGE, 2012.

IBGE - Séries Historicas Estatísticas: População e demografia. Disponível em: <http://seriesestatisticas.ibge.gov.br/>. Acesso em: 31 out. 2013.

IJBRJ, J. B. DO R. DE J. Lista de Espécies da Flora do Brasil 2013. Disponível em: <http://floradobrasil.jbrj.gov.br/>. Acesso em: 28 out. 2013.

INCRA. Mapa de Terras Quilombolas - INCRA. Disponível em: $<$ http://acervofundiario.incra.gov.br/>. Acesso em: 10 out. 2015.

INOCÊNCIO, M. E.; CALAÇA, M. Fronteira da Produção Agrícola Capitalista do Século XX. XIX Encontro Nacional de Geografia Agrária, p. 1-16, 2009.

INPE. Projeto de Estimativa do Desflorestamento Bruto da Amazônia - PRODES. Disponível em: <http://www.obt.inpe.br/prodes/index.php>. Acesso em: 30 set. 2015.

IUCN. IUCN Red List of Threatened Species: Summary Statistics for Globally Threatened Species. Disponível em: 〈http://www.iucnredlist.org/about/summary-statistics>. Acesso em: 28 out. 2013.

KLINK, C. A.; MOREIRA, A. G. Past and current human occupation and land-use. In: OLIVEIRA, P. S.; MARQUIS, R. J. (Eds.). . The Cerrado of Brazil. Ecology and natural history of a neotropical savanna. New York: Columbia University Press, 2002. p. 69-88.

KNIGHT, A. T.; COWLING, R. M.; CAMPBELL, B. M. An operational model for implementing conservation action. Conservation Biology, v. 20, n. 2, p. 408-419, 2006.

LAPIG/UFG. Sistema Integrado de Alertas de Desmatamento - SIAD. Disponível em: <https://www.lapig.iesa.ufg.br/lapig/index.php/noticias/22-ufg>. Acesso em: 22 out. 2012.

MACHADO, R. B. et al. Estimativas de perda da área do Cerrado brasileiro.Conservação Internacional - Brasil. Relatório Técnico. Brasília, DF: Conservação Internacional - Brasil, 2004.

MANTOVANI, J. E.; PEREIRA, A. Estimativa da Integridade da Cobertura Vegetal de Cerrado Através de Dados TM/Landsat. Anais IX Simpósio Brasileiro de Sensoriamento Remoto, p. 1455-1466, 1998.

MARGULES, C. R.; PRESSEY, R. L. Systematic conservation planning. Nature, v. 405, n. 6783, p. 243-53, 11 maio 2000.

MEDONÇA, R. C. et al. Flora vascular do bioma Cerrado: checklist com 12.356 espécies. In: SCARIOT, A.; SOUSA-SILVA, J. C.; FELFILI, J. M. (Eds.). . Cerrado: Ecologia e Flora. Brasília, DF: Embrapa Informação Tecnológica, 2008. p. V.2.

MISTRY, J. Fire in the savannas of Brazil: an ecological review. Progress in Physical Geography, v. 22, n. 4, p. 425-448, 1998.

MMA. Mapeamento do Uso e Cobertura do Cerrado: Projeto TerraClass Cerrado (2013). Brasília: MMA, 2015. 
MMA/CONABIO. Resolução CONABIO n 06, de setembro de 2013: Dispóe sobre as Metas Nacionais de Biodiversidade para 2020, 2013.

MMA; SBF. Biodiversidade brasileira: avaliação e identificação de áreas e ações prioritárias para conservação, utilização sustentável e repartição dos venefícios da biodiversidade nos biomas brasileiros. Brasília, Distrito Federal, Brazil: MMA/SBF, 2002.

MOREIRA, A. G. Effects of fire protection on savanna structure in central Brazil. Journal of Biogeography, v. 27, n. 4, p. 1021-1029, 2000.

MYERS, N. et al. Biodiversity hotspots for conservation priorities. Nature, v. 403, p. 853858, 24 fev. 2000.

NAUGHTON-TREVES, L.; HOLLAND, M. B.; BRANDON, K. The Role of Protected Areas in Conserving Biodiversity and Sustaining Local Livelihoods. Annual Review of Environment and Resources, v. 30, n. 1, p. 219-252, 21 nov. 2005.

OLIVEIRA, P. S.; MARQUIS, R. J. The Cerrados of Brazil. New York: Columbia University Press, 2002.

PAGLIA, A. P. et al. Annotated Checklist of Brazilian Mammals. Occasional Papers in Conservation Biology, v. 6, p. 76pp, 2012.

RATTER, J. A. et al. Analysis of the floristic composition of the brazilian cerrado vegetation II: comparison of the woody vegetation of 98 areas. Endiburg Journal of Botaniy, v. 53, n. 2, p. 153-180, 1996.

RATTER, J. A.; BRIDGEWATER, S.; RIBEIRO, J. F. Analysis of the floristic composition of the brazilian cerrado vegetation III: comparison of the woody vegetation of 376 areas. Endiburg Journal of Botaniy, v. 60, n. 1, p. 57-109, 2003.

RATTER, J. A.; RIBEIRO, J. F.; BRIDGEWATER, S. The Brazilian Cerrado Vegetation and Threats to its Biodiversity. Annals of Botany, v. 80, n. 3, p. 223-230, set. 1997.

REATTO, A. et al. Solos do Bioma Cerrado: Aspectos pedológicos. In: SANO, S. M.; ALMEIDA, S. P. DE; RIBEIRO, J. F. (Eds.). . Cerrado: Ecologia e Flora. Brasília, DF: Embrapa Informação Tecnológica, 2008. p. 109-149.

RIBEIRO, J. F. et al. Ocupação do bioma Cerrado e conservação da sua diversidade vegetal. In: SCARIOT, A.; SOUSA-SILVA, J. C.; FELFILI, J. M. (Eds.). . Cerrado: Ecologia, Biodiversidade e Conservação. Brasília, DF: MMA, 2005. p. 385-399.

RIBEIRO, J. F.; WALTER, B. M. T. Fitofisionomias do bioma cerrado. In: SANO, S. M.; ALMEIDA, S. P. (Eds.). . Cerrado: ambiente e flora. Brasília: Embrapa-CPAC, 1998. p. 89-166.

ROCHA, G. F. et al. Detecção de desmatamentos no Bioma Cerrado entre 2002 e 2009: Padroes, Tendências e Impactos. Revista Brasileira de Cartografia, v. 63, n. 3, p. 341-349, 2011.

ROSA, R. S.; LIMA, F. C. T. Os peixes brasileiros ameaçados de extinção. In: MACHADO, A. B. M.; DRUMMOND, G. M.; PAGLIA, A. P. (Eds.). . Livro vermelho da fauna brasileira ameaçada de extinção. Brasília, DF: MMA, 2008. p. 9-285.

SALIM, C. A. As políticas econômica e tecnológica para o desenvolvimento agrário nas áreas de cerrados no Brasil: avaliação e perspectivas. Cadernos de Difusão de Tecnologia, v. 3, n. 2, p. 297-342, 1986.

SANO, E. E. et al. Mapeamento do Uso do Solo e Cobertura Vegetal Bioma Cerrado Ano-Base 2002. Brasília: MMA/SBF, 2010. 
SANO, E. E.; JESUS, E. T. DE; BEZERRA, H. DA S. Uso de um Sistema de Informações Geograficas para Quantificação de Áreas Remanescentes do Cerrado. Comunicado Técnico Embrapa Cerrados, v. 62, p. 1-4, 2001.

SCARIOT, A.; SOUSA-SILVA, J. C.; FELFILI, J. M. (EDS.). Cerrado: Ecologia, Biodiversidade e Conservação. Brasília, DF: MMA, 2005.

SCHMITT, C. B. et al. Global analysis of the protection status of the world's forests. Biological Conservation, v. 142, n. 10, p. 2122-2130, 2009.

SEGALLA, M. V. et al. Brazilian amphibians - List of species. Disponível em: <www.sbherpetologia.org.br>. Acesso em: 28 out. 2013.

SILVA, F. A. M. DA; ASSAD, E. D.; EVANGELISTA, B. A. Caracterização Climática do Bioma Cerrado. In: SANO, S. M.; ALMEIDA, S. P. DE; RIBEIRO, J. F. (Eds.). . Cerrado: Ecologia e Flora. Brasília, DF: Embrapa Informação Tecnológica, 2008. p. 69-88.

SILVA, J. M. C.; BATES, J. M. Biogeographic Patterns and Conservation in the South American Cerrado: A Tropical Savanna Hotspot. BioScience, v. 52, n. 3, p. 225-234, 2013.

SILVA, J. M. C. DA; SANTOS, M. P. D. A importância relativa dos processos biogeográficos na formação da avifauna do Cerrado e de outros biomas brasileiros. In: SCARIOT, A.; SOUSA-SILVA, J. C.; FELFILI, J. M. (Eds.). . Cerrado: Ecologia, Biodiversidade e Conservação. Brasília, DF: MMA, 2005. p. 218-233.

SOHL, T.; SLEETER, B. Role of Remote Sensing for Land-Use and Land-Cover Change Modeling. In: GIRI, C. P. (Ed.). . Remote Sensing of Land Use and Land Cover. Boca Raton, FL: CRC Press, 2011. p. 225-239.

STONER, C. et al. Assessment of effectiveness of protection strategies in Tanzania based on a decade of survey data for large herbivores. Conservation Biology, v. 21, n. 3, p. 635-646, 2007.

$\mathrm{UNEP} / \mathrm{CDB} / \mathrm{COP}-10$. Decision adopted by the conference of the parties to the convention on biological diversity at its tenth meeting.UNEP, , 2010.

VALERIANO, D. DE M. et al. Metodologia do sistema DETER - B (Sistema de Detecção do Desmatamento e Alterações na Cobertura Florestal em Tempo Quase Real) mapeamento de alertas com imagens dos sensores awifs-resourcesat-2 e wfi-cbers-4. São José dos Campos, Brasil: INPE, 2016.

WALTER, B. M. T. Fitofisionomias do bioma Cerrado: síntese terminológica e relações florísticas. [s.1.] Universidade de Brasília, 2006.

WALTER, B. M. T.; CARVALHO, A. M. DE; RIBEIRO, J. F. O Conceito de Savana e de seu Componente Cerrado. In: SANO, S. M.; ALMEIDA, S. P. DE; RIBEIRO, J. F. (Eds.). . Cerrado: Ecologia e Flora. Brasília, DF: Embrapa Informação Tecnológica, 2008. p. 19-45.

YOSHII, K.; CAMARGO, A. J. A. DE; ORIOLI, Á. L. (EDS.). Environmental monitoring of Proceder agricultural development projects. Planaltina, DF: Embrapa Cerrados, 2000. 
CAPÍTULO 2 - ANÁLISE DE IMAGEM BASEADA EM OBJETOS (GEOBIA) APLICADA AO MAPEAMENTO DO USO E COBERTURA DA TERRA NO BIOMA CERRADO: IDENTIFICAÇÃO DE DESMATAMENTOS PARA OS ANOS DE 1985 E 1995. 


\section{RESUMO}

O monitoramento de alterações no Uso e Cobertura da Terra (Land-Use and LandCover Change - LULC) e a geração de produtos cartográficos relacionados são elementos de grande importância para se compreender processos, identificar padrões e modelar fenômenos relacionados à dinâmica de desmatamento. No Bioma Cerrado, área de interesse deste estudo, mapeamentos de uso e cobertura da terra estão disponíveis apenas para períodos posteriores a 2002, permitindo a formação de séries históricas curtas, o que dificulta a realização de análises ou a modelagem de processos relacionados ao desmatamento. No presente capítulo, objetivou-se propor metodologia de mapeamento voltado ao uso e cobertura da terra com a utilização de GEOBIA, levando em conta as características específicas do Cerrado. Objetivou-se, também, a obtenção de mapeamento temático com as classes antrópico, natural e corpo d'água para os anos de 1985 e 1995 abrangendo toda a região delimitada pelo bioma. No estudo demonstrou-se a importância da utilização de ferramentas de GEOBIA para iniciativas que visem mapear ou identificar eventos de desmatamento, resultando na obtenção de resultados de forma ágil e com elevada qualidade. O trabalho foi realizado em quatro etapas principais: obtenção e pré-processamento das imagens; identificação dos melhores parâmetros de segmentação; determinação de atributos relevantes para a discriminação de feições entre as classes de interesse, com a utilização da mineração de dados; obtenção de agrupamentos de objetos por meio da análise de agrupamento, além da interpretação visual e classificação dos agrupamentos de objetos. Os mapeamentos realizados permitiram observar que em 1985 o Cerrado era recoberto majoritariamente por áreas naturais, as quais ocupavam $75.66 \%$ de sua totalidade. Áreas pertencentes à classe antrópica ocupavam 23,69\% e corpo d'água $0.65 \%$. No período entre 1985 e 2002 houve a supressão de 19,77\% de áreas naturais, em um total de $404.482 \mathrm{~km}^{2}$, representando as taxas de desmatamento mais elevadas de toda a série histórica disponível para a região. O mapeamento do ano de 1985 apresentou como indicadores de qualidade o valor de $91 \%$ para o Índice Global de Acurácia e de $87 \%$ para o Índice Kappa, e o mapeamento do ano de 1995 apresentou o valor de 90\% para o Índice Global de Acurácia e de $85 \%$ para o Índice Kappa. Teste realizado comparando resultados obtidos por meio da metodologia proposta com o mapeamento oficial de referência apontou grande concordância entre os produtos gerados, obtendo-se um Índice Global de Acurácia com valor médio de $88 \%$ e o Índice Kappa q (Kq) com valor médio de $82 \%$.

Palavras-Chave: GEOBIA, mapeamento do uso e cobertura da terra, desmatamento, Cerrado. 


\section{SUMÁRIO}

1. INTRODUÇÃ

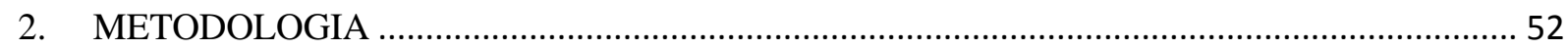

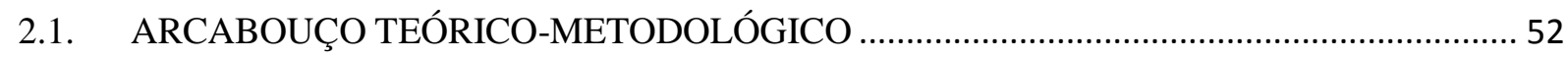

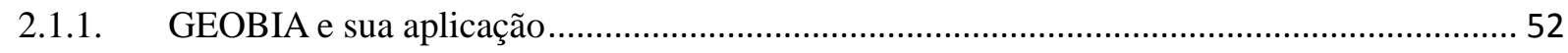

2.1.2. Mineração de dados e sua aplicação ao mapeamento ………………………..................... 62

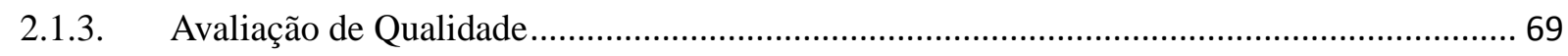

2.2. CARACTERÍSTICAS GERAIS DA METODOLOGIA DE MAPEAMENTO ........................ 76

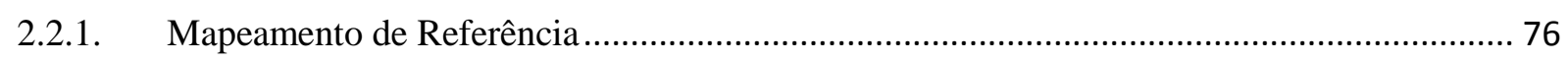

2.2.2. Processo de Atualização do Mapeamento de Referência ...................................................... 77

2.3. OBTENÇÃO DE DADOS E PRÉ-PROCESSAMENTO.......................................................... 83

2.4. DETERMINAÇÃO DE PARÂMETROS DE SEGMENTAÇÃO ............................................ 85

2.5. DETERMINAÇÃO DE ATRIBUTOS RELEVANTES PARA A CLASSIFICAÇÃO .............. 89

2.5.1. Visão Geral do Processo de Determinação de Atributos ......................................................... 91

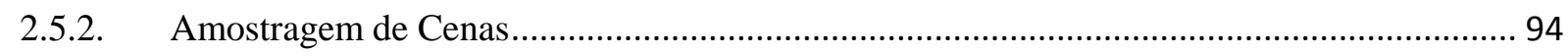

2.5.3. Seleção de Amostras de Treinamento.................................................................................. 95

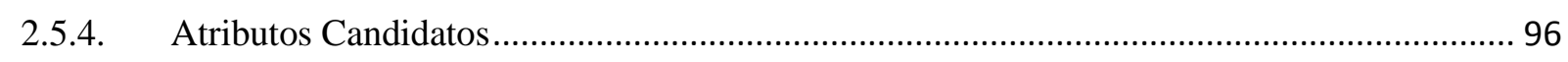

2.5.5. Regras de Mineração de Dados e Classificação ..................................................................... 96

2.5.6. Avaliação de Qualidade dos Modelos ............................................................................... 98

2.5.7. Seleção dos Melhores Atributos ....................................................................................... 99

2.6. MAPEAMENTO DO USO DA TERRA DOS ANOS DE 1985 E 1995 …………................. 100

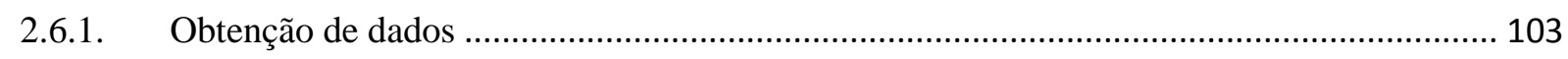

2.6.2. Geração de Objetos e Obtenção de Atributos .................................................................. 103

2.6.3. Processamento de Dados e Análise de Agrupamento ......................................................... 104

2.6.4. Interpretação Visual e Correção Individual de Erros ........................................................ 107

2.6.5. Avaliação da Qualidade do Mapeamento ......................................................................... 111

2.7. AVALIAÇÃO DE COMPATIBILIDADE ENTRE METODOLOGIAS ............................... 112

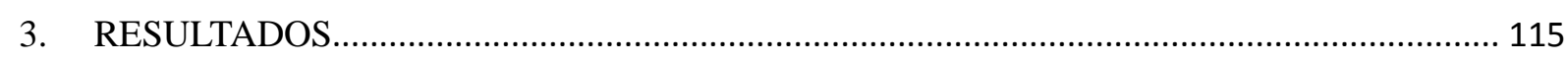

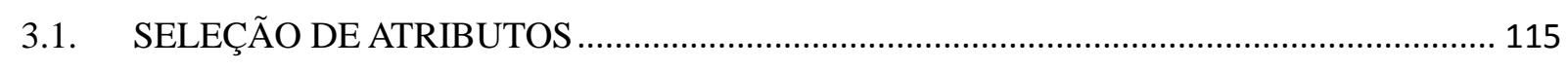

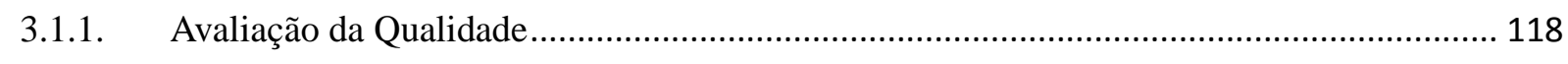

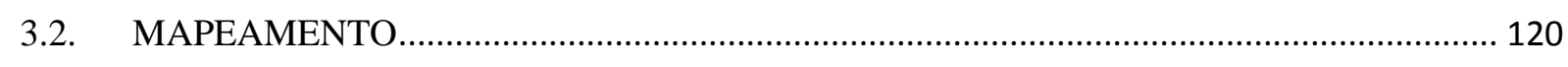

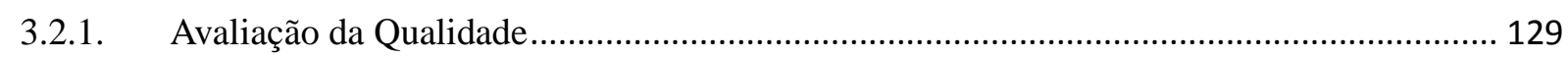

3.3. AVALIAÇÃO DE COMPATIBILIDADE ENTRE METODOLOGIAS …........................... 130 


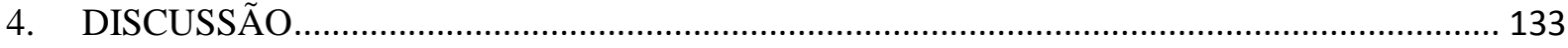

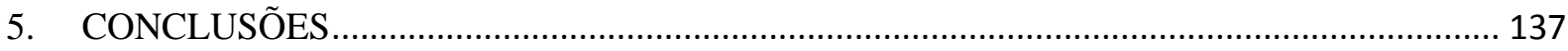

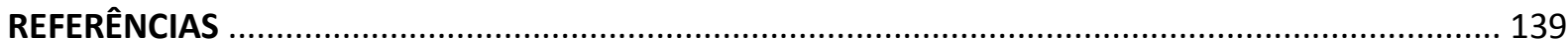

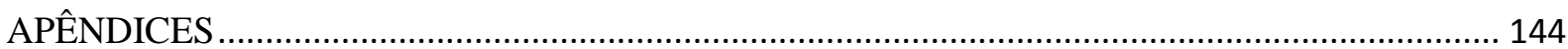

Apêndice 1 - Imagens LANDSAT 5 TM selecionadas (órbita/ponto) para serem utilizadas na do

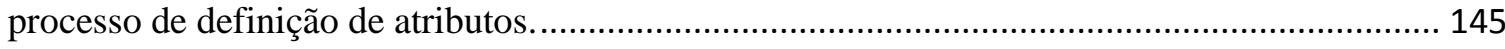

Apêndice 2 - Listagem de atributos testados, apresentando o número de ocorrências de sua utilização entre as 20 imagens classificadas, sua importância média e a importância ponderada

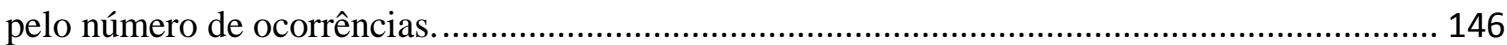

Apêndice 3 - Imagens LANDSAT 5 TM selecionadas (órbita/ponto) para a realização do

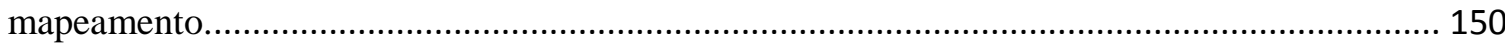

Apêndice 4 - Algoritmo para processamento de dados R, com a obtenção de cluster.................. 153

Apêndice 5 - Algoritmos utilizados para a obtenção de métricas de qualidade do mapeamento.155

Apêndice 6 - Variação na área entre os anos por unidade da federação. 160

Apêndice 7 - Os 100 municípios com maior taxa de desmatamento para o período entre 1985 e 2002. 


\section{ÍNDICE DE TABELAS}

Tabela 1 - Matriz de erro para $n$ classes de uso e cobertura do solo.

Tabela 2 - Matriz de erro com dois avaliadores e duas classes. Fonte: adaptado de Cunningham (2009).

Tabela 3 - Grau ou nível de concordância entre avaliadores baseado no valor de Kappa. Classificação de Landis \& Koch (1977).

Tabela 4 - Feições naturais do cerrado de interesse para o mapeamento e características relevantes para sua identificação. As feições de interesse foram agrupadas na classe natural.

Tabela 5 - Feições antrópicas do cerrado de interesse para o mapeamento e características relevantes para sua identificação. As feições de interesse foram agrupadas na classe antrópico.

Tabela 6 - Características principais das feições relacionadas à classe corpo d'água.

Tabela 7 - Atributos selecionados para a obtenção dos objetos (lista completa no Apêndice 2)......... 115

Tabela 8 - Estatísticas relacionadas aos atributos utilizados em cada uma das cenas classificadas. .. 116 Tabela 9 - Qualidade obtida para a classificação realizada de acordo com a Seção 2.5. Da tabela observam-se estatísticas de qualidade para a matriz completa de dados (Antrópico, Corpo D'água e Natural - Matriz 3x3) e para a submatriz (Antrópico e Natural - Matriz 2x2) 118

Tabela 10 - Erros de omissão e comissão entre as classes consideradas para a etapa de seleção de atributos 119

Tabela 11 - Área de cobertura por classe (Corpo D’água, Antópico e Natural) para os mapeamentos de 1985,1995 e 2002. 120

Tabela 12 - Variação na área de cobertura das classes antrópico e natural para o período entre 1985 e 2002

Tabela 13 - Percentual de cobertura natural e sua variação entre as unidades da federação no período analisado

Tabela 14 - Percentual de área natural por Estado baseado na área total do Cerrado, ranqueados por taxa de desmatamento. 125

Tabela 15 - Qualidade obtida para o mapeamento, considerando-se a matriz completa de dados com as classes Corpo D'água, Antrópico e Natural (Matriz 3x3) e a apenas a matriz formada pelas classes Antrópico e Natural (Matriz 2x2)

Tabela 16 - Erros de omissão e comissão entre as classes consideradas para os mapeamentos dos anos de 1985 e 1995.

130

Tabela 17 - Qualidade obtida para o conjunto de dados de compatibilidade por cena, considerando-se a matriz completa de dados com as classes Corpo D'água, Antrópico e Natural (Matriz 3x3) e a apenas a matriz formada pelas classes Antrópico e Natural (Matriz 2x2). Os índices referem-se ao nível de coincidência entre os mapeamentos comparados. 131

Tabela 18 - Área total, percentual de cobertura por classe e diferença entre os valores obtidos para os mapeamentos comparados 


\section{ÍNDICE DE FIGURAS}

Figura 1 - Formações e fitofisionomias do Bioma Cerrado. Fonte: Ribeiro \& Walter (2008).............. 55 Figura 2 - Elementos de interpretação de imagem: Ordem e Métodos de Pesquisa. Fonte: adaptado de Jensen (2007).

Figura 3 - Exemplo de feições de tipo natural, com a presença de formações vegetacionais florestais, savânicas e campestres (RGB453).

Figura 4 - Exemplo de feições de tipo antrópico, com a presença de feições urbanas, agricultura, solo exposto (RGB453).

Figura 5 - Etapas em um processo de Descoberta de Conhecimento em Bases de Dados (KDD). Fonte: Adaptação de Fayyad et al. (1996).

Figura 6 - Estrutura de uma árvore de decisão apresentado uma origem (raiz), sistema dendrítico de decisão com nós e decisões internas, além de elementos finais (folhas). Observa-se também exemplos de critérios de decisão com valores de variáveis e números de elementos divididos entre os nós terminais

Figura 7 - Duas diferentes funções polinomiais (linha em vermelho) geradas a partir de dados de treinamento (pontos em azul). A população de dados foi gerada a partir da função polinomial representada pela linha verde. Observa-se na figura a direita o efeito do overfitting. Fonte: Bishop (2006).

Figura 8 - Primeira etapa do processo de atualização consistiu na identificação da área de interesse do mapeamento, dada pela região classificada como antrópica pelo PMDBBS para o ano de 2002, destacada em amarelo. Imagem Landsat 5 TM do ano de 2002.

Figura 9 - Aplicação da área de interesse à imagem do ano de 1985, com vistas à identificação de áreas naturais ou corpo d'água e posterior atualização do mapeamento de referência. 78 Figura 10 - Área de interesse mapeada, com a identificação da classe natural e corpo d'água a ser atualizada no mapeamento de referência, gerando como resultado mapeamento do uso e cobertura da terra no ano de 1985.

Figura 11 - Fluxograma com as principais etapas do trabalho. As imagens obtidas para classificação foram utilizadas em todos os processos (etapa 1); os parâmetros determinados para a segmentação (etapa 2) foram utilizados nas etapas 3 e 4; os atributos determinados por meio da etapa 3, foram utilizados no processo final de mapeamento (etapa 4).

Figura 12 - Fluxograma da etapa de pré-processamento de dados (Etapa 1 da Figura 11).

Figura 13 - No gráfico acima, gerado pelo pacote ESP, podemos observar os valores de LV e ROC, utilizando parâmetros de forma e compacidade com valor igual a 0.2. Nele, o valor de ROC apresenta picos nos parâmetros de escala de valor 21, 38 e 58. Para o parâmetro de escala de valor 21, observase também um ponto de máxima local do valor de LV, indicando a boa definição de objetos representativos.

Figura 14 - Segmentação obtida para região com objetos de forma e características bastante diversas (silvicultura, mata de galeria, cerrado, agricultura, pasto) (composição colorida RGB453).

Figura 15 - Conjunto de regras (Rule Set) utilizado para a classificação com o uso de mineração de dados e obtenção de relatórios com informações para a definição dos melhores atributos (aplicativo eCognition 9)......

Figura 16 - Fluxograma da etapa de definição dos melhores atributos a serem utilizados para a

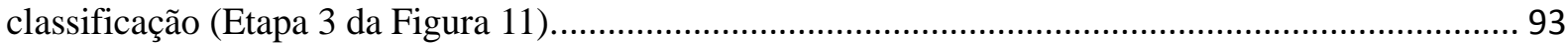

Figura 17 - Regiões delimitadas e cenas selecionadas para a etapa de definição de atributos.............. 94 Figura 18 - Fluxograma da etapa de realização e atualização do mapeamento e obtenção de estatísticas de qualidade (Etapa 4 da Figura 11). 
Figura 19 - Conjunto de regras (Rule Set) utilizado para a obtenção de objetos e atributos utilizados no mapeamento (aplicativo eCognition 9).

Figura 20 - Vários segmentos organizados em grupos, os quais, posteriormente serão submetidos ao processo de classificação. Observa-se a tabela de atributos dos dados vetoriais, onde estão armazenados o identificador único do objeto e o grupo a que pertence. Regiões das quais não constam objeto devem-se à aplicação de máscara, conforme Seção 2.2.

Figura 21 - Objetos e grupos respectivos em processo de classificação. Na imagem e na tabela de atributos, observa-se que alguns grupos já foram reclassificados para a classe final (antrópico, natural e corpo d'água) e alguns ainda necessitam sofrer interpretação visual e a atualização de seus atributos no campo classe (segmentos em tonalidades de vermelho/laranja). Utilizou-se a ferramenta Find and Replace para a realização dessa tarefa. 108

Figura 22 - Processo de atualização do atualização do mapeamento de referência: a) área antrópica definida pelo mapeamento de referência; b) área antrópica atualizada para o ano de 1995; c) mapeamento final obtido para o ano de 1995, constando todas as classes (antrópico, natural e corpo d'água).

Figura 23 - Distribuição das amostras utilizadas para obter dados de qualidade do mapeamento ao longo do Cerrado.

Figura 24 - Regiões delimitadas e cenas selecionadas para a etapa de verificação da compatibilidade entre mapeamentos. 113

Figura 25 - Fluxograma utilizado para a avaliação de compatibilidade entre o mapeamento de referência e o executado. 114 Figura 26 - Distribuição do valor de importância entre os atributos utilizados para a classificação da cena 221/69. São observados 8 atributos dominantes e 9 atributos de menor contribuição geral para os resultados do modelo. Linha em cinza representa a importância acumulada. 117

Figura 27 - Mapeamento obtido para o Cerrado no ano de 1985.

Figura 28 - Mapeamento obtido para o Cerrado no ano de 1995

Figura 29 - Mapeamento realizado pelo PMDBBS para o Cerrado no ano de 2002 . ......................... 122

Figura 30 - Evolução percentual da área de cobertura por classe entre os anos de 1985 e 2011........ 122

Figura 31 - Taxa de desmatamento para a série histórica disponível, entre 1985 e 2011.

Figura 32 - Variação da área de cobertura natural entre 1985 e 2002 para as unidades da federação com ocorrência no Cerrado.

Figura 33 - Variação percentual por Estado da área de cobertura natural em relação à área total do Cerrado.

Figura 34 - Variação percentual da área antrópica entre os municípios para o período entre 1985 e 1995.

Figura 35 - Variação percentual da área antrópica entre os municípios para o período entre 1995 e 2002

Figura 36 - Variação percentual da área antrópica entre os municípios para o período entre 1985 e 2002 .

Figura 37 - Principais frentes e áreas indutoras de desmatamento observadas entre os anos de 1985 e 2002. 


\section{INTRODUÇÃO}

Grandes porções do ambiente natural têm sido submetidas à conversão para o uso humano, resultando em extensas alterações do uso e cobertura da terra. Em grande medida, tais alterações são especialmente dirigidas por fatores relacionados a pressões demográficas, econômicas, tecnológicas e culturais, além de outros fatores que facilitam o acesso e uso de uma determinada região geográfica pelo homem (Allen, Barnes e Barnest, 2013; Geist e Lambin, 2002; Lambin et al., 2001).

Tais alterações apresentam impactos negativos graves em um âmbito global e regional (Foley, 2005) e apresentam-se especialmente relevantes por acarretarem a perda de biodiversidade (eg. Newbold et al., 2016), alterações no ciclo biogeoquímico e alterações climáticas (eg. Mahmood, Hubbard, Niyogi, \& Bonan, 2010), perdas quantitativas e qualitativas de recursos hídricos (Kiersch, 2000), dentre outros impactos negativos sobre o meio ambiente. Os resultados efetivos podem ser agravados pelo efeito sinérgico entre esses impactos (eg. Brook, Sodhi, \& Bradshaw, 2008). Nesse contexto, o monitoramento de alterações no Uso e Cobertura da Terra (Land-Use and Land-Cover Change - LULC) e a geração de produtos cartográficos relacionados são elementos de grande importância para se compreender processos, identificar padrões e modelar fenômenos, passos os quais são fundamentais para a geração de conhecimento e para a tomada de decisão no âmbito governamental e do planejamento territorial.

A disponibilidade de dados primários, representados por produtos cartográficos, é um primeiro desafio a ser enfrentado por pesquisas que visem compreender e modelar fenômenos do ambiente e que envolvam esses tipos de alterações (LULC). Em regra, a compreensão e modelagem de fenômenos nessa área requer a formação de uma série temporal mínima capaz de abranger alterações históricas do evento investigado e do uso e cobertura da terra (Sohl e Sleeter, 2011), sendo relevante a obtenção e disponibilização de dados atuais e históricos, bem como o desenvolvimento de novas soluções metodológicas para a produção eficiente desse tipo de informação.

Produtos de sensoriamento remoto, como fotografias aéreas e imagens de satélite, constituem-se as principais fontes de dados utilizados para a geração de produtos cartográficos relacionados ao mapeamento desses tipos de alterações do ambiente. Mapeamentos com esse objetivo geralmente mesclam classes temáticas tipicamente 
relacionadas à Cobertura da Terra (privilegia características físicas naturais da superfície terrestre), com aquelas afeitas ao Uso da Terra (privilegia a descrição de tipologias de alterações antrópicas no ambiente), conceitos que apesar de serem intimamente relacionados, possuem definição própria (Comber, Fisher e Wadsworth, 2005; Fisher, Comber e Wadsworth, 2005).

Imagens de satélite têm tradicionalmente sido exploradas por meio de metodologias que acessam e identificam as informações de interesse, a identificação de feições geográficas relevantes para aquele mapeamento, a partir da análise individualmente de cada um dos pixels das imagens, conhecido como o paradigma pixel-pixel (Castilla e Hay, 2008). Tal abordagem metodológica geralmente não é eficiente em apreender padrões espaciais que se refletem sobre conjuntos de pixels e que constituem parte fundamental do processo semântico que envolve a identificação de uma feição com existência geográfica e com representação em um mapeamento e sua atribuição à classe temática de um produto cartográfico. Tal limitação é especialmente relevante quando os produtos de sensoriamento remoto analisados apresentam alta ou altíssima resolução espacial, onde cada pixel representa pequenas porções do território, resultando em uma grande variabilidade de dados em pequenas áreas (eg. o satélite GeoEye-1 é capaz de representar em um pixel uma área delimitada por um quadrado de $41 \mathrm{~cm}$ de lado).

O processamento de dados para a obtenção de resultados nessa área de estudo passa, atualmente, por um momento de quebra dos paradigmas tradicionais, especialmente pelo surgimento de nova área de conhecimento que integra elementos de Sensoriamento Remoto e Sistema de Informações Geográficas - GIS (Geographic Information System) para a obtenção de informações a partir de produtos de sensoriamento remoto. Conhecida como Análise de Imagem Baseada em Objetos (Geographic Object-Based Image Analysis - GEOBIA), essa nova subdisciplina foi definida por Hay \& Castilla (2008) como:

"Geographic Object-Based Image Analysis (GEOBIA) is a sub-discipline of Geographic Information Science (GIScience) devoted to developing automated methods to partition remote sensing imagery into meaningful image-objects, and assessing, their characteristics through spatial, spectral and temporal scales, so as to generate new geographic information in GIS-ready format". (Hay e Castilla, 2008)

De acordo com os autores mencionados, um processo de conhecimento e interpretação via GEOBIA abrange a segmentação, classificação e a habilidade de pesquisar e relacionar objetos no espaço e no tempo, tendo como um de seus elementos chave a definição 
de unidade mínima de análise que é definida por sua relação semântica com uma feição geográfica representada. Em contextos semânticos diversos e em escalas espaciais diferentes pode-se compreender um objeto como a porção unitária representativa para uma determinada escala de um sistema geográfico (Blaschke et al., 2014), sendo sua definição prática variável de acordo com os objetivos que se almeja em um mapeamento.

A quebra do paradigma pixel-pixel possibilita a consideração de fatores que vão além de características espectrais das imagens obtidas e mais se aproxima do processo de conhecimento e interpretação realizado por um intérprete humano (Hay \& Castilla, 2008). A subdivisão da imagem em objetos menores semanticamente relevantes possibilita a consideração de diversas características adicionais (e.g., textura, forma, relação com outros objetos), que expressam a identidade de um objeto real no espaço. Relevante, também, é a possibilidade de aplicação de novos métodos de reconhecimento de feições, como o caso da utilização de procedimentos de mineração de dados, o qual permite a análise de grandes volumes de dados e a identificação de padrões complexos que resultem na ágil discriminação de alvos de interesse.

Inicialmente impelida por limitações do paradigma baseado no pixel em lidar com imagens de alta ou altíssima resolução espacial, a GEOBIA abriu oportunidades para que as técnicas desenvolvidas fossem também aplicadas a imagens com média resolução espacial. Vários trabalhos têm explorado as possibilidades da utilização da GEOBIA em imagens de média resolução espacial, com a definição de objetos de maiores dimensões planimétricas. Por exemplo, Yang et al. (2015) avaliaram o potencial dessa ferramenta para o mapeamento de uso do solo na China com dados SPOT 5; Aplin and Smith (2000) utilizaram imagens LANDSAT 5 TM na Grã-Bretanha para a mesma finalidade do trabalho anteriormente citado; Jhonnerie et al. (2015), utilizando imagens LANDSAT 5 TM, realizou o mapeamento de regiões de mangue na Indonésia; Bertani et al. (2013) utilizaram imagens LANDSAT 7 ETM+ para a identificação e mapeamento de paleocanais na região amazônica; Ozelkan et al. (2016) fizeram uso de imagens LANDSAT 8 OLI para avaliar a influência de áreas irrigadas em monitoramentos de secas na Turquia.

Neste trabalho, a partir de imagens de média resolução espacial (LANDSAT 5 TM), tivemos por objetivo principal a atualização de base de dados oficial relativa ao Uso e Cobertura da Terra no Bioma Cerrado brasileiro para períodos pretéritos (anos de 1985 e 1995). Objetiva-se, também, desenvolver metodologia com a utilização de GEOBIA, que sirva para o aperfeiçoamento de tarefas de mapeamento e monitoramento da região de 
interesse. O desenvolvimento de novas metodologias nessa área não só contribuem para a aquisição dos resultados imediatos pretendidos, o produto cartográfico final, como também são importantes para uma maior eficiência no atendimento de demandas de diversas áreas de aplicação, como a modelagem, monitoramento e planejamento do território.

Iniciativas voltadas ao mapeamento de uso e cobertura da terra no Brasil, em especial relacionados à identificação de processos de antropização de habitats naturais, têm como referência principal o Projeto de Estimativa do Desflorestamento Bruto da Amazônia PRODES, realizado pelo Instituto Nacional de Pesquisas Espaciais, o qual, a partir do ano de 1988, passou a identificar eventos de desmatamento na Amazônia Legal (INPE, 2015), com a utilização de imagens de satélite.

Apesar de experiência relativamente antiga no Bioma Amazônico, o Cerrado passou a ser monitorado de forma sistemática apenas recentemente, em especial após iniciativa vinculada ao Projeto de Conservação e Utilização Sustentável da Diversidade Biológica Brasileira - PROBIO I, que realizou o mapeamento do Cerrado para o ano de 2002 e cujos resultados foram disponibilizados a partir do ano de 2007 (Sano et al., 2007; Sano, Rosa, Brito, Jorge L S, et al., 2010; Sano, Rosa, Brito, Jorge Luís Silva, et al., 2010).

Importantes iniciativas foram realizadas desde o trabalho executado no âmbito do PROBIO, das quais se destacam o Projeto de Monitoramento do Desmatamento dos Biomas Brasileiros por Satélite - PMDBBS (CSR/IBAMA) e o Sistema Integrado de Alerta de Desmatamento - SIAD (LAPIG/UFG). O PMDBBS, executado pelo Centro de Sensoriamento Remoto do Instituto Brasileiro do Meio Ambiente e dos Recursos Naturais Renováveis (CSR/IBAMA), realizou o monitoramento do Cerrado com base na análise de imagens dos satélites LANDSAT TM e ETM e CBERS2B, promovendo o mapeamento das classes antrópico, natural e corpo d'água para áreas a partir de 2 hectares em todo o bioma (IBAMA, 2009, 2011a, 2011b).

O SIAD, por sua vez, utilizando-se de imagens índices de vegetação (produto MOD13Q1), com resolução espacial de 250 metros, realizou o monitoramento do Bioma a partir do ano de 2002, e teve como objetivo a identificação ágil de alterações no uso da terra com área mínima de 50 hectares, gerando alertas de desmatamento (Ferreira, L. G., Ferreira, et al., 2009; Ferreira, L. G., Rocha, et al., 2009; Ferreira et al., 2007; Rocha et al., 2011).

Ações recentes, em especial vinculadas ao Programa de Monitoramento Ambiental dos Biomas Brasileiros (PMABB), passam a integrar iniciativas oficiais voltadas ao 
mapeamento e monitoramento do uso da terra no Cerrado. Nesse contexto, destaca-se o programa TerraClass Cerrado (MMA, 2015), o qual tem por objetivo promover o mapeamento sistemático na escala de 1:250.000 (área mínima suscetível de mapeamento de 6,25 hectares), considerando 13 classes e 3 superclasses (antrópico, natural e corpo d'água); e, também, o Sistema de Detecção do Desmatamento e Alterações na Cobertura Florestal em Tempo Quase Real (Deter-B). Esse tem por objetivo realizar um levantamento ágil buscando evidências de alteração na cobertura natural e orientar ações de fiscalização (Valeriano et al., 2016). Inicialmente dedicado à Amazônia Legal, o Deter passou, a partir do ano de 2016, também, a monitorar o Bioma Cerrado. O sistema Deter-B utiliza dados do sensor AWiFS (Advanced Wide Field Sensor), a bordo do satélite RESOURCESAT 2, com resolução espacial de 56 metros (ISRO, 2014), e permite o monitoramento de alterações com área mínima de 3 hectares.

Dados dos diferentes mapeamentos realizados recentemente indicam que cerca de metade da área abrangida pelo Cerrado já foi convertida para uso antrópico (IBAMA, 2016; MMA, 2015) e que o desmatamento continua a apresentar taxas elevadas quando comparados a outros biomas (MMA, 2011; Soares-filho et al., 2014). Por exemplo, para o ano de 2011, as taxas mostraram-se superiores ao dobro daquelas observadas para a Amazônia Legal - 0,12\% $\left(6.418 \mathrm{~km}^{2}\right.$ de área desmatada de um total de $\left.5.020 .000 \mathrm{~km}^{2}\right)$ e 0,35\% para o Cerrado $(7.247$ $\mathrm{km}^{2}$ de área desmatada em um total de 2.039.386) (IBAMA, 2015; INPE, 2015). Além disso, indicam processo de ocupação pouco ordenado, colocando em risco a biodiversidade e o uso sustentável de recursos ambientais.

Diferentes metodologias foram utilizadas nos mapeamentos realizados para o Cerrado, especialmente envolvendo a análise por pixel e análise por região, aliada à interpretação visual. Até o momento, contudo, as principais iniciativas existentes continuam a não se valerem de importantes possibilidades metodológicas disponibilizadas pela GEOBIA, o que destaca a importância de iniciativas que visem desenvolver metodologias com a inclusão dessas novas técnicas.

O Cerrado constitui-se em um caso de especial interesse entre os biomas brasileiros para a aplicação e desenvolvimento desse tipo de metodologia. O Bioma tem por característica apresentar alta heterogeneidade ambiental no que diz respeito a solos, geologia e características geomorfológicas, sendo formado por um intrincado mosaico de formações vegetacionais (Eiten, 1972; Klink \& Machado, 2005; Silva, Fariñas, Felfili, \& Klink, 2006; Walter, Carvalho, \& Ribeiro, 2008). Tais características contribuem para que atributos 
relacionados aos alvos variem intensamente em virtude da alta heterogeneidade espacial. Além disso, a marcante sazonalidade climática, com duas estações bem definidas (seca e úmida), contribui para uma ainda maior variabilidade dos alvos.

Ainda que na maioria das vezes a ação antrópica nesse ambiente tenha o efeito de simplificar a complexidade do mosaico de paisagens naturalmente observadas, em algumas situações, pode haver um aumento da complexidade dessas paisagens, especialmente em casos de maior integração entre ambientes antrópicos e naturais (eg. pastagem natural e antrópica). Uma perspectiva de monitoramento a partir da definição de objetos, nesse contexto, tende a ser especialmente relevante e profícua.

Considerando que dados sobre o desmatamento nesse bioma estão disponíveis apenas para períodos relativamente recentes e que séries temporais maiores são importantes para a identificação de padrões e para a modelagem de vários tipos de fenômenos nesse ambiente; levando ainda em consideração o grande potencial apresentado por metodologias que envolvam a utilização de ferramentas que utilizem análises de imagens baseadas em objetos (GEOBIA), cada vez mais frequentemente utilizadas no mundo e ainda relativamente pouco exploradas para o mapeamento no Brasil; observando, adicionalmente, que as analises propostas como tema central desta dissertação requerem ou preconizam a utilização de séries temporais mais extensas; no presente capítulo, objetivou-se propor e aplicar metodologia de mapeamento voltado ao uso e cobertura da terra com a utilização de GEOBIA, levando em consideração as características específicas do Cerrado. Objetivou-se, igualmente, realizar a atualização de mapeamento temático de referência para os anos de 1985 e 1995, elegendo-se como mapeamento de referência aquele disponibilizado pelo PMDBBS para o ano de 2002 (IBAMA, 2016). Os anos selecionados para mapeamento foram eleitos em função da disponibilidade de dados históricos existentes (LANDSAT 5 TM) e, também, procurando-se abranger maior período, com vistas a se estender a série histórica existente. 


\section{METODOLOGIA}

\subsection{ARCABOUÇO TEÓRICO-METODOLÓGICO}

\subsubsection{GEOBIA e sua aplicação}

Avanços recentes obtidos por meio do desenvolvimento de técnicas de Análise de Imagens Baseada em Objetos (GEOBIA) têm facilitado a extração de informações temáticas a partir de imagens de sensoriamento remoto. A GEOBIA surgiu como uma alternativa ao paradigma de análise baseado no pixel, o qual assume como porção mínima unitária o pixel de uma imagem e apresenta técnicas de processamento e estatísticas voltadas à análise desses elementos. A GEOBIA baseia-se na ideia de que pixels não ocorrem isoladamente, mas sim integrados em uma imagem repleta de padrões espaciais, os quais podem ser explorados de forma integrada a partir de métodos e técnicas de análises que utilizam como unidades básicas objetos ao invés de pixels (Hay e Castilla, 2006).

Castilla \& Hay (2008), ao buscarem uma definição de objeto, fizeram distinção entre um image-object e um geo-object. No primeiro caso, os autores conceituam como uma região discreta de uma imagem digital que é internamente coerente e diferente de sua vizinhança. De acordo com esse conceito, um image-object deve idealmente apresentar: limites bem definidos; um conjunto consistente de atributos observáveis a uma certa escala, sua assinatura estrutural; e o contraste de seus atributos em relação a outros objetos em sua vizinhança.

Um geo-object foi definido pelos autores como "a bounded geographic region that can be identified for a period of time as the reference of a geographic term", ou seja, um objeto com existência geográfica e com representação em um mapeamento. Enquanto um geo-object existe no espaço geográfico, nem sempre com limites facilmente determináveis, um image-object possui existência em uma instância de uma imagem digital.

O processo de segmentação da imagem é fundamental para que seja estabelecida a relação entre esses dois elementos, sendo que um segmento (o output da segmentação de uma imagem digital) é a efetiva representação de um image-object. Esses elementos podem ser referidos como meaningful image-object quando representam de forma apropriada um geoobject, considerando-se uma determinada escala e o objetivo do mapeamento em questão.

A classificação de imagens digitais baseada em objetos, nesse contexto, é o processo de associação entre um image-object (segmento) e uma classe de um geo-object (classe de 
mapeamento). Tal classificação ocorre com a observação de características de um imageobject e de sua relação com seus vizinhos. Meaningful image-object podem agrupar-se em estruturas hierárquicas, formando super-objetos. Por simplicidade, abaixo, nos referiremos, em regra, aos meaningful image-object apenas como objetos.

Um dos principais benefícios do conjunto de técnicas representado pela GEOBIA, ao levar em conta como elementos unitários os objetos, é a possibilidade de se descrever e integrar diversos atributos, tais quais características espectrais, texturais, espaciais e topológicas, o que torna possível o uso mais amplo das informações implícitas em uma imagem (Hay e Castilla, 2008). A consideração de tais propriedades dos objetos permite que seja transposta para o ambiente do aplicativo de processamento de imagens a experiência e o conhecimento do analista sobre as feições a serem identificadas, classificadas e mapeadas, algo muito além do que é oferecido por uma análise do tipo pixel-pixel para determinadas aplicações.

Outra vantagem de uma análise por meio de GEOBIA é a facilidade de obtenção de informações em mais de uma escala de trabalho. Conforme observado por Blaschke et al. (2005), não existe uma única escala correta para que sistemas sejam descritos espacialmente, sendo a escala mais apropriada aquela que permite a identificação de alvos semanticamente relevantes para os objetivos específicos que se almeja com uma representação do espaço geográfico. Conforme Woodcock \& Strahler, (1987) e Woodcock \& Harward (1992) a identificação de alvos ou objetos semanticamente relevantes pode se dar em uma única escala ou, até mesmo, em mais de uma escala, no caso de escalas aninhadas, requerendo-se, nesse caso, níveis de segmentação diferentes para a realização do trabalho.

A GEOBIA destaca-se, ainda, por fornecer um arcabouço metodológico que coloca à disposição tipos de análises mais diversificadas e customizáveis, com resultados mais acurados e ágeis, por exemplo, com a utilização de métodos automáticos de análise e interpretação e a modelagem de classes. Além disso, permite, em uma mesma análise, a integração com outros tipos de dados (eg. dados relativos à topografia de uma região) para a identificação correta de alvos, como mostram, por exemplo, Bertani et al. (2013).

No caso em estudo, temos por objetivo o mapeamento das classes antrópico, natural e corpo d'água para toda a região do Cerrado, englobando dados de períodos pretéritos (anos de 1985 e 1995), sendo relevante o conhecimento sobre características específicas das feições representadas por cada uma das classes mapeadas. 
Feições naturais no ambiente do Cerrado apresentam alta variabilidade espacial de suas características. Especialmente relevante nesse caso é a sua marcante heterogeneidade fitofisionômica. Dois diferentes sistemas de classificação vegetacionais são normalmente aplicados para o Cerrado. Um primeiro, proposto pelo Instituto Brasileiro de Geografia e Estatística - IBGE (IBGE, 2012), tem por principal vantagem permitir a classificação padronizada de todos os tipos de vegetação ocorrentes no Brasil e adotar sistema de classificação fitogeográfico com características universais. Por sua vez, Ribeiro e Walter (1998 e 2008) baseados especificamente em tipos vegetacionais do Cerrado, propuseram sistema de classificação próprio para esse Bioma, identificando três grandes grupos de formações vegetacionais (campestres, savânicas e florestais) e 11 tipos fitofisionômicos principais, os quais contam, por vezes, com subtipos. A principal vantagem deste sistema é a maior clareza e simplicidade de aplicação para essa região, tendo grande divulgação e uso na ciência.

Abaixo se observam os tipos fitofisionômicos pertencentes a cada uma das formações descritas por Ribeiro \& Walter (2008), bem como uma descrição sumária das principais características dessas:

1) Formações Florestais - Mata Ciliar, Mata de Galeria (Não Inundável ou Inundável), Mata Seca (Sempre-Verde, Semidecídua ou Decídua) e Cerradão (Mesotrófico ou Distrófico);

"Formações florestais englobam os tipos de vegetação com predominância de espécies arbóreas, com a formação de dossel contínuo. A Mata Ciliar e a Mata de Galeria são fisionomias associadas a cursos de água, que podem ocorrer em terrenos bem drenados ou mal drenados. A Mata Seca e Cerradão ocorrem nos interflúvios em terrenos bem drenados, sem associação com cursos de água." (Ribeiro e Walter, 2008)

2) Formações Savânicas - Cerrado Sentido Restrito (Denso, Típico, Ralo e Rupestre), Parque de Cerrado, Palmeiral (Babaçual, Buritizal, Guerobal ou Macaubal), Vereda;

"Formações savânicas - englobam quatro tipos fitofisionômicos principais, o Cerrado sentido restrito, o Parque de Cerrado, o Palmeiral e a Vereda. O Cerrado sentido caracteriza-se pela presença dos estratos arbóreo e arbustivo-herbáceo definidos, com as árvores distribuídas aleatoriamente sobre o terreno em diferentes densidades, sem que se forme um dossel contínuo. No Parque de Cerrado a 
ocorrência de árvores é concentrada em locais específicos do terreno. No Palmeiral, que pode ocorrer tanto em áreas bem drenadas quanto em áreas mal drenadas, há a presença marcante de determinada espécie de palmeira arbórea, e as árvores de outras espécies não têm destaque. Já a Vereda também se caracteriza pela presença de uma única espécie de palmeira, o buriti, que ocorre, porém, em menor densidade do que em um Palmeiral. Além disso, a Vereda é circundada por um estrato arbustivo-herbáceo característico.” (Ribeiro e Walter, 2008)

3) Formações Campestres - Campo Sujo (Seco, Úmido ou com Murundús), Campo Limpo (Seco, Úmido ou com Murundús), Campo Rupestre;

\begin{abstract}
"As formações campestres do Cerrado englobam três tipos fitofisionômicos principais: o Campo Sujo, o Campo Limpo e o Campo Rupestre. O Campo Sujo caracteriza-se pela presença evidente de arbustos e subarbustos entremeados no estrato arbustivo-herbáceo. No Campo Limpo, a presença de arbustos e subarbustos é insignificante. O Campo Rupestre possui trechos com estrutura similar ao Campo Sujo ou ao Campo Limpo, diferenciando-se tanto pelo substrato, composto por afloramentos de rocha, quanto pela composição florística, que inclui muitos endemismos." (Ribeiro e Walter, 2008)
\end{abstract}

Abaixo, na Figura 1, observam-se representadas as principais formações vegetacionais e tipos fitofisionômicos do Cerrado:

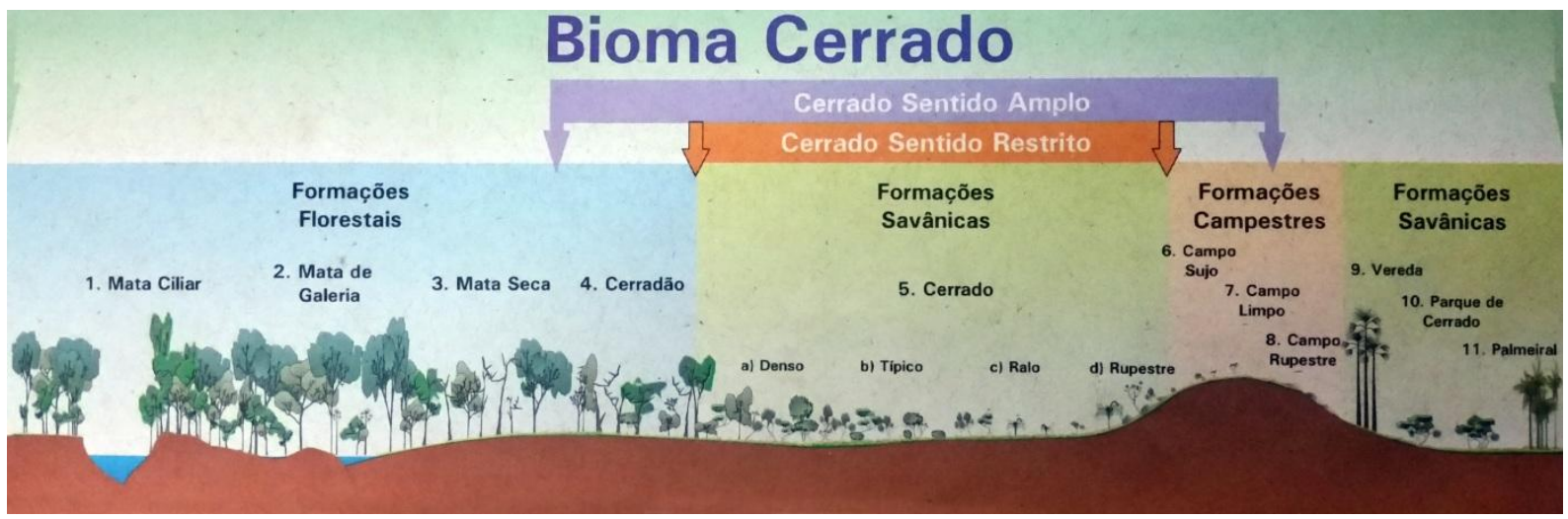

Figura 1 - Formações e fitofisionomias do Bioma Cerrado. Fonte: Ribeiro \& Walter (2008).

A descrição do Cerrado em formações vegetacionais, definidas por sua composição florística e pela distribuição de espécies de hábito arbóreo, arbustivo e herbáceo ao longo de um gradiente pautado por características edáficas, climáticas e hidrológicas, apresenta aspectos relevantes para seu mapeamento. Características relacionadas à estruturação da comunidade sob um ponto de vista espacial, tanto em um plano horizontal, como em um plano vertical, representando seu padrão de distribuição (organização/densidade) e variação em altura, ao lado da interação individual (eg. variação pigmentar) ou em conjunto dos 
espécimes (eg. sombreamento) com o espectro eletromagnético, têm implicações diretas sobre os dados obtidos por sensores remotos e, por consequência, sobre o processo de interpretação visual das imagens obtidas.

A interpretação visual de uma imagem de satélite diz respeito ao exame de dados obtidos remotamente (uma imagem orbital ou fotografia aérea), com o propósito de identificar objetos e avaliar o seu significado (Jensen, 2007). A realização de uma tarefa de interpretação visual permite a obtenção de informações espaciais que dificilmente seriam acessíveis a partir de uma visada que partisse de um observador no solo. Considerando imagens tomadas a partir de plataforma orbital ou aérea, em uma perspectiva geralmente oblíqua, abrangendo grande extensão geográfica, é possível a identificação de feições, padrões e processos decorrentes da interação do ser humano com seu meio.

Um variado conjunto de elementos de interpretação de imagem é utilizado pelo analista para a obtenção de informações, como a localização, cor, tonalidade, tamanho, forma, textura, padrão, sombra, altura e profundidade, volume, declividade, aspecto, sítio, situação e associação. Esses foram classificados por Jensen (2007) de acordo com sua ordem de importância para um processo genérico de interpretação em quatro níveis de importância (Figura 2). Em um processo de interpretação, tais características são avaliadas de forma integrada pelo analista para obter o significado de uma feição de acordo com os objetivos da investigação realizada.

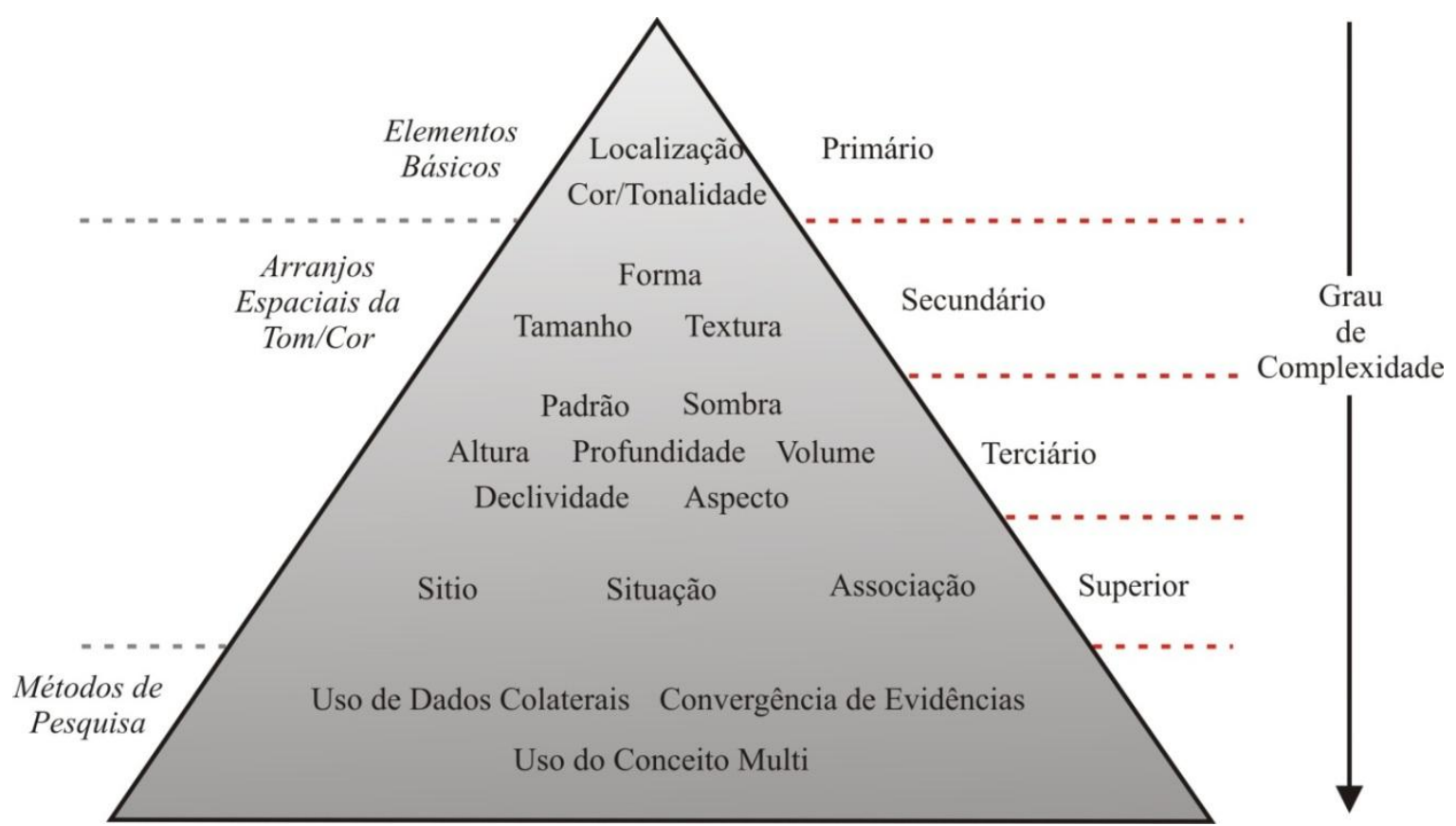

Figura 2 - Elementos de interpretação de imagem: Ordem e Métodos de Pesquisa. Fonte: adaptado de Jensen (2007). 
No caso em estudo, que se fixa sobre a interpretação de feições com vistas a identificar o seu pertencimento às três classes de interesse (antrópico, natural e corpo d'água), são especialmente relevantes a cor/tonalidade, a textura, a forma e o contexto em que as feições se encontram.

A tonalidade é elemento derivado da resposta espectral dos alvos, sendo representada por variações nos tons de cinza de uma imagem, criando uma escala de intensidade. Ao se realizar uma composição colorida a partir da atribuição de diferentes bandas aos canais RGB de um monitor de vídeo, são introduzidos a matiz e a saturação. Os três elementos mencionados, intensidade, matiz e saturação, são responsáveis por gerar a percepção de cor e tonalidade em uma imagem (Jensen, 2007).

Tais fatores, elementos primários no processo de interpretação, podem ser submetidos a diferentes tratamentos para que destaquem características das feições de interesse. Por exemplo, técnicas de realce das imagens (eg. expansão histogrâmica) promovem a redistribuição da frequência dos valores digitais de uma imagem, alterando a estrutura de seu histograma, resultando em um maior contraste entre feições. Outra técnica frequentemente utilizada para destacar alvos de interesse é a composição de bandas. Nela, utiliza-se diferentes configurações do sistema de cores aditivas RGB (Vermelho - Red, Verde Green e Azul - Blue), variando-se as bandas da imagem entre os canais disponíveis (RGB), para se explorar vantagens relacionadas a uma maior acuidade humana para determinadas cores, como o vermelho, e para ajustar eventuais variações individuais na percepção de cada analista.

Umas das composições de banda mais utilizadas para a classificação de uso e cobertura da terra com dados LANDSAT 5 TM é a RGB453 - banda 4 (0,76 - 0,90 $\mu \mathrm{m}$; infravermelho próximo) no canal vermelho $(\mathrm{R})$, banda 5 (1,55 - 1,75 $\mu \mathrm{m}$; infravermelho médio) no canal verde $(\mathrm{G})$ e banda $3(0,63$ - 0,69 $\mu \mathrm{m}$; faixa espectral do vermelho) no canal azul (B). É destacada nessa composição variações entre diferentes tipos de vegetação; e entre a vegetação e intervenções antrópicas (eg. rodovias, edificações, aglomerados urbanos).

Com essa composição de bandas, alvos com cobertura vegetal densa apresentam-se na coloração vermelha (eg. tipologias de formações vegetais florestais; áreas de silvicultura); alvos referentes a regiões arborizadas do Cerrado apresentam-se em coloração vermelhoesverdeada e marrom, refletindo características do estrato arbóreo e herbáceo; e formações 
naturais predominantemente campestres em verde com tonalidade variando de escuro a médio (Figura 3).

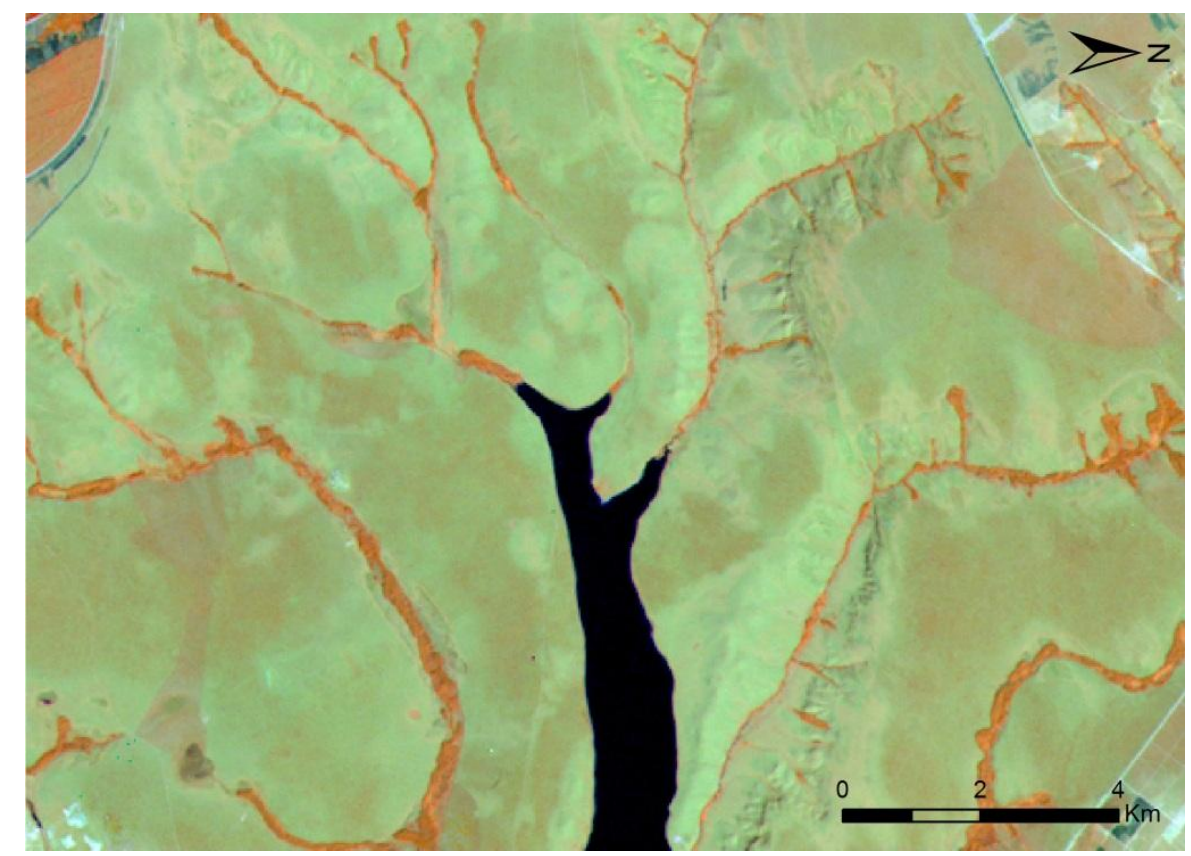

Figura 3 - Exemplo de feições de tipo natural, com a presença de formações vegetacionais florestais, savânicas e campestres (RGB453).

Alvos antrópicos, como no caso de áreas urbanas adensadas, apresentam-se em tonalidades de azul; regiões de agricultura anual ocorrem na cor magenta e verde claro; áreas de solo exposto aparecem nas colorações branco e ciano, em tonalidade mais claras; pastagens plantadas, por sua vez, ocorrem na cor verde clara, nem sempre sendo evidente a diferenciação entre elas e os ambientes campestres naturais (Figura 4). 


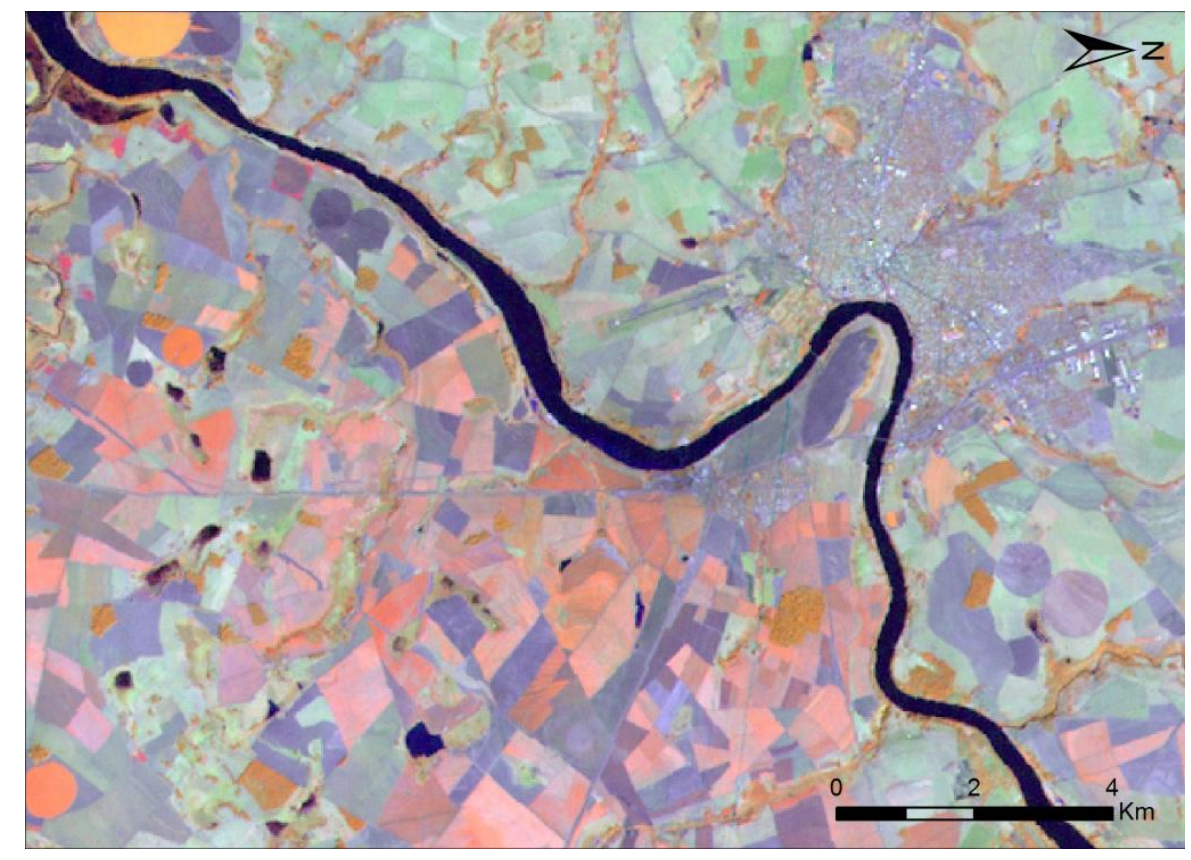

Figura 4 - Exemplo de feições de tipo antrópico, com a presença de feições urbanas, agricultura, solo exposto (RGB453).

Outro elemento importante para a interpretação visual das imagens é a textura dos alvos. De forma geral, a textura é percebida intuitivamente a partir das características de uma superfície, estando relacionada à percepção tátil humana e a impressões visuais de um objeto, as quais podem ser descritas por termos como áspero, rugoso, liso. Em aplicações voltadas à análise de imagens, a textura pode ser definida como padrões complexos repetitivos com variações locais, caracterizada pela distribuição de níveis de cinza em uma vizinhança, que atuem em uma escala inferior àquela necessária para a definição de objetos individuais e que demarcam uma região de textura (Jain, Kasturi e Schunck, 1995).

Tais padrões observados nas imagens refletem as características reais da superfície de um alvo e de sua interação com a energia eletromagnética, caracterizando superfícies difusoras e especulares (Meneses, 2012). Alvos com aparência mais rugosa em uma imagem de satélite estão, por exemplo, associadas a ambientes que apresentem maiores variações verticais em relação à superfície ou que apresentem uma maior variação quanto a seus elementos constituintes, sendo importante característica a ser considerada em um processo de interpretação visual. Por exemplo, dosséis formados por indivíduos arbóreos em ambiente natural tendem a apresentar uma maior rugosidade se comparado àqueles de ambientes antrópicos (ex. silvicultura), refletindo uma maior variedade em termos de espécies e características fenotípicas de seus indivíduos (eg. altura, largura, pigmentação) do que em ambientes formado pelo cultivo de uma única espécie. 
Destaca-se, ainda, a importância das formas das feições e o contexto em que estas se encontram para a sua correta interpretação. A forma geométrica de uma feição, por exemplo, é elemento fundamental para a distinção entre feições naturais e antrópicas. Frequentemente, feições antrópicas assumem formatos regulares, com arestas lineares, enquanto na natureza esse tipo de padrão é raro para a escala de observação empregada neste trabalho. Para feições naturais e antrópicas com atributos espectrais e de textura semelhantes, como é o caso de pastagem cultivada e áreas com cobertura campestre natural do Cerrado, por vezes, a forma pode ser um dos principais elementos para se definir corretamente a classe de tal alvo, sendo também importante o contexto em que esse se encontra.

O contexto (sitio, situação e associação) de uma feição é dado não só por suas características distintivas próprias, mas também por sua relação com outras feições próximas. Muitas vezes a ocorrência de determinados eventos pressupõe a presença de outros. Por exemplo, a ocorrência de grandes áreas de cultivo normalmente é associada à presença de estradas de acesso e edificações. De outra parte, não é esperado que em extensas áreas naturais, sem aparente intervenção humana, pequenas regiões campestres sejam relacionadas à ocorrência de pastagem antrópica, mas sim decorrente de variações naturais. Nesse caso, o contexto facilita o processo de interpretação e identificação de um alvo entre as classes consideradas pelo analista.

Enquanto em uma intepretação visual, a representação das feições naturais ou antrópicas têm especial influência sobre a cor, tonalidade, textura e forma de elementos de uma imagem; em uma análise quantitativa dos dados obtidos, há influência sobre um conjunto mais variado de atributos.

Dados quantitativos relacionados às imagens podem ser avaliados, em um contexto de GEOBIA, a partir de duas instâncias não excludentes: uma referente a descritores de informações que privilegiam o aspecto individual de um objeto; e outra referente a descritores de informações que privilegiam a relação mutua existente entre objetos ou entre esses e superobjetos.

Dentre atributos individuais, muitos dos aplicativos fazem referência a "atributos baseados no pixel", normalmente relacionados ao contexto de cada objeto individualmente. É o caso, por exemplo, de características relacionadas a: sua extensão espacial (eg. área, perímetro); forma e textura (atributos que têm por descritor diversos tipos de índices); valor médio, máximo, mínimo, desvio padrão ou descritor do tipo de distribuição estatística dos 
valores em uma banda (obtidos para cada objeto); a contribuição que uma banda apresenta para o brilho total da imagem - ratio (obtido para cada objeto); o valor médio da banda para a região limítrofe e interna de um objeto (obtido para parte de um objeto).

Além de valores dados em números digitais (DN) no espaço espectral de uma imagem - DN $(x, y)$, podem ser considerados, também, transformações desses valores, como razões de banda ou índices espectrais. Conforme Schowengerdt (2007), transformações do espaço espectral são úteis em processos de classificação temática e são coletivamente chamadas de feature spaces. Esses espaços derivados não adicionam novas informações às imagens, mas redistribuem as informações originais de uma forma mais útil. Exemplo desse tipo de transformação são razões de banda e índices espectrais, os quais podem ser compreendidos como procedimentos de aritmética que combinam respostas em duas ou mais porções do espectro eletromagnético (bandas) e têm por finalidade destacar uma feição de interesse.

Uma grande diversidade de razões de banda ou índices espectrais foram descritos na literatura científica, com finalidades diversas: destacar determinadas características vegetacionais, litológicas ou pedológicas; facilitar a identificação de determinados eventos, como emissão de poluentes, incidência de incêndio florestal; auxiliar na identificação e destacar características que indiquem a qualidade de corpos d'água; dentre outros. Todos esses índices podem ser levados em conta como características individuais de um objeto e observados seus descritores (eg. média, desvio padrão, distribuição), de forma semelhante aos números digitais.

Por sua vez, atributos que privilegiam um contexto comparativo, normalmente referidos como "atributos de vizinhança", levam em consideração dados quantitativos de objetos próximos, além do próprio valor de um determinado objeto. Esse é o caso, por exemplo, dos atributos: diferença média em relação aos vizinhos para o valor de uma banda (obtido a partir de comparação entre objetos próximos); diferença média em relação a objetos com determinados tipos de restrições, por exemplo, com maior valor de brilho (obtido a partir de comparação entre objetos próximos). É possível, também, comparar o valor de um objeto com o valor de um super-objeto ou mesmo com um descritor obtido para toda a cena analisada.

Características também relevantes que podem ser utilizadas em um mapeamento nesse contexto são atributos hierárquicos (eg. "não está contido no superobjeto"), atributos 
topológicos ou de proximidade (eg. "ao lado de", "a uma distância definida de"), interações com planos vetoriais temáticos (eg. "sobrepõe-se ao plano em um percentual de"). Vários outros atributos e múltiplas opções de integração entre eles estão disponíveis em aplicativos de GEOBIA, em um ambiente geralmente flexível e customizável, não sendo propósito deste estudo uma listagem exaustiva, mas apenas exemplificativa de eventuais elementos que podem ser utilizado em mapeamentos temáticos como o deste trabalho.

Como acima observado, em um processo de GEOBIA, faz-se necessária a segmentação e a obtenção de diversos atributos e inúmeros objetos. Quando se considera grandes regiões, ou mesmo uma cena típica de satélite, quantidades expressivas de dados podem ser gerados. Uma cena Landsat 5 TM, por exemplo, tem uma extensão de $175 \mathrm{~km}$ por $185 \mathrm{~km}$ (aproximadamente $32 \mathrm{mil} \mathrm{km²}$ ou 32 milhões e 200 mil hectares). No caso de uma escala que reconheça como área mínima 2 hectares e na hipótese de todos os objetos apresentarem a área mínima, para a análise de uma cena, podem ser gerados até 16 milhões de objetos, com o descritor de dezenas de atributos vinculados a cada um deles.

A quantidade massiva de dados e a complexidade de análises sobre os atributos impedem o uso de qualquer técnica convencional para a categorização desses objetos em classes. Estratégia especialmente profícua é a utilização de soluções capazes de identificar padrões e gerar modelos hierarquizados e com capacidade de generalização para a realização da classificação, como é o caso de técnicas relacionadas à Descoberta de Conhecimento em Bases de Dados - KDD (Knowledge Discovery in Databases - KDD) ou Mineração de Dados (Data Mining).

\subsubsection{Mineração de dados e sua aplicação ao mapeamento}

A mineração de dados (Data Mining) ou mineração de conhecimento (Knowledge Mining) é geralmente indicada como passo central de um processo de Descoberta de Conhecimento em Bases de Dados (Fayyad, Piatetsky-shapiro e Smyth, 1996), indicado posteriormente como KDD. O componente de mineração de dados de um KDD refere-se a técnicas ou à ciência que, utilizando-se do conhecimento de diversas áreas de estudo, tais quais o aprendizado de máquina (machine learning), estatística, reconhecimento de padrões, inteligência artificial, banco de dados e computação de alta performance, têm por principal objetivo a descoberta de padrões e relacionamentos anteriormente desconhecidos a partir de grande volume de dados e a identificação e descrição automática de modelos que explicitem novas informações úteis a partir de tal análise. 
Um processo completo de conhecimento pode ser dividido em diferentes fases. Em uma abordagem integradora da literatura sobre o tema, Rokach \& Maimon (2008) propuseram oito passos, os quais, interativamente, podem seguir uma via bidirecional (aceita o retorno aos passos anteriores). São eles:

a) A compreensão prévia do domínio da aplicação, conhecimentos prévios relevantes e os objetivos do usuário em relação à análise a ser realizada;

b) Seleção dos dados sobre os quais o processo de conhecimento será aplicado;

c) Pré-processamento dos dados, envolvendo a redução de dimensões, a limpeza e eventuais transformações dos dados sob análise;

d) A escolha adequada das tarefas a serem desempenhadas pelo minerador de dados (classificação, regressão, agrupamento, sumarização);

e) A escolha do algoritmo de mineração e métodos específicos de busca de padrões;

f) Aplicação do algoritmo de mineração;

g) Avaliação e interpretação dos padrões obtidos;

h) A utilização do conhecimento obtido em aplicações ou sua documentação e descrição;

As principais etapas estão representadas na Figura 5, abaixo:

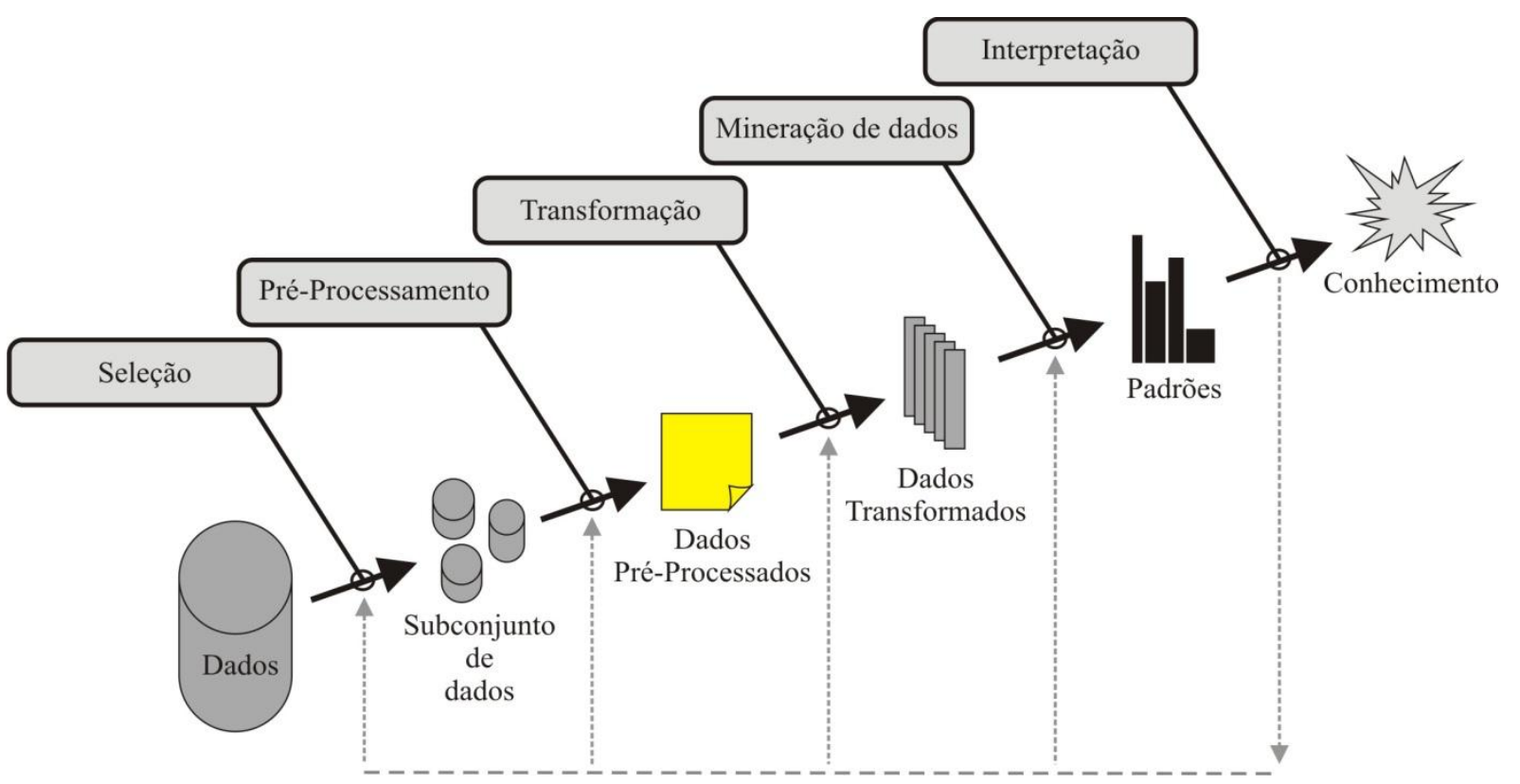

Figura 5 - Etapas em um processo de Descoberta de Conhecimento em Bases de Dados (KDD). Fonte: Adaptação de Fayyad et al. (1996).

Fayyad et al. (1996) fazem distinção entre dois tipos principais de análises por meio da mineração de dados: análise orientada à verificação, em que o sistema limita-se a verificar 
as hipóteses testadas; e análise orientada à descoberta, em que o sistema tem por objetivo encontrar novos padrões de forma autônoma. No caso do presente estudo, a abordagem utilizada é a de uma análise voltada à descoberta, em que se busca identificar os padrões e níveis de decisão que resultem na classificação dos dados entre as classes de mapeamento consideradas.

Em uma análise voltada à descoberta são relevantes duas características principais do processo de mineração de dados, a predição e a descrição (Fayyad, Piatetsky-shapiro e Smyth, 1996). A primeira característica envolve o uso de variáveis de um banco de dados para predizer valores desconhecidos de outras variáveis de interesse. Trata-se da construção de um modelo de comportamento dos dados, o qual se volta, no caso de uma análise de descoberta de padrões, a prever valores de uma ou mais variáveis relacionadas à amostra ou a encontrar conjuntos de amostras com especial significado. A característica de descrição, por sua vez, volta-se a entender como o padrão dos dados opera em uma maneira interpretável por um humano. Processos de descrição e predição, muitas vezes estão intimamente relacionados.

A maioria das técnicas de mineração de dados exige o fornecimento de amostras de treinamento, além do banco de dados sobre os quais essas técnicas serão aplicadas, o que é conhecido como um processo supervisionado. As amostras de treinamento vinculam um conjunto de registros do banco de dados ao objetivo final da análise e é feito pela intervenção direta do usuário. As amostras de treinamento são empregadas para a formação de um modelo capaz de descrever o comportamento da população de dados. Idealmente, esses modelos devem descrever e explicar fenômenos escondidos nos dados e prever corretamente um atributo-objetivo, levado em consideração outras características expressas em um registro. Trata-se de um processo de generalização a partir de um aprendizado indutivo (Rokach e Maimon, 2008).

O minerador de dados pode gerar modelos de classificação ou de regressão. Modelos de classificação são aqueles que geram como resultados funções que atribuem um registro de dados a uma dentre duas ou mais classes pré-definidas. Modelos de Regressão, por sua vez, geram funções que predizem o valor de uma variável atribuída a um registro de dados.

No caso do presente estudo, a partir de uma base de dados formada por objetos (segmentos) e seus atributos, têm-se por fim a categorização dos registros em cada uma das classes definidas: antrópico, natural e corpo d'água. Em uma análise hipotética, nesse contexto, deve-se fornecer ao aplicativo de mineração de dados, além da base de dados, um conjunto de amostras de treinamento pertencentes a cada uma das classes que se tem por 
objetivo. Tais amostras devem ser compostas por objetos de uma imagem que, a partir da interpretação visual, sejam determinados como pertencentes a cada uma das classes de interesse pelo intérprete.

Dentre várias alternativas de métodos de classificação disponíveis (eg. vector machines, sumaries probabilistic, algebraic functions, neural network) destacam-se, pela simplicidade e clareza de seus resultados, as árvores de decisão ou árvores de classificação. Estas se referem a modelos hierárquicos de decisão que têm por característica serem compostos por uma origem (raiz) e um sistema dendrítico de decisão, formado por ramos e nós, além de elementos intermediários ou finais (folhas). Os nós de uma árvore de decisão recebem apenas um ramo e podem ser internos, quando dele se originam novos ramos, ou terminais, quando esse se encontra no estágio final de decisão (Rokach e Maimon, 2008; Utgoff, 1989).

Os elementos anteriormente apresentados formam um sistema encadeado que parte da raiz e conclui-se em uma folha, sendo intercalado por diversos nós. Cada nó interno divide o espaço amostral definido em dois ou mais sub-espaços de acordo com as regras de decisão adotadas, normalmente, baseadas no valor de um único atributo. Quando se trata de atributos quantitativos, a regra de decisão define um intervalo de valores para seccionar os dados entre os ramos ou nó terminal. No estágio final, cada folha atribui, de acordo com um objetivo, o valor final (uma classe) a um conjunto de registros que cumpriram os requisitos determinados ao longo do sistema de decisão (Figura 6) (Rokach e Maimon, 2008; Utgoff, 1989). 


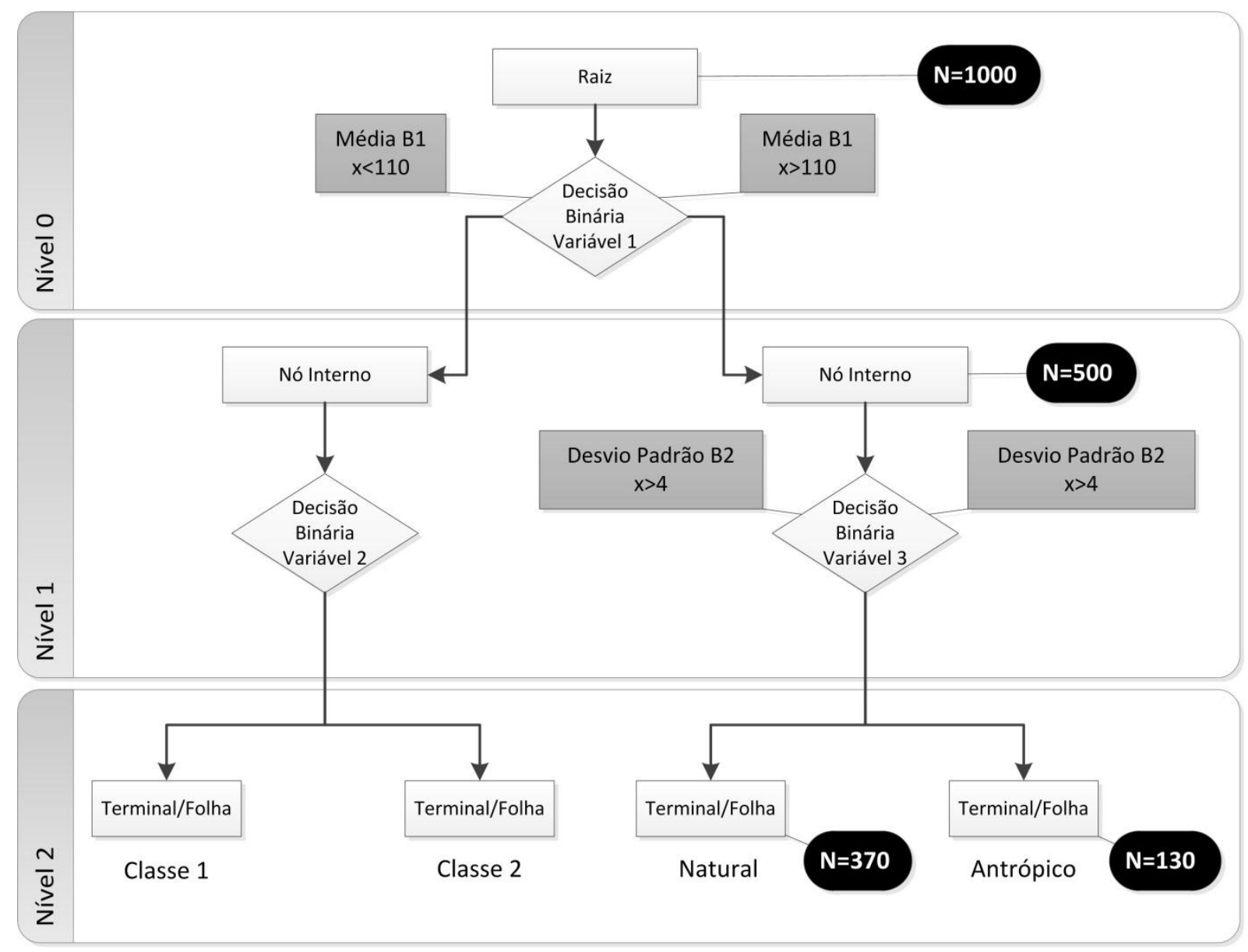

Figura 6 - Estrutura de uma árvore de decisão apresentado uma origem (raiz), sistema dendrítico de decisão com nós e decisões internas, além de elementos finais (folhas). Observa-se também exemplos de critérios de decisão com valores de variáveis e números de elementos divididos entre os nós terminais.

Um dos elementos centrais de um processo realizado por meio de uma árvore de decisão é o algoritmo de indução (induction algorithm, inducer ou learner) que é utilizado. Esse é responsável por gerar automaticamente o modelo a partir dos dados de entrada (amostras de treinamento) e que será aplicado, a partir de regras generalizáveis, ao conjunto de registros do banco de dados. Geralmente as regras aplicadas são univariadas (utilizam apenas uma variável na decisão) de forma que o algoritmo de indução deve encontrar o melhor critério para seccionar o conjunto de dados em cada nó. Deve levar em conta, também, eventuais limitações relativas ao tamanho da árvore de decisão e critérios de finalização.

Vários são os tipos de indutores desenvolvidos pela literatura científica, sendo os mais conhecidos o ID3 (Quinlan, 1986), o C4.5 (Quinlan, 1993), o CART (Breiman et al., 1984). Esses diferem, especialmente, mas não exclusivamente, pelos critérios adotados para a escolha dos atributos que serão levados em conta na decisão (eg. Information Theory Criteria, Impurity Based Criteria). 
Outros importantes elementos do processo de conhecimento por meio de uma árvore de decisão são o critério de finalização (stopping criteria) e o critério de redução (prunning criteria). O primeiro estabelece que, a partir do momento em que determinada condição é atingida, o processo de crescimento e adição de nós à árvore deve ser interrompido e concluído o modelo a partir das condições até então estabelecidas. Exemplos de critério de finalização são: quando todos os registros das amostras de treinamento forem atribuídos a uma classe-objetivo; quando a árvore de decisão atingir determinado número de nós ou graus hierárquicos.

O critério de redução, por sua vez, busca uma melhor adequação da árvore de decisão a seu objetivo principal, a obtenção de um modelo hierárquico generalizável. Esse critério permite que sejam adicionados novos nós até que o modelo se adeque excessivamente aos dados da amostra de treinamento (overfitting), o que resultaria em perda da generalidade. Posteriormente, promove-se a exclusão de nós e ramos que não contribuem para um aumento da acurácia e da capacidade de generalização do modelo. Esse método contribui para a obtenção de regras generalizáveis, que atendam adequadamente ao processo de classificação dos registros de toda a base de dados.

O sobre-ajuste de um modelo ou overfitting ocorre quando um modelo fere o princípio da parcimônia, também conhecido como Navalha de Occam (Occam's Razor). Esse princípio indica que um fenômeno deve assumir apenas as premissas estritamente necessárias e eliminar todas as que não causariam qualquer diferença aparente nas predições da hipótese ou teoria (Hawkins, 2004). Quando ocorre overfitting em um modelo, esse apresenta um excesso de parâmetros ou excessiva complexidade/flexibilidade, ajustando-se de forma quase perfeita aos valores da amostra de treinamento (Figura 7). Nesse caso, passa a descrever não o fenômeno observado, mas também erros randômicos implícitos em qualquer conjunto de dados. Um modelo sobre-ajustado tem uma baixa performance preditiva e um alto erro de generalização. 

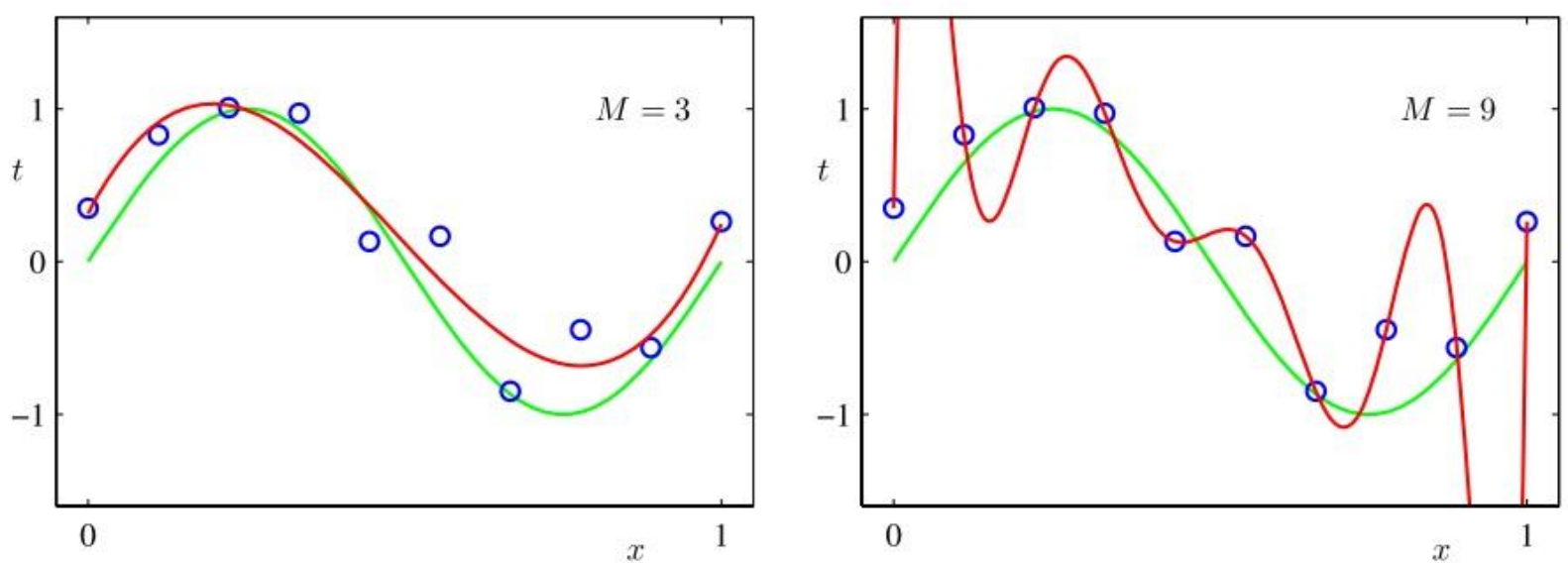

Figura 7 - Duas diferentes funções polinomiais (linha em vermelho) geradas a partir de dados de treinamento (pontos em azul). A população de dados foi gerada a partir da função polinomial representada pela linha verde. Observa-se na figura a direita o efeito do overfitting. Fonte: Bishop (2006).

Em árvores de decisão, um sobre-ajuste ocorre geralmente com a adição de um número excessivo de nós (decisões), passando o modelo a ser uma descrição de um conjunto de dados (a amostra de treinamento) e não o reconhecimento de um padrão subjacente aos dados (Rokach e Maimon, 2008). Geralmente há um trade-off entre o erro de treinamento (medida que represente uma relação entre o número de registros da amostra de treinamento e o número de corretas classificações) e a capacidade de generalização do modelo.

Dois tipos de mecanismos principais podem ser utilizados para a diminuição do erro relacionado ao overfitting: a adoção de um critério que evite que novos nós e ramos sejam adicionados ao modelo, no caso de esses não mais contribuírem para a compreensão do padrão subjacente. Por exemplo, a avaliação da significância de um critério de conhecimento antes de adicionar um nó além da adoção de um critério de redução.

É conveniente em uma análise, como a que é proposta neste estudo, a limitação do tamanho total da árvore de decisão, adotando-se um critério de finalização, bem como utilizar recursos de controle de orverfitting como os acima mencionados. O algoritmo CART, utilizado neste estudo, tem disponível funções de redução de erro de generalização (prunning criteria e stopping criteria).

Um último passo necessário em um processo de mineração de dados com árvore de decisão, ou outro processo KDD, é a avaliação do modelo obtido. Diversos estimadores de qualidade foram propostos para essa finalidade (Rokach e Maimon, 2008). Baseiam-se, por exemplo, em validação-cruzada (cross-validation), índices de acurácia (sensitivity, specificity, precision, accuracy), curvas de ROC (Receiver Operating Characteristic), matriz de confusão e índices de qualidade. De especial interesse para a finalidade deste trabalho são avaliações 
baseadas em matriz de confusão e índices de qualidade. Tais estimadores são extensamente utilizados na área de mapeamento, melhor se enquadrando às características específicas deste estudo.

\subsubsection{Avaliação de Qualidade}

A realização de uma avaliação quantitativa sobre a qualidade dos dados de um mapeamento temático tem por principal função o estabelecimento e verificação de padrões de qualidade e permitir ao usuário avaliar se um determinado mapeamento pode ser utilizado para as finalidades pretendidas (Congalton, 2004).

Stehman \& Czaplewski (1998) dividiram o processo de avaliação de qualidade em três pontos principais: a estratégia de amostragem (sampling design), a estratégia de verificação (response design); e protocolos de análise e estimação dos resultados.

De acordo os autores mencionados, a avaliação de acurácia inicia-se pela definição da população alvo, que, no caso de mapeamentos, pode ser compreendida como toda a área representada pelo mapa de uso e cobertura da terra. As unidades amostrais podem ser representadas por pontos (adimensional) ou por pequenas áreas relacionadas à escala do mapeamento. Essas devem ser lançadas ao longo do espaço definido pela população em número e em distribuição que sejam capazes de, a partir de procedimentos estatísticos adequados, representar os parâmetros de qualidade da população.

Exemplos típicos de estratégia amostrais válidas estatisticamente são a amostragem aleatória simples, a amostragem aleatória estratificada e a amostragem sistemática. No primeiro caso, são lançadas unidades amostrais no espaço em número representativo, obtendo-se como resultado número de amostras em cada classe proporcional à área ocupada por essas. Na amostragem aleatória estratificada é determinada a distribuição de amostras a partir de cada uma das classes mapeadas, sendo o número de amostras igual entre as classes ou proporcional à área. No caso de amostragem sistemática é definido critério prévio para a distribuição das amostras, por exemplo, a distribuição de unidades amostrais de forma regular ao longo do território mapeado (e.g. uma amostra por hectare).

Não há na literatura a indicação da melhor estratégia amostral para qualquer situação. Essa deve ser definida de acordo com a situação fática observada na relação entre o produto de mapeamento gerado e os objetivos que essa visa atingir. Contudo, a alocação intencional de amostras (e.g. onde se quer examinar o mapa) ou de acordo com critérios de oportunidade 
(e.g. onde é mais fácil de ser acessado e verificado) não se enquadram em estratégias de amostragem estatisticamente confiáveis (Rossiter, 2004).

A estratégia de verificação é aquela que define o parâmetro a partir do qual cada uma das amostras estabelecidas, com dados do mapeamento a ser avaliado, será comparada. Nesse caso, é estabelecida a verdade de campo que pode ser obtida a partir da análise de imagens de satélite, fotografia aérea, visitas ao local ou mais de uma dessas referências. A partir da comparação dos dados do mapeamento e da verdade obtida pode-se estabelecer o protocolo de quantificação da qualidade.

Métodos quantitativos voltados a esse tipo de avaliação geralmente utilizam matrizes de confusão para obter os estimadores de qualidade. Conforme Congalton (2004), uma matriz de confusão ou matriz de erro é uma matriz regular com valores em suas linhas e colunas que expressam números de amostras atribuídos a categorias ou classes do mapeamento. Os valores atribuídos a linhas representam os observados a partir do mapeamento temático (perspectiva usuário/consumidor), enquanto os que estão organizados nas colunas refletem a verdade obtida a partir de uma estratégia de verificação (perspectiva do produtor). Na Tabela 1, podese observar uma matriz de confusão típica.

Tabela 1 - Matriz de erro para $n$ classes de uso e cobertura do solo.

\begin{tabular}{|c|c|c|c|c|c|c|}
\hline & \multicolumn{6}{|c|}{$\begin{array}{c}\text { Referência } \\
\text { (Visão do Produtor) }\end{array}$} \\
\hline \multirow{6}{*}{ 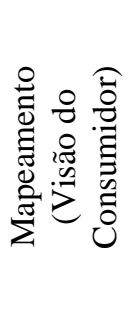 } & Classe & 1 & 2 & $\ldots$ & n & Total \\
\hline & 1 & $\mathrm{X}_{11}$ & & $\ldots$ & $\mathrm{X}_{1 \mathrm{i}}$ & $\mathrm{X}_{1+}$ \\
\hline & 2 & & $X_{22}$ & $\ldots$ & $\mathrm{X}_{2 \mathrm{i}}$ & $\mathrm{X}_{2+}$ \\
\hline & ... & $\cdots$ & $\cdots$ & $\ldots$ & $\ldots$ & $\cdots$ \\
\hline & $\mathbf{n}$ & $X_{\mathrm{i} 1}$ & $\mathrm{X}_{\mathrm{i} 2}$ & $\ldots$ & $\mathrm{X}_{\mathrm{ii}}$ & $\mathrm{X}_{1+}$ \\
\hline & Total & $X_{+1}$ & $X_{+2}$ & $\ldots$ & $X_{+i}$ & $X_{++}$ \\
\hline
\end{tabular}

Fonte: Adaptação de Stehman \& Czaplewski (1998).

A matriz de erro possibilita a obtenção de uma série bastante diversa de indicadores os quais refletem o grau de coincidência entre os dados mapeados e a verdade estabelecida, além de indicar a fonte de eventuais erros observados. Dentre os indicadores de coincidência, o mais simples é a Acurácia Global ( $\mathrm{A}_{\mathrm{g}}$ ) (Story e Congalton, 1986). Esse representa a proporção de amostras concordantes observadas no conjunto de dados $\left(\mathrm{P}_{\mathrm{o}}\right)$, sendo dado pelo somatório das unidades amostrais da diagonal da matriz dividido pelo número total de amostras: 


$$
A_{G}=\frac{1}{n} \sum_{i=1}^{r} x_{i i}
$$

Onde,

- $\mathrm{x}_{\mathrm{ij}}$ é o elemento situado na linha i e na coluna $\mathrm{j}$;

- r é o número de linhas;

- n é o número total de amostras;

O uso desse índice por si só é insuficiente, haja vista que não leva em consideração o fato de que parte da concordância observada pode dever-se meramente ao acaso, fato o qual é especialmente relevante quando uma determinada classe de mapeamento ocupa área significativamente maior do que as demais (Rossiter, 2004).

O Índice Kappa ( $K$ ), proposto por Cohen (1960), é extensamente utilizado para aferir a qualidade de mapeamentos temáticos. Esse índice leva em conta não só a proporção de dados coincidentes observados $\left(\mathrm{P}_{\mathrm{o}}\right)$, mas também a proporção de concordância esperada ao acaso $\left(\mathrm{P}_{\mathrm{e}}\right)$, sendo interpretado como a proporção de concordâncias entre classificadores após a remoção da concordância devida ao acaso. Esse pode ser calculado como:

$$
K=\frac{P_{o}-P_{e}}{1-P_{e}}
$$

A concordância esperada é dada por:

$$
P_{e}=\frac{1}{n^{2}} \sum_{i}^{r} x_{i+} x_{+i}
$$

Onde:

- $\mathrm{x}_{\mathrm{i}+}$ é o somatório da linha $\mathrm{i}$;

- $\mathrm{x}_{+\mathrm{i}}$ é o somatório da coluna i;

$\mathrm{O}$ valor do índice varia de $-1 \mathrm{a}+1$, indicando perfeita divergência ou perfeita concordância entre o classificador e a verdade de campo. Apesar de amplamente utilizado, não há consenso sobre a capacidade do índice de bem representar a real concordância implícita nos dados de uma matriz, sendo usualmente criticado por superestimar o valor da concordância pelo acaso $\left(\mathrm{P}_{\mathrm{e}}\right)$, além de ser excessivamente dependente em relação à distribuição dos totais marginais da matriz (Stehman, 1997). 
A ocorrência de totais marginais não equilibrados tende a provocar a ocorrência de duas situações conhecidas como Paradoxos de Kappa, descritas por Cicchetti \& Feinstien (1990). O primeiro paradoxo diz que "“'If $P_{e}$ is large, the chance correction process can convert a relatively high value of $P_{o}$ into a relatively low value of Kappa”. O Segundo Paradoxo diz que "Unbalanced marginal totals produce higher values of $\kappa$ than more balanced total". Ambos os paradoxos estão relacionados a uma distribuição desigual no número de amostras na diagonal da matriz de confusão (symmetrical unbalance) ou uma distribuição desigual ao longo de toda a matriz (asymmetrical unbalance) os quais se refletem sobre os totais marginais.

Para uma eventual solução das inconsistências apresentadas pelo índice Kappa, dois passos são necessários: 1) a verificação do equilíbrio ou desequilíbrio nos totais marginais e 2) a utilização de métrica apropriada, capaz de medir corretamente a concordância em situações de totais marginais não equilibrados.

Várias métricas foram propostas com vistas a se acessar a homogeneidade dos totais marginais de uma matriz. Por seu uso mais frequente ou maior adequação para a área de interesse deste trabalho, destacamos as medidas de viés (BI) e prevalência (PI), propostas por Byrt, Bishop, \& Carlin (1993) e o teste de homogeneidade dos totais marginais de StuartMaxwell (Maxwell, 1970; Stuart, 1955). Considere-se a Tabela 2:

Tabela 2 - Matriz de erro com dois avaliadores e duas classes. Fonte: adaptado de Cunningham (2009).

\begin{tabular}{|c|c|c|c|c|}
\hline \multirow{5}{*}{ 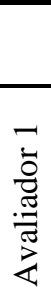 } & \multicolumn{4}{|c|}{$\begin{array}{c}\text { Avaliador } \\
2 \\
\end{array}$} \\
\hline & Classe & $\mathbf{A}$ & B & Total \\
\hline & $\mathbf{A}$ & $\mathrm{a}$ & $\mathrm{b}$ & $a+b$ \\
\hline & B & $\mathrm{c}$ & $\mathrm{d}$ & $c+d$ \\
\hline & Total & $a+c$ & $b+d$ & $\mathrm{n}$ \\
\hline
\end{tabular}

Tendo por referência a matriz de erro acima, o viés (BI) pode ser calculado como:

$$
B I=\frac{a+b}{n}-\frac{a+c}{n}=\frac{b-c}{n}
$$

E a prevalência (PI) como:

$$
P I=\frac{\frac{a+b}{n}+\frac{a+c}{n}}{2}-\frac{\frac{c+d}{n}+\frac{b+d}{n}}{2}=\frac{a-d}{n}
$$


Essas duas métricas, refletem o desequilíbrio dos totais marginais sob a perspectiva de um desequilíbrio simétrico (symmetrical unbalance) ou assimétrico (asymmetrical unbalance), sendo PI sensível no primeiro caso e BI no segundo (Li, 2010).

No teste de homogeneidade de Stuart-Maxwell (Maxwell, 1970; Stuart, 1955), eventuais distribuições em desequilíbrio dos totais marginais são expressas em um único teste, sendo medida simultaneamente e considerando todos os elementos da matriz. O teste baseiase no valor de $\chi^{2}$ (Qui-quadrado) o qual é obtido a partir da matriz de variância e covariância do vetor $d$. Onde o elemento $d$ é dado por:

$$
d=x_{i+}-x_{+i}
$$

Onde,

- $\mathrm{X}_{\mathrm{i}+}$ é o somatório da linha $\mathrm{i}$;

- $\mathrm{x}_{+\mathrm{i}}$ é o somatório da coluna $\mathrm{i}$;

A hipótese nula $\left(\mathrm{H}_{0}\right)$ a ser testada é que o verdadeiro valor dos elementos do vetor $d$ é zero. Estimativas da variância (vâr) e covariância (côv) do teste podem ser obtidos a partir das fórmulas:

$$
\begin{gathered}
v \hat{a} r\left(d_{i}\right)=x_{i+}+x_{+i}-2 x_{i j} \\
\operatorname{cô} v\left(d_{i}\right)=-\left(x_{i j}-x_{j i}\right)
\end{gathered}
$$

Tais valores formam a matriz de variância e covariância $S$. Após exclusão da última linha e coluna dessa matriz, passo necessário para o cálculo, a matriz S passa a ter a dimensão $(\mathrm{K}-1) \mathrm{x}(\mathrm{K}-1)$. O valor final de $\chi^{2}$ pode ser obtido a partir da expressão:

$$
X^{2}=d^{\prime} S^{-1} d
$$

Onde,

- $d$ ' é a transposição do vetor $d$;

- $S^{-1}$ é o inverso da matriz $S$, após a exclusão da última linha e coluna;

O teste Qui-quadrado é realizado a partir do valor obtido e valores tabulados para K1 graus de liberdade, sendo valores de $p$ significativos, para determinado nível de significância $\alpha$, indicativo de uma matriz com totais marginais não equilibrados.

Em casos em que seja verificado o desequilíbrio dos totais marginais é esperado que o valor de Kappa não reflita corretamente a concordância entre os dados representados na matriz de confusão, sendo subestimado ou superestimado. Solução proposta por Byrt, Bishop, 
\& Carlin (1993) é ajustar os valores de Kappa em relação ao viés e prevalência, obtendo-se o Prevalence-adjusted Bias-adjusted Kappa (PABAK).

Tendo como referência a matriz da Tabela 2, o Kappa PABAK $(K p)$ é calculado como:

$$
K p=\frac{\left[\frac{x}{x+y}\right]-0.5}{1-0.5}=2 P_{o}-1(\text { para duas classes })
$$

Onde,

- $\mathrm{x}=\mathrm{b}+\mathrm{c} / 2$

- $\mathrm{y}=\mathrm{a}+\mathrm{d} / 2$

A relação entre o Kappa de Cohen $(K)$ e o Kappa PABAK $(K p)$ é dado por:

$$
K=\frac{K p-P I^{2}+B I^{2}}{1-P I^{2}+B I^{2}}
$$

Generalização do índice $S$ de Bennet é aplicável para $q$ classes e apresenta resultados similares ao Kappa PABAK (Gwet, 2014). O Kappa $q$ é dado por:

$$
K q=\frac{P_{o}-\frac{1}{q}}{1-\frac{1}{q}} \quad(\text { para q classes })
$$

Em testes realizados pelos autores mencionados, essas medidas de concordância mostraram-se adequadas em casos em que o Kappa não teve bom desempenho, apresentando uma boa resistência a variações nos valores de viés e prevalência.

A partir dos valores de Kappa ou Kappa PABAK/Kappa $q$ esses podem ser categorizados em níveis de concordância, os quais, de acordo com a classificação de Landis \& Koch (1977), pode variar de muito baixo até quase perfeito (Tabela 3).

Tabela 3 - Grau ou nível de concordância entre avaliadores baseado no valor de Kappa. Classificação de Landis $\&$ Koch (1977).

\begin{tabular}{cc}
\hline Kappa & Nível de Concordância \\
\hline$<0.00$ & Muito Baixo \\
$0.00-0.20$ & Baixo \\
$0.21-0.40$ & Razoável \\
$0.41-0.60$ & Moderado \\
$0.61-0.80$ & Substancial \\
$0.81-1.0$ & Quase Perfeito \\
\hline
\end{tabular}


Após ser verificado o grau de concordância geral entre os elementos da matriz, podese investigar as principais fontes de erros identificando-se, por exemplo, os erros de comissão e omissão.

Um erro de comissão ocorre quando o classificador incorretamente inclui o elemento em uma classe diversa àquela da verdade estabelecida, passando aquela classe a ter área maior do que realmente deveria apresentar. Além de um maior erro de comissão $\left(\mathrm{E}_{\mathrm{co}}\right)$, isso leva a um menor valor de acurácia do usuário $\left(\mathrm{A}_{u}\right)$. Essas medidas são calculadas como:

$$
\begin{gathered}
E_{C O}=\frac{x_{+i}-x_{i i}}{x_{+i}} \\
A_{u}=\frac{x_{i i}}{x_{+i}}
\end{gathered}
$$

Onde,

- $\mathrm{x}_{+\mathrm{i}}$ é o somatório da linha $\mathrm{i}$;

Por sua vez, um erro de omissão ocorre quando o classificador falha em incluir um determinado sítio na classe em que esse realmente deveria pertencer. Isso leva a que uma classe tenha área menor do que deveria apresentar, refletindo-se sobre um maior valor de erro de omissão $\left(E_{0}\right)$ ou menor valor de acurácia do produtor $\left(A_{p}\right)$. Esses índices podem ser calculados como:

$$
\begin{gathered}
E_{O}=\frac{x_{i+}-x_{i i}}{x_{i+}} \\
A_{p}=\frac{x_{i i}}{x_{i+}}
\end{gathered}
$$

Onde,

- $\mathrm{x}_{\mathrm{i}+}$ é o somatório da coluna $\mathrm{i}$;

As medidas, índices ou testes mencionados, com exceção do teste de homogeneidade de Stuart-Maxwell, constam de protocolo de avaliação de qualidade proposto por Cunningham (2009) e por Rossiter (2004), os quais foram adotados como referência neste trabalho. 


\subsection{CARACTERÍSTICAS GERAIS DA METODOLOGIA DE MAPEAMENTO}

Considerando-se o arcabouço teórico metodológico formado pela GEOBIA e KDD, bem como conhecimento acerca de características relevantes do Cerrado, foi desenvolvida metodologia específica com vistas a se realizar a identificação e mapeamento de áreas desmatadas no período de 1985 e 1995, tendo por mapeamento de referência aquele realizado pelo PMDBBS para o ano de 2002. Trata-se, pois, de um trabalho voltado à atualização de base de dados oficial já disponibilizada, com foco sobre eventos de desmatamento, para períodos pretéritos.

\subsubsection{Mapeamento de Referência}

O trabalho de mapeamento realizado pelo CSR/IBAMA, por meio do PMDBBS, teve por objetivo específico a identificação de desmatamentos ocorrentes no Cerrado entre os anos de 2002 e 2008, 2008 e 2009, 2009 e 2010, e entre 2010 e 2011. Para isso adotou como mapeamento de referência aquele realizado pelo Projeto de Conservação e Utilização Sustentável da Diversidade Biológica Brasileira - PROBIO (MMA, 2007) para o ano de 2002 na escala de 1:250.000.

O procedimento de mapeamento adotado pelo PMDBBS consistiu na aplicação de máscara selecionando-se apenas a classe natural do mapeamento PROBIO, sendo essa região referida como "área útil" do trabalho (IBAMA, 2009). Enquanto o mapeamento PROBIO adotou a escala de 1:250.000, o mapeamento PMDBBS adotou, em sua área útil, a escala de 1:50.000 e área mínima de 2 hectares. A classe antrópica do mapeamento PROBIO, excluída da área útil, foi assumida como verdade, permanecendo em escala diversa àquela do novo mapeamento em execução.

Em face da adoção de diferentes escalas, entre o PMDBBS e o PROBIO, houve a necessidade de ajuste para a área útil determinada (classe natural do mapeamento de referência). O processo de ajuste de escala ocorreu mediante a identificação de desmatamentos no interior da classe natural PROBIO, existentes no ano de 2002, mas que teriam sido desconsiderados em função da escala adotada por esse trabalho. De outra parte, a classe antrópica do mapeamento base, que fora descartada da análise, permaneceu na escala de 1:250.000, não tendo ocorrido a identificação de fragmentos naturais observáveis a partir de uma escala de 1:50.000. 
Em função dos procedimentos mencionados, o mapeamento do ano de 2002, considerando-se todas as classes (Antrópico, Natural e Corpo D’água), compõe-se por regiões com a identificação de feições em diferentes escalas, onde: a classe antrópica é formada por dados obtidos nas escalas de 1:250.000 e 1:50.000, enquanto a classe natural é formada por dados na escala de 1:50.000.

Como resultado do trabalho realizado pelo PMDBBS, foram gerados dados temáticos em formato vetorial (shapefile) dos quais constam em diferentes camadas (layers) as classes antrópico, natural e corpo d'água. Foi registrado na tabela de atributos dos dados: o período do desmatamento, apresentando os valores “ $\leq 2002$ " (anterior a 2002) e "2002-2008" (entre os anos de 2002-2008); área em hectares de cada segmento; fonte dos dados (CSRIBAMA/MMA ou PROBIO/MMA); e município em que se encontra.

A metodologia de mapeamento PMDBBS utilizou-se da classificação por região, identificação visual e edição manual de feições, realizadas por intérpretes a partir de imagens CBERS2B e Landsat 5 TM. Essas imagens sofreram prévio processamento, consistindo em correção geométrica (georeferenciamento a partir do processo image-to-image com cenas obtidas do Global Land Cover Facility - GLCF) e correções radiométricas. Adotou-se como sistema de projeção UTM (Universal Transversa de Mercator) e datum SAD69.

\subsubsection{Processo de Atualização do Mapeamento de Referência}

No presente estudo, utilizou-se o mapeamento atualizado pelo PMDBBS para o ano de 2002, procurando-se respeitar aspectos gerais adotados pela metodologia utilizada para a realização desse. Desse modo, foi estabelecida a escala de 1:50.000 e área mínima de mapeamento de 2 hectares (aproximadamente 12 pixels de uma imagem LANDSAT 5 TM), adotando o mesmo sistema de referência geográfica, além de procedimento de atualização semelhante.

Enquanto no mapeamento realizado pelo PMDBBS foi selecionada a classe natural para a identificação de desmatamento em períodos posteriores; neste trabalho, ao contrário, foi realizada máscara selecionando-se apenas a classe antrópica do mapeamento PMDBBS 2002. A partir da região selecionada, foram identificados fragmentos naturais ou de corpo d'água em dados pretéritos, os quais, posteriormente, foram subtraídos da classe antrópica do mapeamento base, obtendo-se como resultado a atualização da base de dados para os anos de 1985 e 1995 (Figuras 8, 9 e 10). Assim como na série de mapeamentos realizada pelo órgão oficial (IBAMA), não foi considerada a eventual ocorrência de regeneração natural. 


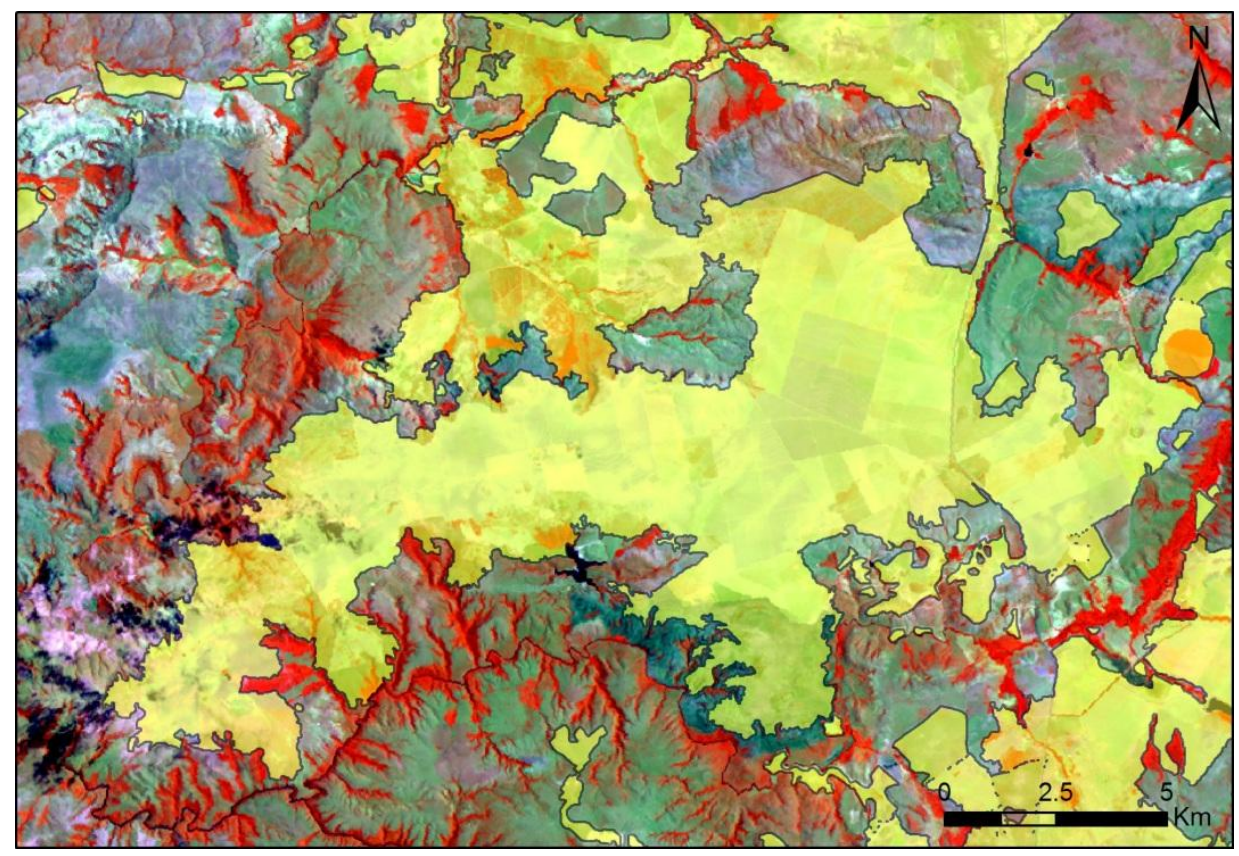

Figura 8 - Primeira etapa do processo de atualização consistiu na identificação da área de interesse do mapeamento, dada pela região classificada como antrópica pelo PMDBBS para o ano de 2002, destacada em amarelo. Imagem Landsat 5 TM do ano de 2002.

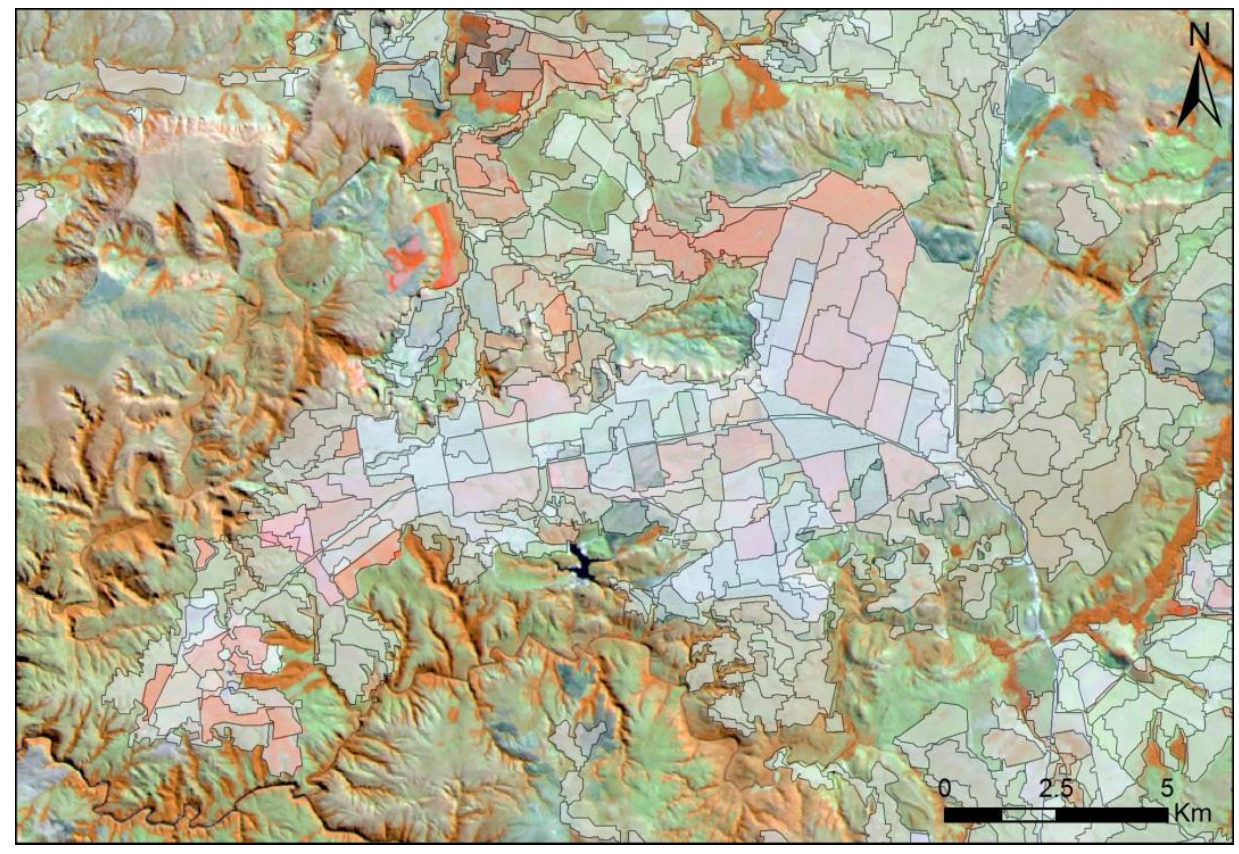

Figura 9 - Aplicação da área de interesse à imagem do ano de 1985, com vistas à identificação de áreas naturais ou corpo d'água e posterior atualização do mapeamento de referência. 


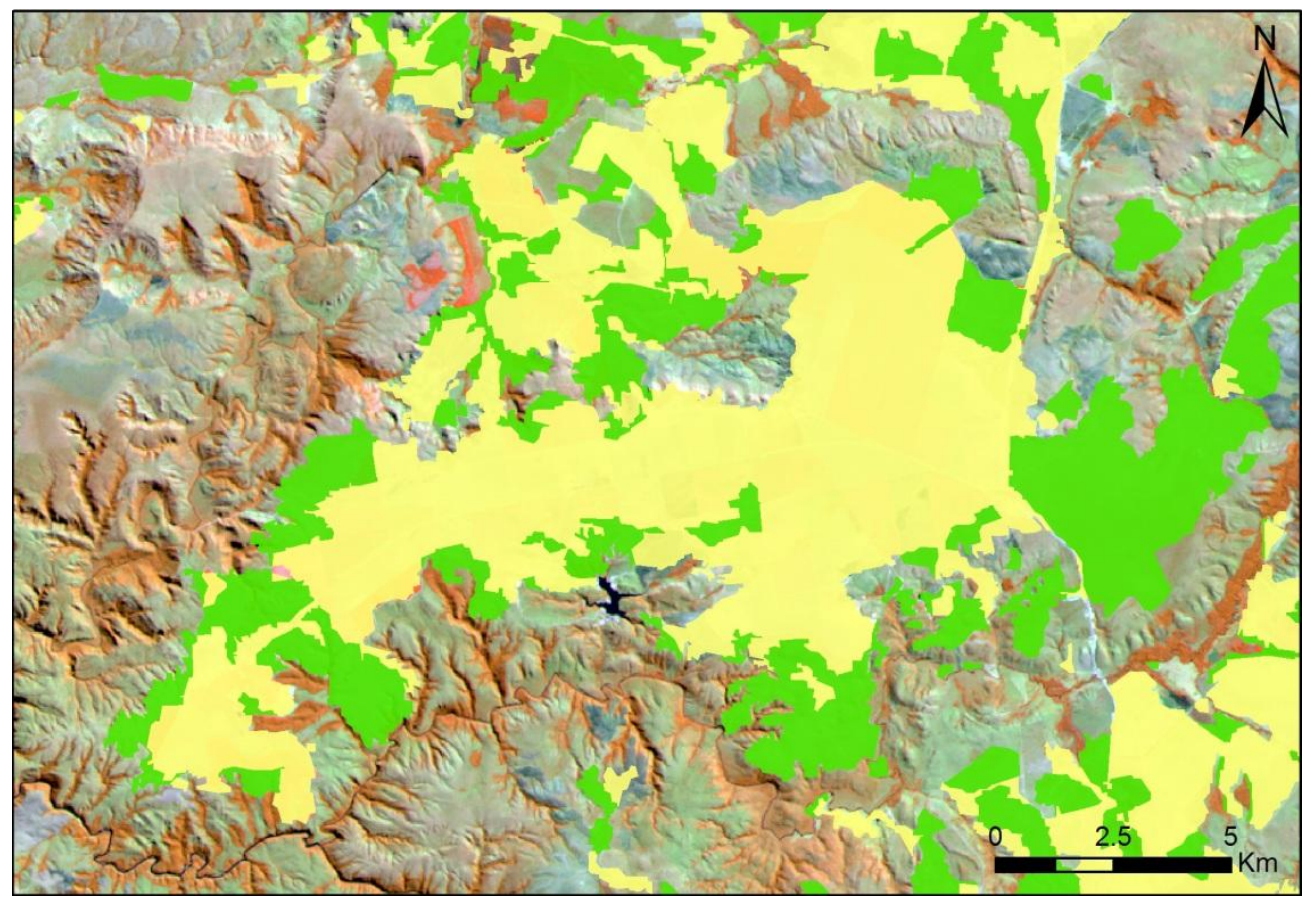

Figura 10 - Área de interesse mapeada, com a identificação da classe natural e corpo d'água a ser atualizada no mapeamento de referência, gerando como resultado mapeamento do uso e cobertura da terra no ano de 1985.

Apesar de seguir diretivas gerais do mapeamento base, neste trabalho desenvolveu-se arranjo metodológico próprio para a realização das tarefas de classificação, a qual teve por principais objetivos diminuir a influência do intérprete sobre a classificação (redução da subjetividade inerente à interpretação) e automatizar tarefas, diminuindo-se o trabalho extensamente manual observado na metodologia de classificação do mapeamento PMDBBS. Tais características têm potencial influência sobre a coerência geral do mapeamento e sobre a eficiência do processo (relação entre rapidez e qualidade).

A metodologia contou com quatro etapas principais: obtenção e pré-processamento dos dados (etapa 1); determinação dos parâmetros de segmentação (etapa 2); mineração de dados e identificação dos melhores atributos a serem utilizados na discriminação das classes de interesse (etapa 3); análise de agrupamento e classificação dos objetos para a obtenção do mapeamento (etapa 4) (Figura 11). Cada uma dessas principais etapas do trabalho é composta por sub-etapas, as quais são tratadas em seção própria. 


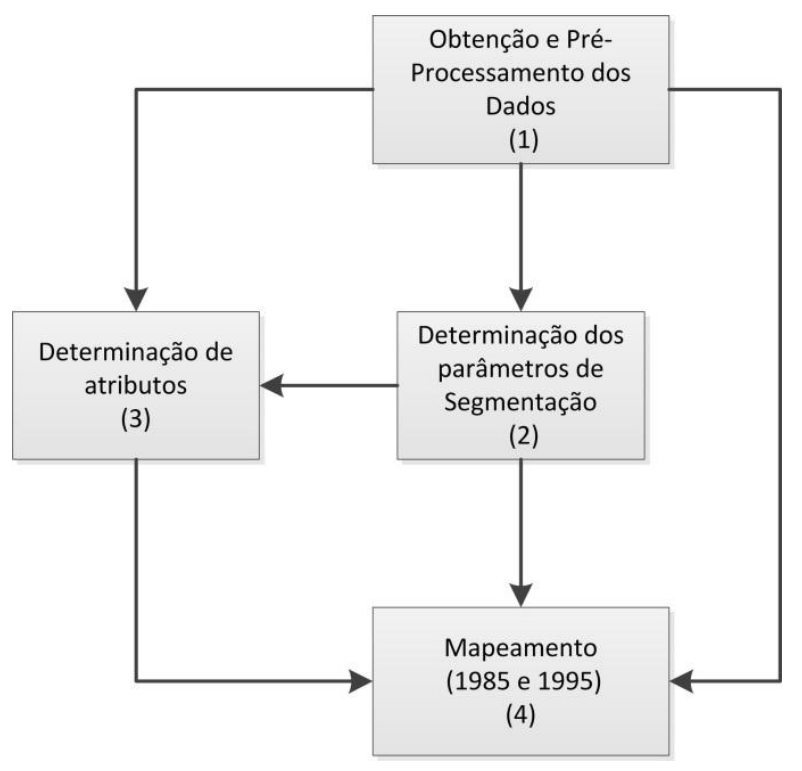

Figura 11 - Fluxograma com as principais etapas do trabalho. As imagens obtidas para classificação foram utilizadas em todos os processos (etapa 1); os parâmetros determinados para a segmentação (etapa 2) foram utilizados nas etapas 3 e 4; os atributos determinados por meio da etapa 3, foram utilizados no processo final de mapeamento (etapa 4).

Além das fases mencionadas, houve, ainda, a avaliação da compatibilidade entre os produtos gerados a partir da metodologia do PMDBBS e a do presente trabalho. Para isso, foi reproduzida a metodologia de mapeamento utilizada para imagens de 2002 e comparados com os resultados do mapeamento de referência (PMDBBS 2002).

Sempre que esteve envolvida a interpretação visual em algumas das sub-etapas adotou-se composição colorida com a banda $4(0,76-0,90 \mu \mathrm{m}$; infravermelho próximo) no canal vermelho $(\mathrm{R})$, banda $5(1,55-1,75 \mu \mathrm{m}$; infravermelho médio) no canal verde $(\mathrm{G})$ e banda $3(0,63-0,69 \mu \mathrm{m}$; faixa espectral do vermelho) no canal azul (B).

Duas chaves de classificação foram utilizadas como referência, uma relacionada a feições naturais e outra relacionada a feições antrópicas. Feições relacionadas às classes naturais no Cerrado, para a escala de mapeamento adotada e consideradas neste trabalho, referem-se principalmente a áreas florestais, de cerrado arborizado e formações campestres (Tabela 4). 
Tabela 4 - Feições naturais do cerrado de interesse para o mapeamento e características relevantes para sua identificação. As feições de interesse foram agrupadas na classe natural.

\begin{tabular}{|c|c|c|c|}
\hline \multicolumn{4}{|c|}{ Classe Natural } \\
\hline & Feições Mapeadas & $\begin{array}{c}\text { Imatem Landsat } 5 \text { TM Composição } \\
4(\mathrm{R}), 5(\mathrm{G}), 3(\mathrm{~B})\end{array}$ & Interpretação Visual \\
\hline \multirow{5}{*}{\multicolumn{2}{|c|}{ Florestal }} & & Cor: vermelho \\
\hline & & & Tonalidade: escura \\
\hline & & & Textura: rugosa \\
\hline & & & Forma: irregular a regular \\
\hline & & & $\begin{array}{l}\text { Contexto: áreas de vegetação arbórea } \\
\text { com predominância de dossel contínuo }\end{array}$ \\
\hline \multirow{10}{*}{ 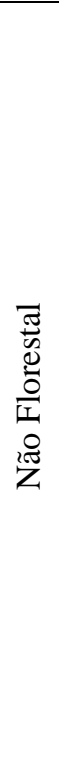 } & \multirow{5}{*}{ Savânica } & & Cor: vermelho/marrom \\
\hline & & & Tonalidade: escura \\
\hline & & & Textura: rugosa \\
\hline & & & Forma: irregular a regular \\
\hline & & & $\begin{array}{l}\text { Contexto: áreas de vegetação com } \\
\text { formação arbustivo-herbáceas, sem } \\
\text { dossel contínuo }\end{array}$ \\
\hline & \multirow{5}{*}{ Campestre } & & Cor: verde \\
\hline & & & Tonalidade: escura \\
\hline & & & Textura: lisa \\
\hline & & & Forma: irregular \\
\hline & & & $\begin{array}{l}\text { Contexto: áreas de vegetação } \\
\text { predominantemente herbáceas com } \\
\text { eventual ocorrência de espécies arbóreas } \\
\text { e arbustivas }\end{array}$ \\
\hline
\end{tabular}

Fonte: adaptado de MMA (2015).

Feições relacionadas à classe antrópica no Cerrado, para a escala de mapeamento adotada (1:50.000), referem-se principalmente a área de agricultura (anual e perene), silvicultura, pastagem plantada, área urbana (vegetada e não vegetada), área de mineração e solo exposto (Tabela 5). Abaixo são observadas as principais características dessas áreas nas imagens utilizadas. 
Tabela 5 - Feições antrópicas do cerrado de interesse para o mapeamento e características relevantes para sua identificação. As feições de interesse foram agrupadas na classe antrópico.

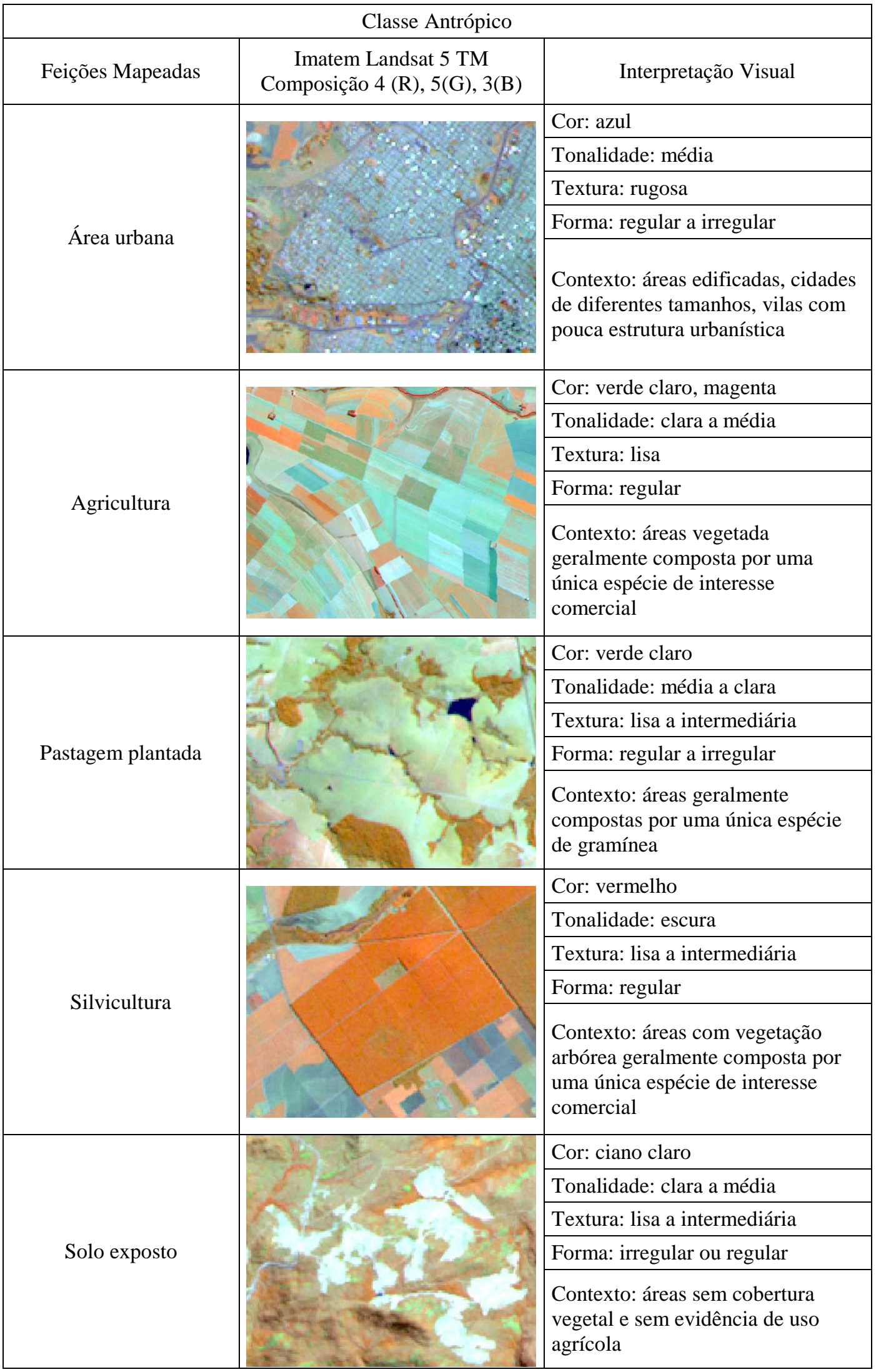

Fonte: adaptado de MMA (2015). 
Além das classes natural e antrópico, também foi de interesse a classe corpo d'água, cujas características principais encontram-se na Tabela 6.

Tabela 6 - Características principais das feições relacionadas à classe corpo d'água.

\begin{tabular}{|c|c|c|}
\hline \multicolumn{3}{|c|}{ Classe Corpo D'água } \\
\hline Feições Mapeadas & $\begin{array}{l}\text { Imatem Landsat } 5 \text { TM Composição } 4 \\
(\mathrm{R}), 5(\mathrm{G}), 3(\mathrm{~B})\end{array}$ & Interpretação Visual \\
\hline \multirow{5}{*}{ Corpo d'água } & & Cor: azul escuro a preto \\
\hline & & Tonalidade: escura \\
\hline & & Textura: lisa \\
\hline & & Forma: irregular \\
\hline & & $\begin{array}{l}\text { Contexto: áreas constituídas por rios, } \\
\text { lagos e represas }\end{array}$ \\
\hline
\end{tabular}

Fonte: adaptado de MMA (2015).

\subsection{OBTENÇÃO DE DADOS E PRÉ-PROCESSAMENTO}

Utilizamos como dados primários imagens obtidas a partir do sensor Thematic Mapper embarcado no satélite LANDSAT 5. O satélite foi lançado ao espaço em março de 1984 e o sensor Thematic Mapper manteve-se em operação até novembro de 2011. O sensor utilizado obtém imagens a partir de 7 diferentes regiões do espectro eletromagnético com 8 bits (256 níveis) de resolução radiométrica. Os dados apresentam resolução espacial de 30 metros para a Banda $1(0.45-0.52 \mu \mathrm{m})$, Banda $2(0.52-0.60 \mu \mathrm{m})$, Banda $3(0.63-0.69 \mu \mathrm{m})$, Banda $4(0.76-0.90 \mu \mathrm{m})$, Banda $5(1.55-1.75 \mu \mathrm{m})$ e Banda $7(2.08-2.35 \mu \mathrm{m})$; e de 120 metros para a Banda 6, na região do infravermelho termal (Banda 6 - 10.40-12.50 $\mu \mathrm{m}$ ).

As imagens utilizadas foram obtidas prioritariamente a partir da base de dados mantida em sítio eletrônico pelo Instituto Nacional de Pesquisas Espaciais - INPE (www.dgi.inpe.br/CDSR/) e, suplementarmente, a partir do sitio eletrônico do United States Geological Survey - USGS (earthexplorer.usgs.gov).

Foram adquiridos três conjuntos de dados independentes, considerando as diferentes etapas envolvidas no processo de mapeamento:

a) Conjunto exploratório de dados - composto por 20 imagens, obtido com a finalidade de se definir características relevantes capazes de discriminar as classes consideradas neste estudo;

b) Conjunto de dados de execução - obtido para a finalidade de realização do objetivo deste trabalho - anos de 1985 e 1995; 
c) Conjunto de dados referente ao ano de 2002 - composto por 20 imagens, obtido com a finalidade de se efetuar teste relacionado à compatibilidade entre os resultados gerados por meio da metodologia proposta neste estudo e aquela do mapeamento de referência.

Os dados utilizados para a obtenção de atributos e os utilizados para o efetivo mapeamento foram obtidos, sempre que possível, para os meses entre junho e agosto, procurando-se manter características espectrais próximas entre as imagens obtidas, além de uma reduzida cobertura de nuvem. Já o conjunto de dados utilizado para avaliação de compatibilidade entre metodologias seguiu a descrição das imagens utilizadas pelo mapeamento PROBIO/2002 (Sano et al., 2010), tendo a mesma data e características que as imagens nele utilizadas.

Em uma primeira etapa do pré-processamento foi realizada verificação prévia da qualidade aparente das imagens obtidas, observando-se, em especial, a eventual ocorrência de erros relevantes nos dados, em extensão e intensidade que pudessem afetar de forma importante as etapas posteriores. Nesse caso, foi observada, especialmente, a ocorrência de erros do tipo striping (pixels, conjunto sistemático de pixels ou linhas ruidosas) e dropped lines (ausência de dados ao longo de uma linha ou conjunto de pixels).

Após a verificação, os arquivos foram submetidos à união de bandas em um mesmo arquivo (por vezes referido como empilhamento) e à etapa de georreferenciamento, sendo todo processo realizado por meio do software Arcgis 10.2 (ArcMap e ArcCatalog).

A união de bandas em um único arquivo se deu por meio da função composite bands no aplicativo ArcCatalog e utilizando-se da opção de processamento em lote (batch processing). Foram consideradas nesta etapa as bandas 1, 2, 3, 4, 5 e 7 de cada uma das cenas de interesse, observando-se a ordem dessas bandas para a geração do arquivo final.

O georreferenciamento foi executado por meio do método image-to-image. Como imagem de referência foram utilizadas cenas disponibilizadas pelo PMDBBS (mapeamento de 2002), obtidas a partir do sitio eletrônico do projeto; ou, quando essas não estavam disponíveis ou apresentavam erro, como no caso de 6 cenas, utilizamos como referência imagens obtidas a partir do GLCF (Global Land Cover Facility). Nesse último caso, além do registro, foi executada verificação posterior, tendo por referência os vetores do mapeamento gerados pelo PMDBBS para essas cenas. 
O procedimento de georreferenciamento se deu mediante a seleção de pontos espacialmente comuns entre as imagens, considerando-se como limite de erro aceitável 1 pixel (RMS $\leq 1)$. A imagem final retificada foi gerada a partir do método de reamostragem pelo vizinho mais próximo (Nearest Neighbor).

$\mathrm{Na}$ Figura 12, abaixo, observa-se o fluxograma seguido na etapa de préprocessamento dos dados, envolvendo os passos anteriormente mencionados.

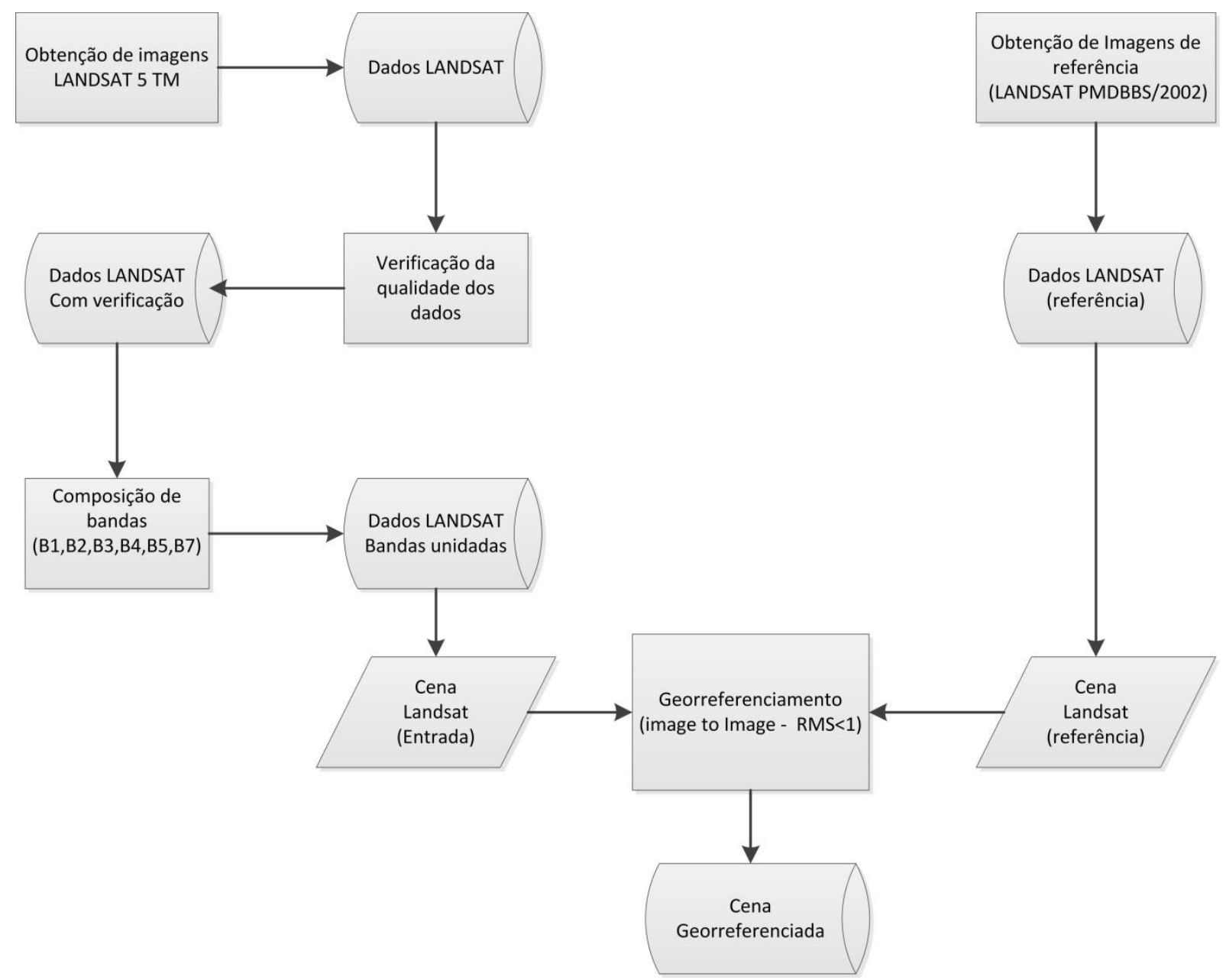

Figura 12 - Fluxograma da etapa de pré-processamento de dados (Etapa 1 da Figura 11).

\subsection{DETERMINAÇÃO DE PARÂMETROS DE SEGMENTAÇÃO}

Segmentos são regiões geradas por um ou mais critérios de homogeneidade, os quais possuem identidade com um image-object. O processo de segmentação ocorre mediante um procedimento de otimização que, para um dado número de objetos, objetiva minimizar a heterogeneidade média e maximizar a homogeneidade de atributos relevantes (Blaschke, 2010). Permite-se, dessa forma, combinar pixels com atributos similares em objetos maiores e, ao mesmo tempo, discriminar os alvos de interesse (Vieira et al., 2012). 
O resultado de uma segmentação é influenciado por vários fatores, tais quais a qualidade da imagem, o número de bandas consideradas e a complexidade dos alvos na área de interesse da cena (Belgiu e Dragut, 2014; Fortin et al., 2000). Com a finalidade de se obter segmentos que representem corretamente os alvos de interesse, a maioria dos algoritmos necessita de ajustes empíricos gerados pelos usuários, com avaliações repetidas e de caráter subjetivo (Arvor et al., 2013; Blaschke et al., 2014). Esse processo além de consumir muito tempo de processamento e análise, nem sempre leva a resultados satisfatórios, dependendo, principalmente, de critérios subjetivos e da experiência do usuário.

Recentemente, algumas ferramentas e métodos têm surgido com vistas a facilitar a obtenção de parâmetros adequados para a segmentação (Belgiu e Dragut, 2014). Tais ferramentas são classificadas entre supervisionadas e não supervisionadas, a depender se os algoritmos utilizam informações prévias definidas pelo usuário segundo as quais os segmentos serão ajustados ou se utilizam apenas estatísticas obtidas a partir da imagem.

Neste estudo, foi utilizada uma ferramenta não supervisionada para a definição do parâmetro de escala, além de testes com diferentes parâmetros de compacidade e forma para a obtenção dos objetos. A ferramenta utilizada foi a Estimation of Scale Parameter - ESP (Dragut, Tiede, \& Levick, 2010), implementada como uma extensão customizada acoplada ao aplicativo eCognition, e aplicada à segmentação multirresolução (Baatz e Schäpe, 2000).

A segmentação multirresolução é uma técnica de união de regiões do tipo bottom-up que particiona a imagem em objetos a partir de um critério de homogeneidade (Baatz e Schäpe, 2000). Esses podem ser alterados pelo usuário de acordo com parâmetros tais como a escala, a forma e a compacidade dos objetos que se busca obter. O algoritmo de segmentação multirresolução disponível no aplicativo eCognition, além dos parâmetros de escala, compacidade e forma, apresenta a opção de atribuir diferentes pesos a cada uma das bandas das imagens que serão segmentadas. Permite, também, a aplicação da segmentação a um nível hierárquico (super-objeto) ou a regiões definidas por uma camada vetorial.

A ferramenta ESP auxilia na obtenção de parâmetros que resultem na identificação de meaningful image-objects, considerando diferentes possíveis escalas. Utiliza como indicadores, os valores da variância local dos dados (LV) e da taxa de alteração da variância local entre o parâmetro de escala atual e o anterior (ROC). Para isso, utiliza procedimentos repetidos, com o incremento padronizado do parâmetro de escala. 
A variância local dos dados (LV) é obtida a partir da média dos valores de desvio padrão (SD) em uma janela móvel (eg. 3x3 pixels), após percorrer toda a cena. Esse valor, que representa a variabilidade local de uma imagem, é um indicador de um parâmetro de escala representativo. Conforme Dragut et al (2010), os valores de LV, quando plotados contra o parâmetro de escala utilizado, tendem a produzir um padrão ascendente e alcançar um pico ótimo local em um valor em que os segmentos produzem objetos semanticamente relevantes para uma determinada escala. Isso ocorre em função de que, em uma escala não significativa, a maioria das medidas de SD ao longo da imagem apresentará valores altamente correlacionados, refletindo-se sobre a diminuição da variância local (LV). Quando objetos aproximam-se de um tamanho representativo, a probabilidade de esses apresentarem valores similares de SD é reduzida, o que resulta em um aumento do valor de LV. Em se tratando de várias possíveis escalas, esse padrão pode apresentar mais de um valor ótimo.

O ESP utiliza, ainda, como indicador a taxa de alteração da variância local entre o parâmetro de escala atual e o anterior (ROC). Esse é dado pela fórmula:

$$
R O C=\left[\frac{L-(L-1)}{L-1}\right] * 100
$$

Onde L é igual a LV para o parâmetro de escala sob análise e L-1 é o valor de LV para o parâmetro de escala imediatamente anterior.

Picos obtidos para o valor de ROC indicam, igualmente, parâmetros de escala em que uma imagem pode ser segmentada de maneira apropriada, obtendo-se elementos representativos para uma determinada escala.

A partir dos indicadores LV e ROC, é possível se obter, após análise dos relatórios gerados pelo ESP, um conjunto de parâmetros a serem utilizados para a realização de uma segmentação, resultando na obtenção de objetos representativos para determinada escala (Dragut et al., 2010).

O teste para a determinação dos atributos de segmentação utilizou o pacote mencionado, o ESP (Dragut et al., 2010), o qual foi aplicado a diferentes imagens, atribuindose mesmo peso a todas as 6 bandas consideradas na análise. Levou-se em conta nos testes realizados, além do parâmetro de escala, os atributos de compacidade e forma, atribuindo-se diferentes valores de importância a esses atributos. A análise dos resultados consistiu na observação dos relatórios gerados pelo ESP, bem como a avaliação visual da segmentação nos múltiplos testes efetuados. 
Como resultado, os dados obtidos a partir do ESP apresentaram parâmetros de escala ideais próximo a 21, 38 e 58 (Figura 13). Considerando a escala de trabalho e a área mínima de mapeamento ( 2 hectares), optamos pelo parâmetro de escala de valor 21, o qual identifica menores áreas. Em relação aos atributos de forma e compacidade, os melhores resultados foram obtidos atribuindo-se o valor de 0.2 para cada um desses atributos.

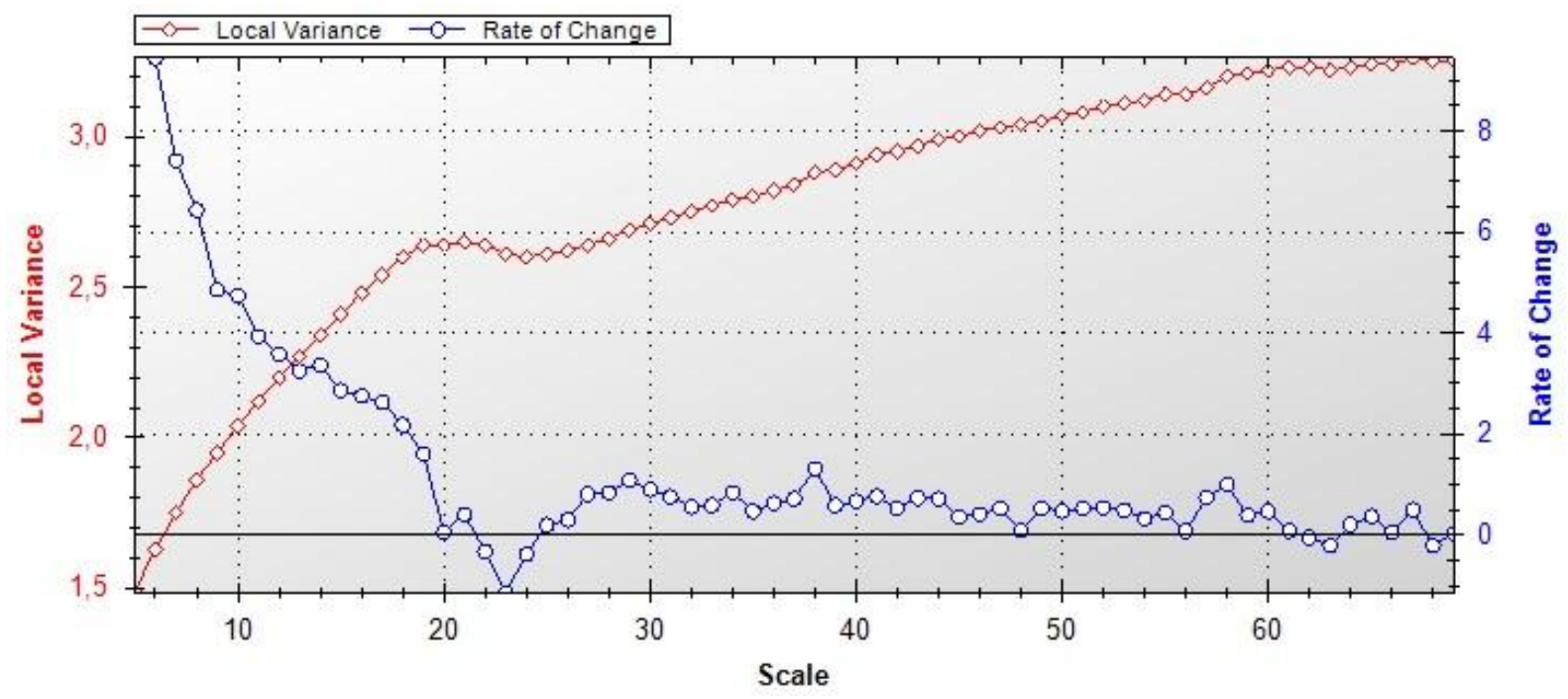

Figura 13 - No gráfico acima, gerado pelo pacote ESP, podemos observar os valores de LV e ROC, utilizando parâmetros de forma e compacidade com valor igual a 0.2. Nele, o valor de ROC apresenta picos nos parâmetros de escala de valor 21, 38 e 58. Para o parâmetro de escala de valor 21, observa-se também um ponto de máxima local do valor de LV, indicando a boa definição de objetos representativos.

Com base nas análises realizadas, foram adotados os parâmetros de segmentação observados (parâmetro de escala $=21$; peso 1 para as 6 bandas; peso de 0.2 para os parâmetros de compacidade e forma) os quais foram aplicados por meio do algoritmo de multirresolução (Baatz e Schäpe, 2000) disponível no aplicativo eCognition. Passo subsequente e incorporado ao processo de segmentação foi o ajuste de escala, aplicando-se algoritmo (grow region) para a eliminação de objetos com tamanho inferior a 2 hectares.

O procedimento de segmentação descrito foi utilizado em diferentes contextos deste trabalho, normalmente integrado a outras tarefas prévias ou subsequentes no ambiente hierárquico de análise do aplicativo eCognition, referido como árvore de processos.

A segmentação aplicada permitiu a identificação de fragmentos relativamente pequenos de vegetação natural em meio a áreas antrópicas com diferentes características e tamanhos, bem como corpos d’água.

Na Figura 14, é possível observar região com alta heterogeneidade, com a presença de feições antrópicas e naturais. Mesmo em ambientes complexos, os parâmetros adotados neste estudo foram capazes de identificar objetos semanticamente relevantes, a exemplo das 
regiões de silvicultura (com formato retangular), agricultura (e.g. pivôs), regiões naturais com limites irregulares (e.g. mata de galeria) ou regulares (e.g. remanescentes de cerrado) vistos na imagem. Em paisagens menos complexas, os parâmetros obtidos apresentaram desempenho superior.

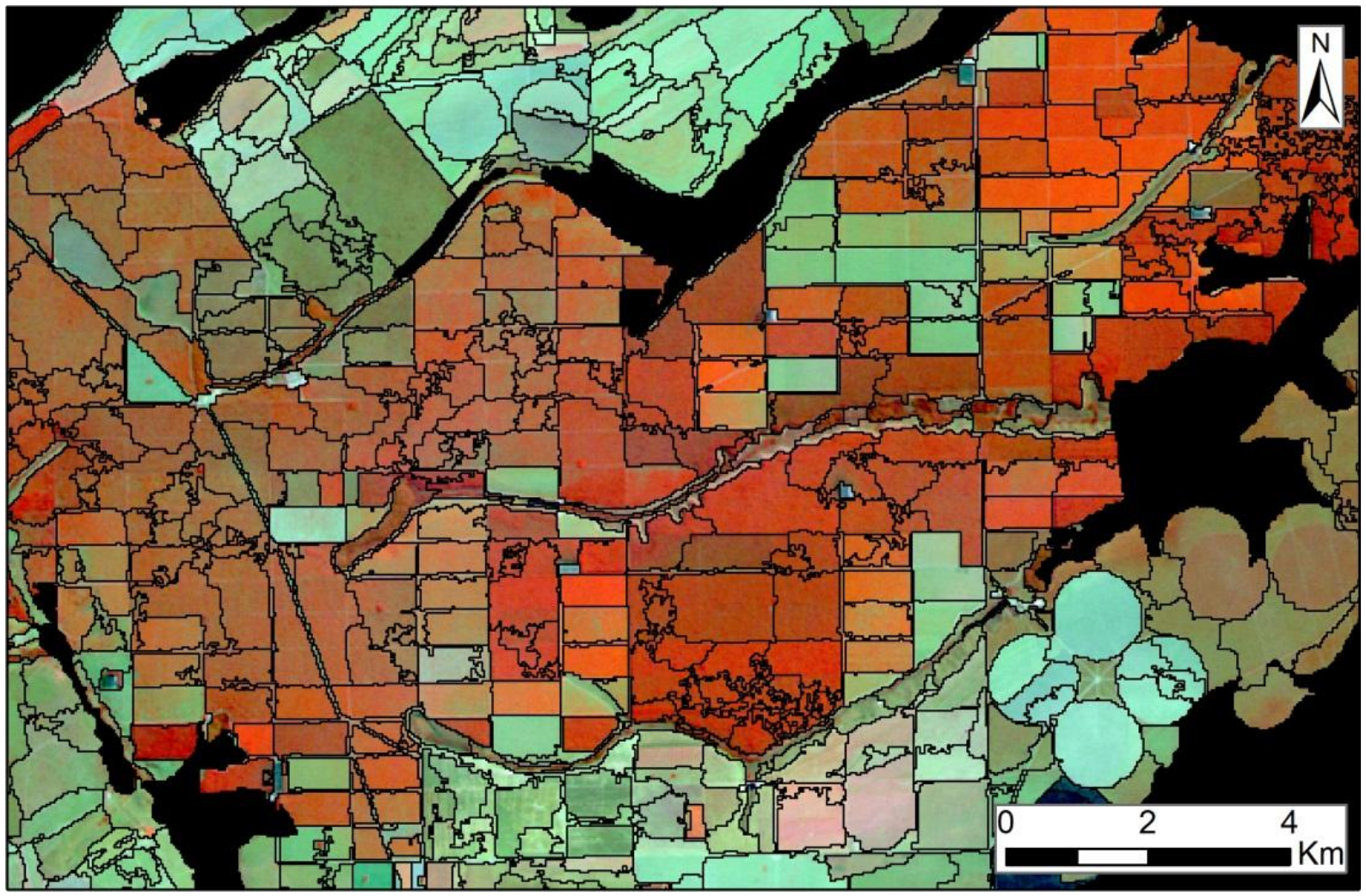

Figura 14 - Segmentação obtida para região com objetos de forma e características bastante diversas (silvicultura, mata de galeria, cerrado, agricultura, pasto) (composição colorida RGB453).

\subsection{DETERMINAÇÃO DE ATRIBUTOS RELEVANTES PARAA CLASSIFICAÇÃO}

Etapa de grande importância para a metodologia adotada é a determinação dos atributos que têm maior relevância para a discriminação entre as classes de interesse na área abrangida pelo Bioma Cerrado. Trata-se de investigação exploratória de caráter empírico sobre características distintivas de feições relacionadas às classes natural, antrópico e corpo d'água ocorrentes na área de estudo.

A determinação de atributos distintivos das classes consideradas serve tanto a etapas posteriores deste trabalho, como também são relevantes enquanto investigação independente. Características definidoras das classes investigadas para a escala de trabalho elegida e para o tipo de imagem utilizada ou a metodologia desenvolvida para a sua determinação, podem ser 
aplicadas para outros tipos de alvos, outras regiões de interesse, outros tipos de imagens e para outras aplicações na área de geociências.

De especial interesse no presente estudo, é a grande variação sub-regional das feições observadas no ambiente investigado. Dentro dos limites do bioma Cerrado (IBGE, 2004), observa-se a predominância de formações vegetais típicas de savana e suas variações, mas também ocorrem extensas regiões florestadas (e.g. região oeste dos estados de Tocantins, Maranhão e porções do estado do Mato Grosso) e grandes regiões campestres (e.g. regiões a oeste do estado de Mato Grosso). Além disso, observa-se grandes regiões cuja cobertura natural foi convertida para uso antrópico (e.g. sul do estado de Goiás, porções do estado de Minas Gerais e a maior parte do estado de São Paulo).

A variação nas características de feições naturais e antrópicas típicas de determinadas sub-regiões devem se refletir sobre o conjunto de características definidoras ou distintivas das classes a serem determinadas. Em função disso, esta etapa do trabalho tem por principal objetivo a obtenção de atributos generalizáveis a partir do conhecimento individual de cada sub-região da área investigada. Nesse contexto, é esperado a existência de um trade-off entre acurácia da classificação e a generalidade da definição de um conjunto de atributos que sirvam para a distinção entre classes de interesse em toda a área de estudo. Ou seja, embora determinados conjuntos de atributos sirvam para uma acurada distinção entre classes de feição investigadas em uma escala sub-regional, nem sempre será a melhor solução para toda a área de investigação.

No caso em análise, privilegiamos características capazes de distinguir feições em todo o ambiente do Cerrado. Procurou-se, dessa forma, determinar, sob um ponto de vista quantitativo, aqueles atributos que melhor refletissem a capacidade de discriminação entre as classes de interesse ao longo de toda a área de estudo, partindo-se da obtenção de informações das unidades mínimas de análise (para cada uma das cenas levadas em consideração no estudo) e das sub-regiões definidas, as quais serviram para garantir a representatividade das feições típicas observadas na área de estudo.

Trata-se de uma análise multidimensional, com a utilização de um processo de Descoberta de Conhecimento em Bases de Dados (KDD), tendo como requisitos: a definição dos atributos a serem testados; a fixação das classes-objetivos e a seleção de amostras de treinamento; a definição da metodologia de mineração de dados a ser empregada; a avaliação dos resultados obtidos por meio da metodologia aplicada; e a análise dos dados gerados a 
partir de tal processo, culminando na definição dos atributos a serem considerados na etapa de mapeamento deste trabalho.

\subsubsection{Visão Geral do Processo de Determinação de Atributos}

A metodologia aplicada partiu da definição de uma estratégia de amostragem capaz de garantir a representatividade de tipos diversos de feição ocorrentes no Cerrado. Para tanto, foram definidas sub-regiões e a amostragem em área com extensão suficiente (Seção 2.5.1).

Após o procedimento prévio de amostragem, as imagens foram obtidas e submetidas à etapa de pré-processamento, conforme procedimento previamente descrito na Seção 2.3. As imagens foram segmentadas, de acordo com parâmetros obtidos na Seção 2.4, sendo executado processamento prévio da imagem com vistas a se excluir porções com dados não válidos (no data e regiões de borda).

A área composta por objetos válidos foi submetida à análise por KDD, sendo selecionadas amostras de treinamento para cada uma das classes no interior de cada cena (Seção 2.5.2). As amostras foram submetidas à classificação, considerando-se diversos atributos candidatos (Seção 2.5.3) e características específicas do processo de conhecimento selecionadas (Seção 2.5.4). Obteve-se como resultado desse processo a efetiva classificação de toda a cena, bem como relatórios estatísticos e parâmetros definidos para classificação.

A avaliação dos modelos de classificação gerados foi realizada por meio da obtenção de índices de acurácia sobre os resultados da classificação (Seção 2.5.5). As etapas anteriores de seleção de amostras de treinamento e classificação da imagem por KDD foi repetida até que fossem obtidos resultados com nível de acurácia adequada.

Passo final no processo de determinação dos atributos foi a aquisição de relatórios e análise de dados, obtendo-se um conjunto de atributos comum capaz de discriminar a maioria das feições das classes mapeadas na área de interesse (Seção 2.5.6).

Com exceção da etapa de pré-processamento, todas as demais, inclusive a mineração de dados e classificação, foram executadas no aplicativo eCognition 9. O procedimento seguiu um conjunto de etapas encadeadas definidas na árvore de processos do aplicativo, que são denominadas conjuntamente como um conjunto de regras (Rule Set) (Figura 15). Na Figura 16 observa-se o fluxograma geral desta etapa do trabalho. 


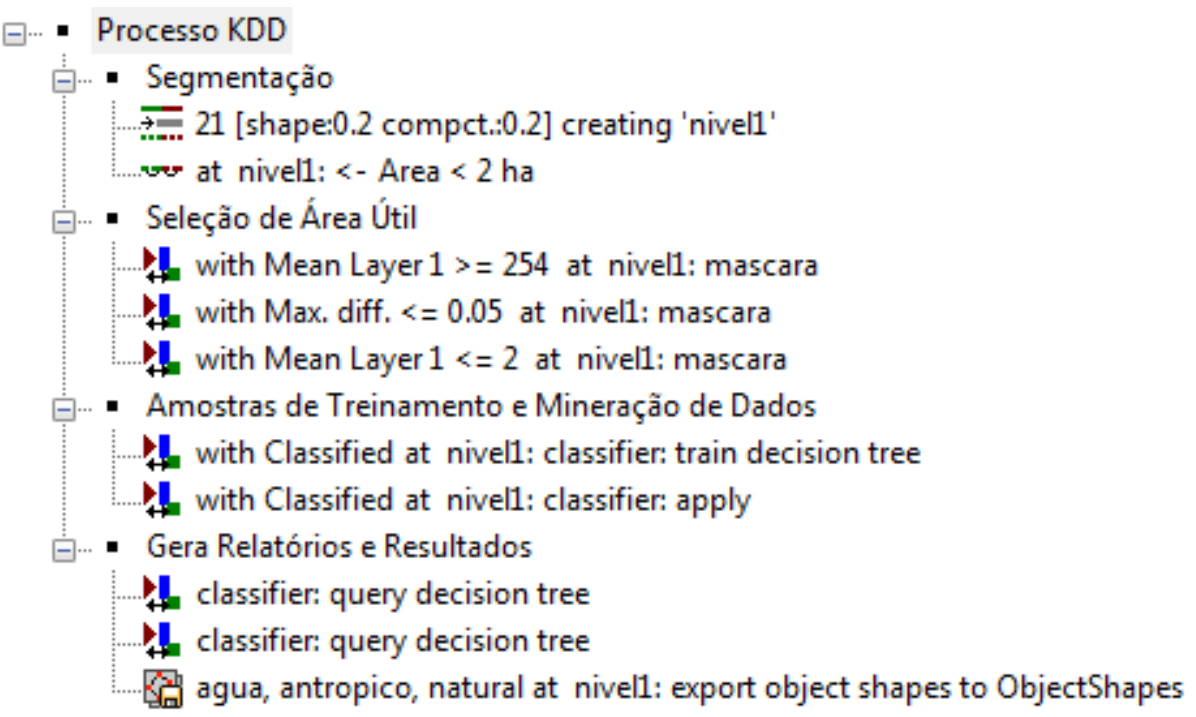

Figura 15 - Conjunto de regras (Rule Set) utilizado para a classificação com o uso de mineração de dados e obtenção de relatórios com informações para a definição dos melhores atributos (aplicativo eCognition 9). 


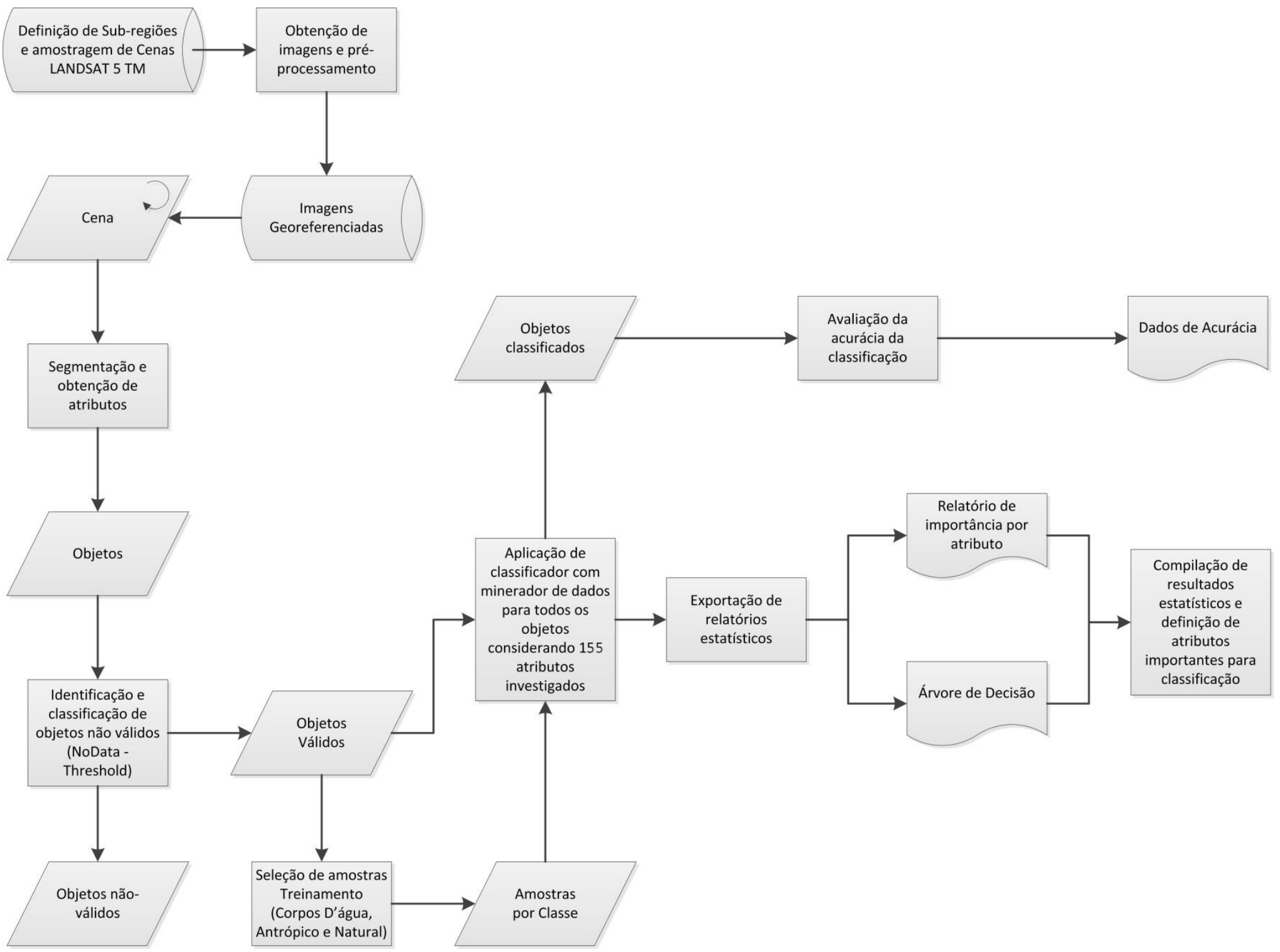

Figura 16 - Fluxograma da etapa de definição dos melhores atributos a serem utilizados para a classificação (Etapa 3 da Figura 11). 


\subsubsection{Amostragem de Cenas}

Com vistas a se obter amostras representativas para as feições naturais e antrópicas de diferentes regiões e que abranjam a heterogeneidade típica do sistema complexo representado pelo Cerrado, estabeleceu-se, inicialmente, a amostragem de uma área mínima de $30 \%$ de toda a região do Cerrado, conforme os limites definidos pelo Mapa de Biomas do IBGE (IBGE, 2004). Com o intuito de abranger eventuais variações fisiográficas subregionais, o procedimento baseou-se em amostragem estratificada, considerando quatro regiões ao longo da área de estudo: região central, leste/sudeste, oeste e norte (Figura 17).

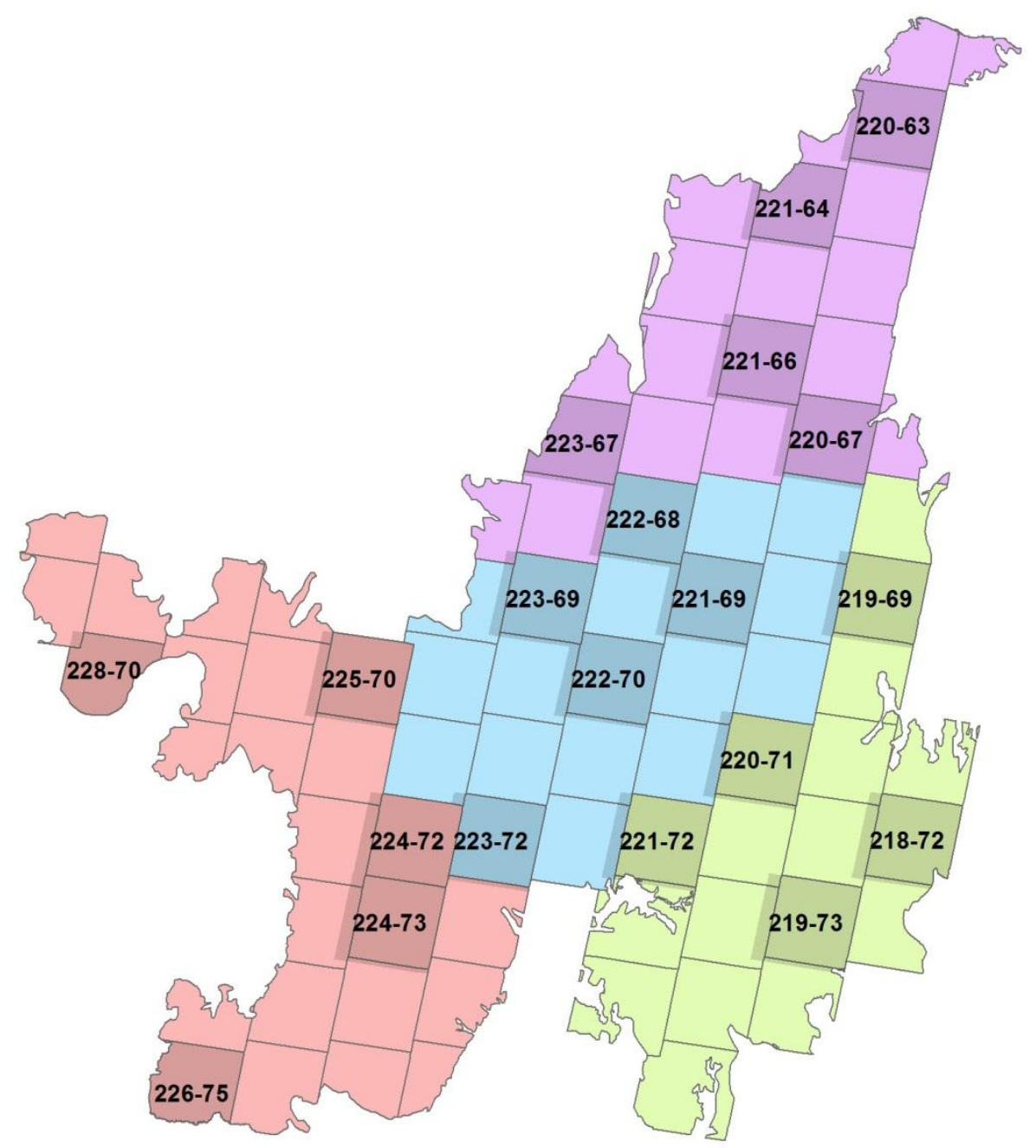

Figura 17 - Regiões delimitadas e cenas selecionadas para a etapa de definição de atributos.

Adotou-se o procedimento mencionado visto que a amostragem aleatória de toda região, indistintamente, pelo acaso, poderia resultar na representação desproporcional de feições de regiões específicas do Cerrado. Procurou-se garantir, dessa forma, não só a amostragem de diferentes tipos de feições para cada uma das classes, mas também a 
representatividade sub-regional de característica do Cerrado que fossem relevantes para a classificação.

Cada uma das regiões mencionadas foi definida pela composição da área individual de cenas LANDSAT 5 TM, buscando-se uma solução que resultasse na definição de regiões com áreas totais o mais semelhante possível entre si. Ou seja, a formação de regiões foi realizada a partir de etapas discretas, com a adição ou exclusão, em cada passo, de toda a área abrangida por uma cena da grade de imagens do LANDSAT 5 TM. Como etapa prévia, foram excluídas todas as cenas situadas nas bordas da área de interesse ou que abrangessem pequenas áreas.

Uma divisão perfeita da região abrangida pelo Cerrado entre as sub-regiões definidas não se mostrou viável, haja vista considerar-se como unidade mínima uma cena. Como resultado, a menor região definida apresentou área de 490 mil km² e a maior de 660 mil km².

Em cada uma das regiões definidas, foram sorteadas 5 cenas aleatoriamente, as quais participaram, posteriormente, do processo de definição dos atributos a serem considerados na etapa de mapeamento deste trabalho.

Como resultado final, selecionou-se aleatoriamente 20 cenas abrangendo diferentes regiões do Cerrado, as quais representaram aproximadamente $30 \%$ da área total do mapeamento (602 mil km²) (Figura 17). No Apêndice 1, constam as informações das imagens (órbita, ponto, data) que participaram efetivamente desta etapa do trabalho.

\subsubsection{Seleção de Amostras de Treinamento}

As imagens selecionadas, conforme design amostral apresentado na seção anterior, foram submetidas à etapa de pré-processamento, conforme Seção 2.3, e à segmentação, utilizando-se dos parâmetros e procedimentos definidos na Seção 2.4, sendo posteriormente submetidas à interpretação visual com o objetivo de se selecionar amostras de treinamento pertencentes às classes corpo d'água, antrópico e natural. O processo de interpretação visual considerou características importantes dos objetos, tais quais: cor, tonalidade, textura, forma e contexto, conforme discutido na Seção 2.1.1. Como chave de interpretação adotou-se aquelas apresentada nas Tabelas 4, 5 e 6.

Adotou-se composição colorida com a banda $4(0,76-0,90 \mu \mathrm{m}$; infravermelho próximo) no canal vermelho $(\mathrm{R})$, banda 5 (1,55 - 1,75 $\mu \mathrm{m}$; infravermelho médio) no canal verde $(\mathrm{G})$ e banda $3(0,63-0,69 \mu \mathrm{m}$; faixa espectral do vermelho) no canal azul (B). Sempre 
que necessário foi realizado o realce das imagens por meio de técnicas de expansão histogrâmica (eg. expansão linear, expansão por equalização, expansão por saturação), os quais resultam em uma maior nitidez das feições e contraste entre os alvos, facilitando sua correta interpretação.

Observando atributos relevantes para uma interpretação visual das imagens e a chave de interpretação, foram selecionados ao longo de cada uma das imagens amostras de treinamento pertencentes às classes antrópico, natural e corpo d'água. A imagem foi percorrida, em um nível de zoom correspondente à escala de 1:50.000, sendo, em regra, selecionado, por imagem, cerca de 2 mil amostras. Procurou-se distribuir homogeneamente os objetos escolhidos ao longo de toda a cena, abrangendo os mais diferentes tipos de feição para cada uma das classes de interesse.

O número efetivo de amostras selecionadas variou em função da complexidade do ambiente analisado (e.g. cenas com diversos tipos de feição natural e antrópica tiveram um maior número de amostras selecionadas do que ambientes mais homogêneos) e dos resultados da avaliação de qualidade do modelo, conforme Seção 2.5.5. No caso de resultados que apontassem inadequação do modelo obtido, as cenas foram submetidas a maior esforço amostral.

\subsubsection{Atributos Candidatos}

Neste trabalho foram considerados atributos descritores de características que privilegiam o aspecto individual de um objeto. Foram considerados atributos espectrais baseados no objeto (e.g. resposta espectral média ou desvio padrão para cada uma das bandas, matiz, saturação e intensidade média), atributos espectrais baseados no pixel (e.g. pixel de menor valor do objeto, razão pixel), índices de forma dos objetos (e.g. assimetria, compacidade), índices de textura (e.g., homogeneidade e entropia), índices espectrais (e.g. NDVI, SAVI, NBR, razão argila).

Foram testados ao todo 155 diferentes atributos em cada uma das 20 imagens selecionadas, os quais estão relacionados no Apêndice 2.

\subsubsection{Regras de Mineração de Dados e Classificação}

O processo de mineração de dados se deu a partir do operador Classifier, com a opção de árvore de decisão, do aplicativo eCognition. O operador mencionado aplica 
algoritmo de mineração de dados para o conhecimento de características das classes-objetivo, considerando as amostras de treinamento tomadas.

No caso do classificador utilizado, o algoritmo de mineração é o Classification and Regression Trees - CART (Breiman et al., 1984). Uma árvore de decisão obtida por esse algoritmo é formada por um conjunto encadeado de decisões binárias (cada nó interno possui exatamente dois ramos de saída) e univariadas (cada decisão é tomada a partir apenas de uma variável), que se inicia considerando todos os conjuntos de dados (raiz) e restringe-se passo a passo para um conjunto mais restrito e homogêneo de registros. Esse algoritmo permite a aplicação de vários critérios de decisão, sendo o mais comumente utilizado o Índice de Gini (Gini Impurity Index).

O índice de Gini é um índice do tipo Impurity Based Criteria, que mede as divergências entre as distribuições de probabilidade dos valores dos atributos de destino. $\mathrm{O}$ valor do índice é utilizado como critério de decisão para o particionamento dos dados em um nó, levando-se em conta o atributo com o menor valor do índice (Mather e Tso, 2009). Esse é calculado para o nó $t$ como:

$$
\operatorname{Gini}\left(t_{X\left(x_{i}\right)}\right)=1-\sum_{j=1}^{m} f\left(t_{x\left(x_{i}\right)}, j\right)^{2}
$$

Onde,

- $f\left(t_{x\left(x_{i}\right)}, j\right)^{2}$ é a proporção de amostras com o valor $\mathrm{x}_{\mathrm{i}}$, pertencentes à classe $\mathrm{j}$ no nó t. probabilidade de ocorrência da classe $i$ no nó $n$;

Especial vantagem do CART é o suporte ao critério de redução (prunning criteria) e ao critério de limitação do tamanho da árvore de decisão. Como abordado na Seção 2.1.2, a aplicação desses elementos auxilia na obtenção de modelos generalizáveis, evitando o overfitting.

Antes da efetiva aplicação do CART houve a seleção da área útil da imagem, sendo retirados aqueles objetos semanticamente não relevantes (Null Values e bordas das cenas), e a seleção de amostras de treinamento para as classes-objetivo. Objetos não relevantes foram representados com valores extremos (ou muito baixos ou muito altos) e com grande homogeneidade (baixo desvio padrão em relação ao valor espectral médio). Para sua identificação, foi suficiente a inserção de regra de atribuição (assign class) baseada no valor médio e desvio padrão da Banda 1 (outras bandas apresentaram resultados semelhantes). 
Dessa forma, objetos com valor médio dos pixels menor que 2 ou maior que 254 e com diferença máxima entre os valores dos pixels de cada objeto menor do que 0.05 , para a banda considerada, foram excluídos da análise posterior.

A área útil restante sofreu processo de amostragem, de acordo com a Seção 2.5.2, sendo aplicado o algoritmo de mineração. Foi definida a utilização do critério de redução e a limitação do tamanho da árvore de decisão para o processo de mineração. Esse último critério esteve relacionado à limitação do número máximo de sete níveis hierárquicos para uma decisão final e o número mínimo de trinta registros em cada uma das folhas da árvore.

Após a aplicação das regras de decisão obtidas por meio do processo de mineração foram gerados: uma camada vetorial composta pelos objetos e sua respectiva classificação; a árvore de decisão com atributos e limiares utilizados em cada decisão; e relatório com a contribuição percentual de cada atributo para os resultados do modelo.

\subsubsection{Avaliação de Qualidade dos Modelos}

A avaliação da qualidade dos modelos obtidos por meio da mineração de dados ocorreu a partir da avaliação do produto final gerado no processo, o mapeamento. O mapa de cobertura da terra com três classes (antrópico, natural e corpo d'água) foi amostrado de forma aleatória e estratificada, por classe, sendo realizada comparação entre a classificação realizada pelo aplicativo e a verdade determinada a partir da interpretação visual de cada ponto. Nesse caso, foi utilizada a própria imagem original que participou da classificação e, quando cabível, outras imagens de maior resolução espacial, disponibilizadas por meio do aplicativo Google Earth.

Cada uma das 20 imagens testadas recebeu 90 amostras, divididas igualmente entre as três classes, obtendo-se um total de 1800 amostras para o conjunto de dados analisado. Cada unidade amostral consistiu em um ponto plotado na imagem, correspondente a um pixel da cena analisada.

A partir das amostras, foi gerada a matriz de confusão de cada imagem, a qual foi analisada por meio do índice global de acurácia e o Índice de Kappa, além de outras métricas discutidas na Seção 2.1.3.

Foi adotado como objetivo a obtenção de modelos com Índice Global de Acurácia superior a $85 \%$ e nível de concordância geral, apontado pelo Índice Kappa ou similar, superior a 80\%, os quais, conforme a classificação de Landis \& Koch (1977), representam modelos com concordância quase perfeita entre os resultados obtidos e a verdade estabelecida. 
No caso de não serem atingidos os índices de qualidade mencionados, foi realizada a seleção de novas amostras de treinamento, especialmente em locais que apresentaram uma má qualidade para o mapeamento obtido, e repetido o processo de mapeamento e avaliação de resultados até que fossem alcançados os melhores resultados possíveis.

\subsubsection{Seleção dos Melhores Atributos}

Após a obtenção de modelos com qualidade adequada, a árvore de decisão (atributos e limiares) obtida para cada cena foi submetida a análise, bem como o relatório de importância dos atributos.

Dos atributos e limiares utilizados nas árvores de decisão para a determinação das classes-objetivo entre os conjuntos de cena, observou-se que a classe corpo d'água apresentou grande homogeneidade entre as cenas para os atributos utilizados em sua definição, enquanto as classes antrópico e natural apresentaram grande variação entre atributos e valores de limiar.

No caso da classe Corpo D’água, foi suficiente a utilização do Land and Water Mask Index (LWM). O índice é calculado de acordo com a equação abaixo (Steele, 2015):

$$
L W M=\frac{M I R}{\text { Green }} * 100
$$

Onde,

- MIR é a banda correspondente à região do infravermelho médio do espectro eletromagnético;

- Green é a banda correspondente à região do verde do espectro eletromagnético;

Entre as árvores de decisão obtidas, observou-se que um limiar próximo ao valor 100, do índice, foi suficiente para a identificação de feições pertencentes à classe Corpo D’água para a escala de mapeamento adotada, sendo necessário apenas pequenos ajustes do valor-limite entre as cenas. Como o índice LWM não teve implicação relevante para a definição das classes antrópico e natural, esse foi excluído de etapa posterior da análise relacionada ao valor de contribuição dos atributos para os modelos obtidos.

A etapa de seleção de atributos teve como objetivo a obtenção de uma classificação ordenada (ranking), por ordem de importância, entre os 155 atributos testados. Como o índice LWM foi excluído desta análise, considerou-se efetivamente 154 atributos candidatos.

A ordenação entre os atributos baseou-se na ponderação entre o valor médio de importância dos atributos entre as 20 cenas analisadas e na frequência em que um 
determinado atributo ocorreu entre elas. O índice de importância ponderada dos atributos foi obtido a partir da padronização e multiplicação desses dois elementos, ranqueando-se os atributos por meio deste índice.

Como resultado final desta etapa obteve uma relação geral da qual constam a descrição do atributo, a frequência de ocorrência entre as cenas analisadas, a importância média e o índice geral de importância (Apêndice 2). Do resultado final, foram selecionados os 35 melhores atributos, os quais foram utilizados conforme descrito nas seções posteriores deste trabalho.

\subsection{MAPEAMENTO DO USO DA TERRA DOS ANOS DE 1985 E 1995}

O processo de conhecimento dos dados, apontado no tópico anterior, tem por vantagem permitir uma avaliação exploratória de características relevantes dos objetos e a determinação daqueles que, potencialmente, sirvam para a discriminação dos objetos entre as classes-objetivo. Apesar de gerar como um de seus produtos o mapeamento de uma região de interesse, a utilização de tal metodologia para grandes áreas é desaconselhável, haja vista o grande esforço amostral necessário para a obtenção de resultados adequados ${ }^{1}$. Pode, no entanto, ser utilizado em etapa independente e posterior, que resulte na otimização em tempo, esforço e qualidade de um do processo de classificação.

Considerando que objetos com características semelhantes em termos de várias características podem ser agrupados por meio da utilização de métodos estatísticos apropriados, o conhecimento sobre características relevantes torna possível o desenvolvimento de um conjunto de tarefas de classificação que atribua conjuntos de objetos a uma classe-objetivo final ao invés da atribuição de objetos individuais. No caso, cada um dos conjuntos de objetos determinados é composto por feições com características semelhantes e que devem idealmente pertencer a uma mesma classe-objetivo do mapeamento.

O agrupamento de feições, conforme proposto, tem impacto potencial sobre a agilidade do processo de classificação e mapeamento, haja vista que um conjunto formado por inúmeros objetos pode ser atribuído a uma classe a partir de um único comando executado pelo analista, após a correta interpretação de um grupo. Além disso, tem impacto potencial sobre a coerência geral da classificação, pois objetos com características multidimensionais semelhantes passarão, em regra, a pertencer a uma mesma classe, diminuindo-se o arbítrio do

\footnotetext{
${ }^{1}$ Foram obtidas aproximadamente 2000 amostras de treinamento para cada uma das 20 imagens para a obtenção de classificação com o nível de exatidão estabelecido.
} 
intérprete e a ocorrência da classificação de objetos com características semelhantes em classes-objetivo distintas ao longo da área mapeada.

A metodologia para mapeamento utilizada tem por principais etapas: 1) obtenção de dados e pré-processamento (Seção 2.6.1); a geração de objetos e a obtenção de atributos (Seção 2.6.2); 2) processamento de dados e execução de análise de agrupamento (Seção 2.6.3); 3) interpretação visual, correção individual de erros e obtenção do mapeamento final (Seção 2.6.4); 5) verificação da qualidade do mapeamento (Seção 2.6.5). A relação entre as etapas informadas está descrita nas seções abaixo e na Figura 18. 


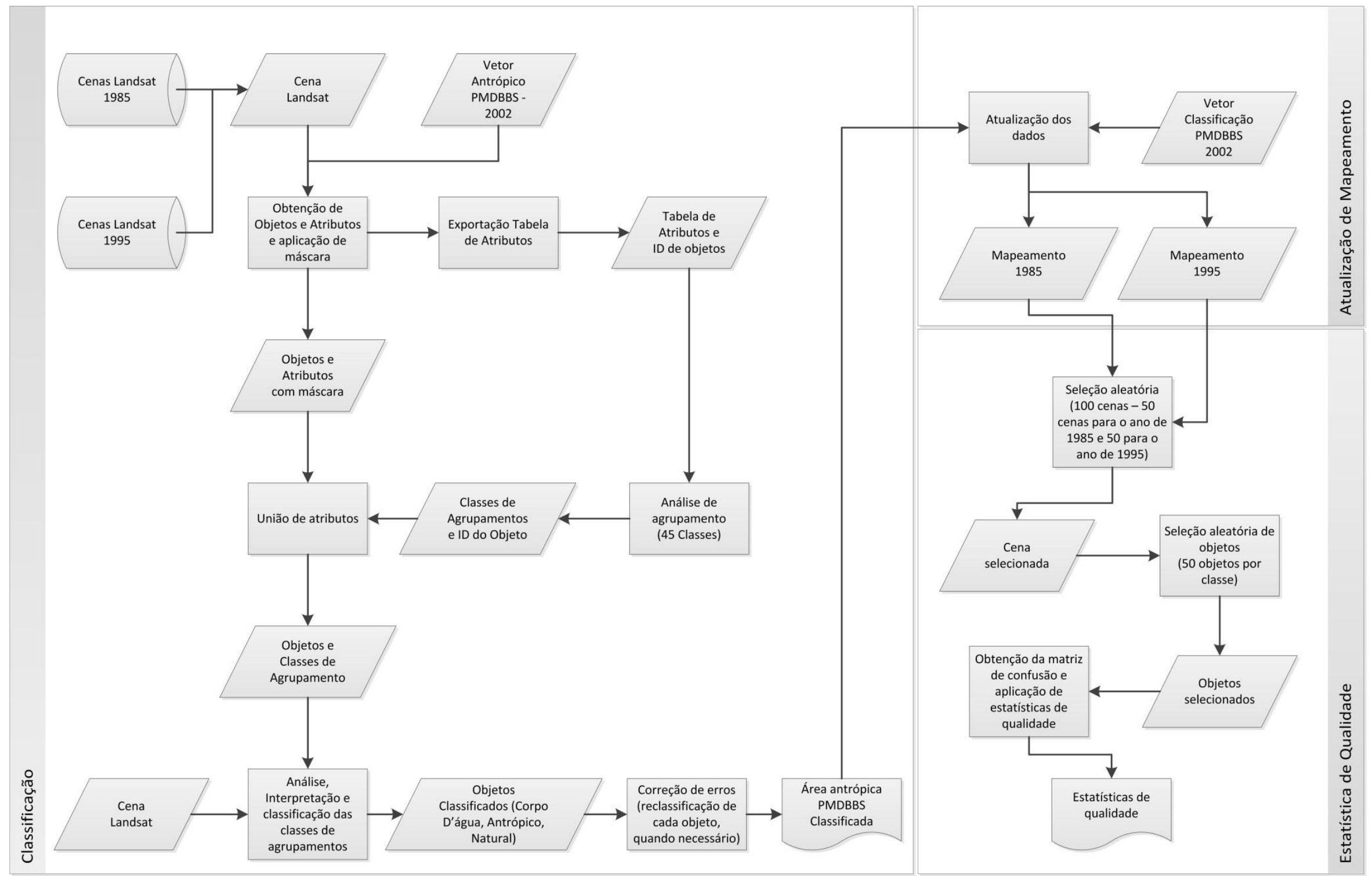

Figura 18 - Fluxograma da etapa de realização e atualização do mapeamento e obtenção de estatísticas de qualidade (Etapa 4 da Figura 11). 


\subsubsection{Obtenção de dados}

Para o mapeamento, foram obtidas imagens de 121 cenas Landsat 5 TM, para cada um dos períodos de interesse 1985 e 1995. Com o objetivo de manterem-se semelhantes características espectrais das imagens em função de variações sazonais da paisagem no Cerrado, priorizaram-se imagens dos meses de junho a agosto.

Em função da baixa disponibilidade de imagens de satélite para o período em análise, optou-se por aceitar no mapeamento imagens com até um ano de diferença em relação à data do mapeamento, ou seja, para o mapeamento do ano de 1985, podem ter sido levadas em consideração imagens dos anos de 1984 e 1986 e, para o mapeamento do ano de 1995, podem ter sido levadas em consideração imagens dos anos de 1994 e 1996. Mais de uma imagem pode ter sido utilizada para o mapeamento de uma mesma cena, no caso, por exemplo, da ocorrência de nuvem, erros e falhas dos dados, ou eventuais dúvidas sobre as classes mapeadas. Nesse último caso, também foram consideradas imagens de outros períodos (eg. 1987, 1993, 1997), sem, contudo, servirem como dado primário para o efetivo mapeamento.

As imagens utilizadas para o mapeamento ou para consulta estão relacionadas no Apêndice 3, sendo: 46 imagens para o ano de 1984, 59 para o ano de 1985, 32 para o ano de 1986, 10 imagens para o ano de 1994, 40 imagens para o ano de 1995 e 80 imagens para o ano de 1996. Todas elas foram submetidas a procedimento de pré-processamento, conforme Seção 2.3, antes de serem encaminhada às etapas posteriores.

\subsubsection{Geração de Objetos e Obtenção de Atributos}

Os atributos determinados na Seção 2.5 foram utilizados para a obtenção de grupos de objetos com características comuns. Para tanto, um conjunto de tarefas teve que ser executado previamente para que se obtivessem objetos com posicionamento espacial determinado e seu conjunto respectivo de atributos.

Esta etapa do trabalho foi realizada por meio do aplicativo eCognition e mediante o desenvolvimento de um conjunto de regras (Rule Set)que executasse adequadamente e de forma encadeada funções específica do aplicativo. O conjunto de regras (Rule Set) desenvolvido possibilita a aquisição de resultados de forma automatizada, sendo necessário apenas o carregamento da imagem pré-processada e da camada temática a ser utilizada para a aplicação de máscara. 
Como passo prévio, foram obtidas máscaras baseadas nas áreas classificadas como antrópico pelo PMDBBS em mapeamento realizado para o ano de 2002, conforme descrito na Seção 2.2. Estas foram geradas a partir do recorte da camada vetorial do mapeamento de referência (antrópico/PMDBBS/2002) e dos limites de cada uma das cenas LANDSAT 5 TM utilizadas.

As tarefas executadas pelo conjunto de regras (Rule Set) (Figura 19) iniciam-se pela aplicação de máscara, a segmentação da imagem (conforme Seção 2.4), a obtenção da área útil da imagem a ser utilizada em etapas posteriores e pela identificação da classe corpo d'água. Uma classe provisória é criada, a classe terra, sendo definida como toda a região de interesse, com exceção de objetos não relevantes e da classe corpo d'água. Na última etapa da árvore de processos são obtidos os atributos de cada objeto e é gerada a camada vetorial no formato ESRI SHP, contendo objetos geoespacializados e sua respectiva tabela de atributos.

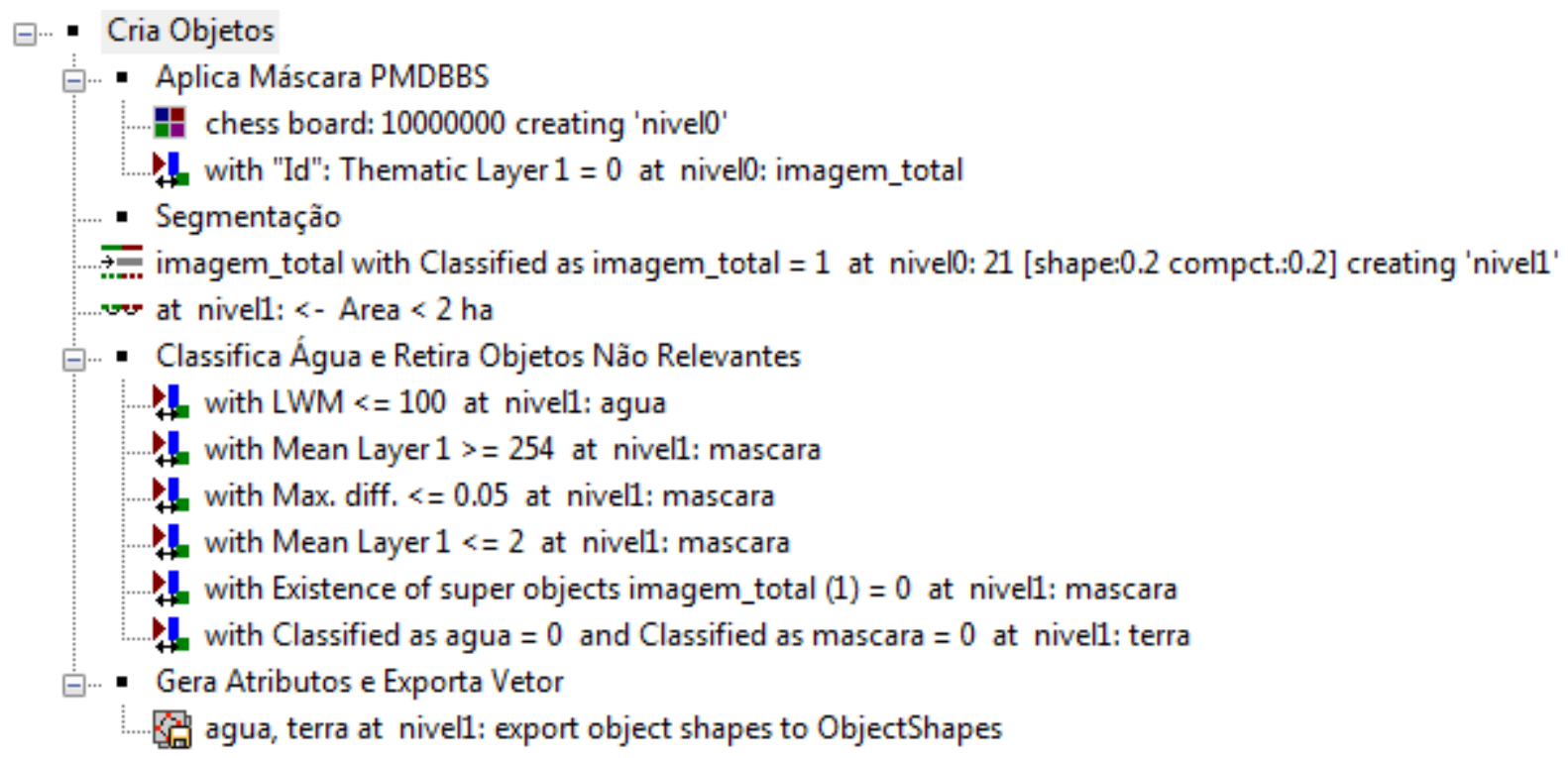

Figura 19 - Conjunto de regras (Rule Set) utilizado para a obtenção de objetos e atributos utilizados no mapeamento (aplicativo eCognition 9).

\subsubsection{Processamento de Dados e Análise de Agrupamento}

A etapa estatística de análise incluiu a importação de objetos e atributos gerados conforme descrito na seção anterior; o processamento dos dados, mantendo-se o identificador único do objeto (ID); a realização da análise de agrupamento e a adição do identificador do agrupamento na tabela de atributos dos objetos. Para realização dessas etapas foi desenvolvido algoritmo no aplicativo R 3.3 para a execução automática das tarefas, o qual se encontra no Apêndice 4. 
A análise de agrupamento (Cluster Analysis) é um conjunto de técnicas multivariadas destinadas ao reconhecimento de padrões e a agregação de objetos em grupos de acordo com características informadas pelo pesquisador (Hair et al., 2009). Um resultado ideal a partir desse tipo de análise tem como característica a obtenção de classes de agrupamentos com alta homogeneidade interna e alta heterogeneidade em relação a outros clusters. A definição das variáveis estatísticas incluídas na análise é um passo crítico para a obtenção de resultados adequados, tendo sido uma etapa de grande importância neste trabalho (Seção 2.5).

O método utilizado para o agrupamento foi o k-means com a utilização de distância euclidiana e a geração aleatória dos pontos de origem dos agrupamentos. Trata-se de método não hierárquico de agrupamento, de uso bastante difundido, cujo objetivo é particionar $n$ observações dentre $k$ agrupamentos, sendo cada uma das observações atribuída ao agrupamento mais próximo de acordo com medida de distância determinada. Foi gerado um número fixo de 45 classes de agrupamento para os dados de cada uma das cenas analisadas.

Optou-se pela geração de número de classes fixo entre as diversas cenas e em quantidade geralmente superior àquela que seria obtida em teste específico para a determinação do número de classes ideal. Tal solução foi adotada buscando-se uma maior discriminação entre diferentes grupos de feições, mesmo que conjuntos de objetos com características próximas viessem a ser eventualmente atribuídos a classes distintas. Além disso, considerou-se a grande variação em termos de complexidade da paisagem entre diferentes cenas, o que exigiria a adoção de um grande número de diferentes soluções em termos de número de classes, onerando desnecessariamente em tempo e trabalho esta etapa, como se pode perceber no caso de cenas com diversas fitofisionomias de Cerrado e tipologias de feições antrópicas que apresentam grande heterogeneidade e exigem a determinação de um número maior de classes. Ao contrário, no caso de grandes áreas florestadas, apresentam-se mais homogêneas e exigem um número menor de classes para uma adequada discriminação entre feições.

Para a aplicação proposta, a obtenção de um número superior de classes não traz prejuízo à análise, pois, por meio do processo de interpretação visual, executado em etapa imediatamente posterior, eventuais discriminações excessivas podem ser reclassificadas com grande facilidade. Já a adoção de uma solução com número insuficiente de classes, implicaria a união de feições com características distintas em uma mesma classe de agrupamento, o que 
resultaria na maior ocorrência de erros e exigiria grande esforço na etapa de correção individual de erros.

Os métodos e parâmetros seguidos na análise de agrupamento foram determinados buscando-se soluções geralmente bem sucedidas e de acordo com requisitos práticos do trabalho, a exemplo da facilidade e rapidez de sua aplicação; bem como considerando o fato de tratar-se de etapa intermediária do processo de mapeamento, o qual seria posteriormente submetido a outros tipos de controle, a exemplo de processo supervisionado de interpretação e correção individual de erros. Destaca-se, no entanto, que a literatura sobre análise de agrupamentos apresenta outras soluções com potenciais vantagens e desvantagens em relação ao método adotado. Embora a solução adotada tenha apresentado um bom desempenho, faz-se necessário o desenvolvimento de pesquisa específica para a determinação de uma solução ótima para a aplicação proposta nesse tipo de estudo.

Os resultados finais gerados por meio da aplicação da análise de agrupamento consistiram na pré-classificação dos objetos em 45 classes distintas, de acordo com as características gerais de cada um deles. O valor da classe foi armazenado em campo próprio, relacionado ao ID do objeto e, posteriormente, foi unido à tabela de atributos dos dados vetoriais respectivos por meio de processamento em lote do aplicativo ArcGis 10.1. Obteve-se dessa forma uma camada vetorial, cuja tabela de atributos relacionada passou a apresentar a pré-classificação do objeto a ser posteriormente submetida à interpretação visual e reclassificação (Figura 20). 


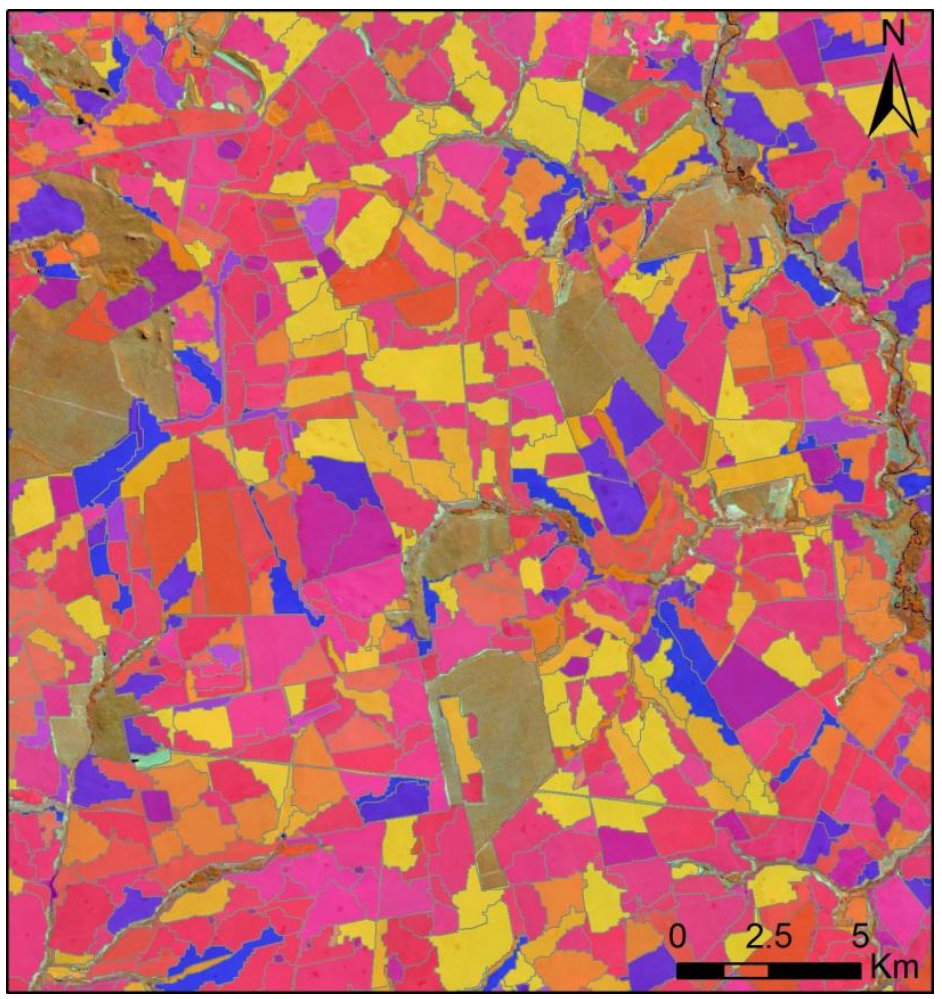

\begin{tabular}{|r|r|l|r|r|}
\hline & FID & Shape & id & grupo \\
\hline & 0 & Polygon & 0 & 30 \\
\hline & 1 & Polygon & 1 & 1 \\
\hline & 2 & Polygon & 2 & 8 \\
\hline 3 & Polygon & 3 & 33 \\
\hline & 4 & Polygon & 4 & 31 \\
\hline 5 & Polygon & 5 & 31 \\
\hline & Polygon & 6 & 31 \\
\hline 7 & Polygon & 7 & 31 \\
\hline 8 & Polygon & 8 & 31 \\
\hline & Polygon & 9 & 31 \\
\hline 10 & Polygon & 10 & 14 \\
\hline 11 & Polygon & 11 & 16 \\
\hline 12 & Polygon & 12 & 40 \\
\hline 13 & Polygon & 13 & 1 \\
\hline 14 & Polygon & 14 & 16 \\
\hline
\end{tabular}

Figura 20 - Vários segmentos organizados em grupos, os quais, posteriormente serão submetidos ao processo de classificação. Observa-se a tabela de atributos dos dados vetoriais, onde estão armazenados o identificador único do objeto e o grupo a que pertence. Regiões das quais não constam objeto devem-se à aplicação de máscara, conforme Seção 2.2.

\subsubsection{Interpretação Visual e Correção Individual de Erros}

A classificação da imagem para as classes-objetivo (antrópico, natural e corpo d'água) foi dividida em duas fases: a reclassificação das categorias pré-definidas por meio da análise de agrupamento para seu valor final e a verificação e correção de erros. Ambas as etapas foram realizadas por meio do aplicativo ArcGis 10.1, incluindo-se como camadas as informações necessárias relativas a cada cena, ou seja, camada vetorial com sua tabela de atributos e imagem LANDSAT 5 TM com a composição RGB453.

A interpretação visual baseou-se no conhecimento do interprete acerca dos tipos de feição apresentadas na imagem, na chave de classificação das Tabelas 4, 5 e 6 e, também, na classificação realizada pelo PMDBBS para o ano de 2002. A classe atribuída a uma determinada feição e aquelas de sua proximidade naquele mapeamento auxiliou na obtenção de conclusões comuns entre o processo interpretativo realizado neste trabalho e no mapeamento de referência. A utilização de tal suporte contribui potencialmente para uma maior compatibilidade entre os resultados dos trabalhos, especialmente levando-se em consideração feições com interpretação nem sempre coincidente, como é o caso de pastagens antrópicas e regiões campestres naturais. 
O processo de reclassificação se deu mediante a inspeção e interpretação de vários objetos de cada um dos 45 agrupamentos obtidos por meio da etapa estatística descrita na seção anterior. Para a execução de tal tarefa, foi adicionado novo campo à tabela de atributos (campo classe - tipo texto) para que esse recebesse o valor da classe-objetivo (Domínio: antrópico, natural e corpo d'água). O processo foi realizado com a utilização da ferramenta Find and Replace, substituindo-se o valor inicial (o valor do agrupamento constante do campo classe), pelo valor final desejado (o valor da classe-objetivo). Na Figura 21, observa-se a descrição do processo utilizado.

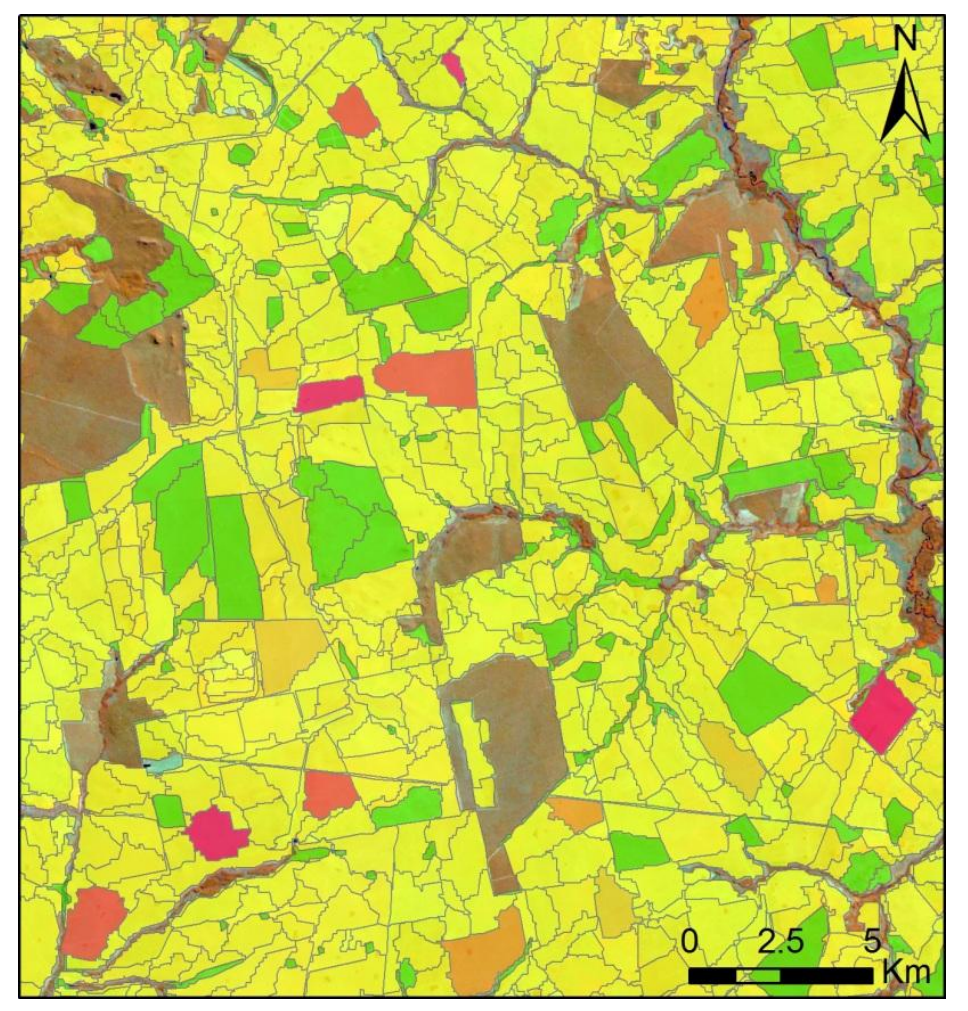

\begin{tabular}{|r|l|l|l|r|l|}
\hline & FID & Shape & id & grupo & classe \\
\hline & 972 & Polygon & 97 & 37 & antropico \\
\hline & 972 & Polygon & 97 & 45 & natural \\
\hline 972 & Polygon & 97 & 38 & 38 \\
\hline 972 & Polygon & 97 & 21 & natural \\
\hline 972 & Polygon & 97 & 45 & natural \\
\hline 972 & Polygon & 97 & 37 & antropico \\
\hline & 972 & Polygon & 97 & 9 & 9 \\
\hline 972 & Polygon & 97 & 45 & natural \\
\hline 973 & Polygon & 97 & 45 & natural \\
\hline 973 & Polygon & 97 & 19 & 19 \\
\hline 973 & Polygon & 97 & 11 & 11 \\
\hline 973 & Polygon & 97 & 21 & natural \\
\hline & 973 & Polygon & 97 & 37 & antropico \\
\hline 973 & Polygon & 97 & 13 & 13 \\
\hline 973 & Polygon & 97 & 41 & natural \\
\hline
\end{tabular}

Figura 21 - Objetos e grupos respectivos em processo de classificação. Na imagem e na tabela de atributos, observa-se que alguns grupos já foram reclassificados para a classe final (antrópico, natural e corpo d'água) e alguns ainda necessitam sofrer interpretação visual e a atualização de seus atributos no campo classe (segmentos em tonalidades de vermelho/laranja). Utilizou-se a ferramenta Find and Replace para a realização dessa tarefa.

Após a reclassificação de todos os clusters para uma dentre as classes finais, executou-se a verificação da adequação da classificação e a correção de erros. O processo consistiu na inspeção da imagem, percorrendo-se toda a área mapeada, em nível de zoom correspondente à escala utilizada. No caso de os objetos ou regiões não terem apresentado classificação final adequada, ou seja, terem classificação não correspondente às características da feição, promoveu-se a seleção e alteração do valor atribuído ao campo classe de cada objeto individualmente. A tarefa foi executada selecionando-se os objetos classificados 
erroneamente e utilizando-se da ferramenta Field Calculator para a inclusão do valor da nova classe-objetivo.

Após a correção realizada, obteve-se o mapeamento preliminar dos anos 1985 e 1995, o qual teve como abrangência a área classificada pelo mapeamento de referência como antrópico.

Para a obtenção do resultado final, realizou-se a atualização da classe antrópico do mapeamento PMDBBS 2002 com os novos dados obtidos. O processo foi efetuado por meio da atualização da classe antrópico do mapeamento de referência, sendo a área por ele abrangida substituída pelas novas informações obtidas neste trabalho (Figura 22, itens $a, b$ e c). Tal tarefa foi executada por meio da função Update disponibilizada no aplicativo ArcGis 10.1 .

a)

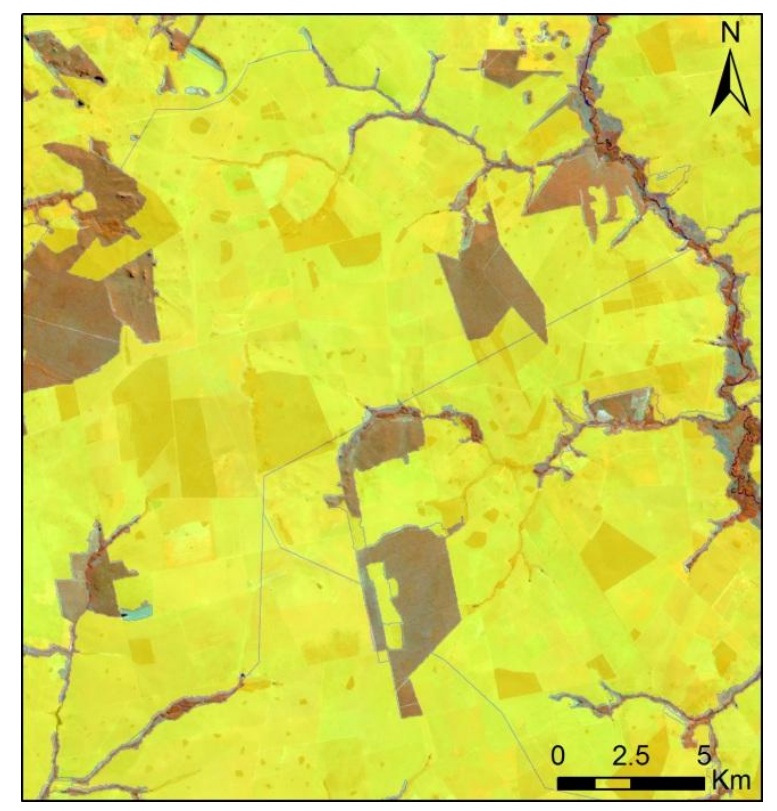

b)

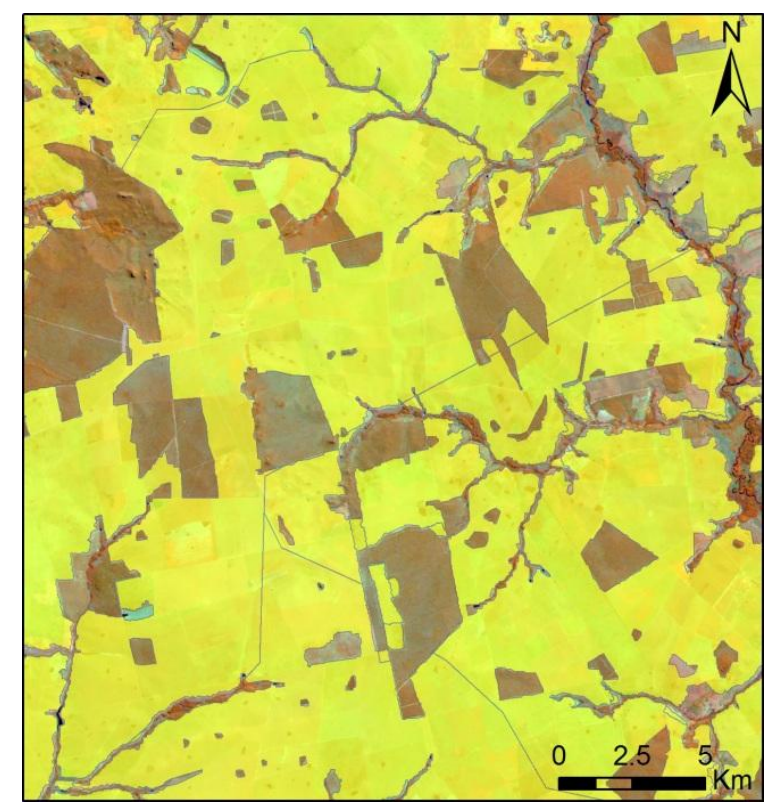


c)

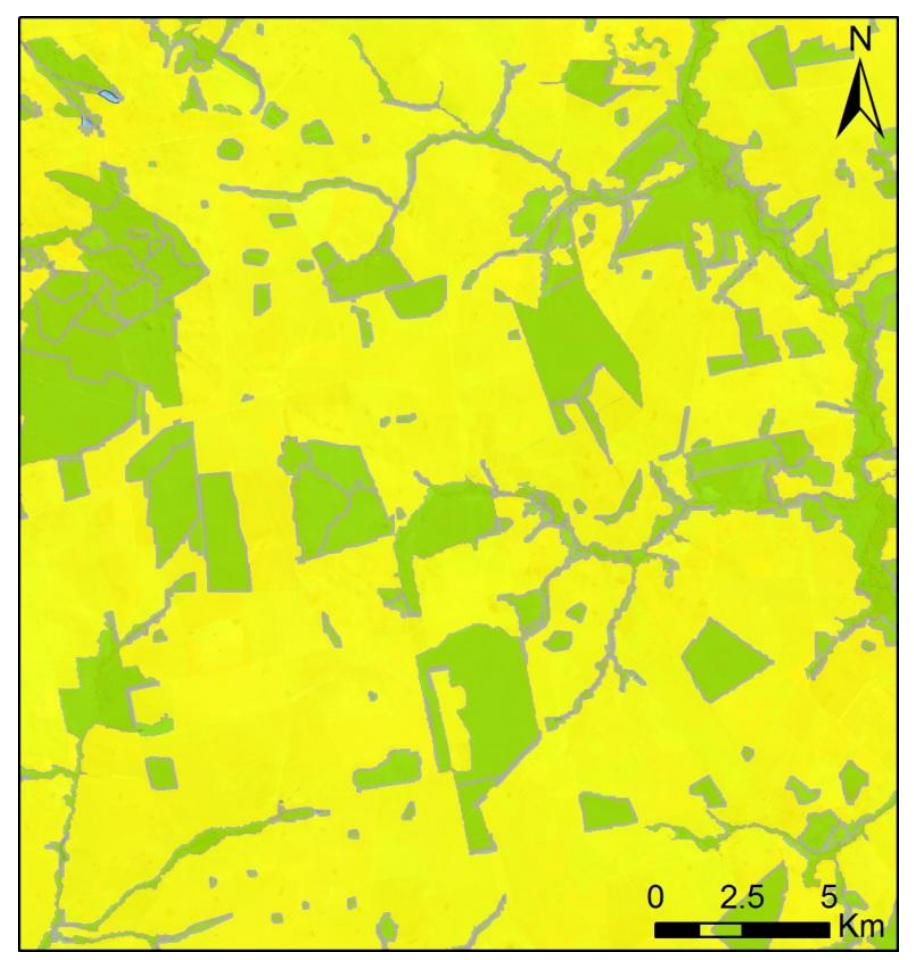

Figura 22 - Processo de atualização do atualização do mapeamento de referência: a) área antrópica definida pelo mapeamento de referência; b) área antrópica atualizada para o ano de 1995; c) mapeamento final obtido para o ano de 1995, constando todas as classes (antrópico, natural e corpo d'água).

O mapeamento final é composto pela classe natural do mapeamento de referência; por regiões naturais que foram suprimidas entre as datas de 1985/1995 e o ano de 2002, identificadas neste trabalho; por regiões que se mantiveram classificadas como antrópico no período informado; bem como pela atualização da classe corpo d'água para a área de interesse da classificação.

A área de cada uma das classes foi estimada para os anos de 1985 e 1995 utilizandose como referência espacial o GCS South American Datum 1969 (SAD 69) (WIKID: 4618). Para fins de comparação, as áreas das classes de interesse foram também obtidas para o ano de 2002, com base nos dados vetoriais disponibilizados pelo PMDBBS, podendo haver pequenas diferenças em relação aos resultados relatados por aquele órgão para o ano de 2002 em função de eventuais processamentos realizados sobre os vetores antes de sua disponibilização ou em função de outros procedimentos específicos utilizados para a quantificação da área por aquele órgão. 


\subsubsection{Avaliação da Qualidade do Mapeamento}

A avaliação de qualidade teve como área de abrangência apenas a região efetivamente mapeada neste trabalho, não tendo sido consideradas na avaliação regiões obtidas a partir do mapeamento de referência (e.g. toda região exterior à máscara aplicada). Para sua realização, foram geradas amostras aleatórias e estratificadas, sendo 1200 amostras lançadas ao acaso para cada uma das classes-objetivo em um total de 3600 amostras, abrangendo toda a região do Cerrado. O total perfaz, aproximadamente, a mesma densidade de pontos obtidos na etapa de avaliação de qualidade da Seção 2.5.5, ou seja, 30 amostras por classe por cena (Figura 23).

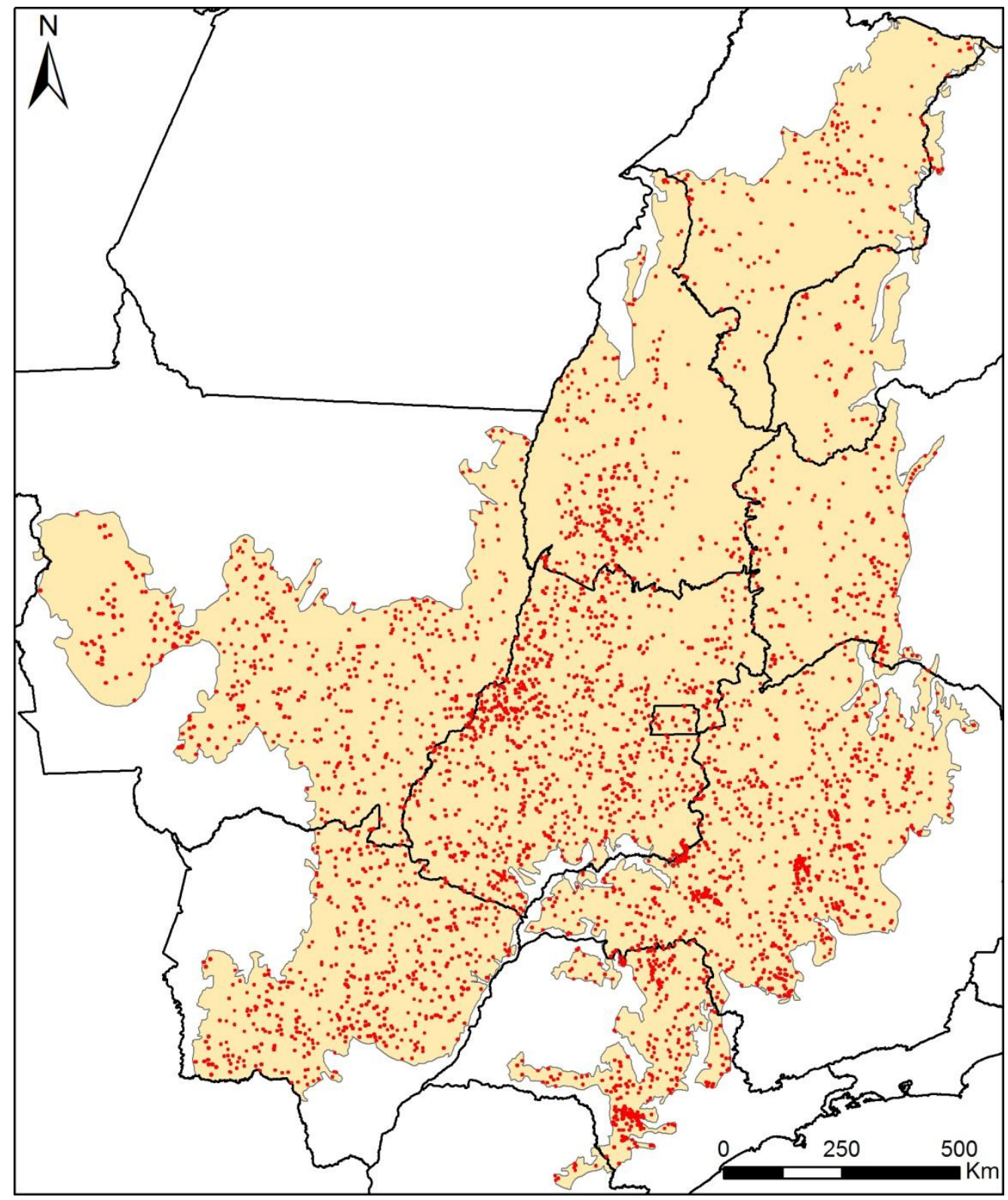

Figura 23 - Distribuição das amostras utilizadas para obter dados de qualidade do mapeamento ao longo do Cerrado. 
A avaliação de qualidade tomou como referência a inspeção e interpretação visual da imagem utilizada na classificação e, quando cabível, a inspeção de outras imagens de maior resolução espacial. Cada ponto foi verificado individualmente, sendo formada matriz de confusão entre a classificação observada no mapeamento e a verdade obtida a partir da interpretação individual de cada ponto. Os resultados de acurácia foram gerados a partir da matriz, obtendo-se índice global de acurácia, Índice de Kappa e demais métricas mencionadas na Seção 2.1.3.

\subsection{AVALIAÇÃO DE COMPATIBILIDADE ENTRE METODOLOGIAS}

Etapa final foi aplicada com o objetivo de se avaliar a compatibilidade dos resultados obtidos entre a metodologia aplicada neste trabalho e aquela do mapeamento de referência. Considerando que o mapeamento PMDBBS está disponível apenas para períodos posteriores a 2002 e que não seria possível realizar tal comparação com os dados do próprio mapeamento executado para os anos de 1985 e 1995; foram obtidas imagens para o ano de 2002 e promoveu-se a reprodução da metodologia aplicada neste trabalho. Levando-se em consideração que a aplicação foi realizada seguindo-se as mesmas etapas e mesmos parâmetros utilizados no trabalho de mapeamento realizado para os anos de 1985/1995, espera-se que os resultados sejam representativos da real compatibilidade entre esses dois mapeamentos.

Seguindo os critérios adotados na Seção 2.5.1, foram sorteadas 20 cenas ao longo do Cerrado, sendo 5 em cada sub-região definida, que resultariam na amostragem de aproximadamente $30 \%$ da área total de mapeamento. As imagens foram obtidas e submetidas aos procedimentos de pré-processamento de acordo com as diretrizes apresentadas na Seção 2.3. Foram obtidas imagens com a mesma data, ou data mais próxima, àquelas utilizadas pelo mapeamento PROBIO/2002 (Sano, Rosa, Brito, Jorge Luís Silva, et al., 2010), o qual foi utilizado como mapeamento base pelo PMDBBS. Não foi possível a verificação da data das imagens efetivamente utilizadas pelo PMDBBS para a atualização do mapeamento do ano de 2002, haja vista não constar informação oficial com a indicação das imagens efetivamente utilizadas para essa atualização. Trata-se, portanto, de uma análise aproximada, indicativa da compatibilidade entre os resultados obtidos e o mapeamento de referência. 


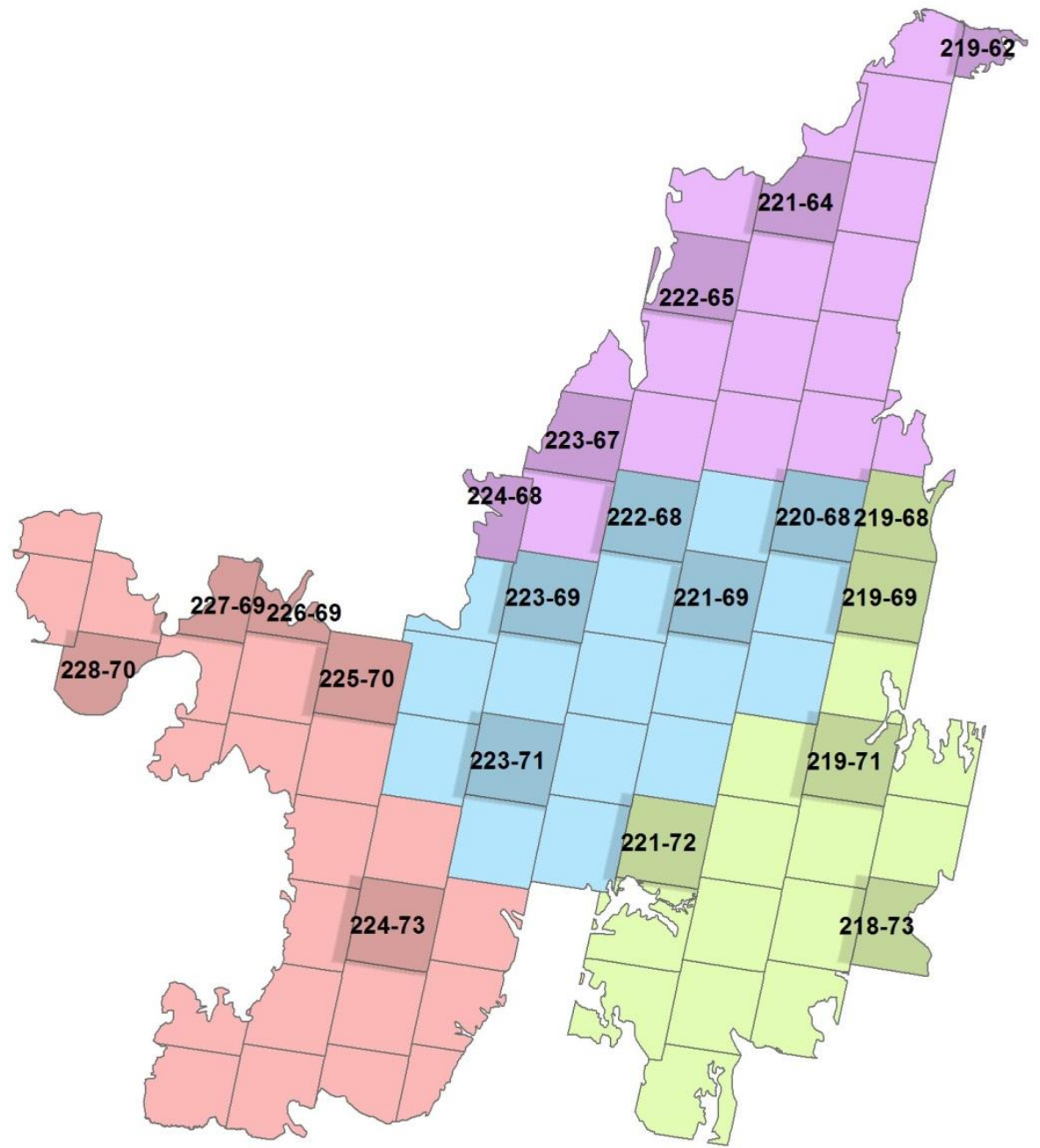

Figura 24 - Regiões delimitadas e cenas selecionadas para a etapa de verificação da compatibilidade entre mapeamentos.

As cenas selecionadas foram submetidas ao mesmo processo de classificação descrito na Seção 2.6.2 a 2.6.4, com exceção da aplicação prévia de máscara para a seleção da área antrópica. Neste caso, selecionou-se para o mapeamento a mesma região definida pelo PMDBBS como área útil, ou seja, regiões pertencentes à classe natural do mapeamento PROBIO/2002.

O procedimento de classificação, conforme as seções mencionadas, envolveu: 1) a obtenção de objetos, seguindo os parâmetros de segmentação obtidos na Seção 2.4, e seus respectivos atributos, determinados na Seção $2.5 ; 2$ ) a realização de análise de agrupamento, conforme Seção 2.6.3; 3) a interpretação visual e reclassificação dos agrupamentos, com posterior correção de erros, de acordo com a Seção 2.6.4.

Para a realização da avaliação da compatibilidade foi gerado uma grade regular com $1 \mathrm{~km}$ x $1 \mathrm{~km}$, distribuindo-se os pontos regularmente ao longo da cena. A avaliação envolveu a análise de um total de 351 mil pontos amostrais. Dados de ambos os mapeamentos foram 
obtidos para cada um dos pontos. Neste caso, as classes corpo d'água, antrópico e natural foram representadas proporcionalmente à sua efetiva ocorrência. Por fim foram utilizados os mesmos procedimentos de análise anteriormente mencionados, ou seja, aqueles constantes do protocolo de avaliação de qualidade propostos por Cunningham (2009) e por Rossiter (2004), conforme Seção 2.1.3, os quais foram implementados de acordo com o Script em R disponível no Apêndice 5.

As etapas do processo de avaliação da compatibilidade estão descritos no fluxograma da Figura 25.

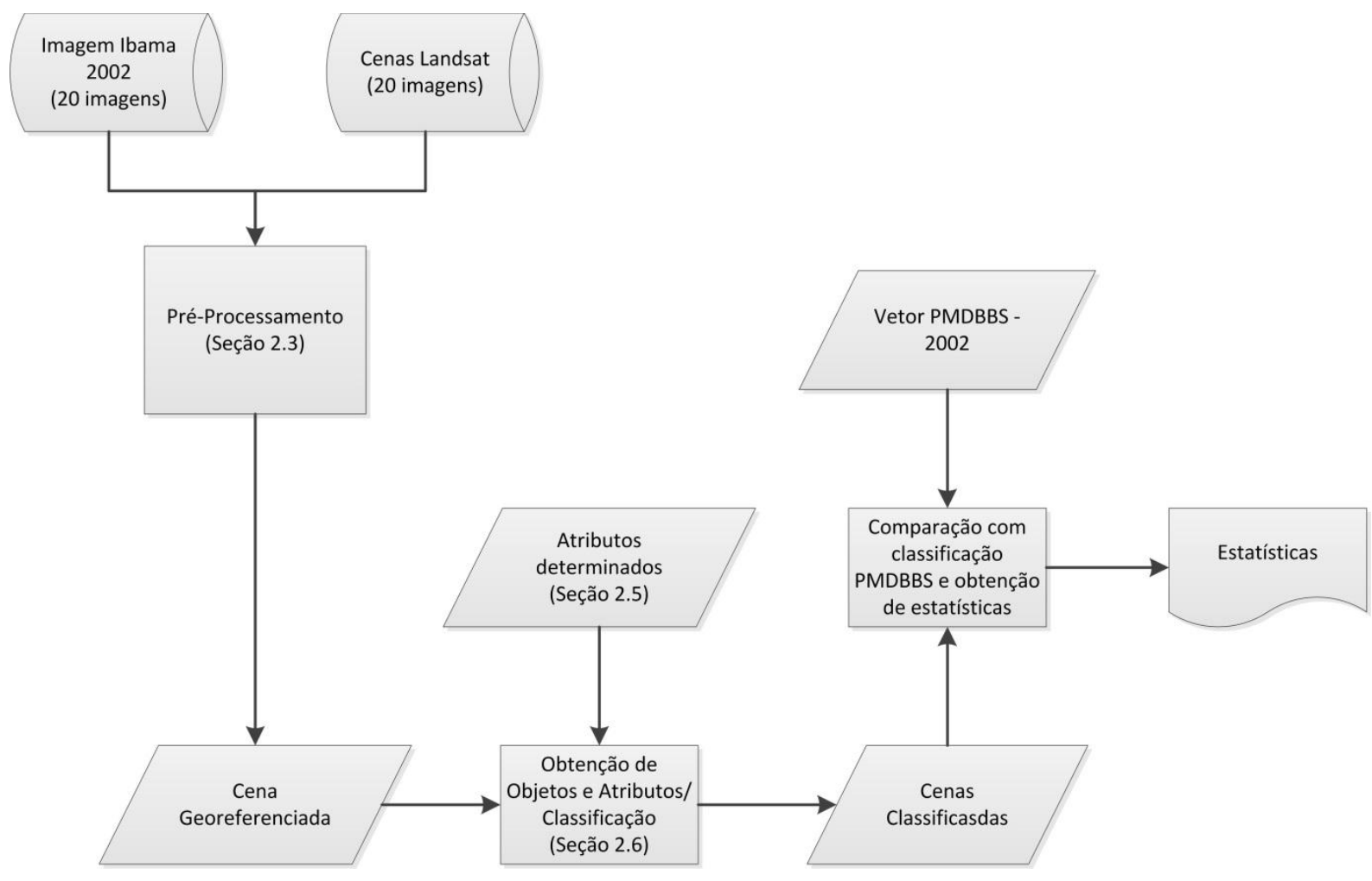

Figura 25 - Fluxograma utilizado para a avaliação de compatibilidade entre o mapeamento de referência e o executado. 


\section{RESULTADOS}

\subsection{SELEÇÃO DE ATRIBUTOS}

Dentre os 154 atributos testados na análise por meio do processo de Descoberta de Conhecimento em Bases de Dados (KDD), conforme abordado na Seção 2.5, 113 atributos ocorreram em ao menos uma das 20 árvores de decisão formadas (Apêndice 2).

Dentre os 35 atributos mais importantes (maior número de ocorrências entre as imagens e maior importância média), estiveram presentes índices espectrais, descritores relacionados aos objetos (e.g. valor médio de bandas), além de atributos de forma e textura (Tabela 7).

Tabela 7 - Atributos selecionados para a obtenção dos objetos (lista completa no Apêndice 2).

\begin{tabular}{|c|c|c|c|c|}
\hline Tipo de Atributo & Atributo & Ocorrência & Importância & $\begin{array}{c}\text { Importância } \\
\text { Ponderada }\end{array}$ \\
\hline Relacionado ao Pixel & Ratio B1 & 11 & 9.15 & 49.18 \\
\hline Relacionado ao Objeto & Brightness & 10 & 8.33 & 41.90 \\
\hline Índice Espectral & GARI & 12 & 6.72 & 40.53 \\
\hline Índice Espectral & ARVI & 5 & 4.73 & 15.48 \\
\hline Índice Espectral & Clay Ratio & 7 & 2.87 & 13.57 \\
\hline Relacionado ao Pixel & Max. diff. & 7 & 2.71 & 13.06 \\
\hline Forma & Compactness & 9 & 1.04 & 9.15 \\
\hline Relacionado ao Objeto & quantile[50](B4) & 7 & 1.86 & 10.24 \\
\hline Relacionado ao Objeto & quantile[50](B5) & 8 & 0.89 & 7.78 \\
\hline Relacionado ao Pixel & Ratio B2 & 6 & 1.91 & 9.28 \\
\hline Relacionado ao Pixel & Ratio B6 & 5 & 2.13 & 8.74 \\
\hline Textura & GLCM Mean B2 & 7 & 1.04 & 7.52 \\
\hline Textura & GLCM Mean B1 & 8 & 0.17 & 5.15 \\
\hline Relacionado ao Objeto & Mean B2 & 5 & 1.65 & 7.48 \\
\hline IHS & $\operatorname{Hue}\left(\mathrm{R}={ }^{\prime} \mathrm{B} 3{ }^{\prime}, \mathrm{G}={ }^{\prime} \mathrm{B} 2{ }^{\prime}, \mathrm{B}={ }^{\prime} \mathrm{B} 11^{\prime}\right)$ & 4 & 2.02 & 7.29 \\
\hline Relacionado ao Objeto & Mean B1 & 5 & 1.46 & 6.98 \\
\hline Relacionado ao Objeto & Mean B3 & 4 & 1.92 & 7.06 \\
\hline Textura & GLCM Dissimilarity & 5 & 1.33 & 6.64 \\
\hline Índice Espectral & PSRI & 4 & 1.50 & 6.12 \\
\hline Relacionado ao Objeto & quantile[50](B1) & 5 & 0.90 & 5.54 \\
\hline Relacionado ao Pixel & Ratio B3 & 3 & 1.90 & 5.89 \\
\hline Relacionado ao Objeto & quantile[50](B6) & 5 & 0.67 & 4.95 \\
\hline Textura & GLCM Contrast B3 & 4 & 1.21 & 5.47 \\
\hline Relacionado ao Pixel & StdDev. to neighbor pixels B4 & 4 & 1.01 & 5.01 \\
\hline Relacionado ao Objeto & Skewness B1 & 5 & 0.40 & 4.23 \\
\hline IHS & Saturation $(\mathrm{R}=\mathrm{B} 3, \mathrm{G}=\mathrm{B} 2, \mathrm{~B}=\mathrm{B} 1)$ & 3 & 1.38 & 4.91 \\
\hline Relacionado ao Objeto & Mean B4 & 3 & 1.33 & 4.83 \\
\hline Relacionado ao Pixel & StdDev. to neighbor pixels B1 & 5 & 0.18 & 3.67 \\
\hline Índice Espectral & iron_ratio & 3 & 1.26 & 4.70 \\
\hline
\end{tabular}




\begin{tabular}{lllll} 
Relacionado ao Objeto & quantile[50](B2) & 5 & 0.11 & 3.49 \\
Textura & GLCM Mean B3 & 3 & 1.18 & 4.55 \\
Forma & Shape index & 4 & 0.63 & 4.16 \\
Relacionado ao Objeto & Mean B5 & 3 & 1.16 & 4.51 \\
Índice Espectral & NMDI & 3 & 1.13 & 4.45 \\
Textura & GLCM Homogeneity B5 & 4 & 0.56 & 4.01 \\
\hline
\end{tabular}

Nesse contexto, tiveram destacada importância índices espectrais e atributos como a razão pixel das bandas (Ratio), brilho (Brightness) e diferença máxima entre os valores do pixel de um mesmo objeto (Max. Diff). A diversidade de descritores quantitativos selecionados guardam relação com o conjunto variado de feições do território, sendo observada a presença de índices de vegetação, índices de forma, índices de textura, além de diferentes descritores de características espectrais.

Os índices Green Atmospherically Resistant Index - GARI (12 ocorrências e importância média de 6.72) e o Atmospherically Resistant Vegetation Index - ARVI (5 ocorrências e importância média de 4.73) foram os que apresentaram melhor desempenho médio dentre os índices espectrais de vegetação utilizados, enquanto a Razão Argila (7 ocorrências e importância média de 2.87) foi o que obteve o melhor desempenho dentre índices espectrais relacionados ao solo. Tais índices estão relacionados à caracterização de diferentes tipos de vegetação ocorrentes na área de estudo ou de diferentes características pedológicas.

Índices de forma e índices de textura, também presentes, apresentam relação mais direta com os tipos de feição observados entre as classes de interesse. Feições da classe antrópico, geralmente, apresentaram valores indicativos de forma mais regular e uma menor variabilidade quanto aos valores do índice de textura do que feições pertencentes à classe natural.

Vários atributos foram utilizados para a classificação de uma imagem, dentre as 20 analisadas, variando entre 9 (para a cena 223/72) e 33 (para a cena 220/63), com número médio de 17 (Tabela 8).

Tabela 8 - Estatísticas relacionadas aos atributos utilizados em cada uma das cenas classificadas.

\begin{tabular}{ccrrr}
\hline Cena & $\begin{array}{c}\text { Número de } \\
\text { Atributos }\end{array}$ & Média & Importância \\
Desvio & Máximo \\
\hline 218_72 & 13 & 7.69 & 6.95 & 21.18 \\
219_69 & 19 & 5.26 & 4.19 & 15.22 \\
219_73 & 24 & 4.17 & 4.63 & 17.17 \\
220_63 & 33 & 3.03 & 3.85 & 16.31 \\
220_68 & 16 & 6.25 & 10.28 & 40.71 \\
220_71 & 27 & 3.70 & 6.12 & 21.91
\end{tabular}




\begin{tabular}{lrrrr} 
221_64 & 19 & 5.26 & 5.57 & 18.69 \\
221_66 & 17 & 5.88 & 6.22 & 20.62 \\
$221 \_69$ & 17 & 5.88 & 7.41 & 29.00 \\
$221 \_72$ & 13 & 7.69 & 8.67 & 26.56 \\
222_68 & 29 & 3.45 & 4.64 & 15.96 \\
222_70 & 16 & 6.25 & 6.08 & 22.21 \\
$223 \_67$ & 13 & 7.69 & 10.11 & 36.03 \\
$223 \_69$ & 13 & 7.69 & 8.92 & 29.32 \\
$223 \_72$ & 9 & 11.11 & 10.73 & 35.90 \\
$224 \_72$ & 11 & 9.09 & 10.04 & 30.57 \\
$224 \_73$ & 10 & 10.00 & 9.22 & 32.40 \\
$225 \_70$ & 19 & 5.26 & 6.39 & 22.52 \\
$226 \_75$ & 12 & 8.33 & 4.60 & 18.06 \\
$228 \_70$ & 25 & 4.00 & 5.46 & 22.56 \\
\hline
\end{tabular}

Apesar de geralmente ter sido considerado número relativamente elevado de atributos por imagem, a contribuição para o valor total de importância (no total de 100\%) esteve concentrada em poucos atributos. Em média, em cada imagem, os 8 primeiros atributos com maior importância concentraram $90 \%$ de toda a contribuição para o modelo, enquanto outros 9 atributos dividiram os $10 \%$ restantes de contribuição. O histograma típico entre as 20 imagens apresenta 3 atributos com importância acima de 10\%, 6 atributos com importância entre $2 \%$ e $10 \%$ e 9 atributos com contribuição abaixo de 2\% (Figura 26).

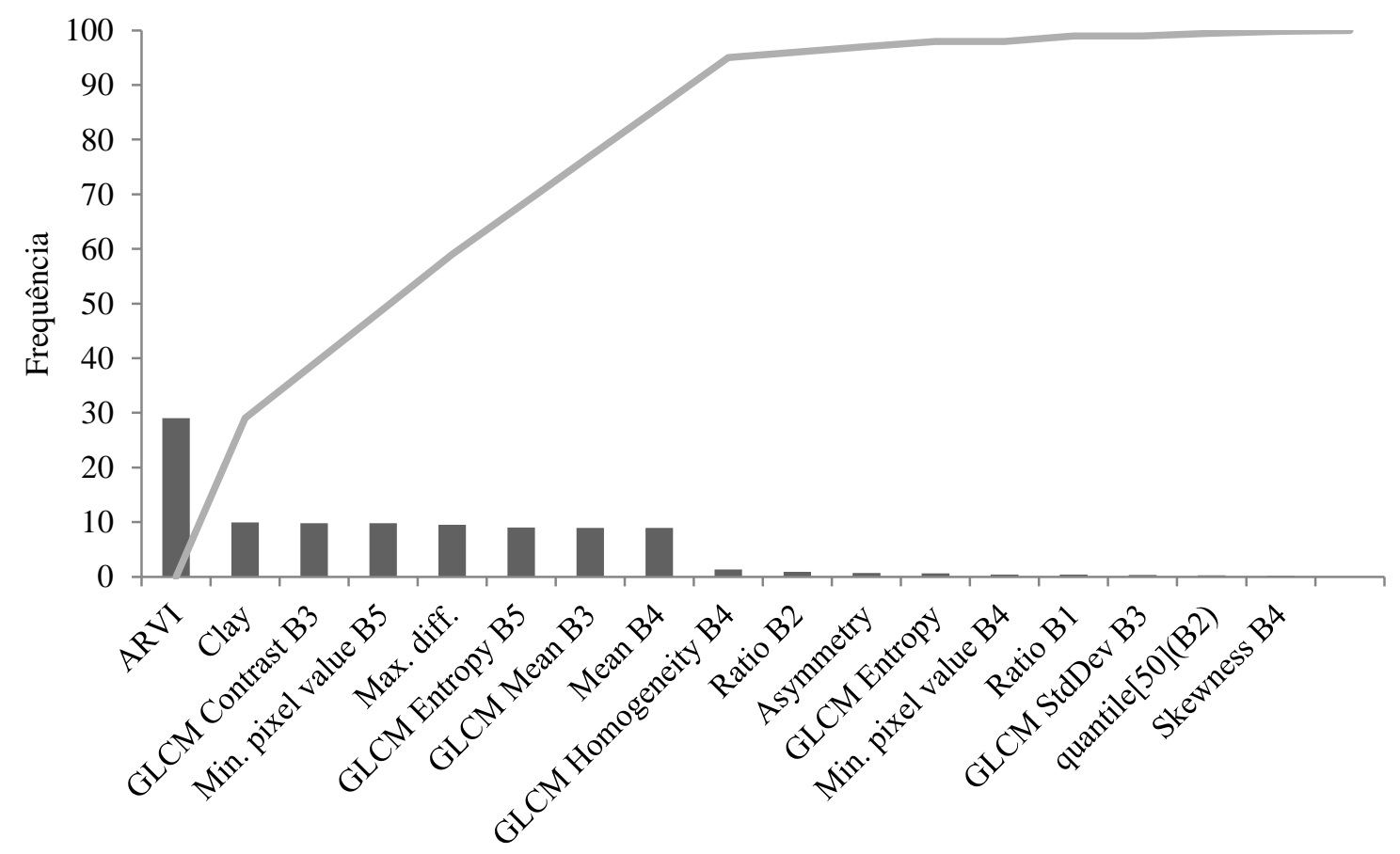

Figura 26 - Distribuição do valor de importância entre os atributos utilizados para a classificação da cena 221/69. São observados 8 atributos dominantes e 9 atributos de menor contribuição geral para os resultados do modelo. Linha em cinza representa a importância acumulada. 


\subsubsection{Avaliação da Qualidade}

O grau de concordância entre a classificação final obtida com os modelos KDD e a verdade, estabelecida por meio da inspeção e interpretação visual de cada ponto amostrado, apresentou-se, em regra, superior àquela que se objetivou, ou seja, com Índice Global de Acurácia superior a $85 \%$ e com Índice Kappa superior a $80 \%$.

Para o conjunto das cenas, considerando-se todas as classes mapeadas (Matriz 3x3), o Índice Global de Acurácia alcançou valores entre $82 \%$ e $96 \%$ (média=0.90, desvio padrão = 0.03). O Índice Kappa, por sua vez, obteve um valor médio de $82 \%$, variando individualmente entre as cenas de $65 \%$ até $93 \%$ (média $=0.89$, desvio padrão $=0.03$ ) (Tabela 9).

Tabela 9 - Qualidade obtida para a classificação realizada de acordo com a Seção 2.5. Da tabela observam-se estatísticas de qualidade para a matriz completa de dados (Antrópico, Corpo D'água e Natural - Matriz 3x3) e para a submatriz (Antrópico e Natural - Matriz 2x2).

\begin{tabular}{|c|c|c|c|c|c|c|c|c|c|c|c|c|}
\hline \multirow{2}{*}{ Cena } & \multicolumn{6}{|c|}{ Matriz 3x3 } & \multicolumn{6}{|c|}{ Matriz 2x2 } \\
\hline & $\mathrm{N}$ & $\mathrm{AG}$ & $\mathrm{K}$ & $X^{2}$ & $\mathrm{p}$ & KP & $\mathrm{N}$ & $\mathrm{AG}$ & $\mathrm{K}$ & $\mathrm{BI}$ & PE & KP \\
\hline 218_72 & 100 & 0.93 & 0.90 & 0.67 & 0.41 & 0.90 & 70 & 0.90 & 0.80 & -0.03 & 0.03 & 0.80 \\
\hline 219_69 & 100 & 0.96 & 0.93 & 4.00 & 0.14 & 0.93 & 70 & 0.95 & 0.90 & -0.05 & 0.05 & 0.90 \\
\hline 219_73 & 100 & 0.88 & 0.82 & 0.29 & 0.59 & 0.82 & 70 & 0.82 & 0.65 & -0.03 & 0.04 & 0.65 \\
\hline 220_68 & 100 & 0.88 & 0.79 & 0.82 & 0.37 & 0.81 & 70 & 0.86 & 0.73 & 0.04 & -0.04 & 0.73 \\
\hline 220_71 & 100 & 0.89 & 0.83 & 2.82 & 0.24 & 0.83 & 70 & 0.86 & 0.73 & -0.04 & 0.04 & 0.73 \\
\hline 221_64 & 100 & 0.90 & 0.85 & 6.50 & 0.04 & 0.86 & 70 & 0.90 & 0.80 & -0.08 & 0.08 & 0.80 \\
\hline 221_66 & 100 & 0.93 & 0.85 & 2.67 & 0.10 & 0.89 & 70 & 0.93 & 0.85 & 0.05 & -0.05 & 0.85 \\
\hline 221_69 & 100 & 0.83 & 0.71 & 4.00 & 0.05 & 0.74 & 70 & 0.80 & 0.60 & -0.10 & 0.10 & 0.60 \\
\hline 221_72 & 100 & 0.92 & 0.87 & 1.00 & 0.32 & 0.87 & 70 & 0.89 & 0.78 & 0.04 & -0.04 & 0.78 \\
\hline 222_68 & 100 & 0.92 & 0.88 & 3.00 & 0.22 & 0.88 & 70 & 0.90 & 0.80 & -0.05 & 0.05 & 0.80 \\
\hline 222_70 & 100 & 0.93 & 0.89 & 3.29 & 0.19 & 0.89 & 70 & 0.91 & 0.83 & -0.04 & 0.04 & 0.83 \\
\hline 223_67 & 100 & 0.89 & 0.78 & 2.78 & 0.10 & 0.83 & 70 & 0.89 & 0.78 & -0.06 & 0.06 & 0.78 \\
\hline 223_69 & 100 & 0.90 & 0.85 & 7.40 & 0.02 & 0.85 & 70 & 0.88 & 0.75 & -0.10 & 0.10 & 0.75 \\
\hline 223_72 & 100 & 0.93 & 0.85 & 2.67 & 0.10 & 0.89 & 70 & 0.93 & 0.85 & -0.05 & 0.05 & 0.85 \\
\hline 224_72 & 100 & 0.91 & 0.83 & 3.57 & 0.06 & 0.87 & 70 & 0.91 & 0.83 & -0.06 & 0.06 & 0.83 \\
\hline 224_73 & 100 & 0.91 & 0.83 & 3.57 & 0.06 & 0.87 & 70 & 0.91 & 0.83 & -0.06 & 0.06 & 0.83 \\
\hline 225_70 & 100 & 0.82 & 0.65 & 1.14 & 0.29 & 0.73 & 70 & 0.82 & 0.65 & 0.05 & -0.06 & 0.65 \\
\hline 226_75 & 100 & 0.88 & 0.75 & 1.60 & 0.21 & 0.81 & 70 & 0.88 & 0.75 & -0.05 & 0.05 & 0.75 \\
\hline 228_70 & 100 & 0.90 & 0.79 & 4.50 & 0.03 & 0.84 & 70 & 0.90 & 0.79 & -0.08 & 0.12 & 0.79 \\
\hline 220_63 & 100 & 0.90 & 0.85 & 8.36 & 0.02 & 0.85 & 70 & 0.86 & 0.72 & 0.11 & -0.13 & 0.72 \\
\hline
\end{tabular}

* Número de amostras (N), Acurácia Global (AG), Cohen's Kappa (K), $\mathrm{X}^{2}$ e p valor (p) do teste de homogeneidade de Stuart-Maxwell, viés (BI), prevalência (PE) e Kappa Pabak (KP).

Em função da estratégia de amostragem adotada, as matrizes apresentaram totais marginais equilibrados, apresentando baixo viés, prevalência e valores não significativos para o teste de homogeneidade de Stuart-Maxwell, sendo, portanto aplicável o Índice Kappa de Cohen. 
Individualmente, o resultado da classificação de seis imagens não alcançou índices iguais ou superiores aos objetivados, mas mantiveram patamar de qualidade próximo ou muito próximo àqueles almejados. No caso do pior resultado obtido, cena 225/70, trata-se de imagem com áreas extensamente antropizadas, dificultando ou impedindo a obtenção de número adequado de amostras naturais, impactando os resultados finais, mesmo com a aplicação de maior esforço amostral. De acordo com a classificação proposta por Landis \& Koch (1977), esses resultados, apesar de não serem ideais, apresentam substancial concordância com a verdade, sendo indicador de qualidade levemente inferior àqueles obtidos para as demais imagens.

De forma geral, os valores apresentados indicaram elevada capacidade dos modelos em classificar corretamente as feições entre as classes antrópico, natural e corpo d'água, tendo o valor médio alcançado o mais elevado patamar de qualidade estabelecido por Landis \& Koch (1977).

Os maiores percentuais de classificações errôneas observadas para as cenas classificadas pelo processo de KDD foram gerados pela inclusão de alvos naturais na classe antrópico. A classe natural apresentou valor médio de erro de comissão de 0.14 (Tabela 10), enquanto a classe antrópico apresentou valor médio de erro de omissão de 0.13. A classe água, em geral, apresentou erros bastante reduzidos.

Tabela 10 - Erros de omissão e comissão entre as classes consideradas para a etapa de seleção de atributos.

\begin{tabular}{lrr}
\hline Classe & Comissão & Omissão \\
\hline Corpos D'Água & 0.01 & 0.00 \\
Antrópico & 0.08 & 0.13 \\
Natural & 0.14 & 0.10 \\
\hline
\end{tabular}

Os resultados observados na Tabela 10 evidenciam uma ligeira superestimava geral da área da classe natural, quando comparada com a verdade identificada pelo analista. Destaque-se, contudo, que os resultados ora observados tiveram o objetivo de nortear a obtenção de modelos adequados, garantindo a seleção dos melhores atributos a serem utilizados em etapas posteriores, não estando relacionados diretamente com o produto final do mapeamento. 


\subsection{MAPEAMENTO}

Os resultados obtidos por meio do sistema de referência espacial adotado (GCS South American Datum 69, WKID: 4618) apresentaram uma área total para o Cerrado de 2.041.218 km², sendo essa considerada como referência neste estudo.

Em 1985 o Cerrado era recoberto majoritariamente por áreas naturais, as quais somavam $1.544 .421 \mathrm{~km}^{2}, 75.66 \%$ de sua área total. A área antrópica ocupava quase toda a área restante, num total de $483.588 \mathrm{~km}^{2}$ ou $23,69 \%$ da cobertura, restando à classe Corpo D’água $13.209 \mathrm{~km}^{2}$ ou $0.65 \%$ da área total (Tabela 11 ).

Tabela 11 - Área de cobertura por classe (Corpo D'água, Antópico e Natural) para os mapeamentos de 1985, 1995 e 2002.

\begin{tabular}{ccccccc}
\hline \multirow{2}{*}{ Ano } & \multicolumn{2}{c}{ Corpo D'água } & \multicolumn{2}{c}{ Antrópico } & \multicolumn{2}{c}{ Natural } \\
& $\mathrm{Km}^{2}$ & $\%$ & $\mathrm{Km}^{2}$ & $\%$ & $\mathrm{Km}^{2}$ & $\%$ \\
\hline 1985 & 13209 & $0.65 \%$ & 483588 & $23.69 \%$ & 1544421 & $75.66 \%$ \\
1995 & 13340 & $0.65 \%$ & 656547 & $32.16 \%$ & 1371330 & $67.18 \%$ \\
2002 & 12332 & $0.60 \%$ & 888070 & $43.51 \%$ & 1140816 & $55.89 \%$ \\
\hline
\end{tabular}

Grandes áreas pertencentes à classe natural foram convertidas para o uso antrópico em um período relativamente curto de tempo. O total de vegetação natural existente em 1985 passou a representar $1.371 .330 \mathrm{~km}^{2}(67.18 \%)$ no ano de 1995. Já no ano de 2002, a partir de dados disponibilizados pelo PMDBBS, foi observada área natural de $1.140 .816 \mathrm{~km}^{2}$, correspondendo a $55 \%$ da área total do Cerrado. $\mathrm{O}$ aumento da área antrópica foi correspondente à diminuição observada na área natural, permanecendo a classe corpo d'água praticamente inalterada no período (Tabela 11 e Figuras 27, 28 e 29). 


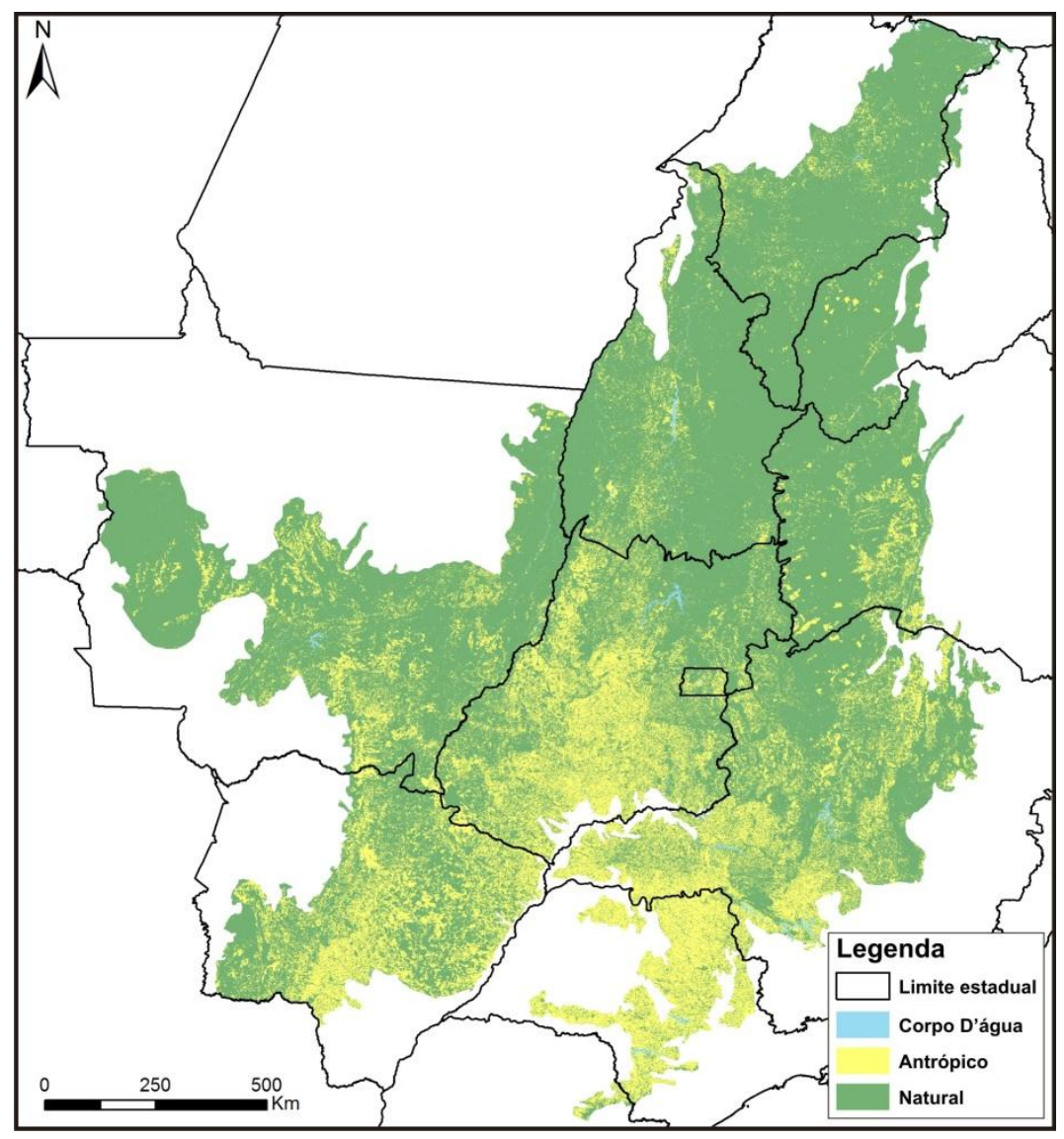

Figura 27 - Mapeamento obtido para o Cerrado no ano de 1985.

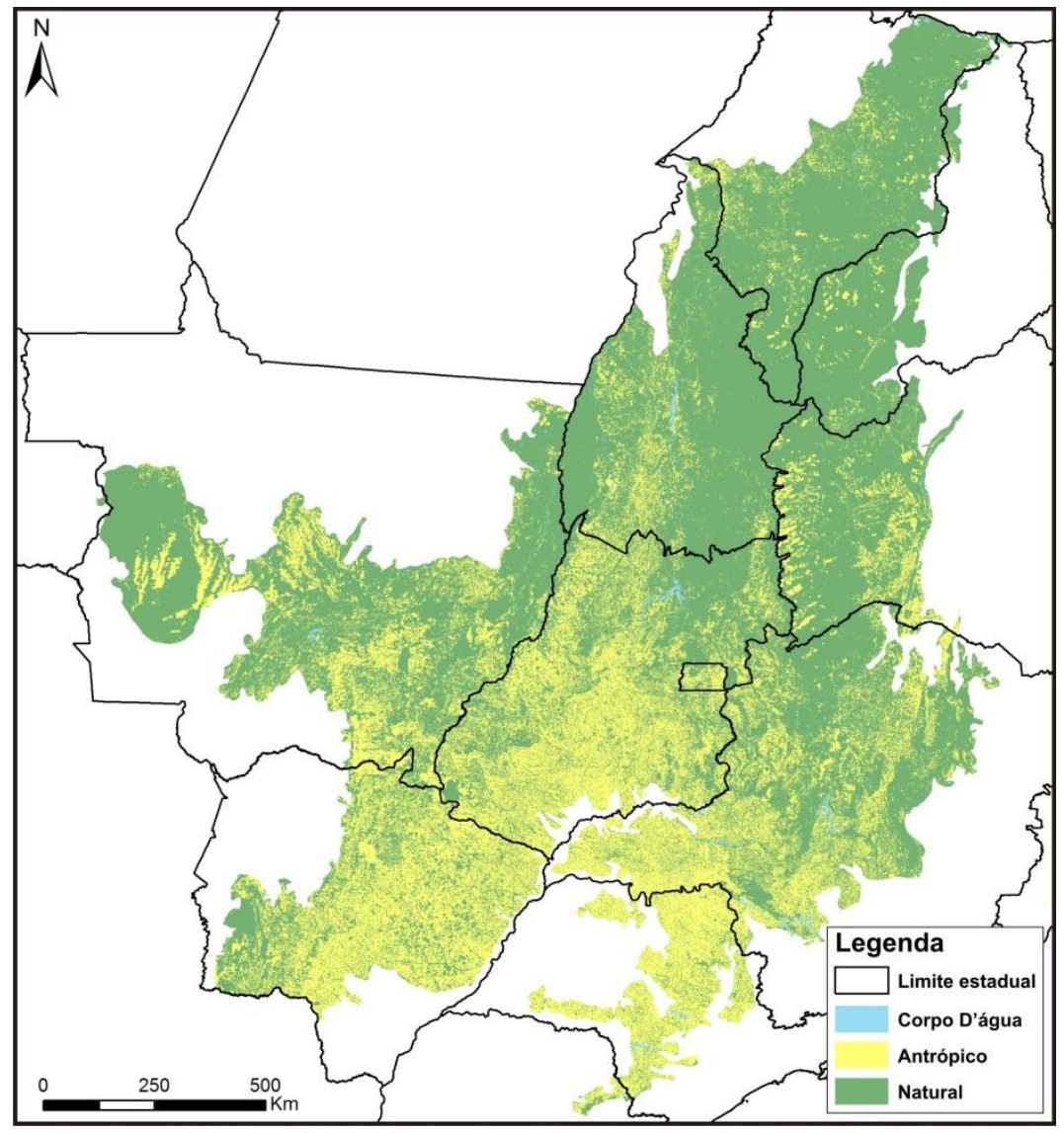

Figura 28 - Mapeamento obtido para o Cerrado no ano de 1995. 


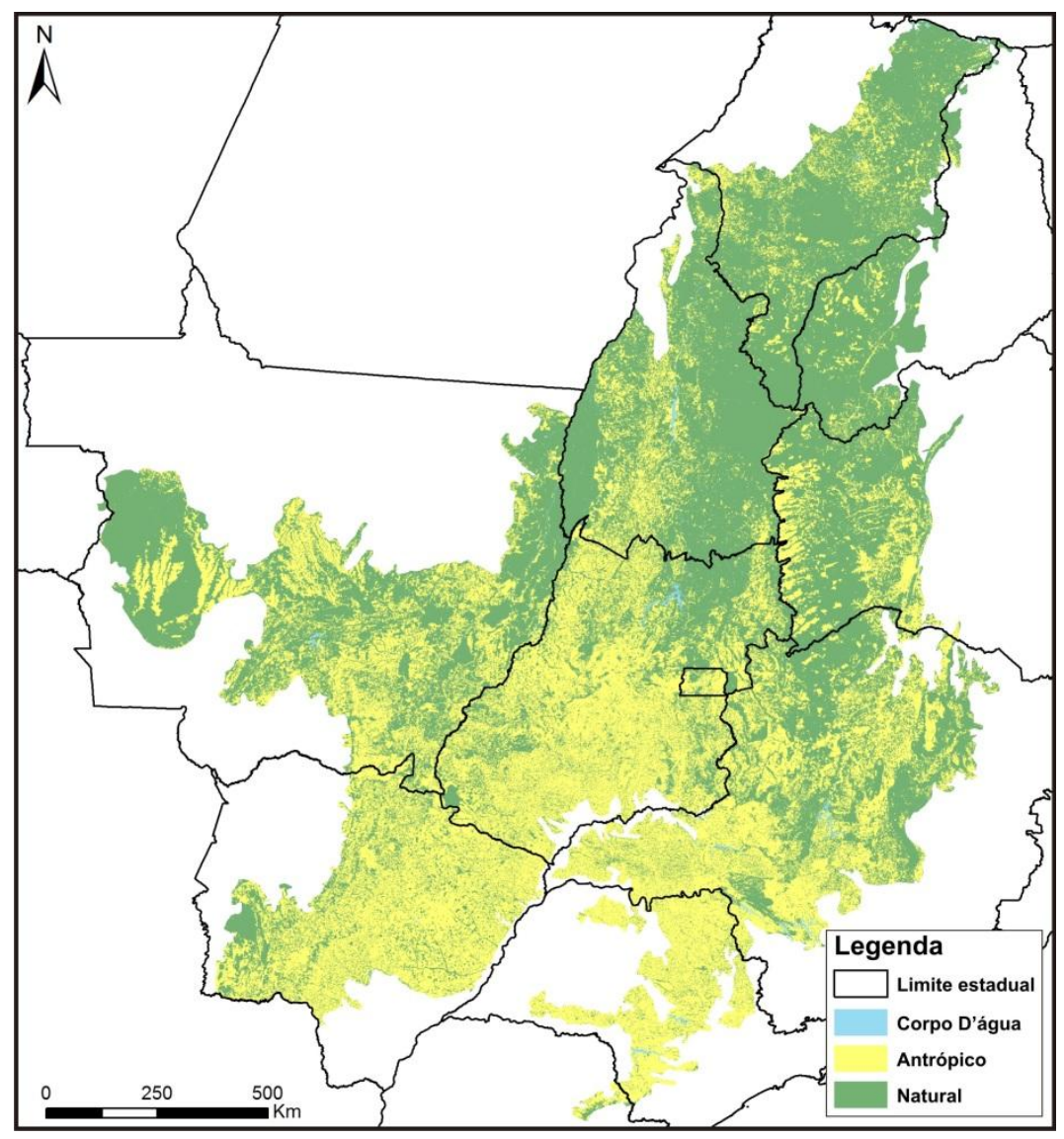

Figura 29 - Mapeamento realizado pelo PMDBBS para o Cerrado no ano de 2002.

Conforme estimativas realizadas pelo PMDBBS, após o ano de 2002, a área de cobertura vegetal nativa no Cerrado alcançou 51,54\% para o ano de 2008; 51,16\% para o ano de 2009; 50,84\% para o ano de 2010; e de 50,45\% para o ano de 2011 (IBAMA, 2009, 2011a; b, 2015). Na Figura 30, pode-se observar a composição do Cerrado em relação às classes de uso e cobertura observadas no período entre 1985 e 2011.

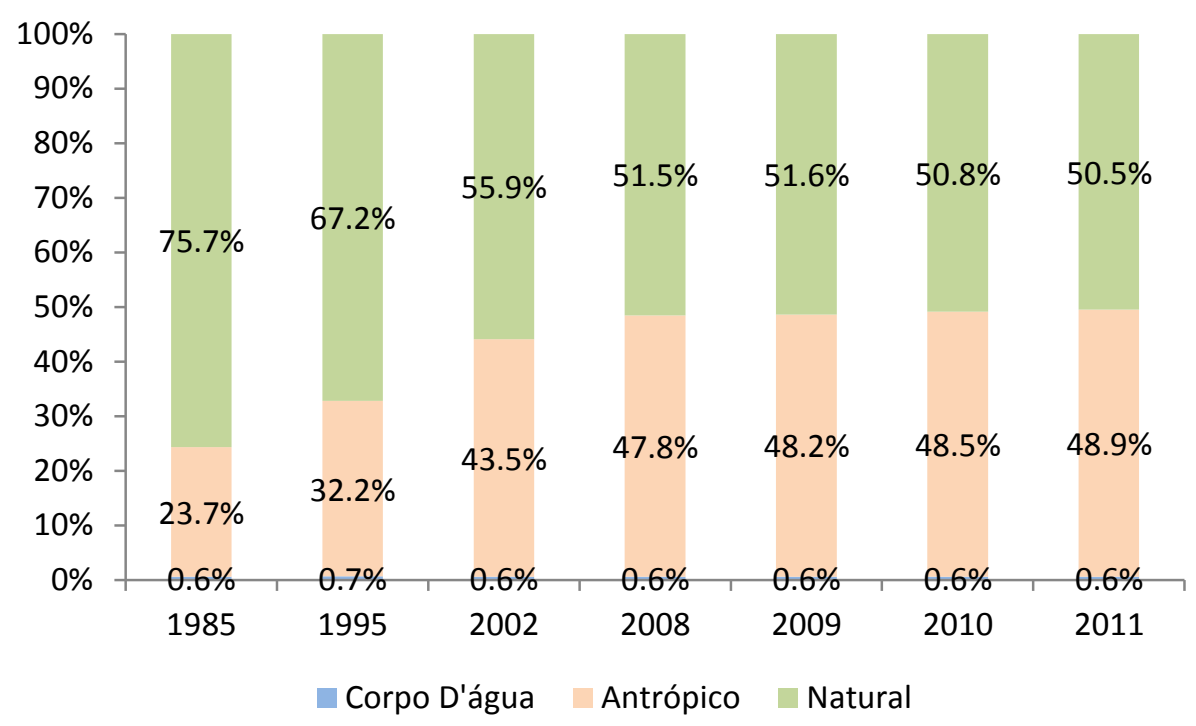

Figura 30 - Evolução percentual da área de cobertura por classe entre os anos de 1985 e 2011. 
Como se depreende da Figura 30, o período entre 1985 e 2002 foi o que apresentou as maiores alterações entre as classes de cobertura analisadas. Entre os anos de 1985 e 1995 houve uma redução na área natural de $173.091 \mathrm{~km}^{2}(8.48 \%)$ e entre 1995 e 2002 de 230.514 km² (11.29\%), áreas comparáveis àquelas dos estados do Paraná e São Paulo respectivamente (Tabela 12). No total, entre 1985 e 2002, foram suprimidos $403.605 \mathrm{~km}^{2}$ de áreas naturais $(19.77 \%)$.

Tabela 12 - Variação na área de cobertura das classes antrópico e natural para o período entre 1985 e 2002.

\begin{tabular}{ccccc}
\hline \multirow{2}{*}{ Período } & \multicolumn{2}{c}{ Antrópico } & \multicolumn{2}{c}{ Natural } \\
& $\mathrm{Km}^{2}$ & $\%$ & $\mathrm{Km}^{2}$ & $-8.48 \%$ \\
\hline $1985-1995$ & 172959 & $8.47 \%$ & -173091 & $-11.29 \%$ \\
$1995-2002$ & 231522 & $11.34 \%$ & -230514 & $-19.77 \%$ \\
$1985-2002$ & 404482 & $19.82 \%$ & -403605 & \\
\hline
\end{tabular}

A taxa anual de desmatamento no período entre 1985 e 1995 alcançou o valor de 17.309 km²/ano, e no período entre 1995 e 2002 alcançou o maior valor da série histórica, importando alterações de $32.930 \mathrm{~km}^{2} /$ ano. Em todo o período analisado, de 1985 a 2002, essa taxa foi de $23.741 \mathrm{~km}^{2} /$ ano. Tais valores são substancialmente superiores àqueles computados pelo PMDBBS para períodos posteriores (Figura 31): $14.200 \mathrm{~km}^{2} /$ ano para período entre 2002 e 2008; $7.637 \mathrm{~km}^{2}$ para o período entre 2008 e 2010; $6.469 \mathrm{~km}^{2}$ para o período entre 2009 e 2010; e $7.247 \mathrm{~km}^{2}$ para período entre 2010 e 2011 (IBAMA, 2009).

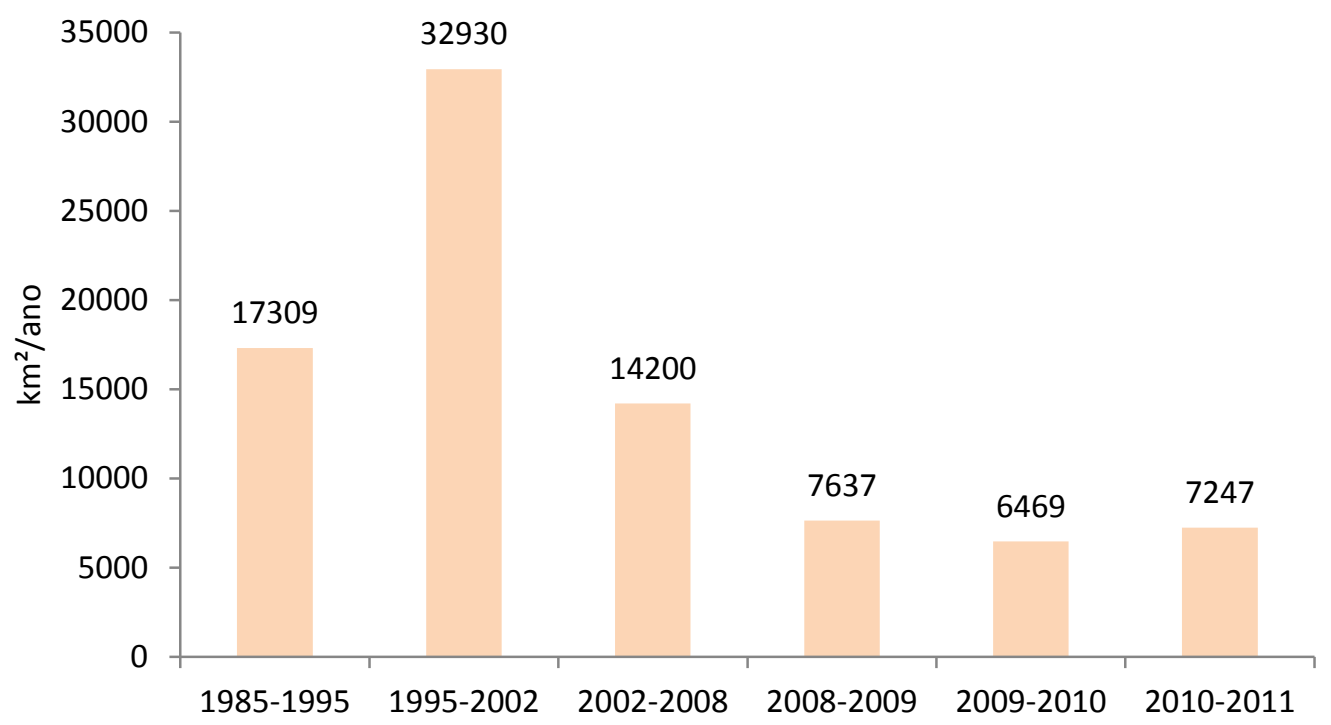

Figura 31 - Taxa de desmatamento para a série histórica disponível, entre 1985 e 2011.

Entre as unidades da Federação, a maior taxa de alteração foi observada no Distrito Federal. Esse apresentava uma área de cobertura total de $64.13 \%$ em 1985, e, em 2002, passou a representar $30.87 \%$, uma alteração de $33.26 \%$. 
$\mathrm{Na}$ Tabela 13, pode-se observar os estados ranqueados por percentual de alteração na área de cobertura da classe natural e na Figura 32 pode-se visualizar as alterações na área de cobertura. Do Apêndice 6 constam dados completos acerca da variação no uso e cobertura da terra entre as unidades da federação.

Tabela 13 - Percentual de cobertura natural e sua variação entre as unidades da federação no período analisado.

\begin{tabular}{c|ccc|ccc}
\hline \multirow{2}{*}{ Estado } & \multicolumn{3}{|c|}{ Percentual Natural do Estado } & \multicolumn{3}{c}{ Variação Entre Períodos } \\
& 1985 & 1995 & 2002 & $1985-1995$ & $1995-2002$ & $1985-2002$ \\
\hline DF & $64.13 \%$ & $47.01 \%$ & $30.87 \%$ & $-17.12 \%$ & $-16.14 \%$ & $-33.26 \%$ \\
MS & $59.32 \%$ & $39.75 \%$ & $27.49 \%$ & $-19.58 \%$ & $-12.26 \%$ & $-31.84 \%$ \\
GO & $62.25 \%$ & $51.79 \%$ & $37.95 \%$ & $-10.45 \%$ & $-13.84 \%$ & $-24.30 \%$ \\
MT & $86.04 \%$ & $74.19 \%$ & $62.08 \%$ & $-11.84 \%$ & $-12.11 \%$ & $-23.95 \%$ \\
MG & $66.80 \%$ & $60.93 \%$ & $46.28 \%$ & $-5.87 \%$ & $-14.65 \%$ & $-20.52 \%$ \\
BA & $87.45 \%$ & $79.90 \%$ & $69.76 \%$ & $-7.55 \%$ & $-10.14 \%$ & $-17.69 \%$ \\
PR & $46.14 \%$ & $40.14 \%$ & $30.04 \%$ & $-6.01 \%$ & $-10.10 \%$ & $-16.11 \%$ \\
TO & $92.12 \%$ & $86.65 \%$ & $78.43 \%$ & $-5.47 \%$ & $-8.22 \%$ & $-13.69 \%$ \\
MA & $94.39 \%$ & $91.82 \%$ & $84.14 \%$ & $-2.58 \%$ & $-7.67 \%$ & $-10.25 \%$ \\
SP & $20.25 \%$ & $20.18 \%$ & $10.91 \%$ & $-0.07 \%$ & $-9.26 \%$ & $-9.33 \%$ \\
PI & $96.51 \%$ & $94.26 \%$ & $89.41 \%$ & $-2.24 \%$ & $-4.86 \%$ & $-7.10 \%$ \\
RO & $99.84 \%$ & $99.56 \%$ & $98.88 \%$ & $-0.28 \%$ & $-0.68 \%$ & $-0.96 \%$ \\
\hline
\end{tabular}

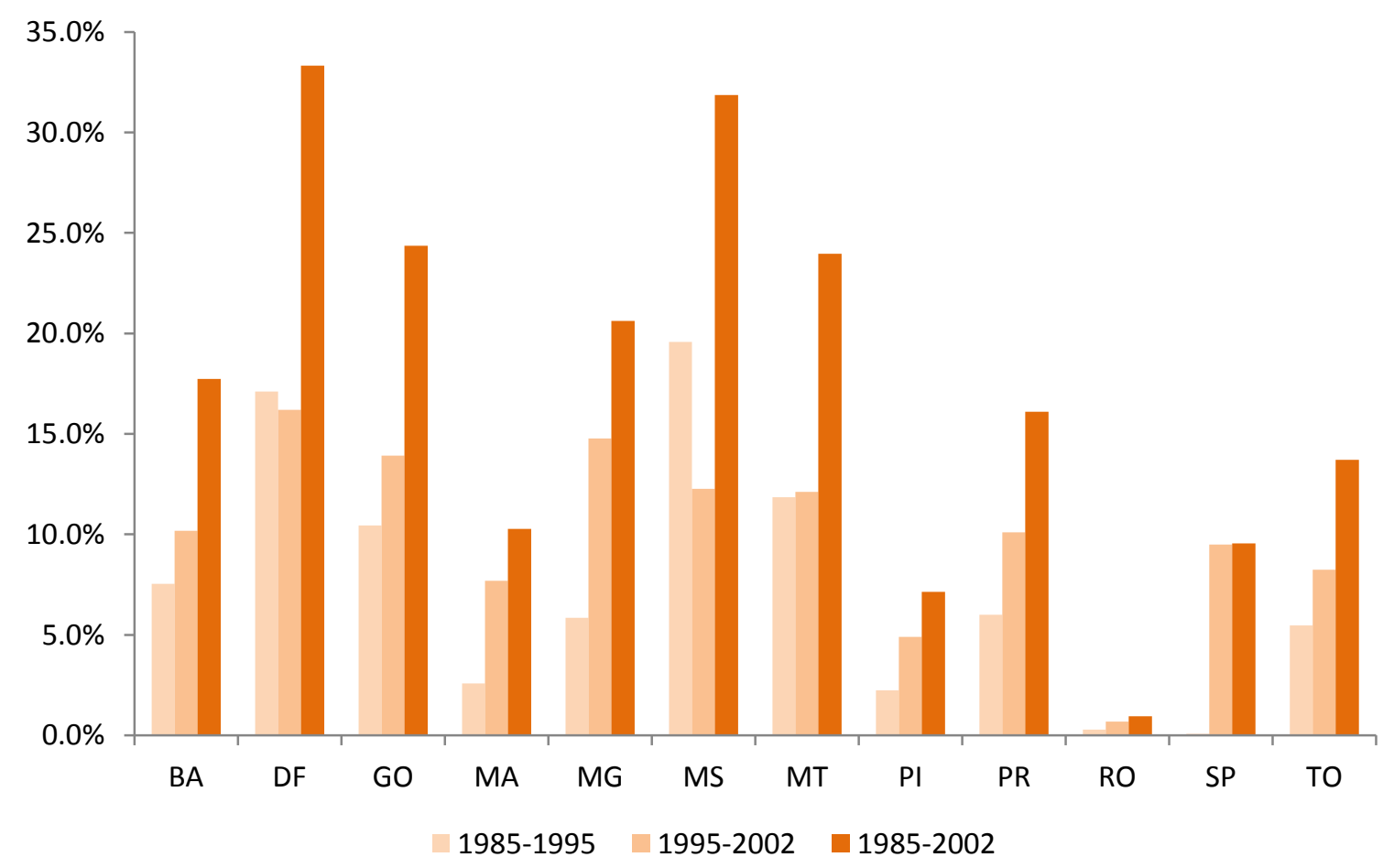

Figura 32 - Variação da área de cobertura natural entre 1985 e 2002 para as unidades da federação com ocorrência no Cerrado. 
Quando consideradas variações em relação à área total do Cerrado (variação absoluta), a unidade da federação com maior contribuição para o desmatamento foi Mato Grosso. Esse estado, que respondia por $15.13 \%$ de toda a área natural do Cerrado em 1985, passou a representar $10.92 \%$ em 2002, uma redução de $4.21 \%$ da área de cobertura natural total do Cerrado. Após Mato Grosso os que apresentaram a maior contribuição para a diminuição total da área natural foram Tocantins, Minas Gerais, Goiás e Maranhão (Tabela 14 e Figura 33).

Tabela 14 - Percentual de área natural por Estado baseado na área total do Cerrado, ranqueados por taxa de desmatamento.

\begin{tabular}{c|ccc|ccc}
\hline \multirow{2}{*}{ Estado } & \multicolumn{3}{|c|}{ Percentual Natural do Cerrado } & \multicolumn{3}{c}{ Variação Entre Períodos } \\
& 1985 & 1995 & 2002 & $1985-1995$ & $1995-2002$ & $1985-2002$ \\
\hline MT & $15.13 \%$ & $13.05 \%$ & $10.92 \%$ & $-2.08 \%$ & $-2.13 \%$ & $-4.21 \%$ \\
TO & $11.41 \%$ & $10.73 \%$ & $9.71 \%$ & $-1.69 \%$ & $-2.24 \%$ & $-3.93 \%$ \\
MG & $10.96 \%$ & $10.00 \%$ & $7.59 \%$ & $-2.07 \%$ & $-1.30 \%$ & $-3.37 \%$ \\
GO & $10.06 \%$ & $8.37 \%$ & $6.13 \%$ & $-0.96 \%$ & $-2.40 \%$ & $-3.37 \%$ \\
MA & $9.81 \%$ & $9.54 \%$ & $8.74 \%$ & $-0.68 \%$ & $-1.02 \%$ & $-1.70 \%$ \\
BA & $6.50 \%$ & $5.94 \%$ & $5.18 \%$ & $-0.56 \%$ & $-0.75 \%$ & $-1.31 \%$ \\
MS & $6.28 \%$ & $4.21 \%$ & $2.91 \%$ & $-0.27 \%$ & $-0.80 \%$ & $-1.07 \%$ \\
PI & $4.42 \%$ & $4.32 \%$ & $4.09 \%$ & $0.00 \%$ & $-0.37 \%$ & $-0.37 \%$ \\
SP & $0.81 \%$ & $0.80 \%$ & $0.43 \%$ & $-0.10 \%$ & $-0.22 \%$ & $-0.32 \%$ \\
DF & $0.18 \%$ & $0.13 \%$ & $0.09 \%$ & $-0.05 \%$ & $-0.05 \%$ & $-0.09 \%$ \\
PR & $0.08 \%$ & $0.07 \%$ & $0.06 \%$ & $-0.01 \%$ & $-0.02 \%$ & $-0.03 \%$ \\
RO & $0.02 \%$ & $0.02 \%$ & $0.02 \%$ & $0.00 \%$ & $0.00 \%$ & $0.00 \%$ \\
\hline
\end{tabular}

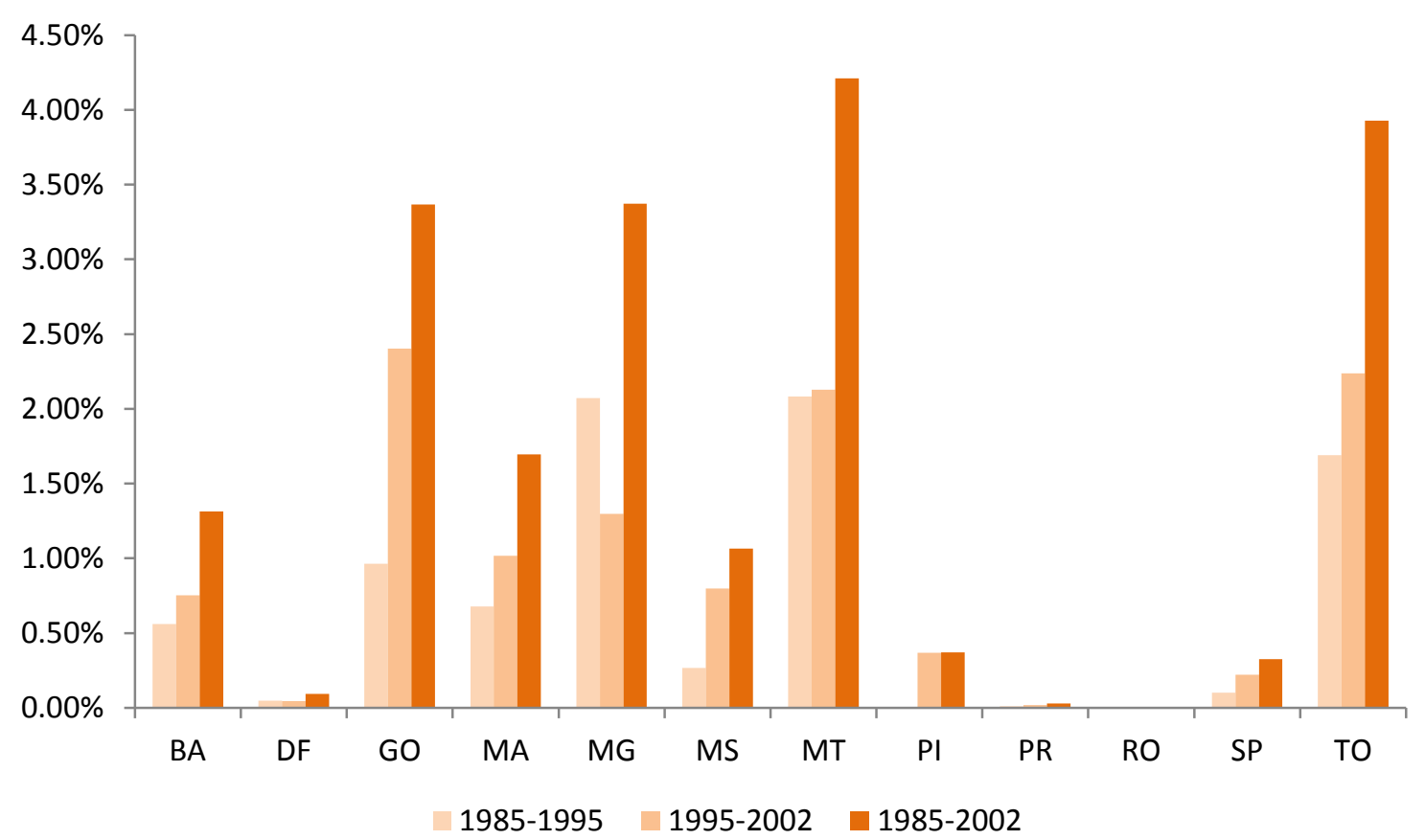

Figura 33 - Variação percentual por Estado da área de cobertura natural em relação à área total do Cerrado. 
Aspectos especialmente relevantes da dinâmica do desmatamento no período podem ser observados a partir de dados dos municípios. Entre 1985 e 1995 quatro principais regiões apresentaram taxas elevadas de desmatamento: 1) região entre o sudoeste de Goiás, centro/leste dos estados de Mato Grosso e Mato Grosso do Sul; 2) frente de desmatamento que parte do centro/oeste do estado de Goiás em direção ao Tocantins; 3) região do Oeste Baiano; 4) região do Distrito Federal e suas proximidades (Figura 34). Do Apêndice 7 constam informações acerca dos 100 municípios com maior taxa de desmatamento no período entre 1985 e 2002.

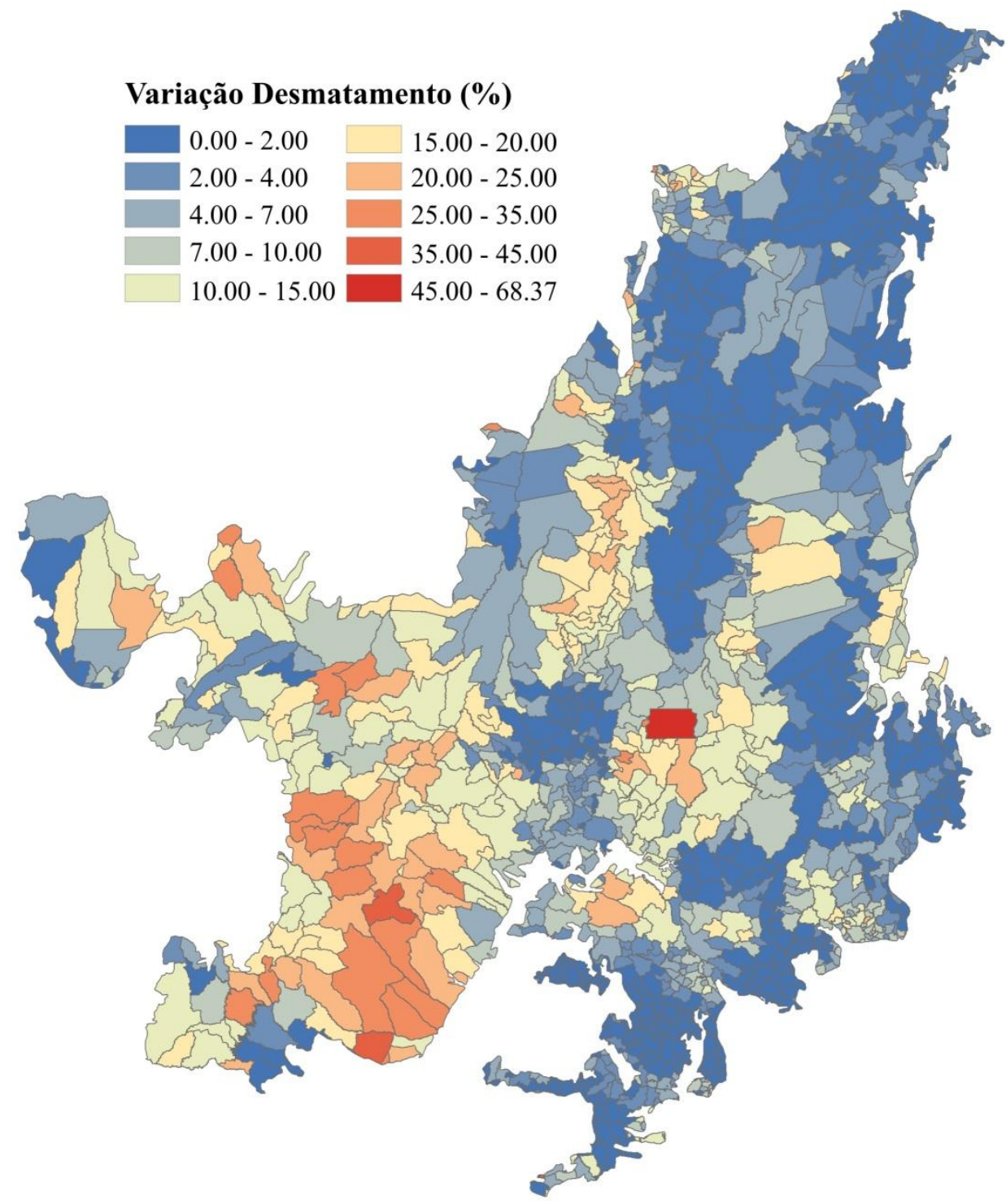

Figura 34 - Variação percentual da área antrópica entre os municípios para o período entre 1985 e 1995.

Entre 1995 e 2002, o desmatamento ocorre de forma mais dispersa ao longo do Cerrado, observando a manutenção do desmatamento nas regiões anteriormente mencionadas. Como novos focos de desmatamento no período observa-se a região centro/norte do estado de 
Minas Gerais, nas proximidades do município de Montes Claros, além de regiões situadas na porção central do Maranhão (Figura 35).

\section{Variação Desmatamento (\%)}

\begin{tabular}{|l|l|}
\hline $0.00-2.00$ & \\
\hline $2.00-4.00$ & \\
\hline & $20.00-200-25.00$ \\
$4.00-7.00$ & $25.00-35.00$ \\
\hline $7.00-10.00$ & $35.00-45.00$ \\
\hline $10.00-15.00$ & $45.00-68.37$ \\
\hline
\end{tabular}
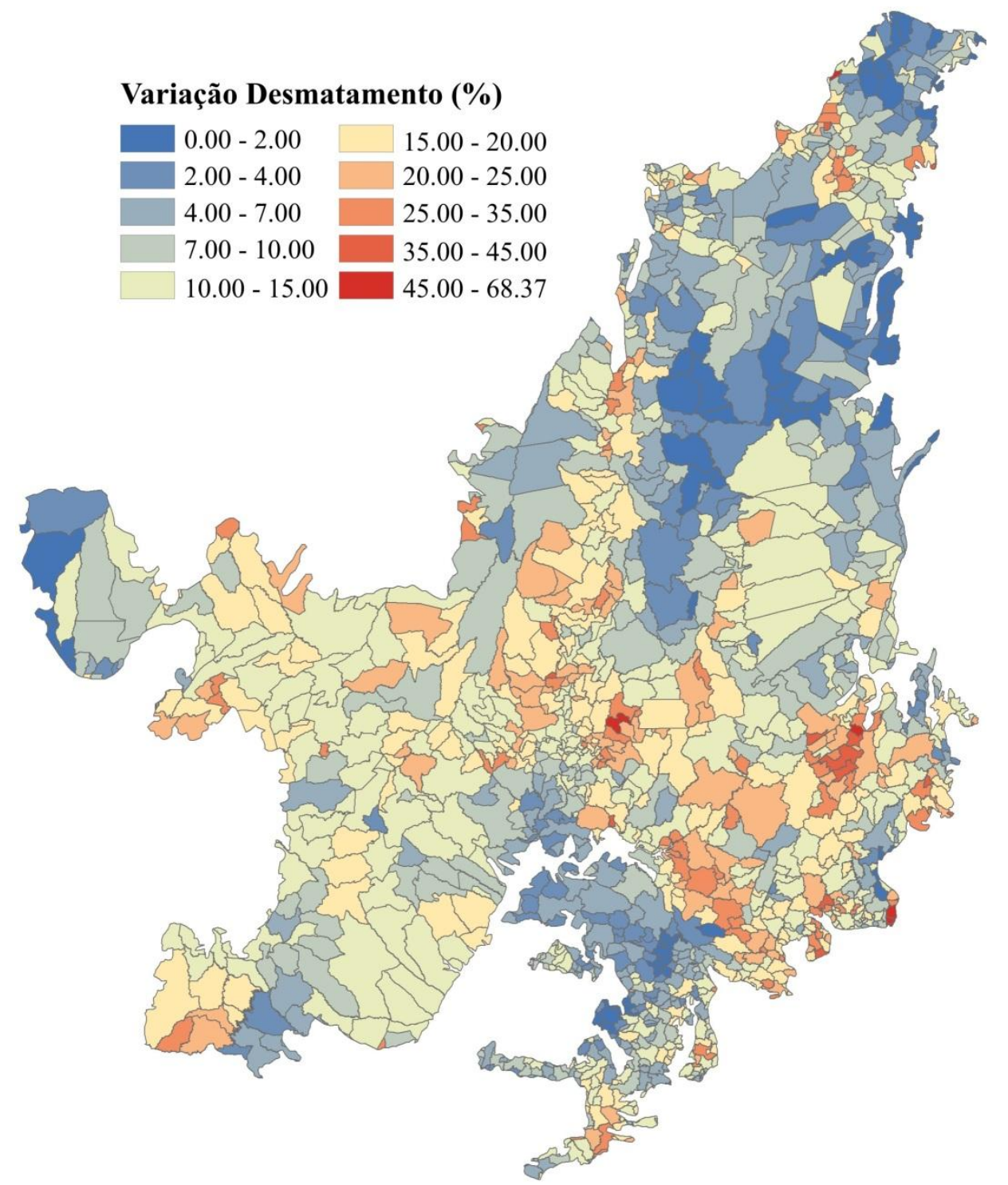

Figura 35 - Variação percentual da área antrópica entre os municípios para o período entre 1995 e 2002.

De forma geral, no período entre 1985 e 2002 (Figura 36), pode-se destacar a ocorrência de duas grandes frentes de desmatamento, além de três outros polos principais de desmatamento. Esses estão indicados pelas setas e círculos na Figura 37. 


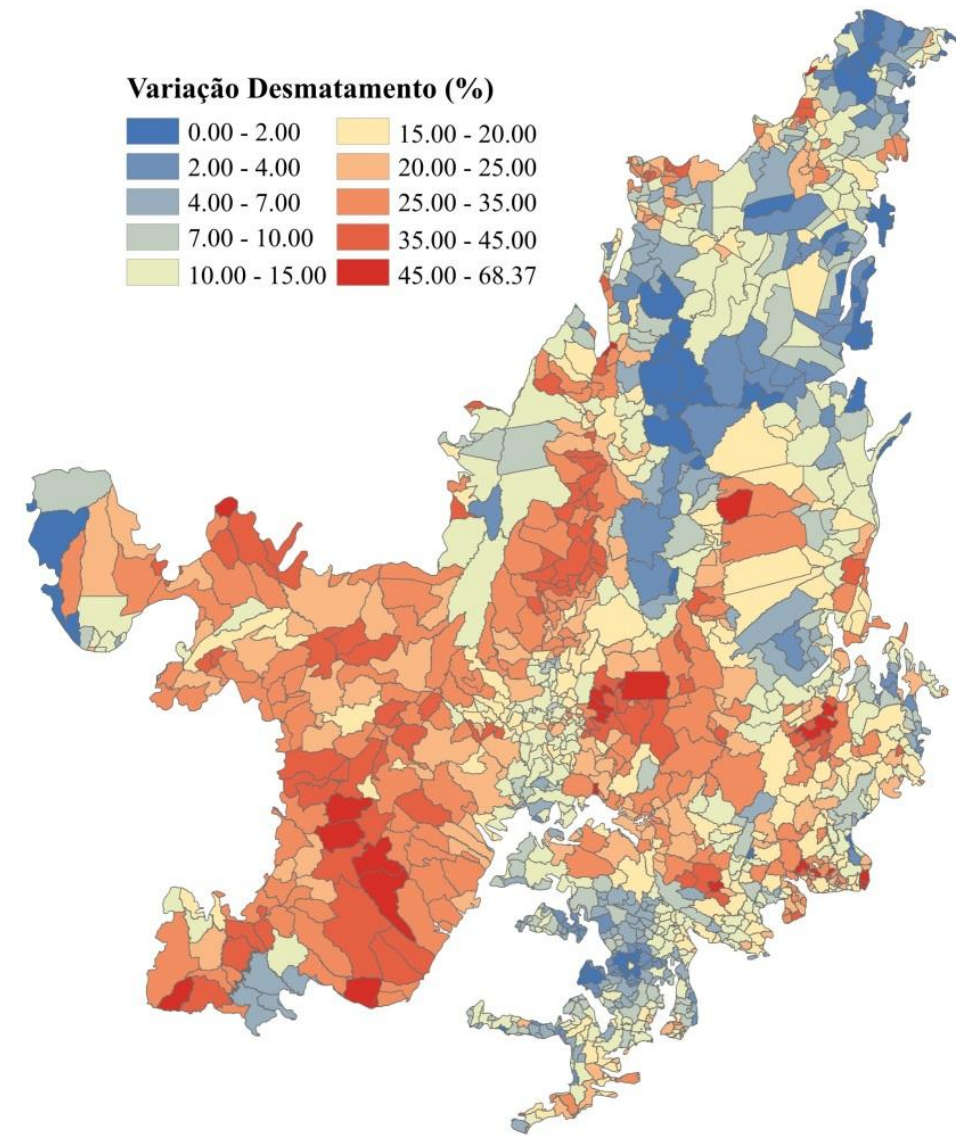

Figura 36 - Variação percentual da área antrópica entre os municípios para o período entre 1985 e 2002.

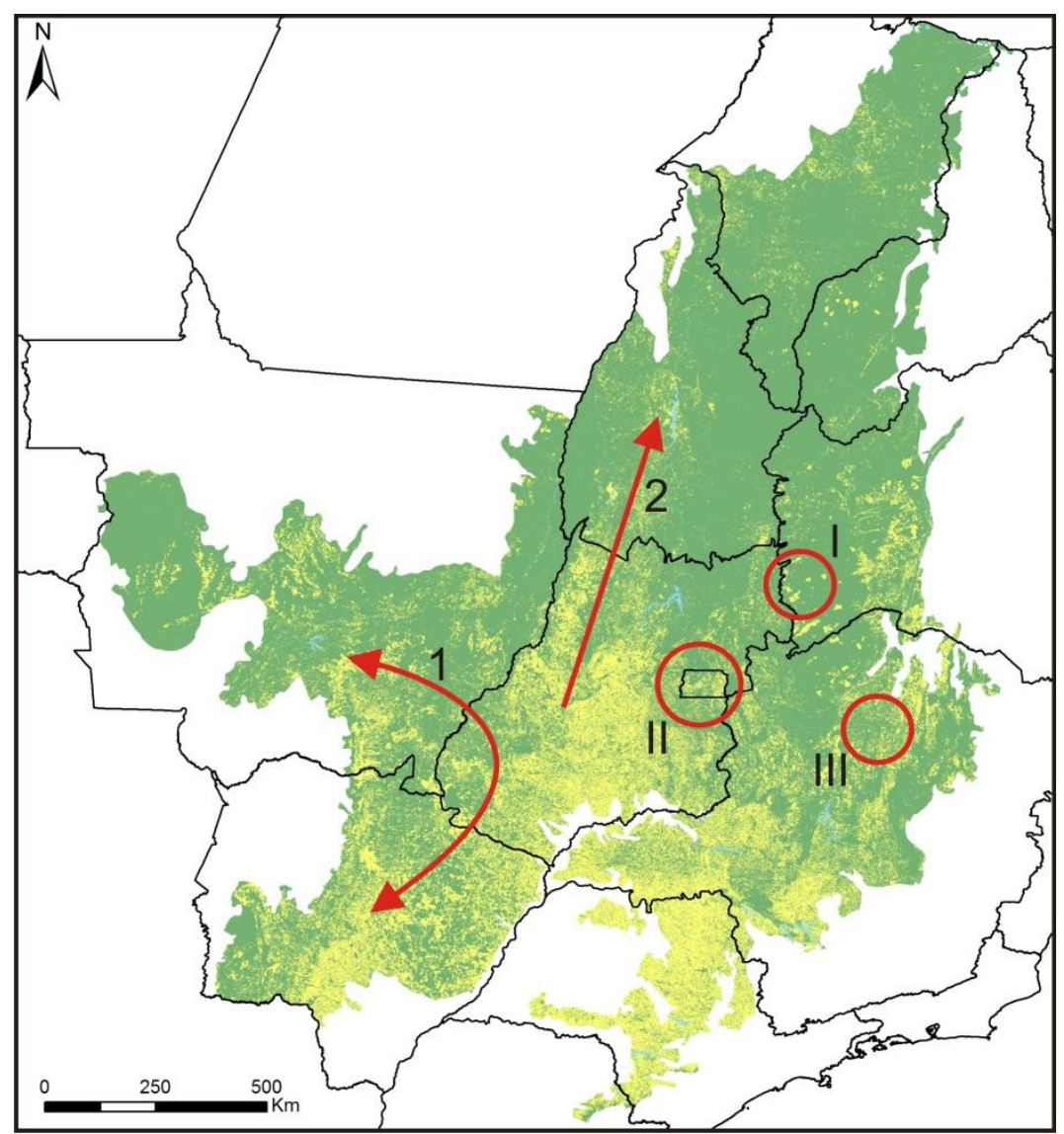

Figura 37 - Principais frentes e áreas indutoras de desmatamento observadas entre os anos de 1985 e 2002. 
Na figura 37, a seta 1 indica o desenvolvimento da frente de desmatamento ocorrente entre o sudoeste de Goiás e regiões centro/leste dos estados de Mato Grosso e Mato Grosso do sul. A seta 2 indica o desenvolvimento de frende de desmatamento partindo do centro/leste de Goiás em direção ao Tocantins e Maranhão. O círculo I indica o desenvolvimento do desmatamento no oeste baiano, o círculo II na região do Distrito Federal e suas proximidades e o círculo III na região centro-norte de Minas Gerais, polos indutores de desmatamento no período.

\subsubsection{Avaliação da Qualidade}

Conforme abordado na Seção 2.6.5, a avaliação de qualidade do mapeamento levou em consideração apenas a área efetivamente mapeada neste estudo, não sendo consideradas regiões complementares do mapeamento de referência.

O mapeamento do ano de 1985 apresentou como indicadores de qualidade o valor de 91\% para o Índice Global de Acurácia e de 87\% para o Índice Kappa, quando consideradas todas as classes mapeadas. Apreciando-se apenas as classes natural e antrópico, os valores variaram levemente, com 90\% para o Índice Global de Acurácia e 80\% para o Índice Kappa (Tabela 15).

Tabela 15 - Qualidade obtida para o mapeamento, considerando-se a matriz completa de dados com as classes Corpo D'água, Antrópico e Natural (Matriz 3×3) e a apenas a matriz formada pelas classes Antrópico e Natural (Matriz 2x2).

\begin{tabular}{c|cccccc|cccccc}
\hline \multirow{2}{*}{ Ano } & \multicolumn{6}{|c|}{ Matriz $3 \times 3$} & \multicolumn{7}{c}{ Matriz 2x2 } \\
& $\mathrm{N}$ & $\mathrm{AG}$ & $\mathrm{K}$ & $\mathrm{X}^{2}$ & $\mathrm{p}$ & $\mathrm{Kq}$ & $\mathrm{N}$ & $\mathrm{AG}$ & $\mathrm{K}$ & $\mathrm{BI}$ & $\mathrm{PR}$ & $\mathrm{KP}$ \\
\hline 1985 & 3600 & 0.91 & 0.87 & 35.40 & 0.000 & 0.87 & 2388 & 0.90 & 0.80 & 0.00 & 0.00 & 0.80 \\
1995 & 3600 & 0.90 & 0.85 & 40.5 & 0.000 & 0.85 & 2389 & 0.88 & 0.77 & 0.01 & -0.01 & 0.77 \\
\hline * Número de amostras (N), Acurácia Global (AG), Cohen's Kappa (K), $\mathrm{X}^{2}$ e p valor (p) do teste de
\end{tabular}
homogeneidade de Stuart-Maxwell, viés (BI), prevalência (PE) e Kappa Pabak (KP).

Por sua vez, o mapeamento do ano de 1995 apresentou o valor de 90\% para o Índice Global de Acurácia e de $85 \%$ para o Índice Kappa, quando consideradas todas as classes mapeadas. Quando foram observados os valores apenas para as classes natural e antrópico, esses alcançaram 88\% para o Índice Global de Acurácia e 77\% para o Índice Kappa.

Os valores apresentados indicaram elevada qualidade dos mapeamentos obtidos, verificando-se elevada concordância entre as classes mapeadas e a verdade para as 3600 amostras testadas em cada ano. Os resultados alcançados são semelhantes aos apresentados por mapeamentos oficiais (MMA, 2015; Sano, Rosa, Brito, Jorge L S, et al., 2010). 
As principais fontes de erro, tanto para o ano de 1985, quanto para o ano de 1995, foi a omissão de alvos naturais, com 0.13 (1985) e 0.15 (1995) (Tabela 16). A classe antrópico apresentou erros de comissão superiores aos da classe natural, com 0.11 (1985) e 0.13 (1995). A classe água apresentou valores de erro reduzidos, com maior comissão (0.5 para ambos os anos) do que omissão (0.01 para ambos os anos). O resultado evidencia uma ligeira subestimativa da classe natural e correspondente superestimativa da classe antrópico.

Tabela 16 - Erros de omissão e comissão entre as classes consideradas para os mapeamentos dos anos de 1985 e 1995.

\begin{tabular}{lcc|cc}
\hline & & & \multicolumn{2}{c}{1995} \\
Classe & Comissão & Omissão & Comissão & Omissão \\
\hline Corpos D'Água & 0.05 & 0.01 & 0.05 & 0.01 \\
Antrópico & 0.11 & 0.11 & 0.13 & 0.13 \\
Natural & 0.10 & 0.13 & 0.11 & 0.15 \\
\hline
\end{tabular}

\subsection{AVALIAÇÃO DE COMPATIBILIDADE ENTRE METODOLOGIAS}

A compatibilidade entre os resultados das metodologias de mapeamento utilizadas neste trabalho e aquela utilizada pelo PMDBBS foi realizada conforme descrito na Seção 2.7, considerando-se amostras sistemáticas, lançada a cada $\mathrm{km}^{2}$, em área que abrange aproximadamente $30 \%$ de todo o Cerrado (20 cenas sorteadas).

As matrizes de confusão formadas apresentaram uma elevada diferença na proporção de dados representados entre as classes, o que reflete a distribuição dessas classes na paisagem. Tendo por referência o mapeamento realizado neste trabalho, unidades amostrais da classe natural responderam por $88 \%$ das unidades amostrais, a classe antrópica por $11 \%$ e a classe natural por $1 \%$, de um total de 351.154 unidades amostradas. Em função da grande desproporção na ocorrência dos dados, o viés, a prevalência e o teste de homogeneidade de Stuart-Maxwell indicaram totais marginais desequilibrados, não sendo adequada a utilização do Kappa de Cohen (Cohen, 1960) nessa situação. No caso, é recomendada a utilização do índice Kappa Pabak (Byrt, Bishop e Carlin, 1993) ou outros índices que não tenham por pressuposto a homogeneidade na distribuição dos totais marginais da matriz.

Para o conjunto das cenas, considerando-se todas as classes mapeadas (Matriz 3x3), o Índice Global de Acurácia alcançou valor médio de 88\% (mínimo = 0.70, máximo = 0.97, desvio padrão $=0.07$ ) e o Índice Kappa $q(\mathrm{Kq})$ obteve um valor médio de $82 \%$ (mínimo = 0.55 , máximo $=0.96$, desvio padrão $=0.10$ ) (Tabela 17). Quando foram considerados apenas as classes antrópico e natural, o valor médio da Acurácia Global foi de $88 \%$ (desvio padrão = 0.06) e do Kappa Pabak de 77\% (desvio padrão = 0.13). 
Tabela 17 - Qualidade obtida para o conjunto de dados de compatibilidade por cena, considerando-se a matriz completa de dados com as classes Corpo D'água, Antrópico e Natural (Matriz 3x3) e a apenas a matriz formada pelas classes Antrópico e Natural (Matriz 2x2). Os índices referem-se ao nível de coincidência entre os mapeamentos comparados.

\begin{tabular}{|c|c|c|c|c|c|c|c|c|c|c|c|c|}
\hline \multirow{2}{*}{ Cena } & \multicolumn{6}{|c|}{ Matriz 3x3 } & \multicolumn{6}{|c|}{ Matriz 2x2 } \\
\hline & $\mathrm{N}$ & $\mathrm{AG}$ & $\mathrm{K}$ & $X^{2}$ & $\mathrm{p}$ & $\mathrm{Kq}$ & $\mathrm{N}$ & $\mathrm{AG}$ & $\mathrm{K}$ & $\mathrm{BI}$ & PR & $\mathrm{KP}$ \\
\hline 218_73 & 17222 & 0.70 & 0.22 & 1943.00 & 0.00 & 0.55 & 17180 & 0.70 & 0.22 & 0.18 & -0.51 & 0.40 \\
\hline 219_62 & 8360 & 0.90 & 0.27 & 345.00 & 0.00 & 0.86 & 8036 & 0.92 & 0.08 & 0.06 & -0.91 & 0.85 \\
\hline 219_68 & 22181 & 0.88 & 0.31 & 704.00 & 0.00 & 0.82 & 21920 & 0.89 & 0.27 & 0.06 & -0.83 & 0.77 \\
\hline 219_69 & 21284 & 0.91 & 0.34 & 446.00 & 0.00 & 0.86 & 21219 & 0.91 & 0.33 & 0.04 & -0.85 & 0.82 \\
\hline 219_71 & 18351 & 0.83 & 0.18 & 109.00 & 0.00 & 0.75 & 18180 & 0.84 & 0.16 & 0.03 & -0.79 & 0.68 \\
\hline 220_68 & 23331 & 0.92 & 0.18 & 900.00 & 0.00 & 0.88 & 23251 & 0.92 & 0.18 & 0.05 & -0.90 & 0.85 \\
\hline 221_64 & 25125 & 0.93 & 0.29 & 262.00 & 0.00 & 0.89 & 25107 & 0.93 & 0.29 & 0.03 & -0.89 & 0.85 \\
\hline 221_69 & 29147 & 0.87 & 0.14 & 1380.00 & 0.00 & 0.80 & 28789 & 0.87 & 0.11 & 0.08 & -0.85 & 0.75 \\
\hline 221_72 & 11024 & 0.72 & 0.25 & 985.00 & 0.00 & 0.58 & 10900 & 0.72 & 0.23 & 0.16 & -0.55 & 0.45 \\
\hline $222 \_65$ & 24782 & 0.90 & 0.17 & 2082.00 & 0.00 & 0.85 & 24573 & 0.91 & 0.09 & 0.09 & -0.89 & 0.81 \\
\hline $222 \_68$ & 21608 & 0.88 & 0.23 & 1173.00 & 0.00 & 0.83 & 21276 & 0.89 & 0.15 & 0.08 & -0.86 & 0.78 \\
\hline 223_67 & 20959 & 0.91 & 0.33 & 861.00 & 0.00 & 0.86 & 20417 & 0.92 & 0.20 & 0.06 & -0.89 & 0.83 \\
\hline 223_69 & 21197 & 0.94 & 0.45 & 213.00 & 0.00 & 0.91 & 20570 & 0.95 & 0.31 & 0.02 & -0.93 & 0.91 \\
\hline $223 \_71$ & 9385 & 0.83 & 0.37 & 605.00 & 0.00 & 0.75 & 9192 & 0.84 & 0.36 & 0.10 & -0.72 & 0.68 \\
\hline $224 \_68$ & 9504 & 0.90 & 0.27 & 135.00 & 0.00 & 0.85 & 9400 & 0.90 & 0.25 & 0.04 & -0.86 & 0.81 \\
\hline 224_73 & 11390 & 0.86 & 0.58 & 174.00 & 0.00 & 0.79 & 11317 & 0.86 & 0.59 & 0.05 & -0.58 & 0.73 \\
\hline $225 \_70$ & 20583 & 0.90 & 0.22 & 491.00 & 0.00 & 0.85 & 20534 & 0.90 & 0.23 & 0.05 & -0.87 & 0.81 \\
\hline 226_69 & 9191 & 0.93 & 0.49 & 82.50 & 0.00 & 0.90 & 9098 & 0.94 & 0.51 & 0.02 & -0.87 & 0.88 \\
\hline 227_69 & 9556 & 0.93 & 0.70 & 54.80 & 0.00 & 0.89 & 9487 & 0.93 & 0.72 & 0.02 & -0.72 & 0.86 \\
\hline 228_70 & 16974 & 0.97 & 0.11 & 288.00 & 0.00 & 0.96 & 16961 & 0.97 & 0.12 & 0.02 & -0.97 & 0.95 \\
\hline
\end{tabular}

* Número de amostras (N), Acurácia Global (AG), Cohen's Kappa (K), X $\mathrm{X}^{2}$ e p valor (p) do teste de homogeneidade de Stuart-Maxwell, viés (BI), prevalência (PR) e Kappa Pabak (KP).

Os valores apresentados indicaram elevada concordância entre os mapeamentos, ainda que, em casos individuais, apontem a eventual necessidade de ajustes. Observa-se no caso das cenas 218/73 e 221/72 valor significativamente abaixo da média (aproximadamente cinco vezes o desvio padrão). Observando-se as imagens referidas, nota-se que a maior parte da diferença é devida à interpretação distinta sobre feições com formações campestres, sendo essas geralmente alocadas na classe antrópica pelo mapeamento executado e na classe natural pelo mapeamento de referência.

Na Tabela 18, observa-se a área mapeada para cada uma das classes, de acordo com os mapeamentos em comparação. Constatou-se que a metodologia adotada neste trabalho, subestimou a área natural em aproximadamente $6 \%$, quando comparado com o realizado pelo PMDBBS. Dessa forma, é esperado que o mapeamento realizado para os anos de 1985 e 1995 também apontem menor área natural do que o órgão oficial o faria, tendo como consequência dados mais conservadores acerca do desmatamento ocorrente entre esses anos e 2002. 
Tabela 18 - Área total, percentual de cobertura por classe e diferença entre os valores obtidos para os mapeamentos comparados.

\begin{tabular}{lcccccc}
\hline \multicolumn{1}{c}{ Classe } & $\begin{array}{c}\text { PMDBBS } \\
\left(\mathbf{K m}^{2}\right)\end{array}$ & $\begin{array}{c}\text { PMDBBS } \\
\mathbf{( \% )}\end{array}$ & $\begin{array}{c}\text { Mapeamento } \\
\left(\mathbf{K m}^{2}\right)\end{array}$ & $\begin{array}{c}\text { Mapeamento } \\
(\mathbf{\%})\end{array}$ & $\begin{array}{c}\text { Dif. } \\
\left(\mathbf{k m}^{2}\right)\end{array}$ & $\begin{array}{c}\text { Dif. } \\
(\boldsymbol{\%})\end{array}$ \\
\hline Corpo D'água & 2634 & $0.7 \%$ & 2783 & $0.8 \%$ & 149 & $0.0 \%$ \\
Antrópico & 18718 & $5.3 \%$ & 40266 & $11.5 \%$ & 21547 & $6.1 \%$ \\
Natural & 329896 & $93.9 \%$ & 308521 & $87.8 \%$ & 21374 & $-6.2 \%$ \\
Total & 351249 & $100 \%$ & 351571 & $100 \%$ & 43071 & $12.3 \%$ \\
\hline
\end{tabular}

Ainda que o teste realizado aponte elevado nível de compatibilidade entre os resultados, esse também sugere que é possível maior aproximação em relação a resultados que seriam esperados caso o mapeamento houvesse sido executado pelo PMDBBS. A diferença observada pode ser devida tanto a interpretação desigual para algumas feições (eg. pastagem plantada e natural), quanto devido a características específicas do mapeamento de referência. Como se observa da comparação entre os resultados do PMDBBS (IBAMA, 2016) e aqueles obtidos pelo Terraclass Cerrado (MMA, 2015), o primeiro mapeamento apresenta uma superestimativa do desmatamento quando comparado com a iniciativa mais recente. Considerando que objetivamos a obtenção de resultados com a máxima compatibilidade possível com a série histórica de mapeamentos do PMDBBS, sugere-se que o mapeamento realizado seja revisado, adotando-se critério de interpretação menos restritivo para a atribuição de feições à classe natural. 


\section{DISCUSSÃO}

Estudos geralmente avaliam a potencialidade de ferramentas de GEOBIA em pequenas áreas e com imagens de alta resolução espacial (Blaschke et al., 2014). Contudo, a aplicação deste conjunto de métodos e ferramentas ao mapeamento de uso e cobertura da terra em regiões com grande extensão e com a utilização de imagens de média resolução espacial apresenta vantagens potenciais sobre métodos usualmente empregados, como a análise de imagens do tipo pixel-pixel ou a análise por região.

Dentre trabalhos que utilizaram a GEOBIA para finalidades análogas às deste, utilizando-se de imagens de média resolução espacial, destacamos Yang et al. (2015) e Aplin \& Smith (2008). Os autores indicaram como vantagens desse tipo de abordagem metodológica uma maior identidade entre as unidades mínimas de classificação e as feições a serem mapeadas, possibilitando a replicação para o ambiente de mapeamento a identificação de características e padrões mais próximos daqueles utilizados por intérpretes humanos para a identificação dos alvos. Jhonnerie et al. (2015), por sua vez, apontaram como diferencial a possibilidade de aplicação de métodos avançados de análise, como a mineração de dados, além de uma maior integração entre diferentes tipos de informação, por exemplo, dados de diferentes sensores (Landsat TM e ALOS PALSAR). Bertani et al. (2013), de forma similar, utilizando-se da possibilidade de uma maior integração de dados, utilizou-se de características do relevo, as quais implicaram em aperfeiçoamento significativo na identificação de feições naquele estudo.

Neste trabalho, a metodologia proposta valeu-se dos aspectos mencionados, e, especialmente, da possibilidade de utilização de uma ampla gama de características definidoras dos objetos, formadoras de sua assinatura estrutural. Conjuntos de atributos, analisados a partir de processos automáticos de descoberta de conhecimento (KDD), mostraram-se capazes de definir os elementos pertencentes às classes investigadas, mesmo considerando a grande extensão e heterogeneidade do ambiente em estudo.

A combinação de métodos de GEOBIA, com análise estatísticas adicionais e a utilização de capacidades de Sistemas de Informação Geográfica, como proposto neste estudo, teve por principal benefício a redução significativa do tempo necessário para o mapeamento, além da facilitação da obtenção de dados com maior coerência e objetividade, reduzindo-se, em certa medida, a influência do intérprete sobre os resultados finais. Elemento central, nesse contexto, foi a etapa de análise de agrupamento aplicadas aos dados, a qual valeu-se de 
informações obtidas a partir das etapas de KDD e GEOBIA, oferecendo novos dados para a etapa final de interpretação visual e classificação.

A etapa estatística mencionada é passível de aperfeiçoamento, bem como a forma de execução ou fluxo de trabalho observado na metodologia. Para o primeiro caso sugere-se que estudos específicos investiguem o impacto de diferentes configurações do tipo de análise estatística utilizada (análise de agrupamento), com vistas a se obter soluções metodológicas ótimas para a aplicação na área de mapeamento do uso e cobertura da terra. No segundo caso, observa-se que, embora se tenha utilizado três diferentes ambientes de software para a execução da metodologia proposta (aplicativo de GEOBIA, aplicativo estatístico e aplicativo GIS), tal processo é passível de ajuste para a execução em um único ambiente, em um fluxo único de trabalho, o que pode ser viabilizado mediante o desenvolvimento de pacote no aplicativo eCognition 9.

Outro fator de interesse foi a aplicação de algoritmos automáticos para a definição do fator escala do processo de segmentação. Os parâmetros obtidos diretamente a partir do ESP, permitiram a determinação de forma objetiva do melhor valor de escala a ser utilizado, sendo necessário apenas ajustes quanto aos atributos de forma e compacidade. Os resultados obtidos para a segmentação, baseados em parâmetros gerados com a utilização de algoritmos automáticos, mostraram-se adequados e aplicáveis às características heterogêneas dos alvos do Bioma. Tais resultados são coerentes com os obtidos por Belgiu \& Dragut (2014) e por Bertani et al. (2013). Esses estudos apontaram que algoritmos de segmentação automáticos, como os utilizados pelo ESP, podem ser tão eficazes quanto procedimentos supervisionados. A utilização dessa ferramenta foi importante para a obtenção de objetos naturais ou antrópicos semanticamente consistentes.

Os resultados obtidos para o mapeamento sugerem grande variação no uso e cobertura da terra entre os anos de 1985, 1995 e 2002, com taxas de desmatamento superiores àquelas observadas em períodos posteriores pelos órgãos oficiais. Destaca-se a taxa de desmatamento do período entre 1995 e 2002, as quais foram mais de 2 vezes superiores às observadas entre 2002 e 2008 (IBAMA, 2009) e 4 vezes maior do que a do período entre 2010 e 2011 (IBAMA, 2015).

A partir do mapeamento foi possível a identificação de duas grandes frentes de desmatamento no período, além de três outros polos de atração (Figura 37). Uma das frentes de desmatamento situou-se entre a região centro/leste dos estados de Mato Grosso, Mato Grosso do Sul e a região sudoeste do estado de Goiás, resultando na conversão de grandes 
porções de habitat natural na região. Outro grande vetor de desmatamento foi observado na região centro/oeste do estado de Goiás, indo em direção aos estados de Tocantins e Maranhão. Três outros destacados polos de atração desse tipo de evento foram a região próxima ao Distrito Federal, oeste do estado da Bahia e centro-norte do estado de Minas Gerais.

Os mapeamentos apresentaram padrões de qualidade elevados e muito similares entre os anos. Para o ano de 1985, a concordância global entre informações do mapeamento e a verdade estabelecida foi de 91\%, com Índice Kappa de 87\%, enquanto para o ano de 1995 esses valores foram de $90 \%$ e $85 \%$, respectivamente. O padrão de qualidade atingido está de acordo com aquele observado em mapeamentos oficiais (MMA, 2015; Sano, Rosa, Brito, Jorge L S, et al., 2010).

Testes de compatibilidade entre os resultados obtidos a partir da metodologia adotada e aquela aplicada ao mapeamento de referência, apontam grande concordância entre os produtos gerados. Considerando-se todas as classes mapeadas, o Índice Global de Acurácia alcançou valor médio de $88 \%$ e o Índice Kappa $q$ obteve um valor médio de $82 \%$ entre as cenas utilizadas para teste. Estimou-se a partir do teste realizado que o mapeamento apresentado para os anos de 1985 e 1995 pode ter área natural com subestimativa da ordem de $6 \%$, tendo como parâmetro o mapeamento de referência. A subestimação tem impacto sobre as taxas de desmatamento do período, resultando em menores taxas do que se esperaria caso o trabalho houvesse sido executado no âmbito daquele programa. Trata-se, portanto, de uma avaliação mais conservadora.

Ainda que a subestimativa do mapeamento realizado neste trabalho em relação ao PMDBBS deva ser objeto de futuras correções, é necessário considerar que os resultados apresentados pelo PMDBBS, quando comparados com aqueles obtidos a partir de mapeamento mais recente, o TerraClass Cerrado (MMA, 2015), traz indicação de que pode ter havido uma superestimativa do desmatamento por parte da primeira iniciativa mencionada. Segundo dados, PMDBBS $49 \%$ da área do Cerrado haviam sido convertidas até o ano de 2011, enquanto o TerraClass Cerrado indicou que 44\% do território do Cerrado havia sido convertido até o ano de 2013 (MMA, 2015). Em função de divergência entre os mapeamentos oficiais mencionados, é interessante a realização de etapa que também avalie a metodologia aplicada em relação ao produto gerado pelo TerraClass, bem como a identificação das principais fontes erro entre os três mapeamentos mencionados.

Considerando-se que o presente trabalho teve como objetivo a geração de produto compatível em relação ao PMDBBS, a despeito do indicado e de forma independente, sugere- 
se promover o aprimoramento da compatibilidade entre o mapeamento de referência e o obtido neste trabalho, o qual já apresenta nível elevado, conforme observado na Seção 3.3. Planeja-se a inclusão de etapa posterior à metodologia aplicada com vistas a se identificar tipos de feições em que o processo de interpretação foi divergente, sendo executada a inspeção individual dos objetos e a eventual correção da classificação de acordo com o parâmetro adotado. O processo, realizado a posteriori, deve reduzir de forma importante a diferença total de $6 \%$ estimada para as classes antrópico e natural, além de promover o aprimoramento da qualidade geral do mapeamento.

Em relação à avaliação de compatibilidade com o TerraClass Cerrado, considerando que o programa realizou a classificação em três superclasses (antrópico, natural e corpo d'água), composta por diferentes subclasses (eg. agricultura perene e área urbana, pertencentes à superclasse antrópico), sugere-se que a metodologia aplicada seja comparada não só em relação às superclasses, mas também seja testada em relação a seu desempenho na identificação de um maior número de subclasses, a exemplo do aplicado pelo TerraClass Cerrado. 


\section{CONCLUSÕES}

O monitoramento de alterações no Uso e Cobertura da Terra (Land-Use and LandCover Change - LULC) e a geração de produtos cartográficos relacionados são elementos de grande importância para se compreender processos, identificar padrões e modelar fenômenos relacionados à dinâmica de desmatamento, passos fundamentais para a geração de conhecimento e para a tomada de decisão no âmbito governamental e do planejamento territorial.

No Cerrado, área de interesse deste estudo, dados oficiais de uso e cobertura da terra estão disponíveis apenas para períodos posteriores a 2002, permitindo apenas a formação de séries históricas curtas, o que dificulta a realização de análises ou a modelagem de processos relacionados ao desmatamento, sendo relevante a obtenção de dados para períodos históricos.

Além da obtenção de produtos cartográficos para outros períodos, extendendo-se série históricas existentes, televante também é o desenvolvimento de novas metodologias que facilitem a aquisição de informações cartográficas relacionadas ao LULC. Essas contribuem para a aquisição dos resultados imediatos pretendidos e, também, são importantes para uma maior eficiência no atendimento de demandas de diversas áreas de aplicação. Destacam-se nesse contexto novas abordagens e ferramentas, como é o caso da Análise de Imagem Baseada em Objetos - GEOBIA.

No presente capítulo, objetivou-se propor e aplicar metodologia de mapeamento voltado ao uso e cobertura da terra com a utilização de GEOBIA, levando em conta as características específicas do Cerrado. Objetivou-se, também, a obtenção de mapeamento temático com as classes antrópico, natural e corpo d'água para os anos de 1985 e 1995 abrangendo toda a região delimitada pelo Cerrado.

No estudo demonstrou-se a importância potencial da utilização de ferramentas de GEOBIA para iniciativas que visem mapear ou identificar eventos de desmatamento, tendo como base imagens de média resolução espacial (LANDSAT 5 TM). A metodologia proposta teve como etapas principais: o reconhecimento de atributos capazes de identificar corretamente as feições de interesse; a obtenção de objetos e atributos; a realização de análise de agrupamento; e a classificação de grupos de feições para as classes finais de interesse mediante interpretação visual. A metodologia permitiu a obtenção de dados cartográficos com elevado nível de qualidade e de forma ágil. 
O trabalho teve como principais desafios: a grande extensão da área de estudo; a grande diversidade de feições em cada uma das classes, relacionada especialmente à heterogeneidade ambiental e variações quanto a aspectos culturais, sociais e econômicos ocorrentes na região com impacto sobre as feições antrópicas; o grande volume de dados a ser analisado. Ponto central na superação desses desafios foi a integração entre a mineração de dados e a análise de agrupamento. Em conjunto, a metodologia proposta possibilitou a análise de grande quantidade de informações, identificação de atributos relevantes para o agrupamento de feições, e a grande agilidade do processo de classificação.

Os produtos gerados indicam que em 1985 o Cerrado era recoberto majoritariamente por áreas naturais, ocupando $75.66 \%$ de sua totalidade, enquanto áreas pertencentes à classe antrópica ocupavam 23,69\% e corpo d'água $0.65 \%$. No período entre 1985 e 2002 houve a supressão de $19,77 \%$ de áreas naturais do Cerrado, em um total de $404.482 \mathrm{~km}^{2}$, com as taxas de desmatamento mais elevadas da série histórica disponível.

No período analisado foram identificadas duas grandes frentes de desmatamento, além de três polos de atração principais. Uma das frentes de desmatamento situou-se entre a região centro/leste dos estados de Mato Grosso, Mato Grosso do Sul e a região sudoeste do estado de Goiás; outro grande vetor de desmatamento foi observado na região centro/oeste do estado de Goiás, indo em direção aos estados de Tocantins e Maranhão. Polos de atração foram identificados na região próxima ao Distrito Federal, oeste do estado da Bahia e centronorte do estado de Minas Gerais.

Teste realizado sugere grande concordância entre os produtos gerados por meio da metodologia adotada e dos resultados apresentados por órgãos oficiais. Divergências observadas, no percentual de 6\%, referem-se à subestimação da área natural, impactando, também, as taxas de desmatamento no período. Os resultados obtidos neste trabalho mostramse ligeiramente mais conservadores do que o mapeamento oficial de referência, sendo prevista etapa futura para o aprimoramento do mapeamento realizado.

Além da revisão do mapeamento, sugerimos neste trabalho: a comparação dos resultados com aqueles obtidos pelo TerraClass Cerrado, de forma semelhante ao que foi realizado com o PMDBBS; a avaliação do desempenho da metodologia proposta para a identificação de um maior número de classes; o desenvolvimento de ferramenta que agrupe em um único ambiente o fluxo de trabalho proposto; bem como a realização de testes para a seleção de solução ótima relacionada à etapa estatística de análise de agrupamento. 


\section{REFERÊNCIAS}

ALLEN, J. C.; BARNES, D. F.; BARNEST, D. F. The Causes of Deforestation Developing Countries. Annals of the Association of American Geographers, v. 75, n. 2, p. 163-184, 2013.

APLIN, P.; SMITH, G. M. Advances in Object-Based Image Classification. The International Archives of the Photogrammetry, Remote Sensing and Spatial Information Sciences, v. XXXVII, n. B7, 2008.

ARVOR, D. et al. Advances in geographic object-based image analysis with ontologies: a review of main contributions and limitations from a remote sensing perspective. ISPRS Journal of Photogrammetry and Remote Sensing, v. 82, p. 125-137, 2013.

BAATZ, M.; SCHÄPE, A. Multiresolution segmentation - an optimization approach for high quality multi-scale image segmentation. In: STROBL, J.; BLASCHKE, T.; GRIESEBNER, G. (Eds.). . Angewandte Geographische Informationsverarbeitung XII. Heidelberg, Germany: Wichmann, 2000. p. 12-23.

BELGIU, M.; DRAGUT, L. Comparing supervised and unsupervised multiresolution segmentation approaches for extracting buildings from very high resolution imagery. ISPRS Journal of Photogrammetry and Remote Sensing, v. 96, p. 67-75, 2014.

BERTANI, T. D. C.; ROSSETTI, D. D. F; ALBUQUERQUE, P. C. G. Object-based classification of vegetation and terrain topography in Southwestern Amazonia (Brazil) as a tool for detecting ancient fluvial geomorphic features. Computers and Geosciences, v. 60, p. 41-50, 2013.

BISHOP, C. M. Pattern Recognition and Machine Learning. Cambridge, UK: Springer, 2006.

BLASCHKE, T. Object based image analysis for remote sensing. ISPRS Journal of Photogrammetry and Remote Sensing, v. 65, n. 1, p. 2-16, 2010.

Geographic Object-Based Image Analysis - Towards a new paradigm. ISPRS Journal of Photogrammetry and Remote Sensing, v. 87, p. 180-191, 2014.

BLASCHKE, T.; LANG, S.; MÖLLER, M. Object-based analysis of remote sensing data for landscape monitoring: Recent developments. Anais XII Simpósio Brasileiro de Sensoriamento Remoto, p. 2879-2885, 2005.

BREIMAN, L. et al. Classification and regression trees. Belmont: Chapman and Hall/CRC Press, 1984.

BROOK, B. W.; SODHI, N. S.; BRADSHAW, C. J. A. Synergies among extinction drivers under global change. Trends in ecology \& evolution, v. 23, n. 8, p. 453-60, ago. 2008.

BYRT, T.; BISHOP, J.; CARLIN, J. B. Bias, prevalence and kappa. Journal of Clinical Epidemiology, v. 46, n. 5, p. 423-429, 1993.

CASTILLA, G.; HAY, G. J. Image objects and geographic objects. In: BLASCHKE, T.; LANG, S.; HAY, G. J. (Eds.). . Object-Based Image Analysis. Berlin: Springer Berlin Heidelberg, 2008. p. 91-110.

CICCHETTI, D. V; FEINSTIEN, A R. High agreement but low Kappa: I. the problems of two paradoxes. Journal of Clinical Epidemiology, v. 43, n. 6, p. 543-549, 1990.

COHEN, J. A Coefficient of Agreement for Nominal Scales. Educational and Psychological Measurement, v. 20, p. 37-46, 1960.

COMBER, A.; FISHER, P.; WADSWORTH, R. What is land cover? Environment and 
Planning B-Planning \& Design, v. 32, n. 2, p. 199-209, 2005.

CONGALTON, R. G. Putting the Map Back in Map Accuracy Assessment. In: LUNNETA, R. S.; LYON, J. G. (Eds.). . Remote Sensing and GIS Accuracy Assessment. [s.1.] CRS Press, 2004. p. 1-12.

CUNNINGHAM, M. More than Just the Kappa Coefficient : A Program to Fully Characterize Inter-Rater Reliability between Two Raters. Sgf 2009, p. 1-7, 2009.

DRAGUT, L. et al. ESP: a tool to estimate scale parameter for multiresolution image segmentation of remotely sensed data. International Journal of Geographical Information Science, v. 24, n. 6, p. 859-871, 2010.

EITEN, G. The Cerrado Vegetation of Brazil. The Botanical Review, v. 38, n. 2, p. 201-327, 1972.

FAYYAD, U.; PIATETSKY-SHAPIRO, G.; SMYTH, P. From Data Mining to Knowledge Discovery in. p. 37-54, 1996.

FERREIRA, L. G.; FERREIRA, M. E.; et al. Dinâmica agrícola e desmatamentos em áreas de Cerrado: uma análise a partir de dados censitários e imagens de resolução moderada. Revista Brasileira de Cartografia, v. 61, n. 2, p. 117-127, 2009.

FERREIRA, L. G.; ROCHA, J. C. S.; et al. Análise sazonal da qualidade e abrangência de imagens MODIS índice de vegetação para o bioma Cerrado. Anais XIV Simpósio Brasileiro de Sensoriamento Remoto, p. 1347-1352, 2009.

FERREIRA, N. C. et al. An operational deforestation mapping system using MODIS data and spatial context analysis. International Journal of Remote Sensing, v. 1, p. 47-62, 2007.

FISHER, P.; COMBER, A.; WADSWORTH, R. Land Use and Land Cover: Contradiction or Complement. Chichester: Wiley, 2005.

FOLEY, J. A. Global Consequences of Land Use. Science, v. 309, n. 5734, p. 570-574, 2005.

FORTIN, M. J. et al. Issues related to the detection of boudaries. Landscape Ecology, v. 15, p. 453-466, 2000.

GEIST, H. J.; LAMBIN, E. F. Proximate Causes and Underlying Driving Forces of Tropical Deforestation. BioScience, v. 52, n. 2, p. 143-150, 2002.

GWET, K. L. Handbook of inter-rater reliability: The definitive guide to measuring the extent of agreement among raters. Gaithersburg, MD: Advanced Analytics, 2014.

HAIR, J. F. et al. Análise Multivariada de Dados. 6a ed. Porto Alegre: Bookman, 2009.

HAWKINS, D. M. The Problem of Overfitting. Journal of Chemical Information and Computer Sciences, v. 44, n. 1, p. 1-12, 2004.

HAY, G. J.; CASTILLA, G. Object-based image analysis: strengths, weaknesses, opportunities and threats (SWOT). International Archives of Photogrammetry Remote Sensing and Spatial Information Sciences, v. 36, p. 4, 2006.

HAY, G. J.; CASTILLA, G. Geographic Object-Based Image Analysis (GEOBIA): A new name for a new discipline. In: BLASCHKE, T.; LANG, S.; HAY, G. J. (Eds.). . Object-Based Image Analysis. Berlin: Springer Berlin Heidelberg, 2008. p. 75-89.

IBAMA. Relatorio Técnico de monitoramento do desmatamento no Bioma Cerrado, 2002 a 2008: Dados Revisados. Relatório Técnico, p. 01-69, 2009.

Relatorio Técnico de monitoramento do desmatamento no Bioma Cerrado, 2008 a 2009.

Relatório Técnico, p. 01-55, 2011a. 
Relatorio Técnico de monitoramento do desmatamento no Bioma Cerrado, 2009 a 2010. Relatório Técnico, p. 01-65, 2011b.

Relatorio Técnico de Monitoramento do Desmatamento nos Biomas Brasileiros Por Satélite: Cerrado 2010-2011. Relatório Técnico, p. 1-16, 2015.

Projeto de Monitoramento do Desmatamento dos Biomas Brasileiros por Satélite PMDBBS: Mapa de áreas desmatadas no Biomas Cerrado - 2002 a 2011. Disponível em: $<\mathrm{http} / / /$ siscom.ibama.gov.br/monitora_biomas/PMDBBS - CERRADO.html>. Acesso em: 1 maio. 2016.

IBGE. Mapa de Biomas do Brasil. Disponível em: <http://www.ibge.gov.br/home/presidencia/noticias/21052004biomas.shtm>. Acesso em: 8 jan. 2013.

Manual Técnico da Vegetação Brasileira. Rio de Janeiro: IBGE, 2012.

INPE. Projeto de Estimativa do Desflorestamento Bruto da Amazônia - PRODES. Disponível em: <http://www.obt.inpe.br/prodes/index.php>. Acesso em: 30 set. 2015.

JAIN, R.; KASTURI, R.; SCHUNCK, B. G. Texture. In: Machine Vision. Cambridge, US: MIT Press and McGraw-Hill Inc, 1995. p. 234-248.

JENSEN, J. R. Remote Sensing of the Environment: An Earth Resource Perspective. Upper Saddle River: Prentice Hall, 2007.

JHONNERIE, R. et al. Random forest classification for mangrove land cover mapping using Landsat 5 TM and ALOS PALSAR imageries. Procedia Environmental Sciences, v. 24, p. 215-221, 2015.

KIERSCH, B. Land use impacts on water resources: a literature review. Discussion paper: Land-Water Lingkages in Rural Watersheds - FAO, v. 1, n. 1, p. 1-10, 2000.

KLINK, C. A.; MACHADO, R. B. Conservation of the Brazilian Cerrado. Conservation Biology, v. 19, p. 707-713, 2005.

LAMBIN, E. F. et al. The causes of land-use and land-cover change: moving beyond the myths. Global Environmental Change, v. 11, p. 261-269, 2001.

LANDIS, J. R.; KOCH, G. G. The Measurement of Observer Agreement for Categorical. Biometrics, v. 33, n. 1, p. 159-174, 1977.

LI, X. Kappa - A Critical Review. Uppsala: [s.n.]. Disponível em: <http://uu.divaportal.org/smash/get/diva2:326034/FULLTEXT01.pdf>.

MAHMOOD, R. et al. Impacts of Land Use / Land Cover Change on Climate and Future Research Priorities. American Meteorological Society, v. 91, n. 1, p. 37-46, 2010.

MATHER, P.; TSO, B. Classification Methods for Remotely Sensed Data. Boca Raton: CRC Press, 2009.

MAXWELL, A. E. Comparing the classification of subjects by two independent judges. British Journal of Psychiatry, v. 116, n. 535, p. 651-655, 1970.

MENESES, P. R. Princípios de Sensoriamento Remoto. In: MENESES, P. R.; ALMEIDA, T. (Eds.). . Introdução ao Processamento de Imagens de Sensoriamento Remoto. Brasília, DF: UnB, 2012. p. 1-31.

MMA. Mapeamento de Cobertura Vegetal do Bioma Cerrado - Relatorio Final. Edital Probio 02/2004, p. 01-93, 2007.

Plano de Ação para Prevenção e Controle do Desmatamento e das Queimadas - 
Cerrado. Brasília: MMA, 2011.

Mapeamento do Uso e Cobertura do Cerrado: Projeto TerraClass Cerrado (2013). Brasília: MMA, 2015.

NEWBOLD, T. et al. Has land use pushed terrestrial biodiversity beyond the planetary boundary? A global assessment. Science2, v. 353, n. 6296, 2016.

OZELKAN, E.; CHEN, G.; BERK, B. International Journal of Applied Earth Observation and Geoinformation Multiscale object-based drought monitoring and comparison in rainfed and irrigated agriculture from Landsat 8 OLI imagery. International Journal of Applied Earth Observations and Geoinformation, v. 44, p. 159-170, 2016.

QUINLAN, J. R. Induction of Decision Trees. Machine Learning, v. 1, p. 81-106, 1986.

C4.5: Programs for Machine Learning. San Mateo: Morgan Kaufmann, 1993.

RIBEIRO, J. F.; WALTER, B. M. T. Fitofisionomias do bioma cerrado. In: SANO, S. M.; ALMEIDA, S. P. (Eds.). . Cerrado: ambiente e flora. Brasília: Embrapa-CPAC, 1998. p. 89166.

As principais fitofisionomias do bioma Cerrado. In: SANO, S. M.; ALMEIDA, S. P. DE; RIBEIRO, J. F. (Eds.). . Cerrado: Ecologia e Flora. Brasília: Embrapa Informação Tecnológica, 2008. p. 153-212.

ROCHA, G. F. et al. Detecção de desmatamentos no Bioma Cerrado entre 2002 e 2009: Padroes, Tendências e Impactos. Revista Brasileira de Cartografia, v. 63, n. 3, p. 341-349, 2011.

ROKACH, L.; MAIMON, O. Data Mining with Decision Trees: Theory and Applications. River Edge, SG: World Scientific Pub Co Inc, 2008.

ROSSITER, D. G. Technical Note: Statistical methods for accuracy assesment of classified thematic maps. GeoInformation Science, p. 1-46, 2004.

SANO, E. E. et al. Mapeamento de Cobertura Vegetal do Bioma Cerrado: estratégias e resultados. Documentos/Embrapa Cerrados, v. 190, p. 33p., 2007.

SANO, E. E.; ROSA, R.; BRITO, J. L. S.; et al. Land cover mapping of the tropical savanna region in Brazil. Environment Monitoring Assessment, v. 166, p. 113-124, 2010.

SANO, E. E.; ROSA, R.; BRITO, J. L. S.; et al. Mapeamento do Uso do Solo e Cobertura Vegetal Bioma Cerrado Ano-Base 2002. Brasília: MMA/SBF, 2010.

SCHOWENGERDT, R. A. Remote Sensing: Models and Methods for Image Processing. 3rd. ed. Burlington: Academic Press, 2007.

SILVA, J. F. et al. Spatial heterogeneity, land use and conservation in the cerrado region of Brazil. Journal of Biogeography, p. 536-548, 2006.

SOARES-FILHO, B. et al. Cracking Brazil's Forest Code. Science, v. 344, p. 363-364, 2014.

SOHL, T.; SLEETER, B. Role of Remote Sensing for Land-Use and Land-Cover Change Modeling. In: GIRI, C. P. (Ed.). . Remote Sensing of Land Use and Land Cover. Boca Raton, FL: CRC Press, 2011. p. 225-239.

STEELE, B. M. Land Cover Mapping Using Combination Classifiers. [s.l.] NASA, 2015. Disponível em: 〈https://www.servirglobal.net>.

STEHMAN, S. V. Selecting and interpreting measures of thematic classification accuracy. Remote Sensing of Environment, v. 62, n. 1, p. 77-89, 1997.

STEHMAN, S. V.; CZAPLEWSKI, R. L. Design and Analysis for Thematic Map Accuracy 
Assessment - an application of satellite imagery. Remote Sensing of Environment, v. 64, n. January, p. 331-344, 1998.

STORY, M.; CONGALTON, R. G. Accuracy assessment: A user's perspective. Photogrammetric Engineering and Remote Sensing, v. 52, p. 397-399, 1986.

STUART, A. A Test for Homogeneity of the Marginal Distributions in a Two-Way Classification. Biometryka, v. 42, n. 3, p. 412-416, 1955.

UTGOFF, P. E. Incremental Induction of Decision Trees. Machine Learning, v. 4, n. 2, p. 161-186, 1989.

VALERIANO, D. DE M. et al. Metodologia do sistema DETER - B (Sistema de Detecção do Desmatamento e Alterações na Cobertura Florestal em Tempo Quase Real) mapeamento de alertas com imagens dos sensores awifs-resourcesat-2 e wfi-cbers-4. São José dos Campos, Brasil: INPE, 2016.

VIEIRA, M. A. et al. Object Based Image Analysis and Data Mining applied to a remotely sensed Landsat time-series to map sugarcane over large areas. Remote Sensing of Environment, v. 123, p. 553-562, 2012.

WALTER, B. M. T.; CARVALHO, A. M. DE; RIBEIRO, J. F. O Conceito de Savana e de seu Componente Cerrado. In: SANO, S. M.; ALMEIDA, S. P. DE; RIBEIRO, J. F. (Eds.). . Cerrado: Ecologia e Flora. Brasília, DF: Embrapa Informação Tecnológica, 2008. p. 19-45.

WOODCOCK, C. E.; HARWARD, V. G. Nested-hierarchical scene models and image segmentation. International Journal of Remote Sensing, v. 13, p. 3167-3187, 1992.

WOODCOCK, C. E.; STRAHLER, A. H. The factor of scale in remote sensing. Remote Sensing of Environment, v. 21, n. 3, p. 311-332, 1987.

YANG, X. T.; LIU, H.; GAO, X. Land cover changed object detection in remote sensing data with medium spatial resolution. International Journal of Applied Earth Observation and Geoinformation, v. 38, p. 129-137, 2015. 


\section{APÊNDICES}

- Apêndice 1 - Imagens LANDSAT 5 TM selecionadas (órbita/ponto) para serem utilizadas na do processo de definição de atributos.

- Apêndice 2 - Listagem de atributos testados, apresentando o número de ocorrências de sua utilização entre as 20 imagens classificadas, sua importância média e a importância ponderada pelo número de ocorrências.

- Apêndice 3 - Imagens LANDSAT 5 TM selecionadas (órbita/ponto) para a realização do mapeamento.

- Apêndice 4 - Algoritmo para processamento de dados R, com a obtenção de cluster.

- Apêndice 5 - Algoritmos utilizados para a obtenção de métricas de qualidade do mapeamento.

- Apêndice 6 - Variação na área entre os anos por unidade da federação.

- Apêndice 7 - Os 100 municípios com maior taxa de desmatamento para o período entre 1985 e 2002. 
Apêndice 1 - Imagens LANDSAT 5 TM selecionadas (órbita/ponto) para serem utilizadas na do processo de definição de atributos.

\begin{tabular}{ccc}
\hline Órbita & Ponto & Data \\
\hline 218 & 72 & $07 / 07 / 1995$ \\
219 & 69 & $30 / 06 / 1996$ \\
219 & 73 & $29 / 05 / 1996$ \\
220 & 63 & $22 / 08 / 1995$ \\
220 & 67 & $21 / 06 / 1996$ \\
220 & 71 & $21 / 06 / 1996$ \\
221 & 64 & $29 / 08 / 1995$ \\
221 & 66 & $28 / 06 / 1996$ \\
221 & 69 & $26 / 06 / 1995$ \\
221 & 72 & $27 / 05 / 1996$ \\
222 & 68 & $19 / 06 / 1996$ \\
222 & 70 & $03 / 07 / 1995$ \\
223 & 67 & $26 / 06 / 1996$ \\
223 & 69 & $12 / 07 / 1996$ \\
223 & 72 & $08 / 06 / 1995$ \\
224 & 72 & $17 / 06 / 1996$ \\
224 & 73 & $17 / 06 / 1996$ \\
225 & 70 & $06 / 06 / 1995$ \\
226 & 75 & $02 / 08 / 1996$ \\
228 & 70 & $13 / 06 / 1996$ \\
\hline
\end{tabular}


Apêndice 2 - Listagem de atributos testados, apresentando o número de ocorrências de sua utilização entre as 20 imagens classificadas, sua importância média e a importância ponderada pelo número de ocorrências.

\begin{tabular}{|c|c|c|c|c|}
\hline Tipo de Atributo & Atributo & Ocorrência & Importância & $\begin{array}{r}\text { Importância } \\
\text { ponderada }\end{array}$ \\
\hline Relacionado ao Pixel & Ratio Layer 1 & 11 & 0.09 & 41.59 \\
\hline Índice Espectral & GARI & 12 & 0.07 & 35.95 \\
\hline Relacionado ao Objeto & Brightness & 9 & 0.08 & 30.61 \\
\hline Índice Espectral & Clay Ratio & 8 & 0.03 & 11.54 \\
\hline Relacionado ao Pixel & Max. diff. & 6 & 0.03 & 8.71 \\
\hline Índice Espectral & ARVI & 4 & 0.04 & 7.49 \\
\hline Relacionado ao Objeto & Mean Layer 2 & 5 & 0.03 & 7.30 \\
\hline Relacionado ao Objeto & quantile[50](Layer 4) & 6 & 0.02 & 6.34 \\
\hline Relacionado ao Pixel & Ratio Layer 2 & 6 & 0.02 & 6.34 \\
\hline Relacionado ao Pixel & Ratio Layer 6 & 5 & 0.02 & 5.31 \\
\hline Forma & Compactness & 8 & 0.01 & 5.25 \\
\hline Textura & GLCM Mean Layer 2 (all dir.) & 7 & 0.01 & 4.61 \\
\hline Relacionado ao Objeto & quantile[50](Layer 5) & 7 & 0.01 & 4.61 \\
\hline IHS & $\begin{array}{l}\text { Hue(R='Layer 3',G='Layer 2',B='Layer } \\
\text { 1') }\end{array}$ & 4 & 0.02 & 4.28 \\
\hline Relacionado ao Objeto & Mean Layer 3 & 4 & 0.02 & 4.28 \\
\hline Relacionado ao Pixel & Ratio Layer 3 & 4 & 0.02 & 4.28 \\
\hline Forma & Asymmetry & 5 & 0.01 & 3.32 \\
\hline Textura & GLCM Dissimilarity (all dir.) & 5 & 0.01 & 3.32 \\
\hline Relacionado ao Objeto & Mean Layer 1 & 5 & 0.01 & 3.32 \\
\hline Relacionado ao Objeto & quantile[50](Layer 6) & 5 & 0.01 & 3.32 \\
\hline Textura & GLCM Contrast Layer 3 (all dir.) & 4 & 0.01 & 2.68 \\
\hline Textura & GLCM Homogeneity Layer 4 (all dir.) & 4 & 0.01 & 2.68 \\
\hline Índice Espectral & PSRI & 4 & 0.01 & 2.68 \\
\hline Relacionado ao Objeto & quantile[50](Layer 1) & 4 & 0.01 & 2.68 \\
\hline Relacionado ao Pixel & StdDev. to neighbor pixels Layer 3 (3) & 4 & 0.01 & 2.68 \\
\hline Textura & GLCM Mean Layer 1 (all dir.) & 7 & 0.00 & 2.62 \\
\hline Textura & GLCM Ang. 2nd moment (all dir.) & 3 & 0.01 & 2.03 \\
\hline Textura & GLCM Mean Layer 3 (all dir.) & 3 & 0.01 & 2.03 \\
\hline Índice Espectral & GNDVI & 3 & 0.01 & 2.03 \\
\hline IHS & $\begin{array}{l}\text { HSI Transformation } \\
\text { Saturation }(\mathrm{R}=\text { Layer } 3, \mathrm{G}=\text { Layer } \\
\text { 2,B=Layer } 1)\end{array}$ & 3 & 0.01 & 2.03 \\
\hline Índice Espectral & iron_ratio & 3 & 0.01 & 2.03 \\
\hline Relacionado ao Objeto & Mean Layer 5 & 3 & 0.01 & 2.03 \\
\hline Textura & GLCM Entropy Layer 2 (all dir.) & 3 & 0.01 & 1.48 \\
\hline Forma & Shape index & 3 & 0.01 & 1.47 \\
\hline Relacionado ao Pixel & StdDev. to neighbor pixels Layer 4 (3) & 3 & 0.01 & 1.43 \\
\hline Textura & GLCM Entropy Layer 5 (all dir.) & 3 & 0.01 & 1.42 \\
\hline Textura & GLCM Homogeneity Layer 5 (all dir.) & 3 & 0.01 & 1.42 \\
\hline Índice Espectral & VARI & 2 & 0.01 & 1.66 \\
\hline Relacionado ao Pixel & StdDev. to neighbor pixels Layer 2 (3) & 2 & 0.01 & 1.55 \\
\hline Índice Espectral & MSI & 2 & 0.01 & 1.49 \\
\hline
\end{tabular}




\begin{tabular}{|c|c|c|c|c|}
\hline Índice Espectral & NMDI & 2 & 0.01 & 1.45 \\
\hline Relacionado ao Objeto & Standard deviation Layer 3 & 2 & 0.01 & 1.44 \\
\hline Textura & GLCM Correlation Layer 5 (all dir.) & 2 & 0.01 & 1.39 \\
\hline Relacionado ao Objeto & Mean Layer 4 & 2 & 0.01 & 1.32 \\
\hline Textura & GLCM StdDev Layer 1 (all dir.) & 2 & 0.01 & 1.3 \\
\hline Relacionado ao Objeto & Standard deviation Layer 6 & 2 & 0.01 & 1.28 \\
\hline Relacionado ao Pixel & Ratio Layer 5 & 2 & 0.01 & 1.23 \\
\hline Textura & GLCM Correlation Layer 2 (all dir.) & 2 & 0.01 & 1.18 \\
\hline Textura & $\begin{array}{l}\text { GLCM Ang. 2nd moment Layer } 2 \text { (all } \\
\text { dir.) }\end{array}$ & 2 & 0.01 & 1.13 \\
\hline Índice Espectral & NBR & 2 & 0.01 & 1.07 \\
\hline Textura & GLCM Entropy Layer 1 (all dir.) & 2 & 0.01 & 1.05 \\
\hline Relacionado ao Pixel & Min. pixel value Layer 5 & 2 & 0.01 & 0.99 \\
\hline Relacionado ao Objeto & quantile[50](Layer 2) & 5 & $<0.01$ & 1.45 \\
\hline Relacionado ao Pixel & Max. pixel value Layer 4 & 4 & $<0.01$ & 1.72 \\
\hline Relacionado ao Objeto & Skewness Layer 1 & 4 & $<0.01$ & 1.64 \\
\hline Textura & GLCM Homogeneity (all dir.) & 4 & $<0.01$ & 1.16 \\
\hline Relacionado ao Pixel & StdDev. to neighbor pixels Layer 1 (3) & 4 & $<0.01$ & 1.13 \\
\hline Textura & GLCM Entropy (all dir.) & 4 & $<0.01$ & 1.11 \\
\hline Relacionado ao Objeto & Standard deviation Layer 1 & 3 & $<0.01$ & 1.22 \\
\hline Textura & GLCM Entropy Layer 4 (all dir.) & 3 & $<0.01$ & 1.02 \\
\hline Textura & GLCM Correlation Layer 3 (all dir.) & 3 & $<0.01$ & 0.98 \\
\hline Relacionado ao Objeto & Skewness Layer 2 & 3 & $<0.01$ & 0.97 \\
\hline Relacionado ao Pixel & Min. pixel value Layer 4 & 3 & $<0.01$ & 0.84 \\
\hline Textura & GLCM Mean Layer 4 (all dir.) & 3 & $<0.01$ & 0.8 \\
\hline Índice Espectral & GVI & 1 & 0.01 & 0.61 \\
\hline Relacionado ao Objeto & Standard deviation Layer 4 & 1 & 0.01 & 0.59 \\
\hline Relacionado ao Pixel & Ratio Layer 4 & 1 & 0.01 & 0.59 \\
\hline Índice Espectral & SIPI & 1 & 0.01 & 0.57 \\
\hline Relacionado ao Pixel & Contrast to neighbor pixels Layer 6 (3) & 1 & 0.01 & 0.56 \\
\hline Relacionado ao Pixel & Max. pixel value Layer 2 & 1 & 0.01 & 0.56 \\
\hline Relacionado ao Pixel & Contrast to neighbor pixels Layer 5 (3) & 2 & $<0.01$ & 0.97 \\
\hline Textura & GLCM Correlation Layer 4 (all dir.) & 2 & $<0.01$ & 0.94 \\
\hline Relacionado ao Pixel & Min. pixel value Layer 6 & 2 & $<0.01$ & 0.9 \\
\hline Relacionado ao Pixel & Max. pixel value Layer 5 & 2 & $<0.01$ & 0.9 \\
\hline Índice Espectral & EVI & 2 & $<0.01$ & 0.89 \\
\hline Textura & GLCM StdDev Layer 3 (all dir.) & 2 & $<0.01$ & 0.65 \\
\hline Textura & GLCM Mean Layer 6 (all dir.) & 2 & $<0.01$ & 0.62 \\
\hline Textura & GLCM Dissimilarity Layer 4 (all dir.) & 2 & $<0.01$ & 0.6 \\
\hline Relacionado ao Objeto & Skewness Layer 6 & 2 & $<0.01$ & 0.6 \\
\hline Textura & GLCM Mean Layer 5 (all dir.) & 2 & $<0.01$ & 0.6 \\
\hline Textura & GLCM StdDev Layer 2 (all dir.) & 2 & $<0.01$ & 0.59 \\
\hline Relacionado ao Objeto & Mean Layer 6 & 2 & $<0.01$ & 0.58 \\
\hline Relacionado ao Objeto & Standard deviation Layer 2 & 2 & $<0.01$ & 0.57 \\
\hline Relacionado ao Pixel & Min. pixel value Layer 1 & 2 & $<0.01$ & 0.56 \\
\hline Relacionado ao Objeto & Skewness Layer 4 & 2 & $<0.01$ & 0.56 \\
\hline Relacionado ao Pixel & StdDev. to neighbor pixels Layer 5 (3) & 1 & $<0.01$ & 0.55 \\
\hline
\end{tabular}




\begin{tabular}{|c|c|c|c|c|}
\hline Textura & $\begin{array}{l}\text { GLCM Ang. 2nd moment Layer } 6 \text { (all } \\
\text { dir.) }\end{array}$ & 1 & $<0.01$ & 0.54 \\
\hline Textura & $\begin{array}{l}\text { GLCM Ang. 2nd moment Layer } 5 \text { (all } \\
\text { dir.) }\end{array}$ & 1 & $<0.01$ & 0.54 \\
\hline Índice Espectral & BAI & 1 & $<0.01$ & 0.53 \\
\hline Textura & GLCM StdDev Layer 4 (all dir.) & 1 & $<0.01$ & 0.5 \\
\hline Textura & GLCM Contrast Layer 6 (all dir.) & 1 & $<0.01$ & 0.49 \\
\hline Relacionado ao Pixel & Min. pixel value Layer 2 & 1 & $<0.01$ & 0.49 \\
\hline Textura & GLCM Homogeneity Layer 2 (all dir.) & 1 & $<0.01$ & 0.47 \\
\hline Relacionado ao Pixel & Max. pixel value Layer 1 & 1 & $<0.01$ & 0.41 \\
\hline Índice Espectral & NLI & 1 & $<0.01$ & 0.4 \\
\hline Textura & $\begin{array}{l}\text { GLCM Ang. 2nd moment Layer } 4 \text { (all } \\
\text { dir.) }\end{array}$ & 1 & $<0.01$ & 0.35 \\
\hline Relacionado ao Pixel & Min. pixel value Layer 3 & 1 & $<0.01$ & 0.35 \\
\hline Textura & GLCM StdDev (all dir.) & 1 & $<0.01$ & 0.34 \\
\hline Relacionado ao Pixel & Max. pixel value Layer 3 & 1 & $<0.01$ & 0.34 \\
\hline Textura & GLCM Mean (all dir.) & 1 & $<0.01$ & 0.33 \\
\hline Textura & GLCM StdDev Layer 5 (all dir.) & 1 & $<0.01$ & 0.32 \\
\hline Índice Espectral & DVI & 1 & $<0.01$ & 0.32 \\
\hline Textura & GLCM Homogeneity Layer 6 (all dir.) & 1 & $<0.01$ & 0.32 \\
\hline Textura & GLCM Correlation (all dir.) & 1 & $<0.01$ & 0.32 \\
\hline Índice Espectral & SLAVI & 1 & $<0.01$ & 0.31 \\
\hline Textura & GLCM Contrast Layer 5 (all dir.) & 1 & $<0.01$ & 0.31 \\
\hline Relacionado ao Objeto & Skewness Layer 3 & 1 & $<0.01$ & 0.31 \\
\hline Textura & GLCM Homogeneity Layer 3 (all dir.) & 1 & $<0.01$ & 0.31 \\
\hline Relacionado ao Objeto & Standard deviation Layer 5 & 1 & $<0.01$ & 0.31 \\
\hline Relacionado ao Objeto & quantile[50](Layer 3) & 1 & $<0.01$ & 0.31 \\
\hline Índice Espectral & TDVI & 0 & $<0.01$ & 0 \\
\hline Relacionado ao Pixel & StdDev. to neighbor pixels Layer 6 (3) & 0 & $<0.01$ & 0 \\
\hline Índice Espectral & SR & 0 & $<0.01$ & 0 \\
\hline Relacionado ao Objeto & Skewness Layer 5 & 0 & $<0.01$ & 0 \\
\hline Índice Espectral & SAVI & 0 & $<0.01$ & 0 \\
\hline Índice Espectral & RVI & 0 & $<0.01$ & 0 \\
\hline Índice Espectral & RDVI & 0 & $<0.01$ & 0 \\
\hline Índice Espectral & OSAVI & 0 & $<0.01$ & 0 \\
\hline Índice Espectral & NDWI & 0 & $<0.01$ & 0 \\
\hline Índice Espectral & NDVI & 0 & $<0.01$ & 0 \\
\hline Índice Espectral & NDSI & 0 & $<0.01$ & 0 \\
\hline Índice Espectral & NDII & 0 & $<0.01$ & 0 \\
\hline Índice Espectral & NDBI & 0 & $<0.01$ & 0 \\
\hline Índice Espectral & MSR & 0 & $<0.01$ & 0 \\
\hline Índice Espectral & MNLI & 0 & $<0.01$ & 0 \\
\hline Relacionado ao Pixel & Max. pixel value Layer 6 & 0 & $<0.01$ & 0 \\
\hline Índice Espectral & LAI & 0 & $<0.01$ & 0 \\
\hline Índice Espectral & IPVI & 0 & $<0.01$ & 0 \\
\hline IHS & $\begin{array}{l}\text { HSI Transformation Intensity }(\mathrm{R}=\text { Layer } \\
3, \mathrm{G}=\text { Layer } 2, \mathrm{~B}=\text { Layer } 1)\end{array}$ & 0 & $<0.01$ & 0 \\
\hline Índice Espectral & GRVI & 0 & $<0.01$ & 0 \\
\hline Textura & GLCM StdDev Layer 6 (all dir.) & 0 & $<0.01$ & 0 \\
\hline
\end{tabular}




\begin{tabular}{|c|c|c|c|c|}
\hline Textura & GLCM Homogeneity Layer 1 (all dir.) & 0 & $<0.01$ & 0 \\
\hline Textura & GLCM Entropy Layer 6 (all dir.) & 0 & $<0.01$ & 0 \\
\hline Textura & GLCM Entropy Layer 3 (all dir.) & 0 & $<0.01$ & 0 \\
\hline Textura & GLCM Dissimilarity Layer 6 (all dir.) & 0 & $<0.01$ & 0 \\
\hline Textura & GLCM Dissimilarity Layer 5 (all dir.) & 0 & $<0.01$ & 0 \\
\hline Textura & GLCM Dissimilarity Layer 3 (all dir.) & 0 & $<0.01$ & 0 \\
\hline Textura & GLCM Dissimilarity Layer 2 (all dir.) & 0 & $<0.01$ & 0 \\
\hline Textura & GLCM Dissimilarity Layer 1 (all dir.) & 0 & $<0.01$ & 0 \\
\hline Textura & GLCM Correlation Layer 6 (all dir.) & 0 & $<0.01$ & 0 \\
\hline Textura & GLCM Correlation Layer 1 (all dir.) & 0 & $<0.01$ & 0 \\
\hline Textura & GLCM Contrast Layer 4 (all dir.) & 0 & $<0.01$ & 0 \\
\hline Textura & GLCM Contrast Layer 2 (all dir.) & 0 & $<0.01$ & 0 \\
\hline Textura & GLCM Contrast Layer 1 (all dir.) & 0 & $<0.01$ & 0 \\
\hline Textura & GLCM Contrast (all dir.) & 0 & $<0.01$ & 0 \\
\hline Textura & $\begin{array}{l}\text { GLCM Ang. 2nd moment Layer } 3 \text { (all } \\
\text { dir.) }\end{array}$ & 0 & $<0.01$ & 0 \\
\hline Textura & $\begin{array}{l}\text { GLCM Ang. 2nd moment Layer } 1 \text { (all } \\
\text { dir.) }\end{array}$ & 0 & $<0.01$ & 0 \\
\hline Índice Espectral & GEMI & 0 & $<0.01$ & 0 \\
\hline Índice Espectral & GDVI & 0 & $<0.01$ & 0 \\
\hline Índice Espectral & ferro_ratio & 0 & $<0.01$ & 0 \\
\hline Relacionado ao Pixel & Contrast to neighbor pixels Layer 4 (3) & 0 & $<0.01$ & 0 \\
\hline Relacionado ao Pixel & Contrast to neighbor pixels Layer 3 (3) & 0 & $<0.01$ & 0 \\
\hline Relacionado ao Pixel & Contrast to neighbor pixels Layer 2 (3) & 0 & $<0.01$ & 0 \\
\hline Relacionado ao Pixel & Contrast to neighbor pixels Layer 1 (3) & 0 & $<0.01$ & 0 \\
\hline
\end{tabular}


Apêndice 3 - Imagens LANDSAT 5 TM selecionadas (órbita/ponto) para a realização do mapeamento.

\begin{tabular}{|c|c|c|c|}
\hline ORBITA & PONTO & 1985 & 1995 \\
\hline 217 & 71 & 05/06/1986 & 02/11/1994 \\
\hline 217 & 72 & 25/09/1986 & 25/12/1996 | - 05/07/1997 \\
\hline 217 & 73 & $25 / 09 / 1986$ & 02/09/1995 - 05/07/1997 \\
\hline 217 & 74 & 17/07/1984 | 04/07/1985 & 01/10/1994 \\
\hline 218 & 67 & 28/06/1986 |-03/09/1987 & $23 / 06 / 1996$ \\
\hline 218 & 68 & 11/05/1986 | - 30/05/1987 & 23/06/1996 \\
\hline 218 & 69 & $11 / 05 / 1986$ & $23 / 06 / 1996$ \\
\hline 218 & 70 & $27 / 05 / 1986$ & 02/06/1994 | -03/09/1993 \\
\hline 218 & 71 & $11 / 05 / 1986$ & 05/09/1995 | - 26/06/1997 \\
\hline 218 & 72 & 09/08/1984 & 07/07/1995 | -26/06/1997 \\
\hline 218 & 73 & 09/08/1984 | 18/10/1986 & 07/07/1995 - 12/07/1997 \\
\hline 218 & 74 & 06/06/1984 | 25/06/1985 & 08/08/1995 \\
\hline 218 & 75 & 09/06/1985 | 14/07/1986 & $26 / 08 / 1996$ \\
\hline 219 & 62 & 19/08/1985 & 29/05/1996 | - 24/07/1993 \\
\hline 219 & 63 & $19 / 08 / 1985$ & $15 / 08 / 1995$ \\
\hline 219 & 64 & 16/06/1985 | - 25/08/1987 & $14 / 07 / 1995$ \\
\hline 219 & 65 & $29 / 06 / 1984$ & $15 / 08 / 1995$ \\
\hline 219 & 66 & $15 / 07 / 1984$ & $15 / 08 / 1995$ \\
\hline 219 & 67 & $21 / 07 / 1986$ & 29/05/1996 \\
\hline 219 & 68 & $21 / 07 / 1986$ & 29/05/1996 \\
\hline 219 & 69 & $21 / 07 / 1986$ & $30 / 06 / 1996$ \\
\hline 219 & 70 & $02 / 07 / 1985$ & $30 / 06 / 1996$ \\
\hline 219 & 71 & $16 / 06 / 1985$ & 29/05/1996 - 03/07/1997 \\
\hline 219 & 72 & 02/07/1985 | 15/07/1984 & 16/07/1996 | 29/05/1996 \\
\hline 219 & 73 & $02 / 05 / 1986$ & 29/05/1996 \\
\hline 219 & 74 & 06/08/1986 | - 08/07/1987 & $12 / 06 / 1995$ \\
\hline 219 & 75 & 02/05/1986 - 09/08/1987 & $17 / 08 / 1996$ \\
\hline 219 & 76 & 31/05/1985 - 09/08/1987 & 24/07/1994 \\
\hline 220 & 62 & $20 / 06 / 1984$ & 03/06/1995 - 10/07/1997 \\
\hline 220 & 63 & $\begin{array}{l}13 / 12 / 1984|10 / 08 / 1985|- \\
29 / 06 / 1987\end{array}$ & 16/06/1994 | 22/08/1995 \\
\hline 220 & 64 & 20/06/1984 & $21 / 07 / 1995$ \\
\hline 220 & 65 & 09/07/1985 & $21 / 06 / 1996$ \\
\hline 220 & 66 & 06/07/1984 & 21/06/1996 \\
\hline 220 & 67 & $23 / 06 / 1985$ & 08/08/1996 \\
\hline 220 & 68 & $23 / 06 / 1985$ & $21 / 06 / 1996$ \\
\hline 220 & 69 & $19 / 05 / 1984$ & 07/07/1996 \\
\hline 220 & 70 & 09/07/1985 & 21/06/1996 \\
\hline 220 & 71 & 20/06/1984 & 21/06/1996 \\
\hline 220 & 72 & 20/06/1984 & 07/07/1996 \\
\hline 220 & 73 & $06 / 07 / 1984$ & 03/06/1995 - 10/07/1997 \\
\hline 220 & 74 & 09/07/1985 & 08/08/1996 \\
\hline 220 & 75 & 10/08/1985 | - 29/06/1987 & 23/07/1996 \\
\hline
\end{tabular}




\begin{tabular}{|c|c|c|c|}
\hline 220 & 76 & $10 / 08 / 1985 \mid-15 / 07 / 1987$ & 02/05/1995 - 10/07/1997 \\
\hline 220 & 77 & $13 / 10 / 1985$ & 02/05/1995 | - 24/06/1997 \\
\hline 221 & 62 & $27 / 06 / 1984$ & $30 / 09 / 1995$ \\
\hline 221 & 63 & 01/08/1985 & 28/06/1996 | - 30/05/1997 \\
\hline 221 & 64 & $27 / 06 / 1984$ & 29/08/1995 | -17/07/1997 \\
\hline 221 & 65 & $27 / 06 / 1984$ & $12 / 07 / 1995$ \\
\hline 221 & 66 & $30 / 06 / 1985$ & $28 / 06 / 1996$ \\
\hline 221 & 67 & $17 / 06 / 1986$ & 28/07/1995 \\
\hline 221 & 68 & $16 / 07 / 1985$ & 28/06/1996 \\
\hline 221 & 69 & $14 / 06 / 1985$ & 26/06/1995 |-01/07/1997 \\
\hline 221 & 70 & $16 / 07 / 1985$ & 14/07/1996 | -01/07/1997 \\
\hline 221 & 71 & $14 / 06 / 1985$ & $27 / 05 / 1996$ \\
\hline 221 & 72 & 17/08/1985 | - 19/05/1987 & $27 / 05 / 1996$ \\
\hline 221 & 73 & $11 / 06 / 1984$ & $14 / 07 / 1996$ \\
\hline 221 & 74 & $11 / 06 / 1984$ & $14 / 07 / 1996$ \\
\hline 221 & 75 & 01/08/1985 | 17/08/1985 & $14 / 07 / 1996$ \\
\hline 221 & 76 & 04/08/1986 & 28/07/1995 \\
\hline 221 & 77 & $27 / 06 / 1984$ & 09/07/1994 | 25/07/1994 \\
\hline 222 & 64 & $21 / 08 / 1984$ & $19 / 06 / 1996$ \\
\hline 222 & 65 & $18 / 06 / 1984$ & 19/07/1995 - 06/06/1997 \\
\hline 222 & 66 & 20/07/1984 & $19 / 06 / 1996$ \\
\hline 222 & 67 & 18/06/1984 & 01/08/1994 | - 22/06/1997 \\
\hline 222 & 68 & $18 / 06 / 1984$ & $19 / 06 / 1996$ \\
\hline 222 & 69 & 18/06/1984 & 03/07/1995 | -22/06/1997 \\
\hline 222 & 70 & $21 / 06 / 1985$ & 03/07/1995 - 08/07/1997 \\
\hline 222 & 71 & 23/05/1986 & $\begin{array}{l}\text { 17/06/1995 | 19/06/1996 | - } \\
22 / 06 / 1997\end{array}$ \\
\hline 222 & 72 & $21 / 06 / 1985$ & 03/07/1995 \\
\hline 222 & 73 & 20/07/1984 | 04/05/1985 & 21/07/1996 | - 22/06/1997 \\
\hline 222 & 74 & 05/06/1985 & 03/07/1995 | -22/06/1997 \\
\hline 222 & 75 & 07/07/1985 & 21/07/1996 \\
\hline 222 & 76 & $23 / 07 / 1985$ & $21 / 07 / 1996$ \\
\hline 223 & 64 & $12 / 08 / 1984$ & $12 / 07 / 1996$ \\
\hline 223 & 65 & $27 / 07 / 1984$ & $26 / 06 / 1996$ \\
\hline 223 & 66 & $30 / 07 / 1985$ & $26 / 06 / 1996$ \\
\hline 223 & 67 & $25 / 06 / 1984$ & 26/06/1996 \\
\hline 223 & 68 & $25 / 06 / 1984$ & $27 / 08 / 1995$ \\
\hline 223 & 69 & 25/06/1984 | - 17/05/1987 & $12 / 07 / 1996$ \\
\hline 223 & 70 & $25 / 06 / 1984 \mid-18 / 06 / 1987$ & 07/07/1994 \\
\hline 223 & 71 & $15 / 06 / 1986$ & 10/07/1995 | - 15/07/1997 \\
\hline 223 & 72 & 25/06/1984 | 12/06/1985 & 08/06/1995 \\
\hline 223 & 73 & $12 / 06 / 1985$ & $10 / 06 / 1996$ \\
\hline 223 & 74 & $12 / 06 / 1985$ & 23/04/1996 | - 15/07/1997 \\
\hline 223 & 75 & $14 / 07 / 1985$ & 04/05/1994 \\
\hline 224 & 67 & $16 / 06 / 1984$ & 15/06/1995 - 06/07/1997 \\
\hline 224 & 68 & $02 / 07 / 1984$ & 03/07/1996 \\
\hline
\end{tabular}




\begin{tabular}{|c|c|c|c|}
\hline 224 & 69 & $02 / 07 / 1984$ & 03/07/1996 \\
\hline 224 & 70 & 06/06/1986 | - 11/07/1987 & 03/07/1996 \\
\hline 224 & 71 & $19 / 06 / 1985$ & 19/07/1996 | 17/06/1996 \\
\hline 224 & 72 & $19 / 06 / 1985$ & $17 / 06 / 1996$ \\
\hline 224 & 73 & 18/07/1984 | 04/09/1984 & 17/06/1996 \\
\hline 224 & 74 & $02 / 07 / 1984$ & $17 / 06 / 1996$ \\
\hline 224 & 75 & $02 / 07 / 1984$ & 19/07/1996 \\
\hline 224 & 76 & 09/08/1986 & 01/07/1995 | 30/05/1995 \\
\hline 225 & 69 & 26/06/1985 | 09/05/1985 & 24/06/1996 \\
\hline 225 & 70 & 09/07/1984 & 06/06/1995 \\
\hline 225 & 71 & 09/07/1984 & 06/06/1995 |08/06/1996 \\
\hline 225 & 72 & 09/07/1984 & 08/06/1996 \\
\hline 225 & 73 & $10 / 06 / 1985$ | 28/05/1986 & 06/06/1995 \\
\hline 225 & 74 & $22 / 05 / 1984 \mid 10 / 06 / 1985$ & 08/06/1996 \\
\hline 225 & 75 & $10 / 06 / 1985$ & 07/05/1996 \\
\hline 225 & 76 & 12/07/1985 | -03/08/1987 & 24/07/1995 | - 13/07/1997 \\
\hline 226 & 69 & $17 / 06 / 1985$ & 13/06/1995 | 15/06/1996 \\
\hline 226 & 70 & $17 / 06 / 1985$ & 01/07/1996 \\
\hline 226 & 71 & 07/08/1986 & 01/07/1996 | 17/07/1996 \\
\hline 226 & 72 & 19/07/1985 | 17/06/1985 & 02/08/1996 \\
\hline 226 & 74 & 04/06/1986 | - 25/07/1987 & $17 / 07 / 1996$ \\
\hline 226 & 75 & 08/09/1986 | 16/05/1985 & 02/08/1996 \\
\hline 227 & 68 & 26/07/1985 | 11/06/1986 & 24/07/1996 \\
\hline 227 & 69 & $27 / 06 / 1986$ & 24/07/1996 \\
\hline 227 & 70 & $27 / 06 / 1986$ & 24/07/1996 | - 09/06/1997 \\
\hline 227 & 71 & $13 / 07 / 1986$ & 24/07/1996 \\
\hline 227 & 74 & 29/07/1986 | - 16/07/1987 & 10/09/1996 \\
\hline 227 & 75 & $27 / 06 / 1986 \mid-01 / 08 / 1987$ & $10 / 09 / 1996$ \\
\hline 228 & 68 & $01 / 07 / 1985$ & 13/07/1995 \\
\hline 228 & 69 & $17 / 07 / 1985$ & $15 / 07 / 1996$ \\
\hline 228 & 70 & $17 / 07 / 1985$ & 13/06/1996 \\
\hline 229 & 68 & $06 / 06 / 1985$ & 06/07/1996 \\
\hline 229 & 69 & $24 / 07 / 1985$ & 06/07/1996 | - 09/07/1997 \\
\hline 229 & 70 & $24 / 07 / 1985$ & 06/07/1996 \\
\hline
\end{tabular}


Apêndice 4 - Algoritmo para processamento de dados R, com a obtenção de cluster.

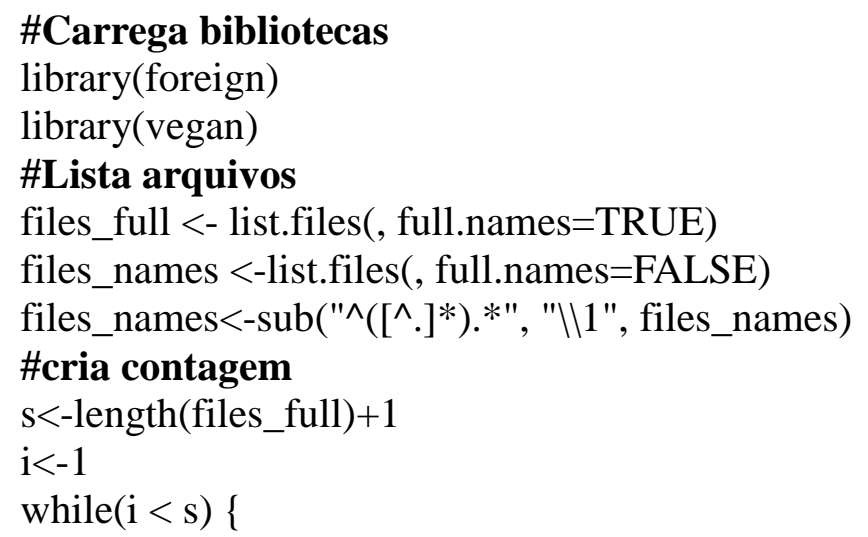

\#Lê Dados

mydata $<$ - data.frame()

data1 <-read.dbf(files_full[i])

mydata<-data.frame(data1)

\#renomeia colunas

names(mydata) $[$ names(mydata) $==" A R V I "]<-" A 1 "$

names(mydata)[names(mydata)=="Asymmetry"]<-"A2"

names(mydata)[names(mydata)=="Brightness"]<-"A3"

names(mydata) $[$ names $($ mydata $)=="$ Class_name"]<-"classe"

names(mydata)[names(mydata)=="Clay"]<-"A4"

names(mydata)[names(mydata)=="Compactnes"]<-"A5"

names(mydata)[names (mydata)=="GARI"]<-"A6"

names (mydata)[names(mydata)=="GLCM_Contr"]<-"A7"

names(mydata)[names(mydata)=="GLCM_Dissi"]<-"A8"

names(mydata)[names(mydata)=="GLCM_Homog"]<-"A09"

names(mydata)[names(mydata)=="GLCM_Mean_"]<-"A10"

names(mydata)[names(mydata)=="GLCM_Mean_.1"]<-"A11"

names(mydata)[names(mydata)=="GLCM_Mean_.2"]<-"A12"

names(mydata)[names(mydata)=="GLDV_Ang_2"]<-"A13"

names(mydata)[names(mydata)=="GNDVI"]<-"A14"

names(mydata)[names(mydata)=="HSI_Transf"]<-"A15"

names(mydata)[names(mydata)=="HSI_Transf.1"]<-"A16"

names(mydata)[names(mydata)=="iron_ratio"]<-"A17"

names(mydata)[names(mydata)=="Max_diff"] $<-" A 18 "$

names(mydata)[names(mydata)=="Mean_Layer"]<-"A19"

names(mydata)[names(mydata)=="Mean_Layer.1"]<-"A20"

names(mydata)[names(mydata)=="Mean_Layer.2"]<-"A21"

names(mydata)[names(mydata)=="Mean_Layer.3"]<-"A22"

names(mydata)[names $($ mydata) $==" P S R I "]<-" A 23 "$

names(mydata)[names(mydata)=="quantile50"]<-"A24"

names(mydata)[names(mydata)=="quantile50.1"]<-"A25"

names(mydata)[names(mydata)=="quantile50.2"]<-"A26"

names(mydata)[names(mydata)=="quantile 50.3"]<-"A27"

names(mydata)[names(mydata)=="Ratio_Laye"]<-"A28"

names(mydata)[names(mydata)=="Ratio_Laye.1"]<-"A29" 
names $($ mydata $)[$ names $($ mydata $)=="$ Ratio_Laye.2"]<-"A30"

names(mydata)[names(mydata)=="Ratio_Laye.3"]<-"A31"

names(mydata)[names(mydata)=="StdDev_to_"]<-"A32"

\#padroniza

pad_data <- mydata[c(1:3,5:33)]

padronizado<-decostand(pad_data, method="standardize")

mydata_pad<-cbind (classe $=$ mydata $\$$ classe, padronizado)

\#cria id

id<-rownames(mydata_pad)

id $1<$-as.numeric(id)

id2<-id1-1

mydata_pad<-cbind(id=id2, mydata_pad)

rm(id, id1, id2)

\#subset mydata - terra

mydata_subset<-mydata_pad[which(mydata_pad\$classe=="terra"),]

mydata_subset $1<$-mydata_subset[,3:34]

\#cria_cluster

fit <- kmeans(mydata_subset1, 45) \# 45 cluster solution

aggregate(mydata_subset1,by=list(fit\$cluster),FUN=mean)

mydataa <- data.frame(mydata_subset, fit\$cluster)

mydata_subset $1<-$ mydata_subset[,3:34]

\#exporta_tabela

write.table(mydata_subset, file=paste(files_names[i],".csv"), sep=";", row.names = F)

\#Limpa dados e atualiza contadores

rm(data1, mydata, mydata_pad, pad_data, padronizado, mydata_subset, mydata_subset1, fit)

$\mathrm{i}<-\mathrm{i}+1$

\}

$\operatorname{rm}(\mathrm{i})$ 
Apêndice 5 - Algoritmos utilizados para a obtenção de métricas de qualidade do mapeamento.

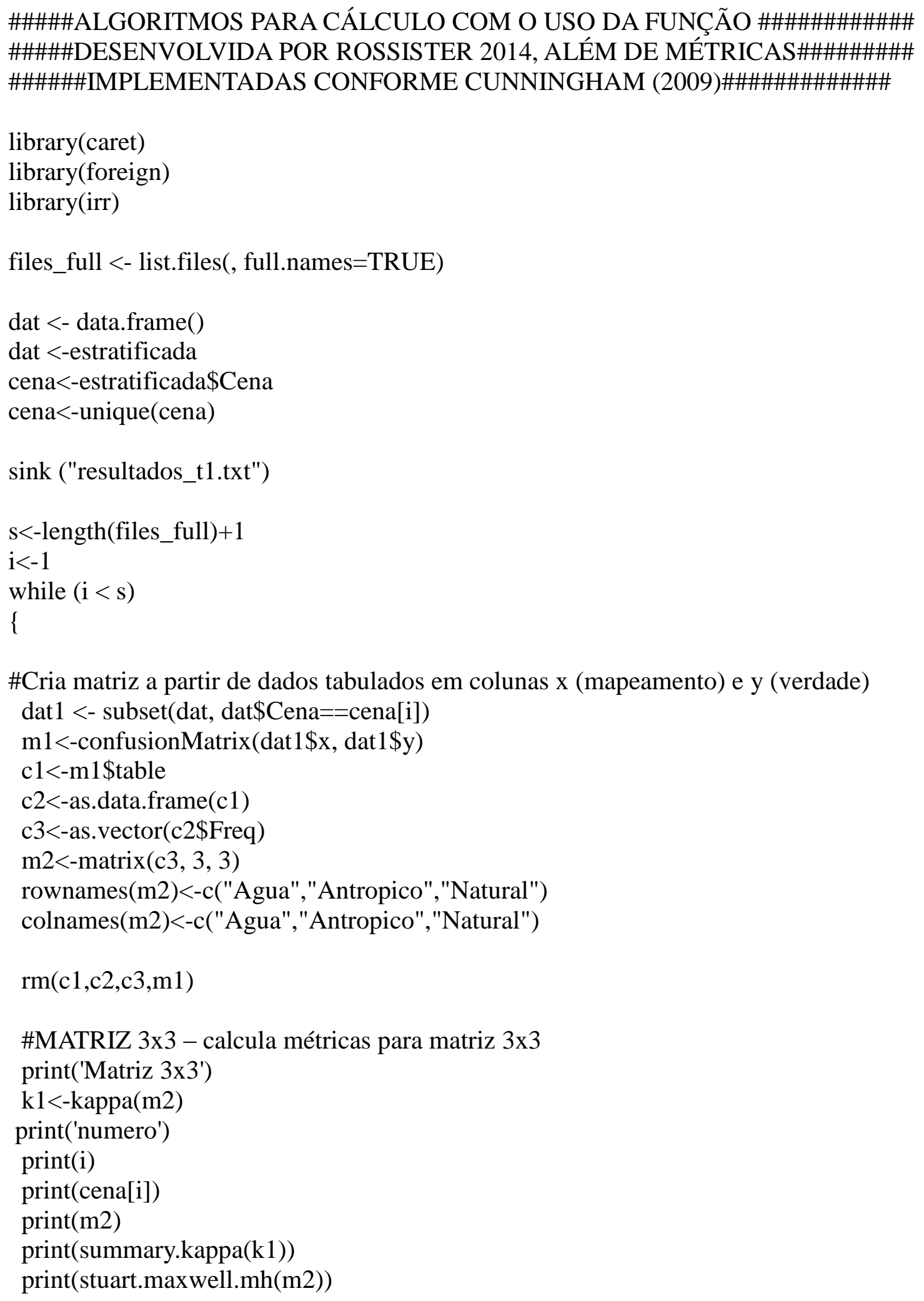


\#Matriz 2x2 - calcula métricas para matriz $2 \times 2$

print('Matriz 2x2')

$\mathrm{m} 1<-\mathrm{m} 2[\mathrm{c}(2,3), \mathrm{c}(2,3)]$

$\mathrm{k} 2<-\mathrm{kappa}(\mathrm{m} 1)$

print('numero')

print(i)

$\operatorname{print}(\mathrm{cena}[\mathrm{i}])$

$\operatorname{print}(\mathrm{m} 1)$

print(summary.kappa(k2))

\#matriz-2x2 descritores

$\mathrm{n}<-\operatorname{sum}(\mathrm{m} 1)$

diagonal<-diag(m1); dsum<-sum(diagonal);

$\mathrm{a}<-\mathrm{m} 1[1,1]$

$\mathrm{b}<-\mathrm{m} 1[1,2]$

$\mathrm{c}<-\mathrm{m} 1[2,1]$

$\mathrm{d}<-\mathrm{m} 1[2,2]$

$\operatorname{sumc} 1<-\operatorname{sum}(\mathrm{m} 1[, 1])$

$\operatorname{sumr} 1<-\operatorname{sum}(\mathrm{m} 1[1]$,

\#P observed e $\mathrm{P}$ expected

p_obs<-dsum $/ \mathrm{n}$

print(paste("P Observed: ", p_obs), quote=F)

csum<-apply(m1,2,sum)

rsum<-apply(m1,1,sum)

p_expect <- sum $($ rsum*csum $) / n^{\wedge} 2$

print(paste("P expected: ", p_expect), quote=F)

\#Bias e prevalence

sensitivity $<-\mathrm{a} / \mathrm{n}$

specificity $<-\mathrm{d} / \mathrm{n}$

pos_agree $<-(2 * a) /(n+a-d)$

neg_agree $<-(2 * d) /(\mathrm{n}-\mathrm{a}+\mathrm{d})$

Prevalence $<-(a-d) / n$

bias $<-(\mathrm{b}-\mathrm{c}) / \mathrm{n}$

se_bias<-1/n*( $\left.\operatorname{sqrt}\left((b+c)-\left((b-c)^{\wedge} 2 / n\right)\right)\right)$

print(paste("Sensitivity: ", sensitivity), quote=F)

print(paste("Specificity: ", specificity), quote=F)

print(paste("Positive Agreement: ", pos_agree), quote=F)

print(paste("Negative Agreement: ", neg_agree), quote=F)

print(paste("Bias 2x2:", bias), quote=F)

print(paste("Bias SE:", se_bias), quote=F)

print(paste("Prevalence 2x2:", Prevalence), quote=F)

\#Kpabak2x2

kapabak<-(2*p_obs)-1

print(paste("Kpabak 2x2:", kapabak), quote=F)

print("RESUMO 2X2")

print("P Observed, P expected, Sensitivity, Specificity, Positive Agreement, Negative Agreement, Bias, Bias SE, Prevalence, Kappa Pabak", quote=F) 
print(paste(p_obs,",", $\quad$ p_expect, $\quad$ sensitivity,,$"$, specificity,",",pos_agree,",",neg_agree,",",bias,",",se_bias,",",Prevalence,",,"kapabak, sep=""), quote $=\mathrm{F}$ )

print(stuart.maxwell.mh(m1))

rm(dat1,n,diagonal,a,b,c,d,sumc1,sumr1,p_obs,csum,rsum,p_expect,

sensitivity,specificity,pos_agree,neg_agree,bias, se_bias,Prevalence,kapabak,k1,m1,m2， k2, dsum)

$\mathrm{i}<-\mathrm{i}+1$

\}

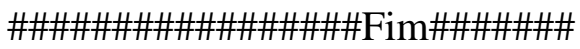

\#\#\#\#\#\#\#\#\#\#\#Função Rossister (2014) com modificações\#\#\#\#\#\#\#\#\#\#\#\#\#\#\#\#\#\#\#

kappa <- function(CM) \{

\#convert both data frames and vectors to matrices

$\mathrm{cmx}<-$ as.matrix $(\mathrm{CM})$

\#try to convert a vector to a square matrix

if $(\operatorname{ncol}(\mathrm{cmx})==1)$

$\mathrm{cmx}<-\operatorname{matrix}(\mathrm{cmx}$, byrow=TRUE, $\operatorname{nrow}=\operatorname{sqrt}(\operatorname{nrow}(\mathrm{cmx})))$

$\mathrm{nr}<-\operatorname{nrow}(\mathrm{cmx}) ; \mathrm{nc}<-\mathrm{ncol}(\mathrm{cmx})$

if $(\mathrm{nr} !=\mathrm{nc})$

$\{$ print("Error: matrix is not square"); return(NULL) \}

$\mathrm{n}<-\operatorname{sum}(\mathrm{cmx})$

d<-diag(cmx); dsum<-sum(d); th1<-dsum/n

th $1 \mathrm{v}<-(($ th $1 *(1-$ th 1$)) / \mathrm{n})$

csum<-apply(cmx,2,sum); rsum<-apply(cmx,1,sum)

ua $<-$ d/rsum; pa $<-$ d/csum

th2 <- sum(rsum*csum) / $\mathrm{n}^{\wedge} 2 ; \mathrm{kh}<-($ th1-th2)/(1-th2)

th3 <- $\operatorname{sum}((\operatorname{csum}+\operatorname{rsum}) * d) / n^{\wedge} 2$;

th4 <- 0 ; for (i in 1:nr) for ( $\mathrm{j}$ in $1: \mathrm{nc})$

th4 <- th4 + (cmx $\left.[\mathrm{i}, \mathrm{j}] *\left((\operatorname{csum}[\mathrm{i}]+\operatorname{rsum}[\mathrm{j}])^{\wedge} 2\right)\right)$;

th4 <- th $4 / \mathrm{n}^{\wedge} 3$;

th1c $<-1-$ th $1 ;$ th2c $<-1-$ th2;

$\mathrm{khv}<-1 / \mathrm{n} *$

( ( ( th1 $*$ th $1 \mathrm{c}) /$ th $\left.2 \mathrm{c}^{\wedge} 2\right)$

$+\left((2 *\right.$ th1c $*((2 * \operatorname{th} 1 * \operatorname{th} 2)-\operatorname{th} 3)) /$ th $\left.2 \mathrm{c}^{\wedge} 3\right)$

$+\left(\left(\right.\right.$ th $1 \mathrm{c}^{\wedge} 2 *($ th $4-(4 *$ th $\left.2 \wedge 2))\right) /$ th $\left.2 \mathrm{c}^{\wedge} 4\right)$

)

\#Alteração na função para cálculo de Kappa Pabak 3x3 e Acurácia esperada

kpabak3_3<-(((3*th1)-1)/2)

pexpect $<$-th2

\#FIMEU

\#per-class kappa, user's accuracy...

$\mathrm{p}<-\mathrm{cmx} / \mathrm{n}$; uap <- apply(p,1,sum); pap <- apply $(\mathrm{p}, 2, \operatorname{sum}) ; \operatorname{dp}<-\operatorname{diag}(\mathrm{p})$;

$\mathrm{kpu}<-(\mathrm{dp} / \mathrm{uap}$ - pap $) /(1$ - pap $)$;

\#...and its variance 
t1 <- uap-dp; t2 <- (pap*uap)-dp; t3 <- dp*(1 - uap - pap + dp);

kpuv <- $\left(\left(\mathrm{t} 1 /\left(\right.\right.\right.$ uap $\left.\left.\left.^{\wedge} 3 *(1-\mathrm{pap})^{\wedge} 3\right)\right) *((\mathrm{t} 1 * \mathrm{t} 2)+\mathrm{t} 3)\right) / \mathrm{n}$;

\#per-class kappa, producer's reliability...

$\mathrm{kpp}<-(\mathrm{dp} / \mathrm{pap}$ - uap)/(1 - uap);

\#...and its variance

t1 <- (pap-dp);

$\mathrm{kppv}<-\left(\left(\mathrm{t} 1 /\left(\operatorname{pap}^{\wedge} 3 *(1-\mathrm{uap})^{\wedge} 3\right)\right) *((\mathrm{t} 1 * \mathrm{t} 2)+\mathrm{t} 3)\right) / \mathrm{n}$;

\#return all statistics as a list

return(list(sum.kpabak3_3=kpabak3_3， sum.pexpect=pexpect， sum.n=n, sum.naive=th1, sum. var $=$ th1v, sum.kappa $=\mathrm{kh}$, sum.kvar $=\mathrm{khv}$, user.naive $=$ ua, prod.naive $=\mathrm{pa}$,

\} user.kappa $=\mathrm{kpu}$, user.kvar=kpuv, prod.kappa $=\mathrm{kpp}$, prod.kvar=kppv))

\#\#\#\#\#\#\#\#\#\#\#\#Relatório Rossister 2014 com modificações \#\#\#\#\#\#\#\#\#\#\#\#\# summary.kappa $<-$ function(kappa, alpha $=0.05)\{$

ciw<-function(var, $n)\{$

qnorm $(1-($ alpha/2) $) * \operatorname{sqrt}(\operatorname{var})+(1 /(2 * n))$

\}

print(paste("Number of observations:", kappa \$sum.n), quote=F)

print("Summary of naive statistics", quote=F)

\# Alteração na função para cálculo de Kappa Pabak 3x3 e Acurácia esperada

print(paste("Expected Accuracy:", kappa \$sum.pexpect), quote=F)

print(paste("Kpabak 3x3:", kappa\$sum.kpabak3_3), quote=F)

\#FIM_EU

print(paste(

"Overall accuracy, stdev, CV\%:",

round(kappa\$sum.naive, 4), ",",

round(sqrt(kappa\$sum.var), 4), ",",

round((sqrt(kappa\$sum.var)/kappa\$sum.naive)*1000,0)/10),

quote $=\mathrm{F})$

w<-ciw(kappa\$sum.var, kappa\$sum.n)

print(paste(

round((1-alpha)*100,0),"\% confidence limits for accuracy:",

round((kappa\$sum.naive-w),4),"...",

round((kappa\$sum.naive+w),4)), quote=F, sep="")

print("User's accuracy", quote=F); print(round(kappa\$user.naive,4));

print("Producer's reliability:", quote=F); $\operatorname{print}(\operatorname{round}($ kappa\$prod.naive,4));

print("Summary of kappa statistics", quote=F)

print(paste("Overall kappa, stdev, \& CV\%:",

round(kappa\$sum.kappa,4), ",",

round(sqrt(kappa\$sum.kvar),4), ",",

round((sqrt(kappa\$sum.kvar)/kappa $\$$ sum.kappa)*1000,0)/10), quote=F)

$\mathrm{w}<$-ciw(kappa\$sum.kvar, kappa\$sum.n)

print(paste(

round((1-alpha)*100,0),"\% confidence limits for kappa:",

round((kappa\$sum.kappa-w),4),"...",

round((kappa\$sum.kappa+w),4)), quote=F, sep="")

print("Per-class kappa, stdev, \& CV\%, for user's accuracy:", quote=F)

print(round(kappa\$ser.kappa,4), quote=F); 
print(round(sqrt(kappa\$user.kvar),4), quote=F);

print(round((sqrt(kappa\$user.kvar)/kappa\$user.kappa)*1000,0)/10, quote=F);

print("Per-class kappa, stdev, \& CV\%, for producer's reliability:", quote=F)

print(round(kappa\$prod.kappa,4), quote=F);

print(round(sqrt(kappa\$prod.kvar),4), quote=F);

$\operatorname{print}(\operatorname{round}((\operatorname{sqrt}($ kappa $\$$ prod.kvar$) /$ kappa\$prod.kappa $) * 1000,0) / 10$, quote=F); \} 
Apêndice 6 - Variação na área entre os anos por unidade da federação.

\begin{tabular}{|c|c|c|c|c|c|c|c|}
\hline \multirow{2}{*}{ Período } & \multirow{2}{*}{ Estado } & \multicolumn{2}{|c|}{ Corpo D'água } & \multicolumn{2}{|c|}{ Antrópico } & \multicolumn{2}{|c|}{ Natural } \\
\hline & & $\mathrm{Km}^{2}$ & $\%$ & $\mathrm{Km}^{2}$ & $\%$ & $\mathrm{Km}^{2}$ & $\%$ \\
\hline $1985-2002$ & $\mathrm{BA}$ & -50 & $0.0 \%$ & 26881 & $17.7 \%$ & -26830 & $-17.7 \%$ \\
\hline 1985-2002 & DF & -3 & $-0.1 \%$ & 1929 & $33.3 \%$ & -1926 & $-33.3 \%$ \\
\hline 1985-2002 & GO & -186 & $-0.1 \%$ & 80357 & $24.4 \%$ & -80170 & $-24.3 \%$ \\
\hline 1985-2002 & MA & -37 & $0.0 \%$ & 21782 & $10.3 \%$ & -21744 & $-10.2 \%$ \\
\hline 1985-2002 & MG & -300 & $-0.1 \%$ & 69039 & $20.6 \%$ & -68739 & $-20.5 \%$ \\
\hline 1985-2002 & MS & -35 & $0.0 \%$ & 68845 & $31.9 \%$ & -68811 & $-31.8 \%$ \\
\hline 1985-2002 & MT & -10 & $0.0 \%$ & 85976 & $24.0 \%$ & -85966 & $-24.0 \%$ \\
\hline 1985-2002 & $\mathrm{PI}$ & -38 & $0.0 \%$ & 6671 & 7.1\% & -6633 & $-7.1 \%$ \\
\hline 1985-2002 & PR & 0 & $0.0 \%$ & 603 & $16.1 \%$ & -603 & $-16.1 \%$ \\
\hline 1985-2002 & RO & 0 & $0.0 \%$ & 4 & $1.0 \%$ & -4 & $-1.0 \%$ \\
\hline 1985-2002 & SP & -184 & $-0.2 \%$ & 7761 & $9.6 \%$ & -7577 & $-9.3 \%$ \\
\hline 1985-2002 & TO & -33 & $0.0 \%$ & 34634 & $13.7 \%$ & -34601 & $-13.7 \%$ \\
\hline $1995-2002$ & $\mathrm{BA}$ & -51 & $0.0 \%$ & 15436 & $10.2 \%$ & -15385 & $-10.1 \%$ \\
\hline 1995-2002 & DF & -3 & $-0.1 \%$ & 938 & $16.2 \%$ & -935 & $-16.1 \%$ \\
\hline 1995-2002 & GO & -216 & $-0.1 \%$ & 45900 & $13.9 \%$ & -45684 & $-13.8 \%$ \\
\hline 1995-2002 & MA & -38 & $0.0 \%$ & 16317 & $7.7 \%$ & -16279 & $-7.7 \%$ \\
\hline 1995-2002 & MG & -395 & $-0.1 \%$ & 49470 & $14.8 \%$ & -49075 & $-14.7 \%$ \\
\hline 1995-2002 & MS & -36 & $0.0 \%$ & 26529 & $12.3 \%$ & -26493 & $-12.3 \%$ \\
\hline 1995-2002 & MT & -13 & $0.0 \%$ & 43465 & $12.1 \%$ & -43452 & $-12.1 \%$ \\
\hline 1995-2002 & $\mathrm{PI}$ & -38 & $0.0 \%$ & 4575 & $4.9 \%$ & -4537 & $-4.9 \%$ \\
\hline 1995-2002 & $P R$ & 0 & $0.0 \%$ & 378 & $10.1 \%$ & -378 & $-10.1 \%$ \\
\hline 1995-2002 & RO & 0 & $0.0 \%$ & 3 & $0.7 \%$ & -3 & $-0.7 \%$ \\
\hline 1995-2002 & SP & -183 & $-0.2 \%$ & 7705 & $9.5 \%$ & -7522 & $-9.3 \%$ \\
\hline 1995-2002 & TO & -35 & $0.0 \%$ & 20805 & $8.2 \%$ & -20770 & $-8.2 \%$ \\
\hline 1985-1995 & BA & 1 & $0.0 \%$ & 11444 & $7.5 \%$ & -11445 & $-7.5 \%$ \\
\hline 1985-1995 & DF & 0 & $0.0 \%$ & 991 & $17.1 \%$ & -991 & $-17.1 \%$ \\
\hline 1985-1995 & GO & 30 & $0.0 \%$ & 34456 & $10.4 \%$ & -34486 & $-10.5 \%$ \\
\hline 1985-1995 & MA & 0 & $0.0 \%$ & 5465 & $2.6 \%$ & -5465 & $-2.6 \%$ \\
\hline 1985-1995 & MG & 95 & $0.0 \%$ & 19569 & $5.8 \%$ & -19664 & $-5.9 \%$ \\
\hline 1985-1995 & MS & 1 & $0.0 \%$ & 42316 & $19.6 \%$ & -42318 & $-19.6 \%$ \\
\hline 1985-1995 & MT & 3 & $0.0 \%$ & 42511 & $11.8 \%$ & -42514 & $-11.8 \%$ \\
\hline 1985-1995 & $\mathrm{PI}$ & 0 & $0.0 \%$ & 2095 & $2.2 \%$ & -2095 & $-2.2 \%$ \\
\hline 1985-1995 & PR & 0 & $0.0 \%$ & 225 & $6.0 \%$ & -225 & $-6.0 \%$ \\
\hline 1985-1995 & RO & 0 & $0.0 \%$ & 1 & $0.3 \%$ & -1 & $-0.3 \%$ \\
\hline 1985-1995 & SP & 0 & $0.0 \%$ & 56 & $0.1 \%$ & -55 & $-0.1 \%$ \\
\hline $1985-1995$ & TO & 2 & $0.0 \%$ & 13829 & $5.5 \%$ & -13831 & $-5.5 \%$ \\
\hline
\end{tabular}


Apêndice 7 - Os 100 municípios com maior taxa de desmatamento para o período entre 1985 e 2002 .

\begin{tabular}{|c|c|c|c|c|c|}
\hline REF & Estado & Município & 1985_1995 & 1995_2002 & 1985_2002 \\
\hline 1 & MG & São Gonçalo do Rio Abaixo & 6.42 & 61.96 & 68.37 \\
\hline 2 & MA & Miranda do Norte & 18.45 & 47.16 & 65.61 \\
\hline 3 & DF & Brasília & 48.81 & 16.18 & 64.99 \\
\hline 4 & MG & Bom Jesus do Amparo & 8.76 & 52.42 & 61.18 \\
\hline 5 & MT & Ipiranga do Norte & 25.57 & 34.87 & 60.44 \\
\hline 6 & MS & Batayporã & 25.77 & 32.36 & 58.13 \\
\hline 7 & GO & Águas Lindas de Goiás & 26.31 & 30.64 & 56.95 \\
\hline 8 & MG & Papagaios & 19.86 & 36.12 & 55.98 \\
\hline 9 & MG & Barão de Cocais & 9.43 & 46.5 & 55.93 \\
\hline 10 & GO & Corumbá de Goiás & 9.39 & 45.05 & 54.44 \\
\hline 11 & MS & Paraíso das Águas & 43.71 & 10.69 & 54.4 \\
\hline 12 & $\mathrm{GO}$ & Gameleira de Goiás & 30.03 & 23.33 & 53.35 \\
\hline 13 & MS & Caracol & 19.93 & 32.81 & 52.74 \\
\hline 14 & MG & Itabira & -1.95 & 54.68 & 52.73 \\
\hline 15 & MG & Coração de Jesus & 9.4 & 42.38 & 51.78 \\
\hline 16 & SP & Sarapuí & 44.03 & 7.28 & 51.31 \\
\hline 17 & MS & Nova Andradina & 36.6 & 13.15 & 49.75 \\
\hline 18 & MS & Figueirão & 33.12 & 16.6 & 49.72 \\
\hline 19 & TO & Fortaleza do Tabocão & 23.11 & 25.98 & 49.09 \\
\hline 20 & GO & Água Limpa & 16.77 & 31.99 & 48.76 \\
\hline 21 & $\mathrm{GO}$ & Abadiânia & 16.83 & 31.91 & 48.73 \\
\hline 22 & MG & Pratinha & 17.78 & 30.17 & 47.96 \\
\hline 23 & MS & Alcinópolis & 28.42 & 19.41 & 47.83 \\
\hline 24 & $\mathrm{GO}$ & Rio Quente & 6.22 & 41.26 & 47.48 \\
\hline 25 & MG & Inhaúma & 14.02 & 33.02 & 47.04 \\
\hline 26 & MG & Prudente de Morais & 21.53 & 25.06 & 46.59 \\
\hline 27 & $\mathrm{BA}$ & Luís Eduardo Magalhães & 24.34 & 21.56 & 45.9 \\
\hline 28 & MG & Mirabela & 3 & 42.75 & 45.74 \\
\hline 29 & MS & Água Clara & 31.97 & 13.77 & 45.74 \\
\hline 30 & GO & Cachoeira de Goiás & 20.3 & 24.69 & 44.99 \\
\hline 31 & TO & Sítio Novo do Tocantins & 22.51 & 22.16 & 44.67 \\
\hline 32 & TO & Sucupira & 24.7 & 19.83 & 44.54 \\
\hline 33 & $\mathrm{GO}$ & Doverlândia & 22.6 & 21.92 & 44.52 \\
\hline 34 & GO & Valparaíso de Goiás & 23.72 & 20.7 & 44.42 \\
\hline 35 & $\mathrm{GO}$ & Bonópolis & 20.17 & 23.95 & 44.12 \\
\hline 36 & GO & Alexânia & 19.28 & 24.67 & 43.95 \\
\hline 37 & TO & Miranorte & 13.81 & 30.08 & 43.89 \\
\hline 38 & MS & Nioaque & 27.25 & 16.36 & 43.61 \\
\hline 39 & MA & Senador La Rocque & 18.5 & 25.05 & 43.56 \\
\hline 40 & BA & Serra do Ramalho & 19.13 & 24.34 & 43.47 \\
\hline 41 & TO & Bandeirantes do Tocantins & 21.9 & 21.46 & 43.36 \\
\hline 42 & PR & Ventania & 36.87 & 6.27 & 43.14 \\
\hline
\end{tabular}




\begin{tabular}{|c|c|c|c|c|c|}
\hline 43 & $\mathrm{MT}$ & Novo São Joaquim & 20.47 & 22.37 & 42.84 \\
\hline 44 & MS & Brasilândia & 29.54 & 13.22 & 42.77 \\
\hline 45 & MG & Cláudio & 5.69 & 37.02 & 42.71 \\
\hline 46 & MG & São João da Lagoa & 6.93 & 35.57 & 42.5 \\
\hline 47 & GO & Ivolândia & 17.03 & 25.48 & 42.5 \\
\hline 48 & MG & São João do Pacuí & 14.17 & 28.26 & 42.43 \\
\hline 49 & $\mathrm{MA}$ & Trizidela do Vale & -1.03 & 43.34 & 42.3 \\
\hline 50 & $\mathrm{MT}$ & Bom Jesus do Araguaia & 16.48 & 25.52 & 42 \\
\hline 51 & GO & Uirapuru & 15.94 & 25.99 & 41.93 \\
\hline 52 & MG & Ibiaí & 8.58 & 33.24 & 41.82 \\
\hline 53 & GO & Trombas & 18.43 & 23.34 & 41.77 \\
\hline 54 & MS & Ribas do Rio Pardo & 28.67 & 13.09 & 41.76 \\
\hline 55 & MG & Capim Branco & 9.77 & 31.97 & 41.73 \\
\hline 56 & $\mathrm{PI}$ & Demerval Lobão & -1.12 & 42.79 & 41.67 \\
\hline 57 & MS & Sonora & 30.94 & 10.63 & 41.57 \\
\hline 58 & $\mathrm{MT}$ & Sorriso & 23.06 & 18.35 & 41.41 \\
\hline 59 & $\mathrm{GO}$ & Silvânia & 20.25 & 20.84 & 41.1 \\
\hline 60 & $\mathrm{MT}$ & Santo Antônio do Leste & 29.06 & 11.93 & 40.99 \\
\hline 61 & MT & Primavera do Leste & 28.17 & 12.77 & 40.94 \\
\hline 62 & MS & Pedro Gomes & 29.66 & 11.02 & 40.68 \\
\hline 63 & MG & Maravilhas & 12.99 & 27.52 & 40.5 \\
\hline 64 & MG & Medeiros & 9.09 & 31.41 & 40.5 \\
\hline 65 & $\mathrm{MT}$ & Torixoréu & 22.75 & 17.61 & 40.35 \\
\hline 66 & MG & Patis & -10.19 & 50.24 & 40.05 \\
\hline 67 & $\mathrm{GO}$ & Leopoldo de Bulhões & 11.59 & 28.33 & 39.92 \\
\hline 68 & MS & Camapuã & 23.92 & 15.87 & 39.79 \\
\hline 69 & GO & Santa Tereza de Goiás & 14.49 & 25.19 & 39.68 \\
\hline 70 & $\mathrm{MA}$ & Bacabal & 5.85 & 33.8 & 39.66 \\
\hline 71 & GO & Novo Planalto & 19.01 & 20.63 & 39.64 \\
\hline 72 & GO & Montividiu do Norte & 18.46 & 21.06 & 39.52 \\
\hline 73 & MS & Santa Rita do Pardo & 26.06 & 13.34 & 39.4 \\
\hline 74 & GO & Mutunópolis & 16.44 & 22.95 & 39.4 \\
\hline 75 & MA & João Lisboa & 22.24 & 17.03 & 39.27 \\
\hline 76 & GO & laciara & 16.96 & 22.14 & 39.1 \\
\hline 77 & $\mathrm{PI}$ & Joca Marques & 28.12 & 10.97 & 39.09 \\
\hline 78 & $\mathrm{GO}$ & Porangatu & 19.7 & 19.38 & 39.08 \\
\hline 79 & TO & Marianópolis do Tocantins & 22.95 & 15.94 & 38.89 \\
\hline 80 & TO & Crixás do Tocantins & 22.04 & 16.84 & 38.88 \\
\hline 81 & MT & Acorizal & 12.66 & 25.91 & 38.57 \\
\hline 82 & MG & Fortaleza de Minas & 16.44 & 22.06 & 38.5 \\
\hline 83 & $\mathrm{GO}$ & Luziânia & 19.9 & 18.59 & 38.49 \\
\hline 84 & $\mathrm{GO}$ & Cristalina & 20.1 & 18.34 & 38.44 \\
\hline 85 & $\mathrm{MT}$ & Vila Rica & 27.6 & 10.82 & 38.42 \\
\hline 86 & $\mathrm{GO}$ & Santo Antônio do Descoberto & 14.44 & 23.83 & 38.27 \\
\hline 87 & $\mathrm{GO}$ & Santa Rita do Araguaia & 20.43 & 17.79 & 38.22 \\
\hline 88 & $\mathrm{GO}$ & Cocalzinho de Goiás & 8.34 & 29.81 & 38.16 \\
\hline
\end{tabular}




\begin{tabular}{rllrrr}
89 & MG & Leme do Prado & 1.53 & 36.6 & 38.13 \\
90 & MG & Ibiá & 10.52 & 27.57 & 38.1 \\
91 & MT & Ribeirãozinho & 17.68 & 20.4 & 38.08 \\
92 & MG & Itaguara & 2.5 & 35.57 & 38.07 \\
93 & TO & Gurupi & 24.12 & 13.91 & 38.02 \\
94 & MT & Itiquira & 32.19 & 5.67 & 37.86 \\
95 & GO & Vila Boa & 8.67 & 29.07 & 37.74 \\
96 & TO & Buriti do Tocantins & 29.47 & 8.06 & 37.53 \\
97 & GO & Bom Jardim de Goiás & 21.94 & 15.48 & 37.42 \\
98 & GO & Cabeceiras & 16.64 & 20.72 & 37.35 \\
99 & MA & Buritirana & 13.73 & 23.6 & 37.33 \\
100 & MT & Jangada & 16.12 & 21.21 & 37.33 \\
\hline
\end{tabular}


CAPÍTULO 3 - O EFEITO DAS ÁREAS PROTEGIDAS SOBRE A MANUTENÇÃO DO HABITAT NATURAL NO BIOMA CERRADO. 


\section{RESUMO}

O planejamento territorial voltado à conservação considera diferentes aspectos atinentes à seleção e implementação de áreas protegidas ou ações de conservação relacionadas a esse tipo de unidade territorial com vistas a aperfeiçoar a utilização de recursos disponíveis. Trabalhos que visem avaliar o efeito de uma rede de unidades já implantada sobre alvos finais da conservação ainda não são comuns para diversas regiões do mundo. Neste estudo objetivouse acessar e avaliar o efeito de Unidades de Conservação, Terras Indígenas e Terras Quilombolas existentes no Bioma Cerrado, levando-se em consideração a capacidade dessas unidades em conservar o habitat natural. Objetivou-se, ainda, observar eventuais diferenças entre as Unidades de Conservação em função de seus atributos, tais quais o nível de restrição das unidades, a esfera governamental a que pertencem, o tamanho das unidades e o tempo decorrido desde sua implantação. Com a finalidade de se acessar o efeito das áreas protegidas utilizou-se o método de matching excluindo-se a área de influência imediata das unidades territoriais investigadas (buffer), realizando-se, dessa forma, o controle de outras variáveis sobre o estimador (efeito da correlação) e o controle da autocorrelação sobre os resultados (efeito da autocorrelação e efeito vazamento). As análises realizadas neste trabalho indicam que as unidades investigadas desempenham importante papel na proteção do habitat natural na região do Bioma Cerrado, evitando, em conjunto, que 12,18 ha/ $/ \mathrm{km}^{2}$ fossem convertidos para uso antrópico na região ocupada por essas unidades. Além disso, foi observada a influência das áreas protegidas em sua região externa, a uma distância de até $10 \mathrm{~km}$ a partir de seus limites, região utilizada para definir o buffer de exclusão. Diferenças foram observadas em relação aos tipos de unidades consideradas (UC's, TI's e TQ's) e em função dos atributos das Unidades de Conservação. Tal diferença foi especialmente observada entre unidades com diferentes níveis de restrição e entre unidades com criação mais recente e aquelas com criação mais antiga. Outras características, como o tamanho e a esfera governamental a que pertencem as UC's, nem sempre apresentaram influência relevante, variando entre subgrupos de unidades. Os resultados do trabalho sugerem que políticas públicas voltadas à contenção do desmatamento e que considerem a utilização de áreas protegidas, devem priorizar o aumento da área total das unidades de conservação das categorias I, II e IV da IUCN, bem como adotar ações de conservação específicas voltadas a aumentar a capacidade de unidades pertencentes às categorias V e VI em evitar a ocorrência do desmatamento. Aponta, também, a necessidade de se considerar nessas políticas o papel desempenhado pelas Terras Indígenas, haja vista sua grande capacidade em promover a preservação do habitat.

Palavras-Chave: Áreas Protegidas, Unidades de Conservação, Desmatamento, Cerrado. 


\section{SUMÁRIO}

1. INTRODUÇÃO

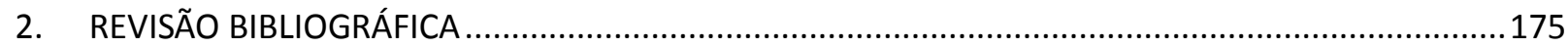

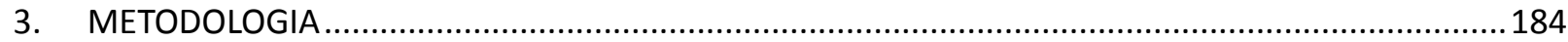

3.1. CARACTERÍSTICAS RELEVANTES DAS ÁREAS PROTEGIDAS NO CERRADO ...............................184

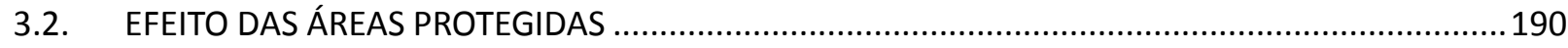

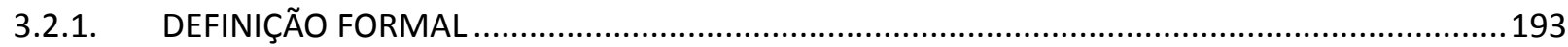

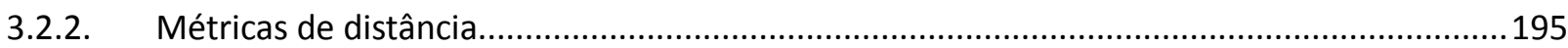

3.2.3. Estimação do efeito médio do tratamento (ATT) ………..................................................197

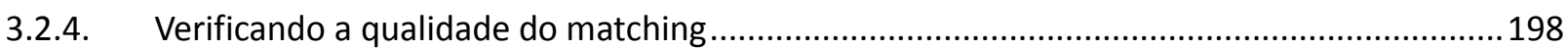

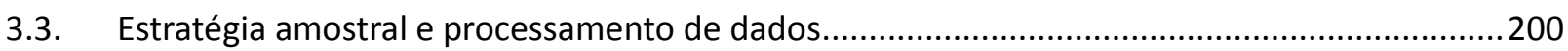

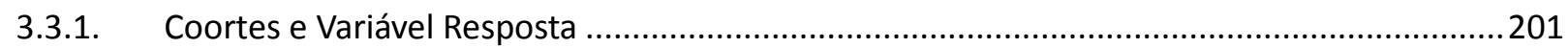

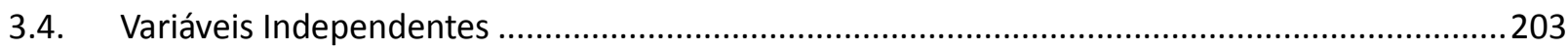

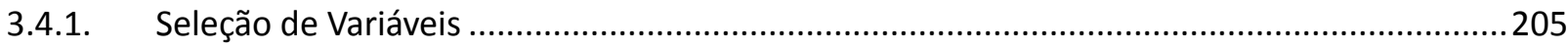

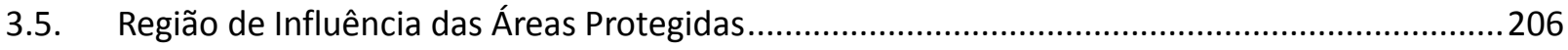

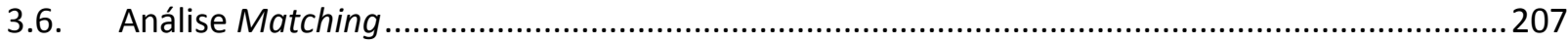

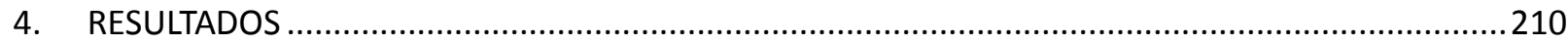

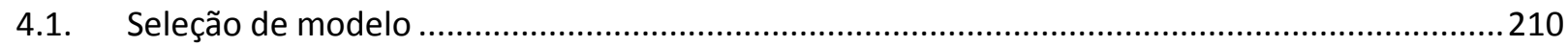

4.2. Influência da área protegida sobre a região próxima.............................................................213

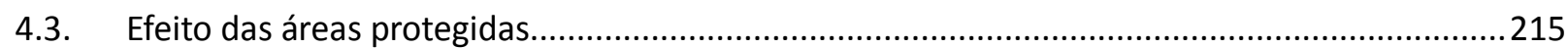

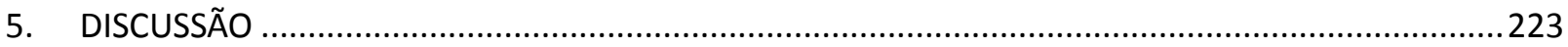

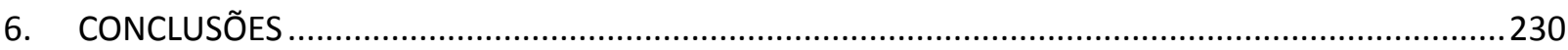

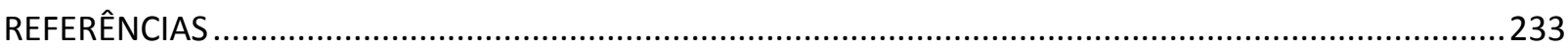

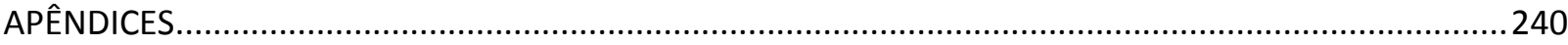

Apêndice 1 -Unidades de Conservação, Terras Indígenas e Terras Quilombola que cumpriram os critérios de amostragem, sendo efetivamente levadas em consideração na análise. Unidades com áreas descontínuas estão listadas independentemente na tabela (ID 41, 230 e 227).

Apêndice 2 - Discussão sobre o efeito do mapeamento nos resultados e questões atinentes à variável resposta.

Apêndice 3 - Variáveis consideradas no estudo e respectiva fonte dos dados..................... 263

Apêndice 4 - Script R para o cálculo do índice relativo (ATT\%)............................................... 265

Apêndice 5 - Sumário de estatísticas obtidas para o grupo dos 15 melhores conjuntos de variáveis (resumido).

Apêndice 6-Resultados obtidos individualmente para os 15 melhores modelos escolhidos.267 
Apêndice 7 - Imagem apresenta a distribuição das unidades amostrais do grupo controle efetivamente utilizadas e scores de Mahalanobis.................................................................... 274

Apêndice 8 - Teste de sensibilidade ao viés oculto de Rosembaum................................... 275

Apêndice 9 - Teste de Wilcoxon-Mann-Whitney para os grupos de unidades analisados. .. 278 


\section{TABELAS}

Tabela 1 - Relação entre as classificações de áreas protegidas, conforme as categorias do SNUC e da IUCN. 185

Tabela 2 - Unidades de Conservação agrupadas por categoria, considerando toda a extensão do território continental brasileiro (Brasil), para o Bioma Cerrado de acordo com dados compilados pelo CNUC/MMA ou paras as unidades que efetivamente participaram deste estudo (Estudo). 186 Tabela 3 - Unidades de conservação agrupadas em relação à esfera de governo, considerando toda a área continental brasileira (Brasil) ou para as unidades do Cerrado que efetivamente participaram deste estudo (Estudo)

Tabela 4 - Unidades amostrais do grupo tratamento e controle resultantes em cada uma das coortes definidas.

Tabela 5 - Percentual de coincidências entre valores preditos e observados para a regressão logística, observando diferentes níveis de antropismo, para os 100 melhores conjuntos e para os 15 conjuntos posteriormente selecionados.

Tabela 6 - Valores obtidos para o matching realizado entre unidades pertencentes aos buffers delimitados e as unidades controle.

Tabela 7 - Estatísticas obtidas para o melhor conjunto de covariáveis, apresentando o efeito das UC's, TI's, TQ's e subgrupos analisados.

Tabela 8 - Estatísticas obtidas para as unidades do grupo controle efetivamente utilizadas para a obtenção dos valores de eficácia.

Tabela 9 - Estatísticas obtidas para o efeito das Unidades de Conservação, agrupadas conforme classificação da IUCN. 


\section{FIGURAS}

Figura 1 - Número de UC's, TI's e TQ's criadas no Cerrado entre 1949 e 2010.

Figura 2 - Fluxograma da metodologia adotada no estudo, a qual tem como principais etapas: préseleção dos melhores conjuntos de variáveis; definição da área de influência imediata; realização de matching para o conjunto teste, realizando-se a seleção dos melhores modelos; realização matching para a obtenção dos resultados finais. 193

Figura 3 - Figura ilustrativa da grade regular com unidades amostrais com dimensão de $1000 \mathrm{~m}$ por $1000 \mathrm{~m}$. A figura apresenta diferentes tipos de unidades do grupo tratamento e unidades do grupo controle após a exclusão das unidades definidas conforme o delineamento amostral adotado. 201 Figura 4 - Imagem representativa com a identificação das 6 coortes de áreas protegidas consideradas, os anos base de cada coorte e o ano de referência a partir do qual foi obtida a variável resposta.

Figura 5 - Causas da conversão antrópica de habitats naturais na região tropical, baseado em diagrama apresentado por Geist \& Lambin (2002). Cinco grandes grupos de forças motrizes subjacentes (ou processos sociais fundamentais) sustentando as causas imediatas do desmatamento, que são as ações humanas imediatas que impactam diretamente a cobertura natural.

Figura 6 - Distribuição dos valores dos escores obtidos para as covariáveis das unidades amostrais do grupo tratamento e controle, demonstrando o suporte comum entre os grupos. 211 Figura 7 - Efeito absoluto dos buffers utilizados para a obtenção da região de influência das unidades territoriais investigadas.

Figura 8 - Correlograma de Moran I, apresentando a relação entre distância das áreas protegidas e antropismo para os primeiros $10 \mathrm{~km}$. Pontos preenchidos $\mathrm{p}<0,05$, pontos vazios $\mathrm{p}>0,05$. 215 Figura 9 - Efeito geral das unidades territoriais investigadas (UC's, TI's e TQ's) e de subgrupos das áreas protegidas. a) efeito absoluto do tratamento; b) efeito relativo do tratamento. Legenda: PA - Todas as unidades; UC - Unidades de Conservação; TI - Terra Indígena; TQ - Terra Quilombola; PI Proteção Integral; US - Uso Sustentável; FE - Esfera Federal; ES - Esfera Estadual; G - maior tamanho; P - menor tamanho; $<02$ - unidades criadas em período anterior a 2002; $>02$ - unidades criadas em período posterior a 2002

Figura 10 - Efeito das Unidades de Conservação subdivididas entre os grupos de Proteção Integral e Uso Sustentável. Legenda: PI - Proteção Integral; US - Uso Sustentável; FE - Esfera Federal; ES Esfera Estadual; $\mathrm{G}$ - maior tamanho; P - menor tamanho; $<02$ - unidades criadas em período anterior a $2002 ;>02$ - unidades criadas em período posterior a 2002.

Figura 11 - Efeito das Unidades de Conservação subdivididas entre os grupos federal e estadual. Legenda: PI - Proteção Integral; US - Uso Sustentável; FE - Esfera Federal; ES - Esfera Estadual; G maior tamanho; $\mathrm{P}$ - menor tamanho; $<02$ - unidades criadas em período anterior a 2002; >02 - unidades criadas em período posterior a 2002

Figura 12 - Efeito das Unidades de Conservação subdivididas entre os unidades de maior tamanho $\left(>271,6 \mathrm{~km}^{2}\right)$ e unidades de menor tamanho $\left(<271,6 \mathrm{~km}^{2}\right)$. Legenda: PI - Proteção Integral; US - Uso Sustentável; FE - Esfera Federal; ES - Esfera Estadual; G - maior tamanho; P - menor tamanho; <02 unidades criadas em período anterior a 2002; $>02$ - unidades criadas em período posterior a $2002 . . .221$ Figura 13 - Efeito das Unidades de Conservação subdivididas entre unidades com criação mais antiga (antes 2002) e unidades com criação mais recente (após 2002). Legenda: PI - Proteção Integral; US Uso Sustentável; FE - Esfera Federal; ES - Esfera Estadual; G - maior tamanho; P - menor tamanho; $<02$ - unidades criadas em período anterior a 2002; >02 - unidades criadas em período posterior a 2002 


\section{INTRODUÇÃO}

A degradação e conversão de habitats naturais para o uso antrópico na região tropical ocupa uma importante posição nas agendas políticas nacionais e globais. No Brasil, o Bioma Cerrado passou a ter recentemente maior relevância em um contexto institucional voltado ao planejamento e execução de políticas públicas destinadas à conservação da biodiversidade e controle do desmatamento, especialmente, em função do elevado grau de ameaça a seus atributos ambientais e bióticos.

O Bioma compreende cerca de $30 \%$ das espécies conhecidas no Brasil e $5 \%$ no mundo (Aguiar, Machado e Marinho-Filho, 2004; Lewinsohn e Prado, 2005) e sofre com acelerado processo de degradação ambiental, a exemplo da perda de habitat natural (IBAMA, 2015), fragmentação da paisagem (Aquino e Miranda, 2008; Carvalho, Marco, De e Ferreira, 2009; Machado, 2000), ameaça aos recursos hídricos (Lima e Silva, 2008) e degradação de solos (Klink e Machado, 2005; Reatto et al., 2008; Resck et al., 2008). O efeito sobre a biota é igualmente relevante, levando o Cerrado a ocupar a segunda pior posição no ranking de biomas com espécies ameaçadas, à frente, apenas, do Bioma Mata Atlântica (Machado, Drummond e Paglia, 2008).

O impacto antrópico sobre áreas naturais no Cerrado são decorrência do processo de ocupação e do modelo de desenvolvimento adotado, com ocupação extensiva do território, cuja intensificação ocorreu a partir da década de 1950, com a fundação da nova capital na região Centro-Oeste (Dias, 2008; Klink e Moreira, 2002; Ribeiro et al., 2005). As políticas com foco no desenvolvimento econômico, levadas a cabo de forma pouco integrada com a preservação de recursos naturais e da biodiversidade, apresentam como resultados mediatos efeitos marcadamente negativos sobre diversos atributos ambientais e ecológicos, além da redução da área total de cobertura vegetal nativa. Sua importância em termos de biodiversidade e o elevado grau de pressão antrópica sobre as áreas naturais, colocaram o Cerrado, desde o ano 2000, entre os hotspots mundiais, áreas especialmente ameaçadas e prioritárias para a conservação no mundo (Mittermeier et al., 2005; Myers et al., 2000).

Avaliações oficiais sobre a preservação do habitat natural no Brasil colocam o Cerrado como o bioma com a maior área absoluta desmatada, com área convertida de 997.063 $\mathrm{km}^{2}$ para o ano de 2011 (IBAMA, 2015) de acordo com o PMDBBS e de $885.021 \mathrm{~km}^{2}$ de acordo com o TerraClass Cerrado (MMA, 2015a), representando 49\% ou 44\% de sua área original (2,03 milhões de $\mathrm{km}^{2}$ ), respectivamente. Apesar de, em termos relativos, outros 
biomas brasileiros encontrarem-se em situação mais crítica, como o Bioma Mata Atlântica, o Cerrado apresenta, recorrentemente, as maiores taxas de desmatamento nos últimos anos (MMA, 2011; Soares-filho et al., 2014).

Recentes alterações na legislação voltada à proteção da vegetação nativa, Lei 12.651, de 25 de maio de 2012, conhecida como Lei de Proteção da Vegetação Nativa, tendem a agravar este cenário, pois o Cerrado é o bioma em que houve a maior redução do débito florestal em função da legalização de desmatamentos pretéritos (16 mil km²), além de ser a região com maiores áreas que se tornaram disponíveis legalmente para a conversão futura (399 mil km²) (Brancalion et al., 2016; Soares-filho et al., 2014).

Em um contexto de ameaça aos recursos ambientais e bióticos, ações que promovam a redução das taxas de desmatamento se fazem necessárias, sendo as áreas protegidas uma das ferramentas mais relevantes. Essas são conceituadas como uma:

\footnotetext{
"área definida geograficamente que é destinada, ou regulamentada, e administrada para alcançar objetivos específicos de conservação" (UNEP/CBD, 1992)

"uma área com limites geográficos definidos e reconhecidos, cujo intuito, manejo e gestão buscam atingir a conservação da natureza, de seus serviços ecossistêmicos e valores culturais associados de forma duradoura, por meios legais ou outros meios efetivos" (Dudley e Stolton, 2008).
}

Tais unidades territoriais, de forma geral, têm por finalidade precípua a conservação in situ da biodiversidade e, embora possam fazer parte de estratégias de conservação com características diversas, a exemplo de unidades que visem conciliar a conservação da natureza com o uso sustentável dos recursos naturais, comumente têm como um de seus pressupostos a manutenção do habitat natural, sendo relacionadas como um dos fatores de influência mediata sobre a dinâmica do desmatamento (Geist e Lambin, 2002).

Ainda que seja reconhecidamente uma das mais importantes medidas utilizadas na contenção do desmatamento (Chape, Spalding e Jenkins, 2008; Naughton-Treves, Holland e Brandon, 2005; Schmitt et al., 2009), as áreas protegidas no Brasil e, também, em outras regiões do mundo, sofrem com limitações e desafios que podem contribuir para que essas não alcancem os resultados esperados, inclusive na manutenção do habitat natural. Exemplos de tais limitações são: a carência de recursos humanos, financeiros e de estrutura física/equipamentos; a capacidade de efetiva guarda do território e a regularidade fundiária (domínio e posse); a compatibilidade do uso efetivo com os objetivos da unidade o qual está relacionado à existência e cumprimento de plano de manejo.

Em levantamento realizado por Lemos de Sá e Ferreira (2000), considerando 86 unidades de conservação no Brasil e as características relevantes dessas, apenas 8,4\% das 
áreas puderam ser consideradas razoavelmente implementadas, sendo 37\% apontadas como minimamente implementadas e 55\% apontadas em situação precária ou não implementadas. Áreas protegidas criadas por meio de instrumentos legais, mas às quais não são efetivamente alocados recursos ou, de forma genérica, que não cumprem minimamente os objetivos a que se destinam, são conhecidas na literatura como paper parks (Figueiredo, 2007; Joppa, Loarie e Pimm, 2008).

Estudos mais recentes e envolvendo um maior número de unidades de conservação no Brasil, também indicaram carência que têm impacto direto sobre o grau de implementação e gestão das áreas protegidas, ainda que destaque a evolução dos indicadores para períodos recentes (IBAMA e WWF, 2007; ICMBIO e WWF, 2012). Nas avaliações realizadas para os anos de 2005-2006 e 2010, levou-se em consideração 245 e 292 Unidades de Conservação no Brasil, respectivamente, e se utilizou o método Rappam (Rapid Assessment and Prioritization) (Ervin, 2003). Nelas, destacaram-se carências relacionadas a recursos humanos, infraestrutura, planejamento da gestão (pesquisa, avaliação e monitoramento) e ao amparo legal das unidades de conservação (regularização fundiária, fiscalização e delimitação).

Embora novos investimentos tenham sido feitos na última década, 56\% das unidades de conservação federais do Cerrado permanecem sem plano de manejo, instrumento imprescindível para a gestão eficiente dessas unidades (ICMBio, 2016). Além disso, em avaliação realizada pelo Plano de Ação Para Prevenção e Controle do Desmatamento e das Queimadas no Cerrado - PPCerrado (MMA, 2011), foi observado que mesmo dentro dos limites de Unidades de Proteção Integral houve a ocorrência de áreas desmatadas, num total de $727 \mathrm{~km}^{2}$. Unidades de Uso Sustentável apresentam valores absolutos de áreas convertidas bastante superiores, com $3.893 \mathrm{~km}^{2}$. Embora ainda não haja informação oficial sobre passivos fundiários relacionados às áreas protegidas no Brasil, estimativas apontam que 15\% da área ocupada pelas Unidades de Conservação não tem regularidade fundiária, percentual que inclui, principalmente, unidades da categoria de Proteção Integral. Tais fatores podem eventualmente indicar que grupos, categorias ou determinados tipos de unidades de conservação do Cerrado não alcançam seus objetivos, dentre os quais é de interesse especial a este trabalho a relação existente entre esse tipo de unidade territorial e a manutenção do habitat natural.

A partir de compromisso assumido na $10^{\mathrm{a}}$ Conferência das Partes da Convenção sobre Diversidade Biológica - COP 10, por meio do Plano Estratégico Para a Biodiversidade (UNEP/CDB/COP-10, 2010), conhecido como as Metas de Aichi, ou em relação às metas 
estabelecidas pela Resolução $\mathrm{n}^{\mathrm{o}} 6$ da Comissão Nacional de Biodiversidade (MMA/CONABIO, 2013), o Brasil deve ter área mínima de 17\% do território de cada Bioma (e 30\% no Bioma Amazônico) protegidos por esse tipo de unidade territorial, com áreas demarcadas, regularizadas e efetivamente geridas, com vistas a garantir a conectividade e representatividade da paisagem e da biota. O PPCerrado (MMA, 2011), política pública que tem por objetivo a redução de ao menos $40 \%$ da taxa de desmatamento no Bioma, prevê, dentre outras ações, um aumento percentual desse tipo de unidade territorial no Cerrado e a efetiva consolidação das áreas já existentes com vistas a atingir as metas propostas.

Para melhor compreender o papel empiricamente desempenhado pelas áreas protegidas, a literatura científica aborda o efeito ou eficácia dessas unidades sob diferentes enfoques e considerando diferentes objetos de análise. Um dos mais comuns é a influência das áreas protegidas sobre o processo de conversão antrópica de áreas naturais (Geldmann et al., 2013; Joppa e Pfaff, 2010; Nagendra, 2008; Naughton-Treves, Holland e Brandon, 2005).

Bruner et al. (2001) foram um dos primeiros a tratar sobre esse tema tendo como objetivo a mensuração do efeito dessas unidades territoriais. Ainda que a literatura tenha se tornado progressivamente mais sofisticada e especializada, o efeito das áreas protegidas sobre o desmatamento tem sido quantificado como uma medida comparativa da influência dessas unidades territoriais sobre a conversão antrópica do hábitat natural, acessada a partir da comparação com áreas não protegidas.

Tal atributo pode variar em função de: diferenças regionais e locais; métodos utilizados para a avaliação (Geldmann et al., 2013; Joppa e Pfaff, 2010); e em função de diferentes categorias de restrição a que pertencem as áreas protegidas (Joppa e Pfaff, 2011; Nelson e Chomitz, 2009, 2011; Nepstad et al., 2006). Conforme observado por Paiva, Brites, \& Machado (2015), outros atributos podem ter influência relevante sobre o efeito dessas áreas, tais quais: a esfera governamental a que pertencem; o tempo decorrido desde o ato de criação da área; e o tamanho da unidade. Como resultado desse conjunto diverso de fatores, há estudos que apontam a existência de unidades ou categorias de unidades cujos efeitos são positivos (eg. Andam et al., 2008), não são diferentes daqueles percebidos em regiões não protegidas (eg. Nelson, Harris e Stone, 2013) e até mesmo estudos que apontam influência negativa de determinados tipos de áreas protegidas sobre a preservação do habitat (eg. Spracklen et al., 2015).

Para avaliar adequadamente o efeito das áreas protegidas sobre processos antrópicos de conversão do uso e cobertura da terra, como observam Ferraro et al. (2007), Andam et al. (2008), Pfaff et al. (2008), Pfaff (2014), alguns desafios devem ser considerados, como o 
controle sobre o efeito de outras variáveis que também influenciam a probabilidade de conversão antrópica (ex: declividade, intensidade da atividade econômica, tamanho da população, etc); a natureza não aleatória da localização das áreas protegidas ao longo do território; e o efeito da autocorrelação espacial. Embora a literatura a respeito do tema nem sempre se preocupe em realizar adequadamente o controle da influência desses fatores, atualmente adota-se soluções metodológicas que indiquem resultados mais confiáveis, diminuindo eventuais superestimativas ou subestimativas.

A grande maioria dos estudos existentes sobre o tema no Brasil se referem ao Bioma Amazônico (Adeney, Christensen e Pimm, 2009; Nepstad et al., 2006; Soares-Filho et al., 2006; Yanai et al., 2012), sendo ainda escassos os trabalhos que abordem a região do Cerrado. A pouca atenção dada a ambientes não florestais, como o Cerrado, não é coerente com a importância biológica e a pressão antrópica que sofre essa região.

Em um contexto de ameaça à biodiversidade, recursos e serviços ambientais, e em que se observa a continuidade do processo de conversão de habitats naturais no Cerrado, é relevante conhecer o efeito esperado das áreas protegidas sobre a manutenção do habitat natural, se essas unidades territoriais são potencialmente eficazes na diminuição do processo de conversão antrópica em uma escala regional e se diferentes atributos dessas áreas têm influência sobre seu efeito.

O trabalho proposto abordou os questionamentos acima relacionados, tratando de um tema ainda pouco explorado na literatura científica sobre o Cerrado e de aspecto relevantes da dinâmica do desmatamento nesta região. Os resultados possibilitam uma avaliação sobre o papel desempenhado por essa ferramenta de conservação, trazendo-nos informações sobre: o desempenho relativo das unidades de área protegida em relação à região não protegida; o desempenho relativo entre diferentes subgrupos das unidades territoriais investigadas (tipo de unidade, nível de restrição, esfera governamental, tamanho, tempo desde sua fundação); além de se obter a influência das áreas protegidas sobre regiões fora de seus limites e imediatamente próximas (buffer).

Além de servir como um diagnóstico da situação efetivamente observada, os resultados contribuem para a obtenção de informações fundamentais para a elaboração de políticas públicas voltadas à conservação do meio ambiente e da biodiversidade, em especial para o planejamento territorial ou políticas que visem a contenção do desmatamento, incluindo o uso potencial de tais informações na modelagem de cenários futuros. 


\section{REVISÃO BIBLIOGRÁFICA}

A eficácia das áreas protegidas sobre a preservação do habitat natural passou a ser tópico de interesse da literatura científica internacional, em especial, a partir da última década. Por vezes, na literatura associada, sobre a conservação da biodiversidade e do planejamento territorial, têm-se observado referências a unidades com baixa capacidade de gerenciamento, com existência institucional/legal, mas nem sempre com efetiva implantação e, portanto, com questionável cumprimento de seus objetivos (Figueiredo, 2007; Joppa et al., 2008).

Em face de tais questionamentos, a literatura sobre o efeito das áreas protegidas surgiu com o objetivo de investigar a influência fática dessas unidades territoriais sobre objetivos voltados à conservação do habitat, partindo de uma abordagem empírica. Nos trabalhos que abordam a relação entre área protegida e a conversão antrópica do habitat natural, a eficácia ou efeito é tratado como medida comparativa da influência das áreas protegidas (unidade territorial com uso e acesso especialmente regulados) com regiões não protegidas, levando-se em conta a variável quantitativa capaz de apontar o efeito desse tipo de unidade territorial (Andam et al., 2008).

Naughton-Treves et al. (2005), Nagendra (2008) e Geldmann et al. (2013), realizaram revisões bibliográficas dos estudos produzidos sobre o tema, abrangendo período até o ano de $2010^{1}$. Os autores relacionaram 64 artigos, sendo o primeiro estudo publicado no ano de 1992, ainda que a literatura sobre o tema tenha ganhado maior destaque a partir de 2001, com a publicação de Bruner et al. (2001). A partir da literatura relacionada, os autores obtiveram indicações sobre algumas características importantes relativas aos trabalhos como: as regiões tipicamente abrangidas nos estudos, os tipos de ambientes mais pesquisados, os tipos de resultados obtidos para o efeito dessas áreas e os fatores de influência, além da escala abrangida pelos trabalhos.

Os autores verificaram que os estudos existentes sobre o tema abrangem de forma desigual diferentes regiões geográficas, tratando de forma mais recorrente áreas protegidas na região tropical. Além disso, apenas uma quantidade residual de trabalhos tratava de ambientes com formações vegetacionais tipicamente não-florestais, a exemplo do Cerrado.

\footnotetext{
${ }^{1}$ Em levantamento bibliográfico, ainda em curso, abrangendo período entre 2010 e 2015, observou-se aproximadamente 110 novas publicações sobre o tema, informação indicativa da importância crescente do tema em estudo.
} 
Em geral, os trabalhos desenvolvidos reportam resultados positivos para a estimativa do efeito das áreas protegidas em manter o habitat natural. Nas revisões bibliográficas acima citadas, observa-se que 109 conjuntos de dados reportaram um efeito positivo das áreas protegidas, 13 reportaram efeito nulo, 12 efeito negativo e 7 não tiveram resultado conclusivo apontado. Embora a grande maioria dos estudos indique a eficácia dessas áreas em conter a conversão de habitats naturais, a magnitude de tais resultados varia em função do método utilizado para a estimativa, da escala do trabalho e também em função de características inerentes às áreas protegidas.

O fator de influência sobre o efeito das áreas protegidas na preservação do habitat mais comumente considerado nos estudos realizados são os grupos/categorias de restrição ao uso e acesso a que essas pertencem. Vários estudos mostram que aquelas unidades pertencentes a categorias de maior restrição apresentam maior efeito sobre a preservação do habitat do que aquelas com menor restrição (Joppa e Pfaff, 2011; Nelson e Chomitz, 2009, 2011; Nepstad et al., 2006). Além disso, avaliações realizadas apontam que, apesar de não serem internacionalmente consideradas como áreas protegidas, as Terras Indígenas apresentam influência compatível com as categorias de maior restrição (Nelson e Chomitz, 2009; Nepstad et al., 2006).

Quanto à escala espacial, observam-se estudos que abrangem desde uma escala local, com resultados geralmente mais sensíveis (um efeito da escala do trabalho), até todo o sistema terrestre, com resultados menos sensíveis a pequenas variações. Exemplos para uma escala local são os trabalhos realizados por Curran et al. (2004), em Bornéu (Indonésia), e por Wang et al. (2013), nas Ilhas Hainan (China), em que os autores investigaram a influência de uma ou poucas unidades de área protegida sobre o território contiguo, com uma extensão espacial de até $100 \mathrm{~km}^{2}$. Para escalas regionais, Barber et al. (2012) e Nepstad et al. (2006), por exemplo, avaliaram a influência de diferentes tipos de áreas protegidas sobre a preservação de habitats naturais na área definida para todo o Bioma Amazônico. Tais estudos investigaram a influência de um número variável de unidades sobre grandes áreas. Em uma escala que abrange todo o sistema terrestre, estudos como os de Bruner et al. (2001), DeFries et al. (2005), Nelson e Chomitz (2011) e Spracklen et al. (2015), consideraram toda a região tropical para a investigação da influência das áreas protegidas.

A literatura científica sobre o tema aplica uma ampla diversidade de abordagens metodológicas para a obtenção de indicador que expresse o efeito das áreas protegidas. Conforme observado por Geldmann et al. (2013) e Joppa \& Pfaff (2011) e Andam et al. (2008), os principais fatores que diferenciam as metodologias existentes são: 1) a variável 
resposta ou estimador considerado na análise; 2) a definição do elemento utilizado como base para comparação com aquele obtido para áreas protegidas (elemento contrafactual); 3) utilização de controles de viés estatístico, ou seja, o controle da influência de outras variáveis sobre o evento investigado (ocorrência de desmatamento).

Quanto à variável resposta ou variável estimadora, esse tipo de avaliação leva em conta eventos com efeitos diretos ou correlacionados à conversão antrópica de habitats naturais. A maioria dos estudos utiliza estimadores baseados no cômputo de áreas de desmatamento ou na presença de classes de uso antrópico (e.g. urbano, agrícola, pastagens artificiais, solo exposto), analisando dados absolutos (áreas totais convertidas) para um mesmo período ou sua variação entre períodos diferentes. Nesse mesmo contexto, também são utilizadas taxas de alteração entre períodos ou, ainda, a probabilidade de alteração entre diferentes estados (antrópico x natural) (eg. Pelkey, Stoner e Caro, 2000; Yanai et al., 2012). Para além dessas possibilidades, também são utilizados na literatura eventos correlacionados a alterações no uso e cobertura da terra com vistas a se comparar o desempenho das áreas protegidas. Adeney et al. (2009), Nelson e Chomitz (2011), Nepstad et al.(2006) utilizaram, por exemplo, a ocorrência/frequência de incêndios florestais.

Outro importante fator que define diferentes metodologias adotadas sobre o tema, é o elemento utilizado para comparação com as áreas protegidas. Considerando-se que essas unidades territoriais são regiões que recebem determinado tratamento (restrição ao uso e acesso, normalmente implementados por meio de estrutura física e restrições legais/institucionais), cujo efeito se busca quantificar, faz-se necessária a escolha de um elemento contra o qual a variável resposta escolhida será comparada. Definir de forma apropriada uma referência base para a medida do desflorestamento evitado pode ser desafiador, visto que a comparação com períodos ou regiões diferentes daquelas da própria área que se busca estimar sempre traz erros implícitos que devem ser controlados. Conforme Ferraro et al. (2007), o elemento de comparação ideal, mas inatingível, seria a própria área delimitada pela área protegida, na hipótese de nela não ter sido implantada qualquer unidade dessa natureza.

Os elementos contrafactuais ou de comparação, baseados nas classificações de Joppa \& Pfaff (2010) e de Geldmann et al. (2013), são: comparação com períodos próximos, comparação com toda a área não protegida, comparação com regiões adjacentes às áreas protegidas e comparação com regiões similares. 
A primeira abordagem, ou seja, a comparação com período próximo, abrange trabalhos que utilizam como elemento contrafactual a mesma área em análise, considerando, contudo, períodos diferentes (momento anterior à criação da área protegida). Tais publicações consideram apenas a região delimitada pelas unidades de área protegida ou levam em conta, também, regiões próximas, sendo utilizados períodos anteriores e posteriores à implantação da área protegida para a realização de comparações entre as variáveis estimadoras adotadas, por exemplo, taxas de conversão do habitat. Um dos problemas apresentados por esse tipo de abordagem, que compara estimadores entre diferentes momentos para uma mesma área, é que eventuais variações temporais na pressão antrópica regional podem ocasionar uma subestimação ou superestimação do efeito das áreas protegidas em análise (Nagendra, 2008). No caso de um aumento das taxas de desmatamento regionais, por exemplo, como resultado, seria esperada uma subestimativa do efeito das áreas protegidas, pois em média toda a região, e não só a área delimitada pelas unidades territoriais investigadas, em média, apresentam maiores níveis de conversão antrópica do que período anterior, com menores taxas de desmatamento.

Outra abordagem utilizada é a que compara eventuais alterações antrópicas ocorrentes no interior das áreas protegidas com aquelas observadas em toda a área externa definida em um mesmo momento no tempo. Nesse tipo de abordagem, a área externa utilizada para comparação pode ser toda a área de um país ou território (Pelkey, Stoner e Caro, 2000); toda uma sub-região de interesse (Messina et al., 2006; Sanchez-Azofeifa et al., 2003; Yanai et al., 2012) ou mesmo toda uma região do sistema terrestre, a exemplo da região tropical (DeFries et al., 2005).

A comparação com toda a área externa pode não ser uma abordagem adequada, uma vez que as áreas protegidas não são alocadas aleatoriamente no território, sendo comum situarem-se em regiões com menor propensão ao uso antrópico (Joppa e Pfaff, 2009). É provável nesse caso que, em média, a área externa apresente maior probabilidade de sofrer conversão antrópica quando comparado com as áreas protegidas consideradas, resultando em uma superestimação dos resultados obtidos.

A maioria dos estudos realizados utiliza como elemento de comparação informações colhidas em regiões adjacentes às áreas protegidas, em análise conhecida como "análise de buffer". Normalmente tais estudos analisam estimadores em diferentes distâncias, ou, ainda, como é o caso do estudo realizado por Barber et al. (2012), propõem métricas que visam sumarizar em um único estimador a eficácia das áreas protegidas a partir da comparação com regiões próximas. Um dos principais problemas na utilização deste método é que o espaço 
adjacente às áreas protegidas pode sofrer influência em seu uso decorrentes da presença desse tipo de unidade, aumentando ou diminuindo a probabilidade de ocorrência de eventos de conversão antrópica de forma não proporcional ao restante do território (autocorrelação espacial). Além disso, podem sofrer com evento conhecido como efeito vazamento, abordado abaixo. A comparação dos estimadores de eficácia entre regiões adjacentes e o interior das áreas protegidas pode implicar a subestimação ou superestimação do efeito estimado para aquelas unidades.

As abordagens metodológicas mencionadas falham em relação a duas questões fundamentais a serem observadas pelo desenho experimental adotado: o controle de viés estatístico quanto à não aleatoriedade da alocação das áreas protegidas (erro de correlação espacial) e o controle da autocorrelação espacial (Ewers e Rodrigues, 2008; Ferraro et al., 2007; Joppa e Pfaff, 2010; Nelson e Chomitz, 2009).

Green e Sussman (1990), Hunter e Yonzon (2013), Pauchard e Villarroel (2002), Scott et al. (2001), Brandon e Redford (1998) e Evans (1999) sugerem que Áreas Protegidas são estabelecidas de forma não aleatória ao longo do território em diferentes regiões do mundo. Geralmente a instalação dessas unidades ocorre em regiões com menor adequação para o uso humano, com menor oposição política à sua instalação, ou, ainda, devido à própria natureza dessas áreas, que têm, por definição, o objetivo de preservarem regiões com atributos ambientais ou biológicos especialmente importantes, os quais não estão distribuídos aleatoriamente (MMA e SBF, 2002; Myers et al., 2000; Scaramuzza et al., 2008). Em estudo envolvendo 147 países, considerando a conversão de habitats naturais e sua relação com áreas protegidas, Joppa \& Pfaff (2009) demonstraram uma alta correlação da localização das áreas protegidas com regiões de maior elevação, declividade, distância a estradas e menor adequabilidade à agricultura. Portanto, em trabalhos que visem avaliar o efeito de áreas protegidas na manutenção do habitat natural, o controle de outras variáveis mostra-se necessário a fim de não se atribuir às áreas protegidas efeito decorrente de covariáveis que também têm influência sobre a dinâmica de desmatamento. Esse tipo de viés foi denominado por Ferraro et al. (2007) como erro de correlação espacial (spatial error correlation).

O uso de um modelo amostral que desconsidere formas de controle desse tipo de viés pode tornar frágeis os resultados obtidos, pois comparam regiões com diferentes características ambientais e sob dinâmicas sociais, históricas e econômicas diferentes, implicando probabilidades de conversão antrópica não similares (Ferraro et al., 2007; Joppa e Pfaff, 2009, 2010; Nelson e Chomitz, 2009). Em geral, a falta de controle sobre este tipo de erro tem como resultado uma superestimava da eficácia das áreas protegidas, já que as 
compara com regiões que, em média, possuem maior probabilidade de conversão antrópica do que a das áreas protegidas. É o que ocorre, por exemplo, em abordagens metodológicas que utilizam como elemento contrafactual todo o ambiente externo.

O segundo tipo de erro cujo controle é importante ocorre quando a regulação sobre o uso de determinado território pode afetar a probabilidade do tipo de uso e ocupação de áreas próximas, um efeito relacionado à autocorrelação espacial (Ferraro et al., 2007). No caso de áreas protegidas, observa-se que a regulação e restrição do uso da terra pelo poder público frequentemente resulta em alterações no uso de regiões próximas não reguladas (Ament e Cumming, 2016; Wu, 2000; Wunder, 2008). A comparação com áreas sob a influência direta dessas unidades resulta em viés estatístico, pois o evento cujo efeito busca-se estimar tem influência sobre a região utilizada para comparação.

O efeito vazamento (spillover, leakage, displacement ou enhancement) é um tipo especial de erro relacionado à autocorrelação espacial (Ewers e Rodrigues, 2008; Ferraro et $a l ., 2007)$. No contexto do estudo de áreas protegidas, tal efeito refere-se ao deslocamento de atividades antrópicas de forma acentuada causado pela regulação do uso da terra por parte do poder público (Fearnside, 2008; Joppa e Pfaff, 2010; Yanai et al., 2012).

Ferraro et al. (2007) classificaram o efeito vazamento em negativo, quando a instalação da área protegida ocasiona o aumento da pressão antrópica em suas imediações (eg. aumento de atividades econômicas agrícolas); ou positivo, quando a instalação da área protegida ocasiona uma diminuição da pressão antrópica em suas imediações (eg. formação de novas áreas protegidas próximas, inibição do aumento da infraestrutura de transporte na região).

No caso de efeitos de vazamento positivo, a comparação com a área do entorno das áreas protegidas pode levar a uma subestimação da eficácia daquelas unidades, pois o entorno deve ter uma maior probabilidade de preservação de habitat natural do que áreas similares não imediatamente próximas. Por sua vez, no caso de efeito vazamento negativo, há uma superestimação do efeito dessas áreas, uma vez que o elemento contrafactual possui maior probabilidade de alteração antrópica do que outras regiões não afetadas pela presença dessas unidades territoriais.

Dessa forma, estudos que consideram como elemento contrafactual a área de um buffer são propensos a sofrer viés estatístico devido a externalidades decorrentes da implantação das áreas protegidas. Geldmann et al. (2013) e Joppa \& Pfaff (2011) observaram que, em geral, estudos que utilizaram a análise de buffer reportam maiores efeitos do que aqueles que utilizaram modelos de regressão ou análises com regiões similares. 
Embora a comparação com regiões próximas (análise de buffer) ou com toda a região externa sejam as abordagens metodológicas mais comumente utilizadas (Geldmann et al., 2013; Nagendra, 2008), a estratégia mais promissora é aquela que considera como elemento contrafactual regiões similares àquelas observadas no interior das áreas protegidas, levando em consideração variáveis relevantes no contexto da dinâmica de desmatamento na região de estudo (ex.: altitude, declividade, distância a estradas, distância a cidades, distância a rios, densidade populacional, nível de atividade econômica).

O viés causado pelos dois tipos de erros mencionados pode ser significativamente reduzido com a utilização de metodologia que permita a comparação entre regiões com características similares, mas que difiram apenas em relação à existência ou não de área protegida (tratamento cuja influência almeja-se observar); e, ao mesmo tempo, possibilite que regiões situadas em um espaço não contíguo àquele das áreas protegidas sejam levadas em conta como elementos contrafactuais. Como demonstraram Andam et al. (2008), Ferraro et al.(2007), Joppa e Pfaff (2010), a utilização do método de matching torna possível a obtenção de resultados com o controle do viés estatístico causado pelas covariáveis, além daquele oriundo de efeitos da autocorrelação espacial.

Um dos primeiros estudos que aplicou o método de matching para a obtenção da eficácia das áreas protegidas na contenção da conversão do habitat natural foi o de Andam et al. (2008). Até o ano de 2015, essa metodologia foi utilizada por ao menos 25 estudos, sendo 8 deles publicados em período anterior a 2010 (Geldmann et al., 2013).

No Brasil, a grande maioria dos estudos existentes sobre o tema se refere a ambientes florestais, tratando, em especial, de áreas protegidas do Bioma Amazônico (Adeney, Christensen e Pimm, 2009; Nepstad et al., 2006; Soares-Filho et al., 2006; Yanai et al., 2012). Estudos recentes, no entanto, passaram a abordar também a região definida pelo Bioma Cerrado. Três publicações têm por área de estudo esta região até o momento (Carranza et al., 2013; Françoso et al., 2015; Paiva, Brites e Machado, 2015).

Carranza et al. (2013) consideraram em seu estudo as Unidades de Conservação e Terras Indígenas existentes em toda a área do Cerrado. O estudo teve como elemento de comparação regiões similares, utilizando-se do método de matching para a estimação do efeito das áreas protegidas e elegendo, a partir da literatura, um único conjunto de covariáveis cujo efeito pretendeu-se controlar. As variáveis consideradas foram: distância a estradas, distância a cidades, pluviosidade, adequação à agricultura e tipos vegetacionais. No estudo, foram investigadas variações em relação aos grupos de unidades de conservação de proteção integral e de uso sustentável, além de Terras Indígenas. Utilizou como variável estimadora 
valores binários indicando se uma determinada área foi convertida ou não entre 2002 e 2009, de acordo com dados obtidos do Sistema Integrado de Alertas de Desmatamento (SIAD) (LAPIG/UFG, 2012), tendo sido efetuado controle da influência da área imediatamente próxima sobre os resultados (exclusão do buffer de $10 \mathrm{~km}$ ). Como resultado, foi indicado que UC's de Proteção Integral e Uso Sustentável, bem como Terra Indígena, apresentaram resultados positivos, com efeito mais proeminente para UC's de Proteção Integral e Terra Indígena.

Françoso et al. (2015) restringiu a análise a Unidades de Conservação, não considerando Terra Indígena. Levou em conta fatores como grupo (Proteção Integral e Uso Sustentável), categoria de restrição (categorias previstas na legislação, com exceção de RPPN), esfera governamental (federal, estadual e municipal), e status de expropriação da área (expropriada ou não expropriada). O estudo foi baseado em análise de buffer, comparando-se a área média antrópica no interior das UC's com a área média antrópica existente no interior de um buffer de $10 \mathrm{~km}$. Teve como referência dados de mapeamento do ano de 2008, não sendo mencionada a fonte do mapeamento utilizado. A metodologia empregada não possibilita o controle de viés relacionado ao efeito de covariáveis ou ao efeito da autocorrelação. Os resultados apontaram um maior efeito das UC's de Proteção Integral, do grupo de unidades federais e das áreas expropriadas. Também foi observado que houve diferentes níveis de antropismo entre as áreas utilizadas como controle entre os grupos, o que pode interferir diretamente nos resultados obtidos.

Paiva et al. (2015) realizaram estudo que abrangeu as áreas protegidas existentes na porção central do Bioma (Estado de Goiás). No trabalho foi realizada análise de diferentes grupos de UC's, observando-se variações quanto ao nível de restrição, esfera governamental, tamanho das unidades e tempo desde o ato de criação dessas; levando-se em conta, ainda, Terras Indígenas e Terras Quilombolas existentes na região. Foi utilizado matching methods para a obtenção do efeito das unidades territoriais consideradas, sendo, previamente realizado teste para a escolha dos melhores conjuntos de covariáveis a serem controladas. O estudo teve como variável resposta a variação em área existente entre o ano base (ano mais próximo à data de criação da área protegida) e o ano de referência, considerando unidades amostrais de 1 $\mathrm{km}^{2}$, com base em mapeamento próprio para os anos de 1985 e 1995, além de mapeamento realizado pelo PMDBBS/IBAMA para períodos posteriores (IBAMA, 2016). No trabalho houve o controle da influência da área imediatamente próxima às unidades territoriais investigadas (exclusão de buffer de $10 \mathrm{~km}$ ), além do controle sobre as covariáveis. Os resultados apontaram importante variação entre os grupos analisados, sendo as unidades mais 
efetivas UC's de Proteção Integral (contribuíram para a manutenção, em média, de 25.34 $\mathrm{ha} / \mathrm{km}^{2}$ de habitat natural), pertencentes ao grupo de unidades da esfera federal, unidades com menor área e unidades mais antigas. Terras Indígenas apresentaram desempenho similar a UC's de Proteção Integral. 


\section{METODOLOGIA}

\subsection{CARACTERÍSTICAS RELEVANTES DAS ÁREAS PROTEGIDAS NO CERRADO}

O presente estudo teve como objeto de análise todas as Unidades de Conservação (UC's), Terras Indígenas (TI's) e Terras Quilombolas (TQ’s) com dados espaciais disponibilizados pelos órgãos oficiais para o Cerrado. De acordo com os limites definidos pelo Mapa de Biomas do Brasil (IBGE, 2004), o Cerrado conta com uma área de 2.036.448 $\mathrm{km}^{2}$, dos quais $13,16 \%$ pertencem a algum dos tipos de unidades territoriais mencionados.

As Unidades de Conservação apresentam-se definidas, em âmbito nacional, pelo Sistema Nacional de Unidades de Conservação (SNUC) (Brasil, 2000) e têm como objetivo primário a conservação biológica. São essas unidades consideradas para o cumprimento das metas da Convenção da Biodiversidade estabelecidas pelas Nações Unidas (MMA, 2010; $\mathrm{UNEP} / \mathrm{CDB} / \mathrm{COP}-10,2010)$, sendo referidas internacionalmente como protected areas.

O SNUC divide as UC's em dois grupos principais: 1) Proteção Integral, cujo objetivo principal é "preservar a natureza, sendo admitido apenas o uso indireto dos seus recursos naturais"; 2) Uso Sustentável, cujo objetivo básico é "compatibilizar a conservação da natureza com o uso sustentável de parcela dos seus recursos naturais". Esses grupos diferem quanto ao grau de restrição ao uso de seus recursos ambientais e bióticos e quanto ao acesso à área. Em regra, unidades do grupo de Proteção Integral apresentam maior nível de restrição do que as unidades do grupo de Uso Sustentável.

Pertencem ao Grupo de Proteção Integral cinco categorias de Unidades de Conservação: Estação Ecológica (ESEC); Reserva Biológica (REBIO); Parque Nacional (PARNA); Monumento Natural (MN) e Refúgio da Vida Silvestre (RVS). Essas podem ser enquadradas entre as categorias de I a III da União Internacional para a Conservação da Natureza (UICN).

Por sua vez, o grupo de Uso Sustentável, é formado por sete categorias: Área de Proteção Ambiental (APA); Área de Relevante Interesse Ecológico (ARIE); Floresta Nacional (FLONA); Reserva Extrativista (RESEX); Reserva de Fauna (REFAU); Reserva de Desenvolvimento Sustentável (RDS); e Reserva Particular do Patrimônio Natural (RPPN). Tais unidades pertencem às categorias de IV a VI da International Union for Conservation of Nature - IUCN (Tabela 1). 
Tabela 1 - Relação entre as classificações de áreas protegidas, conforme as categorias do SNUC e da IUCN.

\begin{tabular}{llcc}
\hline Grupo & Categoria SNUC & Sigla & Categoria IUCN \\
\hline Proteção Integral & Estação Ecológica & ESEC & Ia \\
& Reserva Biológica & REBIO & Ia \\
& Parque Nacional & PARNA & II \\
& Monumento Natural & MN & III \\
& Refúgio da Vida Silvestre & REVIS & III \\
\hline Uso Sustentável & Área de Relevante Interesse Ecológico & ARIE & IV \\
& Reserva Particular do Patrimônio Natural & RPPN & IV \\
& Área de Proteção Ambiental & APA & V \\
& Reserva de Desenvolvimento Sustentável & RDS & VI \\
& Reserva de Fauna & REFAU & VI \\
& Reserva Extrativista & RESEX & VI \\
& Floresta Nacional & FLONA & VI \\
\hline
\end{tabular}

Fonte: Informe Nacional de Áreas Protegidas (MMA, 2007)

Algumas das categorias do SNUC podem ser de propriedade privada (eg. RPPN, MN e RVS), desde que respeitada a compatibilidade entre os objetivos da área protegida e o uso efetivo da área, sendo as atividades desenvolvidas submetidas à supervisão do órgão governamental responsável.

As Unidades de Conservação ocupam 8,26\% de toda a área do Cerrado (168.442 mil $\mathrm{km}^{2}$, num total de 384 unidades), sendo 2,93\% pertencente ao grupo de Proteção Integral (59.790 mil km², total de 120 unidades) e 5,17\% ao grupo de Uso Sustentável (105.512 mil $\mathrm{km}^{2}$, num total de 264 unidades), com 0,3\% de sobreposição entre esses grupos (23.814 mil $\mathrm{km}^{2}$ ) (CNUC/MMA, 2016). Os percentuais apresentados são inferiores em relação à média nacional, com 5,99\% da área continental coberta por Unidades de Proteção Integral e 11,25\% por áreas de Uso Sustentável, em um total de 17,52\% da área continental total de 8.514.085 $\mathrm{km}^{2}$ (Tabela 2). Das áreas mencionadas para o Cerrado, são disponibilizados pelo Ministério do Meio Ambiente dados espaciais de 270 Unidades de Conservação, as quais participaram do processo de amostragem deste trabalho. A maioria das unidades ausentes desse conjunto pertence à categoria de RPPN, as quais normalmente apresentam pequenas dimensões espaciais. 
Tabela 2 - Unidades de Conservação agrupadas por categoria, considerando toda a extensão do território continental brasileiro (Brasil), para o Bioma Cerrado de acordo com dados compilados pelo CNUC/MMA ou paras as unidades que efetivamente participaram deste estudo (Estudo).

\begin{tabular}{|c|c|c|c|c|c|c|c|c|c|c|}
\hline \multirow{2}{*}{ Grupo } & \multirow[b]{2}{*}{ IUCN } & \multicolumn{3}{|c|}{ Brasil* } & \multicolumn{3}{|c|}{ Cerrado* } & \multicolumn{3}{|c|}{ Estudo** } \\
\hline & & $\mathbf{N}$ & Área $\left(\mathbf{k m}^{2}\right)$ & $\%$ & $\mathbf{N}$ & Area $\left(\mathbf{k m}^{2}\right)$ & $\%$ & $\mathbf{N}$ & $\operatorname{Area}\left(\mathbf{k m}^{2}\right)$ & $\%$ \\
\hline ESEC & Ia & 95 & 122161 & $1.43 \%$ & 28 & 11435 & $0.56 \%$ & 28 & 11435 & $0.56 \%$ \\
\hline REBIO & Ia & 59 & 55566 & $0.65 \%$ & 5 & 81 & $0.00 \%$ & 5 & 81 & $0.00 \%$ \\
\hline PARNA & II & 388 & 352955 & $4.15 \%$ & 70 & 48692 & $2.39 \%$ & 67 & 41007 & $2.01 \%$ \\
\hline MN & III & 42 & 1419 & $0.02 \%$ & 12 & 314 & $0.02 \%$ & 12 & 314 & $0.02 \%$ \\
\hline REVIS & III & 38 & 3682 & $0.04 \%$ & 5 & 2460 & $0.12 \%$ & 4 & 1671 & $0.08 \%$ \\
\hline Proteção Integral (PI) & - & 622 & 535783 & $6.29 \%$ & 120 & 62982 & $3.09 \%$ & 116 & 54509 & $2.67 \%$ \\
\hline ARIE & IV & 49 & 1017 & $0.01 \%$ & 16 & 87 & $0.00 \%$ & 16 & 87 & $0.00 \%$ \\
\hline RPPN & IV & 808 & 5540 & $0.07 \%$ & 161 & 1069 & $0.05 \%$ & 57 & 441 & $0.02 \%$ \\
\hline APA & $\mathrm{V}$ & 300 & 419616 & $4.93 \%$ & 68 & 108504 & $5.32 \%$ & 62 & 105162 & $5.15 \%$ \\
\hline FLONA & VI & 106 & 314130 & $3.69 \%$ & 11 & 557 & $0.03 \%$ & 11 & 557 & $0.03 \%$ \\
\hline RESEX & VI & 90 & 139362 & $1.64 \%$ & 6 & 883 & $0.04 \%$ & 6 & 880 & $0.04 \%$ \\
\hline RDS & VI & 37 & 112097 & $1.32 \%$ & 2 & 686 & $0.03 \%$ & 2 & 685 & $0.03 \%$ \\
\hline REFAU & VI & 0 & 0 & $0.00 \%$ & 0 & 0 & $0.00 \%$ & 0 & 0 & $0.00 \%$ \\
\hline Uso Sustentável (US) & - & 1390 & 991762 & $11.65 \%$ & 264 & 111786 & $5.48 \%$ & 154 & 107812 & $5.28 \%$ \\
\hline Total com Sobreposição & - & 2012 & 1527545 & $17.94 \%$ & 384 & 174768 & $8.57 \%$ & 268 & 162321 & $7.96 \%$ \\
\hline PI Sem Sobreposição & - & 622 & 509891 & $5.99 \%$ & 120 & 59790 & $2.93 \%$ & - & - & - \\
\hline US Sem Sobreposição & - & 1390 & 957582 & $11.25 \%$ & 264 & 105512 & $5.17 \%$ & - & - & - \\
\hline Total Sem Sobreposição & - & 2012 & 1491287 & $17.52 \%$ & 384 & 168442 & $8.26 \%$ & - & - & - \\
\hline
\end{tabular}

As unidades participantes do SNUC podem pertencer à esfera governamental federal, estadual ou municipal, dependendo dos agentes responsáveis pela regulação e/ou gestão da unidade. Esses fatores possuem potencial influência sobre o grau de implementação de uma Unidade de Conservação, haja vista que a disponibilidade de recursos ou a suscetibilidade a interesses políticos e econômicos locais pode variar entre as esferas mencionadas. Por conseguinte, é esperada variação sobre o efeito geral das unidades na contenção do desmatamento em função desse atributo.

$\mathrm{Na}$ área de estudo foi observada uma maior presença de unidades da esfera estadual (4,85\% da área de estudo), seguida por unidades da esfera federal (3,06\% da área de estudo) e da esfera municipal $(0,05 \%$ da área de estudo) (Tabela 3). Em função da pequena área ocupada e do número reduzido de unidades da esfera municipal, essas áreas não tiveram seu efeito acessado individualmente. 
Tabela 3 - Unidades de conservação agrupadas em relação à esfera de governo, considerando toda a área continental brasileira (Brasil) ou para as unidades do Cerrado que efetivamente participaram deste estudo (Estudo).

\begin{tabular}{lrrrrrr}
\hline \multicolumn{1}{c}{ Grupo } & \multicolumn{3}{c}{ Brasil } & \multicolumn{3}{c}{ Estudo $^{* *}$} \\
& Num. & Área $\left(\mathbf{k m}^{2}\right)$ & \multicolumn{1}{c}{$\%$} & Num. & Area $\left(\mathbf{k m}^{2}\right)$ & \multicolumn{1}{c}{$\%$} \\
\hline Federal & 146 & 382799 & $4.50 \%$ & 22 & 43865 & $2.15 \%$ \\
Estadual & 348 & 157907 & $1.85 \%$ & 88 & 10492 & $0.51 \%$ \\
Municipal & 142 & 590 & $0.01 \%$ & 6 & 151 & $0.01 \%$ \\
Proteção Integral & $\mathbf{6 3 6}$ & $\mathbf{5 4 1 2 9 6}$ & $\mathbf{6 . 3 6 \%}$ & $\mathbf{1 1 6}$ & $\mathbf{5 4 5 0 9}$ & $\mathbf{2 . 6 7 \%}$ \\
\hline Federal & 814 & 410893 & $4.83 \%$ & 69 & 18532 & $0.91 \%$ \\
Estadual & 483 & 604274 & $7.10 \%$ & 83 & 88470 & $4.34 \%$ \\
Municipal & 96 & 26294 & $0.31 \%$ & 2 & 810 & $0.04 \%$ \\
Uso Sustentável & $\mathbf{1 3 9 3}$ & $\mathbf{1 0 4 1 4 6 2}$ & $\mathbf{1 2 . 2 3 \%}$ & $\mathbf{1 5 4}$ & $\mathbf{1 0 7 8 1 2}$ & $\mathbf{5 . 2 8 \%}$ \\
\hline Total Federal & $\mathbf{9 6 0}$ & $\mathbf{7 9 3 6 9 2}$ & $\mathbf{9 . 3 2 \%}$ & $\mathbf{9 1}$ & $\mathbf{6 2 3 9 7 . 3 6 6}$ & $\mathbf{3 . 0 6 \%}$ \\
Total Estadual & $\mathbf{8 3 1}$ & $\mathbf{7 6 2 1 8 1}$ & $\mathbf{8 . 9 5 \%}$ & $\mathbf{1 7 1}$ & $\mathbf{9 8 9 6 2 . 4 4 6}$ & $\mathbf{4 . 8 5 \%}$ \\
Total Municipal & $\mathbf{2 3 8}$ & $\mathbf{2 6 8 8 4}$ & $\mathbf{0 . 3 2 \%}$ & $\mathbf{8}$ & $\mathbf{9 6 1 . 2 0 7 8 8}$ & $\mathbf{0 . 0 5 \%}$ \\
Total & $\mathbf{2 0 2 9}$ & $\mathbf{1 5 8 2 7 5 8}$ & $\mathbf{1 8 . 5 9 \%}$ & $\mathbf{2 6 8}$ & $\mathbf{1 6 2 3 2 1}$ & $\mathbf{7 . 9 6 \%}$ \\
\hline
\end{tabular}

* CNUC de 09/08/2016 (CNUC/MMA, 2016).

** Calculado a partir de dados espaciais fornecidos pelo Ministério do Meio Ambiente (MMA, 2015b). Área total utilizada como referência: $2.040 .167 \mathrm{~km}^{2}$.

O estabelecimento das UC's no Cerrado se deu a partir de 1949. A taxa de criação dessas unidades foi menor até os anos 1990 (3,15 UC's/Ano), tendo o seu ritmo de implantação aumentado de forma relevante no período entre 1990 e 2010 (8,85 UC's). O aumento da taxa de criação de unidades no período após 1990 pode ser observado especialmente para o grupo de Uso Sustentável (0,55 unidades/Ano até 1990 e de 5,55 unidades/ano após 1990), enquanto o grupo de proteção integral apresentou taxa de criação mais próxima entre os períodos (1,24 unidades/ano até 1990 e de 3,30 unidades/ano até 2010) (Figura 1). Quando observada a evolução em área dessas unidades, verifica-se que unidades pertencentes ao grupo de uso sustentável superaram ao longo do período observado as unidades de proteção integral e as terras indígenas (Figura 2), apresentando taxa de criação por área superior ou próxima ao dobro da dos grupos de unidades anteriormente mencionados a partir da década de $1990^{2}$.

\footnotetext{
${ }^{2}$ Taxa de criação por área após 1990: proteção integral, 1.744 km²/ano; uso sustentável 4.831 km²/ano; Terra Indígena $2.829 \mathrm{~km}^{2} /$ ano; Terra Quilombola $245 \mathrm{~km}^{2} / \mathrm{ano}$.
} 


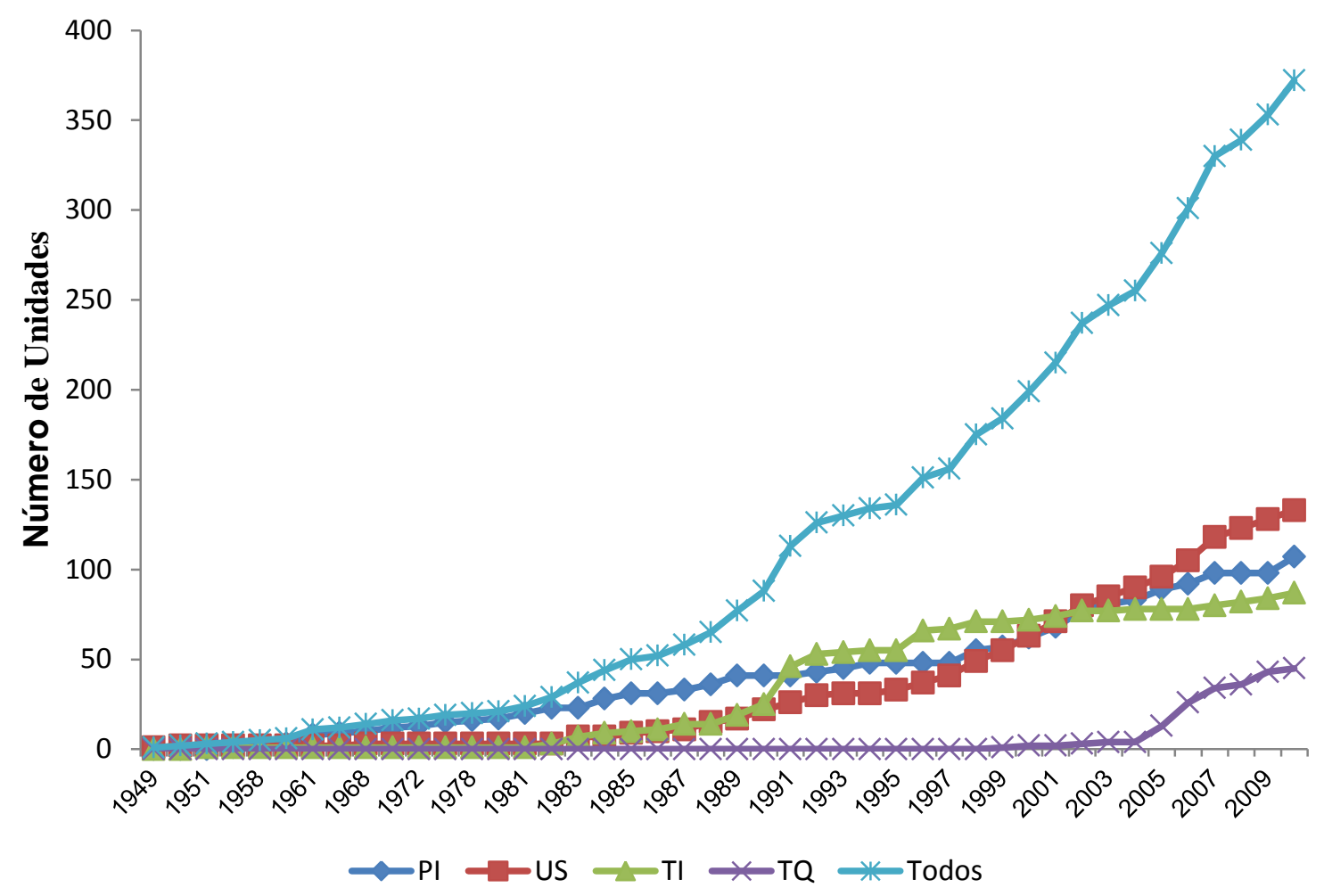

Figura 1 - Evolução em número de UC's, TI's e TQ's criadas no Cerrado entre 1949 e 2010.

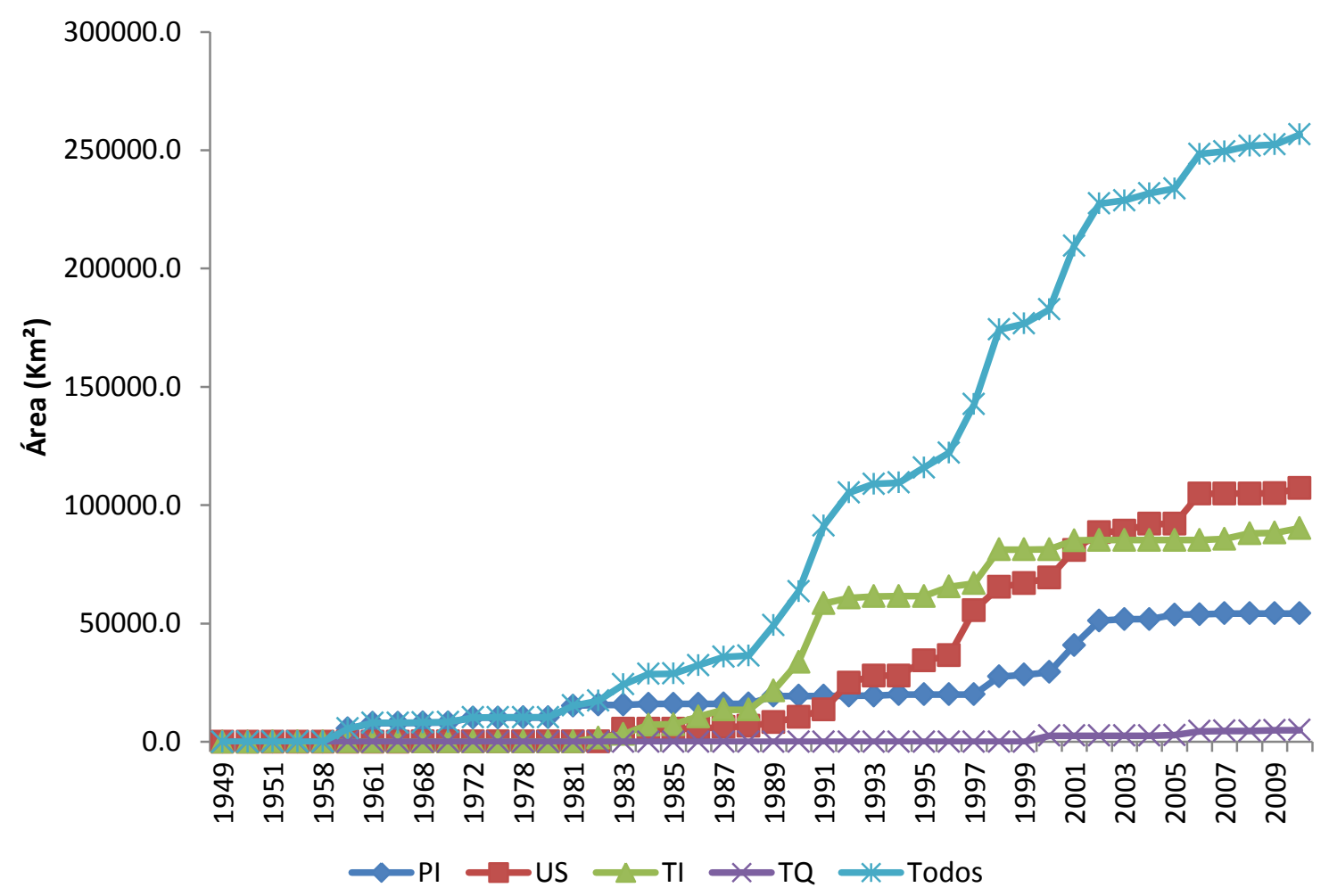

Figura 2 - Evolução em área das UC's, TI's e TQ's criadas no Cerrado entre 1949 e 2010. 
O período com maior ritmo de criação de UC's é coincidente com o estabelecimento da maioria das políticas ambientais em âmbito internacional, das quais destacamos a Convenção da Diversidade Biológica - CDB, e, em âmbito nacional, a Política Nacional do Meio Ambiente, cuja regulamentação se deu por meio do Decreto 99.274/1990 (MMA, 2007).

Entre as Unidades de Conservação que atenderam aos requisitos da amostragem (Apêndice 1), conforme requisitos descritos na Seção 3.3, a idade, ou tempo desde sua criação, variou de 6 a 67 anos, com uma mediana de 18 anos (unidades criadas em 1998 incluídas). O tamanho das unidades variou entre $3,43 \mathrm{~km}^{2}$ e $15.693,05 \mathrm{~km}^{2}$, com média de $1.110,20 \mathrm{~km}^{2}$ e mediana de $271,6 \mathrm{~km}^{2}$. O tempo desde o ato de criação da unidade e o tamanho foram utilizado para a definição de grupos, cujo efeito foi obtido individualmente, conforme descrito na Seção 3.6.

Desde a instituição do Plano Estratégico Nacional de Áreas Protegidas (PNAP) (Brasil, 2006), outras áreas, além das UC's passaram a ser incluídas no contexto de um planejamento amplo e integrado voltado à conservação e manejo da biodiversidade. Além das Unidades de Conservação o plano dá destaque às Terras Indígenas e Terras Quilombolas, unidades territoriais que ocupam extensas regiões naturais e são mantidas e manejadas, geralmente de forma sustentável, por populações tradicionais.

Terras Indígenas e Terras Quilombola têm por função primordial a preservação da diversidade sociocultural, não sendo a conservação biológica ou do habitat seu principal objetivo. Tais unidades territoriais não são reconhecidas pela CDB ou pela IUCN como áreas protegidas, ainda que esses reconheçam o papel de populações tradicionais na conservação da biodiversidade e do habitat natural (IUCN, 2000). Na literatura científica sobre o efeito das áreas protegidas em relação à conservação do habitat, a contribuição das Terras Indígenas é frequentemente considerada (eg. Carranza et al., 2013; Nepstad et al., 2006), enquanto o papel desempenhado pelas Terras Quilombolas permanece ainda muito pouco explorado (Paiva, Brites e Machado, 2015).

Estão presentes na área de estudo 102 unidades de Terra Indígena, com área total aproximada de 96 mil km² (4,7\% da área de estudo) (FUNAI, 2015). A primeira Terra Indígena foi criada no Cerrado em 1951 e, até 1990, apenas 25 outras unidades foram estabelecidas (0,6 unidades/ano). No período entre 1990 e 2010 foram criadas 66 unidades (3,3 unidades/ano). 
As Terras Quilombolas passaram a ter processo de reconhecimento e demarcação iniciados recentemente ${ }^{3}$. A primeira unidade foi estabelecida em 1999, sendo que 51 delas já tiveram seus limites definidos, com área total aproximada de 6 mil $\mathrm{km}^{2}(0,2 \%$ da área de estudo) (INCRA, 2015).

\subsection{EFEITO DAS ÁREAS PROTEGIDAS}

A avaliação do efeito das UC's, TI's e TQ's sobre a conversão antrópica pode ser abordada em um contexto de estudos que observam o efeito médio do tratamento sobre uma variável resposta (Average Treatment Effect on the Treated - ATT). Neste caso, o tratamento pode ser definido como um evento binário, a restrição ou não ao uso e acesso à região delimitada por parte do poder público (área protegida), sendo a variável resposta a área total de habitat natural convertida para uso humano. Nesse contexto, a diferença entre as unidades amostrais do grupo que recebeu tratamento e aquele que não o recebeu quanto à variável resposta pode ser utilizada para se estimar o efeito médio do tratamento.

Conforme previamente mencionado, há dois principais obstáculos a serem superados em um estudo que vise avaliar o efeito desse tipo de unidade territorial, o efeito da correlação e o efeito autocorrelação. O viés causado por esses eventos, contudo, pode ser significativamente reduzido por meio da escolha de um adequado grupo controle, em um desenho amostral que vise mimetizar estudos experimentais randomizados. Nesse tipo de estudo, a avaliação é realizada por meio da designação aleatória de unidades amostrais aos diferentes tratamentos. Tais unidades amostrais diferem apenas quanto às características de interesse no estudo, com demais covariáveis com distribuição comum entre o grupo que recebeu tratamento e aquele que não o recebeu. Em estudos observacionais, como no caso deste trabalho, é desejável a replicação desse tipo de experimento, o mais próximo possível, obtendo-se grupo tratado e controle com covariáveis que possuam distribuição similar entre os grupos (Stuart, 2010).

No método de matching, aplicado a estudos observacionais, o grupo controle é construído ex post. O objetivo geral do método é encontrar, em um grande universo de unidades amostrais que não participaram do tratamento, aquelas que possuem a maior semelhança possível com as unidades que receberam tratamento quanto a características

\footnotetext{
${ }^{3}$ As Terras Quilombolas passaram a ser reconhecidas a partir da Portaria no 307 do Instituto Nacional de Colonização e Reforma Agrária - INCRA, de 22 de novembro de 1995, e, em especial, a partir do Decreto no 4.887, de 20 de novembro de 2003, os quais determinam a identificação, reconhecimento, delimitação, demarcação e titulação das terras ocupadas por remanescentes das comunidades dos quilombos.
} 
relevantes que têm influência sobre a variável resposta (Caliendo e Kopeinig, 2008; Stuart, 2010).

Para a seleção de unidades amostrais do grupo controle (exterior das unidades protegidas) são utilizadas medidas de similaridade. As medidas mais comumente utilizadas nesse caso são o índice de propensão (propensity score) ou medidas de distância multidimensionais, por exemplo, a Distância de Mahalanobis. No primeiro caso, unidades no exterior das áreas protegidas são adicionadas ao grupo controle caso apresentem maior índice de propensão, ou seja, possuam características que indiquem maior probabilidade de pertencerem a uma área protegida. No caso de medidas de distância, unidades amostrais do exterior das áreas protegidas são comparadas com aquelas do interior das áreas protegidas, sendo selecionadas para compor o grupo controle as unidades que apresentem a menor distância em termos de uma medida de distância multivariada.

Para que se obtenham resultados satisfatórios com o uso da referida metodologia deve-se incluir na análise um conjunto relevante de covariáveis, cujo efeito pretende-se controlar. Essas, idealmente, devem explicar na maior medida a probabilidade de ocorrência de eventos de alteração antrópica na área de estudo, refletindo em grande medida as causas diretas ou subjacentes relacionadas à dinâmica do desmatamento na região. A quase totalidade dos estudos não realiza testes estatísticos formais para seleção dos melhores conjuntos de covariáveis, mas as elege a partir da literatura correlata. Além disso, ainda não é comum a avaliação sobre o viés decorrente de covariáveis não incluídas no estudo (hidden bias). A ausência de tais controles pode eventualmente comprometer a qualidade dos resultados obtidos, devendo, idealmente, serem considerados em trabalhos sobre o tema.

Com esse tipo de abordagem é possível se reduzir o viés estatístico causado pelas covariáveis, além de se desviar de efeitos da autocorrelação espacial, uma vez que podem ser levadas em conta unidades amostrais situadas em um espaço não contíguo àquele das áreas protegidas.

Neste estudo, dadas as vantagens mencionadas, foi adotado o método de matching para se acessar o efeito das Unidades de Conservação, Terras Indígenas e Terras Quilombolas sobre a manutenção do habitat natural. Considerando as características do método, Caliendo e Kopeinig (2008) e Stuart (2010) apresentaram como pontos principais para a realização de uma análise com o uso dessa metodologia:

1. A definição das melhores covariáveis que influenciam no resultado da variável estimadora, cujo efeito pretende-se controlar; 
2. A definição de medida de proximidade, com a finalidade de se definir as unidades mais similares. Em geral são utilizados o Índice de Propensão (Propensity Score matching) ou a Distância de Mahalanobis (Mahalanobis Score matching);

3. Características específicas utilizadas pra a implementação de um método matching, dadas as medidas de distância (ex: vizinho mais próximo, Kernel, Raio);

4. Avaliação da qualidade dos resultados obtidos do matching;

Além dos pontos mencionados pelos autores, no caso em estudo, faz-se também fundamental a definição da área de influência das unidades territoriais investigadas, a fim de se controlar o efeito da autocorrelação espacial sobre os resultados.

Baseados nas características do método de análise adotado, bem como nos requisitos teóricos e práticos pertinentes ao tema do presente estudo, subdividiu-se a metodologia em (Figura 3):

a. Definição e obtenção das variáveis de interesse (variável tratamento, variável resposta e covariáveis);

b. Pré-seleção dos 100 conjuntos de covariáveis que melhor expliquem a variação na ocorrência de alterações no uso da terra na região investigada;

c. Definição da área de influência imediata das áreas protegidas e do buffer de exclusão;

d. Realização de matching para o conjunto de 100 melhores covariáveis préselecionadas no item $b$ e seleção dos 15 melhores conjuntos para a obtenção dos resultados finais;

e. Realização e avaliação da qualidade do matching e estimação dos resultados finais; 


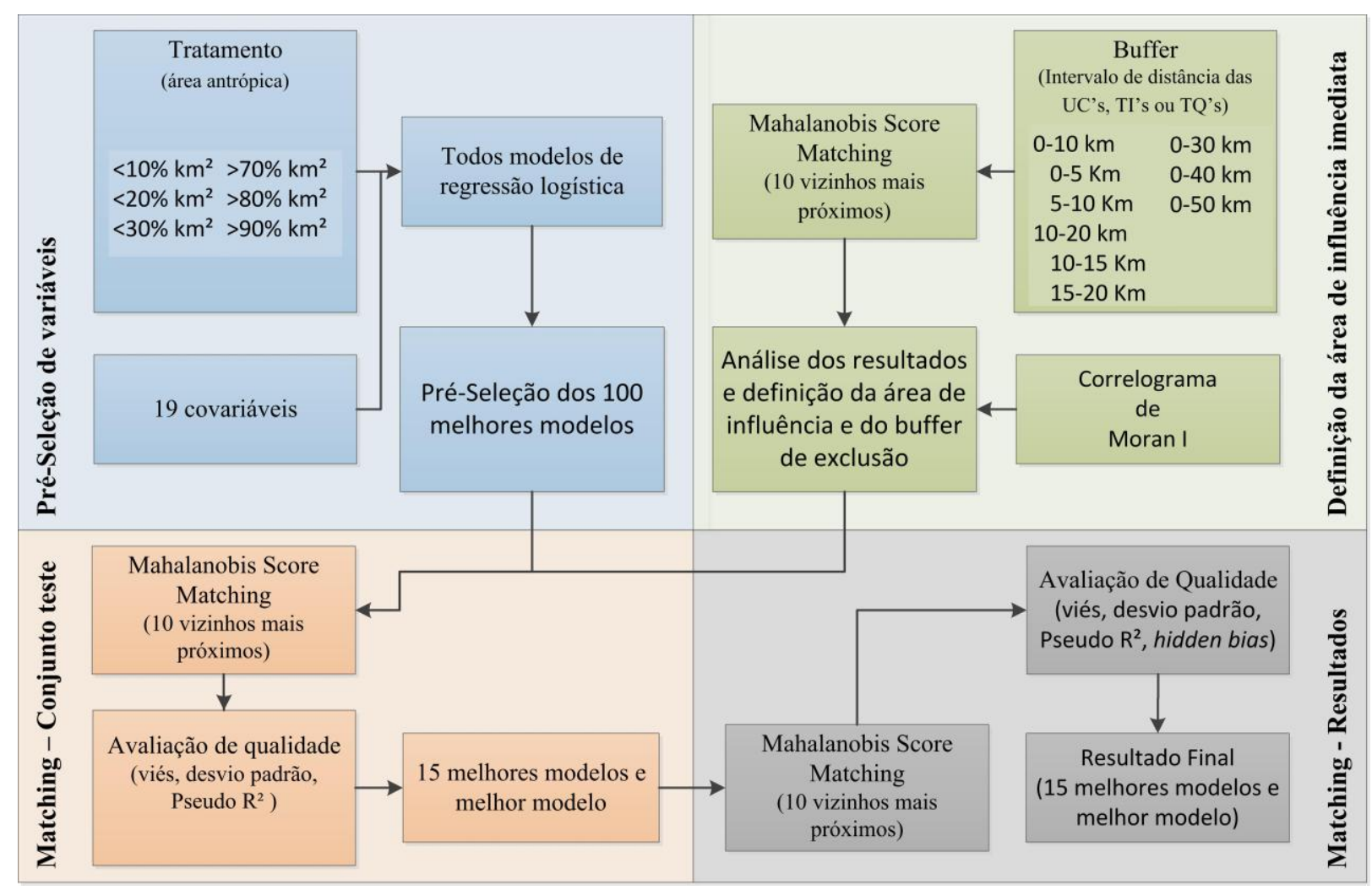

Figura 3 - Fluxograma da metodologia adotada no estudo, a qual tem como principais etapas: pré-seleção dos melhores conjuntos de variáveis; definição da área de influência imediata; realização de matching para o conjunto teste, realizando-se a seleção dos melhores modelos; realização matching para a obtenção dos resultados finais.

\subsubsection{DEFINIÇÃO FORMAL}

O modelo causal de Roy-Rubin (Roy, 1951; Rubin, 1974) formaliza a ideia de inferência causal em termos de resultados potenciais entre grupos que receberam tratamento e aqueles que não o receberam. Nesse modelo, o efeito causal é definido como a diferença entre a observação do resultado entre os grupos tratados e não tratados, os quais correspondem no presente estudo ao conjunto pertencente às Áreas Protegidas e aquele que não faz parte desse tipo de área especialmente regulada, respectivamente.

Sendo $\mathrm{Y}_{\mathrm{iT}}$ o valor da variável resultado para a unidade amostral $i$ pertencente ao grupo $\mathrm{T}$, sendo $\mathrm{T}=1$ para o grupo tratamento e $\mathrm{T}=0$ para o grupo controle, o efeito tratamento $(\tau)$ é idealmente dado para o indivíduo $i$, como:

$$
\tau_{\mathrm{i}}=\mathrm{Y}_{\mathrm{i} \mid 1}-\mathrm{Y}_{\mathrm{i} \mid 0}
$$

Considerando a equação (1), o efeito médio esperado sobre o conjunto de amostras que recebeu tratamento (Average Treatment Effect on the Treated - ATT) poderia ser 
idealmente obtido como a diferença média entre a variável resposta das unidades amostrais $i$ para as situações com e sem tratamento:

$$
\tau \mathrm{ATT}=\mathrm{E}(\tau \mid \mathrm{T}=1)=\mathrm{E}\left[\mathrm{Y}_{1} \mid \mathrm{T}=1\right]-\mathrm{E}\left[\mathrm{Y}_{0} \mid \mathrm{T}=1\right]
$$

As equações 1 e 2 expressam a situação ideal em que uma unidade amostral da área protegida é comparado com aquela mesma unidade, na hipótese de que essa não pertencesse ao grupo tratamento. Considerando não ser possível, para uma situação alternativa binária, uma mesma unidade amostral possuir ambos os valores para a variável resultado (ex: $\mathrm{Y}_{1 \mid 1} \mathrm{e}$ $\mathrm{Y}_{1 \mid 0}$ ), o problema da estimação do efeito tratamento consiste em se obter um substituto adequado para a comparação com as unidades que receberam tratamento, o elemento contrafactual. Esse é representado pelo termo final da equação (2) (“- E[Y(0)|T = 1]”) e não pode ser obtido diretamente, devendo ser estimado a partir da população de dados que não recebeu tratamento.

No caso em análise, não é possível se obter, para uma mesma unidade amostral, integrante do grupo de áreas protegidas, a área antrópica total para a situação em que tal amostra seja integrante do grupo de áreas protegidas e para a situação em que essa mesma amostra não integre o grupo de áreas protegidas. Trata-se, portanto, de uma situação alternativa, em que é necessária a escolha de um bom elemento para a comparação a partir daquelas unidades amostrais disponíveis no restante da área de estudo.

Como elemento contrafactual, não é interessante utilizar o valor médio da variável resultado das amostras não tratadas $\mathrm{E}\left[\mathrm{Y}_{0} \mid \mathrm{T}=0\right]$, visto que, por tratar-se de um estudo observacional, é possível que essas estejam sob a influência de outras covariáveis X (eg. declividade, distância a cidades, distância a estradas), as quais afetam de forma diversa os valores esperados para $\mathrm{T}=1$ e $\mathrm{T}=0$. Em estudos observacionais, as covariáveis quase nunca são equilibradas entre os grupos, pois esses normalmente definem populações distintas de dados (Caliendo e Kopeinig, 2005).

Considerando-se as covariáveis $\mathrm{X}$, pode-se obter amostras com características suficientemente próximas entre os grupos tratamento e controle, de forma que, dadas tais covariáveis, o valor da variável resposta dos grupos possam ser independentes do tratamento, ou seja: $\left(\left\{\mathrm{Y}_{0}, \mathrm{Y}_{1} \perp \mathrm{T}\right\} \mid \mathrm{X}\right)$ (Abadie e Imbens, 2006). A expressão indica que as variáveis pareadas podem, a partir do conjunto de suas variáveis $\mathrm{X}$, apresentar características típicas tanto de unidades do grupo tratamento, quanto do grupo controle, não diferindo em sua probabilidade de pertencimento a um ou outro grupo. $\mathrm{O}$ cumprimento desse pressuposto 
(conhecido na literatura como unconfoundedness) significa que diferenças sistemáticas nos valores das variáveis resultado podem ser atribuídas ao efeito do tratamento, visto que, para as demais covariáveis, as unidades têm comportamento suficientemente semelhante (Stuart, 2010).

Outro pressuposto do método indica a necessidade de que haja sobreposição na variação dos valores das covariáveis entre as unidades amostrais dos grupos tratados e não tratados. Isso permite que, para cada unidade amostral do grupo tratado, seja possível se encontrar uma unidade amostral do grupo não tratado com valor compatível em relação às covariaveis X para estimação do efeito tratamento. O pressuposto da sobreposição é definido como: $0<\operatorname{Pr}(\mathrm{T}=1 \mid \mathrm{X})<1$. Isso assegura que unidades amostrais com valores compatíveis para as covariáveis consideradas possuam uma probabilidade positiva de pertencer aos grupos tratamento ou controle (Caliendo e Kopeinig, 2008). Os dois principais pressupostos (unconfoundedness e overlap) para a realização de uma análise matching são chamados conjuntamente de ignorabilidade.

No processo de escolha dos melhores elementos contrafactuais para comparação com uma determinada unidade amostral, são feitas múltiplas comparações entre possíveis pares, até que se encontre aqueles que possuam a maior similaridade, ou menor distância, em termo das covariáveis de interesse (Caliendo e Kopeinig, 2005; Stuart, 2010). No contexto deste trabalho, a maior similaridade, é definida como a "menor distância" em termos de uma medida multivariada, considerando-se todas as características que individualizam o terreno e que possuam influência sobre a probabilidade de conversão antrópica.

\subsubsection{Métricas de distância}

Garantidos os pressupostos exigidos pelo método matching, pode-se optar por uma ou mais métricas de distância entre as unidades amostrais $i \mid 1$ (para o grupo tratamento) e $i \mid O$ (para o grupo controle), quanto às características de suas covariáveis $\mathrm{X}$, para a escolha das unidades amostrais a serem pareadas.

Para que uma determinada métrica possa ser utilizada como uma medida de distância, é necessário que para cada valor da medida, a distribuição das covariáveis seja semelhante para o grupo tratamento e para o grupo controle, de forma que possibilite a comparação entre os grupos. De tal forma, agrupando-se indivíduos com valores semelhantes, podemos encontrar unidades amostrais com características similares para as covariáveis X. 
Como resultado, podemos obter um grupo controle adequado. A distância (D) entre as unidades amostrais entre os grupos pode ser definida como:

$$
\mathrm{D}=\left|\mathrm{e}_{\mathrm{i} \mid 1}-\mathrm{e}_{\mathrm{i}|0|}\right|
$$

Onde $\mathrm{e}_{\mathrm{i} \mid 1}$ é o valor da métrica que sumariza as covariáveis para o grupo tratamento e $\mathrm{e}_{\mathrm{i} \mid 0} \mathrm{o}$ valor da métrica para o grupo que não recebeu tratamento. As métricas mais comumente utilizadas são o Propensity Score e a Distância de Mahalanobis.

\section{Propensity Score (PS)}

O Propensity Score (PS) pode ser definido como a probabilidade de uma determinada unidade amostral pertencer ao grupo tratado, dadas as covariáveis X (Rosenbaum e Rubin, 1983). Assim, para o indivíduo $i$ podemos definir o Propensity Score $\left(\mathrm{e}_{\mathrm{i}}\left(\mathrm{X}_{\mathrm{i}}\right)\right)$ como:

$$
\mathrm{e}_{\mathrm{i}}\left(\mathrm{X}_{\mathrm{i}}\right)=\mathrm{P}\left(\mathrm{T}_{\mathrm{i}}=1 \mid \mathrm{X}_{\mathrm{i}}\right)
$$

O Propensity Score (PS) varia entre 0 e 1, com valores mais próximos a 0 indicando uma menor probabilidade de pertencimento ao grupo tratamento e 1 uma maior probabilidade de pertencimento. Dessa forma, o elemento $i$, com as covariáveis $X_{i}$ e $e_{i}\left(X_{i}\right)$ com valor próximo a zero, possui uma baixa probabilidade de pertencer ao grupo tratamento $T=1$. Uma maior similaridade quanto ao valor da métrica PS entre duas unidades amostrais, indica uma maior semelhança em termo de suas características observadas.

\section{Distância de Mahalanobis}

A Distância de Mahalanobis (Mahalanobis, 1936) também determina a distância entre as amostras baseada nos valores de suas covariáveis. A Distância de Mahalanobis entre duas amostras é dada como:

$$
\mathrm{D}\left(\mathrm{X}_{\mathrm{i} 0}, \mathrm{X}_{\mathrm{i} 1}\right)=\left\{\left(\mathrm{X}_{\mathrm{i} 0}-\mathrm{X}_{\mathrm{i} 1}\right)^{\mathrm{T}} \mathrm{S}^{-1}\left(\mathrm{X}_{\mathrm{i} 0}-\mathrm{X}_{\mathrm{i} 1}\right)\right\}^{1 / 2}
$$

Onde,

- S é a matriz de covariância;

- $\mathrm{X}_{\mathrm{i} 1}$ é o escore de covariáveis da unidade amostral $i$ que recebeu tratamento $(\mathrm{T}=1)$;

- $\quad \mathrm{X}_{\mathrm{i} 0}$ é o escore de covariáveis da unidade $i$ que não recebeu tratamento $(\mathrm{T}=0)$.

Na Distância de Mahalanobis, cada observação é medida em um espaço multidimensional a partir do centro médio de todas as observações, fornecendo-se um único valor para cada observação. Valores mais elevados representam observações muito afastadas 
da distribuição geral neste espaço multidimensional, sendo a variação dos escores de distância das amostras $X_{i 0}-X_{i 1}$ a distância relativa entre essas unidades amostrais em termo de suas covariáveis.

\subsubsection{Estimação do efeito médio do tratamento (ATT)}

Definidas as distâncias entre as unidades dos tratamentos $T_{i 1}$ e $T_{i 0}$, pode-se definir os pesos correspondentes das covariáveis. Segundo Rubin (1979), de uma forma geral, para o valor esperado da variável resposta $\mathrm{Y}_{\mathrm{i}}$, dado $\mathrm{X}_{\mathrm{i}}$, para o grupo $\mathrm{T}_{\mathrm{i}}$, podemos indicar a superfície de resposta para $\mathrm{Y}_{\mathrm{i}}$ como: $\alpha_{\mathrm{i}}+\mathrm{W}_{\mathrm{i}}(\mathrm{X})$, sendo $\alpha$ constante e $\mathrm{W}$ o peso das covariáveis $\mathrm{X}$. A diferença esperada em relação à variável resposta para os grupos tratamento e controle, com o mesmo valor de $\mathrm{X}$, é dado por $\alpha_{\mathrm{i} 1}-\alpha_{\mathrm{i} 0}+\mathrm{W}_{\mathrm{i} 1}(\mathrm{X})-\mathrm{W}_{\mathrm{i} 0}(\mathrm{X})$. Cumpridos os pressupostos do método matching, a diferença acima pode ser considerada como o efeito do tratamento, sendo a média entre todos os pareamentos seu efeito médio. No caso do presente estudo, todas as variáveis tiveram o mesmo peso, sendo o valor médio do tratamento dado por $\alpha_{\mathrm{i} 1}-\alpha_{\mathrm{i} 0}$.

O cálculo do efeito tratamento pode ser realizado a partir de diferentes algoritmos. Os mais comuns são: vizinho mais próximo, raio e Kernel (Stuart, 2010). No caso do método do vizinho mais próximo (Nearest Neighbor), pode ser considerado o valor da variável resposta de um ou múltiplos vizinhos mais próximos na estimação do efeito do tratamento. Esse método pode ser realizado com ou sem a determinação de uma distância máxima entre os pares (caliper) a serem levados em conta na estimação. Além disso, a estimação pode ocorrer com ou sem reposição, de forma que a unidade amostral do grupo controle $(i \mid 0)$ pode formar apenas um par com uma unidade amostral do grupo tratamento (i|l) ou, no caso de reposição, a unidade do grupo controle pode ser utilizada na formação de mais de um pareamento.

No caso do método raio, é determinado um intervalo de distância a partir do qual todos os pares nele contidos serão incluídos na estimação do efeito tratamento, sendo tomado $\mathrm{Y}_{\mathrm{i}}$ para todas as unidades incluídas nos limites do raio.

O método Kernel, por sua vez, considera todos os pares possíveis entre as populações tratamento e controle, sendo dado um peso maior àqueles pares cuja distância é menor em relação à unidade comparada. O método Kernel pode ser definido também para intervalos determinados da população, sendo conhecido como método estratificado. 
A escolha do método matching a ser utilizado depende principalmente das características dos dados a serem analisados (Stuart, 2010). Por exemplo, quando ocorre a disponibilidade de grande número de amostras no grupo controle, bem distribuídas ao longo da variação do grupo tratamento, havendo, portanto, vários bons possíveis pares para uma única unidade amostral do grupo tratamento, é interessante utilizar procedimento que considere mais de um possível pareamento para a estimação do efeito tratamento. Em situações em que há um pequeno grupo controle, ou em que há uma distribuição não equilibrada desse, é forçoso o uso de pareamento com reposição ou a determinação de uma distância máxima a ser considerada para a formação do pareamento. Tais escolhas implicam uma maior ou menor qualidade do matching, e em um trade-off entre maior viés/menor variância na estimação dos resultados.

\subsubsection{Verificando a qualidade do matching}

A ideia geral no processo de verificação da qualidade do matching baseia-se na comparação entre as diferenças existentes entre o grupo tratamento e controle em um momento anterior à realização do matching e em um momento posterior à sua realização. Grandes diferenças restantes na distribuição entre os grupos após a realização do matching implicam a rejeição do modelo. Um bom matching é obtido quando a distribuição empírica $p$ das unidades amostrais do grupo tratamento são similares às do grupo controle (Stuart, 2010):

$$
p(\mathrm{X} \mid \mathrm{T}=1)=p(\mathrm{X} \mid \mathrm{T}=0)
$$

Nesse caso, há um bom equilíbrio na distribuição entre os grupos para as covariáveis.

As principais formas de verificação de uma boa distribuição são realizadas pela avaliação do viés padronizado (standardized bias) e o viés padronizado médio (Rosenbaum e Rubin, 1985). Esse é definido como o valor percentual que a diferença entre as médias dos grupos tratamento e controle para as covariáveis $\mathrm{X}$ representam em relação à raiz quadrada da média da variância nos dois grupos (ou a média do desvio padrão):

$$
S B=100 * \frac{\bar{X}_{1}-\bar{X}_{0}}{\sqrt{\frac{V_{1}(X)+V_{0}(X)}{2}}}
$$

Onde .

- $\mathrm{V}_{1}(\mathrm{X})$ é a variância de $\mathrm{X}$ para o grupo tratado;

- $\mathrm{V}_{0}(\mathrm{X})$ a variância de $\mathrm{X}$ para o grupo controle; 
O viés padronizado médio é a média obtida para todas as variáveis incluídas no modelo. Para a maioria dos estudos empíricos, um SB inferior a 5\% após o matching é considerado suficiente (Caliendo e Kopeinig, 2008).

Outro estimador da qualidade do matching é a regressão logística das covariáveis em relação aos grupos tratamento e controle. O pseudo- $\mathrm{R}^{2}$ pode ser estimado para antes e após o matching, sendo esse um indicador do quanto a distribuição das variáveis $\mathrm{X}$ explicam a probabilidade de participação em um dos grupos. Após o matching é idealmente esperado que o pseudo- $\mathrm{R}^{2}$ assuma os menores valores possíveis, indicando que, considerando-se apenas as covariáveis de uma dada unidade amostral, essa possa pertencer, indistintamente, tanto ao grupo controle quanto ao grupo tratamento (Caliendo e Kopeinig, 2008).

Um procedimento adicional, após a obtenção dos resultados estimados, é a realização de uma análise de sua sensibilidade a eventuais variáveis não observadas no estudo. A despeito do esforço em controlar características do ambiente com influência sobre a conversão antrópica, é possível que haja outras variáveis não consideradas que possam ser responsáveis por gerar um viés oculto entre o grupo controle e o grupo tratamento, o que pode alterar de forma importante os resultados obtidos.

O método proposto por Rosenbaum (2002) verifica o efeito que a variável não observada $u$ causaria nos resultados para os diferentes níveis de $\Gamma$ (Gamma). Nesse caso, $\Gamma$ é medido em termos de chance, representando quantas vezes uma unidade amostral difere quanto à sua chance de pertencer ao grupo tratamento ou controle em função da variável não observada. Em outras palavras, é o viés oculto causado por características não observadas do ambiente. Um nível $\Gamma=2$, por exemplo, indica que, em função da variável não observada $u$, uma determinada unidade tem 2 vezes mais chance de pertencer ao grupo tratamento (probabilidade de $66,66 \%$ de pertencimento ao grupo tratamento) do que ao grupo controle (probabilidade 33,33\% ao grupo). À medida que o nível $\Gamma$ é aumentado, o efeito da variável não observada sobre os resultados também aumenta. Quando $\Gamma$ tende a valores elevados $(\Gamma \rightarrow \infty)$ a probabilidade de pertencimento das unidades pareadas do matching (i|0 e i $\mid 1$, com valores próximos de co-variáveis, $\mathrm{X}_{\mathrm{i} \mid 0}=\mathrm{X}_{\mathrm{i} \mid 1}$ ) ao grupo tratamento aumenta para próximo de 1 no caso da unidade i $\mid 1$ e diminui para próximo de 0 no caso da unidade i|0.

Para qualquer magnitude de $\Gamma \geq 1$ é calculado o intervalo de possíveis p-valores (Pmáx e Pmín) ou intervalos de confiança do efeito tratamento. As conclusões do estudo são alteradas pelo viés causado por variáveis não observadas para determinado nível de $\Gamma$, em que 
o Pmín apresentar valor reduzido e o Pmáx apresentar valor elevado (maior do que 0.05) (Rosenbaum, 2010). Esse valor é coincidente com a inclusão do efeito nulo no intervalo de confiança para o efeito médio do tratamento. Dessa forma é determinado o viés necessário que a variável não observada deveria causar para que houvesse uma significativa alteração dos resultados obtidos. Estudos que apresentem um Pmáx elevado $(p>0,05)$ para valores de $\Gamma$ próximos de 1 são considerados muito suscetíveis ao viés oculto, enquanto valores $\Gamma$ maiores indicam maior robustez dos resultados. Um valor de $\Gamma$ próximo a 2 é considerado de moderado a alto para estudos observacionais.

\subsection{Estratégia amostral e processamento de dados}

O processamento de dados foi realizado com o objetivo de se obter informações espacializadas referentes às variáveis consideradas (variável tratamento, variável resposta e covariáveis) para uma grade regular com abrangência em toda a área do Cerrado, formada por células com dimensões de $1000 \mathrm{~m}$ por $1000 \mathrm{~m}$.

Cada uma das células da grade regular definiu uma unidade amostral, participando essa do grupo tratamento (células válidas no interior das UC's, TI's ou TQ's), do grupo controle (unidades válidas na região externa às unidades territoriais investigadas) ou do grupo de células excluído da análise (unidades limítrofes, unidades do buffer e unidades com antropismo para a data base de cada coorte). Como resultado da espacialização, previamente à exclusão de unidades em função da seleção realizada, obteve-se uma grade regular com 2.025.394 unidades amostrais, das quais 263.625 referiam-se a unidades pertencentes a áreas protegidas, enquanto 1.761 .739 unidades referiam-se ao restante do território.

Para cada uma das unidades amostrais foram obtidas a eventual ocorrência de área protegida e respectivas características (tipo, grupo, esfera governamental, classe de tamanho e classe de acordo com a data de criação das unidades); a área de uso antrópico em seu interior para os anos de 1985, 1995, 2002, 2008, 2009, 2010 e 2011; além do valor de 19 covariáveis.

O grupo tratamento foi formado por unidades amostrais pertencentes a Unidades de Conservação, Terras Indígenas ou Terras Quilombolas, cujos limites e dados cadastrais foram obtidos a partir de informações oficiais fornecidas pelo Ministério do Meio Ambiente (MMA) (MMA, 2015b), Fundação Nacional do Índio (FUNAI) (FUNAI, 2015) e Instituto Nacional de Colonização e Reforma Agrária (INCRA) (INCRA, 2015). Para o caso de sobreposição espacial entre diferentes tipos de áreas protegidas, considerou-se a unidade amostral como pertencente àquela unidade territorial com maior restrição. Quando ocorreu a sobreposição 
entre diferentes tipos de unidades territoriais, verificado para o caso de UC's e TI's ou entre UC's e TQ's, manteve-se a região como Unidade de Conservação.

Para o caso do grupo tratamento, apenas unidades amostrais completamente incluídas nos limites de uma unidade de área protegida foram consideradas no estudo, sendo descartadas células em regiões limítrofes entre área protegida e área não protegida ou entre áreas protegidas de diferentes tipos ou grupos (Figura 4). Unidades que não cumpriram tal requisito passaram a fazer parte do grupo de exclusão.

Por sua vez, participaram do grupo controle todas aquelas unidades amostrais no exterior das áreas protegidas. Para este grupo, houve a exclusão de unidades amostrais que estivessem na região contigua de influência das áreas protegidas, a qual foi definida de acordo com a análise descrita na Seção 3.5.
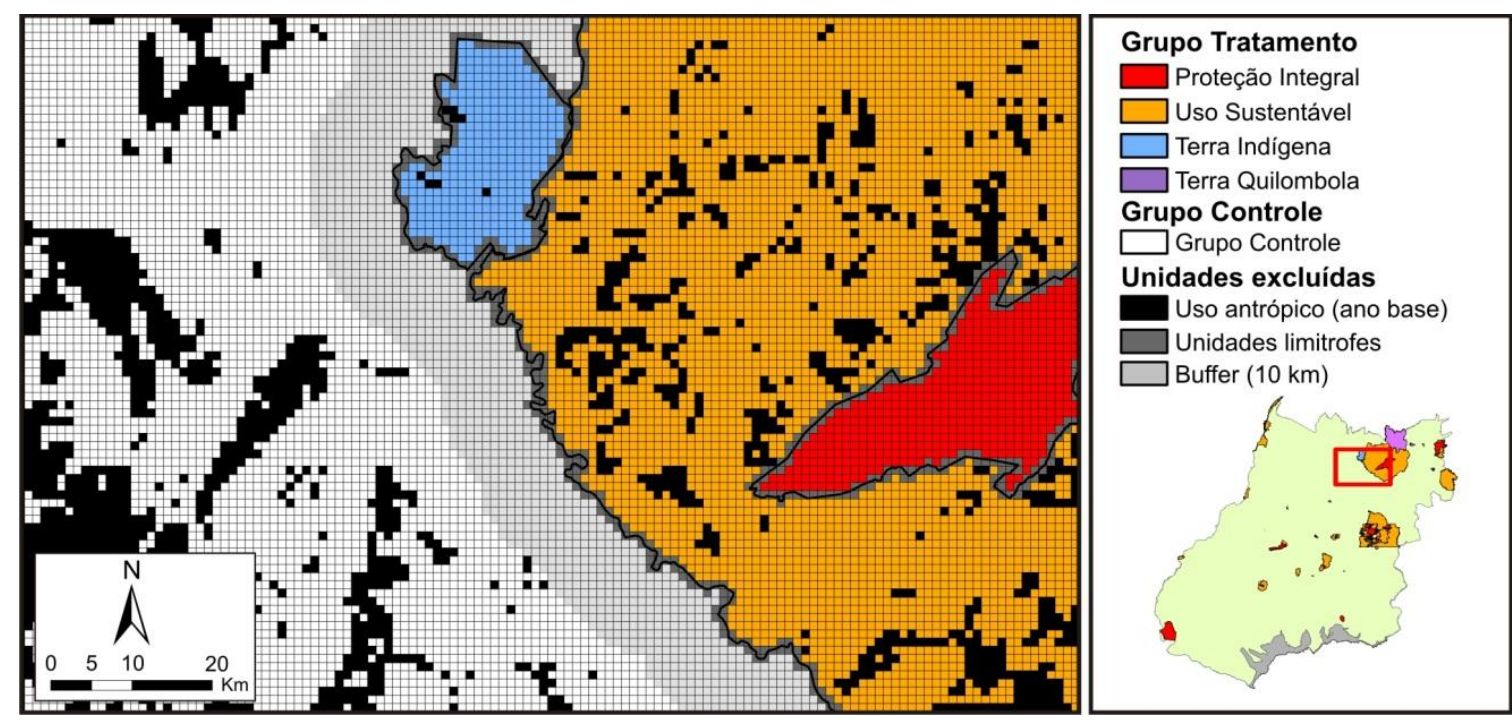

Figura 4 - Figura ilustrativa da grade regular com unidades amostrais com dimensão de $1000 \mathrm{~m}$ por $1000 \mathrm{~m}$. A figura apresenta diferentes tipos de unidades do grupo tratamento e unidades do grupo controle após a exclusão das unidades definidas conforme o delineamento amostral adotado.

Todas as etapas desenvolvidas no geoprocessamento dos dados relacionadas à obtenção das variáveis consideradas ou seleção das unidades amostrais foi realizada com o uso do ArcGis 10.2.2. Processamentos de dados adicionais, para a formação das bases de dados finais, foram realizados com a utilização do aplicativo R 3.3.1.

\subsubsection{Coortes e Variável Resposta}

As unidades amostrais das áreas protegidas foram agrupadas em diferentes coortes, definidas pela data em que dados do uso e cobertura da terra estiveram disponíveis e pela data de criação da unidade. Seis coortes de áreas protegidas foram definidas: criadas em período anterior a 1985 (coorte de 1985); com criação entre 1985 e 1995 (coorte de 1995); com 
criação entre 1995 e 2002 (coorte de 2002); com criação entre 2002 e 2008 (coorte de 2008), com criação entre 2008 e 2009 (coorte de 2009), com criação entre 2009 e 2010 (coorte de 2010). As coortes tiveram influência sobre a definição do valor da variável resposta e sobre o processo de seleção/exclusão de unidades (Figura 5).

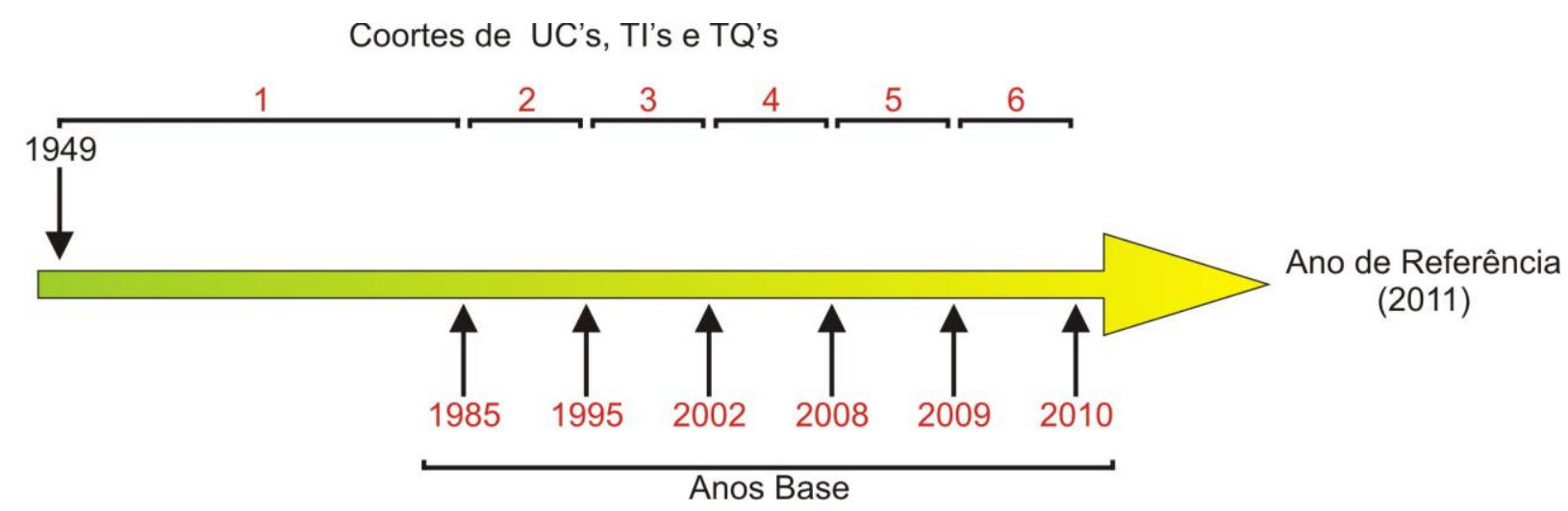

Figura 5 - Imagem representativa com a identificação das 6 coortes de áreas protegidas consideradas, os anos base de cada coorte e o ano de referência a partir do qual foi obtida a variável resposta.

A variável resposta neste estudo foi considerada como a variação de área antrópica existente no interior de cada unidade amostral, dado em metros quadrados $\left(\mathrm{m}^{2}\right)$. A sua obtenção foi realizada entre o ano base (a data final definidora de cada coorte) e o ano de referência (a data do mapeamento mais atual - 2011) e dependeu de processo prévio de seleção de unidades amostrais que teve como referência o ano base.

Como passo inicial, obteve-se a área antrópica no interior de cada uma das unidades amostrais consideradas (grupo tratamento e grupo controle) para todos os anos cujo mapeamento esteve disponível. Os mapeamentos utilizados foram aqueles disponibilizados pelo Projeto de Monitoramento do Desmatamento dos Biomas Brasileiros por Satélite PMDBBS (IBAMA, 2016) referente aos anos de 2002, 2008, 2009, 2010, 2011, além de mapeamento executado, conforme Capítulo 2, para os anos de 1985 e 1995.

Após a obtenção da área antrópica no interior de cada unidade amostral, foram selecionadas aquelas que não apresentassem qualquer nível de antropismo no ano base, sendo descartadas unidades amostrais em que foi observada a ocorrência de desmatamento. $\mathrm{O}$ procedimento foi realizado tanto para unidades do grupo tratamento, quanto para unidades do grupo controle, gerando como resultado seis diferentes conjuntos de dados relativos a cada uma das coortes.

A partir da seleção das unidades, foi obtido o valor da variável resposta, dado como a diferença na área antrópica entre o ano base e o ano de referência. Considerando que as unidades não excluídas apresentaram sempre valor zero de antropismo para o ano base, o 
valor da variável resposta foi dado exclusivamente pela área antrópica existente no ano de referência, ou seja, pelo mapeamento PMDBBS de 2011.

Tal procedimento foi realizado com vistas a se excluir antropismo existente em período anterior à criação de uma área protegida da análise, evitando-se, dessa forma, uma subestimativa do efeito das áreas protegidas. Foi realizado, também, com vistas a se evitar que os resultados fossem afetados por variações decorrentes de diferenças metodológicas ou eventuais incompatibilidades entre os mapeamentos considerados, conforme se discute no Apêndice 2.

Um total de 174.390 unidades amostrais de área protegida apresentaram requisitos de acordo com a amostragem realizada e o número de unidades amostrais do grupo controle variou entre as coortes de 893.159 a 434.111 (Tabela 4). A relação entre o número de unidades amostrais do grupo tratamento e do grupo controle nunca foi inferior a 9 , quantidade considerada elevada e suficiente para que bons pares sejam formados na etapa de matching.

Tabela 4 - Unidades amostrais do grupo tratamento e controle resultantes em cada uma das coortes definidas.

\begin{tabular}{ccccc}
\hline Coorte & N & Tratamento & Controle & Relação \\
\hline 1985 & 35 & 23064 & 893159 & 38.73 \\
1995 & 81 & 68762 & 725855 & 10.56 \\
2002 & 66 & 66615 & 633208 & 9.51 \\
2008 & 49 & 15088 & 539993 & 35.79 \\
2009 & 7 & 202 & 523433 & 2591.25 \\
2010 & 4 & 659 & 434111 & 658.74 \\
\hline
\end{tabular}

\subsection{Variáveis Independentes}

O conjunto ideal de variáveis independentes, com vistas a se realizar efetivo controle do viés decorrente das covariáveis, é aquele que abrange as características do ambiente que melhor determinam a distribuição da probabilidade de conversão antrópica ao longo do território na ausência da variável cujo efeito procura-se estimar (UC's, TI's e TQ's).

O desmatamento está ligado a fatores mediatos e imediatos, locais e regionais, que se originam a partir de combinações de características diversas do contexto social, político, econômico e cultural, e sofre influências de fatores ambientais que predispõem o ambiente à ação humana (Allen, Barnes e Barnest, 2013; Geist e Lambin, 2002; Lambin et al., 2001). Geist \& Lambin (2002), a partir de 152 estudos de caso, abrangendo diferentes localidades na região tropical, relacionaram como as principais causas imediatas da conversão antrópica a ampliação da infraestrutura local, a expansão agrícola, a extração madeireira, além de outros 
fatores de cunho ambiental e bioclimático. Como causas subjacentes, relacionaram fatores demográficos, econômicos, tecnológicos, políticos/institucionais e fatores culturais (Figura 6).

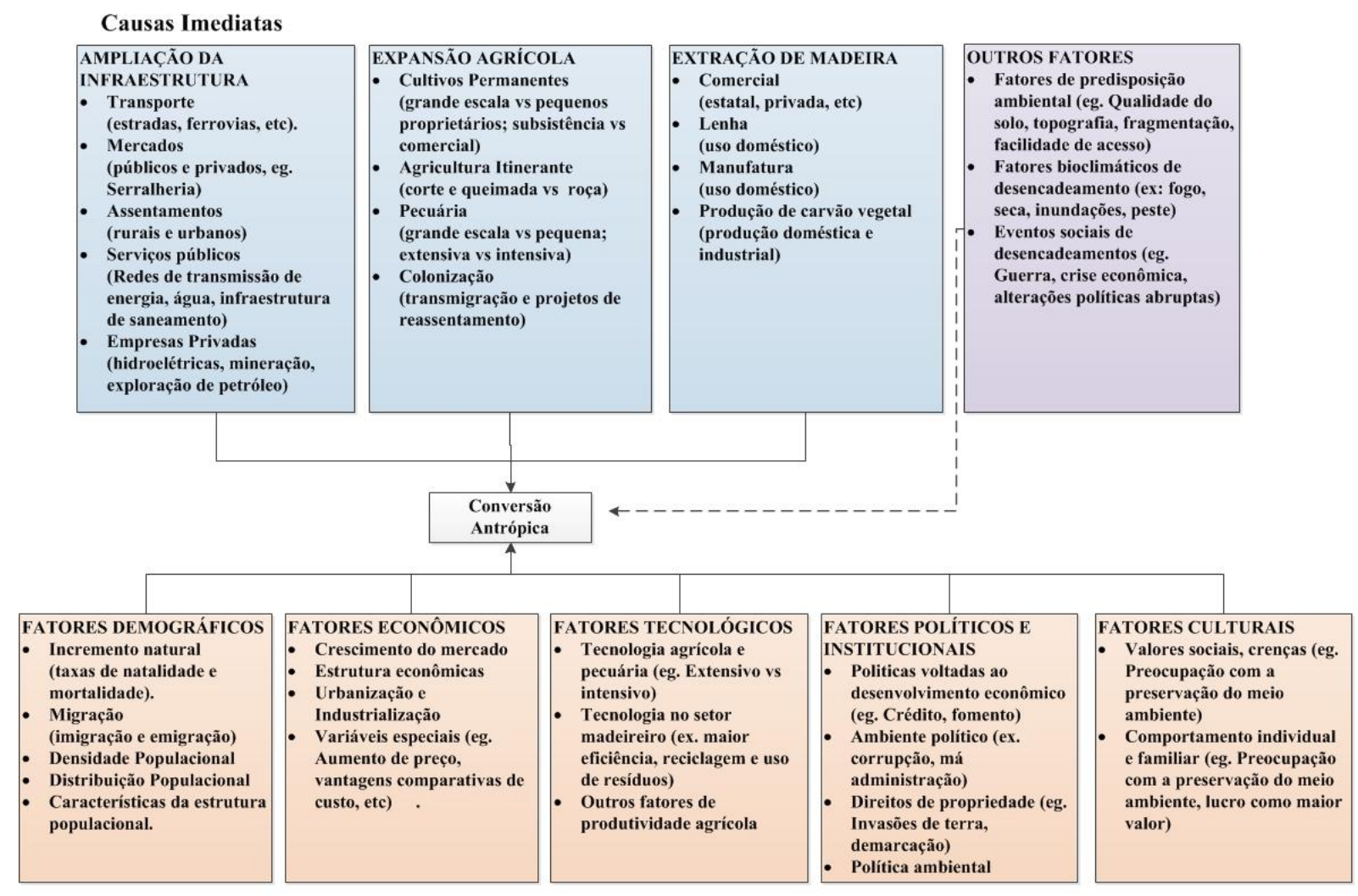

Causas Subjacentes

Figura 6 - Causas da conversão antrópica de habitats naturais na região tropical, baseado em diagrama apresentado por Geist \& Lambin (2002). Cinco grandes grupos de forças motrizes subjacentes (ou processos sociais fundamentais) sustentando as causas imediatas do desmatamento, que são as ações humanas imediatas que impactam diretamente a cobertura natural.

Estudos específicos para a região do Cerrado apresentam, sobretudo, uma relação da conversão antrópica com a expansão agrícola e a ampliação da infraestrutura urbana e de transportes na região, sob influência de atributos ambientais, demográficos, econômicos e políticos/institucionais (eg. Ferreira, L. G. et al., 2009; Ferreira, 2009; Ferreira, M. E. et al., 2009).

Como variáveis que possivelmente possuem influência sobre a conversão antrópica, no presente estudo, foram levados em conta atributos ambientais (altitude, declividade, distância a rios), econômicos (produção pecuária, produção de grãos, PIB municipal, PIB per capita, receita municipal, renda média rural, renda média urbana), censitários/sociais (densidade populacional, densidade populacional rural, densidade populacional urbana, população masculina, população feminina, IDH) e institucionais ou de infraestrutura (área do município, distância a cidades, distância a estradas). Tais informações foram obtidas a partir de dados oficiais fornecidos pelo Instituto Brasileiro de Geografia e Estatística (IBGE), 
Agência Nacional de Águas (ANA), Departamento Nacional de Infraestrutura de Transportes (DNIT), Empresa Brasileira de Pesquisa Agropecuária (Embrapa). As variáveis independentes consideradas e sua respectivas fontes encontram-se listadas no Apêndice 3.

\subsubsection{Seleção de Variáveis}

As variáveis independentes, com efeitos potenciais sobre o desmatamento indicadas na seção anterior, foram submetidas a um processo de seleção que consistiu na: 1) combinação dos diferentes possíveis conjuntos de covariáveis, 2) realização de análise por meio de regressão logística múltipla para diferentes tratamentos, 3) avaliação dos resultados obtidos e seleção dos melhores conjuntos de variáveis para posterior realização do matching.

A regressão logística múltipla é técnica utilizada para a análise da variação de variáveis binárias, em função das variáveis independentes, onde a variável dependente $Y$ assume o valor 1 ou 0 (Mallinis e Koutsias, 2008; Miranda-Aragón et al., 2012). A probabilidade de uma unidade amostral pertencer a uma das condições de tratamento, dado o valor de suas covariáveis, é estimada, sendo possível a realização da comparação entre valores preditos e aqueles realmente observados para os dados empíricos obtidos. Maiores acertos indicam que as variáveis independentes são capazes de prever corretamente o estado da variável $Y$, enquanto menores acertos indicam uma inadequação das covariáveis utilizadas para a realização de tal estimação.

Para a identificação dos melhores conjuntos de variáveis com influência sobre o desmatamento, foram observados seis distintos tratamentos: 1) conversão antrópica menor do que $10 \%$ da área da unidade amostral; 2) conversão antrópica menor do que $20 \%$ da área da unidade amostral; 3) conversão antrópica menor do que 30\% da área da unidade amostral; 4) conversão antrópica maior do que $70 \%$ da área da unidade amostral; 5) conversão antrópica maior do que $80 \%$ da área da unidade amostral; 6) conversão antrópica maior do que $90 \%$ da área da unidade amostral. Para cada uma dessas situações, a variável dependente $Y$ para a unidade amostral $i$ recebeu o valor 1 no caso de cumprir tal requisito, e 0 no caso de não o cumprir.

Após a realização da regressão, foi observado o percentual de unidades amostrais classificadas corretamente, ou seja, o número de observações em que houve a coincidência entre condição estimada pelo modelo com base nas covariáveis e a condição empiricamente observada. A partir da média de corretas classificações obtidas para cada um dos tratamentos realizados, foram escolhidos os 100 melhores conjuntos de variáveis explicativas, os quais 
foram submetidos posteriormente ao método de matching para a escolha dos melhores 15 conjuntos de variáveis a partir das quais foram gerados os resultados finais, conforme Seção 3.6 .

Todas as análises do processo de seleção de variáveis foram realizadas por meio do software R 3.3.1.

\subsection{Região de Influência das Áreas Protegidas}

O controle sobre a região de influência das áreas protegidas é ponto importante para se acessar o efeito dessas unidades territoriais. Conforme discutido na Seção 2, estudos que consideram como elemento contrafactual a área imediatamente próxima às áreas protegidas são propensos a sofrer viés estatístico devido ao efeito da autocorrelação espacial/efeito vazamento, externalidades decorrentes da implantação das áreas protegidas que podem afetar a probabilidade de ocorrência do desmatamento em suas proximidades. Como consequência, os resultados obtidos podem sofrer uma subestimação, no caso do efeito vazamento positivo, ou superestimação, no caso do efeito vazamento negativo (Ferraro et al., 2007; Geldmann et al., 2013; Joppa e Pfaff, 2011), sendo importante o controle sobre a área de influência dessas unidades territoriais antes da realização do matching.

Para a identificação da região de influência, Andam et al. (2008) utilizaram o método de matching para diferentes intervalos de distância no exterior das áreas protegidas (buffers), sendo as unidades amostrais do grupo tratamento aquelas no interior dos buffers definidos e as unidades do grupo controle as demais unidades, com exceção daquelas pertencentes às áreas protegidas. Em caso de não haver influência da área protegida na sua região próxima, é esperado nesse caso que não haja diferença significativa entre os grupos tratamento (buffer) e controle, ou seja, entre as unidades amostrais no interior dos buffers definidos e aquelas em seu exterior.

Neste estudo, foram definidos cinco categorias de intervalos de distância, a partir dos limites das áreas protegidas, além de quatro subcategorias. Os intervalos principais foram delimitados pelas distâncias: de 0 a 10 km; de 10 a 20 km; de 20 a 30 km; de 30 a 40 km; e de 40 a $50 \mathrm{~km}$. As subcategorias de distâncias foram definidas como: de 0 a $5 \mathrm{~km}$; de 5 a $10 \mathrm{~km}$; de 10 a $15 \mathrm{~km}$ e de 15 a $20 \mathrm{~km}$.

O método de matching foi aplicado de forma independente para cada um desses intervalos, observando-se eventual efeito significativo do tratamento para a definição da área de influência das unidades territoriais investigadas. Em função da grande sobreposição entre 
os buffers dos diferentes tipos de unidades, foi observado apenas o efeito global, não sendo considerada a influência para cada grupo ou categoria de unidade.

Adicionalmente, foi obtido o correlograma de Moran I, o qual baseia-se no teste de Moran I (MORAN, 1950). Esse mede a autocorrelação considerando a variável posicional e uma variável independente, podendo o teste ser multi-direcional ou ter direção definida. $\mathrm{O}$ teste baseia-se no valor da medida de autocorrelação $I$, que pode variar entre -1 (autocorrelação negativa) e +1 (autocorrelação positiva), além do valor esperado e da variância para um dado valor de $p$.

O valor de $I$ é calculado como:

$$
I=\frac{n}{\sum_{i=1}^{n} \sum_{j=1}^{n} w_{i, j}} \frac{\sum_{i=1}^{n} \sum_{j=1}^{n} w_{i, j}\left(x_{i}-\bar{x}\right)\left(x_{j}-\bar{x}\right)}{\sum_{i=1}^{n}\left(x_{i}-\bar{x}\right)^{2}}
$$

Onde,

- $n$ é o número de elementos indexados por $i$ e $j$;

- $x$ é o valor da variável de interesse;

- $\bar{x}$ é o valor médio da variável de interesse;

- $W_{i, j}$ é o elemento da matriz de pesos espaciais;

No caso em análise, foi utilizada a variável desmatamento e levada em consideração a eventual existência de autocorrelação para qualquer direção (multidirecional), considerando a distância às áreas protegidas como variável posicional. Dessa forma, a matriz de distância foi definida não pelo posicionamento espacial de cada variável (latitude e longitude), mas pela distância de cada unidade amostral de uma área protegida. Devido a limites do tamanho da matriz, foram selecionadas aleatoriamente 5.000 unidades amostrais.

Todas as análises estatísticas referentes ao procedimento de matching nesta seção foram realizadas por meio do software Stata 14.0, com a utilização do pacote 'psmatch2' (Leuven e Sianesi, 2003). O correlograma de Moran I foi obtido com a utilização do software R 3.3.1, pacote pgirmess (Giraudoux, 2016).

\subsection{Análise Matching}

O procedimento de matching foi realizado em dois momentos distintos da análise. Em etapa prévia, teve-se por objetivo a seleção dos 15 conjuntos de modelos com melhor desempenho, e, dentre eles, o melhor modelo, a partir do conjunto dos 100 melhores modelos previamente selecionados (Seção 3.4.1). Considerou-se, para tanto, os indicadores de qualidade do matching: o viés remanescente, erro padrão do efeito médio do tratamento e 
pseudo-R ${ }^{2}$ dos modelos obtidos. Em um segundo momento, realizou-se a obtenção dos resultados finais considerando o efeito das UC's, TI's e TQ's e dos subgrupos pertencentes às UC's. Além disso, para o melhor modelo, foi realizado o teste para a análise da sensibilidade dos resultados ao viés oculto (hidden bias) (Rosenbaum, 2002).

Para a estimação do efeito médio das áreas protegidas, utilizou-se o Mahalanobis Score Matching, considerando-se os 10 vizinhos mais próximos em relação às características definidas na Seção 3.4. Duas métricas distintas foram obtidas, o efeito médio do tratamento (ATT), o qual apresenta a diferença média absoluta entre as amostras do grupo controle e seus respectivos pares pertencentes ao grupo tratamento, conforme discutido na Seção 3.2; e o efeito médio relativo (ATT\%), a diferença média observada entre as unidades do grupo tratamento e do grupo controle, dividida pela conversão antrópica média observada no grupo controle. Tais métricas são complementares entre si.

A primeira medida fornece informações sobre a magnitude das diferenças entre os dois grupos de unidades amostrais, enquanto a segunda observa o quão longe da linha base de conversão do habitat estão as unidades amostrais das áreas protegidas, o que permite a comparação de resultados entre grupos cujas unidades controle apresentam diferentes níveis de antropismo, ou seja, estão situadas em regiões com pressão antrópica distinta ou possuem características típicas de regiões com pressão antrópica distintas.

O cálculo do efeito absoluto foi realizado conforme indicado na Seção 3.2. Por sua vez, o efeito relativo foi calculado como:

$$
\begin{gathered}
A T T \%_{i}=\left\{\begin{array}{cc}
\frac{a_{c}-a_{p a}}{a_{c}}, & a_{p a} \leq a_{c} \\
-1 *\left(\frac{a_{c *}-a_{p a *}}{a_{c *}}\right), & a_{p a}>a_{c}
\end{array}\right. \\
\text { ATT } \%=\frac{1}{n} \sum_{i=1}^{n} A T T \%_{i}
\end{gathered}
$$

Onde,

- $\quad$ ATT\% $\%_{\mathrm{i}}$ é o efeito relativo para a unidade amostral $i$;

- $a_{c}$ é o valor previsto a partir das unidades controle efetivamente utilizadas para o matching com a unidade amostral $i$; 
- $\mathrm{a}_{\mathrm{pa}}$ é o valor da área antrópica observada para a unidade amostral $i$ do grupo tratamento;

- $\mathrm{a}_{\mathrm{c}} *$ é o valor da área natural observada para a unidade amostral do grupo controle;

- $a_{p^{*}}$ é o valor da área natural observada para a unidade amostral do grupo tratamento ;

Tal procedimento foi repetido independentemente para a obtenção de resultados para cada um dos subgrupos avaliados: 1) Unidades de Conservação, Terras Indígenas e Terras Quilombolas; 2) UC's do grupo de proteção integral e unidades de uso sustentável; 3) UC's da esfera federal e unidades da esfera estadual; 4) UC's de maior tamanho (maior do que a mediana) e de menor tamanho (menor do que a mediana), 5) UC's criadas antes ou após 2002 (valor da coorte mais próximo da mediana da idade das áreas). Além disso, foi realizada a mesma análise para as diferentes categorias de restrição definidas pela IUCN (Categorias de I a VI). Foi utilizado o Teste de Wilcoxon-Mann-Whitney, teste não paramétrico de significância, para a comparação entre os resultados entre os grupos observados.

Todas as análises estatísticas referentes ao procedimento de matching e análise de sensibilidade ao viés oculto foram realizadas por meio do software Stata 14.0, com a utilização do pacote 'psmatch2' (Leuven e Sianesi, 2003) e 'Rbounds' (Gangl, 2004), respectivamente. O cálculo do efeito relativo baseou-se no arquivo de saída gerado pelo software Stata 14.0. Para a obtenção do índice foi desenvolvido script no aplicativo R 3.3.1 para a obtenção do índice (Apêndice 4). 


\section{RESULTADOS}

\subsection{Seleção de modelo}

A seleção dos melhores grupos de variáveis foi realizada utilizando-se teste de regressão logística múltipla, no qual foram consideradas todas as combinações entre as 19 covariáveis utilizadas no estudo. A partir dos resultados obtidos, foi observada a capacidade preditiva dos modelos, levando em consideração a proporção de acertos em relação aos níveis de antropismo expressos pela variável binária, e selecionados os 100 melhores modelos.

No conjunto dos 100 melhores modelos selecionados, observou-se pequena diferença quanto ao percentual de corretas classificações por classe de antropismo. Esses apresentaram percentual considerável de corretas classificações das observações, com até 78,57\% para a classe de menor antropismo $(<10 \%)$. As classes com maior nível de antropismo apresentaram um percentual de classificação ligeiramente inferior, com até $75,77 \%$ de corretas classificações (>70\%) (Tabela 5).

Tabela 5 - Percentual de coincidências entre valores preditos e observados para a regressão logística, observando diferentes níveis de antropismo, para os 100 melhores conjuntos e para os 15 conjuntos posteriormente selecionados.

\begin{tabular}{|c|c|c|c|c|c|c|}
\hline \multicolumn{7}{|c|}{ Classe de Antropismo } \\
\hline & $<10 \%$ & $<\mathbf{2 0 \%}$ & $<30 \%$ & $>70 \%$ & $>80 \%$ & $>90 \%$ \\
\hline \multicolumn{7}{|c|}{100 Melhores } \\
\hline Média & $76.54 \%$ & $75.76 \%$ & $75.39 \%$ & $74.18 \%$ & $73.83 \%$ & $74.24 \%$ \\
\hline Desvio Padrão & $1.54 \%$ & $1.52 \%$ & $1.49 \%$ & $1.39 \%$ & $1.26 \%$ & $0.95 \%$ \\
\hline Máximo & $78.57 \%$ & $77.50 \%$ & $76.99 \%$ & $75.77 \%$ & $75.32 \%$ & $75.52 \%$ \\
\hline Mínimo & $73.07 \%$ & $72.49 \%$ & $71.72 \%$ & $70.98 \%$ & $70.68 \%$ & $71.70 \%$ \\
\hline \multicolumn{7}{|c|}{15 Selecionados } \\
\hline Média & $77.06 \%$ & $76.41 \%$ & $76.08 \%$ & $74.84 \%$ & $74.43 \%$ & $74.71 \%$ \\
\hline Desvio Padrão & $1.22 \%$ & $1.06 \%$ & $0.99 \%$ & $0.94 \%$ & $0.86 \%$ & $0.58 \%$ \\
\hline Máximo & $78.30 \%$ & $77.39 \%$ & $76.93 \%$ & $75.70 \%$ & $75.24 \%$ & $75.32 \%$ \\
\hline Mínimo & $74.53 \%$ & $73.94 \%$ & $73.80 \%$ & $72.17 \%$ & $71.81 \%$ & $73.10 \%$ \\
\hline
\end{tabular}

Os 100 conjuntos pré-selecionados foram submetidos à etapa prévia de matching, obtendo-se uma estimação dos parâmetros de qualidade dos modelos para esse tipo de análise com o objetivo de se selecionar os melhores 15 conjuntos variáveis a serem testadas, além do conjunto com as melhores características.

No teste realizado com os 100 conjuntos de variáveis candidatas pré-selecionadas, para o conjunto de dados de teste, os 15 melhores apresentaram viés médio de 2.61 e Pseudo $\mathrm{R}^{2}$ médio de 1,01\% (Apêndice 5), valores os quais podem ser considerados adequados. 
Os grupos de variáveis selecionados apresentam entre 4 e 10 covariáveis, evitando-se a ocorrência de covariáveis com informações similares em um mesmo grupo (e.g. população do município, população rural do município). Dentre o total de 19 covariáveis consideradas neste estudo, permaneceram no grupo final selecionado 15 covariáveis, não estando presentes área municipal, PIB municipal, população rural e renda média rural. O grupo que apresentou a melhor performance relativa teve por covariáveis: distância a cidades, PIB per capita, renda média urbana, altitude, declividade, população masculina, produção de grãos.

O subgrupo contendo os 15 melhores modelos apresentou suporte comum entre os valores de Mahalanobis, tendo o escore variado entre 15.89 (5 percentil) e 350.43 (95 percentil) para as áreas protegidas e 14.51 (5 percentil) e 350.88 (95 percentil) para o grupo controle (Figura 7). A maior parte dos dados concentrou-se em valores inferiores de escore, sendo que $50 \%$ desses teve valor abaixo de 50.

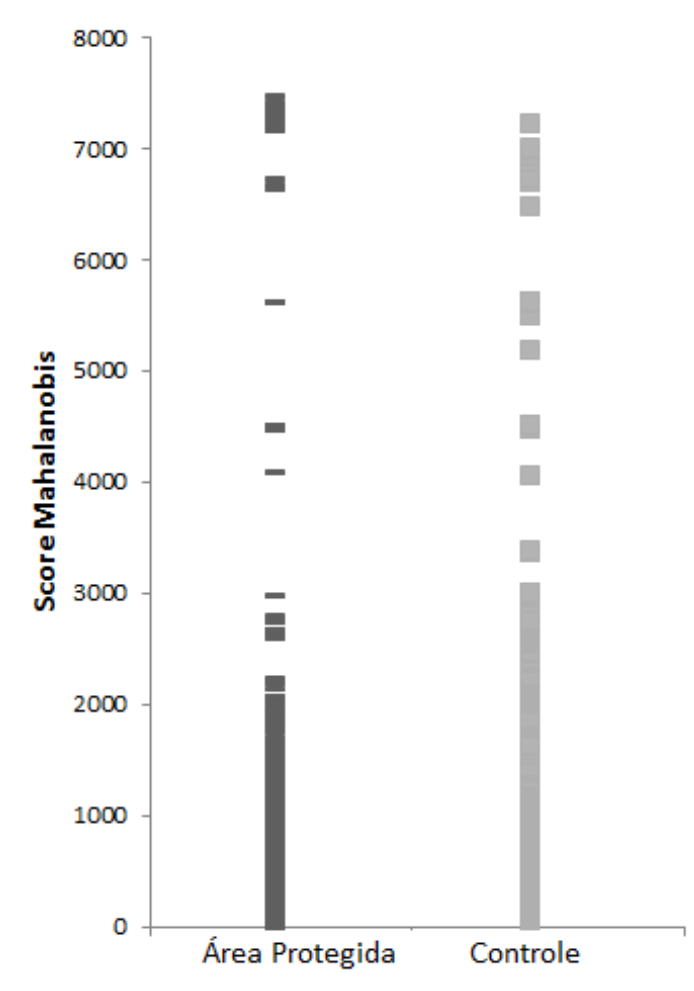

Figura 7 - Distribuição dos valores dos escores obtidos para as covariáveis das unidades amostrais do grupo tratamento e controle, demonstrando o suporte comum entre os grupos.

Para a estimativa do efeito médio do tratamento foram efetivamente utilizadas 77.623 unidades amostrais do grupo controle, de um total disponível de 1.761 .740 para todo o conjunto de dados. A maioria dessas unidades esteve concentrada a uma distância de até 40 $\mathrm{km}$ das áreas protegidas (75\% das unidades), com distância média de $30 \mathrm{~km}$, mínima de 10 km e máxima de 185 km (Apêndice 7). 
Quando aplicado caliper no valor de 2.5, houve a exclusão de algumas unidades do grupo tratamento, as quais passaram a não encontrar pares à distância determinada no grupo controle, e, por consequência, não mais foram considerados na análise (off support). As unidades excluídas representam $1,17 \%$ do total de unidades do grupo tratamento, alcançando o percentual máximo de 6,5\% entre os subgrupos de áreas protegidas analisadas, o qual foi observado para as unidades pertencentes ao grupo IUCN IV. A exclusão das unidades mencionadas não representou impacto significativo sobre o número total de unidades amostrais e não resultou na exclusão por completo de nenhuma unidade de área protegida.

A realização do matching foi capaz de gerar resultados com indicadores de qualidade adequados para o conjunto de dados final, tanto para o melhor conjunto de covariáveis, quanto para os 15 conjuntos de melhores covariáveis. Do Apêndice 6, consta relação completa de estatísticas obtidas pra cada um dos 15 conjuntos de variáveis selecionadas e para cada um dos grupos considerados na análise.

Para o melhor conjunto, dentre os diferentes grupos (UC's, TI's, TQ's) e subgrupos (subgrupos de restrição, esfera governamental, tamanho e tempo desde o ato de criação) foi observado viés médio de 1,83, com valor máximo de 3,37 (para o Grupo de Terras Quilombola) e valor mínimo de 1,1 (para o grupo de unidades com criação mais recente). Em regra, os resultados apresentaram valores muito baixos de Pseudo $\mathrm{R}^{2}$ (Média = 0,05; Máximo $=0,22$; Mínimo =0). Alguns grupos ou subgrupos, no entanto, apresentaram valores relativamente elevados, como no caso de Terra Indígena (Pseudo $\mathrm{R}^{2}=0,22$ ) e Unidades de Conservação com menor tamanho (Pseudo $\mathrm{R}^{2}=0,17$ ). Apesar do valor relativamente elevado desses grupos, conforme se observa do Apêndice 6, valores obtidos para o efeito absoluto ou relativo não foram contrastantes com outros conjuntos de covariáveis que apresentaram valor reduzido para esse indicador, de forma que podem ser considerados igualmente adequados, a despeito do valor elevado de Pseudo $\mathrm{R}^{2}$.

Os resultados obtidos para o melhor modelo mostraram pouca sensibilidade à influência de covariáveis não analisados no estudo e foram resistentes mesmo à influência de viés elevado $(\Gamma \geq 2.0)$ ou viés altamente elevado $(\Gamma \geq 3.0)$ causado por covariáveis não consideradas (Apêndice 8). Outro fator que destaca a robustez do modelo é a baixa variação do efeito ATT e ATT\% entre o melhor modelo e o grupo dos 15 melhores modelos (Apêndice 6). Algumas das coortes dos grupos analisados, no entanto, não apresentaram número suficiente de amostras para a realização do teste de sensibilidade, a exemplo das coortes dos anos de 2008 e 2010 pertencentes ao grupo de unidades de menor tamanho (Apêndice 8). 


\subsection{Influência da área protegida sobre a região próxima}

Além de ter influência sobre a sua própria área, como mencionado na Seção 2, a regulação e restrição ao uso da terra por parte do poder público frequentemente resulta em alterações no uso de regiões próximas não reguladas. Para a determinação da área de influência externa, assim como Andam et al. (2008), foi realizado matching comparando diferentes regiões externas (buffers) com outras regiões mais distantes das áreas protegidas, e, adicionalmente, realizou-se teste de Moran's I para a relação entre as variáveis distância às áreas protegidas e nível de antropismo. A determinação da distância de influência de uma área protegida, nesse contexto, é importante tanto para a delimitação de um buffer de exclusão, quanto para se conhecer eventuais diferenças esperadas para a região externa imediatamente próxima às áreas protegidas.

A partir da análise de matching, considerando-se as classes de distância definidas (0$10 \mathrm{~km}, 0-5 \mathrm{~km}, 5-10 \mathrm{~km}, 10-20 \mathrm{~km}, 10-15 \mathrm{~km}, 15-20 \mathrm{~km}, 20-30 \mathrm{~km}, 30-40 \mathrm{~km}, 40-50 \mathrm{~km}$ ), observou-se, em geral, um reduzido efeito das áreas protegidas sobre a sua região externa. $\mathrm{O}$ efeito observado foi significativo apenas para um buffer de até $10 \mathrm{~km}$ e, especialmente, para os primeiros $5 \mathrm{~km}$ a partir dos limites da área protegida (Tabela 6).

Tabela 6 - Valores obtidos para o matching realizado entre unidades pertencentes aos buffers delimitados e as unidades controle.

\begin{tabular}{ccccccr}
\hline Classe de Distância & \multicolumn{2}{c}{ U.A. } & ATT & S.E. & Viés & P. $\mathbf{R}^{2}$ \\
& Off & All & & & & 0.00 \\
\hline 00 a $10 \mathrm{~km}$ & 793 & 2542071 & -1.10 & 0.57 & 1.67 & 0.01 \\
00 a $05 \mathrm{~km}$ & 458 & 2486494 & -2.37 & 0.72 & 2.07 & 0.00 \\
05 a $10 \mathrm{~km}$ & 377 & 2496233 & -0.15 & 0.63 & 1.87 & 0.00 \\
10 a $20 \mathrm{~km}$ & 189 & 2557631 & 0.52 & 0.47 & 0.83 & 0.00 \\
10 a $15 \mathrm{~km}$ & 174 & 2493733 & 0.99 & 0.59 & 1.03 & 0.00 \\
15 a $20 \mathrm{~km}$ & 27 & 2504554 & 0.09 & 0.51 & 0.80 & 0.03 \\
20 a $30 \mathrm{~km}$ & 149 & 1942885 & -1.01 & 0.49 & 2.22 & 0.02 \\
30 a $40 \mathrm{~km}$ & 465 & 1449557 & -0.11 & 0.60 & 2.75 & 0.02 \\
40 a $50 \mathrm{~km}$ & 203 & 1070485 & -0.24 & 0.87 & 2.03 & 0.02 \\
\hline
\end{tabular}

*U.A. - Unidades Amostrais do grupo tratamento; Off - unidades fora do suporte comum (off support); All todas unidades; ATT - Efeito Absoluto, S.E. - Erro Padrão; P. R² - Pseudo R².

Até a distância de $10 \mathrm{~km}$ foi observado um efeito de $-1,10 \mathrm{ha} / \mathrm{km}^{2}$ (Erro Padrão $=$ 0,57). Dentro desta classe de distância, os primeiros $5 \mathrm{~km}$ apresentou um efeito significativo $\left(\mathrm{ATT}=-2,37 \mathrm{ha} / \mathrm{km}^{2}\right.$, Erro Padrão $\left.=0,72\right)$, enquanto entre $5 \mathrm{~km}$ e $10 \mathrm{~km}$ o efeito não foi diferente de zero $(\mathrm{ATT}=-0,15$, Erro Padrão $=0,63)$. 
Para as demais regiões testadas, o efeito manteve-se muito próximo ou não diferiu significativamente de zero (Figura 8 e Tabela 6). Para os limites entre 10 a $20 \mathrm{~km}$ o efeito observado não diferiu significativamente de zero (ATT = 0,52, Erro Padrão = 0,47); entre 20 e $30 \mathrm{~km}$ o efeito foi significativo, mas com valores reduzidos (ATT=-1,01, Erro Padrão = 0,49); e, a partir de 30 km de distância, manteve-se diferença não significativa.

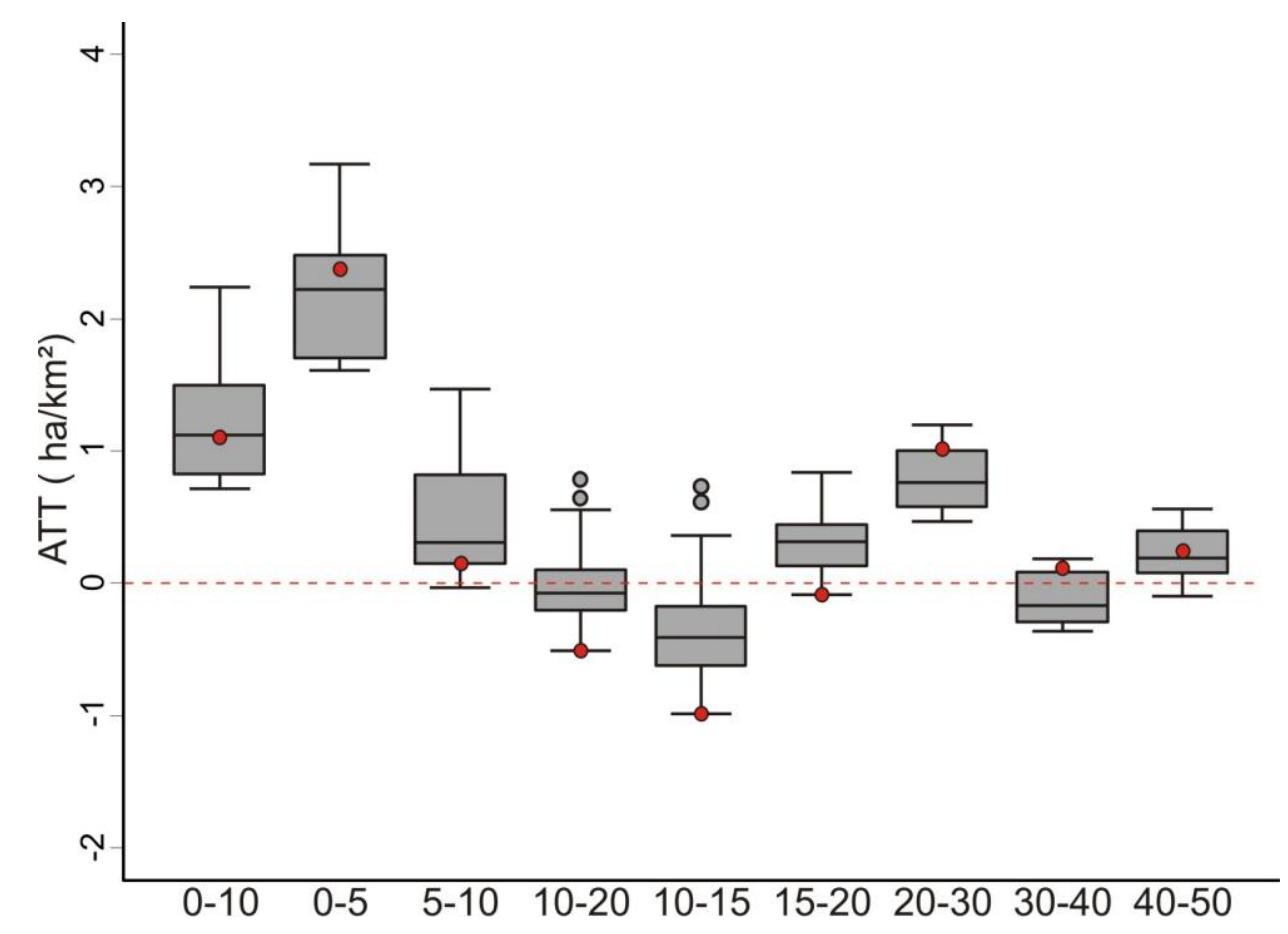

Figura 8 - Efeito absoluto dos buffers utilizados para a obtenção da região de influência das unidades territoriais investigadas.

O efeito observado por meio do matching é confirmado pelo teste de Moran's I. Esse apresenta uma redução da influência das áreas protegidas até uma distância de 6 km, havendo uma relação positiva, ou seja, as unidades contribuem para a manutenção do habitat nessa região. Entre 4 e 6 km, a relação entre as variáveis distância e nível de antropismo deixa de ser significativa (Figura 9). 


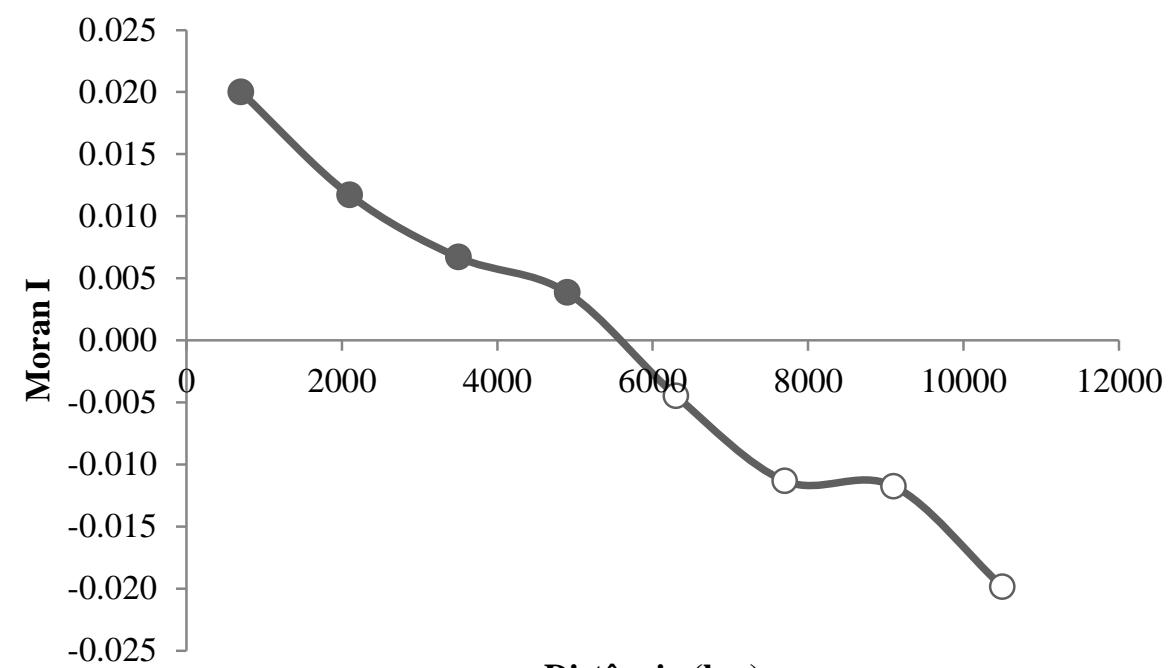

Distância $(\mathbf{k m})$

Figura 9 - Correlograma de Moran I, apresentando a relação entre distância das áreas protegidas e antropismo para os primeiros $10 \mathrm{~km}$. Pontos preenchidos $\mathrm{p}<0,05$, pontos vazios $\mathrm{p}>0,05$.

Considerando-se que outros fatores não observados na análise podem influenciar a ocorrência de antropismo, especialmente a maiores distâncias das áreas protegidas, foi aceita como região de influência apenas os 10 primeiros quilômetros iniciais, sendo esse utilizado como buffer de exclusão para as análises posteriores.

\subsection{Efeito das áreas protegidas}

O efeito absoluto médio do tratamento (ATT) e o efeito relativo médio do tratamento (ATT\%) demostraram que as unidades territoriais do tipo Unidade de Conservação, Terras Indígenas e Terras Quilombola tiveram, em conjunto, efeito positivo sobre a manutenção da área natural no Cerrado (Tabela 7). Os resultados sugerem que, na ausência das unidades territoriais investigadas, em conjunto, seria esperado um acréscimo correspondente a 12,18 ha $/ \mathrm{km}^{2}$ (Erro Padrão $=0.83$ ) de área antrópica nas regiões ocupadas por essas unidades territoriais.

Tabela 7 - Estatísticas obtidas para o melhor conjunto de covariáveis, apresentando o efeito das UC's, TI's, TQ's e subgrupos analisados.

\begin{tabular}{|c|c|c|c|c|c|c|c|c|c|c|c|}
\hline \multirow{2}{*}{ Grupo/Subgrupo } & \multirow{2}{*}{$\mathbf{N}$} & \multicolumn{2}{|c|}{ U.A. } & \multirow{2}{*}{ ATT } & \multirow{2}{*}{ S.E. } & \multirow{2}{*}{ ATT\% } & \multirow{2}{*}{ S.E. } & \multirow{2}{*}{ Dif. } & \multirow{2}{*}{ S.E. } & \multirow{2}{*}{ Viés } & \multirow{2}{*}{ P. $\mathbf{R}^{2}$} \\
\hline & & On & All & & & & & & & & \\
\hline \multicolumn{12}{|l|}{ Geral } \\
\hline Todas as unidades & 242 & 1816 & 174390 & -12.18 & 0.83 & -0.67 & 0.01 & -12.65 & 0.48 & 1.23 & 0.01 \\
\hline \multicolumn{12}{|l|}{ Subtipos } \\
\hline Unidade de Conservação & 145 & 1454 & 99804 & -10.02 & 0.90 & -0.64 & 0.02 & -11.29 & 0.84 & 1.38 & 0.01 \\
\hline Terra Indígena & 72 & 387 & 71656 & -13.72 & 1.06 & -0.74 & 0.03 & -14.14 & 1.04 & 1.50 & 0.22 \\
\hline Terra Quilombola & 25 & 2 & 2930 & -2.50 & 1.64 & -0.66 & 0.02 & -8.26 & 2.70 & 3.37 & 0.07 \\
\hline
\end{tabular}




\section{Grupo de Restrição}

\begin{tabular}{|c|c|c|c|c|c|c|c|c|c|c|c|}
\hline Proteção Integral & 67 & 513 & 45866 & -16.43 & 1.21 & -0.70 & 0.01 & -18.41 & 0.41 & 1.50 & 0.00 \\
\hline Uso sustentável & 78 & 941 & 53938 & 1.06 & 1.92 & -0.41 & 0.04 & -1.17 & 1.18 & 3.08 & 0.02 \\
\hline \multicolumn{12}{|c|}{ Esfera Governamental } \\
\hline Federal & 48 & 1355 & 46392 & -12.56 & 0.82 & -0.69 & 0.03 & -13.77 & 0.81 & 1.15 & 0.10 \\
\hline Estadual & 94 & 473 & 53262 & -11.75 & 1.57 & -0.55 & 0.02 & -6.78 & 0.63 & 2.80 & 0.03 \\
\hline \multicolumn{12}{|c|}{ Grupo de Tamanho } \\
\hline Maior & 129 & 1809 & 99735 & -12.20 & 0.87 & -0.68 & 0.01 & -12.63 & 0.49 & 1.25 & 0.04 \\
\hline Menor & 16 & 8 & 69 & -11.94 & 2.07 & -0.69 & 0.07 & -12.38 & 3.29 & 2.15 & 0.17 \\
\hline \multicolumn{12}{|l|}{ Grupo de Tempo } \\
\hline$>2002$ & 85 & 945 & 82564 & -3.83 & 0.76 & -0.62 & 0.01 & -8.31 & 0.62 & 1.10 & 0.02 \\
\hline$<2002$ & 60 & 3407 & 91826 & -28.88 & 0.99 & -0.77 & 0.00 & -21.33 & 0.18 & 1.50 & 0.00 \\
\hline
\end{tabular}

*U.A. - Unidades Amostrais do grupo tratamento; Off - unidades fora do suporte comum (off support); All todas unidades; ATT - Efeito Absoluto; ATT\% - Efeito Relativo; S.E. - Erro Padrão; Dif. - Diferença antes do matching; P. R² - Pseudo R².

Foi observada importante variação entre os tipos de unidades consideradas no estudo (UC's, TI's e TQ's), bem como entre os subgrupos pertencentes às Unidades de Conservação (grupo de restrição, esfera governamental, tamanho e tempo desde a fundação). As Unidades de Conservação apresentaram desempenho absoluto de 10.02 ha $/ \mathrm{km}^{2}$ (Erro Padrão $=0,90$ ), as Terras Indígenas de $13,72 \mathrm{ha} / \mathrm{km}^{2}$ (Erro Padrão = 1.06) e as Terras Quilombola de 2,50 ha/km² (Erro Padrão 1,64) (Figura 10).

a)

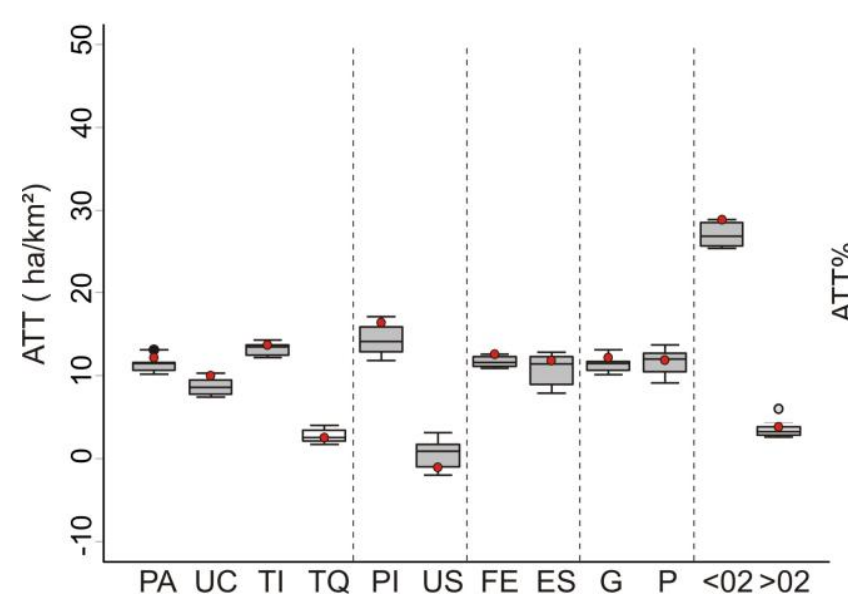

b)

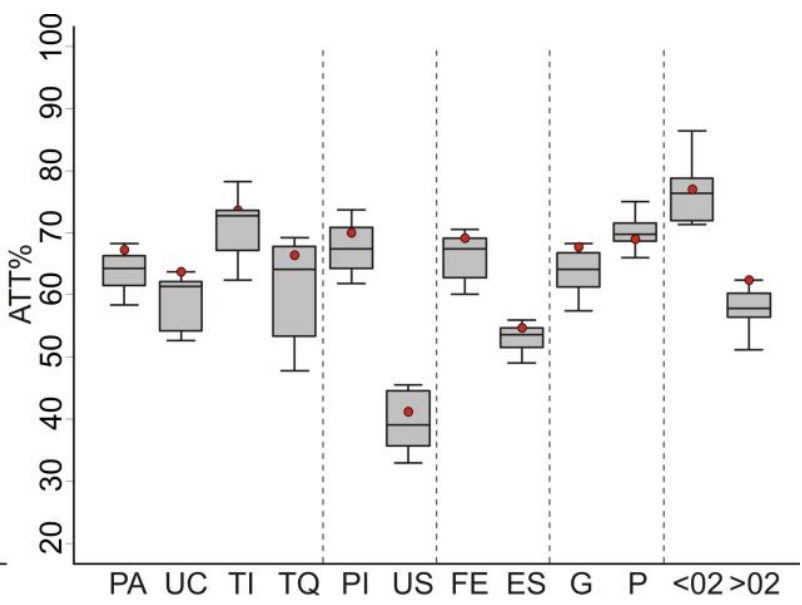

Figura 10 - Efeito geral das unidades territoriais investigadas (UC's, TI's e TQ's) e de subgrupos das áreas protegidas. a) efeito absoluto do tratamento; b) efeito relativo do tratamento. Legenda: PA - Todas as unidades; UC - Unidades de Conservação; TI - Terra Indígena; TQ - Terra Quilombola; PI - Proteção Integral; US - Uso Sustentável; FE - Esfera Federal; ES - Esfera Estadual; G - maior tamanho; P - menor tamanho; $<02$ - unidades criadas em período anterior a 2002; >02 - unidades criadas em período posterior a 2002.

Como se observa na Tabela 8 , unidades amostrais do grupo controle utilizadas para a aferição do efeito das Unidades de Conservação e Terras Indígenas apresentavam nível de antropismo similar, próximo a $85 \mathrm{ha} / \mathrm{km}^{2}$ (ou 85\%). Nesse caso, resultados obtidos para o 
efeito absoluto podem ser diretamente comparados. No caso de UC's e TI's, observou-se, em geral, um maior desempenho das Terras Indígenas, sendo esse próximo ao do grupo de Unidades de Conservação de Proteção Integral (Tabela 7).

Tabela 8 - Estatísticas obtidas para as unidades do grupo controle efetivamente utilizadas para a obtenção dos valores de eficácia.

\begin{tabular}{lccccc}
\hline Grupo/Subgrupo & N & Media & S.E. & Kurtosis & Skewness \\
\hline Geral & & & & & \\
Áreas Protegidas & 862080 & 85.22 & 0.12 & 46.23 & -4.02 \\
Subtipos & & & & & \\
Unidade de Conservação & 491113 & 86.08 & 0.16 & 11.66 & -2.65 \\
Terra Indígena & 356168 & 85.07 & 0.11 & 11.78 & -2.22 \\
Terra Quilombola & 14640 & 95.42 & 0.38 & 27.88 & -3.78 \\
Grupo de Restrição & & & & & \\
Proteção Integral & 226508 & 82.07 & 0.15 & 9.03 & -2.25 \\
Uso sustentável & 264612 & 84.25 & 0.67 & 11.44 & -2.53 \\
Esfera Governamental & & & & & \\
Federal & 597571 & 85.97 & 0.11 & 43.32 & -3.51 \\
Estadual & 263666 & 77.74 & 0.33 & 11.15 & -2.24 \\
Grupo de Tamanho & & & & & \\
Maior & 857697 & 85.19 & 0.13 & 42.48 & -3.92 \\
Menor & 4370 & 85.04 & 0.86 & 6.03 & -1.77 \\
Grupo de Tempo & & & & & \\
$>$ >2002 & 318098 & 94.35 & 0.17 & 16.22 & -3.54 \\
$<2002$ & 173015 & 69.53 & 0.12 & 2.54 & -0.88 \\
\hline
\end{tabular}

N. - número de unidades amostrais; Média - valor médio de área desmatada (ha/ $\left./ \mathrm{km}^{2}\right)$; S.E. - Erro padrão;

No caso das Terras Quilombolas, seu efeito absoluto foi obtido a partir de comparação com regiões com maior pressão antrópica do que as unidades anteriormente mencionadas (95.01 ha/ $\mathrm{km}^{2}$ ou 95\%). Embora o efeito absoluto seja de fato reduzido para essas unidades, os resultados obtidos para seu efeito relativo não foram significativamente diferentes daqueles obtidos para Unidades de Conservação (Teste de Wilcoxon-MannWhitney $\mathrm{W}=89$, p-value $=0.345$ ) (Apendice 9 e Tabela 7). Esse fato sugere que, para os mesmos níveis de pressão antrópica, seria possível esperar desempenho semelhante ao das UC's para as TQ's, ainda que as primeiras unidades apresentem um maior erro padrão de seu efeito (Figura 10.b).

Os subgrupos de restrição das Unidades de Conservação apresentaram resultados marcadamente distintos. Enquanto as unidades de Proteção Integral tiveram efeito elevado sobre a manutenção do habitat (ATT -16.43 ha $/ \mathrm{km}^{2}$, Erro Padrão 1.21 ha/ $/ \mathrm{km}^{2}$ ), as unidades de 
Uso Sustentável não apresentaram efeito diferente de áreas não protegidas (ATT $1.06 \mathrm{ha} / \mathrm{km}^{2}$, erro padrão $1.92 \mathrm{ha} / \mathrm{km}^{2}$ ), apresentando reduzido efeito absoluto e elevado erro padrão.

Conforme observa-se da Figura 11, abaixo, os resultados superiores para unidades de Proteção Integral se repetem quando considerado conjuntamente a influência de outras características (esfera governamental; tamanho das unidades; tempo decorrido desde sua criação). Unidades do subgrupo Uso Sustentável apresentam melhor desempenho apenas quando consideradas unidades de menor tamanho. Nesse caso, o melhor desempenho pode ser atribuído a variações entre as categorias de UC's pertencentes ao grupo Uso Sustentável. Nesse caso observa-se especialmente a influência de unidades da categoria RPPN, que, apesar de pertencerem ao grupo Uso Sustentável, apresentam elevado grau de restrição, e estão majoritariamente representadas entre as unidades de menor tamanho.

a)

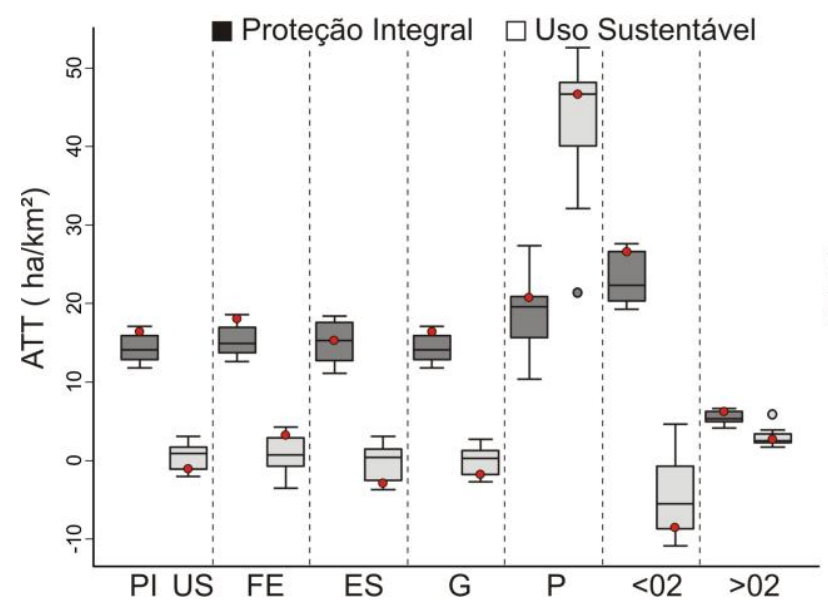

b)

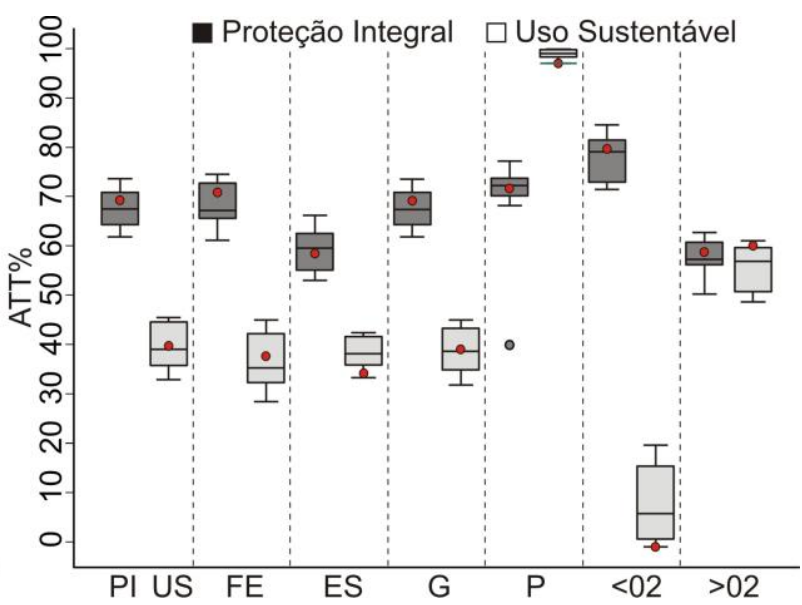

Figura 11 - Efeito das Unidades de Conservação subdivididas entre os grupos de Proteção Integral e Uso Sustentável. Legenda: PI - Proteção Integral; US - Uso Sustentável; FE - Esfera Federal; ES - Esfera Estadual; G - maior tamanho; P - menor tamanho; $<02$ - unidades criadas em período anterior a $2002 ;>02$ - unidades criadas em período posterior a 2002.

Variações no grau de restrição podem ser observadas mais detalhadamente quando se considera as categorias adotadas pela IUCN. Nem sempre foram obtidos grupos com número de unidades territoriais e unidades amostrais em quantidade suficiente para a obtenção de um efeito estatístico relevante. As categorias Ia, II, V e VI apresentam número de unidades amostrais e unidades territoriais adequado, enquanto os grupos III e IV possui tamanho reduzido, sendo seus resultados aqui tratados apenas como indicadores (Tabela 9). 
Tabela 9 - Estatísticas obtidas para o efeito das Unidades de Conservação, agrupadas conforme classificação da IUCN.

\begin{tabular}{|c|c|c|c|c|c|c|c|c|c|c|c|}
\hline \multirow{2}{*}{ Categoria } & \multirow{2}{*}{$\mathbf{N}$} & \multicolumn{2}{|c|}{ U.A. } & \multirow{2}{*}{ ATT } & \multirow{2}{*}{ S.E. } & \multirow{2}{*}{ АTT\% } & \multirow{2}{*}{ S.E. } & \multirow{2}{*}{ Dif. } & \multirow{2}{*}{ S.E. } & \multirow{2}{*}{ Viés } & \multirow{2}{*}{ P. $\mathbf{R}^{2}$} \\
\hline & & Off & All & & & & & & & & \\
\hline Ia & 17 & 92 & 10324 & -14.48 & 5.02 & -0.55 & 0.07 & -14.29 & 2.59 & 3.50 & 0.12 \\
\hline II & 47 & 421 & 34119 & -16.87 & 1.22 & -0.72 & 0.01 & -18.49 & 0.43 & 1.80 & 0.00 \\
\hline III & 3 & 0 & 1423 & -5.27 & 1.10 & -0.53 & 0.01 & -14.56 & 0.80 & 1.30 & 0.08 \\
\hline IV & 6 & 7 & 108 & -9.96 & 2.92 & -0.88 & 0.03 & -14.77 & 6.74 & 11.00 & 0.51 \\
\hline V & 60 & 922 & 52773 & 2.24 & 2.13 & -0.35 & 0.03 & 0.95 & 0.65 & 3.20 & 0.03 \\
\hline VI & 12 & 13 & 1056 & 0.35 & 3.54 & -0.31 & 0.06 & 3.79 & 2.14 & 7.00 & 0.49 \\
\hline
\end{tabular}

*N - número de unidades territoriais; U.A. - Unidades Amostrais do grupo tratamento; Off - unidades fora do suporte comum (off support); All - todas unidades; ATT - Efeito Absoluto; ATT\% - Efeito Relativo; S.E. - Erro Padrão; Dif. - Diferença antes do matching; P. R² - Pseudo R².

Os resultados demonstram desempenho superior para as unidades das categorias Ia a III (Grupo Proteção Integral), quando comparado com as unidades das categorias de IV a VI (Grupo Uso Sustentável). As categorias de maior restrição Ia (ESEC e REBIO) e II (PARNA), não apresentaram diferença significativa (Teste de Wilcoxon-Mann-Whitney W = 78 , p-value $=0.158$, havendo um maior erro padrão para as unidades da categoria Ia do que da categoria II. A categoria III, formada por Monumento Natural e Refúgio da Vida Silvestre, não apresentou número adequado de unidades territoriais ou amostrais, mas, os dados observados indicam um desempenho inferior aos da categoria Ia e II.

As unidades correspondentes ao grupo de Uso Sustentável apresentaram maior variação para os resultados entre categorias (IV, V e VI). Enquanto unidades formadas pelas categorias IV (ARIE e RPPN) apresentaram desempenho elevado (ATT $=-9.96 \mathrm{ha} / \mathrm{km}^{2}$, Erro Padrão = 2,92), unidades da categoria V (APA) e VI (RESEX e FLONA) não apresentaram resultados diferentes de áreas não protegidas (Tabela 9). Importante observar que unidades da categoria IV além de terem importante desempenho para o índice absoluto, apresentaram elevado valor para seu efeito relativo, indicativo de que esse tipo de unidade tem elevada eficácia mesmo em regiões com alta pressão antrópica. Levando-se em conta a distribuição do número de unidades territoriais e unidades amostrais entre as categorias do grupo Uso Sustentável, observa-se que o seu baixo desempenho geral é devido especialmente às unidades da categoria V (APAs).

Entre as esferas governamentais, houve também diferença entre as categorias consideradas (federal e estadual), ainda que em menor grau. Embora o efeito absoluto tenha sido semelhante entre unidades da esfera federal (ATT $-12.56 \mathrm{ha} / \mathrm{km}^{2}$, Erro Padrão 0.82 $\mathrm{ha} / \mathrm{km}^{2}$ ) e da esfera estadual (ATT $-11.75 \mathrm{ha} / \mathrm{km}^{2}$, Erro Padrão 1.57 ha/ $/ \mathrm{km}^{2}$ ) (Figura 12.a), 
deve-se observar que o primeiro tipo de unidade esteve situado ou apresentou características que pressupõem um maior nível de pressão antrópica (Tabela 8). Tal diferença se reflete em maiores efeitos relativos observados para a esfera federal. Quando foram consideradas outras características relacionadas às unidades, observou-se que a diferença para a esfera governamental nem sempre foi confirmada. Por exemplo, unidades de Uso Sustentável, de menor tamanho ou com ato de criação mais recente não apresentaram variação quanto a seu efeito relativo em função da esfera governamental a que pertenciam (Figura 12.b).

a)

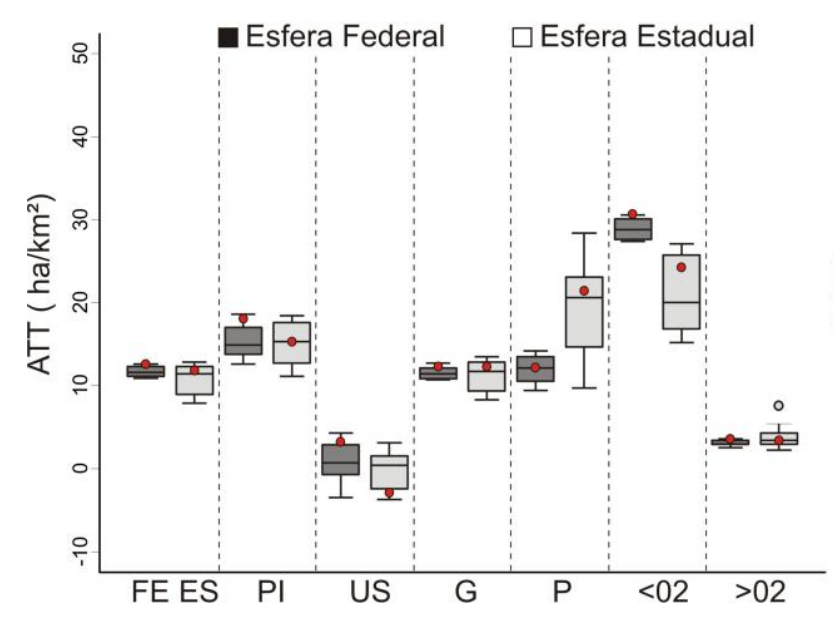

b)

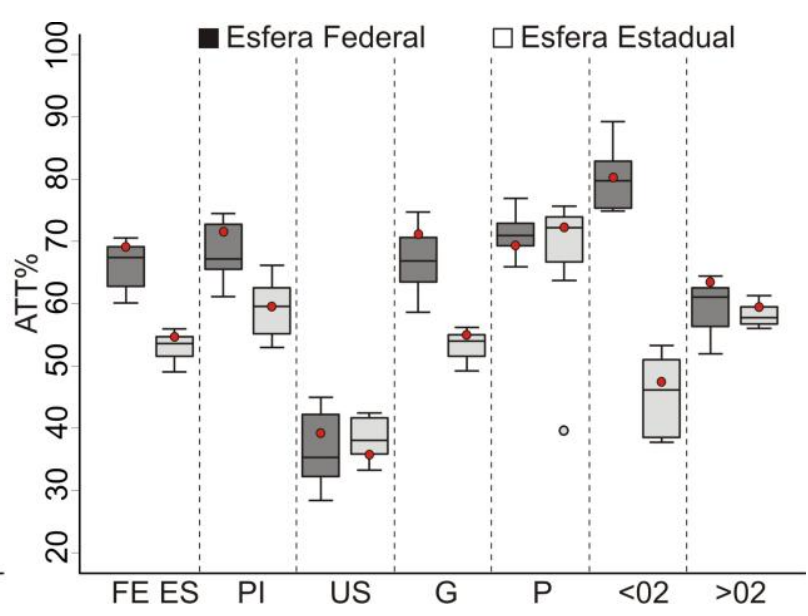

Figura 12 - Efeito das Unidades de Conservação subdivididas entre os grupos federal e estadual. Legenda: PI Proteção Integral; US - Uso Sustentável; FE - Esfera Federal; ES - Esfera Estadual; G - maior tamanho; P menor tamanho; $<02$ - unidades criadas em período anterior a 2002; >02 - unidades criadas em período posterior a 2002

O tamanho médio das unidades geralmente não implicou grandes diferenças entre os subgrupos, ainda que eventualmente as pequenas diferenças tenham sido consideradas significativas pelos testes estatísticos aplicados (Apêndice 9). Para todo o conjunto de dados, Unidades de maior tamanho apresentaram efeito absoluto de $-12,20 \mathrm{ha} / \mathrm{km}^{2}$ (Erro Padrão = 0,87), e efeito relativo de $-0,68$ (Erro Padrão $=0.01$ ), enquanto unidades de menor tamanho tiveram efeito absoluto de -11.94 (Erro Padrão 2.07) e efeito relativo de -0,69 (Erro Padrão = 0.07) (Figura 13). Quando existiu diferença significativa, unidades de menor tamanho tiveram melhor desempenho, como no caso dos subgrupos de Uso Sustentável, unidades federais e estatuais e no caso de unidades com ato de criação mais recente. No primeiro caso, a grande diferença observada deve-se à seleção de unidades da categoria IUCN IV, que apresentam menor tamanho e elevado efeito quando comparado com as demais unidades do grupo Uso Sustentável (e.g. Área de Proteção Ambiental). 
a)

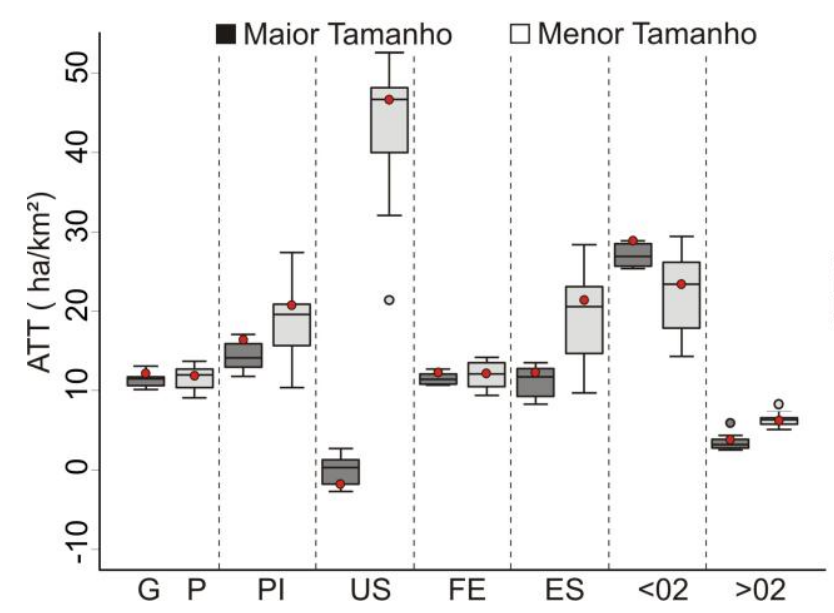

b)

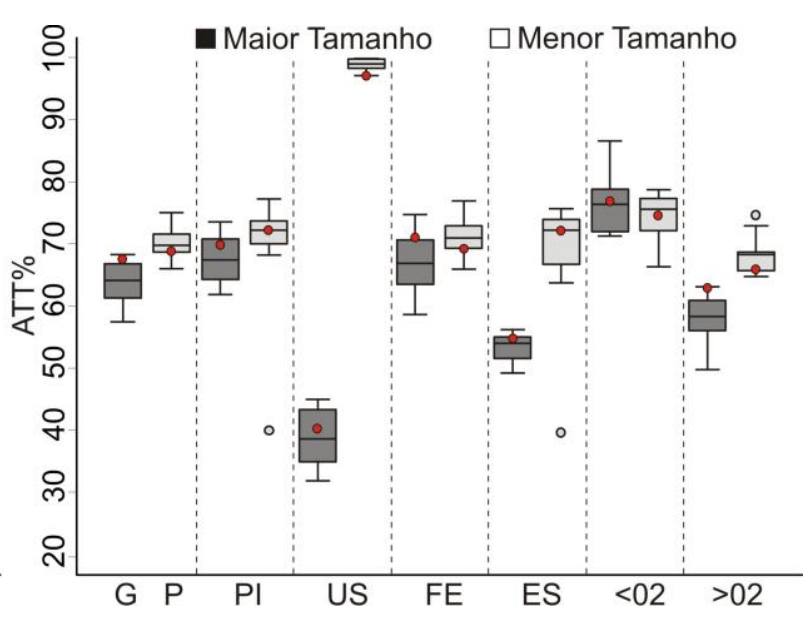

Figura 13 - Efeito das Unidades de Conservação subdivididas entre os unidades de maior tamanho $\left(>271,6 \mathrm{~km}^{2}\right)$ e unidades de menor tamanho $\left(<271,6 \mathrm{~km}^{2}\right)$. Legenda: PI - Proteção Integral; US - Uso Sustentável; FE - Esfera Federal; ES - Esfera Estadual; G - maior tamanho; P - menor tamanho; $<02$ - unidades criadas em período anterior a 2002; >02 - unidades criadas em período posterior a 2002

Quando considerado o tempo desde o ato de criação das unidades, dividindo-se essas entre os grupos de UC's com ato de criação mais antiga (anterior a 2002) e com ato de criação mais recente (posterior a 2002), é observável padrão claro tanto para o índice absoluto quanto para o índice relativo. Nesse caso, observa-se que, com exceção das unidades de uso sustentável e unidades da esfera estadual, aquelas criadas há mais tempo apresentam um melhor desempenho do que aquelas com criação mais recente (Figura 14). Para o primeiro grupo mencionado foi observado valor de efeito absoluto de $-28,88 \mathrm{ha} / \mathrm{km}^{2}$ (Erro Padrão = 0,99 ) e efeito relativo de $-0,62$ (Erro Padrão $=0,01$ ). Por sua vez, para unidades com ato de criação mais recente, foi observado efeito absoluto de $-3,83$ ha/ $/ \mathrm{km}^{2}$ (Erro Padrão $=0,76$ ) e efeito relativo de -0,77(Erro Padrão < 0,01). A grande diferença observada entre os grupos de tempo, deve-se, em parte, à presença desproporcional de unidades de menor restrição entre os grupos de unidades com criação mais recente. A despeito disso, quando se considera os subgrupos de unidades, na maioria dos casos, o padrão geral observado se mantém (Figura 14). 
a)

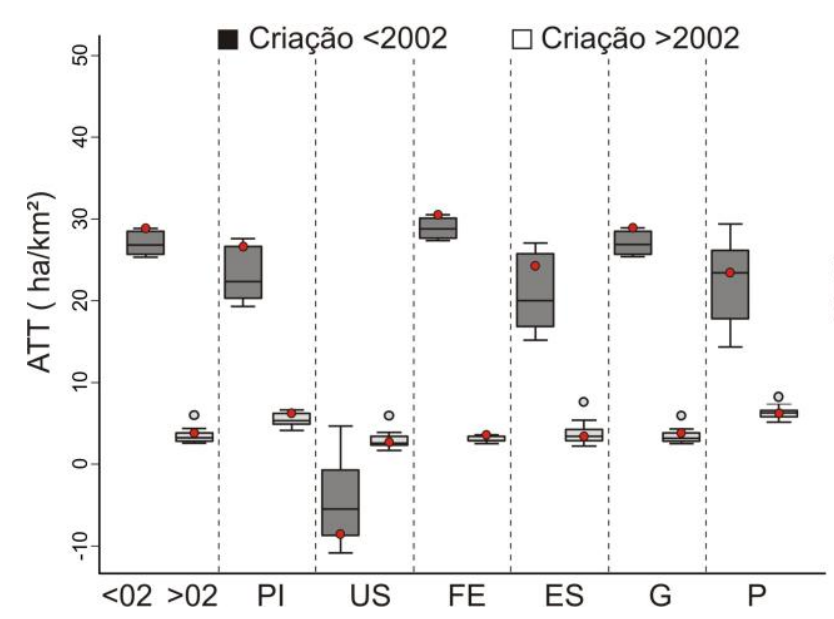

b)

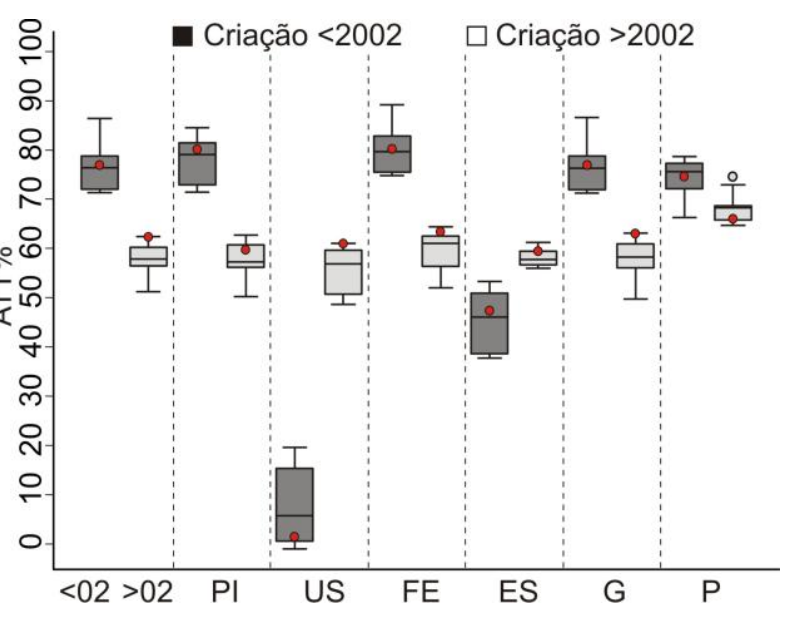

Figura 14 - Efeito das Unidades de Conservação subdivididas entre unidades com criação mais antiga (antes 2002) e unidades com criação mais recente (após 2002). Legenda: PI - Proteção Integral; US - Uso Sustentável; FE - Esfera Federal; ES - Esfera Estadual; G - maior tamanho; P - menor tamanho; $<02$ - unidades criadas em período anterior a 2002; >02 - unidades criadas em período posterior a 2002 


\section{DISCUSSÃO}

O debate sobre a conservação do Cerrado aponta para grandes perdas de habitat natural e da diversidade biológica para um futuro próximo (eg. Faleiro, Machado e Loyola, 2013). A avaliação de instrumentos utilizados para a conservação é fundamental nesse contexto, em especial para o direcionamento de ações de conservação que venham a ter resultados práticos positivos para a contenção do desmatamento. É desejável em tal tipo de análise levar em consideração características que apreendam adequadamente os fatores sociais, econômicos e ambientais que definem, de forma singular, o processo de conversão de habitats naturais na região de estudo. Assim como em outros tipos de estudos (eg. Faleiro e Loyola, 2013), a consideração de outros fatores implicados no processo de desmatamento é fundamental para o tipo de análise realizado neste trabalho, permitindo a obtenção de resultados assertivos e aplicáveis para a região de interesse.

As savanas, por sua grande extensão e características ambientais favoráveis ao uso antrópico, respondem de forma especialmente importante pelo total de habitat natural convertido no globo e vem sendo apontadas como uma das regiões de maior risco para a conservação da biodiversidade (Mittermeier et al., 2005) e como uma das principais fontes de liberação de carbono para a atmosfera (Moutinho e Schwartzman, 2005). Para se evitar perdas em biodiversidade ou da qualidade ambiental, a manutenção do habitat natural é fundamental (Fahrig, 2003), mas outros fatores também devem ser considerados, como mudanças climáticas (Thomas et al., 2004) e efeitos diretos, indiretos ou sinérgicos (Brook, Sodhi e Bradshaw, 2008). Nesse contexto, tem relevância o papel desempenhado pelas áreas protegidas, implicadas em ações que visam tanto a manutenção da biodiversidade quanto a manutenção do habitat natural, atributos intimamente relacionados.

Os resultados obtidos neste trabalho ratificam a importância das áreas protegidas para a contenção da conversão de habitats naturais e aponta padrões gerais relacionados a diferentes tipos de unidades, as quais apresentaram uma grande variação na magnitude de seu desempenho.

Dentre as Unidades de Conservação, foi observada importante variação quanto aos grupos Proteção Integral e Uso Sustentável. O primeiro deles apresentou maior desempenho em evitar o desmatamento (-16.43 ha/ $/ \mathrm{km}^{2}$, Erro Padrão 1,21), porém tais unidades ocupam pequena área total no Cerrado (2,93\% da área total). Unidades de Uso Sustentável, mais numerosas e com maior área total (5,17\% área total), mostraram efeito não diferente da área não protegida (1.06 ha/ $/ \mathrm{km}^{2}$, Erro Padrão 1,92), de forma que essas não contribuem, em média, para a contenção de processos de desmatamento. A diferença observada entre os grupos é 
consistente com resultados obtidos por outros estudos existentes para o Cerrado (Carranza et al., 2013; Françoso et al., 2015; Paiva, Brites e Machado, 2015) ou para outras regiões (Barber et al., 2012; Bruner et al., 2001; Geldmann et al., 2013; Nelson e Chomitz, 2011).

O baixo desempenho das unidades de Uso Sustentável deve-se, especialmente, às unidades da categoria V (APAs) e VI (RDS, REFAU, RESEX e FLONA) da IUCN, as quais apresentaram reduzida contribuição para a manutenção do habitat natural e uma maior representação em termos de área e unidades amostrais. Os resultados para as categorias anteriormente mencionadas são contrastantes com unidades da categoria IV (ARIE e RPPN), que, apesar do reduzido número de amostras, apresentaram resultados indicativos com bom desempenho para a contenção do desmatamento, mesmo pertencendo ao grupo de UC's de Uso Sustentável.

O baixo desempenho das categorias V e VI, em conjunto, são indicadores de que essas unidades têm baixa influência sobre a preservação do habitats natural e que carecem da proposição de ações de conservação que enfoquem esse aspecto. Fazem-se necessários, contudo, estudos mais aprofundados que avaliem outras características, além das observadas, com influência potencial sobre o efeito dessas áreas sobre a manutenção do habitat, como a existência de plano de manejo atualizado, a existência de um conselho gestor operante e a comparação com outros grupos de unidades. Deve-se destacar, ainda, que essas unidades, de menor restrição, cumprem outros tipos de objetivo, a exemplo do ordenamento do processo de ocupação e a exploração de recursos ambientais de forma sustentável, e nem sempre estão sob o direto domínio do poder público. É o caso, por exemplo, das Áreas de Proteção Ambiental, que têm por principal função "proteger a diversidade biológica, disciplinar o processo de ocupação e assegurar a sustentabilidade do uso dos recursos naturais" (Brasil, 2000). Embora os resultados sejam indicadores sobre a capacidade das APA's em proteger a biodiversidade ou recursos naturais, dada a relação entre esses tópicos e a manutenção do habitat natural, avaliação da capacidade lato sensu dessas unidades em relação a cada um desses objetivos deve ser abordada de forma específica e considerando um contexto integrado, características que vão além dos limites de abrangência deste trabalho.

Políticas voltadas à manutenção do hábitat natural no Cerrado devem considerar o elevado desempenho apresentado pelas unidades de proteção integral, além daquelas pertencentes à categoria IV da IUCN. Tais unidades, em conjunto, representam apenas 2,98\% da área do Cerrado. Juntamente com as Terras Indígenas, essas unidades apresentaram o 
maior efeito sobre a manutenção do habitat, sendo desejável a busca por um aumento da representatividade dessas unidades em termos de área na região de estudo.

Os resultados sugerem que eventuais reclassificações das unidades que impliquem a redução do nível de restrição ou a redução em área das unidades (Downgrading, Downsizing, Degazettement, and Reclassification), como observado por Bernard, Penna e Araújo (2014) para algumas regiões do Brasil, deve ter como resultado aumento das taxas de desmatamento nas regiões afetadas.

Outras características das UC's nem sempre foram tão importantes para seu desempenho em conter o desmatamento. A esfera governamental geralmente teve influência sobre o efeito das unidades, mas variou quando foram observadas outras características. Por exemplo, unidades de Uso Sustentável pertencentes à esfera federal e estadual não apresentaram desempenho diferente entre si. No caso em que houve diferença significativa, vários fatores podem estar relacionados, por exemplo, uma maior influência do poder político e econômico local sobre as medidas regulatórias do uso da terra, além de uma menor disponibilidade de recursos econômicos, de infraestrutura e de pessoal para a manutenção de áreas protegidas estaduais quando comparados com áreas da esfera federal.

O tamanho das unidades geralmente não teve influência importante sobre o desempenho dessas em conter o desmatamento. Quando existiu diferença, as áreas protegidas menores apresentaram um melhor desempenho, como no caso de unidades de Uso Sustentável, da esfera estadual e áreas com criação mais recente. Em geral, os resultados são coincidentes com o estudo realizado por Naughton-Treves, Holland e Brandon (2005). De forma semelhante a este estudo, a publicação mencionada relatou uma correlação não significativa do tamanho da área protegida com a sua capacidade em conter o desmatamento. Naqueles casos em que houve diferença significativa (e.g. unidades da esfera estadual), o efeito observado pode-se dever a uma maior disponibilidade de recursos por unidade de área, o que pode favorecer unidades de menor tamanho.

Por sua vez, como geralmente observado na literatura (eg. Andam et al., 2008), áreas protegidas com maior tempo de existência foram mais eficazes. Embora o presente estudo reforce essa afirmação como regra geral, observou-se que certos tipos de unidades podem responder diferentemente, como é o caso das UC's de Uso Sustentável e da esfera estadual, em que o grupo de unidades com criação mais recente mostrou-se mais efetiva. Os padrões observados em relação aos grupos de idade podem ser influenciados pela eficácia da gestão 
dessas unidades (eg. maior experiência dos agentes envolvidos em lidar com a gestão da unidade ao longo do tempo) e pela disponibilidade de recursos (pessoal, infra-estruturas, equipamentos), que tendem a ter maior disponibilidade com o passar do tempo (Leverington et al., 2010).

Os resultados obtidos para as Terras Indígenas no Cerrado são semelhantes àqueles obtidos por Carranza et al. (2013). Embora essas unidades territoriais não sejam especificamente destinadas à conservação ambiental, os dados obtidos sugerem desempenho semelhante ou superiores quando comparadas com as Unidades de Conservação. A mesma relação já foi observada para outras regiões, como o bioma Amazônico, onde este tipo de unidade também mostrou ter efeito tão elevado quanto o de UC's de Proteção Integral (eg. Nepstad et al., 2006). Quanto às Terras Quilombolas, embora essas unidades tenham apresentado um baixo desempenho para a manutenção do habitat em termos absolutos, esse pode se dever ao fato de essas áreas localizarem-se, em média, em regiões com maior pressão antrópica. O efeito relativo dessas unidades é indicativo de capacidade semelhante ao das UC's em conter o desmatamento, o que, em regra, é coerente com modo de exploração menos impactante sobre o meio ambiente tradicionalmente utilizado por essas populações. Sugere-se, contudo, a realização de investigação específica que considere características de cada unidade para que se obtenha um resultado conclusivo.

O efeito das UC's, TI's e TQ's não se ateve aos limites dessas unidades territoriais. A influência dessas sobre a região exterior foi obtida utilizando-se dois tipos de análise distintos. A diferença observada entre a região imediatamente próxima às áreas protegidas e regiões a uma maior distância pode estar relacionado a uma maior presença e atuação dos órgãos governamentais nas regiões imediatamente próximas e/ou a eventuais efeitos sobre características sociais e econômicas locais (Andrade e Rhodes, 2012; Ferraro et al., 2007). Confome Andrade e Rhodes (2012), o sucesso das áreas protegidas em atingir seus objetivos é devido, em parte, à capacidade dos gestores em conciliar os objetivos de conservação da biodiversidade com as questões sociais e econômicas e promover uma maior conformidade das comunidades locais com as estratégias de conservação.

A partir do correlograma de Moran I, observou-se influência positiva e com pequena magnitude da autocorrelação espacial, sendo essa significativa até uma distância de $6 \mathrm{~km}$ a partir dos limites das áreas protegidas. Dale e Fortin (2002) chamam a atenção para o fato de que esse tipo de teste, aplicado a eventos em um contexto natural/ecológico, tende a apresentar resultados mais significativos do que os dados geralmente permitem (erro tipo I), especialmente quando os valores obtidos para os descritores da autocorrelação não são 
elevados, como no caso deste estudo. Os resultados obtidos por meio do correlograma de Moran I são, contudo, confirmados pela análise de matching a qual apresentou diferenças significativas para os buffers de 0-5 km e de 0-10 km, ainda que com pequena magnitude do efeito médio do tratamento.

A baixa magnitude da resposta do índice de Moran I e do efeito médio do tratamento podem ser decorrentes da grande diversidade de tipos de unidades considerado na análise (UC's de várias categorias, TI's e TQ's), sendo os resultados uma média geral. Para as finalidades do estudo proposto os resultados obtidos são adequados, haja vista que foi possível identificar a distância em que as unidades territoriais influenciam o evento investigado, permitindo o seu controle por meio da exclusão de unidades amostrais. Embora a maior parte da influência observada deva se ater aos primeiros $10 \mathrm{~km}$, é possível que haja variação entre os diferentes grupos de unidades, tanto em magnitude, quanto em distância. Para a verificação da influência específica e com maiores detalhes dessas unidades territoriais sobre a região externa sugere-se a realização de estudos específicos que considerem a influência de diferentes características das unidades territoriais em estudo.

O método de matching, juntamente com o procedimento utilizado para a escolha dos melhores conjuntos de variáveis, foi capaz de reduzir de forma muito elevada o viés na estimação do efeito médio das áreas protegidas sobre o desmatamento, reduzindo a influência de outras variáveis. Permitiu, também, que fosse controlada de forma adequada a influência do efeito da autocorrelação. Os testes de sensibilidade realizados demonstraram ser os resultados bastante resistentes quanto a eventuais características não consideradas no estudo que tenham potencial influência sobre a probabilidade de conversão de habitats naturais. A utilização de mais de um conjunto de variáveis, além de reforçar os testes de sensibilidade, permitiu a observação de eventuais variações ocasionais nos resultados.

Os padrões observados têm potencial impacto sobre diferentes aspectos de um planejamento territorial voltado à conservação: tem influência sobre a melhoria de modelos que tratem acerca da identificação de áreas prioritárias, aperfeiçoando um análise sobre este alvo específico da conservação (a manutenção do habitat natural); pode ser utilizado como um indicador acerca de falhas existentes entre as etapas de planejamento e implementação (planning gap); traz uma indicação acerca da necessidade da adoção de ações de conservação voltadas à manutenção do habitat natural e o tipo de unidades que devem ser priorizadas, a exemplo, no caso observado, de unidades pertencentes às categorias V e VI. 
Além de resultados acerca do efeito das áreas protegidas sobre o desmatamento, observaram-se indicações importantes sobre outros aspectos de sua dinâmica no Cerrado. A comparação entre os resultados obtidos neste estudo com aqueles apresentados por Paiva, Brites e Machado (2015), trabalho o qual analisou apenas a região central do Cerrado, sugere a existência de relevante variação sub-regional entre as variáveis que influenciam o processo de desmatamento e em relação ao efeito das áreas protegidas na manutenção do habitat. Embora o trabalho mencionado tenha utilizado os mesmos métodos que este estudo para acessar as variáveis implicadas no processo de desmatamento, observou-se maior percentual geral de previsões corretas em relação às classes de antropismo determinadas para a regressão logística. Além disso, houve importante diferença quando observada a frequência das covariáveis nos melhores conjuntos selecionados, por exemplo, com uma maior participação da variável produção pecuária para a região central do Cerrado do que quando considerado todo o Bioma. Em relação ao efeito das áreas protegidas, em geral, observou-se efeitos médios inferiores para todo o Bioma quando comparado com a região pesquisada naquela publicação. Por exemplo, no caso das UC's de Proteção Integral, observou-se efeito absoluto de $-25,34 \mathrm{ha} / \mathrm{km}^{2}$ para a região central do Bioma e de $-16.43 \mathrm{ha} / \mathrm{km}^{2}$ para todo o Cerrado. Tal diferença pode estar relacionada tanto a uma maior disponibilidade de recursos e à boa gestão das áreas nessa região quando comparado com todo o Bioma, quanto a eventuais diferenças no grau de pressão antrópica observando-se um nível sub-regional. A fim de se determinar a origem das diferenças observadas, faz-se necessário não só a realização de outros trabalhos em um nível sub-regional, como a comparação com resultados de avaliações acerca da efetividade da gestão das áreas protegidas.

A comparação entre os estudos sugere que a dinâmica de desmatamento na região foi influenciada por diferentes fatores em um nível sub-regional de forma que análises realizadas para todo o Bioma podem não refletir situações específicas de determinadas sub-regiões. Além disso, demonstram que o efeito das áreas protegidas pode ser obtido com maior controle sobre as covariáveis considerando-se regiões específicas do Cerrado do que todo o Bioma. Os trabalhos, realizados para diferentes escalas, trazem informações complementares e motivam a realização de novos estudos com um enfoque sub-regional. Sugere-se, não só a execução de trabalhos para essa escala, como, também, a realização de pesquisa específica com a finalidade de se delimitar regiões com dinâmicas de desmatamento semelhantes, o que pode nortear políticas públicas voltadas à contenção do desmatamento específicas para cada subregião e mais assertivas.

O efeito das áreas protegidas sobre o habitat natural tem característica dinâmica, podendo evoluir durante o tempo de forma negativa ou positiva. A reprodução periódica deste 
tipo de análise é capaz de trazer-nos um diagnóstico acurado acerca da evolução da relação entre áreas protegidas e esse importante alvo da conservação, podendo, inclusive, servir como um indicador acerca do impacto de ações de conservação executadas em períodos anteriores. Uma vez que características dos produtos cartográficos utilizados têm impacto sobre os resultados do efeito das áreas protegidas, a comparação com os resultados deste estudo com eventuais futuras iniciativas pendem quanto à disponibilização de dados sobre o monitoramento do uso e cobertura da terra com características compatíveis aos dados utilizados neste estudo (eg. dados PMDBBS para anos posteriores) ou quanto à realização de trabalho específico a fim de se avaliar o impacto de novas fontes dados utilizados sobre os resultados (eg. dados TerraClass).

Além dos aspectos mencionados, sugere-se a execução de novos estudos que visem a integração dos resultados aqui obtidos com aqueles oriundos de iniciativas que avaliam a efetividade da gestão dessas unidades territoriais, a exemplo do Rappam (Rapid Assessment and Prioritization of Protected Area Management), tanto para o nível regional, quanto para o nível sub-regional. Esse tipo de estudo possibilitaria a obtenção de indicadores objetivos acerca do impacto da gestão das unidades sobre alvos específicos da conservação. 


\section{CONCLUSÕES}

O planejamento territorial voltado à conservação considera diferentes aspectos atinentes à seleção e implementação de áreas protegidas ou ações de conservação relacionadas a essas unidades a fim de aperfeiçoar a utilização de recursos escassos, tendo em vista objetivos específicos a serem atingidos. Trabalhos que visem avaliar o efeito de uma rede de unidades já implantada sobre alvos finais da conservação, com base na situação fática existente, no entanto, ainda não são comuns para diversas regiões do mundo. Informações obtidas a partir desse tipo de abordagem são potencialmente úteis tanto para etapas relacionadas ao planejamento sistemático voltado à seleção e implantação de novas áreas protegidas, quanto para a elaboração de ações de conservação.

Este estudo objetivou acessar e avaliar o efeito de Unidades de Conservação, Terras Indígenas e Terras Quilombolas existentes no Bioma Cerrado, levando-se em consideração a capacidade dessas unidades em conservar o habitat natural. Ainda teve como objetivo observar eventuais diferenças entre as Unidades de Conservação em função de seus atributos, tais quais o nível de restrição das unidades, a esfera governamental a que pertencem, o tamanho das unidades e o tempo decorrido desde a implantação dessas.

As análises realizadas neste trabalho indicam que as unidades investigadas desempenham importante papel na proteção do habitat natural na região do Bioma Cerrado, evitando, em conjunto, que $12,18 \mathrm{ha} / \mathrm{km}^{2}$ fossem convertidos para uso antrópico. Além de influência no interior da área delimitada por essas unidades territoriais, foi observada uma redução da ocorrência do desmatamento, também, em áreas imediatamente próximas, até uma distância de $10 \mathrm{~km}$.

Diferenças foram observadas em relação aos tipos de unidades (UC's, TI's e TQ's) e em função dos atributos considerados. Apesar de não ter como principal objetivo a conservação do habitat ou da biodiversidade, as Terras Indígenas apresentaram elevada capacidade em conter o desmatamento, compatível com UC's de Proteção Integral. As Terras Quilombolas, por sua vez, apresentaram baixo efeito absoluto quando comparado com as Unidades de Conservação.

No que se refere ao grau de restrição das UC's, observou-se grande variação, tanto entre os grupos de Proteção Integral e Uso Sustentável, quanto para as categorias definidas pela IUCN. Observou-se que as UC's de Proteção Integral apresentaram elevado desempenho em conter o desmatamento, enquanto UC's de Uso Sustentável não diferiram em relação à área não protegida. 
Apesar de grupos de menor restrição responderem por grande parte da área de UC's no Cerrado, a exemplo da categoria V da IUCN (APA's), esses apresentaram desempenho reduzido quando comparado com outros grupos de unidades. Observou-se, no entanto, que determinadas categorias pertencentes ao grupo de Uso Sustentável são efetivas em manter o habitat natural, como é o caso da categoria IV (ARIE e RPPN) da IUCN.

Outras características, como o tamanho e a esfera governamental a que pertencem as UC's, nem sempre apresentaram influência relevante, variando entre subgrupos de unidades. Como anteriormente já observado na literatura, unidades com maior tempo decorrido desde o ato de sua criação foram mais efetivas do que unidades com criação mais recente.

Os resultados do trabalho sugerem que políticas públicas voltadas à contenção do desmatamento e que considerem a utilização de áreas protegidas no Cerrado, observem o elevado desempenho das unidades de conservação das categorias I, II e IV da IUCN e buquem por um aumento da representatividade dessas unidades em termos de área na região de estudo, bem como adotar ações de conservação específicas voltadas a aumentar a capacidade de unidades pertencentes às categorias V e VI em evitar a ocorrência do desmatamento. Aponta, também, a necessidade de se considerar nessas políticas o papel desempenhado pelas Terras Indígenas, haja vista sua grande capacidade em promover a preservação do habitat.

O método utilizado, com a seleção de diferentes conjuntos de covariáveis e a utilização do matching, mostrou-se capaz de reduzir de forma muito eficaz o viés na estimação do efeito médio das unidades territoriais investigadas. Além disso, os resultados mostraram-se resistentes à influência de outras variáveis não consideradas no estudo (hidden bias).

Em conjunto com outros resultados publicados (Carranza et al., 2013; Paiva, Brites e Machado, 2015), foi possível observar lacunas no conhecimento a respeito da dinâmica do desmatamento no Cerrado. Os dados deste trabalho sugerem que o desmatamento pode ser influenciado por diferentes fatores em uma escala sub-regional, sendo importante a realização de novos estudos considerando essa escala. Ademais, sugere-se a realização de trabalho específico a fim de melhor se compreender a influência das áreas protegidas na região externa e imediatamente próxima, considerando diferentes características das unidades, bem como uma análise específica sobre o efeito das Terras Quilombolas, levando em conta características particulares dessas unidades territoriais. Sugere-se, ainda, a reprodução periódica da avaliação do efeito das áreas protegidas na região e a realização de estudos que 
visem integrar as informações obtidas com aquelas disponíveis a partir da avaliação da efetividade da gestão das áreas protegidas do Cerrado. 


\section{REFERÊNCIAS}

ABADIE, A.; IMBENS, G. W. Large Sample Properties of Matching Estimators for Average treatment Effects. Econometrica, v. 74, n. 1, p. 235-267, 2006.

ADENEY, M. J.; CHRISTENSEN, N. L.; PIMM, S. L. Reserves protect against deforestation fires in the Amazon. PloS One, v. 4, n. 4, p. e5014, jan. 2009.

AGUIAR, L. M. DE S.; MACHADO, R. B.; MARINHO-FILHO, J. A Diversidade Biológica do Cerrado. In: AGUIAR, L. M. DE S.; CAMARGO, A. J. A. DE (Eds.). . Cerrado: ecologia e caracterização. Brasília: Embrapa Cerrados, 2004. p. 19-42.

ALLEN, J. C.; BARNES, D. F.; BARNEST, D. F. The Causes of Deforestation Developing Countries. Annals of the Association of American Geographers, v. 75, n. 2, p. 163-184, 2013.

AMENT, J. M.; CUMMING, G. S. Scale dependency in effectiveness, isolation, and socialecological spillover of protected areas. Conservation Biology, v. 0, n. February, p. 1-10, 2016.

ANDAM, K. S. et al. Measuring the effectiveness of protected area networks in reducing deforestation. Proceedings of the National Academy of Sciences of the United States of America, v. 105, n. 42, p. 16089-94, 21 out. 2008.

ANDRADE, G. S. M.; RHODES, J. R. Protected areas and local communities: An inevitable partnership toward successful conservation strategies? Ecology and Society, v. 17, n. 4, 2012.

AQUINO, F. DE G.; MIRANDA, G. H. B. Consequências Ambientais da Fragmentação de habitats no Cerrado. In: SANO, S. M.; ALMEIDA, S. P. DE; RIBEIRO, J. F. (Eds.). . Cerrado: Ecologia e Flora. Brasília, DF: Embrapa Informação Tecnológica, 2008. p. 386398.

BARBER, C. P. et al. Dynamic performance assessment of protected areas. Biological Conservation, v. 149, n. 1, p. 6-14, 2012.

BERNARD, E.; PENNA, L. A.; ARAÚJO, E. Downgrading, Downsizing, Degazettement, and Reclassification of Protected Areas in Brazil. Conservation Biology, v. 28, n. 2, p. 15231739, 2014.

BRANCALION, P. H. S. et al. A critical analysis of the Native Vegetation Protection Law of Brazil (2012): updates and ongoing initiatives. Natureza \& Conservação, v. 14, n. 1, p. in press, 2016.

BRAnDOn, K.; REDFORD, K. H. Parks in Peril: People, Politics, and Protected Areas. Washington, DC: Island Press, 1998. v. 6

BRASIL. Lei 9.985, 18 de julho de 2000: institui o Sistema Nacional de Unidades de Conservação da Natureza.Presidência da República, , 2000.

Plano Estratégico Nacional de Áreas Protegidas - PNAP, 2006.

BRAY, D. B. et al. Tropical Deforestation, Community Forests, and Protected Areas in the Maya Forest. Ecology and Society, v. 13, n. 2, p. 56, 2008.

BROOK, B. W.; SODHI, N. S.; BRADSHAW, C. J. A. Synergies among extinction drivers under global change. Trends in ecology \& evolution, v. 23, n. 8, p. 453-60, ago. 2008.

BRUNER, A. G. et al. Effectiveness of parks in protecting tropical biodiversity. Science, v. 291, p. 125-128, 5 jan. 2001.

CALIENDO, M.; KOPEINIG, S. Some Practical Guidance for the Implementation of 
Propensity Score Matching. IZA Discussion Paper, v. 1588, p. 1-32, 2005.

Some Practical Guidance for the Implementation of Propensity Score Matching. Journal of Economic Surveys, v. 22, n. 1, p. 31-72, fev. 2008.

CARRANZA, T. et al. Protected area effectiveness in reducing conversion in a rapidly vanishing ecosystem: the Brazilian Cerrado. Conservation Letters, v. 0, p. 1-8, 26 jul. 2013.

CARVALHO, F. M. V.; MARCO, P. DE; FERREIRA, L. G. The Cerrado into-pieces: Habitat fragmentation as a function of landscape use in the savannas of central Brazil. Biological Conservation, v. 142, n. 7, p. 1392-1403, 2009.

CHAPE, S.; SPALDING, M.; JENKINS, M. (EDS.). The World's Protected Areas: status, values and prospects in the 21st century. London, England: UNEP-WCMC, 2008.

CNUC/MMA. Cadastro Nacional de Unidades de Conservação: tabela consolidada das Unidades de Conservação. Disponível em: <http://www.mma.gov.br/areasprotegidas/cadastro-nacional-de-ucs/dados-consolidados>. Acesso em: 9 ago. 2016.

CURRAN, L. M. et al. Lowland Forest Loss in Protected Areas of Indonesian Borneo. Science, v. 303, n. 5660, p. 1000-1003, 2004.

DALE, M. R. T.; FORTIN, M. J. Spatial autocorrelation and statistical tests in ecology. Écoscience, v. 9, n. 2, p. 162-167, 2002.

DEFRIES, R. et al. Increasing isolation of protected areas in tropical forests over the past twenty years. Ecological applications, v. 15, n. 1, p. 19-26, 2005.

DIAS, B. F. DE S. Conservação da Biodiversidade no Bioma Cerrado: histórico dos impactos antrópicos no Bioma Cerrado. In: FALEIRO, F. G.; NETO, A. L. DE F. (Eds.). . Savanas: desafios e estratégias para o equilíbrio entre sociedade, agronegócios e recursos naturais. Brasília, Distrito Federal, Brazil: Embrapa Informação Tecnológica, 2008. p. 303333.

DUDLEY, N.; STOLTON, S. Defining protected areas: An international conference in Almeria, Spain. Gland, Switzerland: IUCN, 2008.

ERVIN, J. Rapid Assessment and Prioritization of Protected Area Management (RAPPAM) Methodology. Gland, Switzerland: WWF, 2003.

EVANS, S. The Green Republic: A Conservation History of Costa Rica. Austin, Texas: University of Texas Press, 1999. v. 89

EWERS, R. M.; RODRIGUES, A. S. L. Estimates of reserve effectiveness are confounded by leakage. Trends in ecology \& evolution, v. 23, n. 3, p. 113-6, mar. 2008.

FAHRIG, L. Effects of Habitat Fragmentation on Biodiversity. Annual Review of Ecology, Evolution, and Systematics, v. 34, n. 1, p. 487-515, nov. 2003.

FALEIRO, F. V.; LOYOLA, R. D. Socioeconomic and political trade-offs in biodiversity conservation: A case study of the Cerrado Biodiversity Hotspot, Brazil. Diversity and Distributions, v. 19, n. 8, p. 977-987, 2013.

FALEIRO, F. V.; MACHADO, R. B.; LOYOLA, R. D. Defining spatial conservation priorities in the face of land-use and climate change. Biological Conservation, v. 158, p. 248-257, 2013.

FEARNSIDE, P. M. O Valor de Áreas Protegidas em Evitar a Mudança Climática na Amazônia. In: WIEGLAND, J.; ALBERNAZ, A. L. (Eds.). . Atualização das Áreas Prioritárias para a Conservação, Uso Sustentável e Repartição dos Benefícios da Biodiversidade - Bioma Amazônia. Brasília, DF: MMA, 2008. p. 8-11. 
FERRARO, P. J. et al. Protected Areas and avoided deforestation: a statistical evaluation. US: [s.n.].

FERREIRA, L. G. et al. Dinâmica agrícola e desmatamentos em áreas de Cerrado: uma análise a partir de dados censitários e imagens de resolução moderada. Revista Brasileira de Cartografia, v. 61, n. 2, p. 117-127, 2009.

FERREIRA, M. E. Modelagem da dinâmica de paisagem do cerrado. [s.1.] Universidade Federal de Goiás - UFG, 2009.

Ativos ambientais do Bioma Cerrado: uma análise da cobertura vegetal nativa e sua relação com o preço da terra no estado de Goiás. Revista Brasileira de Cartografia, v. 61, n. 1, p. 37-50, 2009.

FIGUEIREDO, C. C. M. DE. From paper parks to real conservation: Case studies of national park management effectiveness in Brazil. [s.l.] Ohio State University, 2007.

FRANÇOSO, R. D. et al. Habitat loss and the effectiveness of protected areas in the Cerrado Biodiversity Hotspot. Natureza e Conservacao, v. 13, n. 1, p. 35-40, 2015.

FUNAI. Mapa de Terras Indígenas do Brasil. Disponível em: <http://mapas.funai.gov.br/>. Acesso em: 10 out. 2015.

GANGL, M. RBOUNDS: Stata module to perform Rosenbaum sensitivity analysis for average treatment effects on the treated.BerlinSocial Science Centre Berlin, , 2004.

GEIST, H. J.; LAMBIN, E. F. Proximate Causes and Underlying Driving Forces of Tropical Deforestation. BioScience, v. 52, n. 2, p. 143-150, 2002.

GELDMANN, J. et al. Effectiveness of terrestrial protected areas in reducing habitat loss and population declines. Biological Conservation, v. 161, n. March, p. 230-238, 2013.

GIRAUDOUX, P. Package pgirmess version 1.6.5 for Software R.Franche-ComtéR Foundation for Statistical Computing, , 2016.

GREEN, G. M.; SUSSMAN, R. W. Deforestation History of the Eastern Rain Forests of Madagascar from Satellite Images. Science, v. 248, p. 212-215, 1990.

HUNTER, M. L.; YONZON, P. Altitudinal Distributions of Birds, Mammals, People, Forests and Parks in Nepal. Conservation Biology, v. 7, n. 2, p. 420-423, 2013.

IBAMA. Relatorio Técnico de Monitoramento do Desmatamento nos Biomas Brasileiros Por Satélite: Cerrado 2010-2011. Relatório Técnico, p. 1-16, 2015.

Projeto de Monitoramento do Desmatamento dos Biomas Brasileiros por Satélite PMDBBS: Mapa de áreas desmatadas no Biomas Cerrado - 2002 a 2011. Disponível em: $<\mathrm{http}$ //siscom.ibama.gov.br/monitora_biomas/PMDBBS - CERRADO.html>. Acesso em: 1 maio. 2016.

IBAMA; WWF. Efetividade de Gestão das Unidades de Conservação Federais do Brasil. Brasília, Distrito Federal, Brazil: IBAMA, 2007.

IBGE. Mapa de Biomas do Brasil. Disponível em: <http://www.ibge.gov.br/home/presidencia/noticias/21052004biomas.shtm>. Acesso em: 8 jan. 2013.

ICMBiO. RELAÇÃO DE UCS COM PLANO DE MANEJO. Disponível em: <http://www.icmbio.gov.br/portal/planosmanejo>. Acesso em: 21 nov. 2016.

ICMBIO; WWF. Efetividade de Gestão das unidades de conservação federais. Avaliação comparada das aplicações do método Rappam nas unidades de conservação federais, 
nos ciclos 2005-06 e 2010. Brasília, Distrito Federal, Brazil: ICMBio, 2012.

INCRA. Mapa de Terras Quilombolas - INCRA. Disponível em: $<$ http://acervofundiario.incra.gov.br/>. Acesso em: 10 out. 2015.

IUCN. Indigenous and Traditional Peoples and Protected Areas: Principles, Guidelines and Case Studies. Gland, Switzerland: IUCN-WCPA-WWF, 2000.

JOPPA, L. N.; LOARIE, S. R.; PIMM, S. L. On the protection of Protected Areas. PNAS, v. 105, n. 18, p. 6673-6678, 2008.

JOPPA, L. N.; PFAFF, A. High and Far: Biases in the Location of Protected Areas. PloS one, v. 4, n. 12, p. 1-6, 2009.

Reassessing the forest impacts of protection: the challenge of nonrandom location and a corrective method. Annals of the New York Academy of Sciences, v. 1185, p. 135-49, jan. 2010. 2011.

Global protected area impacts. Proceedings of the Royal Society, v. 278, p. 1633-1638,

KLINK, C. A.; MACHADO, R. B. Conservation of the Brazilian Cerrado. Conservation Biology, v. 19, p. 707-713, 2005.

KLINK, C. A.; MOREIRA, A. G. Past and current human occupation and land-use. In: OLIVEIRA, P. S.; MARQUIS, R. J. (Eds.). . The Cerrado of Brazil. Ecology and natural history of a neotropical savanna. New York: Columbia University Press, 2002. p. 69-88.

LAMBIN, E. F. et al. The causes of land-use and land-cover change: moving beyond the myths. Global Environmental Change, v. 11, p. 261-269, 2001.

LAPIG/UFG. Sistema Integrado de Alertas de Desmatamento - SIAD. Disponível em: <https://www.lapig.iesa.ufg.br/lapig/index.php/noticias/22-ufg>. Acesso em: 22 out. 2012.

LEMOS DE SÁ, R. M.; FERREIRA, L. V. Áreas Protegidas ou Espaços Ameaçados: O grau de implementação e a vulnerabilidade das Unidades de Conservação federais Brasileiras de Uso Indireto. Brasília, Distrito Federal, Brazil: WWF Brasil, 2000.

LEUVEN, E.; SIANESI, B. PSMATCH2: Stata module to perform full Mahalanobis and propensity score matching, common support graphing, and covariate imbalance testing testing.BostonBoston College Department of Economics, , 2003.

LEVERINGTON, F. et al. Management effectiveness evaluation in protected areas - a global study Second edition - 2010. Brisbane, Australia: The University of Queensland, 2010.

LEWINSOHN, T. M.; PRADO, P. I. Quantas espécies há no Brasil? Megadiversidade, v. 1, n. 1, p. 36-42, 2005.

LIMA, J. E. F. W.; SILVA, E. MEDRADO DA. Recursos Hídricos do Bioma Cerrado: Importância e Situação. In: SANO, S. M.; ALMEIDA, S. P. DE; RIBEIRO, J. F. (Eds.). . Cerrado: Ecologia e Flora. Brasília, DF: Embrapa Informação Tecnológica, 2008. p. 91106.

MACHADO, A. B. M.; DRUMMOND, G. M.; PAGLIA, A. P. (EDS.). The Red Book of the Brazilian Fauna Threatened with Extinction. Brasília, DF e Belo Horizonte, MG: MMA/Fundação Biodiversitas, 2008. v. I

MACHADO, R. B. A fragmentação do Cerrado e efeitos sobre a avifauna na região de Brasília- DF. [s.l.] Universidade de Brasília, 2000. 
MAHALANOBIS, P. C. On the generalised distance in statistics. Proceedings of the National Institute of Sciences of India, v. 2, n. 1, p. 49-55, 1936.

MALLINIS, G.; KOUTSIAS, N. Spectral and Spatial-Based Classification for Broad-Scale Land Cover Mapping Based on Logistic Regression. Sensors, v. 8, n. 12, p. 8067-8085, 8 dez. 2008.

MESSINA, J. P. et al. Land tenure and deforestation patterns in the Ecuadorian Amazon: Conflicts in land conservation in frontier settings. Applied Geography, v. 26, p. 113-128, 2006.

MIRANDA-ARAGÓN, L. et al. Modeling susceptibility to deforestation of remaining ecosystems in North Central Mexico with logistic regression. Journal of Forestry Research, v. 23, n. 3, p. 345-354, 29 mar. 2012.

MITTERMEIER, R. A. et al. Hotspots Revisited: Earth's Biologically Richest and Most Endangered Terrestrial Ecoregions. Washington, DC: Conservation International, 2005.

MMA. Informe Nacional sobre Áreas Protegidas no Brasil. Brasília: MMA, 2007.

Fourth National Report to the Convention on Biological Diversity: Brazil, 2010.

Plano de Ação para Prevenção e Controle do Desmatamento e das Queimadas Cerrado. Brasília: MMA, 2011.

Mapeamento do Uso e Cobertura do Cerrado: Projeto TerraClass Cerrado (2013). Brasília: MMA, 2015a.

Mapa de Unidades de Conservação - MMA. Disponível em: <mapas.mma.gov.br〉. Acesso em: 1 set. $2015 b$.

MMA/CONABIO. Resolução CONABIO n⿳0 06, de setembro de 2013: Dispóe sobre as Metas Nacionais de Biodiversidade para 2020., 2013.

MMA; SBF. Biodiversidade brasileira: avaliação e identificação de áreas e ações prioritárias para conservação, utilização sustentável e repartição dos venefícios da biodiversidade nos biomas brasileiros. Brasília, Distrito Federal, Brazil: MMA/SBF, 2002.

MORAN, P. A. P. Notes on Continuous Stochastic Phenomena. Biometrika, v. 37, n. 1-2, p. 17-23, 1950.

MOUTINHO, P.; SCHWARTZMAN, S. (EDS.). Tropical Deforestation and Climate Change. Belém, Brasil: IPAM - Instituto de Pesquisa Ambiental da Amazônia, 2005.

MYERS, N. et al. Biodiversity hotspots for conservation priorities. Nature, v. 403, p. 853858, 24 fev. 2000.

NAGENDRA, H. Do parks work? Impact of protected areas on land cover clearing. Ambio, v. 37, n. 5, p. 330-7, jul. 2008.

NAUGHTON-TREVES, L.; HOLLAND, M. B.; BRANDON, K. The Role of Protected Areas in Conserving Biodiversity and Sustaining Local Livelihoods. Annual Review of Environment and Resources, v. 30, n. 1, p. 219-252, 21 nov. 2005.

NELSON, A.; CHOMITZ, K. M. Protected Area Effectiveness in Reducing Tropical Deforestation. Washington: The World Bank, 2009.

Effectiveness of Strict vs . Multiple Use Protected Areas in Reducing Tropical Forest Fires: a Global Analysis Using Matching Methods. PloS one, v. 6, n. 8, p. 1-14, 2011.

NELSON, G. C.; HARRIS, V.; STONE, S. W. Deforestation, Land Use, and Property Rights: Empirical evidence from Darién, Panama. Land Economics, v. 77, n. 2, p. 187-205, 2013. 
NEPSTAD, D. et al. Inhibition of Amazon Deforestation and Fire by Parks and Indigenous Lands. Conservation Biology, v. 20, n. 1, p. 65-73, 2006.

PAIVA, R. J. O.; BRITES, R. S.; MACHADO, R. B. The Role of Protected Areas in the Avoidance of Anthropogenic Conversion in a High Pressure Region: A Matching Method Analysis in the Core Region of the Brazilian Cerrado. PloS one, p. 1-24, 2015.

PAUCHARD, A.; VILLARROEL, P. Protected Areas in Chile: History, Current Status, and Challenges. Natural Areas Journal, v. 22, n. 4, p. 318-330, 2002.

PELKEY, N. W.; STONER, C. J.; CARO, T. M. Vegetation in Tanzania: assessing long term trends and effects of protection using satellite imagery. Biological Conservation, v. 94, p. 297-309, 2000.

PFAFF, A. et al. Location Affects Protection: Observable Characteristics Drive Park Impacts in Costa Rica. Working Papers Series/Duke University, v. 8, n. 6, p. 29p, 2008.

Governance, Location and Avoided Deforestation from Protected Areas: Greater Restrictions Can Have Lower Impact, Due to Differences in Location. World Development, v. 55, p. 7-20, mar. 2014.

REATTO, A. et al. Solos do Bioma Cerrado: Aspectos pedológicos. In: SANO, S. M.; ALMEIDA, S. P. DE; RIBEIRO, J. F. (Eds.). . Cerrado: Ecologia e Flora. Brasília, DF: Embrapa Informação Tecnológica, 2008. p. 109-149.

RESCK, B. S. et al. Estoque de carbono do solo sob diferentes sistemas de manejo na bacia hidrográfica do córrego taquara, Distrito Federal. II Simpósio internacional de Savanas Tropicais, p. 1-6, 2008.

RIBEIRO, J. F. et al. Ocupação do bioma Cerrado e conservação da sua diversidade vegetal. In: SCARIOT, A.; SOUSA-SILVA, J. C.; FELFILI, J. M. (Eds.). . Cerrado: Ecologia, Biodiversidade e Conservação. Brasília, DF: MMA, 2005. p. 385-399.

ROSENBAUM, P. R. Observational Studies. 2nd. ed. New York: Springer, 2002.

Design of Observational Studies. New York: Springer, 2010.

ROSENBAUM, P. R.; RUBIN, D. B. The Central Role of the Propensity Score in Observational Studies for Causal Effects. Biometrika, v. 70, n. 1, p. 41-55, 1983.

Constructing a control group using multivariate matched sampling methods that incorporate the propensity score. The American Statistician, v. 39, n. 1, p. 33-38, 1985.

ROY, A. D. Some Thoughts on the Distribution of Earnings. Oxford Economic Papers, v. 3, n. 2, p. 135-146, 1951.

RUBIN, D. B. Estimating causal effects to treatments in randomised and nonrandomised studies. Journal of Educational Psychology, v. 66, n. 5, p. 688-701, 1974.

SANCHEZ-AZOFEIFA, G. A. et al. Integrity and isolation of Costa Rica's national parks and biological reserves: examining the dynamics of land-cover change. Biological Conservation, v. 109, p. 123-135, 2003.

SCARAMUZZA, C. A. DE M. et al. Áreas Prioritárias Para a Conservação da Biodiversidade em Goiás. In: UFG, E. (Ed.). . A encruzilhada Socioambiental: biodiversidade, economia e sustentabilidade no cerrado. Goiânia: [s.n.]. p. 13-66.

SCHMITT, C. B. et al. Global analysis of the protection status of the world's forests. Biological Conservation, v. 142, n. 10, p. 2122-2130, 2009.

SCOTT, M. J. et al. Nature reserves: do they capture the full range of america's biological 
diversity? Ecological Applications, v. 11, n. 4, p. 999-1007, 2001.

SOARES-FILHO, B. et al. Cracking Brazil's Forest Code. Science, v. 344, p. 363-364, 2014.

SOARES-FILHO, B. S. et al. Modelling conservation in the Amazon basin. Nature, v. 440, n. 7083, p. 520-3, 23 mar. 2006.

SPRACKLEN, B. D. et al. A Global Analysis of Deforestation in Moist Tropical Forest Protected Areas. Plos One, v. 10, n. 12, p. e0143886, 2015.

STUART, E. A. Matching methods for causal inference: A review and a look forward. Statistical science a review journal of the Institute of Mathematical Statistics, v. 25, n. 1, p. 1-21, 1 fev. 2010.

THOMAS, C. D. et al. Extinction risk from climate change. Nature, v. 427, n. 6970, p. 1458, 8 jan. 2004.

UNEP/CBD. Convention on Biological Diversity.United Nations, 1992.

$\mathrm{UNEP} / \mathrm{CDB} / \mathrm{COP}-10$. Decision adopted by the conference of the parties to the convention on biological diversity at its tenth meeting.UNEP, , 2010.

WANG, W. et al. Effectiveness of Nature Reserve System for Conserving Tropical Forests: A Statistical Evaluation of Hainan Island, China. Plos One, v. 8, n. 2, p. 1-6, 2013.

WU, J. Slipage Effects of the Conservation Reserve Program. American Journal of Agricultural Economics, v. 82, n. 4, p. 979-992, 2000.

WUNDER, S. How do we deal with leakage? In: ANGELSEN, A. (Ed.). . Moving Ahead with REDD: Issues, Options and Implications. Bongor, Indonesia.: CIFOR, 2008. p. 6575 .

YANAI, A. M. et al. Avoided deforestation in Brazilian Amazonia: Simulating the effect of the Juma Sustainable Development Reserve. Forest Ecology and Management, v. 282, p. 78-91, out. 2012. 


\section{APÊNDICES}

- Apêndice 1 - Unidades de Conservação, Terras Indígenas e Terras Quilombola que cumpriram os critérios de amostragem, sendo efetivamente levadas em consideração na análise. Unidades com áreas descontínuas estão listadas independentemente na tabela (ID 41, 230 e 227).

- Apêndice 2 - Discussão sobre o efeito do mapeamento nos resultados e questões atinentes à variável resposta.

- Apêndice 3 - Variáveis consideradas no estudo e respectiva fonte dos dados.

- Apêndice 4 - Script R para o cálculo do índice relativo (ATT\%).

- Apêndice 5 - Sumário de estatísticas obtidas para as unidades o grupo dos 15 melhores conjuntos de variáveis.

- Apêndice 6 - Resultados obtidos individualmente para os 15 melhores modelos escolhidos.

- Apêndice 7 - Imagem apresenta a distribuição das unidades amostrais do grupo controle efetivamente utilizadas e scores de Mahalanobis.

- Apêndice 8 - Teste de sensibilidade ao viés oculto de Rosembaum.

- Apêndice 9 - Teste de Wilcoxon-Mann-Whitney para os grupos de unidades analisados. 
Apêndice 1 - Unidades de Conservação, Terras Indígenas e Terras Quilombola que cumpriram os critérios de amostragem, sendo efetivamente levadas em consideração na análise. Unidades com áreas descontínuas estão listadas independentemente na tabela (ID 41, 230 e 227).

\begin{tabular}{|c|c|c|c|c|c|c|c|c|c|c|}
\hline ID & NOME & ANO & TIPO & SUBTIPO & COORTE & ESFERA & $\begin{array}{l}\text { GRUPO DE } \\
\text { RESTRIÇÃO }\end{array}$ & IUCN & TAMANHO & AREA \\
\hline 1 & FLORESTA NACIONAL DE SILVÂNIA & 1949 & UC & FLONA & 1986 & FEDERAL & US & VI & MENOR & 4.86 \\
\hline 2 & JARUDORE & 1951 & TI & TI & 1986 & FEDERAL & TI & NA & MENOR & 47.69 \\
\hline 3 & PARQUE NACIONAL DO ARAGUAIA & 1959 & $\mathrm{UC}$ & PARNA & 1986 & FEDERAL & PI & II & MAIOR & 5555.20 \\
\hline 4 & PARQUE NACIONAL DA CHAPADA DOS VEADEIROS & 1961 & $\mathrm{UC}$ & PARNA & 1986 & FEDERAL & PI & II & MAIOR & 647.95 \\
\hline 5 & PARQUE NACIONAL DE BRASÍLIA & 1961 & $\mathrm{UC}$ & PARNA & 1986 & FEDERAL & PI & II & MAIOR & 423.56 \\
\hline 6 & PARQUE NACIONAL DAS EMAS & 1961 & $\mathrm{UC}$ & PARNA & 1986 & FEDERAL & PI & II & MAIOR & 1327.85 \\
\hline 7 & ESTAÇÃO ECOLÓGICA DE ÁGUAS EMENDADAS & 1968 & $\mathrm{UC}$ & ESEC & 1986 & ESTADUAL & PI & Ia & MAIOR & 91.81 \\
\hline 8 & PARQUE ESTADUAL DE VASSUNUNGA & 1970 & $\mathrm{UC}$ & PARNA & 1986 & ESTADUAL & PI & II & MENOR & 13.71 \\
\hline 9 & PARQUE ESTADUAL DA SERRA DE CALDAS NOVAS & 1970 & $\mathrm{UC}$ & PARNA & 1986 & ESTADUAL & PI & II & MAIOR & 121.59 \\
\hline 10 & PARQUE NACIONAL DA SERRA DA CANASTRA & 1972 & $\mathrm{UC}$ & PARNA & 1986 & FEDERAL & PI & II & MAIOR & 1978.10 \\
\hline 11 & ESTAÇÃO ECOLÓGICA DE ACAUÃ & 1974 & $\mathrm{UC}$ & ESEC & 1986 & ESTADUAL & PI & Ia & MAIOR & 64.55 \\
\hline 12 & PARQUE ESTADUAL DE ÁGUAS QUENTES & 1978 & $\mathrm{UC}$ & PARNA & 1986 & ESTADUAL & PI & II & MENOR & 15.07 \\
\hline 13 & ESTAÇÃO ECOLÓGICA DE IQUÊ & 1981 & $\mathrm{UC}$ & ESEC & 1986 & FEDERAL & PI & Ia & MAIOR & 2159.71 \\
\hline 14 & ESTAÇÃO ECOLÓGICA DE URUÇUÍ-UNA & 1981 & $\mathrm{UC}$ & ESEC & 1986 & FEDERAL & PI & Ia & MAIOR & 1351.22 \\
\hline 15 & PARQUE NACIONAL DOS LENÇOIS MARANHENSES & 1981 & $\mathrm{UC}$ & PARNA & 1986 & FEDERAL & PI & II & MAIOR & 1458.14 \\
\hline 16 & ESTAÇÃO ECOLÓGICA JATAÍ & 1982 & $\mathrm{UC}$ & ESEC & 1986 & ESTADUAL & PI & Ia & MAIOR & 90.00 \\
\hline 17 & ESTAÇÃO ECOLÓGICA DA SERRA DAS ARARAS & 1982 & $\mathrm{UC}$ & ESEC & 1986 & FEDERAL & PI & Ia & MAIOR & 271.60 \\
\hline 18 & GOVERNADOR & 1982 & TI & $\mathrm{TI}$ & 1986 & FEDERAL & TI & NA & MAIOR & 416.31 \\
\hline 19 & KANELA & 1982 & $\mathrm{TI}$ & TI & 1986 & FEDERAL & $\mathrm{TI}$ & NA & MAIOR & 1255.76 \\
\hline 20 & $\begin{array}{l}\text { APA CORUMBATAÍ BOTUCATU TEJUPA PERIMETRO } \\
\text { BOTUCATU }\end{array}$ & 1983 & $\mathrm{UC}$ & APA & 1986 & ESTADUAL & US & V & MAIOR & 1374.25 \\
\hline 21 & $\begin{array}{l}\text { ÁREA DE PROTEÇÃO AMBIENTAL DA BACIA DO RIO SÃO } \\
\text { BARTOLOMEU }\end{array}$ & 1983 & UC & APA & 1986 & FEDERAL & US & V & MAIOR & 826.80 \\
\hline 22 & $\begin{array}{l}\text { ÁREA DE PROTEÇÃO AMBIENTAL DA BACIA DO RIO } \\
\text { DESCOBERTO }\end{array}$ & 1983 & UC & APA & 1986 & FEDERAL & US & V & MAIOR & 417.84 \\
\hline 23 & $\begin{array}{l}\text { APA CORUMBATAÍ, BOTUCATU E TEJUPÁ PERIMETRO } \\
\text { CORUMBATAÍ }\end{array}$ & 1983 & UC & APA & 1986 & ESTADUAL & US & V & MAIOR & 2756.17 \\
\hline 24 & TAPIRAPÉ/KARAJÁ & 1983 & TI & TI & 1986 & FEDERAL & TI & NA & MAIOR & 660.76 \\
\hline 25 & RODEADOR & 1983 & $\mathrm{TI}$ & TI & 1986 & FEDERAL & $\mathrm{TI}$ & NA & MENOR & 23.24 \\
\hline 26 & ESTAÇÃO ECOLÓGICA DE ITIRAPINA & 1984 & $\mathrm{UC}$ & ESEC & 1986 & ESTADUAL & PI & Ia & MENOR & 22.06 \\
\hline 27 & PARQUE NACIONAL DA SERRA DA CIPÓ & 1984 & $\mathrm{UC}$ & PARNA & 1986 & FEDERAL & PI & II & MAIOR & 316.39 \\
\hline 28 & KADIWÉU & 1984 & TI & $\mathrm{TI}$ & 1986 & FEDERAL & TI & NA & MAIOR & 3794.42 \\
\hline
\end{tabular}




\begin{tabular}{|c|c|c|c|c|c|c|c|c|c|c|}
\hline 29 & PIRINEUS DE SOUZA & 1984 & TI & TI & 1986 & FEDERAL & TI & NA & MAIOR & 256.84 \\
\hline 30 & $\begin{array}{l}\text { ÁREA DE RELEVANTE INTERESSE ECOLÓGICA } \\
\text { CAPETINGA/TAQUARA }\end{array}$ & 1985 & $\mathrm{UC}$ & ARIE & 1986 & FEDERAL & US & IV & MENOR & 20.57 \\
\hline 31 & ESTAÇÃO ECOLÓGICA DE SANTA MARIA & 1985 & UC & ESEC & 1986 & ESTADUAL & PI & Ia & MENOR & 13.12 \\
\hline 32 & ESTAÇÃO ECOLÓGICA DE ANGATUBA & 1985 & $\mathrm{UC}$ & ESEC & 1986 & ESTADUAL & PI & Ia & MENOR & 13.63 \\
\hline 33 & VALE DO GUAPORÉ & 1985 & TI & TI & 1986 & FEDERAL & TI & NA & MENOR & 146.54 \\
\hline 34 & $\begin{array}{l}\text { APA DA BACIA DOS RIBEIRÕES DO GAMA E CABEÇA DE } \\
\text { VEADO }\end{array}$ & 1986 & UC & APA & 1986 & ESTADUAL & US & V & MAIOR & 237.41 \\
\hline 35 & PIMENTEL BARBOSA & 1986 & TI & TI & 1986 & FEDERAL & TI & NA & MAIOR & 3275.86 \\
\hline 36 & PARQUE ESTADUAL DOS PIRINEUS & 1987 & UC & PARNA & 1996 & ESTADUAL & PI & II & MENOR & 28.37 \\
\hline 37 & APA IBITINGA & 1987 & $\mathrm{UC}$ & APA & 1996 & ESTADUAL & US & $\mathrm{V}$ & MAIOR & 534.78 \\
\hline 38 & ESTAÇÃO ECOLÓGICA DE PIRAPITINGA & 1987 & $\mathrm{UC}$ & ESEC & 1996 & FEDERAL & PI & Ia & MENOR & 13.84 \\
\hline 39 & MERURE & 1987 & TI & TI & 1996 & FEDERAL & TI & NA & MAIOR & 827.86 \\
\hline 40 & XACRIABÁ & 1987 & TI & TI & 1996 & FEDERAL & TI & NA & MAIOR & 462.21 \\
\hline 41 & MENKÜ & 1987 & TI & TI & 1996 & FEDERAL & TI & NA & MAIOR & 449.95 \\
\hline 42 & MENKÜ & 1987 & $\mathrm{TI}$ & TI & 1996 & FEDERAL & TI & NA & MAIOR & 1192.70 \\
\hline 43 & APA DE CAFURINGA & 1988 & UC & APA & 1996 & ESTADUAL & US & $\mathrm{V}$ & MAIOR & 465.08 \\
\hline 44 & PARQUE ESTADUAL LAGOA DO CAJUEIRO & 1988 & $\mathrm{UC}$ & PARNA & 1996 & ESTADUAL & PI & II & MAIOR & 48.16 \\
\hline 45 & PARQUE NACIONAL GRANDE SERTÃO VEREDAS & 1989 & $\mathrm{UC}$ & PARNA & 1996 & FEDERAL & PI & II & MAIOR & 2308.54 \\
\hline 46 & APA DO LAGO PARANOÁ & 1989 & $\mathrm{UC}$ & APA & 1996 & ESTADUAL & US & $\mathrm{V}$ & MAIOR & 160.71 \\
\hline 47 & PARQUE NACIONAL DA CHAPADA DOS GUIMARÃES & 1989 & $\mathrm{UC}$ & PARNA & 1996 & FEDERAL & PI & II & MAIOR & 326.47 \\
\hline 48 & PARQUE ESTADUAL DE TERRA RONCA & 1989 & $\mathrm{UC}$ & PARNA & 1996 & ESTADUAL & PI & II & MAIOR & 569.82 \\
\hline 49 & $\begin{array}{l}\text { ÁREA DE PROTEÇÃO AMBIENTAL CAVERNAS DO } \\
\text { PERUAÇU }\end{array}$ & 1989 & UC & APA & 1996 & FEDERAL & US & V & MAIOR & 1387.41 \\
\hline 50 & RESERVA BIOLÓGICA CULUENE & 1989 & $\mathrm{UC}$ & REBIO & 1996 & ESTADUAL & PI & Ia & MAIOR & 36.14 \\
\hline 51 & UMUTINA & 1989 & TI & TI & 1996 & FEDERAL & TI & NA & MAIOR & 244.87 \\
\hline 52 & SÃO MARCOS - MT & 1989 & TI & TI & 1996 & FEDERAL & TI & NA & MAIOR & 1742.11 \\
\hline 53 & PARQUE DO ARIPUANÃ & 1989 & TI & TI & 1996 & FEDERAL & TI & NA & MAIOR & 4031.25 \\
\hline 54 & XERENTE & 1989 & TI & TI & 1996 & FEDERAL & TI & NA & MAIOR & 1713.74 \\
\hline 55 & SANTANA & 1989 & $\mathrm{TI}$ & TI & 1996 & FEDERAL & TI & NA & MAIOR & 358.48 \\
\hline 56 & $\begin{array}{l}\text { RESERVA PARTICULAR DO PATRIMÔNIO NATURAL } \\
\text { FAZENDA LAGEADO }\end{array}$ & 1990 & UC & RPPN & 1996 & FEDERAL & US & IV & MAIOR & 125.52 \\
\hline 57 & ÁREA DE PROTEÇÃO AMBIENTAL SERRA DA TABATINGA & 1990 & $\mathrm{UC}$ & APA & 1996 & FEDERAL & US & $\mathrm{V}$ & MAIOR & 417.80 \\
\hline 58 & ÁREA DE PROTEÇÃO AMBIENTAL MORRO DA PEDREIRA & 1990 & $\mathrm{UC}$ & APA & 1996 & FEDERAL & US & $\mathrm{V}$ & MAIOR & 1317.69 \\
\hline 59 & $\begin{array}{l}\text { ÁREA DE PROTEÇÃO AMBIENTAL CARSTE DA LAGOA } \\
\text { SANTA }\end{array}$ & 1990 & $\mathrm{UC}$ & APA & 1996 & FEDERAL & US & $\mathrm{V}$ & MAIOR & 399.57 \\
\hline
\end{tabular}




\begin{tabular}{|c|c|c|c|c|c|c|c|c|c|c|}
\hline 60 & IRANTXE & 1990 & TI & TI & 1996 & FEDERAL & TI & NA & MAIOR & 157.07 \\
\hline 61 & NAMBIKWARA & 1990 & TI & TI & 1996 & FEDERAL & $\mathrm{TI}$ & NA & MAIOR & 8703.84 \\
\hline 62 & ARARIBOIA & 1990 & TI & TI & 1996 & FEDERAL & $\mathrm{TI}$ & NA & MENOR & 100.30 \\
\hline 63 & KRAOLANDIA & 1990 & TI & TI & 1996 & FEDERAL & $\mathrm{TI}$ & NA & MAIOR & 3058.32 \\
\hline 64 & $\begin{array}{l}\text { ÁREA DE PROTEÇÃO AMBIENTAL DA FOZ DO RIO DAS } \\
\text { PREGUIÇAS - PEQUENOS LENÇÓIS - REGIÃO LAGUNAR } \\
\text { ADJACENTE }\end{array}$ & 1991 & $\mathrm{UC}$ & APA & 1996 & ESTADUAL & US & V & MAIOR & 1967.97 \\
\hline 65 & APA PIRACICABA JUQUERI MIRIM ÁREA I & 1991 & $\mathrm{UC}$ & APA & 1996 & ESTADUAL & US & $\mathrm{V}$ & MAIOR & 871.68 \\
\hline 66 & $\begin{array}{l}\text { ÁREA DE PROTEÇÃO AMBIENTAL DA BAIXADA } \\
\text { MARANHENSE }\end{array}$ & 1991 & $\mathrm{UC}$ & APA & 1996 & ESTADUAL & US & V & MAIOR & 179.38 \\
\hline 67 & SANGRADOURO/VOLTA GRANDE & 1991 & TI & TI & 1996 & FEDERAL & TI & NA & MAIOR & 1024.59 \\
\hline 68 & NIOAQUE & 1991 & TI & TI & 1996 & FEDERAL & TI & NA & MENOR & 29.52 \\
\hline 69 & RIO FORMOSO & 1991 & TI & TI & 1996 & FEDERAL & TI & NA & MAIOR & 196.85 \\
\hline 70 & TADARIMANA & 1991 & TI & TI & 1996 & FEDERAL & TI & NA & MENOR & 95.43 \\
\hline 71 & TAUNAY/IPEGUE & 1991 & TI & TI & 1996 & FEDERAL & TI & NA & MENOR & 137.91 \\
\hline 72 & ENAWENÊ-NAWÊ & 1991 & TI & TI & 1996 & FEDERAL & TI & NA & MAIOR & 7459.01 \\
\hline 73 & TIRECATINGA & 1991 & TI & TI & 1996 & FEDERAL & TI & NA & MAIOR & 1304.79 \\
\hline 74 & UTIARITI & 1991 & TI & $\mathrm{TI}$ & 1996 & FEDERAL & TI & NA & MAIOR & 4097.97 \\
\hline 75 & SÃO DOMINGOS - MT & 1991 & TI & TI & 1996 & FEDERAL & TI & NA & MENOR & 63.45 \\
\hline 76 & CANA BRAVA/GUAJAJARA & 1991 & TI & TI & 1996 & FEDERAL & TI & NA & MAIOR & 1355.85 \\
\hline 77 & FUNIL & 1991 & TI & TI & 1996 & FEDERAL & TI & NA & MAIOR & 158.37 \\
\hline 78 & IBOTIRAMA & 1991 & TI & TI & 1996 & FEDERAL & $\mathrm{TI}$ & NA & MENOR & 17.95 \\
\hline 79 & LAGOA COMPRIDA & 1991 & TI & TI & 1996 & FEDERAL & $\mathrm{TI}$ & NA & MENOR & 132.47 \\
\hline 80 & URUCU/JURUÁ & 1991 & TI & TI & 1996 & FEDERAL & TI & NA & MENOR & 116.81 \\
\hline 81 & VARGEM ALEGRE & 1991 & TI & TI & 1996 & FEDERAL & TI & NA & MENOR & 9.81 \\
\hline 82 & BAKAIRI & 1991 & TI & TI & 1996 & FEDERAL & TI & NA & MAIOR & 626.60 \\
\hline 83 & PARABUBURE & 1991 & TI & TI & 1996 & FEDERAL & TI & NA & MAIOR & 2249.85 \\
\hline 84 & PARESI & 1991 & TI & TI & 1996 & FEDERAL & TI & NA & MAIOR & 5625.61 \\
\hline 85 & $\begin{array}{l}\text { ÁREA DE PROTEÇÃO AMBIENTAL ESTADUAL DA } \\
\text { ESCARPA DEVONIANA }\end{array}$ & 1992 & $\mathrm{UC}$ & APA & 1996 & ESTADUAL & US & $\mathrm{V}$ & MAIOR & 2047.01 \\
\hline 86 & ESTAÇÃO ECOLÓGICA DO JARDIM BOTÂNICO & 1992 & $\mathrm{UC}$ & ESEC & 1996 & ESTADUAL & PI & Ia & MAIOR & 45.03 \\
\hline 87 & $\begin{array}{l}\text { RESERVA EXTRATIVISTA EXTREMO NORTE DO } \\
\text { TOCANTINS }\end{array}$ & 1992 & $\mathrm{UC}$ & RESEX & 1996 & FEDERAL & US & VI & MAIOR & 90.71 \\
\hline 88 & RESERVA EXTRATIVISTA MATA GRANDE & 1992 & $\mathrm{UC}$ & RESEX & 1996 & FEDERAL & US & VI & MAIOR & 114.32 \\
\hline 89 & $\begin{array}{l}\text { ÁREA DE PROTEÇÃO AMBIENTAL DE UPAON-AÇU / } \\
\text { MIRITIBA / ALTO PREGUIÇAS }\end{array}$ & 1992 & $\mathrm{UC}$ & APA & 1996 & ESTADUAL & US & $\mathrm{V}$ & MAIOR & 9162.96 \\
\hline
\end{tabular}




\begin{tabular}{|c|c|c|c|c|c|c|c|c|c|c|}
\hline 90 & ESTAÇÃO ECOLÓGICA DE ASSIS & 1992 & $\mathrm{UC}$ & ESEC & 1996 & ESTADUAL & PI & Ia & MENOR & 17.48 \\
\hline 91 & ESTIVADINHO & 1992 & TI & TI & 1996 & FEDERAL & TI & NA & MENOR & 20.34 \\
\hline 92 & FIGUEIRAS & 1992 & TI & TI & 1996 & FEDERAL & TI & NA & MENOR & 98.54 \\
\hline 93 & OFAYÉ-XAVANTE & 1992 & TI & TI & 1996 & FEDERAL & TI & NA & MENOR & 4.83 \\
\hline 94 & PIRAKUA & 1992 & TI & TI & 1996 & FEDERAL & TI & NA & MENOR & 23.60 \\
\hline 95 & TAIHANTESU & 1992 & TI & TI & 1996 & FEDERAL & TI & NA & MENOR & 48.02 \\
\hline 96 & KRIKATI & 1992 & TI & TI & 1996 & FEDERAL & TI & NA & MAIOR & 1450.67 \\
\hline 97 & JUININHA & 1992 & TI & TI & 1996 & FEDERAL & TI & NA & MAIOR & 703.26 \\
\hline 98 & PARQUE ESTADUAL ALTAMIRO DE MOURA PACHECO & 1993 & $\mathrm{UC}$ & PARNA & 1996 & ESTADUAL & PI & II & MAIOR & 31.39 \\
\hline 99 & $\begin{array}{l}\text { ÁREA DE PROTEÇÃO AMBIENTAL BACIA DO RIO DE } \\
\text { JANEIRO }\end{array}$ & 1993 & $\mathrm{UC}$ & APA & 1996 & ESTADUAL & US & V & MAIOR & 3003.06 \\
\hline 100 & MARAIWATSEDE & 1993 & TI & TI & 1996 & FEDERAL & TI & NA & MAIOR & 625.99 \\
\hline 101 & PARQUE ESTADUAL RIO PRETO & 1994 & $\mathrm{UC}$ & PARNA & 1996 & ESTADUAL & PI & II & MAIOR & 121.85 \\
\hline 102 & PARQUE ESTADUAL SERRA AZUL & 1994 & $\mathrm{UC}$ & PARNA & 1996 & ESTADUAL & PI & II & MAIOR & 110.07 \\
\hline 103 & PARQUE ESTADUAL VEREDAS DO PERUAÇU & 1994 & $\mathrm{UC}$ & PARNA & 1996 & ESTADUAL & PI & II & MAIOR & 312.50 \\
\hline 104 & GERALDA TOCO PRETO & 1994 & TI & TI & 1996 & FEDERAL & TI & NA & MENOR & 54.60 \\
\hline 105 & $\begin{array}{l}\text { ÁREA DE PROTEÇÃO AMBIENTAL DA CHAPADA DOS } \\
\text { GUIMARÃES }\end{array}$ & 1995 & $\mathrm{UC}$ & APA & 1996 & ESTADUAL & US & $\mathrm{V}$ & MAIOR & 2534.46 \\
\hline 106 & $\begin{array}{l}\text { ÁREA DE PROTEÇÃO AMBIENTAL BACIA DO RIO } \\
\text { PANDEIROS }\end{array}$ & 1995 & $\mathrm{UC}$ & APA & 1996 & ESTADUAL & US & $\mathrm{V}$ & MAIOR & 3804.79 \\
\hline 107 & $\begin{array}{l}\text { ÁREA DE PROTEÇÃO AMBIENTAL SERRA GERAL DE } \\
\text { GOIÁS }\end{array}$ & 1996 & $\mathrm{UC}$ & APA & 1996 & ESTADUAL & US & V & MAIOR & 441.47 \\
\hline 108 & ÁREA DE PROTEÇÃO AMBIENTAL DELTA DO PARNAIBA & 1996 & $\mathrm{UC}$ & APA & 1996 & FEDERAL & US & $\mathrm{V}$ & MAIOR & 1621.36 \\
\hline 109 & ÁREA DE PROTEÇÃO AMBIENTAL SERRA DA IBIAPABA & 1996 & $\mathrm{UC}$ & APA & 1996 & FEDERAL & US & $\mathrm{V}$ & MAIOR & 127.31 \\
\hline 110 & AREÕES & 1996 & TI & TI & 1996 & FEDERAL & TI & NA & MAIOR & 1802.79 \\
\hline 111 & KARAJÁ DE ARUANÃ II & 1996 & TI & TI & 1996 & FEDERAL & TI & NA & MENOR & 8.94 \\
\hline 112 & LALIMA & 1996 & TI & TI & 1996 & FEDERAL & $\mathrm{TI}$ & NA & MENOR & 29.37 \\
\hline 113 & TEREZA CRISTINA & 1996 & TI & TI & 1996 & FEDERAL & TI & NA & MENOR & 52.37 \\
\hline 114 & URUBU BRANCO & 1996 & TI & TI & 1996 & FEDERAL & TI & NA & MAIOR & 733.13 \\
\hline 115 & MARECHAL RONDON & 1996 & TI & TI & 1996 & FEDERAL & TI & NA & MAIOR & 1002.96 \\
\hline 116 & AVÁ-CANOEIRO & 1996 & TI & TI & 1996 & FEDERAL & TI & NA & MAIOR & 387.03 \\
\hline 117 & $\begin{array}{l}\text { ÁREA DE PROTEÇÃO AMBIENTAL DUNAS E VEREDAS DO } \\
\text { BAIXO MÉDIO SÂO FRANCISCO }\end{array}$ & 1997 & $\mathrm{UC}$ & APA & 2002 & ESTADUAL & US & V & MAIOR & 1764.26 \\
\hline 118 & $\begin{array}{l}\text { ÁREA DE PROTEÇÃO AMBIENTAL FOZ DO RIO SANTA } \\
\text { TEREZA }\end{array}$ & 1997 & $\mathrm{UC}$ & APA & 2002 & ESTADUAL & US & V & MAIOR & 501.44 \\
\hline 119 & ÁREA DE PROTEÇÃO AMBIENTAL SERRA DO LAJEADO & 1997 & $\mathrm{UC}$ & APA & 2002 & ESTADUAL & US & $\mathrm{V}$ & MAIOR & 1118.83 \\
\hline 120 & ÁREA DE PROTEÇÃO AMBIENTAL ILHA DO & 1997 & $\mathrm{UC}$ & APA & 2002 & ESTADUAL & US & $\mathrm{V}$ & MAIOR & 15693.18 \\
\hline
\end{tabular}




\begin{tabular}{|c|c|c|c|c|c|c|c|c|c|c|}
\hline & BANANAL/CANTÃO & & & & & & & & & \\
\hline 121 & APINAYÉ & 1997 & TI & TI & 2002 & FEDERAL & TI & NA & MAIOR & 1417.55 \\
\hline 122 & PARQUE ESTADUAL DO CANTÃO & 1998 & $\mathrm{UC}$ & PARNA & 2002 & ESTADUAL & PI & II & MAIOR & 1004.00 \\
\hline 123 & $\begin{array}{l}\text { ÁREA DE PROTEÇÃO AMBIENTAL MEANDROS DO } \\
\text { ARAGUAIA }\end{array}$ & 1998 & $\mathrm{UC}$ & APA & 2002 & FEDERAL & US & V & MAIOR & 3591.90 \\
\hline 124 & PARQUE ESTADUAL VERDE GRANDE & 1998 & $\mathrm{UC}$ & PARNA & 2002 & ESTADUAL & PI & II & MAIOR & 175.74 \\
\hline 125 & PARQUE ESTADUAL GRÃO MOGOL & 1998 & $\mathrm{UC}$ & PARNA & 2002 & ESTADUAL & PI & II & MAIOR & 348.61 \\
\hline 126 & ÁREA DE PROTEÇÃO AMBIENTAL ÁGUAS VERTENTES & 1998 & $\mathrm{UC}$ & APA & 2002 & ESTADUAL & US & $\mathrm{V}$ & MAIOR & 196.85 \\
\hline 127 & PARQUE ESTADUAL SERRA DAS ARARAS & 1998 & $\mathrm{UC}$ & PARNA & 2002 & ESTADUAL & PI & II & MAIOR & 135.53 \\
\hline 128 & ÁREA DE PROTEÇÃO AMBIENTAL DA SERRA DOURADA & 1998 & $\mathrm{UC}$ & APA & 2002 & ESTADUAL & US & $\mathrm{V}$ & MAIOR & 370.39 \\
\hline 129 & PARQUE ESTADUAL BIRIBIRI & 1998 & $\mathrm{UC}$ & PARNA & 2002 & ESTADUAL & PI & II & MAIOR & 173.81 \\
\hline 130 & $\begin{array}{l}\text { ÁREA DE PROTEÇÃO AMBIENTAL DAS CABECEIRAS DO } \\
\text { RIO CUIABÁ }\end{array}$ & 1998 & $\mathrm{UC}$ & APA & 2002 & ESTADUAL & US & V & MAIOR & 4732.12 \\
\hline 131 & ÁREA DE PROTEÇÃO AMBIENTAL LAJEDÃO & 1998 & $\mathrm{UC}$ & APA & 2002 & ESTADUAL & US & $\mathrm{V}$ & MAIOR & 101.19 \\
\hline 132 & ÁREA DE PROTEÇÃO AMBIENTAL SERRA DO SABONETAL & 1998 & $\mathrm{UC}$ & APA & 2002 & ESTADUAL & US & $\mathrm{V}$ & MAIOR & 795.80 \\
\hline 133 & PARQUE ESTADUAL SERRA NEGRA & 1998 & $\mathrm{UC}$ & PARNA & 2002 & ESTADUAL & PI & II & MENOR & 19.39 \\
\hline 134 & PARQUE NACIONAL SERRA DAS CONFUSÕES & 1998 & $\mathrm{UC}$ & PARNA & 2002 & FEDERAL & PI & II & MAIOR & 5652.64 \\
\hline 135 & CHÃO PRETO & 1998 & TI & TI & 2002 & FEDERAL & TI & NA & MENOR & 126.78 \\
\hline 136 & LIMÃO VERDE & 1998 & TI & TI & 2002 & FEDERAL & TI & NA & MENOR & 52.36 \\
\hline 137 & UBAWAWE & 1998 & TI & TI & 2002 & FEDERAL & TI & NA & MAIOR & 519.13 \\
\hline 138 & PARQUE DO ARAGUAIA & 1998 & $\mathrm{TI}$ & $\mathrm{TI}$ & 2002 & FEDERAL & $\mathrm{TI}$ & NA & MAIOR & 13594.04 \\
\hline 139 & PARQUE ESTADUAL DAS NASCENTES DO RIO TAQUARI & 1999 & $\mathrm{UC}$ & PARNA & 2002 & ESTADUAL & PI & II & MAIOR & 305.97 \\
\hline 140 & ÁREA DE PROTEÇÃO AMBIENTAL LAGO DE PALMAS & 1999 & $\mathrm{UC}$ & APA & 2002 & ESTADUAL & US & $\mathrm{V}$ & MAIOR & 638.59 \\
\hline 141 & PARQUE NACIONAL CAVERNAS DO PERUAÇU & 1999 & $\mathrm{UC}$ & PARNA & 2002 & FEDERAL & PI & II & MAIOR & 520.12 \\
\hline 142 & $\begin{array}{l}\text { ÁREA DE PROTEÇÃO AMBIENTAL DAS NASCENTES DE } \\
\text { ARAGUAINA }\end{array}$ & 1999 & $\mathrm{UC}$ & APA & 2002 & ESTADUAL & US & V & MAIOR & 152.95 \\
\hline 143 & $\begin{array}{l}\text { ÁREA DE PROTEÇÃO AMBIENTAL MUNICIPAL DO ARICÁ- } \\
\text { AÇU }\end{array}$ & 1999 & $\mathrm{UC}$ & APA & 2002 & $\begin{array}{l}\text { MUNICIPA } \\
\text { L }\end{array}$ & US & V & MAIOR & 754.42 \\
\hline 144 & FLORESTA NACIONAL DE BRASÍLIA & 1999 & $\mathrm{UC}$ & FLONA & 2002 & FEDERAL & US & VI & MAIOR & 93.36 \\
\hline 145 & $\begin{array}{l}\text { ÁREA DE PROTEÇÃO AMBIENTAL ESTRADA PARQUE DE } \\
\text { PIRAPUTANGA }\end{array}$ & 2000 & $\mathrm{UC}$ & APA & 2002 & ESTADUAL & US & V & MAIOR & 101.27 \\
\hline 146 & ÁREA DE PROTEÇÃO AMBIENTAL JALAPÃO & 2000 & $\mathrm{UC}$ & APA & 2002 & ESTADUAL & US & $\mathrm{V}$ & MAIOR & 1349.50 \\
\hline 147 & ÁREA DE PROTEÇÃO AMBIENTAL DOS PIRENEUS & 2000 & $\mathrm{UC}$ & APA & 2002 & ESTADUAL & US & $\mathrm{V}$ & MAIOR & 191.83 \\
\hline 148 & ÁREA DE PROTEÇÃO AMBIENTAL SERRA DA JIBÓIA & 2000 & $\mathrm{UC}$ & APA & 2002 & ESTADUAL & US & $\mathrm{V}$ & MAIOR & 171.62 \\
\hline 149 & $\begin{array}{l}\text { ÁREA DE PROTEÇÃO AMBIENTAL RIO CÊNICO ROTAS } \\
\text { MONÇOEIRAS }\end{array}$ & 2000 & $\mathrm{UC}$ & APA & 2002 & ESTADUAL & US & V & MAIOR & 172.06 \\
\hline 150 & PARQUE NACIONAL DA SERRA DA BODOQUENA & 2000 & $\mathrm{UC}$ & PARNA & 2002 & FEDERAL & PI & II & MAIOR & 769.76 \\
\hline
\end{tabular}




\begin{tabular}{|c|c|c|c|c|c|c|c|c|c|c|}
\hline 151 & $\begin{array}{l}\text { RESERVA EXTRATIVISTA MARINHA DO DELTA DO } \\
\text { PARNAIBA }\end{array}$ & 2000 & $\mathrm{UC}$ & RESEX & 2002 & FEDERAL & US & VI & MAIOR & 259.85 \\
\hline 152 & MONUMENTO NATURAL DAS ÁRVORES FOSSILIZADAS & 2000 & $\mathrm{UC}$ & $\mathrm{MN}$ & 2002 & ESTADUAL & PI & III & MAIOR & 292.46 \\
\hline 153 & KALUNGA & 2000 & TQ & $\mathrm{TQ}$ & 2002 & FEDERAL & TQ & NA & MAIOR & 2618.31 \\
\hline 154 & XAKRIABÁ RANCHARIA & 2000 & TI & TI & 2002 & FEDERAL & TI & NA & MENOR & 62.86 \\
\hline 155 & APA RIO BATALHA & 2001 & $\mathrm{UC}$ & APA & 2002 & ESTADUAL & US & $\mathrm{V}$ & MAIOR & 1341.97 \\
\hline 156 & ESTACAO ECOLOGICA SERRA GERAL DO TOCANTINS & 2001 & $\mathrm{UC}$ & ESEC & 2002 & FEDERAL & PI & Ia & MAIOR & 7070.81 \\
\hline 157 & $\begin{array}{l}\text { ÁREA DE PROTEÇÃO AMBIENTAL FAZENDA CAPITÃO } \\
\text { EDUARDO }\end{array}$ & 2001 & $\mathrm{UC}$ & APA & 2002 & ESTADUAL & US & $\mathrm{V}$ & MENOR & 4.94 \\
\hline 158 & PARQUE ESTADUAL DO JALAPÃO & 2001 & $\mathrm{UC}$ & PARNA & 2002 & ESTADUAL & PI & II & MAIOR & 1589.71 \\
\hline 159 & REFÚGIO DE VIDA SILVESTRE CORIXÃO DA MATA AZUL & 2001 & $\mathrm{UC}$ & REVIS & 2002 & ESTADUAL & PI & III & MAIOR & 357.08 \\
\hline 160 & PARQUE ESTADUAL DO ARAGUAIAA & 2001 & $\mathrm{UC}$ & PARNA & 2002 & ESTADUAL & PI & II & MAIOR & 2299.21 \\
\hline 161 & $\begin{array}{l}\text { ÁREA DE PROTEÇÃO AMBIENTAL DAS NASCENTES DO } \\
\text { RIO VERMELHO }\end{array}$ & 2001 & UC & APA & 2002 & FEDERAL & US & V & MAIOR & 1763.22 \\
\hline 162 & ÁREA DE PROTEÇÃO AMBIENTAL DO ITACURU & 2001 & $\mathrm{UC}$ & APA & 2002 & $\begin{array}{l}\text { MUNICIPA } \\
\text { L }\end{array}$ & US & V & MAIOR & 55.61 \\
\hline 163 & PARQUE ESTADUAL DO LAJEADO & 2001 & $\mathrm{UC}$ & PARNA & 2002 & ESTADUAL & PI & II & MAIOR & 107.50 \\
\hline 164 & FLORESTA NACIONAL DE CRISTÓPOLIS & 2001 & $\mathrm{UC}$ & FLONA & 2002 & FEDERAL & US & VI & MAIOR & 128.41 \\
\hline 165 & ÁREA DE PROTEÇÃO AMBIENTAL POUSO ALTO & 2001 & $\mathrm{UC}$ & APA & 2002 & ESTADUAL & US & $\mathrm{V}$ & MAIOR & 8394.93 \\
\hline 166 & INAWEBOHONA & 2001 & TI & TI & 2002 & FEDERAL & TI & NA & MAIOR & 3773.48 \\
\hline 167 & FLORESTA ESTADUAL DO ARAGUAIA & 2002 & UC & FLONA & 2002 & ESTADUAL & US & VI & MAIOR & 223.38 \\
\hline 168 & $\begin{array}{l}\text { ÁREA DE PROTEÇÃO AMBIENTAL LAGO DE } \\
\text { PEIXE/ANGICAL }\end{array}$ & 2002 & $\mathrm{UC}$ & APA & 2002 & ESTADUAL & US & $\mathrm{V}$ & MAIOR & 754.51 \\
\hline 169 & ÁREA DE PROTEÇÃO AMBIENTAL DO SALTO MAGESSI & 2002 & $\mathrm{UC}$ & APA & 2002 & ESTADUAL & US & $\mathrm{V}$ & MAIOR & 78.45 \\
\hline 170 & PARQUE ESTADUAL ÁGUAS DO CUIABÁ & 2002 & $\mathrm{UC}$ & PARNA & 2002 & ESTADUAL & PI & II & MAIOR & 109.62 \\
\hline 171 & $\begin{array}{l}\text { REFUGIO DE VIDA SILVESTRE VEREDAS DO OESTE } \\
\text { BAIANO }\end{array}$ & 2002 & UC & REVIS & 2002 & FEDERAL & PI & III & MAIOR & 1280.49 \\
\hline 172 & ÁREA DE PROTEÇÃO AMBIENTAL JOÃO LEITE & 2002 & $\mathrm{UC}$ & APA & 2002 & ESTADUAL & US & $\mathrm{V}$ & MAIOR & 713.42 \\
\hline 173 & PARQUE ESTADUAL DE PARAÚNA & 2002 & $\mathrm{UC}$ & PARNA & 2002 & ESTADUAL & PI & II & MAIOR & 33.35 \\
\hline 174 & $\begin{array}{l}\text { ÁREA DE PROTEÇÃO AMBIENTAL LAGO DE SÃO } \\
\text { SALVADOR DO TOCANTINS, PARANÃ E PALMEIRÓPOLIS }\end{array}$ & 2002 & UC & APA & 2002 & ESTADUAL & US & V & MAIOR & 142.25 \\
\hline 175 & $\begin{array}{l}\text { ÁREA DE PROTEÇÃO AMBIENTAL DA SERRA DAS GALÉS } \\
\text { E DA PORTARIA }\end{array}$ & 2002 & UC & APA & 2002 & ESTADUAL & US & V & MAIOR & 462.85 \\
\hline 176 & $\begin{array}{l}\text { ÁREA DE PROTEÇÃO AMBIENTAL DO PLANALTO } \\
\text { CENTRAL }\end{array}$ & 2002 & $\mathrm{UC}$ & APA & 2002 & FEDERAL & US & V & MAIOR & 5034.19 \\
\hline 177 & PARQUE ESTADUAL DOM OSÓRIO STOFFEL & 2002 & $\mathrm{UC}$ & PARNA & 2002 & ESTADUAL & PI & II & MAIOR & 64.21 \\
\hline 178 & PARQUE NACIONAL DAS NASCENTES DO RIO PARNAIBA & 2002 & $\mathrm{UC}$ & PARNA & 2002 & FEDERAL & PI & II & MAIOR & 7497.48 \\
\hline 179 & PARQUE ESTADUAL DO ARAGUAIA & 2002 & $\mathrm{UC}$ & PARNA & 2002 & ESTADUAL & PI & II & MAIOR & 46.63 \\
\hline
\end{tabular}




\begin{tabular}{|c|c|c|c|c|c|c|c|c|c|c|}
\hline 180 & RESERVA BIOLÓGICA DA CONTAGEM & 2002 & $\mathrm{UC}$ & REBIO & 2002 & FEDERAL & PI & Ia & MAIOR & 34.12 \\
\hline 181 & PARQUE NACIONAL DAS SEMPRE VIVAS & 2002 & UC & PARNA & 2002 & FEDERAL & PI & II & MAIOR & 1241.55 \\
\hline 182 & ÑANDE RU MARANGATU & 2002 & TI & TI & 2002 & FEDERAL & TI & NA & MENOR & 92.88 \\
\hline 183 & $\begin{array}{l}\text { RESERVA DE DESENVOLVIMENTO SUSTENTÁVEL } \\
\text { VEREDAS DO ACARI }\end{array}$ & 2003 & UC & RDS & 2008 & ESTADUAL & US & VI & MAIOR & 587.80 \\
\hline 184 & ÁREA DE PROTEÇÃO AMBIENTAL DO ENCANTADO & 2003 & $\mathrm{UC}$ & APA & 2008 & ESTADUAL & US & $\mathrm{V}$ & MAIOR & 94.44 \\
\hline 185 & ESTAÇÃO ECOLÓGICA DE SAGARANA & 2003 & $\mathrm{UC}$ & ESEC & 2008 & ESTADUAL & PI & Ia & MENOR & 23.44 \\
\hline 186 & PARQUE ESTADUAL DA SERRA DOURADA & 2003 & $\mathrm{UC}$ & PARNA & 2008 & ESTADUAL & PI & II & MAIOR & 286.43 \\
\hline 187 & PARQUE ESTADUAL SERRA NOVA & 2003 & $\mathrm{UC}$ & PARNA & 2008 & ESTADUAL & PI & II & MAIOR & 320.32 \\
\hline 188 & FLORESTA NACIONAL DA MATA GRANDE & 2003 & UC & FLONA & 2008 & FEDERAL & US & VI & MENOR & 20.10 \\
\hline 189 & $\begin{array}{l}\text { RESERVA PARTICULAR DO PATRIMÔNIO NATURAL } \\
\text { ESTÂNCIA CAIMAN }\end{array}$ & 2004 & $\mathrm{UC}$ & RPPN & 2008 & FEDERAL & US & IV & MAIOR & 54.60 \\
\hline 190 & PARQUE ESTADUAL CAMPOS ALTOS & 2004 & $\mathrm{UC}$ & PARNA & 2008 & ESTADUAL & PI & II & MENOR & 7.83 \\
\hline 191 & ÁREA DE PROTEÇÃO AMBIENTAL COCHÁ E GIBÃO & 2004 & UC & APA & 2008 & ESTADUAL & US & $\mathrm{V}$ & MAIOR & 2848.45 \\
\hline 192 & MACHADINHO & 2004 & TQ & TI & 2008 & FEDERAL & TI & NA & MENOR & 22.17 \\
\hline 193 & PARQUE NACIONAL DA CHAPADA DAS MESAS & 2005 & $\mathrm{UC}$ & PARNA & 2008 & FEDERAL & PI & II & MAIOR & 1599.52 \\
\hline 194 & ESTAÇÃO ECOLÓGICA DO RIO PRETO & 2005 & $\mathrm{UC}$ & ESEC & 2008 & ESTADUAL & PI & Ia & MAIOR & 48.80 \\
\hline 195 & PARQUE ESTADUAL DA SERRA DO CABRAL & 2005 & $\mathrm{UC}$ & PARNA & 2008 & ESTADUAL & PI & II & MAIOR & 222.99 \\
\hline 196 & SANTA JOANA & 2005 & TQ & TQ & 2008 & FEDERAL & TQ & NA & MENOR & 11.97 \\
\hline 197 & ARVORE VERDE & 2005 & TQ & TQ & 2008 & FEDERAL & TQ & NA & MAIOR & 25.50 \\
\hline 198 & IPIRANGA DO CARMINA & 2005 & TQ & TQ & 2008 & FEDERAL & TQ & NA & MENOR & 14.24 \\
\hline 199 & MATOES MOREIRA & 2005 & TQ & TQ & 2008 & FEDERAL & TQ & NA & MAIOR & 55.58 \\
\hline 200 & PIQUI/SANTA MARIA & 2005 & TQ & TQ & 2008 & FEDERAL & TQ & NA & MAIOR & 33.12 \\
\hline 201 & RESERVA EXTRATIVISTA LAGO DO CEDRO & 2006 & $\mathrm{UC}$ & RESEX & 2008 & FEDERAL & US & VI & MAIOR & 171.79 \\
\hline 202 & $\begin{array}{l}\text { RESERVA EXTRATIVISTA DO RECANTO DAS ARARAS DE } \\
\text { TERRA RONCA }\end{array}$ & 2006 & $\mathrm{UC}$ & RESEX & 2008 & FEDERAL & US & VI & MAIOR & 123.49 \\
\hline 203 & ÁREA DE PROTEÇÃO AMBIENTAL DE SÃO DESIDÉRIO & 2006 & UC & APA & 2008 & ESTADUAL & US & $\mathrm{V}$ & MAIOR & 109.70 \\
\hline 204 & $\begin{array}{l}\text { ÁREA DE PROTEÇÃO AMBIENTAL NASCENTES DO RIO } \\
\text { PARAGUAI }\end{array}$ & 2006 & $\mathrm{UC}$ & APA & 2008 & ESTADUAL & US & $\mathrm{V}$ & MAIOR & 708.57 \\
\hline 205 & PARQUE NATURAL MUNICIPAL DO POMBO & 2006 & $\mathrm{UC}$ & PARNA & 2008 & $\begin{array}{l}\text { MUNICIPA } \\
\text { L }\end{array}$ & PI & II & MAIOR & 80.33 \\
\hline 206 & PARQUE ESTADUAL DA LAPA GRANDE & 2006 & $\mathrm{UC}$ & PARNA & 2008 & ESTADUAL & PI & II & MAIOR & 96.68 \\
\hline 207 & ÁREA DE PROTEÇÃO AMBIENTAL VARGEM DAS FLORES & 2006 & $\mathrm{UC}$ & APA & 2008 & ESTADUAL & US & $\mathrm{V}$ & MAIOR & 68.98 \\
\hline 208 & ÁREA DE PROTEÇÃO AMBIENTAL LAGO DE SOBRADINHO & 2006 & $\mathrm{UC}$ & APA & 2008 & ESTADUAL & US & $\mathrm{V}$ & MAIOR & 54.78 \\
\hline 209 & ÁREA DE PROTEÇÃO AMBIENTAL DO RIO PRETO & 2006 & $\mathrm{UC}$ & APA & 2008 & ESTADUAL & US & $\mathrm{V}$ & MAIOR & 11468.71 \\
\hline 210 & LAGOA DAS PIRANHAS & 2006 & TQ & TQ & 2008 & FEDERAL & TQ & NA & MAIOR & 99.53 \\
\hline
\end{tabular}




\begin{tabular}{|c|c|c|c|c|c|c|c|c|c|c|}
\hline 211 & RIACHO DA SACUTIABA E SACUTIABA & 2006 & TQ & TQ & 2008 & FEDERAL & TQ & NA & MAIOR & 122.91 \\
\hline 212 & NOVA BATALHINHA & 2006 & TQ & TQ & 2008 & FEDERAL & TQ & NA & MAIOR & 74.75 \\
\hline 213 & LAGO GRANDE & 2006 & TQ & TQ & 2008 & ESTADUAL & TQ & NA & MAIOR & 21.40 \\
\hline 214 & MATA CAVALO & 2006 & TQ & TQ & 2008 & FEDERAL & TQ & NA & MAIOR & 147.58 \\
\hline 215 & CIPO & 2006 & TQ & TQ & 2008 & ESTADUAL & TQ & NA & MAIOR & 24.77 \\
\hline 216 & USINA VELHA & 2006 & TQ & TQ & 2008 & ESTADUAL & TQ & NA & MENOR & 12.16 \\
\hline 217 & FAZENDA JATOBA & 2006 & TQ & TQ & 2008 & FEDERAL & TQ & NA & MAIOR & 144.94 \\
\hline 218 & PARATECA E PAU DARCO & 2006 & TQ & TQ & 2008 & FEDERAL & TQ & NA & MAIOR & 416.05 \\
\hline 219 & KALUNGA DO MIMOSO & 2006 & TQ & TQ & 2008 & FEDERAL & TQ & NA & MAIOR & 574.12 \\
\hline 220 & LAGOA DO PEIXE & 2006 & TQ & TQ & 2008 & FEDERAL & TQ & NA & MENOR & 10.92 \\
\hline 221 & PARQUE ESTADUAL CAMINHO DOS GERAIS & 2007 & $\mathrm{UC}$ & PARNA & 2008 & ESTADUAL & PI & II & MAIOR & 214.75 \\
\hline 222 & PARQUE ESTADUAL SERRA DO INTENDENTE & 2007 & $\mathrm{UC}$ & PARNA & 2008 & ESTADUAL & PI & II & MAIOR & 134.79 \\
\hline 223 & RESERVA EXTRATIVISTA CHAPADA LIMPA & 2007 & UC & RESEX & 2008 & FEDERAL & US & VI & MAIOR & 119.73 \\
\hline 224 & BREJO DE CRIOULOS & 2007 & TQ & TQ & 2008 & FEDERAL & TQ & NA & MAIOR & 40.47 \\
\hline 225 & FAMILIA MAGALHAES & 2007 & TQ & TQ & 2008 & FEDERAL & TQ & NA & MAIOR & 54.90 \\
\hline 226 & SAO FRANCISCO MALAQUIAS & 2007 & TQ & TQ & 2008 & FEDERAL & TQ & NA & MENOR & 10.87 \\
\hline 227 & CACHOEIRINHA & 2007 & TI & $\mathrm{TI}$ & 2008 & FEDERAL & TI & NA & MENOR & 27.35 \\
\hline 228 & CACHOEIRINHA & 2007 & TI & TI & 2008 & FEDERAL & TI & NA & MENOR & 128.46 \\
\hline 229 & CACIQUE FONTOURA & 2007 & TI & TI & 2008 & FEDERAL & TI & NA & MAIOR & 323.30 \\
\hline 230 & BACURIZINHO & 2008 & TI & TI & 2008 & FEDERAL & $\mathrm{TI}$ & NA & MAIOR & 826.57 \\
\hline 231 & BACURIZINHO & 2008 & TI & TI & 2008 & FEDERAL & TI & NA & MAIOR & 1341.21 \\
\hline 232 & $\begin{array}{l}\text { RESERVA PARTICULAR DO PATRIMÔNIO NATURAL } \\
\text { RESERVA NATURAL DO TOMBADOR }\end{array}$ & 2009 & $\mathrm{UC}$ & RPPN & 2009 & FEDERAL & US & IV & MAIOR & 87.17 \\
\hline 233 & $\begin{array}{l}\text { RESERVA PARTICULAR DO PATRIMÔNIO NATURAL } \\
\text { FAZENDA CALIXTO }\end{array}$ & 2009 & $\mathrm{UC}$ & RPPN & 2009 & FEDERAL & US & IV & MENOR & 3.43 \\
\hline 234 & ARACA/CARIACA/ PATO/ PEDRAS/RETIRO & 2009 & TQ & TQ & 2009 & FEDERAL & TQ & NA & MAIOR & 82.61 \\
\hline 235 & MANGAL E BARRO VERMELHO & 2009 & TQ & TQ & 2009 & FEDERAL & TQ & NA & MAIOR & 90.42 \\
\hline 236 & BACO PARI & 2009 & TQ & TQ & 2009 & FEDERAL & TQ & NA & MAIOR & 31.48 \\
\hline 237 & KRENREHÉ & 2009 & TI & TI & 2009 & FEDERAL & TI & NA & MENOR & 59.78 \\
\hline 238 & UIRAPURU & 2009 & TI & TI & 2009 & FEDERAL & $\mathrm{TI}$ & NA & MAIOR & 216.65 \\
\hline 239 & $\begin{array}{l}\text { ÁREA DE PROTEÇÃO AMBIENTAL DOS MORROS } \\
\text { GARAPENSES }\end{array}$ & 2010 & UC & APA & 2010 & ESTADUAL & US & V & MAIOR & 2094.59 \\
\hline 240 & $\begin{array}{l}\text { RESERVA PARTICULAR DO PATRIMÔNIO NATURAL } \\
\text { CACHOEIRAS DO SÃO BENTO }\end{array}$ & 2010 & UC & RPPN & 2010 & ESTADUAL & US & IV & MAIOR & 30.35 \\
\hline 241 & PITORO DOS PRETOS & 2010 & TQ & TQ & 2010 & FEDERAL & TQ & NA & MAIOR & 43.06 \\
\hline 242 & PONTE DE PEDRA & 2010 & TI & TI & 2010 & FEDERAL & TI & NA & MENOR & 27.39 \\
\hline
\end{tabular}


Apêndice 2 - Discussão sobre o efeito do mapeamento nos resultados e questões atinentes à variável resposta.

Neste apêndice discutimos aspectos específicos sobre a obtenção e processamento relativo à variável resposta, bem como a compatibilidade e possíveis implicações sobre o resultado decorrentes da utilização de dados de mapeamento de diferentes origens, especificamente, mapeamento realizado conforme Capítulo 2 e mapeamento PMDBBS.

\section{Possíveis tratamentos para a variável estimadora}

A imagem abaixo representa a área antrópica de 2011 (vermelho), uma área protegida que foi criada em 2002 (delimitado pela linha magenta). As células do grid representam as unidades amostrais do tipo tratamento (no interior da área protegida) ou controle (no exterior).

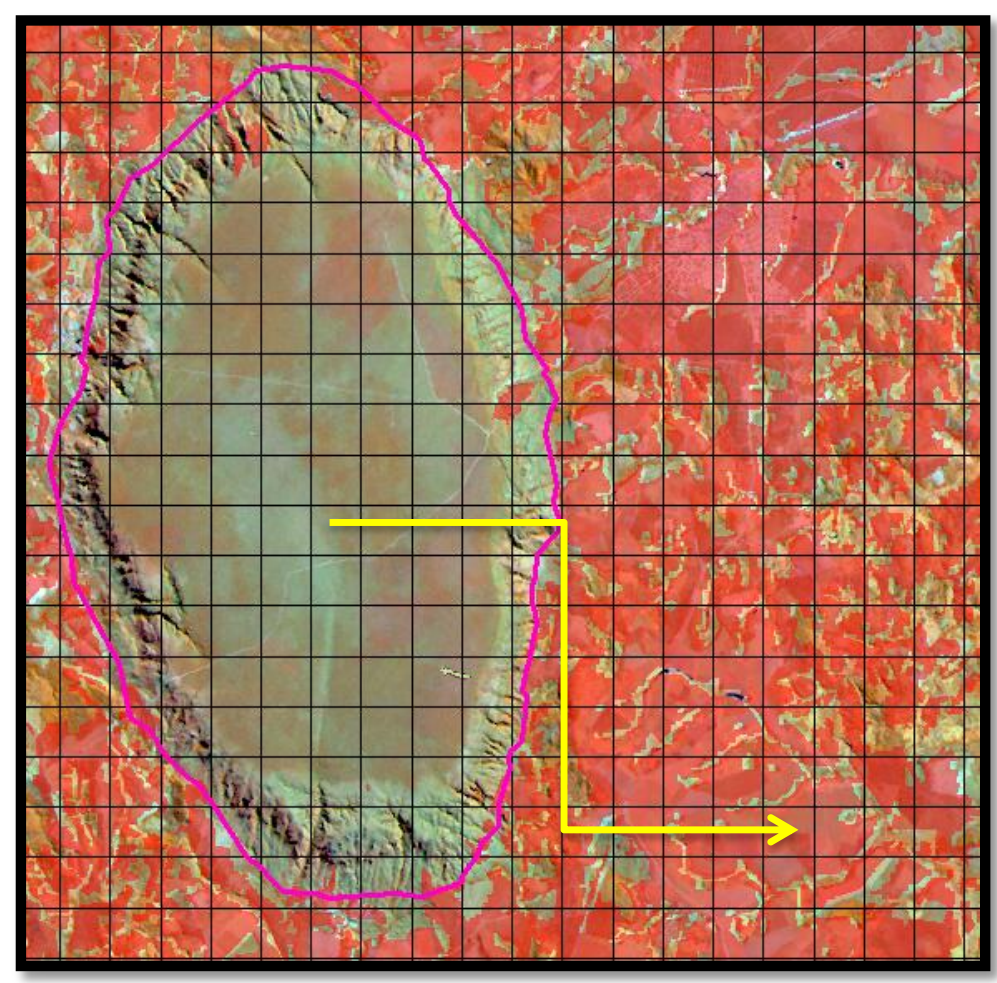

\section{Legenda}

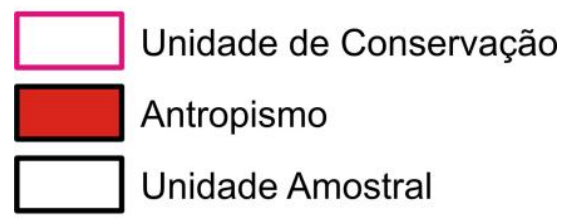

Unidades Pareadas

Figura 1 - Unidade de conservação e área antrópica para o ano de 2011 (PMDBBS).

Duas possibilidades principais de obtenção da variável resposta são dadas por:

a) O valor da área antrópica existente no ano de 2011;

b) A variação da área antrópica entre um ano anterior (ano base) e o ano de 2011 (ano de referência);

No primeiro caso, pode-se utilizar a metodologia de matching para se comparar a área antrópica da população de unidades amostrais do grupo tratamento com as do grupo controle. Ou seja, cada unidade amostral do interior de uma área protegida seria comparada com uma 
unidade amostral semelhante em relação às covariáveis $\mathrm{X}$ em seu exterior, como é representado pela seta amarela na imagem acima. A partir de todos os pares formados, pode-se obter o efeito médio do tratamento.

A primeira abordagem, item $a$, considerando-se apenas uma data para a obtenção da variável resposta é sujeita a críticas. Considerando que a análise é realizada com vistas a se compreender o papel das áreas protegidas, é necessário que, no período em que houve variação na área antrópica analisada, a área protegida ali já existisse. Deve-se, portanto, considerar, no caso da área protegida hipotética acima, criada em 2002, apenas as alterações ocorrentes em período posterior ao ano de 2002.

Utilizando-se apenas um ano como referência para a obtenção da variável resposta, como indicado no item $a$, não é possível garantir que a conversão de habitat em uma região no interior da unidade territorial tenha se dado em período posterior à criação dessa.

Por exemplo, supondo que a imagem abaixo represente a data de criação da unidade de interesse (ano de 2002), nota-se que o mapeamento para esta data já identificava duas áreas de antropismo no interior da unidade de conservação destacada (círculos em amarelo). No caso de se utilizar apenas uma data para a obtenção da variável resposta, o antropismo observado na imagem implicaria a diminuição indevida do efeito da área protegida, já que esses ocorreram em data anterior à existência da unidade territorial.

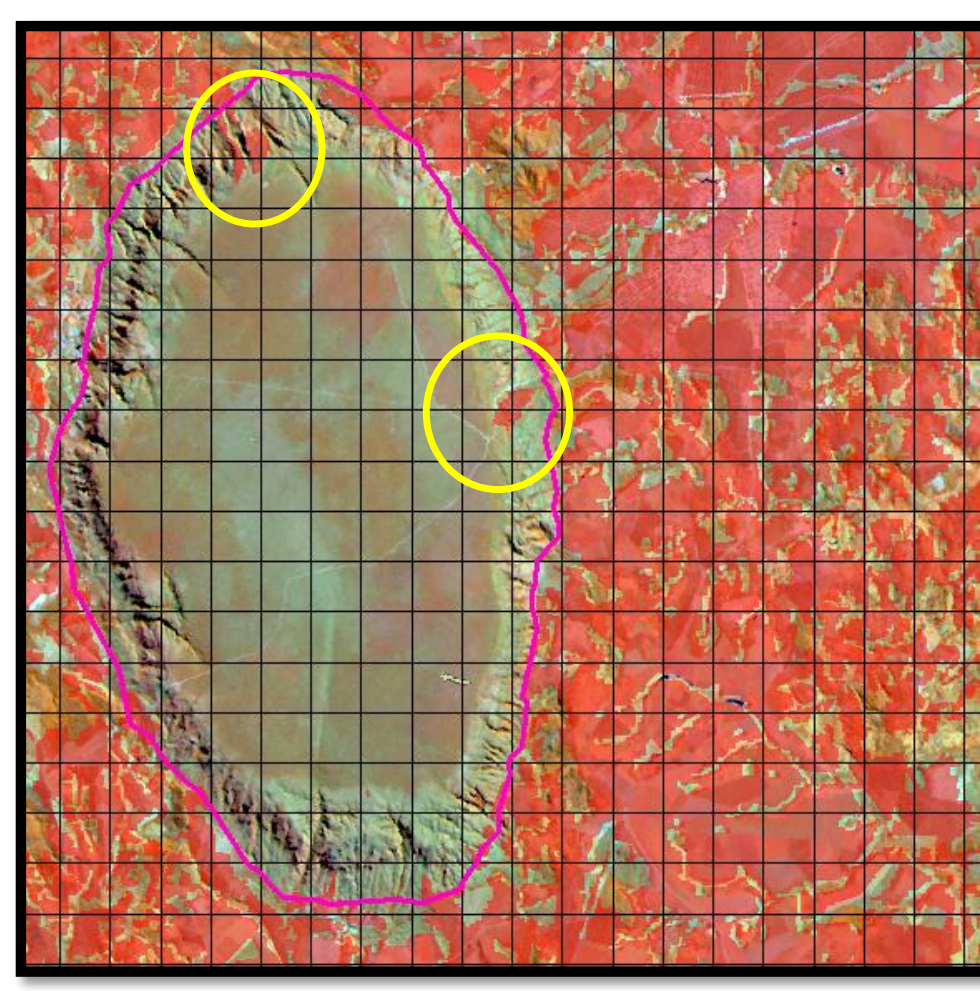

\section{Legenda}

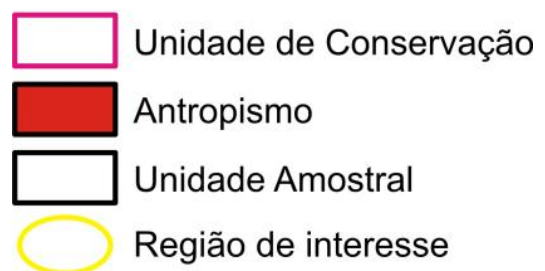

Figura 2 - Área antrópica no interior da Unidade de Conservação para data anterior a sua data de criação. 
Alternativa a essa abordagem é a consideração de duas datas distintas para a obtenção da variável resposta, um ano base (idealmente a data de criação da área protegida) e um ano de referência.

Tendo-se adotado a segunda abordagem, duas possibilidades se afiguram para a obtenção da variável resposta:

a) Calcular a variável resposta como a subtração da área antrópica, no interior de cada unidade amostral, existente no ano de referência (2011) pela área antrópica existente no ano base (2002) (Variável resposta = área 2011 - área 2002).

b) Excluir aquelas células com antropismo na data de criação da unidade e considerar a variável resposta como a variação entre a data base (sempre zero) e o ano de referência. Nesse caso, a decisão é discreta binária (se tem antropismo, exclui; senão mantém). Na prática, a variável estimadora terá sempre o valor da data de referência, tendo como implicação variações na quantidade de unidades amostrais que participam efetivamente do estudo.

Considere-se as células 1, 2, 3 e 4 e a área antrópica existente em seu interior para o ano base e o ano de referência, como no exemplo abaixo:

Grade de Células

\begin{tabular}{|l|l|}
\hline 1 & 2 \\
\hline 3 & 4 \\
\hline
\end{tabular}

Ano Base

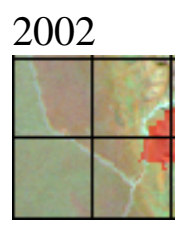

Área antrópica por célula $\mathrm{km}^{2}$

\begin{tabular}{|l|l|}
\hline 0 & 0,1 \\
\hline 0 & 0,2 \\
\hline
\end{tabular}

$1-0 \mathrm{~km}^{2}$

$2-0,1 \mathrm{~km}^{2}$

$3-0 \mathrm{~km}^{2}$

$4-0,2 \mathrm{~km}^{2}$
Ano de Referência

2011

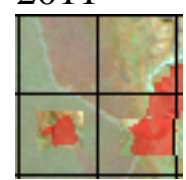

Área antrópica por célula $\mathrm{km}^{2}$

\begin{tabular}{|l|l|}
\hline 0 & 0,1 \\
\hline 0,3 & 0,6 \\
\hline
\end{tabular}

$1-0 \mathrm{~km}^{2}$

$2-0,1 \mathrm{~km}^{2}$

$3-0,3 \mathrm{~km}^{2}$

$4-0,6 \mathrm{~km}^{2}$

Caso a variável resposta fosse quantificada conforme disposto no item $a$, ou seja, como a variação da área entre os anos (área 2011 - área 2002), para as células de 1 a 4, teríamos como resultado: 


$$
\begin{array}{|l|l|}
\hline 0 & 0 \\
\hline 0,3 & 0,4 \\
\hline
\end{array}
$$

No caso da segunda opção, descrita no item $b$, devemos considerar apenas unidades que na data base não apresentam antropismo, ou seja, apenas as células 1 e 3 . Como valor final da variável resposta, seria considerado o valor existente para o ano de referência. Nessa hipótese, as células de 1 a 4 teria os valores:

\begin{tabular}{|l|l|}
\hline 0 & Excluído \\
\hline 0,3 & Excluído \\
\hline
\end{tabular}

A opção descrita no item a é uma alternativa ideal, na qual o valor da variável resposta é obtido sem a diminuição da população de unidades amostrais participantes da investigação. Para essa primeira opção, a variação na área antrópica é realizada levando-se em conta dois mapeamentos distintos e, para uma mesma unidade amostral, em ambos pode-se observar qualquer valor entre 0 e $1 \mathrm{~km}^{2}$.

A alternativa mencionada mostra-se muito sensível a variações decorrentes da aplicação de diferentes metodologias de mapeamento entre os anos considerados. Variações na escala do mapeamento, por exemplo, entre o ano base e o ano de referência têm impacto potencial relevante sobre os resultados, sendo exigida compatibilidade muito precisa entre os mapeamentos utilizados para que os resultados não sejam afetados em função de eventual diferença metodológica ou incompatibilidade entre mapeamentos. No caso da utilização de mapeamentos que tenham como origem mais de uma fonte (autores diferentes), torna-se difícil a obtenção de resultados confiáveis.

Na segunda opção, item $b$, o cômputo da variável estimadora ocorre apenas no ano de referência e considera-se a área antrópica existente no interior da unidade amostral apenas para essa data. A data base sempre tem o valor zero e a variável estimadora é computada exclusivamente a partir da área antrópica observada na data de referência.

Para essa estratégia, é suficiente que diferentes mapeamentos sejam compatíveis em relação a uma restrição binária: a identificação ou não de antropismo no interior da área de 1 $\mathrm{km}^{2}$, sendo a compatibilidade observada em uma escala discreta (antropismo ou não antropismo), enquanto a variável resposta é estimada na escala do mapeamento para o ano de referência.

No estudo realizado neste capítulo, adotou-se a opção do item $b$ e considerou-se mapeamentos de duas diferentes fontes (PMDBBS e Capítulo 2 deste trabalho), os quais foram realizados para uma escala de 1:50.000, identificando áreas mínimas de 2 hectares (2\% de 1 $\mathrm{km}^{2}$ ). A condição de compatibilidade entre os mapeamentos, no entanto, ocorre em uma escala 
de 1:2.000.000, escala correspondente em que $1 \mathrm{~km}^{2}$ é a área mínima identificável, conforme Padrão de Exatidão Cartográfico A.

\section{Exclusão de unidades e sua relação com as coortes}

Tendo-se adotado uma das alternativas, o passo seguinte é se realizar a avaliação do impacto da exclusão de unidades amostrais sobre o total de unidades disponíveis. Tal evento guarda relação com a data estabelecida para a formação das coortes e a propensão das unidades em sofrer desmatamento.

Considerando-se ambiente com taxa de desmatamento positiva, com área antrópica crescente ao longo do tempo, o estabelecimento das coortes deve ser realizado para a data mais antiga e próxima à data de criação das UC's possível. No caso do estudo, observando-se o conjunto de unidades consideradas na análise e a disponibilidade de mapeamentos, foram definidas as coortes:

- Coorte 1 - criação entre 1949 e 1985

- Coorte 2 - criação entre 1985 e 1995 ;

- Coorte 3 - criação entre 1995 e 2002;

- Coorte 4 - criação entre 2002 e 2008;

- Coorte 5 - criação entre 2008 e 2009 ;

- Coorte 6 - criação entre 2009 e 2010 ;

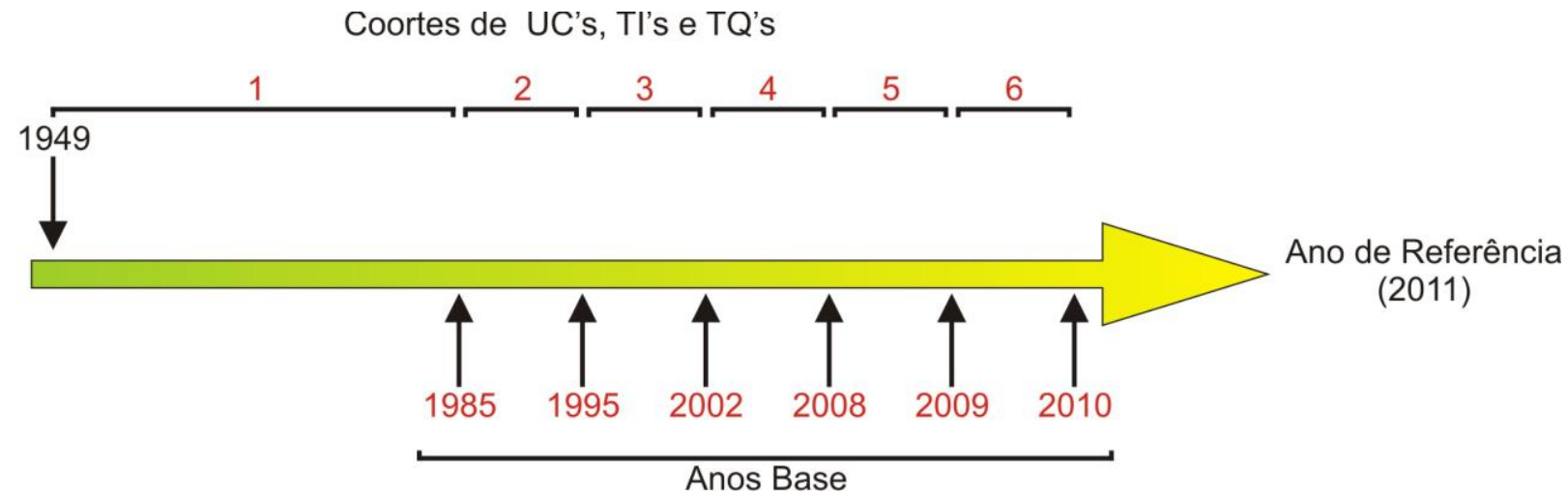

Figura 3 - Coortes, anos base e ano de referência definidos neste capítulo.

Decisões relacionadas à data de estabelecimentos da coorte têm efeito principalmente sobre áreas protegidas menos restritivas, que aceitam intervenções em seu interior, por exemplo, APAs. No decorrer do tempo seria esperado um aumento do antropismo no interior desse tipo de áreas protegidas havendo a necessidade de exclusão de muitas unidades amostrais do grupo tratamento e até mesmo unidades territoriais inteiras seriam excluídas da análise. 
Por exemplo, supondo que a área protegida abaixo (figura 4) tenha sido criada em 1970 (a área protegida delimitada pela linha magenta), caso seja considerado o mapeamento realizado no Capítulo 2 e utilizada como data base da coorte o ano de 1985, seria observado o seguinte cenário:

a)

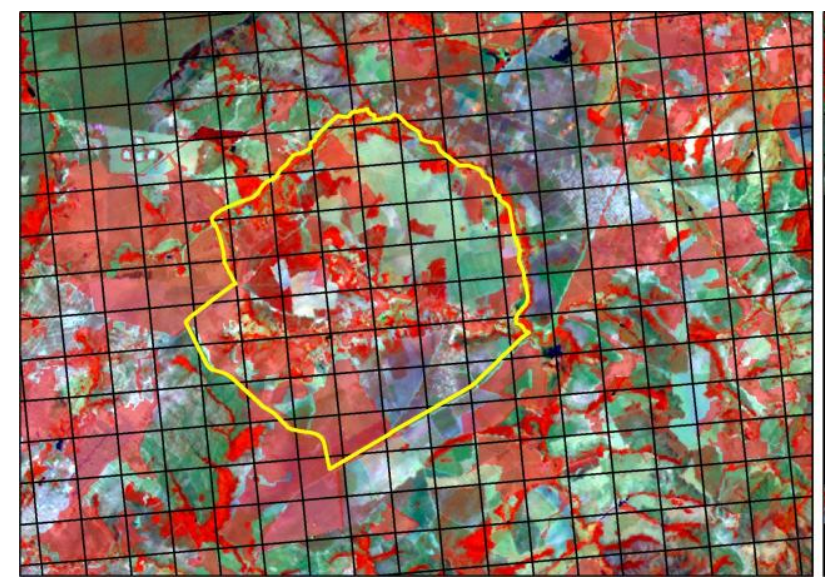

b)

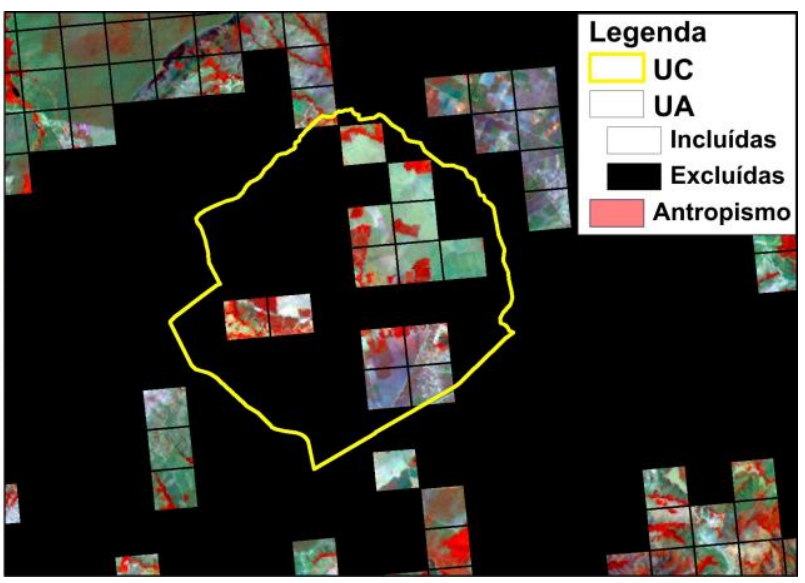

Figura 4 - Unidades amostrais (UA) incluídas e excluídas na análise para o ano de 1985. Unidades no interior da Unidade de Conservação (UC) participa do grupo tratamento e unidades do exterior da UC participam do grupo controle. a) Área antrópica no ano de 1985; b) unidades amostrais remanescentes.

Neste caso, observa-se a exclusão de várias unidades no interior da área protegida, porém, ainda permanece quantidade razoável de unidades amostrais para participação no estudo.

Caso considere-se o mapeamento do ano de 2002 para o estabelecimento da coorte para a mesma região, tem-se o resultado da imagem abaixo.

a)

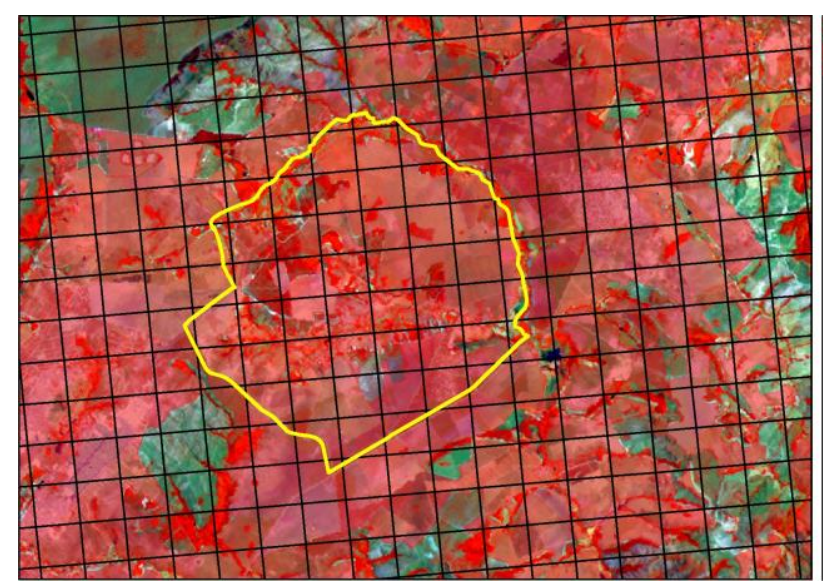

b)

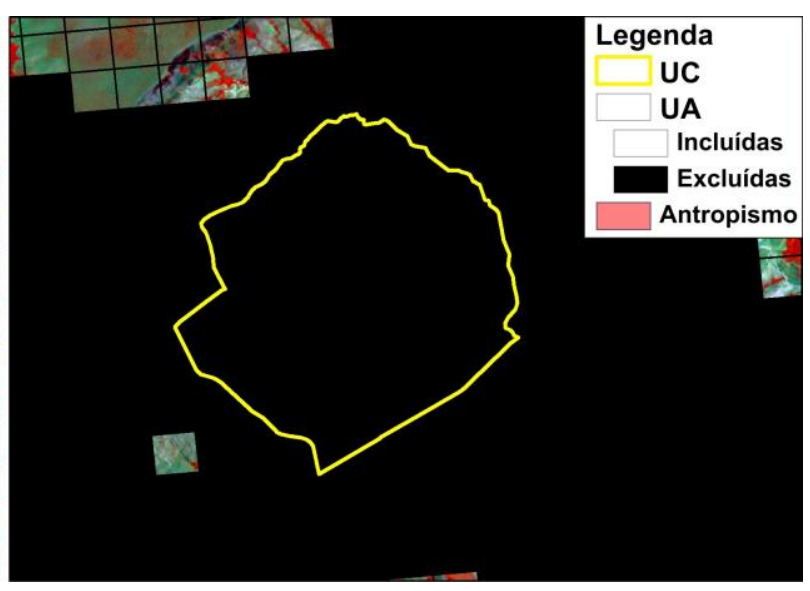

Figura 5 - Unidades amostrais (UA) incluídas e excluídas na análise para o ano de 2002. Unidades no interior da Unidade de Conservação (UC) participa do grupo tratamento e unidades do exterior da UC participam do grupo controle. a) Área antrópica no ano de 2002; b) unidades amostrais remanescentes. 
No último caso, observa-se que praticamente todas as unidades amostrais no interior da unidade de conservação (uma APA) apresentaria antropismo (vermelho) no ano de 2002. Nenhuma unidade amostral pertencente a essa unidade territorial poderia ser considerada no estudo, resultando na exclusão da unidade territorial da análise.

Observa-se que, em um cenário com taxas de desmatamento positivo, é importante a obtenção de mapeamentos e o estabelecimento de coortes o mais próximos à data de criação das unidades, sendo esse um dos motivos para a realização do mapeamento disposto no Capítulo 2, sem o qual unidades territoriais criadas em períodos anteriores a 2002 poderiam sofrer sérias restrições quanto à obtenção de seu efeito.

\section{Compatibilidade entre mapeamentos}

Em face de possíveis impactos decorrentes do mapeamento sobre o efeito das áreas protegidas, importa-nos, especialmente, demonstrar a compatibilidade do mapeamento executado no Capítulo 2 em relação àquele realizado pelo PMDBBS para o ano de 2002, sob a perspectiva da metodologia adotada no presente capítulo.

Inicialmente, observa-se que, a partir das considerações anteriores e do método adotado, eventuais diferenças metodológicas entre mapeamentos têm impacto apenas sobre a manutenção ou não de unidades amostrais, mas não apresentam qualquer influência sobre o valor da variável resposta, a qual foi exclusivamente obtida a partir do mapeamento PMDBBS 2011.

A compatibilidade entre mapeamentos deve ser aferida, portanto, a partir de análise em relação ao impacto que a manutenção ou não de unidades amostrais tem sobre os resultados do efeito das unidades territoriais consideradas sobre o desmatamento.

A fim de se testar tal influência, a metodologia aplicada neste trabalho foi reproduzida para dois distintos cenários:

1) em que se utilizou como ano base o mapeamento referente ao ano de 2002 realizado pelo PMDBBS;

2) em que se utilizou como ano base mapeamento referente ao ano de 2002 realizado conforme metodologia aplicada no Capítulo 2.

O teste realizado considerou 30 cenas LANDSAT 5 TM e as áreas protegidas nela existentes e não toda a área do Cerrado.

Considerando a concordância ou não em relação à existência de antropismo em uma dada unidade amostral e os cenários acima mencionados, tem-se como possíveis casos:

- Unidades amostrais não possuem qualquer área antrópica em ambos os mapeamentos; 
- As unidades amostrais seriam igualmente mantidas na análise e teriam como valor da variável estimadora a área antrópica existente no ano de 2011.

○ Não há qualquer impacto sobre os resultados;

- Unidades amostrais apresentam antropismo em ambos os mapeamentos:

- As unidades seriam igualmente excluídas na análise.

- Não há qualquer impacto sobre os resultados;

- Unidade amostral apresenta antropismo no segundo cenário (mapeamento de acordo com o Capítulo 2), mas apresenta-se completamente preservada no primeiro cenário (mapeamento PMDBBS):

- Ocorre a exclusão de uma unidade amostral que seria mantida no caso de o mapeamento ter sido realizado pelo PMDBBS;

○ Os impactos dizem respeito à diminuição de unidades amostrais:

- Para o caso do grupo tratamento isso pode resultar na exclusão de áreas protegidas por inteiro ou apenas na diminuição do número de unidades amostrais a partir das quais o efeito médio será obtido. No caso de elevado número de amostras disponíveis para o grupo tratamento não seria esperada grande diferença nos resultados em função do mapeamento, haja vista que o efeito obtido se refere à média todas as unidades que participam do grupo tratamento.

- Para o caso de unidades amostrais do grupo controle o impacto também é a diminuição do número de unidades amostrais disponíveis. Caso não haja um grande número de unidades amostrais pode haver um impacto sobre o viés na análise, visto que a diminuição das UAs pode resultar em uma maior dissimilaridade em termos de covariáveis entre UAs tratamento e UAs controle. Em casos de um número de amostras elevado não seria esperada grande diferença nos resultados.

- Unidade amostral está completamente preservada no cenário 2, mas apresenta antropismo no cenário 1 :

- Ocorre a inclusão de uma unidade amostral que seria excluída da análise no caso de o mapeamento ter sido aquele realizado pelo PMDBBS;

○ Os impactos dizem respeito à adição de unidades amostrais:

- A inclusão de amostras no grupo tratamento não deve influenciar tão fortemente os resultados de eficácia, haja vista que a inclusão de algumas unidades amostrais não deve influenciar significativamente resultados que são obtidos em termos de média.

- No caso do grupo controle, igualmente, não deve haver impacto significativo. Caso haja, será no sentido da diminuição do viés.

O impacto de eventuais diferenças é sempre mais importante se incidir sobre as unidades do grupo tratamento, devido ao menor número de amostras e sua relação com os resultados finais do estudo. Diferenças no grupo controle têm por efeito alterações no viés. 
As situações descritas são exemplificadas abaixo:

\section{Cenário 1 (Mapeamento Capítulo 2)}

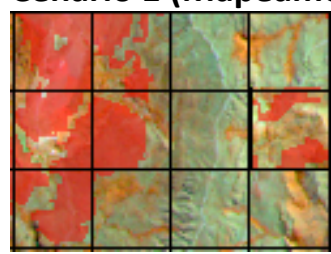

Máscara de exclusão

\begin{tabular}{|l|l|l|l|}
\hline Excluído & Excluído & Mantém & Mantém \\
\hline Excluído & Excluído & Mantém & Excluído \\
\hline Excluído & Mantém & Mantém & Mantém \\
\hline
\end{tabular}

Valor em 2011 - área antrópica $\mathrm{km}^{2}$

\begin{tabular}{|l|l|l|l|}
\hline Excluído & Excluído & 0 & 0,1 \\
\hline Excluído & Excluído & 0,1 & Excluído \\
\hline Excluído & 0,3 & 0,4 & 1 \\
\hline
\end{tabular}

Cenário 2 (Mapeamento PMDBBS)

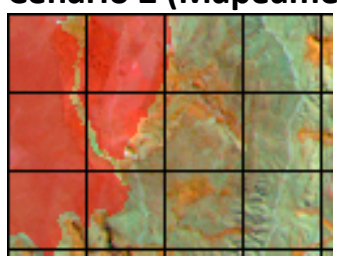

Máscara origem

\begin{tabular}{|l|l|l|l|}
\hline Excluído & Excluído & Mantém & Mantém \\
\hline Excluído & Excluído & Mantém & Mantém \\
\hline Excluído & Excluído & Mantém & Mantém \\
\hline
\end{tabular}

Valor em 2011 - área antrópica km²

\begin{tabular}{|l|l|l|l|}
\hline Excluído & Excluído & 0 & 0,1 \\
\hline Excluído & Excluído & 0,1 & 0,4 \\
\hline Excluído & Excluído & 0,4 & 1 \\
\hline
\end{tabular}

Após a elaboração dos testes para o ano de 2002, com as 30 cenas, foi obtida a eventual influência do mapeamento sobre a manutenção ou exclusão de unidades amostrais presentes nas imagens testadas. Foram obtidos os seguintes valores:

Tabela 1 - Concordâncias e discordâncias entre os cenários.

\begin{tabular}{lrr} 
Concordância/Discordância na seleção de unidades amostrais do grupo controle entre os cenários & $\mathbf{N}$ & $\%$ \\
Concordância & $\mathbf{6 2 5 0 0 2}$ & $\mathbf{8 4 . 7 \%}$ \\
Grupo Tratamento & 78967 & $10.7 \%$ \\
Grupo Controle & 546035 & $74.0 \%$ \\
Discordância & $\mathbf{1 1 3 0 1 5}$ & $\mathbf{1 5 . 3 \%}$ \\
Acréscimos de unidades em relação ao PMDBBS & $\mathbf{2 8 5 7 2}$ & $\mathbf{3 . 9 \%}$ \\
$\quad$ Grupo Tratamento & 3837 & $0.5 \%$ \\
$\quad$ Grupo Controle & 24735 & $3.4 \%$ \\
Decréscimo de unidades em relação ao PMDBBS & $\mathbf{8 4 4 4 3}$ & $\mathbf{1 1 . 4 \%}$ \\
$\quad$ Grupo Tratamento & 12035 & $1.6 \%$ \\
$\quad$ Grupo Controle & 72408 & $9.8 \%$ \\
\hline Total de Amostras & $\mathbf{7 3 8 0 1 7}$ & \\
\hline
\end{tabular}

*Percentual em relação ao valor total de unidades amostrais.

Observou-se uma diferença geral de $15 \%$ nas unidades amostrais selecionadas para o estudo em função de diferenças entre os mapeamentos. As unidades amostrais acrescentadas na análise apresentam um percentual de 3,9\%, enquanto as unidades amostrais retiradas da análise representam 11,4\% do total. Observa-se que a utilização do mapeamento, conforme Capítulo 2, implica maior exclusão do que inclusão de unidades amostrais no estudo. 
Do total de $15 \%$ de diferenças entre os mapeamentos, o grupo tratamento responde por $2,1 \%$ e o grupo controle por $13,2 \%$ das diferenças observadas.

Os resultados abaixo mostram que unidades amostrais do grupo tratamento tiveram a mesma propensão de pertencerem a "concordâncias" ou "discordâncias" do que aquelas unidades do grupo controle. Dessa forma, as diferenças percentuais observadas são devidas apenas a diferenças na área ocupada por esses tipos de unidades no mapeamento.

Tabela 2 - Total de unidades, exclusão e sua relação com a área.

\begin{tabular}{lrr} 
& Unidades amostrais por grupo & \\
Grupo Tratamento & 94839 & $12.9 \%$ \\
Grupo Controle & 643178 & $87.1 \%$ \\
\hline Total de Amostras & $\mathbf{7 3 8 0 1 7}$ & \\
\hline
\end{tabular}

\begin{tabular}{|c|c|c|c|c|}
\hline \multicolumn{5}{|c|}{ Valores esperados e observados } \\
\hline \multicolumn{5}{|c|}{ Concordância } \\
\hline & \multicolumn{2}{|c|}{ Observado } & \multicolumn{2}{|c|}{ Esperado } \\
\hline Grupo Tratamento & 78967 & $10.7 \%$ & 80316 & $10.9 \%$ \\
\hline Grupo Controle & 546035 & $74.0 \%$ & 544686 & $73.8 \%$ \\
\hline \multicolumn{5}{|c|}{ Discordância } \\
\hline \multicolumn{5}{|c|}{ Acréscimos de unidades em relação ao PMDBBS } \\
\hline & \multicolumn{2}{|c|}{ Observado } & \multicolumn{2}{|c|}{ Esperado } \\
\hline Grupo Tratamento & 3837 & $0.5 \%$ & 3672 & $0.5 \%$ \\
\hline Grupo Controle & 24735 & $3.4 \%$ & 24900 & $3.4 \%$ \\
\hline \multicolumn{5}{|c|}{ Decréscimo de unidades em relação ao PMDBBS } \\
\hline & \multicolumn{2}{|c|}{ Observado } & \multicolumn{2}{|c|}{ Esperado } \\
\hline Grupo Tratamento & 12035 & $1.6 \%$ & 10851 & $1.5 \%$ \\
\hline Grupo Controle & 72408 & $9.8 \%$ & 73592 & $10.0 \%$ \\
\hline
\end{tabular}

\section{Dados dos mapeamentos de 1985 e 1995}

Importante aqui observarmos dados do mapeamento realizado para os anos de $1985 \mathrm{e}$ 1995 e o resultado na formação da população de unidades amostrais do grupo controle e do grupo tratamento antes de tratarmos de eventuais efeitos da compatibilidade do mapeamento.

A população de unidades amostrais do estudo é formada por 2.025.394 unidades amostrais, visto que o Cerrado conta com aproximadamente 2 milhões de $\mathrm{km}^{2}$. Dessas unidades, $87 \%$ pertencem ao grupo controle e $13 \%$ ao grupo tratamento.

Tabela 3 - Unidades pertencentes ao grupo tratamento e controle para os anos de 1985 e 1995.

\section{Unidades amostrais Disponíveis}


A exclusão de uma unidade amostral da análise pode se dar em função de vários fatores:

- Por apresentarem antropismo na data do mapeamento base;

- Por pertencerem à área de buffer;

- Por intersectarem o limite de uma áreas protegida (a unidade amostral teria uma porção no interior da área protegida e outra em seu exterior).

O efeito do mapeamento só é observado em relação à exclusão de unidades devido à presença ou ausência de antropismo. Outras unidades podem ter sido excluídas em função dos outros motivos relacionados (buffer, limites). Abaixo analisamos apenas o efeito do antropismo na manutenção ou exclusão de unidades amostrais dos anos de 1985 e 1995 (também apresentamos os dados para os outros anos).

Para as unidades amostrais do estudo, dos anos de 1985 a 2010, em função da presença de área antrópica, ou de outros eventos que implicam a exclusão de unidades amostrais, observou-se os valores das tabelas abaixo:

Tabela 4 - Unidades amostrais mantidas ou excluídas por coorte.

\begin{tabular}{rrrrrr}
\multicolumn{5}{c}{ Unidades amostrais por grupo } \\
Coorte & Disponíveis & Excluídas & $\begin{array}{r}\text { Percentual } \\
\text { Excluído }\end{array}$ & Mantidas & Percentual \\
Mantido \\
1985 & $\mathbf{1 7 6 1 7 3 9}$ & $\mathbf{8 6 8 5 8 0}$ & $\mathbf{4 9 . 3 \%}$ & $\mathbf{8 9 3 1 5 9}$ & $\mathbf{5 0 . 7 \%}$ \\
$\mathbf{1 9 9 5}$ & $\mathbf{1 7 6 1 7 3 9}$ & $\mathbf{1 0 3 5 8 8 4}$ & $\mathbf{5 8 . 8 \%}$ & $\mathbf{7 2 5 8 5 5}$ & $\mathbf{4 1 . 2 \%}$ \\
2002 & 1761739 & 1128531 & $64.1 \%$ & 633208 & $35.9 \%$ \\
2008 & 1761739 & 1221746 & $69.3 \%$ & 539993 & $30.7 \%$ \\
2009 & 1761739 & 1238306 & $70.3 \%$ & 523433 & $29.7 \%$ \\
2010 & 1761739 & 1327628 & $75.4 \%$ & 434111 & $24.6 \%$ \\
& & & Grupo tratamento & \\
Coorte & Disponíveis & Excluídas & Percentual & & Mantido \\
1985 & $\mathbf{3 3 3 3 9}$ & $\mathbf{7 2 8 9}$ & Excluído & Mantidas & $\mathbf{7 8 . 1 \%}$ \\
1995 & $\mathbf{8 9 1 2 6}$ & $\mathbf{1 1 6 9 7}$ & $\mathbf{2 1 . 9 \%}$ & $\mathbf{2 6 0 5 0}$ & $\mathbf{8 6 . 9 \%}$ \\
2002 & 105518 & 30252 & $\mathbf{1 3 . 1 \%}$ & $\mathbf{7 7 4 2 9}$ & $\mathbf{7 1 . 3 \%}$ \\
2008 & 25525 & 6941 & $28.7 \%$ & 75266 & $\mathbf{7 2 . 8 \%}$ \\
2009 & 690 & 366 & $27.2 \%$ & 18584 & $47.0 \%$ \\
2010 & 2529 & 1762 & $53.0 \%$ & 324 & $30.3 \%$ \\
\hline
\end{tabular}

Em princípio, observamos para os anos em que houve mapeamento, conforme Capítulo 2, uma quantidade expressiva de unidades amostrais que permaneceram no estudo, tanto no grupo controle (893159 UAs para o ano de 1985 e 725855 UAs para o ano de 1995), quanto para o grupo tratamento (26050 UAs para o ano de 1985 e 77429 UAs para o ano de 1995). 
Trata-se de um bom indicador, pois eventuais divergências entre os mapeamentos têm que ser muito significativas para ter um impacto s sobre os resultados.

A exclusão de unidades amostrais pertencentes ao grupo tratamento foi de $49 \%$ para o ano de 1985 e de 58\% para o ano de 1995 . Observe que à medida que se considera anos mais recentes, menos unidades do grupo controle são consideradas no estudo, devido à ocorrência de novos antropismos no bioma.

O número de unidades amostrais do grupo tratamento depende, além da ocorrência de antropismo, da coorte a que pertencem as áreas protegidas em questão e do tamanho médio das unidades de cada coorte (unidades menores têm maior borda). No ano de 1985 foi observada a exclusão de $21 \%$ das unidades amostrais originais e no ano de 1995 houve a exclusão de $13,1 \%$.

Em termos de unidades territoriais excluídas como um todo, decorrente da exclusão de todas as suas unidades amostrais, observa-se o quadro abaixo:

Tabela 5 - Unidades territoriais mantidas ou excluídas por coorte.

\begin{tabular}{cccccc}
\hline \multicolumn{5}{c}{ Efeito da exclusão por área sobre as Unidades de área protegida } \\
\hline Coorte & Disponível & Excluído & $\begin{array}{c}\text { Percentual } \\
\text { Excluído }\end{array}$ & Mantido & $\begin{array}{c}\text { Percentual } \\
\text { Mantido }\end{array}$ \\
\hline $\mathbf{1 9 8 5}$ & $\mathbf{3 8}$ & $\mathbf{3}$ & $\mathbf{7 . 9 \%}$ & $\mathbf{3 5}$ & $\mathbf{9 2 . 1 \%}$ \\
$\mathbf{1 9 9 5}$ & $\mathbf{8 8}$ & $\mathbf{7}$ & $\mathbf{8 . 0 \%}$ & $\mathbf{8 1}$ & $\mathbf{9 2 . 0 \%}$ \\
2002 & 68 & 3 & $4.4 \%$ & 65 & $95.6 \%$ \\
2008 & 55 & 6 & $10.9 \%$ & 49 & $89.1 \%$ \\
2009 & 9 & 2 & $22.2 \%$ & 7 & $77.8 \%$ \\
2010 & 4 & 0 & $0.0 \%$ & 4 & $100.0 \%$ \\
\hline
\end{tabular}

Nesse caso, para o ano de 1985, houve a exclusão de 3 unidades de área protegida devido à exclusão de unidades amostrais com antropismo. Para o ano de 1995 ocorreu a exclusão de 7 , de um total de 88 unidades de área protegida.

A exclusão de unidades amostrais resultou na eliminação de algumas unidades de área protegida do estudo, mas não afetou de forma importante o numero total de amostras dos anos de 1985 (35 unidades de um total de 38 permaneceram) ou 1995 (81 unidades de um total de 88 permaneceram).

Tanto para as unidades amostrais, quanto para as unidades territoriais, levando em consideração os anos de 1985 e 1995 e comparando-os com os anos de 2002, 20082009 e 2010 (anos em que utilizamos o mapeamento PMDBBS para seleção de unidades), em princípio, não foi possível identificar eventual diferença no padrão de exclusão. 


\section{Efeito esperado sobre os resultados}

Considerando os dados obtidos com o teste efetuado para o ano de 2002 (tabela 1) pode-se simular o impacto sobre as unidades amostrais dos anos de 1985 e 1995, a fim de se estimar eventuais diferenças quantitativas nas unidades amostrais incluídas no estudo ou no efeito obtido para as unidades territoriais investigadas.

Aplicando-se os percentuais observados na Tabela 1 às unidades amostrais do grupo tratamento e grupo controle dos anos de 1985 e 1995, obtemos a tabela abaixo:

Tabela 5 - Efeito esperado do mapeamento sobre unidades amostrais.

\section{Efeito do mapeamento sobre unidades amostrais de 1985 e 1995}

\begin{tabular}{|c|c|c|}
\hline Ano & 1985 & 1995 \\
\hline \multicolumn{3}{|l|}{ Grupo Controle } \\
\hline \multicolumn{3}{|c|}{ Valor observado no mapeamento realizado } \\
\hline Unidades amostrais & 893159 & 725855 \\
\hline \multicolumn{3}{|c|}{ Efeito do mapeamento (valor esperado caso fosse realizado pelo ibama) } \\
\hline Acréscimos & 30367 & 24679 \\
\hline Decréscimos & 87629 & 71215 \\
\hline Subtotal & 950421 & 772391 \\
\hline \multicolumn{3}{|l|}{ Grupo tratamento } \\
\hline \multicolumn{3}{|c|}{ Valor observado no mapeamento realizado } \\
\hline Unidades amostrais & 26050 & 77429 \\
\hline \multicolumn{3}{|c|}{ Efeito do mapeamento (valor esperado caso fosse realizado pelo ibama) } \\
\hline Acréscimos & 130 & 387 \\
\hline Decréscimos & 425 & 1263 \\
\hline Subtotal & 26345 & 78305 \\
\hline
\end{tabular}

Subtotal = unidades amostrais do mapeamento - acréscimos + decréscimos

Como se observa, caso o mapeamento houvesse sido executado pelo IBAMA, seria esperado um aumento de 57262 (6,4\%) unidades amostrais do grupo controle e 295 (1,1\%) unidades amostrais para o grupo tratamento no ano de 1985. Para o ano de 1995, seria esperado um aumento de $46536(6 \%)$ para o grupo tratamento e de $876(1,1 \%)$ para o grupo controle.

O impacto esperado sobre o grupo tratamento é bastante reduzido em face da grande população de unidades amostrais pertencentes a esse grupo. Como exposto anteriormente, eventuais alterações no total de amostras do grupo tratamento são determinantes sobre os resultados. A pequena diferença observada $(1,1 \%)$ não deve alterar significativamente os resultados.

Por sua vez, eventuais reduções no número de unidades amostrais do grupo controle só seriam importantes se não houvesse a disponibilidade de uma população suficiente. Na literatura sobre matching methods, considera-se geralmente adequado um total de amostras para o grupo controle 5 vezes superior ao total de amostras para o grupo tratamento. 
A redução de 57262 (1985) ou 46536 (1995) unidades amostrais mostra-se irrelevante, não sendo esperado impacto sobre o viés obtido para a análise, uma vez que o total de amostras do grupo controle é superior a 30 vezes ao total de amostras do grupo tratamento para o ano de 1985 e de aproximadamente 10 vezes para o ano de 1995, mesmo considerando-se a exclusão dessas unidades. Não é esperada qualquer alteração significativa para o viés dos resultados obtidos em função de eventuais diferenças nos mapeamentos.

Realizou-se matching para a região utilizada para o teste (30 cenas de teste), considerando-se as áreas protegidas existentes e unidades amostrais do grupo controle. Reproduziu-se a mesma metodologia descrita na Seção 3.3 deste capítulo para a seleção e exclusão de unidades de ambos os grupos.

Como resultado, observou-se que não houve diferença significativa entre o efeito absoluto obtido a partir do mapeamento realizado pelo PMDBBS (ATT $=0,03 \mathrm{ha} / \mathrm{km}^{2}$, Erro Padrão $=0,02)$ e aquele obtido a partir do mapeamento realizado conforme Capítulo 2 (ATT = $0,02 \mathrm{ha} / \mathrm{km}^{2}$, Erro Padrão = 0,04). Os resultados indicam que a diminuição no número de unidades amostrais do grupo tratamento não impactou significativamente o índice.

Tabela 5 - Estatísticas relacionadas ao efeito esperado do mapeamento sobre unidades amostrais considerando cenários testados.

\begin{tabular}{|c|c|c|c|c|c|c|c|c|c|c|c|}
\hline \multirow{2}{*}{ Grupo/Subgrupo } & \multirow{2}{*}{$\mathbf{N}$} & \multicolumn{2}{|c|}{ Tratamento } & \multicolumn{2}{|c|}{ Controle } & \multirow{2}{*}{ ATT } & \multirow{2}{*}{ S.E. } & \multirow{2}{*}{ Dif. } & \multirow{2}{*}{ S.E. } & \multirow{2}{*}{ Viés } & \multirow{2}{*}{ P. $\mathbf{R}^{2}$} \\
\hline & & Off & All & Off & All & & & & & & \\
\hline \multicolumn{12}{|l|}{ Todas as unidades } \\
\hline Mapeamento PMDBBS 2002 & 42 & 302 & 8495 & 0 & 105608 & 0.03 & 0.02 & 0.14 & 0.01 & 7.50 & 0.01 \\
\hline Mapeamento metodologia Capítulo 2 & 42 & 126 & 3395 & 0 & 44690 & 0.02 & 0.04 & 0.00 & 0.03 & 7.50 & 0.01 \\
\hline
\end{tabular}

Além disso, não foi observada diferença em relação ao viés ou ao Pseudo $\mathrm{R}^{2}$, indicando que a diminuição no número de unidades controle não teve efeito considerável sobre a formação de pares adequados para a comparação entre unidades tratamento e controle.

Os resultados obtidos para o teste realizado com 30 cenas indicam que a metodologia adotada neste estudo foi capaz de lidar com eventuais diferenças existentes entre os mapeamentos utilizados. Os testes não indicam implicações relevantes sobre os resultados em função desse fator. 
Apêndice 3 - Variáveis consideradas no estudo e respectiva fonte dos dados.

\begin{tabular}{|c|c|c|c|c|c|c|c|c|}
\hline Variável & Sigla & $\begin{array}{l}\text { Tipo de } \\
\text { Variável }\end{array}$ & Unidade & Fonte & Ano & Escala & Descrição & Acesso \\
\hline Área Antrópica & - & Resposta & $\mathrm{km}^{2}$ & PMDBBS /IBAMA & 2015 & $\begin{array}{c}1: 50000 \\
1: 250000\end{array}$ & $\begin{array}{l}\text { Mapa de uso e cobertura da terra } \\
\text { do período entre } 2002 \text { e } 2011 \\
\text { fornecidos pelo } \\
\text { PMDBBS/IBAMA. }\end{array}$ & $\begin{array}{l}\text { siscom.ibama.gov.br/monitorabiomas/ce } \\
\text { rrado/index.htm }\end{array}$ \\
\hline $\begin{array}{l}\text { Unidades de } \\
\text { Conservação }\end{array}$ & UC & Tratamento & Binária & CNUC/MMA & 2015 & $1: 250000$ & $\begin{array}{l}\text { Dados espaciais e cadastrais das } \\
\text { Unidades de Conservação do } \\
\text { Brasil }\end{array}$ & $\begin{array}{l}\text { http://mapas.mma.gov.br/i3geo/datadow } \\
\text { nload.htm }\end{array}$ \\
\hline Terra Indígena & TI & Tratamento & Binária & FUNAI & 2015 & $1: 250000$ & $\begin{array}{l}\text { Dados espaciais e cadastrais das } \\
\text { Terras Indígenas do Brasil }\end{array}$ & http://mapas.funai.gov.br/ \\
\hline Terras Quilombola & QL & Tratamento & Binária & INCRA & 2015 & $1: 250000$ & $\begin{array}{l}\text { Dados espaciais e cadastrais das } \\
\text { Terras Quilombola do Brasil }\end{array}$ & http://acervofundiario.incra.gov.br \\
\hline Altitude & alt & Covariável & $\mathrm{m}$ & SRTM/EMBRAPA & 2015 & - & $\begin{array}{l}\text { Informação obtida a partir do } \\
\text { processamento de imagens SRTM } \\
\text { (Shuttle Radar Topography } \\
\text { Mission) fornecido pela Embrapa. }\end{array}$ & $\begin{array}{l}\text { https://www.cnpm.embrapa.br/projetos/r } \\
\text { elevobr/download/ }\end{array}$ \\
\hline Declividade & decl & Covariável & $\%$ & SRTM/EMBRAPA & 2005 & - & $\begin{array}{l}\text { Informação obtida a partir do } \\
\text { processamento de imagens SRTM } \\
\text { (Shuttle Radar Topography } \\
\text { Mission) fornecido pela Embrapa. }\end{array}$ & $\begin{array}{l}\text { https://www.cnpm.embrapa.br/projetos/r } \\
\text { elevobr/download/ }\end{array}$ \\
\hline Distância a Cidades & dist_urb & Covariável & $\mathrm{m}$ & IBGE & 2009 & $1: 250000$ & $\begin{array}{l}\text { Processed information from spatial } \\
\text { data of cities. }\end{array}$ & $\begin{array}{l}\text { http://www.inde.gov.br/geo- } \\
\text { servicos/diretorio-brasileiro-de-dados- } \\
\text { geoespaciais }\end{array}$ \\
\hline Distância a Estradas & dist_est & Covariável & $\mathrm{m}$ & DNIT & 2009 & $1: 250000$ & $\begin{array}{l}\text { Processed information from spatial } \\
\text { data of roads. }\end{array}$ & $\begin{array}{l}\text { http://www.inde.gov.br/geo- } \\
\text { servicos/diretorio-brasileiro-de-dados- } \\
\text { geoespaciais }\end{array}$ \\
\hline Distância a Rios & dist_rio & Covariável & $\mathrm{m}$ & ANA & 2009 & $1: 250000$ & $\begin{array}{l}\text { Dados espaciais e cadastrais dos } \\
\text { corpos d'água }\end{array}$ & Obtido mediante solicitação ao órgão \\
\hline Área do Município & area & Covariável & $\mathrm{km}^{2}$ & IBGE & 2014 & $1: 250000$ & $\begin{array}{l}\text { Dados espaciais e cadastrais dos } \\
\text { municípios }\end{array}$ & $\begin{array}{l}\text { http://www.ibge.gov.br/webcart/tabelas. } \\
\text { php }\end{array}$ \\
\hline Produção de gado & prod_boi & Covariável & cabeças $/ \mathrm{km}^{2}$ & IBGE & 2014 & - & $\begin{array}{l}\text { Dados sobre o número de cabeças } \\
\text { de gado por município }\end{array}$ & $\begin{array}{l}\text { http://www.ibge.gov.br/webcart/tabelas. } \\
\text { php }\end{array}$ \\
\hline
\end{tabular}




\begin{tabular}{|c|c|c|c|c|c|c|c|c|}
\hline Produção de grãos & prod_grao & Covariável & $\mathrm{kg} / \mathrm{km}^{2}$ & IBGE & 2014 & - & $\begin{array}{l}\text { Dados sobre a produção de grãos } \\
\text { por município }\end{array}$ & $\begin{array}{l}\text { http://www.ibge.gov.br/webcart/tabelas. } \\
\text { php }\end{array}$ \\
\hline PIB municipal & pib & Covariável & $\mathrm{R} \$$ & IBGE & 2014 & - & Produto interno bruto municipal & $\begin{array}{l}\text { http://www.ibge.gov.br/webcart/tabelas. } \\
\text { php }\end{array}$ \\
\hline PIB per capita & pib_p & Covariável & $\mathrm{R} \$$ & IBGE & 2014 & - & $\begin{array}{l}\text { Produto interno bruto per capita } \\
\text { municipal }\end{array}$ & $\begin{array}{l}\text { http://www.ibge.gov.br/webcart/tabelas. } \\
\text { php }\end{array}$ \\
\hline receita municipal & rec_mi & Covariável & $\mathrm{R} \$$ & IBGE & 2014 & - & Receita do município & $\begin{array}{l}\text { http://www.ibge.gov.br/webcart/tabelas. } \\
\text { php }\end{array}$ \\
\hline Renda média rural & rend_rur & Covariável & $\mathrm{R} \$$ & IBGE & 2014 & - & Renda média rural & $\begin{array}{l}\text { http://www.ibge.gov.br/webcart/tabelas. } \\
\text { php }\end{array}$ \\
\hline Renda média urbana & rend_urb & Covariável & $\mathrm{R} \$$ & IBGE & 2014 & - & Renda média urbana & $\begin{array}{l}\text { http://www.ibge.gov.br/webcart/tabelas. } \\
\text { php }\end{array}$ \\
\hline População & pop_tot & Covariável & habitantes $/ \mathrm{km}^{2}$ & IBGE & 2014 & - & População total do município & $\begin{array}{l}\text { http://www.ibge.gov.br/webcart/tabelas. } \\
\text { php }\end{array}$ \\
\hline População rural & pop_rur & Covariável & habitantes $/ \mathrm{km}^{2}$ & IBGE & 2014 & - & População rural do município & $\begin{array}{l}\text { http://www.ibge.gov.br/webcart/tabelas. } \\
\text { php }\end{array}$ \\
\hline População urbana & pop_urb & Covariável & habitantes $/ \mathrm{km}^{2}$ & IBGE & 2014 & - & População urbana do município & $\begin{array}{l}\text { http://www.ibge.gov.br/webcart/tabelas. } \\
\text { php }\end{array}$ \\
\hline $\begin{array}{l}\text { População } \\
\text { masculina }\end{array}$ & pop_h & Covariável & habitantes $/ \mathrm{km}^{2}$ & IBGE & 2014 & - & População masculina do município & $\begin{array}{l}\text { http://www.ibge.gov.br/webcart/tabelas. } \\
\text { php }\end{array}$ \\
\hline População feminina & pop_m & Covariável & habitantes $/ \mathrm{km}^{2}$ & IBGE & 2014 & - & População feminina do município & $\begin{array}{l}\text { http://www.ibge.gov.br/webcart/tabelas. } \\
\text { php }\end{array}$ \\
\hline IDH & idh & Covariável & IDH Índice & IBGE & 2014 & - & $\begin{array}{l}\text { Índice de Desenvolvimento } \\
\text { Humano do município }\end{array}$ & $\begin{array}{l}\text { http://www.ibge.gov.br/webcart/tabelas. } \\
\text { php }\end{array}$ \\
\hline
\end{tabular}


Apêndice 4 - Script R para o cálculo do índice relativo (ATT\%).

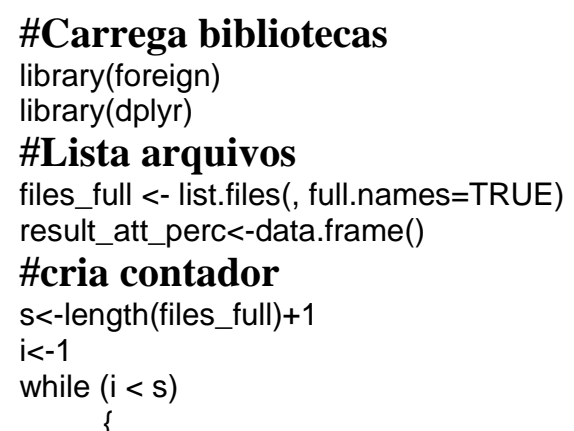

\section{\#Lê Dados}

tmp <- read.csv(files_full[i], header $=$ TRUE, sep = ";")

indice<-subset(tmp, select=c("X_id", "dif_2011"))

calc_base<-subset(tmp, select=c("X_id","X_treated", "X_support","X_weight",

"X_dif_2011","X_n1","X_n2","X_n3","X_n4","X_n5"))

calc_base<-subset(calc_base,calc_base $\$ X \_t r e a t e d==" T r e a t e d " ~ \&$ calc_base $\$$ X_support=="On $\mathrm{rm}(\mathrm{tmp})$ support")

\section{\#Join n1 to n5}

nt<-as.data.frame (calc_base $\$ X$ id)

names(nt)[1]<-paste("X_id")

nt<-left_join(nt,indice)

names(nt)[2]<-paste("nt")

calc_base $<-$ cbind(calc_base,nt $\$$ nt)

names(calc_base)[11]<-paste("nt")

$\mathrm{rm}(\mathrm{nt})$

\section{\#Calcula Índices}

calc_base $\$ a n t \_n t<-1000000$-calc_base $\$$ nt

calc_base\$ant_dif<-1000000-calc_base\$X_dif_2011

calc_base $\$$ att_perc1<-ifelse(calc_base $\$ a n t \_n t>=$ calc_base $\$ a n t \_d i f,\left(-1^{*}(((1000000-\right.$

calc base $\$$ ant dif)-(1000000-calc base $\$$ ant $n t) \bar{l} /(1000000$ -

calc_base\$ant_dif $))),\left(\left(\right.\right.$ calc_base $\left.\$ a n t \_d i f-c a l c \_b a s e \$ a n t \_n t\right) /\left(\right.$ calc_base $\left.\left.\left.\$ a n t \_d i f\right)\right)\right)$

att_perc1_mean<-mean(calc_base\$att_perc1)

att_perc1_sd<-sd(calc_base\$att_perc1)

att_perc1_n<-nrow(calc_base)

att_perc1_se<-att_perc1_sd/sqrt(att_perc1_n)

att_perc1_med<-median(calc_base\$att_perc1)

att_perc1_min<-min (calc_base\$att_perc1)

att_perc1_max<-max(calc_base\$att_perc1)

mean_nt<-mean(calc_base $\$$ nt)

mean_dif<-mean(calc_base $\$ X \_d i f$ 2011)

ant_nt $<-1000000-$ mean_nt

ant_dif $<-1000000$-mean_dif

att_perc2<-(ant_dif-ant_nt)/ant_dif

\section{\#armazena dados para exportação}

tmp2<-data.frame()

tmp2<-cbind(files_full[i], att_perc1_n, att_perc1_mean,att_perc1_sd, att_perc1_se, att_perc1_med, att_perc1_min, att_perc1_max, att_perc2) result_att_perc<-rbind(result_att_perc,tmp2)

\section{\#Limpa dados e atualiza contadores}

rm(tmp2,indice,calc_base,ant_dif,ant_nt,mean_dif,mean_nt, att_perc2, att_perc1_max, att_perc1_min, $\mathrm{i}<-\mathrm{i}+1$ att_perc1_med, att_perc1_se, att_perc1_n, att_perc1_sd, att_perc1_mean)

\section{\#Exporta Tabela Final}

write.table(result_att_perc, file = "ATT_PERC2.csv", sep = ";") 
Apêndice 5 - Sumário de estatísticas obtidas para o grupo dos 15 melhores conjuntos de variáveis (resumido).

\begin{tabular}{|c|c|c|c|c|c|c|c|c|c|c|c|}
\hline \multirow{2}{*}{ REF } & \multirow{2}{*}{ Variáveis } & \multirow{2}{*}{$\mathbf{N}$} & \multicolumn{3}{|c|}{ Matching } & \multicolumn{6}{|c|}{ Classe de Antropismo } \\
\hline & & & Bias & P. $\mathbf{R}^{2}$ & S.E & $<10 \%$ & $<\mathbf{2 0 \%}$ & $<\mathbf{3 0 \%}$ & $>70 \%$ & $>\mathbf{8 0 \%}$ & $>90 \%$ \\
\hline & pib_p rend_urb decl prod_grao & 4 & 0.32 & 0.99 & 3.0 & 0.75 & 0.74 & 0.74 & 0.72 & 0.72 & 0.73 \\
\hline & pib_p rend_urb alt decl prod_grao & 5 & 1.05 & 1.03 & 3.8 & 0.75 & 0.75 & 0.75 & 0.74 & 0.74 & 0.74 \\
\hline 3 & ref_mi rend_urb decl_std pop_total_ha prod_grao & 5 & 0.72 & 0.99 & 3.8 & 0.75 & 0.74 & 0.74 & 0.74 & 0.74 & 0.74 \\
\hline 4 & dist_urb idh pib_p rend_urb decl_std prod_grao & 6 & 0.79 & 1.03 & 3.6 & 0.77 & 0.76 & 0.76 & 0.74 & 0.74 & 0.74 \\
\hline 5 & dist_urb pib_p rend_urb alt decl prod_grao & 6 & 1.60 & 0.89 & 3.8 & 0.77 & 0.76 & 0.76 & 0.75 & 0.75 & 0.75 \\
\hline 6 & dist_urb pib_p rend_urb alt decl pop_h prod_grao & 7 & 0.80 & 0.91 & 3.9 & 0.77 & 0.77 & 0.76 & 0.75 & 0.75 & 0.75 \\
\hline 7 & dist_urb idh pib_p rend_urb alt decl prod_grao & 7 & 0.99 & 0.88 & 4.0 & 0.77 & 0.77 & 0.76 & 0.75 & 0.75 & 0.75 \\
\hline 8 & dist_est dist_urb pib_p rend_urb alt decl prod_grao & 7 & 2.34 & 0.99 & 2.8 & 0.78 & 0.77 & 0.76 & 0.75 & 0.75 & 0.75 \\
\hline 9 & dist_est dist_urb idh pib_p rend_urb alt decl prod_grao & 8 & 2.40 & 1.00 & 2.9 & 0.78 & 0.77 & 0.77 & 0.75 & 0.75 & 0.75 \\
\hline 10 & dist_est dist_urb pib_p rend_urb alt decl pop_m prod_grao & 8 & 2.20 & 1.07 & 2.8 & 0.78 & 0.77 & 0.77 & 0.75 & 0.75 & 0.75 \\
\hline & dist_urb idh pib_p rend_urb alt decl pop_urb prod_grao & 8 & 1.50 & 1.05 & 3.8 & 0.78 & 0.77 & 0.77 & 0.75 & 0.75 & 0.75 \\
\hline & dist_est dist_urb idh pib_p rend_urb alt decl pop_m prod_grao & 9 & 1.99 & 1.10 & 3.0 & 0.78 & 0.77 & 0.77 & 0.75 & 0.75 & 0.75 \\
\hline 13 & dist_est dist_urb pib_p rend_urb alt decl prod_boi pop_m prod_grao & 9 & 2.59 & 1.12 & 3.3 & 0.78 & 0.77 & 0.77 & 0.76 & 0.75 & 0.75 \\
\hline 14 & dist_est dist_urb idh pib_p rend_urb alt decl prod_boi pop_m prod_grao & 10 & 2.44 & 1.14 & 3.4 & 0.78 & 0.77 & 0.77 & 0.76 & 0.75 & 0.75 \\
\hline & dist_est dist_rio dist_urb idh pib_p rend_urb alt decl pop_m prod_grao & 10 & 2.46 & 1.03 & 2.6 & 0.78 & 0.77 & 0.77 & 0.75 & 0.75 & 0.75 \\
\hline
\end{tabular}

* Altitude (alt); Declividade (decl); Distância a Cidades (dist_urb); Distância a Estradas (dist_est); Distância a Rios (dist_rio); Área do Município (area); Produção de gado (prod_boi); Produção de grãos (prod_grao); PIB municipal (pib); PIB per capita (pib_p); receita municipal (rec_mi); Renda média rural (rend_rur); Renda média urbana (rend_urb); População (pop_tot); População rural (pop_rur); População urbana (pop_urb); População masculina (pop_h); População feminina (pop_m); IDH (idh).

*ATT - Efeito Absoluto, ATT\% - Efeito Relativo; S.E. - Erro Padrão; P. R² - Pseudo R 
Apêndice 6 - Resultados obtidos individualmente para os 15 melhores modelos escolhidos.

\begin{tabular}{|c|c|c|c|c|c|c|c|c|c|c|c|c|}
\hline \multirow[t]{2}{*}{ REF } & \multicolumn{6}{|c|}{$\begin{array}{c}\text { Regressão Logística Múltipla } \\
\text { Classe de Antropismo }\end{array}$} & \multicolumn{6}{|c|}{$\begin{array}{c}\text { Mahalanobis Matching } \\
\text { UC's, TI's e TQ's }\end{array}$} \\
\hline & $<10 \%$ & $<20 \%$ & $<30 \%$ & $>70 \%$ & $>\mathbf{8 0 \%}$ & $>90 \%$ & ATT & S.E. & АTT\% & S.E. & Viés & P. $\mathbf{R}^{2}$ \\
\hline 1 pib_p rend_urb decl prod_grao & 0.75 & 0.74 & 0.74 & 0.72 & 0.72 & 0.73 & -11.65 & 0.56 & -0.66 & 0.01 & 0.43 & 0.00 \\
\hline 2 pib_p rend_urb alt decl prod_grao & 0.75 & 0.75 & 0.75 & 0.74 & 0.74 & 0.74 & -10.67 & 0.81 & -0.53 & 0.01 & 1.23 & 0.00 \\
\hline 3 rec_mi rend_urb decl_std pop_total_ha prod_grao & 0.75 & 0.74 & 0.74 & 0.74 & 0.74 & 0.74 & -13.14 & 0.69 & -0.68 & 0.01 & 0.83 & 0.00 \\
\hline 4 dist_urb idh pib_p rend_urb decl_std prod_grao & 0.77 & 0.76 & 0.76 & 0.74 & 0.74 & 0.74 & -11.49 & 0.75 & -0.65 & 0.01 & 1.07 & 0.00 \\
\hline 5 dist_urb pib_p rend_urb alt decl prod_grao & 0.77 & 0.76 & 0.76 & 0.75 & 0.75 & 0.75 & -11.57 & 0.78 & -0.66 & 0.01 & 2.07 & 0.01 \\
\hline 6 dist_urb pib_p rend_urb alt decl pop_h prod_grao & 0.77 & 0.77 & 0.76 & 0.75 & 0.75 & 0.75 & -12.18 & 0.83 & -0.67 & 0.01 & 1.23 & 0.01 \\
\hline 7 dist_urb idh pib_p rend_urb alt decl prod_grao & 0.77 & 0.77 & 0.76 & 0.75 & 0.75 & 0.75 & -11.63 & 0.85 & -0.66 & 0.01 & 1.40 & 0.01 \\
\hline 8 dist_est dist_urb pib_p rend_urb alt decl prod_grao & 0.78 & 0.77 & 0.76 & 0.75 & 0.75 & 0.75 & -10.40 & 0.58 & -0.61 & 0.01 & 3.18 & 0.02 \\
\hline 9 dist_est dist_urb idh pib_p rend_urb alt decl prod_grao & 0.78 & 0.77 & 0.77 & 0.75 & 0.75 & 0.75 & -10.39 & 0.55 & -0.61 & 0.01 & 3.13 & 0.02 \\
\hline 10 dist_est dist_urb pib_p rend_urb alt decl pop_m prod_grao & 0.78 & 0.77 & 0.77 & 0.75 & 0.75 & 0.75 & -10.64 & 0.58 & -0.62 & 0.01 & 2.87 & 0.02 \\
\hline 11 dist_urb idh pib_p rend_urb alt decl pop_urb prod_grao & 0.78 & 0.77 & 0.77 & 0.75 & 0.75 & 0.75 & -11.38 & 0.81 & -0.66 & 0.01 & 1.98 & 0.05 \\
\hline 12 dist_est dist_urb idh pib_p rend_urb alt decl pop_m prod_grao & 0.78 & 0.77 & 0.77 & 0.75 & 0.75 & 0.75 & -10.72 & 0.58 & -0.62 & 0.01 & 2.57 & 0.03 \\
\hline 13 dist_est dist_urb pib_p rend_urb alt decl prod_boi pop_m prod_grao & 0.78 & 0.77 & 0.77 & 0.76 & 0.75 & 0.75 & -11.77 & 0.68 & -0.64 & 0.01 & 3.10 & 0.03 \\
\hline 14 dist_est dist_urb idh pib_p rend_urb alt decl prod_boi pop_m prod_grao & 0.78 & 0.77 & 0.77 & 0.76 & 0.75 & 0.75 & -11.65 & 0.70 & -0.64 & 0.01 & 3.00 & 0.04 \\
\hline 15 dist_est dist_rio dist_urb idh pib_p rend_urb alt decl pop_m prod_grao & 0.78 & 0.77 & 0.77 & 0.75 & 0.75 & 0.75 & -10.20 & 0.50 & -0.58 & 0.01 & 2.90 & 0.05 \\
\hline
\end{tabular}

Altitude (alt); Declividade (decl); Distância a Cidades (dist_urb); Distância a Estradas (dist_est); Distância a Rios (dist_rio); Área do Município (area); Produção de gado (prod_boi); Produção de grãos (prod_grao); PIB municipal (pib); PIB per capita (pib_p); receita municipal (rec_mi); Renda média rural (rend_rur); Renda média urbana (rend_urb); População (pop_tot); População rural (pop_rur); População urbana (pop_urb); População masculina (pop_h); População feminina (pop_m); IDH (idh).

*ATT - Efeito Absoluto, ATT\% - Efeito Relativo; S.E. - Erro Padrão; P. R² - Pseudo R². 
Apêndice 6 - (Continuação)

\begin{tabular}{|c|c|c|c|c|c|c|c|c|c|c|c|c|c|c|c|c|c|c|c|c|c|c|c|c|}
\hline \multirow{3}{*}{ REF } & \multicolumn{24}{|c|}{ Mahalanobis Matching } \\
\hline & \multicolumn{6}{|c|}{ Unidade de Conservação } & \multicolumn{6}{|c|}{ Terra Indígena } & \multicolumn{6}{|c|}{ Terra Quilombola } & \multicolumn{6}{|c|}{ Proteção Integral } \\
\hline & ATT & S.E. & АTT \% & S.E. & Viés & P. $\mathbf{R}^{2}$ & TT & S.E. & АТT\% & S.E. & Viés & P. $\mathbf{R}^{2}$ & ATT & S.E. & ATT \% & S.E. & Viés & $\mathrm{R}^{2}$ & ATT & S.E. & ATT \% & S.E. & Viés & P. $\mathbf{R}^{2}$ \\
\hline 1 & -9.03 & 0.68 & -0.63 & 0.02 & 0.63 & 0.00 & -14.25 & 0.83 & -0.74 & 0.04 & 0.10 & 0.00 & -3.63 & 1.49 & -0.51 & 0.03 & 1.33 & 0.09 & -13.99 & 0.00 & -0.74 & 0.01 & 0.43 & 0.00 \\
\hline 2 & -8.55 & 0.87 & -0.62 & 0.02 & 1.73 & 0.01 & -12.64 & 1.24 & -0.60 & 0.04 & 0.50 & 0.07 & -1.80 & 1.67 & -0.48 & 0.03 & 1.00 & 0.01 & -14.65 & 0.96 & -0.71 & 0.01 & 1.38 & 0.00 \\
\hline 3 & -10.34 & 0.79 & -0.61 & 0.02 & 1.08 & 0.01 & -13.83 & 0.82 & -0.78 & 0.03 & 0.13 & 0.00 & -2.51 & 1.19 & -0.52 & 0.03 & 1.23 & 0.06 & -14.22 & 0.71 & -0.72 & 0.01 & 0.50 & 0.00 \\
\hline 4 & -8.99 & 0.86 & -0.62 & 0.02 & 0.98 & 0.01 & -13.62 & 1.05 & -0.73 & 0.03 & 1.30 & 0.02 & -3.99 & 2.17 & -0.51 & 0.03 & 2.67 & 0.07 & -16.58 & 1.12 & -0.68 & 0.01 & 1.35 & 0.00 \\
\hline 5 & -9.58 & 0.84 & -0.62 & 0.02 & 2.20 & 0.01 & -13.48 & 1.04 & -0.73 & 0.03 & 2.57 & 0.20 & -2.23 & 1.56 & -0.48 & 0.02 & 3.37 & 0.06 & -17.12 & 1.12 & -0.71 & 0.01 & 1.60 & 0.00 \\
\hline 6 & -10.02 & 0.90 & -0.64 & 0.02 & 1.38 & 0.01 & -13.72 & 1.06 & -0.74 & 0.03 & 1.50 & 0.22 & -2.50 & 1.64 & -0.50 & 0.02 & 3.37 & 0.07 & -16.43 & 1.21 & -0.70 & 0.01 & 1.50 & 0.00 \\
\hline 7 & -9.49 & 0.87 & -0.62 & 0.02 & 1.45 & 0.01 & -13.58 & 1.07 & -0.73 & 0.03 & 1.30 & 0.20 & -3.45 & 2.00 & -0.51 & 0.02 & 3.75 & 0.15 & -15.93 & 1.20 & -0.69 & 0.01 & 1.45 & 0.00 \\
\hline 8 & -7.54 & 0.64 & -0.53 & 0.02 & 5.53 & 0.15 & -12.46 & 0.79 & -0.67 & 0.04 & 4.00 & 0.18 & -1.70 & 1.19 & -0.39 & 0.03 & 7.60 & 0.08 & -14.11 & 0.74 & -0.66 & 0.01 & 4.08 & 0.01 \\
\hline 9 & -7.60 & 0.65 & -0.54 & 0.02 & 4.12 & 0.14 & -12.42 & 0.77 & -0.67 & 0.04 & 3.13 & 0.24 & -2.15 & 1.09 & -0.40 & 0.03 & 5.55 & 0.11 & -13.19 & 0.79 & -0.66 & 0.01 & 3.70 & 0.01 \\
\hline 10 & -7.73 & 0.66 & -0.54 & 0.02 & 2.58 & 0.02 & -12.38 & 0.81 & -0.67 & 0.04 & 3.43 & 0.25 & -1.76 & 1.08 & -0.40 & 0.03 & 7.57 & 0.11 & -13.74 & 0.76 & -0.65 & 0.01 & 3.95 & 0.01 \\
\hline 11 & -8.78 & 0.89 & -0.62 & 0.02 & 1.64 & 0.00 & -13.71 & 1.10 & -0.74 & 0.03 & 1.24 & & -3.93 & 1.86 & -0.52 & 0.02 & 2.30 & 0.13 & -15.67 & 1.2 & -0.67 & 0.01 & 1.58 & 0.00 \\
\hline 12 & -7.76 & 0.67 & -0.56 & 0.02 & 3.27 & 0.14 & -12.46 & 0.84 & -0.68 & 0.04 & 2.62 & 0.26 & -2.28 & 1.09 & -0.40 & 0.03 & 9.00 & 0.07 & -12.65 & 0.78 & -0.64 & 0.01 & 3.43 & 0.01 \\
\hline 13 & -8.60 & 0.75 & -0.56 & 0.02 & 3.18 & 0.07 & -13.39 & 0.87 & -0.71 & 0.04 & 2.55 & 0.26 & -2.73 & 1.44 & -0.43 & 0.03 & 3.80 & 0.03 & -12.20 & 0.82 & -0.63 & 0.01 & 3.43 & 0.02 \\
\hline 14 & -8.27 & 0.76 & -0.56 & 0.02 & 4.60 & 0.16 & -13.56 & 0.90 & -0.73 & 0.04 & 2.24 & 0.21 & -2.95 & 1.46 & -0.42 & 0.03 & 2.00 & 0.05 & -11.81 & 0.84 & -0.62 & 0.01 & 2.73 & 0.02 \\
\hline 15 & -7.45 & 0.56 & -0.54 & 0.02 & 3.53 & 0.14 & -12.17 & 0.67 & -0.62 & 0.03 & 3.43 & 0.24 & -2.22 & 1.10 & -0.36 & 0.03 & 7.50 & 0.10 & -12.91 & 0.64 & -0.64 & 0.01 & 3.45 & 0.02 \\
\hline
\end{tabular}

*ATT - Efeito Absoluto, ATT\% - Efeito Relativo; S.E. - Erro Padrão; P. R² - Pseudo R². 
Apêndice 6 - (Continuação)

\begin{tabular}{|c|c|c|c|c|c|c|c|c|c|c|c|c|c|c|c|c|c|c|c|c|c|c|c|c|}
\hline \multirow{3}{*}{ REF } & \multicolumn{24}{|c|}{ Mahalanobis Matching } \\
\hline & \multicolumn{6}{|c|}{ Uso Sustentável } & \multicolumn{6}{|c|}{ Federal } & \multicolumn{6}{|c|}{ Estatual } & \multicolumn{6}{|c|}{ Maior } \\
\hline & ATT & S.E. & ATT\% & S.E. & Viés & P. $\mathbf{R}^{2}$ & ATT & S.E. & АTT\% & S.E. & Viés & P. $\mathbf{R}^{2}$ & ATT & S.E. & ATT\% & S.E. & Viés & P. $\mathbf{R}^{2}$ & ATT & S.E. & ATT \% & S.E. & Viés & P. $\mathbf{R}^{2}$ \\
\hline 1 & -1.19 & 1.64 & -0.45 & 0.02 & 2.02 & 0.01 & -12.04 & 0.58 & -0.70 & 0.03 & 0.16 & 0.00 & -11.48 & 1.34 & -0.55 & 0.02 & 1.76 & 0.00 & -11.60 & 0.58 & -0.67 & 0.01 & 0.47 & 0.00 \\
\hline 2 & -3.07 & 1.98 & -0.45 & 0.03 & 4.33 & 0.02 & -11.20 & 0.82 & -0.56 & 0.03 & 0.85 & 0.01 & -11.60 & 1.64 & -0.56 & 0.02 & 3.16 & 0.00 & -10.67 & 0.84 & -0.52 & 0.01 & 1.28 & 0.00 \\
\hline 3 & -1.78 & 1.90 & -0.39 & 0.04 & 1.82 & 0.03 & -11.75 & 0.53 & -0.71 & 0.03 & 0.22 & 0.01 & -11.35 & 1.74 & -0.54 & 0.02 & 1.90 & 0.02 & -13.08 & 0.70 & -0.68 & 0.01 & 0.90 & 0.01 \\
\hline 4 & 1.06 & 1.46 & -0.43 & 0.02 & 2.85 & 0.05 & -12.23 & 0.87 & -0.71 & 0.02 & 0.94 & 0.00 & -8.22 & 1.46 & -0.53 & 0.02 & 2.12 & 0.02 & -11.50 & 0.76 & -0.64 & 0.01 & 1.13 & 0.01 \\
\hline 5 & -1.74 & 1.64 & -0.45 & 0.02 & 4.85 & 0.06 & -12.40 & 0.80 & -0.68 & 0.03 & 1.83 & 0.10 & -12.35 & 1.52 & -0.55 & 0.02 & 3.56 & 0.01 & -11.57 & 0.82 & -0.66 & 0.01 & 2.17 & 0.02 \\
\hline 6 & 1.06 & 1.92 & -0.41 & 0.04 & 3.08 & 0.02 & -12.56 & 0.82 & -0.69 & 0.03 & 1.15 & 0.10 & -11.75 & 1.57 & -0.55 & 0.02 & 2.80 & 0.03 & -12.20 & 0.87 & -0.68 & 0.01 & 1.25 & 0.04 \\
\hline 7 & -2.61 & 1.83 & -0.45 & 0.02 & 1.66 & 0.01 & -12.26 & 0.88 & -0.68 & 0.03 & 1.07 & 0.10 & -12.77 & 1.80 & -0.54 & 0.02 & 3.66 & 0.08 & -11.64 & 0.90 & -0.66 & 0.01 & 1.40 & 0.04 \\
\hline 8 & -1.05 & 1.42 & -0.37 & 0.02 & 6.78 & 0.19 & -11.04 & 0.58 & -0.62 & 0.03 & 3.58 & 0.08 & -12.29 & 1.37 & -0.54 & 0.02 & 2.72 & 0.02 & -10.30 & 0.60 & -0.60 & 0.01 & 3.45 & 0.02 \\
\hline 9 & -1.29 & 1.58 & -0.39 & 0.02 & 3.68 & 0.16 & -10.95 & 0.55 & -0.63 & 0.03 & 3.48 & 0.02 & -12.50 & 1.69 & -0.53 & 0.02 & 4.46 & 0.10 & -10.33 & 0.56 & -0.61 & 0.01 & 3.18 & 0.03 \\
\hline 10 & 2.05 & 1.75 & -0.33 & 0.04 & 2.96 & 0.03 & -11.08 & 0.55 & -0.62 & 0.03 & 3.70 & 0.02 & -9.67 & 1.43 & -0.53 & 0.02 & 3.34 & 0.03 & -10.61 & 0.58 & -0.61 & 0.01 & 3.02 & 0.05 \\
\hline 11 & 0.68 & 1.97 & -0.42 & 0.04 & 2.96 & 0.01 & -12.41 & 0.85 & -0.69 & 0.03 & 1.06 & 0.01 & -8.69 & 1.72 & -0.50 & 0.02 & 2.98 & 0.05 & -11.39 & 0.84 & -0.67 & 0.01 & 2.07 & 0.13 \\
\hline 12 & 1.50 & 1.83 & -0.35 & 0.04 & 3.87 & 0.14 & -11.07 & 0.57 & -0.63 & 0.03 & 2.94 & 0.03 & -8.89 & 1.66 & -0.50 & 0.02 & 3.54 & 0.07 & -10.69 & 0.58 & -0.62 & 0.01 & 2.55 & 0.07 \\
\hline 13 & -0.87 & 1.91 & -0.36 & 0.04 & 4.24 & 0.08 & -11.46 & 0.65 & -0.64 & 0.03 & 3.07 & 0.15 & -11.24 & 1.76 & -0.54 & 0.02 & 4.40 & 0.09 & -11.77 & 0.72 & -0.64 & 0.01 & 3.33 & 0.11 \\
\hline 14 & -0.01 & 1.96 & -0.36 & 0.04 & 5.33 & 0.17 & -11.56 & 0.67 & -0.64 & 0.03 & 2.28 & 0.04 & -9.36 & 1.76 & -0.51 & 0.02 & 4.32 & 0.10 & -11.66 & 0.73 & -0.64 & 0.01 & 3.18 & 0.12 \\
\hline 15 & 2.00 & 1.73 & -0.33 & 0.04 & 4.45 & 0.15 & -11.08 & 0.49 & -0.60 & 0.03 & 3.18 & 0.04 & -7.86 & 1.48 & -0.49 & 0.02 & 4.82 & 0.08 & -10.14 & 0.51 & -0.57 & 0.01 & 2.92 & 0.08 \\
\hline
\end{tabular}

*ATT - Efeito Absoluto, ATT\% - Efeito Relativo; S.E. - Erro Padrão; P. R² - Pseudo R². 
Apêndice 6 - (Continuação)

\begin{tabular}{|c|c|c|c|c|c|c|c|c|c|c|c|c|c|c|c|c|c|c|c|c|c|c|c|c|}
\hline \multirow{3}{*}{ REF } & \multicolumn{24}{|c|}{ Mahalanobis Matching } \\
\hline & \multicolumn{6}{|c|}{ Menor } & \multicolumn{6}{|c|}{ IUCN Ia } & \multicolumn{6}{|c|}{ IUCN II } & \multicolumn{6}{|c|}{ IUCN III } \\
\hline & ATT & S.E. & АTT\% & S.E. & Viés & P. $\mathbf{R}^{2}$ & ATT & S.E. & ATT \% & S.E. & Viés & P. $\mathbf{R}^{2}$ & ATT & S.E. & ATT\% & S.E. & Viés & P. $\mathbf{R}^{2}$ & ATT & S.E. & ATT\% & S.E. & Viés & P. $\mathbf{R}^{2}$ \\
\hline 1 & -9.07 & 1.69 & -0.66 & 0.07 & 0.42 & 0.00 & -16.35 & 3.02 & -0.64 & 0.05 & 2.75 & 0.02 & -14.19 & 0.70 & -0.74 & 0.01 & 0.43 & 0.00 & -3.62 & 0.60 & -0.59 & 0.01 & 0.00 & 0.00 \\
\hline 2 & -10.00 & 1.75 & -0.69 & 0.07 & 0.90 & 0.08 & -14.83 & 3.43 & -0.70 & 0.04 & 4.00 & 0.15 & -15.01 & 1.02 & -0.71 & 0.01 & 1.60 & 0.00 & -3.77 & 0.67 & -0.47 & 0.01 & 0.10 & 0.00 \\
\hline 3 & -10.28 & 1.69 & -0.68 & 0.07 & 0.67 & 0.02 & -12.71 & 3.88 & -0.57 & 0.07 & 0.20 & 0.00 & -14.17 & 0.78 & -0.74 & 0.01 & 0.58 & 0.00 & -4.23 & 0.64 & -0.64 & 0.01 & 0.00 & 0.00 \\
\hline 4 & -10.95 & 1.92 & -0.75 & 0.06 & 2.10 & 0.03 & -21.65 & 4.07 & -0.55 & 0.05 & 3.53 & 0.20 & -16.44 & 1.06 & -0.69 & 0.01 & 1.23 & 0.00 & -8.92 & 1.02 & -0.66 & 0.01 & 0.30 & 0.00 \\
\hline 5 & -13.57 & 2.07 & -0.69 & 0.07 & 2.80 & 0.17 & -20.13 & 4.43 & -0.66 & 0.05 & 5.97 & 0.19 & -17.43 & 1.13 & -0.73 & 0.01 & 1.98 & 0.00 & -5.38 & 1.03 & -0.53 & 0.01 & 1.50 & 0.01 \\
\hline 6 & -11.94 & 2.07 & -0.69 & 0.07 & 2.15 & 0.17 & -14.48 & 5.02 & -0.55 & 0.07 & 3.50 & 0.12 & -16.87 & 1.22 & -0.72 & 0.01 & 1.80 & 0.00 & -5.27 & 1.10 & -0.53 & 0.01 & 1.30 & 0.08 \\
\hline 7 & -12.75 & 2.01 & -0.68 & 0.07 & 2.17 & 0.19 & -13.31 & 4.54 & -0.56 & 0.06 & 3.00 & 0.03 & -16.22 & 1.21 & -0.71 & 0.01 & 1.43 & 0.00 & -4.43 & 1.39 & -0.54 & 0.01 & 0.10 & 0.00 \\
\hline 8 & -13.65 & 1.93 & -0.72 & 0.07 & 3.68 & 0.19 & -18.77 & 3.11 & -0.62 & 0.05 & 8.65 & 0.28 & -14.64 & 0.78 & -0.68 & 0.01 & 4.30 & 0.02 & -6.01 & 0.76 & -0.50 & 0.01 & 3.80 & 0.04 \\
\hline 9 & -13.63 & 1.92 & -0.72 & 0.07 & 4.26 & 0.18 & -10.71 & 3.78 & -0.51 & 0.07 & 4.60 & 0.20 & -13.81 & 0.83 & -0.67 & 0.01 & 4.05 & 0.02 & -7.61 & 1.29 & -0.55 & 0.01 & 2.10 & 0.06 \\
\hline 10 & -12.02 & 2.00 & -0.71 & 0.07 & 3.65 & 0.21 & -12.06 & 3.90 & -0.50 & 0.07 & 5.07 & 0.28 & -14.47 & 0.81 & -0.66 & 0.01 & 3.93 & & -5.65 & 0.75 & -0.50 & 0.01 & 4.60 & 0.33 \\
\hline 11 & -12.13 & 2.11 & -0.69 & 0.07 & 3.02 & 0.20 & -12.72 & 4.79 & -0.55 & 0.07 & 0.80 & 0.29 & -15.98 & 1.24 & -0.69 & 0.01 & 1.45 & 0.00 & -4.39 & 1.39 & -0.53 & 0.01 & 0.10 & 0.00 \\
\hline 12 & -12.12 & 2.03 & -0.71 & 0.07 & 3.98 & 0.26 & -6.18 & 4.30 & -0.44 & 0.08 & 2.33 & 0.28 & -13.36 & 0.82 & -0.66 & 0.01 & 3.98 & 0.02 & -7.30 & 1.26 & -0.55 & 0.01 & 2.00 & 0.06 \\
\hline 13 & -10.40 & 2.00 & -0.70 & 0.07 & 3.64 & 0.19 & -6.52 & 4.34 & -0.44 & 0.08 & 3.03 & 0.14 & -12.81 & 0.87 & -0.65 & 0.01 & 4.03 & 0.02 & -6.38 & 1.23 & -0.54 & 0.01 & 2.20 & 0.04 \\
\hline 14 & -10.52 & 2.01 & -0.70 & 0.07 & 2.53 & 0.25 & -6.06 & 4.33 & -0.43 & 0.08 & 1.13 & 0.28 & -12.47 & 0.90 & -0.64 & 0.01 & 3.48 & 0.02 & -6.02 & 1.17 & -0.54 & 0.01 & 2.20 & 0.05 \\
\hline 15 & -12.15 & 1.94 & -0.73 & 0.07 & 4.72 & 0.19 & -5.00 & 4.07 & -0.47 & 0.07 & 2.65 & 0.30 & -13.68 & 0.67 & -0.65 & 0.01 & 3.98 & 0.03 & -11.19 & 1.08 & -0.58 & 0.01 & 2.70 & 0.10 \\
\hline
\end{tabular}

*ATT - Efeito Absoluto, ATT\% - Efeito Relativo; S.E. - Erro Padrão; P. R² - Pseudo R². 
Apêndice 6 - (Continuação)

\begin{tabular}{|c|c|c|c|c|c|c|c|c|c|c|c|c|c|c|c|c|c|c|c|c|c|c|c|c|}
\hline \multirow{3}{*}{ REF } & \multicolumn{24}{|c|}{ Mahalanobis Matching } \\
\hline & \multicolumn{6}{|c|}{ IUCN IV } & \multicolumn{6}{|c|}{ IUCN V } & \multicolumn{6}{|c|}{ IUCN VI } & \multicolumn{6}{|c|}{1985} \\
\hline & ATT & S.E. & ATT\% & S.E. & Viés & P. $\mathbf{R}^{2}$ & ATT & S.E. & АTT \% & S.E. & Viés & P. $\mathbf{R}^{2}$ & ATT & S.E. & АTT\% & S.E. & Viés & P. $\mathbf{R}^{2}$ & ATT & S.E. & АTT\% & S.E. & Viés & P. $\mathbf{R}^{2}$ \\
\hline 1 & -18.45 & 3.76 & -0.68 & 0.04 & 3.48 & 0.25 & -0.86 & 1.79 & -0.39 & 0.02 & 2.44 & 0.03 & 1.47 & 5.43 & -0.33 & 0.05 & 3.10 & 0.10 & -25.37 & 2.67 & -0.64 & 0.02 & 3.18 & 0.09 \\
\hline 2 & -21.94 & 4.08 & -0.68 & 0.04 & 1.00 & 0.17 & -3.25 & 2.24 & -0.43 & 0.02 & 4.72 & 0.04 & 0.03 & 4.64 & -0.27 & 0.05 & 5.60 & 0.18 & -28.76 & 3.38 & -0.63 & 0.02 & 4.82 & 0.02 \\
\hline 3 & -8.31 & 3.59 & -0.38 & 0.06 & 0.00 & 0.00 & -1.60 & 2.14 & -0.37 & 0.03 & 2.26 & 0.06 & 3.47 & 5.47 & -0.29 & 0.05 & 3.40 & 0.13 & -20.58 & 2.56 & -0.54 & 0.03 & 1.34 & 0.01 \\
\hline 4 & -16.07 & 4.80 & -0.62 & 0.06 & 4.48 & 0.27 & 1.96 & 1.59 & -0.38 & 0.02 & 3.34 & 0.10 & 1.40 & 4.73 & -0.27 & 0.06 & 4.05 & 0.24 & -26.23 & 3.11 & -0.63 & 0.02 & 4.78 & 0.14 \\
\hline 5 & -25.05 & 4.75 & -0.73 & 0.02 & 8.63 & 0.35 & -1.49 & 1.82 & -0.40 & 0.02 & 5.56 & 0.08 & -0.55 & 4.77 & -0.24 & 0.06 & 5.97 & 0.23 & -31.92 & 3.46 & -0.62 & 0.02 & 4.75 & 0.05 \\
\hline 6 & -9.96 & 3.65 & -0.53 & 0.03 & 11.00 & 0.51 & 2.24 & 2.13 & -0.35 & 0.03 & 3.20 & 0.03 & 0.35 & 4.71 & -0.24 & 0.06 & 7.00 & 0.49 & -23.17 & 3.22 & -0.49 & 0.03 & 3.63 & 0.02 \\
\hline 7 & -25.48 & 6.07 & -0.52 & 0.03 & 0.30 & 0.17 & -2.27 & 1.98 & -0.41 & 0.02 & 8.58 & 0.19 & -3.28 & 4.99 & -0.29 & 0.06 & 4.37 & 0.42 & -32.65 & 4.19 & -0.55 & 0.02 & 6.13 & 0.11 \\
\hline 8 & -21.56 & 4.60 & -0.65 & 0.03 & 25.15 & 0.87 & -0.91 & 1.56 & -0.38 & 0.02 & 4.24 & 0.07 & -0.12 & 4.04 & -0.25 & 0.06 & 5.83 & 0.23 & -27.48 & 2.99 & -0.58 & 0.02 & 4.99 & 0.06 \\
\hline 9 & -25.27 & 4.71 & -0.46 & 0.04 & 12.07 & 0.86 & -0.94 & 1.70 & -0.39 & 0.02 & 7.76 & 0.18 & -0.37 & 4.20 & -0.26 & 0.06 & 6.57 & 0.49 & -29.27 & 3.22 & -0.51 & 0.02 & 7.41 & 0.13 \\
\hline 10 & -8.06 & 2.95 & -0.45 & 0.03 & & & 3.12 & 1.93 & -0.33 & 0.03 & 3.14 & 0.04 & -0.48 & 4.13 & -0.23 & 0.06 & 7.83 & 0.52 & -18.58 & 2.66 & -0.45 & 0.03 & 4.37 & 0.03 \\
\hline 11 & -10.25 & 3.77 & -0.52 & 0.03 & 0.20 & 0.17 & 1.87 & 2.17 & -0.36 & 0.03 & 3.88 & 0.04 & -7.15 & 5.76 & -0.31 & 0.06 & 13.40 & 1.00 & -23.84 & 3.31 & -0.51 & 0.03 & 3.23 & 0.03 \\
\hline 12 & -8.52 & 3.24 & -0.47 & 0.04 & 9.70 & 0.86 & 2.69 & 2.00 & -0.33 & 0.03 & 3.26 & 0.05 & -4.94 & 4.11 & -0.29 & 0.06 & 7.50 & 0.57 & -18.81 & 2.81 & -0.45 & 0.03 & 4.87 & 0.05 \\
\hline 13 & -10.13 & 3.37 & -0.46 & 0.03 & 11.70 & 0.92 & -0.22 & 2.13 & -0.36 & 0.03 & 4.83 & 0.03 & -3.96 & 4.85 & -0.27 & 0.06 & 16.85 & 0.76 & -18.42 & 2.80 & -0.46 & 0.03 & 4.22 & 0.04 \\
\hline 14 & -10.68 & 3.68 & -0.46 & 0.03 & 6.40 & 0.70 & 0.91 & 2.18 & -0.35 & 0.03 & 4.85 & 0.07 & -5.46 & 4.85 & -0.30 & 0.06 & 13.35 & 0.82 & -17.47 & 2.84 & -0.44 & 0.04 & 3.64 & 0.05 \\
\hline 15 & -9.43 & 2.98 & -0.39 & 0.05 & 9.40 & 0.90 & 3.19 & 1.89 & -0.32 & 0.03 & 4.26 & 0.07 & -2.07 & 3.85 & -0.30 & 0.06 & 5.95 & 0.33 & -18.57 & 2.59 & -0.45 & 0.04 & 4.98 & 0.06 \\
\hline
\end{tabular}

*ATT - Efeito Absoluto, ATT\% - Efeito Relativo; S.E. - Erro Padrão; P. R² - Pseudo R². 
Apêndice 6 - (Continuação)

\begin{tabular}{|c|c|c|c|c|c|c|c|c|c|c|c|c|c|c|c|c|c|c|c|c|c|c|c|c|}
\hline \multirow{3}{*}{ REF } & \multicolumn{24}{|c|}{ Mahalanobis Matching } \\
\hline & \multicolumn{6}{|c|}{1995} & \multicolumn{6}{|c|}{2002} & \multicolumn{6}{|c|}{2008} & \multicolumn{6}{|c|}{2009} \\
\hline & ATT & S.E. & ATT\% & S.E. & Viés & P. $\mathbf{R}^{2}$ & ATT & S.E. & ATT\% & S.E. & Viés & P. $\mathbf{R}^{2}$ & ATT & S.E. & ATT\% & S.E. & Viés & P. $\mathbf{R}^{2}$ & ATT & S.E. & АTT\% & S.E. & Viés & P. $\mathbf{R}^{2}$ \\
\hline 1 & -13.28 & 2.40 & -0.64 & 0.02 & 1.84 & 0.03 & -6.73 & 0.82 & -0.64 & 0.01 & 0.41 & 0.00 & -6.81 & 1.16 & -0.71 & 0.02 & 0.30 & 0.00 & -0.94 & 0.88 & -0.59 & 0.06 & 0.00 & 0.00 \\
\hline 2 & -15.00 & 2.80 & -0.41 & 0.03 & 3.10 & 0.08 & -6.55 & 1.16 & -0.60 & 0.01 & 1.28 & 0.00 & -3.52 & 0.98 & -0.69 & 0.02 & 0.89 & 0.03 & -0.08 & 1.03 & -0.52 & 0.06 & 1.03 & 0.11 \\
\hline 3 & -10.77 & 2.76 & -0.60 & 0.03 & 0.88 & 0.02 & -6.96 & 0.79 & -0.64 & 0.01 & 0.57 & 0.02 & -9.17 & 1.12 & -0.70 & 0.02 & 0.45 & 0.00 & -0.59 & 0.77 & -0.52 & 0.06 & 0.00 & 0.00 \\
\hline 4 & -13.57 & 2.73 & -0.57 & 0.03 & 1.27 & 0.05 & -7.39 & 1.11 & -0.61 & 0.01 & 1.48 & 0.02 & -4.58 & 1.47 & -0.59 & 0.02 & 1.78 & 0.04 & -0.38 & 0.77 & -0.58 & 0.06 & 0.43 & 0.01 \\
\hline 5 & -17.49 & 3.12 & -0.62 & 0.02 & 5.19 & 0.15 & -8.56 & 1.09 & -0.61 & 0.01 & 2.20 & 0.01 & -2.66 & 1.09 & -0.64 & 0.02 & 3.36 & 0.02 & -0.40 & 0.96 & -0.61 & 0.06 & 1.71 & 0.13 \\
\hline 6 & -15.04 & 3.31 & -0.59 & 0.03 & 4.61 & 0.16 & -7.94 & 1.09 & -0.60 & 0.01 & 1.63 & 0.05 & -2.76 & 1.14 & -0.65 & 0.02 & 2.21 & 0.03 & -0.42 & 0.98 & -0.61 & 0.06 & 0.68 & 0.21 \\
\hline 7 & -14.63 & 3.21 & -0.59 & 0.03 & 1.89 & 0.07 & -7.89 & 1.14 & -0.60 & 0.01 & 1.69 & 0.06 & -4.36 & 1.19 & -0.66 & 0.02 & 2.28 & 0.05 & -0.55 & 1.19 & -0.61 & 0.06 & 0.08 & 0.15 \\
\hline 8 & -16.09 & 2.48 & -0.59 & 0.02 & 6.80 & 0.14 & -7.01 & 0.73 & -0.56 & 0.01 & 4.80 & 0.03 & -3.13 & 0.87 & -0.60 & 0.02 & 3.89 & 0.07 & -0.40 & 0.96 & -0.47 & 0.06 & 8.72 & 0.38 \\
\hline 9 & -12.38 & 2.77 & -0.55 & 0.03 & 4.77 & 0.15 & -7.10 & 0.83 & -0.56 & 0.01 & 3.90 & 0.05 & -4.11 & 0.92 & -0.62 & 0.02 & 3.93 & 0.13 & -0.11 & 0.72 & -0.50 & 0.06 & 5.20 & 0.37 \\
\hline 10 & -13.61 & 2.68 & -0.55 & 0.03 & 3.83 & 0.09 & -6.56 & 0.74 & -0.55 & 0.01 & 4.89 & 0.09 & -3.44 & 0.91 & -0.61 & 0.02 & 3.62 & 0.09 & 0.14 & 0.82 & -0.46 & 0.06 & 3.60 & 0.25 \\
\hline 11 & -15.07 & 3.48 & -0.59 & 0.03 & 3.75 & 0.09 & -6.73 & 1.16 & -0.59 & 0.01 & 1.61 & 0.04 & -4.80 & 1.35 & -0.67 & 0.02 & 1.95 & 0.09 & -0.63 & 1.00 & -0.60 & 0.06 & 0.10 & 0.14 \\
\hline 12 & -11.70 & 2.88 & -0.53 & 0.03 & 4.21 & 0.16 & -6.88 & 0.83 & -0.56 & 0.01 & 3.60 & 0.08 & -4.30 & 0.94 & -0.62 & 0.02 & 3.35 & 0.16 & 0.05 & 0.82 & -0.51 & 0.06 & 4.80 & 0.45 \\
\hline 13 & -13.36 & 2.97 & -0.54 & 0.03 & 4.95 & 0.16 & -7.21 & 0.97 & -0.57 & 0.01 & 4.54 & 0.07 & -6.84 & 1.28 & -0.67 & 0.02 & 3.78 & 0.03 & 0.03 & 0.82 & -0.48 & 0.06 & 3.63 & 0.26 \\
\hline 14 & -13.24 & 3.08 & -0.54 & 0.03 & 4.44 & 0.11 & -7.30 & 0.98 & -0.56 & 0.01 & 2.18 & 0.03 & -6.61 & 1.29 & -0.67 & 0.02 & 4.17 & 0.17 & 0.00 & 0.84 & -0.49 & 0.06 & 5.76 & 0.38 \\
\hline 15 & -11.09 & 2.64 & -0.52 & 0.03 & 4.50 & 0.11 & -7.32 & 0.73 & -0.57 & 0.01 & 4.09 & 0.09 & -3.84 & 0.77 & -0.60 & 0.02 & 3.87 & 0.18 & -0.19 & 0.97 & -0.37 & 0.06 & 4.59 & $0.4 S$ \\
\hline
\end{tabular}

*ATT - Efeito Absoluto, ATT\% - Efeito Relativo; S.E. - Erro Padrão; P. R² - Pseudo R². 
Apêndice 6 - (Continuação)

\begin{tabular}{|c|c|c|c|c|c|c|}
\hline \multirow{3}{*}{ REF } & \multicolumn{6}{|c|}{ Mahalanobis Matching } \\
\hline & & & 2010 & & & \\
\hline & ATT & S.E. & ATT $\%$ & S.E. & Viés & P. $\mathbf{R}^{2}$ \\
\hline 1 & -0.42 & 0.75 & -0.37 & 0.06 & 1.24 & 0.04 \\
\hline 2 & -0.82 & 0.73 & -0.51 & 0.06 & 1.33 & 0.04 \\
\hline 3 & -2.74 & 1.34 & -0.46 & 0.06 & 2.64 & 0.06 \\
\hline 4 & -1.44 & 0.90 & -0.55 & 0.04 & 1.71 & 0.05 \\
\hline 5 & -0.87 & 0.61 & -0.50 & 0.06 & 2.24 & 0.20 \\
\hline 6 & -2.94 & 0.76 & -0.55 & 0.05 & 0.88 & 0.20 \\
\hline 7 & -0.80 & 0.62 & -0.51 & 0.06 & 1.34 & 0.21 \\
\hline 8 & -0.93 & 0.61 & -0.49 & 0.06 & 2.07 & 0.23 \\
\hline 9 & -0.86 & 0.59 & -0.49 & 0.06 & 1.84 & 0.22 \\
\hline 10 & -2.17 & 0.70 & -0.52 & 0.06 & 1.24 & 0.21 \\
\hline 11 & -0.25 & 0.55 & -0.52 & 0.06 & 1.96 & 0.41 \\
\hline 12 & -2.18 & 0.68 & -0.52 & 0.06 & 0.88 & 0.21 \\
\hline 13 & -1.94 & 0.69 & -0.51 & 0.06 & 2.00 & 0.42 \\
\hline 14 & -1.96 & 0.70 & -0.51 & 0.06 & 1.90 & 0.37 \\
\hline 15 & -0.72 & 0.59 & -0.52 & 0.06 & 1.65 & 0.16 \\
\hline
\end{tabular}

*ATT - Efeito Absoluto, ATT\% - Efeito Relativo; S.E. - Erro Padrão; P. R² - Pseudo R². 
Apêndice 7 - Imagem apresenta a distribuição das unidades amostrais do grupo controle efetivamente utilizadas e scores de Mahalanobis.

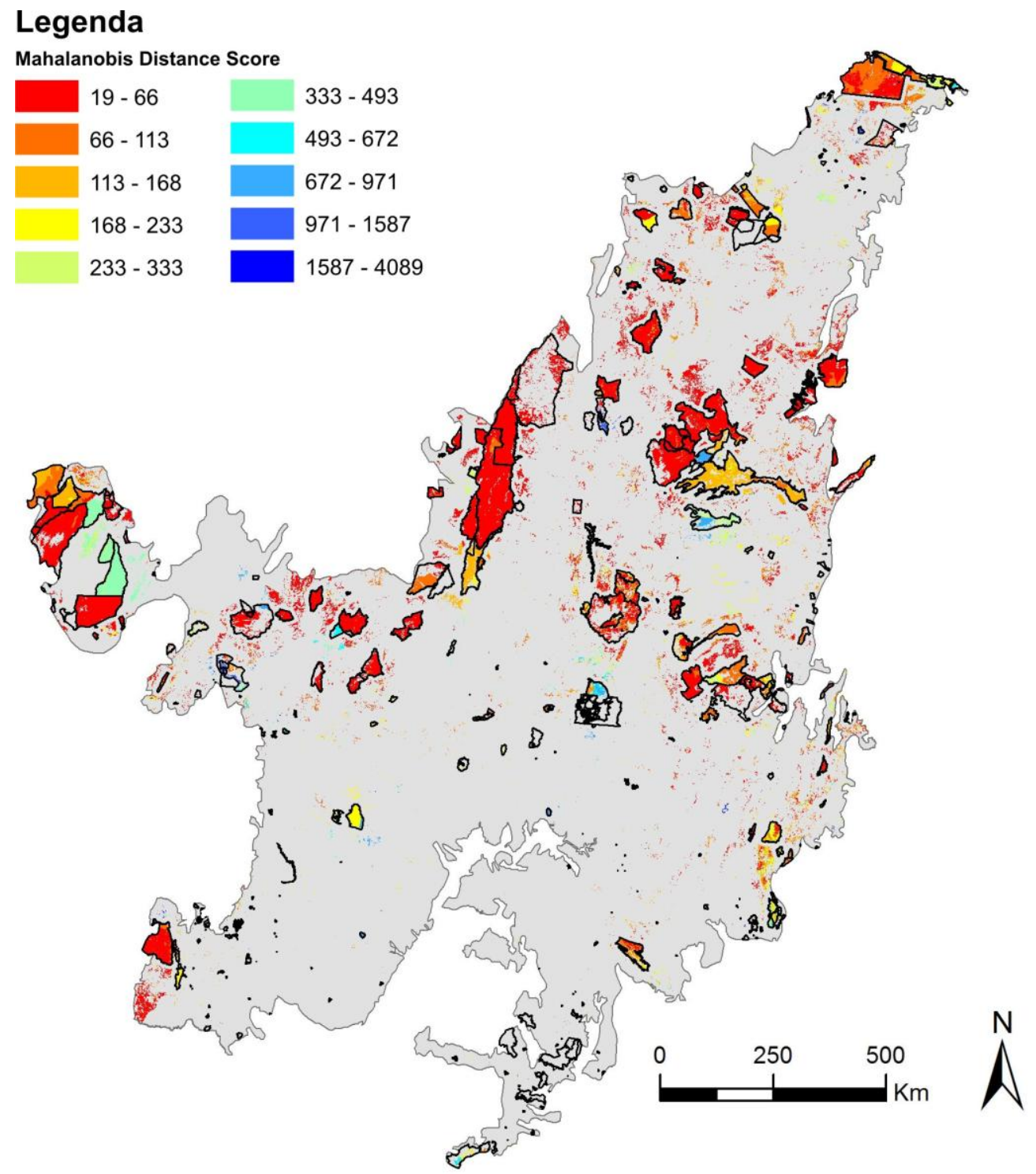


Apêndice 8 - Teste de sensibilidade ao viés oculto de Rosembaum.

\begin{tabular}{|c|c|c|c|c|c|c|c|c|c|c|c|c|c|c|c|c|c|c|c|c|c|c|c|c|}
\hline \multirow{2}{*}{$\Gamma$} & \multicolumn{6}{|c|}{ PA } & \multicolumn{6}{|c|}{ UC } & \multicolumn{6}{|c|}{$\mathrm{TI}$} & \multicolumn{6}{|c|}{ TQ } \\
\hline & 1985 & 1995 & 2002 & 2008 & 2009 & 2010 & 1985 & 1995 & 2002 & 2008 & 2009 & 2010 & 1985 & 1995 & 2002 & 2008 & 2009 & 2010 & 1985 & 1995 & 2002 & 2008 & 2009 & 2010 \\
\hline 1.0 & NS & NS & NS & NS & NS & NS & NS & NS & NS & NS & - & NS & NS & NS & NS & NS & NS & - & - & - & NS & NS & NS & - \\
\hline 1.2 & NS & NS & NS & NS & NS & NS & NS & NS & NS & NS & - & NS & NS & NS & NS & NS & NS & - & - & - & NS & NS & NS & - \\
\hline 1.6 & NS & NS & NS & NS & NS & NS & NS & NS & NS & NS & - & NS & NS & NS & NS & NS & 1.6 & - & - & - & NS & NS & NS & - \\
\hline 2.2 & NS & NS & NS & NS & NS & NS & NS & NS & NS & NS & - & NS & NS & NS & NS & NS & - & - & - & - & NS & NS & NS & - \\
\hline 2.4 & NS & NS & NS & NS & 2.4 & NS & NS & NS & NS & NS & - & NS & NS & NS & NS & NS & - & - & - & - & NS & 2.4 & NS & - \\
\hline 2.6 & NS & NS & NS & NS & & 2.6 & NS & NS & NS & NS & - & 2.6 & NS & NS & NS & NS & - & - & - & - & NS & & NS & - \\
\hline 2.8 & NS & NS & NS & NS & & & NS & 2.8 & 2.8 & NS & - & & NS & NS & NS & NS & - & - & - & - & NS & & NS & - \\
\hline 3.0 & NS & NS & NS & NS & & & NS & & & NS & - & & NS & NS & NS & NS & - & - & - & - & 3 & & NS & - \\
\hline 3.4 & NS & NS & NS & NS & & & NS & & & NS & - & & NS & NS & NS & NS & - & - & - & - & & & NS & - \\
\hline 3.6 & NS & NS & NS & NS & & & NS & & & NS & - & & NS & NS & NS & NS & - & - & - & - & & & NS & - \\
\hline 3.8 & NS & NS & NS & 3.8 & & & NS & & & 3.8 & - & & NS & NS & NS & NS & - & - & - & - & & & NS & - \\
\hline 4.2 & NS & NS & 4.2 & & & & NS & & & & - & & NS & NS & NS & NS & - & - & - & - & & & NS & - \\
\hline 4.4 & NS & NS & & & & & NS & & & & - & & NS & NS & NS & NS & - & - & - & - & & & NS & - \\
\hline 4.6 & NS & NS & & & & & NS & & & & - & & NS & NS & NS & 4.6 & - & - & - & - & & & NS & - \\
\hline 4.8 & NS & NS & & & & & NS & & & & - & & NS & NS & NS & & - & - & - & - & & & NS & - \\
\hline 5.0 & $>5.0$ & $>5.0$ & & & & & $>5.0$ & & & & - & & $>5.0$ & $>5.0$ & $>5.0$ & & - & - & - & - & & & $>5.0$ & - \\
\hline $\mathrm{N}$ & 22369 & 68023 & 66236 & 15085 & 202 & 659 & 13508 & 21174 & 50173 & 12803 & 47 & 645 & 8861 & 46821 & 14157 & 1309 & 109 & 12 & 0 & 0 & 1907 & 973 & 46 & 2 \\
\hline
\end{tabular}


Apêndice 8 - (Continuação)

\begin{tabular}{|c|c|c|c|c|c|c|c|c|c|c|c|c|c|c|c|c|c|c|c|c|c|c|c|c|}
\hline \multirow{2}{*}{$\Gamma$} & \multicolumn{6}{|c|}{ PI } & \multicolumn{6}{|c|}{ US } & \multicolumn{6}{|c|}{ FED } & \multicolumn{6}{|c|}{ EST } \\
\hline & 1985 & 1995 & 2002 & 2008 & 2009 & 2010 & 1985 & 1995 & 2002 & 2008 & 2009 & 2010 & 1985 & 1995 & 2002 & 2008 & 2009 & 2010 & 1985 & 1995 & 2002 & 2008 & 2009 & 2010 \\
\hline 1.0 & NS & NS & NS & NS & - & - & - & NS & NS & NS & - & NS & NS & NS & NS & NS & NS & - & NS & NS & NS & NS & - & NS \\
\hline 1.2 & NS & NS & NS & NS & - & - & - & NS & NS & NS & - & NS & NS & NS & NS & NS & NS & - & NS & NS & NS & NS & - & NS \\
\hline 1.6 & NS & NS & NS & NS & - & - & - & NS & NS & NS & - & NS & NS & NS & NS & NS & NS & - & NS & NS & NS & NS & - & NS \\
\hline 2.2 & NS & NS & NS & NS & - & - & - & NS & 2.2 & NS & - & NS & NS & NS & NS & NS & NS & - & NS & NS & NS & NS & - & NS \\
\hline 2.4 & NS & NS & NS & NS & - & - & - & 2.4 & & NS & - & NS & NS & NS & NS & NS & 2.4 & - & NS & NS & 2.4 & NS & - & NS \\
\hline 2.6 & NS & NS & NS & NS & - & - & - & & & NS & - & 2.6 & NS & NS & NS & NS & & - & NS & 2.6 & & NS & - & 2.6 \\
\hline 2.8 & NS & NS & NS & NS & - & - & - & & & NS & - & & NS & NS & NS & NS & & - & NS & & & NS & - & \\
\hline 3.0 & NS & NS & NS & NS & - & - & - & & & NS & - & & NS & NS & NS & NS & & - & NS & & & NS & - & \\
\hline 3.4 & NS & NS & 3.4 & NS & - & - & - & & & NS & - & & NS & NS & NS & NS & & - & 3.4 & & & NS & - & \\
\hline 3.6 & NS & NS & & NS & - & - & - & & & 3.6 & - & & NS & NS & NS & NS & & - & & & & 3.6 & - & \\
\hline 3.8 & NS & NS & & NS & - & - & - & & & & - & & NS & NS & NS & NS & & - & & & & & - & \\
\hline 4.2 & NS & NS & & NS & - & - & - & & & & - & & NS & NS & NS & NS & & - & & & & & - & \\
\hline 4.4 & NS & NS & & NS & - & - & - & & & & - & & NS & NS & NS & 4.4 & & - & & & & & - & \\
\hline 4.6 & NS & NS & & NS & - & - & - & & & & - & & NS & NS & NS & & & - & & & & & - & \\
\hline 4.8 & NS & NS & & NS & - & - & - & & & & - & & NS & NS & NS & & & - & & & & & - & \\
\hline 5.0 & $>5.0$ & $>5.0$ & & $>5.0$ & - & - & - & & & & - & & $>5.0$ & $>5.0$ & $>5.0$ & & & - & & & & & - & \\
\hline$N$ & 13475 & 3204 & 26639 & 2035 & 0 & 0 & 32 & 17969 & 23536 & 10768 & 47 & 645 & 22156 & 51766 & 41600 & 3858 & 202 & 14 & 212 & 16243 & 24545 & 11171 & 0 & 645 \\
\hline
\end{tabular}


Apêndice 8 - (Continuação)

\begin{tabular}{|c|c|c|c|c|c|c|c|c|c|c|c|c|}
\hline \multirow{2}{*}{$\Gamma$} & \multicolumn{6}{|c|}{ MAIOR } & \multicolumn{6}{|c|}{ MENOR } \\
\hline & 1985 & 1995 & 2002 & 2008 & 2009 & 2010 & 1985 & 1995 & 2002 & 2008 & 2009 & 2010 \\
\hline 1.0 & NS & NS & NS & NS & NS & NS & NS & NS & NS & - & - & - \\
\hline 1.2 & NS & NS & NS & NS & NS & NS & NS & NS & NS & - & - & - \\
\hline 1.6 & NS & NS & NS & NS & NS & NS & NS & NS & NS & - & - & - \\
\hline 2.2 & NS & NS & NS & NS & NS & NS & NS & NS & NS & - & - & - \\
\hline 2.4 & NS & NS & NS & NS & NS & NS & NS & NS & NS & - & - & - \\
\hline 2.6 & NS & NS & NS & NS & NS & 2.6 & NS & NS & NS & - & - & - \\
\hline 2.8 & NS & NS & NS & NS & 2.8 & & NS & NS & NS & - & - & - \\
\hline 3.0 & NS & NS & NS & NS & & & NS & NS & NS & - & - & - \\
\hline 3.4 & NS & NS & NS & NS & & & NS & NS & NS & - & - & - \\
\hline 3.6 & NS & NS & NS & NS & & & NS & NS & NS & - & - & - \\
\hline 3.8 & NS & NS & NS & 3.8 & & & NS & NS & NS & - & - & - \\
\hline 4.2 & NS & NS & 4.2 & & & & NS & NS & NS & - & - & - \\
\hline 4.4 & NS & NS & & & & & NS & NS & NS & - & - & - \\
\hline 4.6 & NS & NS & & & & & NS & NS & NS & - & - & - \\
\hline 4.8 & NS & NS & & & & & 4.8 & NS & NS & - & - & - \\
\hline 5.0 & $>5.0$ & $>5.0$ & & & & & & $>5.0$ & $>5.0$ & - & - & - \\
\hline $\mathrm{N}$ & 22247 & 67449 & 66126 & 15050 & 180 & 647 & 122 & 573 & 110 & 35 & 22 & 12 \\
\hline
\end{tabular}


Apêndice 9 - Teste de Wilcoxon-Mann-Whitney para os grupos de unidades analisados.

\begin{tabular}{|c|c|c|c|c|c|c|}
\hline \multirow{2}{*}{ Grupo de Análise } & \multirow{2}{*}{ Referência } & \multirow{2}{*}{ Referência } & \multicolumn{2}{|c|}{ ATT } & \multicolumn{2}{|c|}{ АTT\% } \\
\hline & & & W & P Value & W & P Value \\
\hline \multirow{2}{*}{ Tipo de Unidade } & UC & $\mathrm{TI}$ & 0 & $<0.001$ & 2 & $<0.001$ \\
\hline & UC & TQ & 225 & $<0.001$ & 89 & 0.345 \\
\hline \multirow{7}{*}{ Grupo de Restrição } & $\mathrm{PI}$ & US & 225 & $<0.001$ & 225 & $<0.001$ \\
\hline & PI_FED & US_FED & 225 & $<0.001$ & 225 & $<0.001$ \\
\hline & PI_EST & US_EST & 225 & $<0.001$ & 225 & $<0.001$ \\
\hline & PI_MAIOR & US_MAIOR & 225 & $<0.001$ & 225 & $<0.001$ \\
\hline & PI_MENOR & US_MENOR & 3 & $<0.001$ & 0 & $<0.001$ \\
\hline & PI_<2002 & US_<2002 & 225 & $<0.001$ & 225 & $<0.001$ \\
\hline & $\mathrm{PI}>2002$ & US_>2002 & 214 & $<0.001$ & 143 & 0.217 \\
\hline \multirow{7}{*}{ Esfera Governamental } & FED & EST & 139 & 0.280 & 225 & $<0.001$ \\
\hline & FED_PI & EST_PI & 122 & 0.709 & 208 & $<0.001$ \\
\hline & FED_US & EST_US & 140.5 & 0.254 & 90 & 0.361 \\
\hline & FED_MAIOR & EST_MAIOR & 113.5 & 0.983 & 225 & $<0.001$ \\
\hline & FED_MENOR & EST_MENOR & 26.5 & $<0.001$ & 112 & 0.999 \\
\hline & FED_<2002 & EST_<2002 & 225 & $<0.001$ & 225 & $<0.001$ \\
\hline & FED_>2002 & EST_>2002 & 71.5 & 0.093 & 134 & 0.389 \\
\hline \multirow{7}{*}{ Grupo de Tamanho } & MAIOR & MENOR & 87 & 0.299 & 7 & $<0.001$ \\
\hline & MAIOR_PI & MENOR_PI & 43 & 0.004 & 44 & 0.004 \\
\hline & MAIOR_US & MENOR_US & 0 & $<0.001$ & 0 & $<0.001$ \\
\hline & MAIOR_FED & MENOR_FED & 94 & 0.455 & 60 & 0.030 \\
\hline & MAIOR_EST & MENOR_EST & 19.5 & $<0.001$ & 15 & $<0.001$ \\
\hline & MAIOR_<2002 & MENOR_<2002 & 182 & 0.003 & 130 & 0.486 \\
\hline & MAIOR_>2002 & MENOR_>2002 & 4 & $<0.001$ & 0 & $<0.001$ \\
\hline \multirow{7}{*}{ Grupo de Tempo } & $<2002$ & $>2002$ & 225 & $<0.001$ & 225 & $<0.001$ \\
\hline & $<2002$ _PI & >2002_PI & 225 & $<0.001$ & 225 & $<0.001$ \\
\hline & <2002_US & >2002_US & 24 & $<0.001$ & 0 & $<0.001$ \\
\hline & $<2002$ FED & $>2002$ FED & 225 & $<0.001$ & 225 & $<0.001$ \\
\hline & $<2002 \_$EST & $>2002 \_E S T$ & 225 & $<0.001$ & 0 & $<0.001$ \\
\hline & $<2002$ _MAIOR & >2002_MAIOR & 225 & $<0.001$ & 225 & $<0.001$ \\
\hline & $<2002$ _MENOR & >2002_MENOR & 225 & $<0.001$ & 189 & $<0.001$ \\
\hline
\end{tabular}

*Unidade de Conservação (UC); Terra Indígena (TI); Terra Quilombola (TQ); Proteção Integral (PI); Uso Sustentável (US); Esfera Federal (FED); Esfera Estadual (EST); Tamanho maior que a mediana (MAIOR); Tamanho menor que a mediana (MENOR); Criadas antes de 2002 (<2002); Criadas após 2002 (>2002). 